\title{
Options for Kentucky's Energy Future
}

November 2012

The INL is a

U.S. Department of Energy National Laboratory

operated by

Battelle Energy Alliance

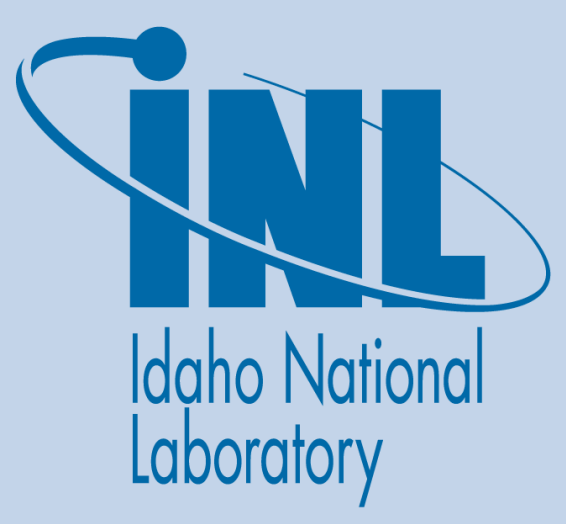

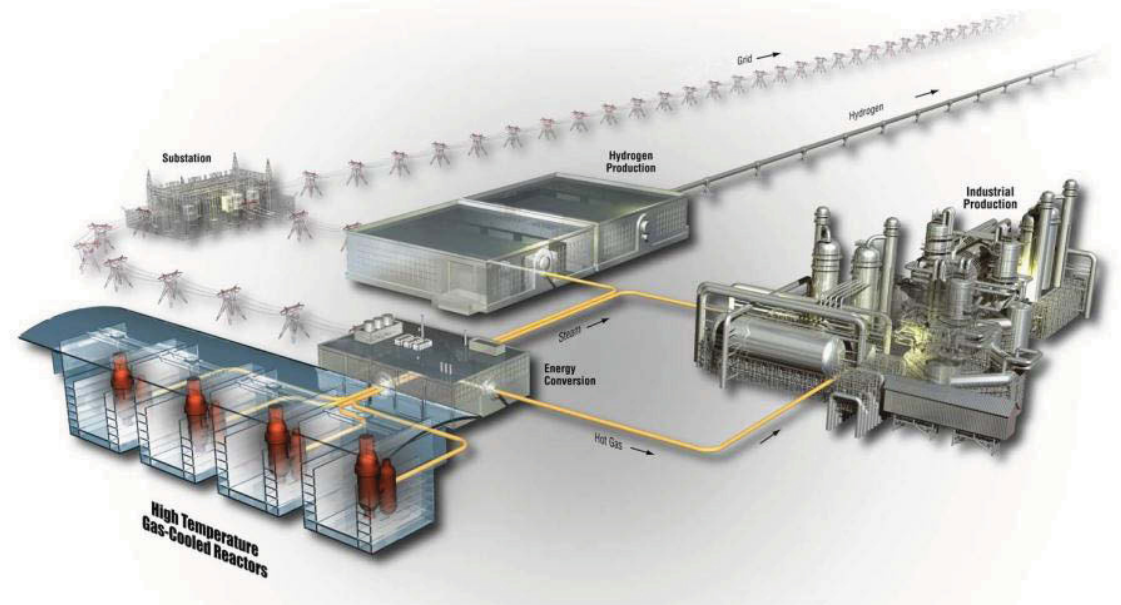

NGNP Industry Alliance

Cleun Sustainable Energy for the 21st Century 


\section{DISCLAIMER}

This information was prepared, in part, as an account of work sponsored by an agency of the U.S. Government. Neither the U.S.

Government nor any agency thereof, nor any of their employees, makes any warranty, expressed or implied, or assumes any legal liability or responsibility for the accuracy, completeness, or usefulness, of any information, apparatus, product, or process disclosed, or represents that its use would not infringe privately owned rights. References herein to any specific commercial product, process, or service by trade name, trade mark, manufacturer, or otherwise, does not necessarily constitute or imply its endorsement, recommendation, or favoring by the U.S. Government or any agency thereof. The views and opinions of authors expressed herein do not necessarily state or reflect those of the U.S. Government or any agency thereof. 
INL/EXT-12-26710

\section{Options for Kentucky's Energy Future}

November 2012

Idaho National Laboratory

Idaho Falls, Idaho 83415

http://www.inl.gov

in collaboration with:

Kentucky Energy and Environment Cabinet

NGNP Industry Alliance Limited

Prepared for the Commonwealth of Kentucky

Energy and Environment Cabinet and for the

U.S. Department of Energy

Under DOE Idaho Operations Office

Contract DE-AC07-05ID14517 



\begin{abstract}
The Kentucky Energy and Environment Cabinet, the NGNP Industry Alliance Limited, and the Idaho National Laboratory, have conducted an evaluation of energy development opportunities for Kentucky that identifies that the deployment of a carbon conversion industry producing synthetic transportation fuels and chemicals can provide a long term and stable market and add considerable value to Kentucky's indigenous coal and natural gas resources with the potential of providing substantive economic benefit to the Commonwealth. The evaluation has also developed a notional strategy for transformation of Kentucky's electricity generation from an industry dominated by coal-fired plants to a more diverse mix of generating technologies that meets Kentucky's long term objectives on improving energy diversity and reducing greenhouse gas emissions.
\end{abstract}




\title{
EXECUTIVE SUMMARY
}

\section{Kentucky's Energy Challenges}

\begin{abstract}
Kentucky's challenge for the 21st century is to develop clean, reliable, affordable energy sources that help us improve our energy security, reduce our carbon dioxide emissions, and provide economic prosperity. Kentucky can beand in fact must be - a leader in this energy revolution.

Energy independence is a top challenge to the state and the nation in the 21st century, a challenge that has been made at once more urgent and more complex by the equally pressing issue of global climate change. For a major coalproducing state that also relies on coal to generate more than 90 percent of its electricity, addressing these two issues - energy security and climate change - is especially problematic.
\end{abstract}

We have to contend with the reality that, going forward, our state's energy policy will be increasingly shaped by decisions at the national level, decisions which in turn are being driven by significant global issues and events. As a state, it is imperative that we have policies and programs in place that allow us to shape our own energy future by making sure we utilize our energy resources in an environmentally sound manner. [Our] strategic action plan, Intelligent Energy

Choices for Kentucky's Future, is intended to place Kentucky on such a path.

These are the opening paragraphs from Governor Beshear's seven-point strategy for energy independence that was issued in November 2008. This seven-point strategy is described as evolutionary, providing an opportunity for all stakeholders to achieve a consensus for a comprehensive plan that defines the energy future for Kentucky. In the five years since completion of Governor Beshear's energy strategy, there have been substantive changes in the energy landscape. In North America, natural gas is more available and considerably cheaper, imported crude oil is considerably more expensive, and we are moving toward independence from importing crude oil and natural gas, perhaps becoming a net exporter of these carbon resources. Hence, Strategy 4 for conversion of coal to synthetic hydrocarbon liquids remains viable. However, because of the increased supply and low prices of natural gas Strategy 5 for conversion of coal to synthetic natural gas does not appear viable in the foreseeable future.

Internationally, fossil energy prices remain high and there is considerable volatility in fossil energy prices, particularly as European countries and Japan re-examine their national energy policies and strategies for the future - clearly wanting reliable and clean energy production, but struggling in the wake of the devastating earthquake, tsunami and subsequent nuclear power plant accident in Japan in March 2011.

In December 2011, Secretary Peters concluded that a contemporary evaluation of Kentucky's energy strategy in selected areas was warranted that included assessing options for the use of high temperature gas-cooled reactor (HTGR) technology to provide the energy needs for a new carbon conversion industry and to be part of a transformed electric power industry comprised of a diverse mix of energy production technologies. This evaluation was collaboratively performed by representatives of Kentucky's Energy and Environment Cabinet, members of the NGNP Industry Alliance Limited and Idaho National Laboratory. The evaluation examined technically and economically viable approaches for increasing the value to the Commonwealth's economy of extracting and processing coal and natural gas, the potential for integrating nuclear energy technology, and infrastructure capabilities important to supporting Kentucky's long term energy future. 
Two particular focuses were included in the evaluation: the opportunities for the Paducah area to take advantage of the experienced workforce resulting from the pending cessation of enrichment operations at the Department of Energy's (DOE's) Paducah Gaseous Diffusion Plant (PGDP), and the need for a stable long term market for eastern Kentucky coal.

The evaluation both expanded on and performed a contemporary, comprehensive assessment of the underlying technologies and economics for Strategies 4 through 7 described in Intelligent Energy Choices for Kentucky's Future. Specifically, the evaluation:

- Assessed alternative carbon conversion processes using detailed process models for producing synthetic hydrocarbon products including transportation fuels, chemical feedstock and commodity chemicals that are the building blocks for the chemical industry

- Examined integration of HTGR nuclear energy technology with the candidate carbon conversion processes to provide the considerable energy needs rather than using fossil fuels, with excess energy available as electric power for use on the grid

- Determined the technical and economic viability of the various alternatives, including comparison with competing sources of hydrocarbon products

- Developed short and long term notional strategies for deploying a carbon conversion industry in Kentucky

- Assessed long term notional deployment options for achieving a diverse mix of electric power generating technologies that (1) account for the anticipated retirement of Kentucky's ageing coalfired generating plants, (2) provide for modifications to some existing coal-fired plants to reduce greenhouse gas emissions, (3) ensure that new generating technology has minimal effect on the environment, (4) acknowledge the anticipated timing for commercialization of carbon capture and sequestration technologies, and advanced nuclear energy technologies, and (5) offer the flexibility to respond to the changing global energy landscape

- Identified opportunities for developing advanced manufacturing capabilities in the Commonwealth

- Estimated the effect of the notional deployment strategies on the Commonwealth's gross domestic product (GDP).

\section{The Opportunities}

Important opportunities exist for the energy future of Kentucky that will:

- Sustain and possibly grow its coal and natural gas industries

- Add substantive value to its indigenous coal and natural gas resources

- Reduce dramatically the environmental effect of energy production and power generation capability

- Add substantive opportunities to develop an advanced manufacturing industry in the Commonwealth

- Increase the Commonwealth's GDP.

Kentucky has a wealth of primary energy resources in the forms of coal and natural gas. Most of Kentucky's coal resources are exported in an unprocessed form rather than as more refined, higher value products. Further, important challenges arise from expanding and ever more demanding government environmental requirements whether these resources are used within the Commonwealth or exported for use elsewhere. Kentucky's leadership recognizes the opportunity to broaden the Commonwealth's economic base by using its energy resources to make value-added products such as synthetic transportation fuels and commodity chemicals. Producing these higher value products in an environmentally responsible manner will require use of clean energy technologies including nuclear 
energy. These higher value products can be used by Kentucky's populace and industry, and considerably larger quantities exported to regional, national, and international markets.

An industry-Commonwealth-federal partnership could facilitate research, development and demonstration projects. Collaboration with national laboratories and international institutions can be beneficial. A vibrant work force of thousands of qualified construction workers, trained operators, instrument and controls technicians, skilled maintenance workers, health physicists, and all fields of engineering ranging from environmental to civil, electrical, mechanical, chemical, and nuclear engineers will be required to realize this goal. An advanced manufacturing industry that supports the carbon conversion and nuclear energy industries will be required and will add to Kentucky's GDP to the extent developed within the Commonwealth.

Regardless of the approach to Kentucky's energy future, the investment decisions made by industry and enabled by Kentucky must be technologically diverse and flexible to allow Kentucky and its industries to adjust to the changing global energy landscape.

\section{The Approach}

These opportunities can be realized through:

\section{- Strengthening the coal and natural gas economy in Kentucky by building a carbon conversion industry}

Coal is Kentucky's most abundant energy resource. The extraction and utilization of coal is an important part of Kentucky's economy. However, the traditional primary use for coal is being increasingly challenged by competing sources for electric power generation and ever more demanding environmental requirements. Further, over $70 \%$ of the extracted coal is exported from the Commonwealth and hence not used to directly expand the Commonwealth's economy beyond the severance taxes on coal production.

New industries are needed that are focused on value-added processes, which will retain more of the end-use value of indigenous carbon resources within Kentucky and increase the Commonwealth's GDP. Strengthening the carbon resource economy by targeting new markets can be achieved through development of a carbon conversion industry built around its largest indigenous resource - coal - for transformation to synthetic transportation fuels and commodity chemicals that are the building blocks for the chemical industry. Over the longer term, environmentally clean nuclear energy can provide the substantial energy needs of a carbon conversion industry, reducing the quantities of coal and natural gas required.

As a far reaching example, notionally redirecting the current Kentucky coal production to making synthetic fuels (e.g., gasoline or diesel) could supply over $15 \%$ of the current total U.S. consumption of liquid hydrocarbon fuels - at prices competitive with traditional refining processes. However, the capital investment to achieve this capability would be substantial. Practically carving out the achievable part of this possible energy future requires developing a far-sighted partnership with industry, starting with an incremental strategy that can set Kentucky on the path to becoming a major player in an environmentally responsible carbon conversion industry and in deployment of next generation nuclear energy technology.

Entry into a carbon conversion industry can be phased through construction of process facilities using conventional technologies that can be operational within the next decade focused initially on producing transportation fuels.

Kentucky's initial carbon conversion industry could include two coal to liquids facilities - one for the high sulfur coal in western Kentucky and one for the low sulfur coal in eastern Kentucky. 
- The western Kentucky facility, suggested to be located in Paducah, addresses a short-term goal of developing a viable economic future for the highly trained and experienced workforce in the Paducah area. Today that work force supports, and is supported by, the operations of DOE's PGDP that could cease enrichment operations as early as May 2013.

- The other plant could be located in eastern Kentucky using the low sulfur eastern Kentucky coal as feedstock and natural gas for production of hydrogen needed in the process. This would begin to provide an internal stable market for eastern Kentucky coal and natural gas to offset the steady reduction in its production experienced over the last decade and projected to continue because of the retirement of coal based electricity generation in Kentucky and nationally; the principal market for eastern Kentucky coal.

For these type facilities, natural gas would be utilized primarily in steam reforming processes to produce the substantial amounts of hydrogen required in the coal conversion processes. Similar phased construction of additional coal conversion facilities could be extended over the following decades to build a substantive industry benefitting the local and Commonwealth economies.

Eventually, expansion of a carbon conversion industry potentially using the distributed process model shown at right can be realized. The design of carbon conversion facilities should be intentionally compatible with integration of nuclear energy technology ${ }^{\mathrm{a}}$. Because the commercialization of new nuclear energy technology is expected to extend over the next 10 to 25 years, a notional strategy would be to deploy carbon conversion facilities using conventional processes in the short term and anticipate incorporation of the nuclear reactors over the longer term. Nuclear energy integration will result in the greatest environmental benefits while providing a reliable, stable cost of energy for several decades of operation.

- Developing a viable economic future for the highly trained and experienced workforce in the Paducah area

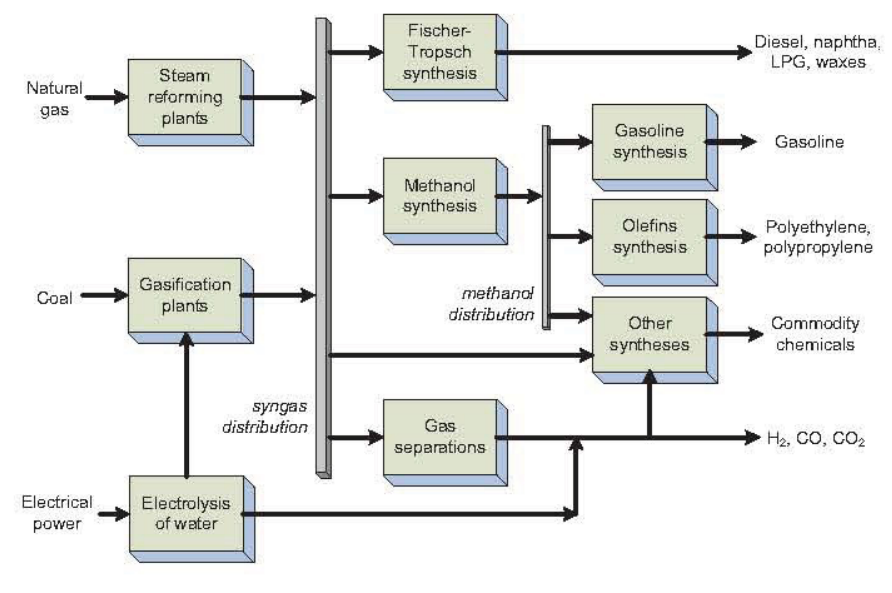

Today, that workforce supports, and is supported by, the operations of DOE's PGDP. However, the PGDP could cease enrichment operations as soon as May 2013. The phased construction of a coal conversion facility in the Paducah area, as described above, is an important part of implementation of a Commonwealth-wide carbon conversion industry and provides both short and long term opportunities for utilizing Paducah's experienced workforce and strengthening the regional economy.

- Ensuring continued reliable and affordable sources of energy for Kentucky's industries and populace by diversifying the technologies for generating electric power

Today, over $90 \%$ of Kentucky's electricity is generated by burning coal with a delivered electric power price that is among the lowest in the United States. Anticipated environmental requirements for greenhouse gas emissions necessitate looking at alternative forms of energy production, and in particular electric power generation.

a Nuclear energy provides an environmentally responsible source of energy that addresses anticipated carbon constraining regulatory requirements. Further, nuclear energy mitigates the effects of volatile fossil fuel energy pricing. HTGR nuclear energy technology provides highly efficient generation of electricity and high temperature process heat that fulfills the requirements of process plants. 
The anticipated retirement over the next several decades of Kentucky's ageing coal-fired electric power generating fleet - both a challenge and an opportunity - requires long range planning to ensure that the replacement power generating technologies fulfill the desired or policy-imposed business and environmental requirements. Selecting a diverse set of replacement power generating technologies is warranted, considering the uncertainties inherent in predicting future energy resources and demand, both nationally and internationally. The figure at the right shows a notional strategy for replacement of existing coal-fired generation. Best available information suggests that the transformation to this diverse set of technologies should initially include natural gas combined cycle generation, subsequently complemented by clean coal technologies and nuclear energy - the mix primarily determined by:

- Anticipated national and international energy price trends,

- Kentucky's long term industrial base,

- Extent of desired energy selfsufficiency, and

- Kentucky's energy export posture.

A diverse technology mix will allow Kentucky and its industries to adjust to an evolving global energy landscape.

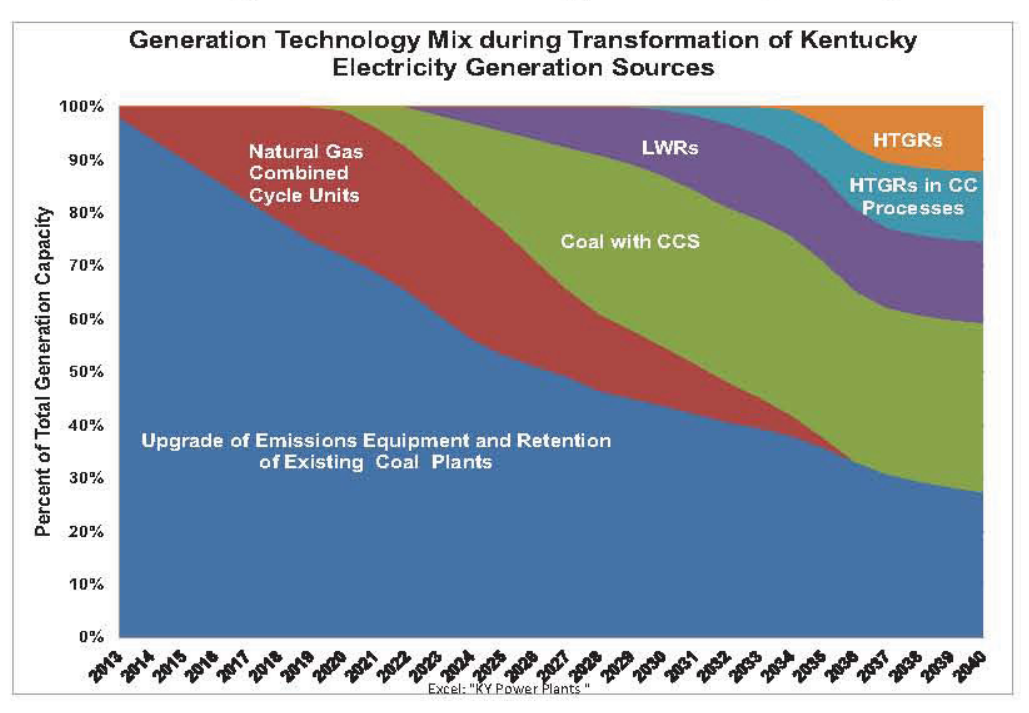

\section{The Result}

The deployment of a notional carbon conversion industry will have a positive effect on Kentucky's economy by providing a continuing demand for indigenous coal and natural gas resources and increasing the value of these resources by transforming them into higher value products. The investment in constructing the facilities that will make up this industry will also add value to the GDP during construction, and the construction activity and operation of the facilities will provide lasting job growth. The same is true of the investment required to transform the electricity generation sources in Kentucky. During construction of the new generation and upgrade of the emissions control equipment of the retained generation the investment will add value to the GDP and will create jobs on the plant sites. The figure below shows the projected contributions from these two initiatives and the total annual contribution to the GDP in 2011 \$. In 2011 the mining industry contributed $~ 3 \%$ of the total Kentucky GDP or about \$5B. At the peak of construction the deployment of the carbon conversion industry and the transformation of the electric generation industry will be in the order of $\$ 12 \mathrm{~B}(2011 \$)$, or more than twice that of the mining contribution in 2011. Once the initial notional carbon conversion industry is fully deployed it will add $\sim 88.5 \mathrm{~B}$ to the annual GDP or $70 \%$ more than the mining industry contributed in 2011 . These are substantive contributions on a real dollar basis and support the Commonwealth's objectives of revitalizing the coal and natural gas production industry in eastern Kentucky and providing a viable sustainable mix of electricity generation over the long term. Also, it should be noted that the economic multiplier effects of business growth (e.g., real estate, retail sales growth) that accompanies such industry development and transformation have not been included. 


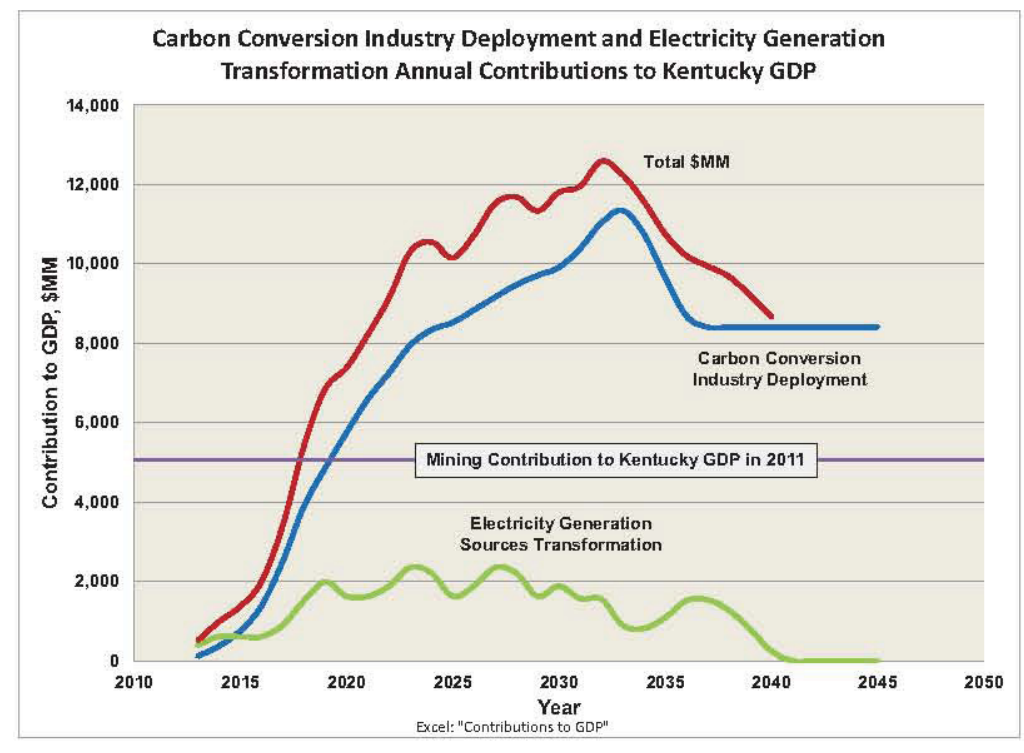

An important consideration in evaluating the long term effect is the extent to which the carbon conversion industry may continue to grow beyond the notional assumptions evaluated. As an example, if the carbon conversion industry were to continue to grow to utilize the entire current coal production in Kentucky, the effect on the GDP would be an order of magnitude larger. Long term planning in the Commonwealth would be well advised to include such considerations in evaluating the overall benefit to Kentucky of developing and growing such industry.

\section{The Next Steps}

The suggested approaches to Kentucky's energy future are bold. However, the transformation and growth can be achieved in phases that can be accommodated by industry and Kentucky with the opportunity to adjust direction as Kentucky's energy future matures and becomes clearer. The following provide suggested near term steps that can put Kentucky on the road to an energy, industry, and economic transformation.

- Establish forward-looking partnerships between industry and Kentucky that are used to develop mutual goals and success criteria. Such partnerships would include existing Kentucky industry as well as new industries that will invest in energy and processing technologies. The public-private partnerships' goals and success criteria can address use of indigenous resources, economic figures-ofmerit that measure progress and consider both the needs of the Commonwealth and industry, approaches to reducing regulatory burden, incentives that attract investment, and approaches that reduce investment uncertainty and risk.

- Update the multi-decade energy strategy, Intelligent Energy Choices for Kentucky's Future, that codifies Kentucky's vision and plan for transforming its energy industry and developing its industrial and educational infrastructure. This strategy, issued in November 2008, should be updated to reflect the substantial changes in the energy landscape that have been experienced over the last five years and to reflect the comprehensive evaluation summarized herein. This updated strategy then can be used as a backdrop against which industry investment can be made with reduced business risk and provides a benchmark against which necessary course corrections can be recognized.

- Expand the role of the Energy and Environment Cabinet or establish a statutory agency that provides the ongoing leadership for Kentucky's energy transformation. Industry evaluates the market and chooses the technological approaches for achieving the goals of Kentucky's energy policy. An empowered Kentucky agency is necessary to guide industry on the path to transformation, provide a clearing house for implementation of the Commonwealth's energy policy and assist in removing roadblocks that will be encountered at the Commonwealth and federal level.

- Actively support state, regional and national initiatives, both in industry and government, which will enable the success of Kentucky's energy transformation. This could take the form of supporting industry and federal activities that will commercialize energy technologies such as next generation 
nuclear energy technologies, transmission system expansion and innovation, and commercialization of cogeneration technologies. More specifically, as examples:

- Via the updated energy strategy, indicate that Kentucky is interested in hosting first-of-a-kind facilities using next generation nuclear energy technology and cogeneration concepts to support the growth of its carbon conversion industry and transform its electric power generation industry

- Actively support industry's commercialization efforts for next generation nuclear energy technologies (e.g., HTGRs and other small modular reactors) and other enabling technologies (e.g., high temperature steam electrolysis for hydrogen and oxygen production) that can contribute substantially to the success of Kentucky's carbon conversion industry

- Engage the DOE National Laboratories to leverage the intellectual capacity, simulation tools, and testing and development investments designed to address challenging research and development problems. Federal/State/Industry collaboration can accelerate analysis and assessments that may help define and optimize energy system architectures. Government and industry partnerships may also be key to providing incentives that can overcome specific market barriers, including for example, regulatory barriers. National Laboratories can facilitate international cooperation through approved Protocol Agreements that can help accelerate nuclear energy technology. Finally, National Laboratories can enhance education and workforce training through research internships and visiting faculty programs.

To reach a comprehensive set of conclusions and develop notional deployment strategies, the evaluation summarized herein makes many assumptions about factors beyond the control of the authors. These include the developmental timeline for high temperature gas-cooled nuclear reactor technology, assumptions about growth and other developmental goals, future environmental or other regulations and requirements, and costs of commodities such as oil, coal, and natural gas. Consequently, the conclusions and recommendations summarized herein show a possible path forward for Kentucky's energy future, and do not necessarily constitute policy or initiatives of the Commonwealth of Kentucky. 


\section{CONTENTS}

ABSTRACT iii

EXECUTIVE SUMMARY iv

ACRONYMS xvii

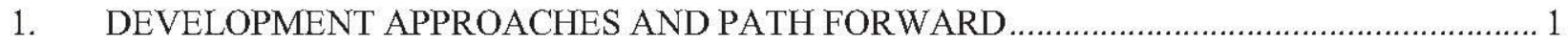

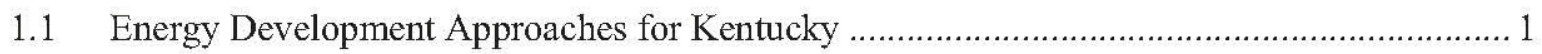

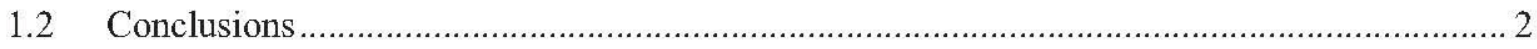

1.3 Suggested Overall Path Forward .............................................................................. 4

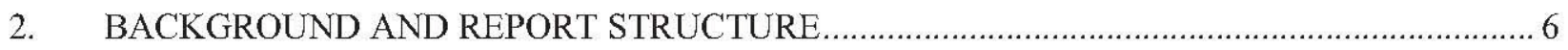

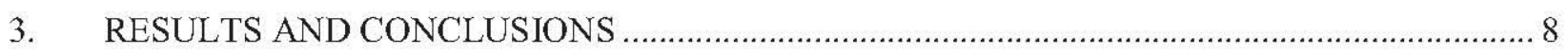

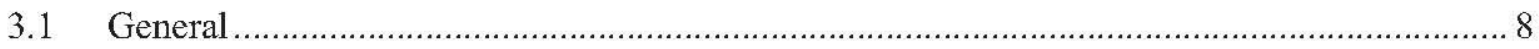

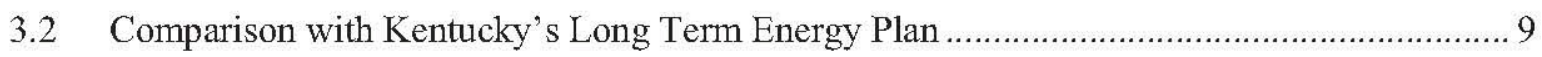

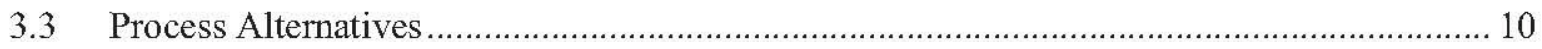

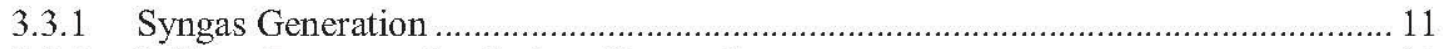

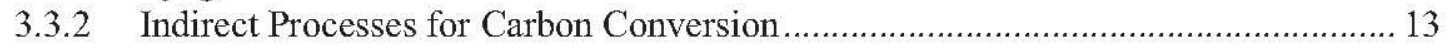

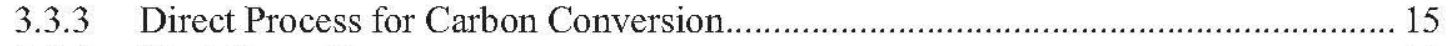

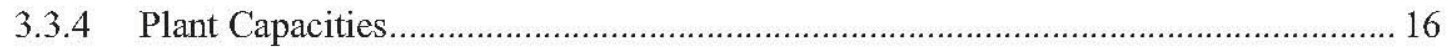

3.3.5 Comparison of $\mathrm{CO}_{2}$ Emissions for Indirect Processes ..................................... 16

3.3.6 Economics of the Alternative Processes ......................................................... 17

3.3.7 Effects of Variations in Natural Gas Prices and Costs of $\mathrm{CO}_{2}$ Disposition on the Economics of the Alternative processes......................................................... 21

3.4 Notional Selection of the Processes for Evaluating Deployment of a Carbon

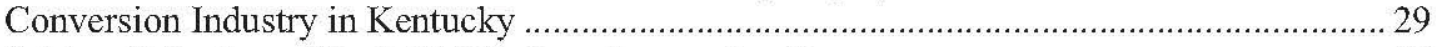

3.4.1 Selection of the Initial Carbon Conversion Process.......................................... 29

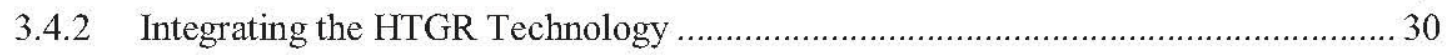

3.4.3 Notional Plant Performance, Costs and Revenues .............................................. 31

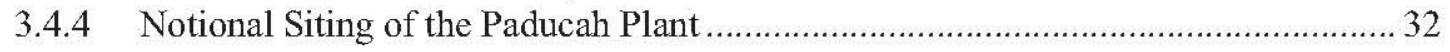

3.5 Deployment of the Carbon Conversion Industry ..................................................... 35

3.6 Transformation of Kentucky Electricity Generation Industry ........................................ 41

3.7 Composite Effect of Developing a Carbon Conversion Industry and the Electric

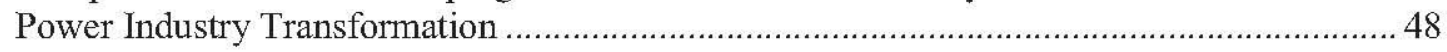

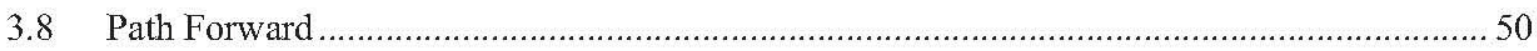

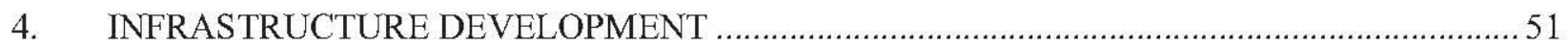

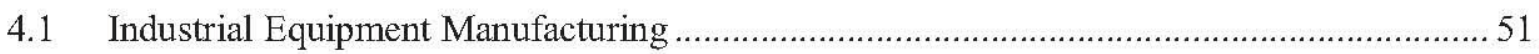

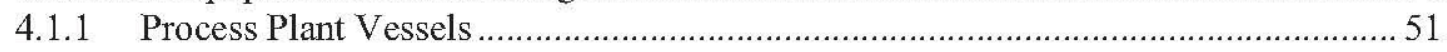

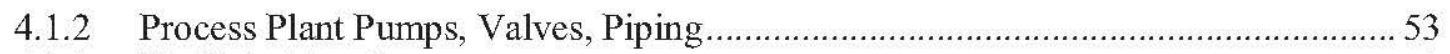

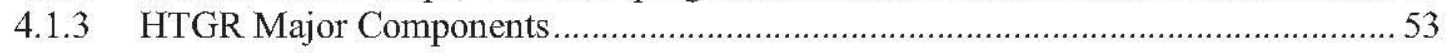

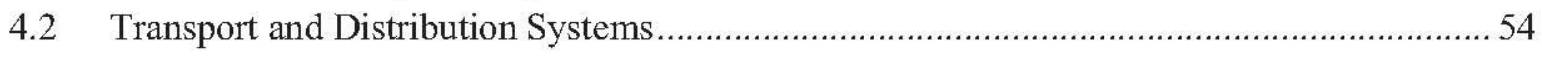

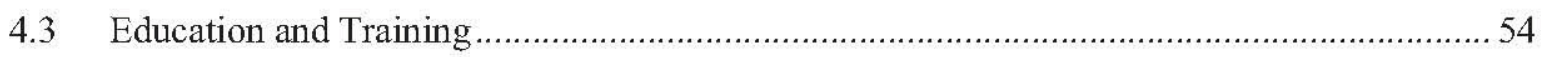

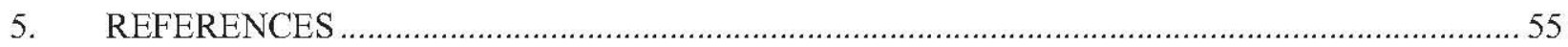


Appendix A Evaluation Team and Summary of Paducah Area Characteristics ................................5 59

Appendix B High Temperature Gas-cooled Reactor Technology and Safety Basis............................ 65

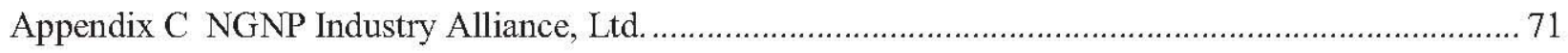

Appendix D Process Alternatives Functional and Performance Characteristics ................................. 73

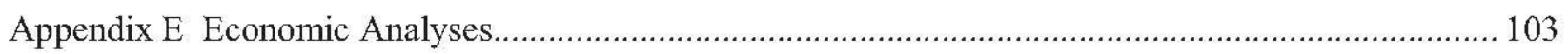

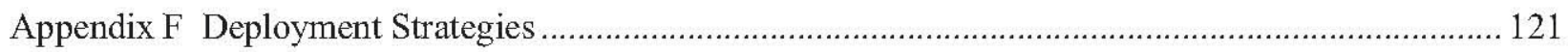

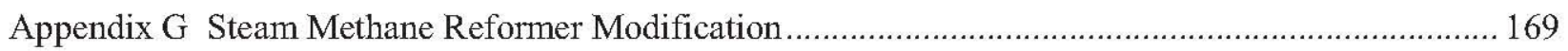

Attachment, NGNP Industry Alliance Limited Business Plan ............................................... 172

\section{FIGURES}

Figure 3-1. Syngas generation.

Figure $3-2$. Alternative syngas supply feed stocks and configurations........................................ 13

Figure 3-3. Conventional FT production of diesel, naphtha and LPG..................................... 14

Figure 3-4. Alternative further processing of F-T naphtha to produce chemicals. ............................. 14

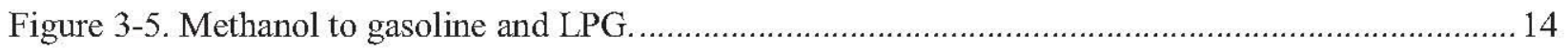

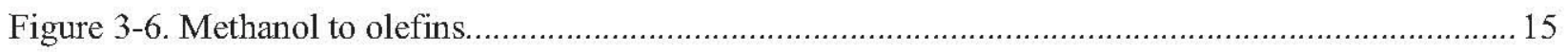

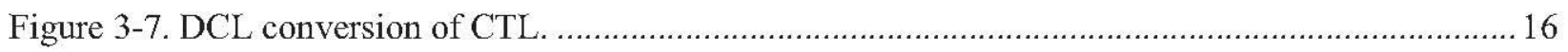

Figure 3-8. Comparison of $\mathrm{CO}_{2}$ emissions of alternative processes......................................... 17

Figure 3-9. Comparison of the production costs of carbon conversion processes with the production cost of diesel refined from crude oil versus the price of crude oil.

Figure 3-10. Comparison of the production costs of carbon conversion processes with the production cost of gasoline refined from crude oil versus the price of crude oil. .18

Figure 3-11. EIA projections on future crude oil prices. 19

Figure 3-12. Comparison of the production costs for the alternative processes. ....................................20

Figure 3-13. Production costs of CTG processes vs. natural gas price; no $\mathrm{CO}_{2}$ costs.......................22

Figure 3-14. Production costs of CTG processes vs. costs of natural gas; $\$ 50 /$ ton $\mathrm{CO}_{2}$ costs.

Figure 3-15. Comparison of gasoline production costs for natural GTG process with refining from crude oil as a function of the costs of natural gas, $\mathrm{CO}_{2}$ and crude oil. .25

Figure 3-16. Effect of $\mathrm{CO}_{2}$ disposition on gasoline production costs for the conventional CTG process.

Figure 3-17. Effect of $\mathrm{CO}_{2}$ disposition on gasoline production costs for the CTG process with SMR. .29

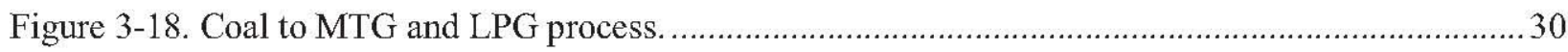

Figure 3-19. Potential site for the Paducah carbon conversion plant. .33 
Figure 3-20. Notional layout of coal to MTG and HTGR plants.............................................. 34

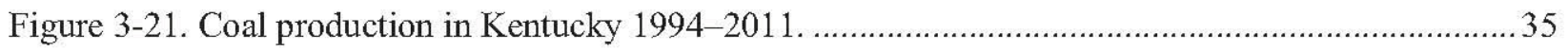

Figure 3-22. Kentucky natural gas production and interstate receipts........................................ 36

Figure 3-23. Coal mine and natural gas well locations in Kentucky. ........................................... 37

Figure $3-24$. Carbon conversion industry deployment by calendar year. ....................................... 38

Figure 3-25. Carbon conversion industry coal and natural gas consumption. .................................. 38

Figure 3-26. Carbon conversion industry deployment annual revenues and contributions to

Kentucky GDP.

Figure 3-27. Estimated expenditures and contributions to GDP during initial deployment of

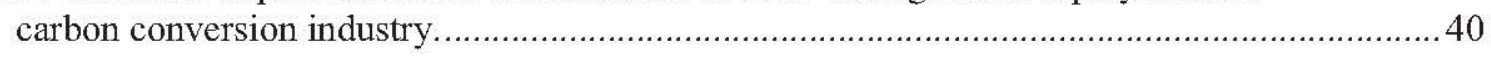

Figure 3-28. Distributed approach to deployment of a carbon conversion industry...........................4 41

Figure 3-29. Electricity generation transformation strategic goal.............................................. 42

Figure $3-30$. Transformation of electricity generation sources. ...................................................4 44

Figure 3-31. Comparison of electricity generation costs for HTGR with other power conversion

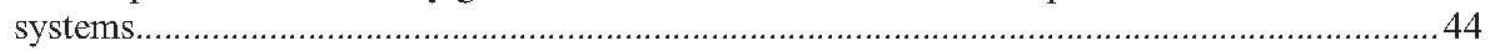

Figure 3-32. Generation technology mix during transformation of Kentucky's electricity generation sources.

Figure 3-33. Estimate of capital cost and annual contributions during the electricity generation transformation.

Figure 3-34. Estimate of increase in generation costs resulting from electricity generation transformation

Figure 3-35. $\mathrm{CO}_{2}$ emissions during the electricity generation sources transformation.

Figure 3-36. Contributions of carbon conversion industry and electricity generation transformation to the Kentucky GDP.

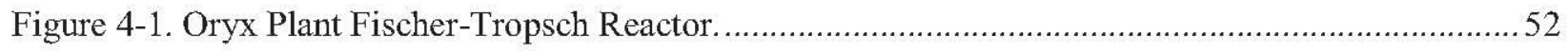

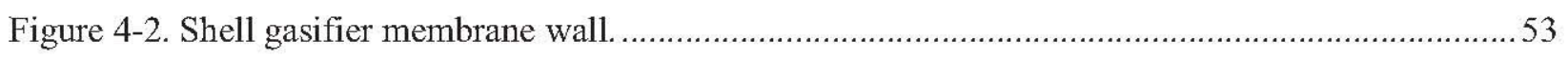

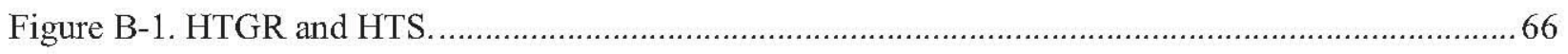

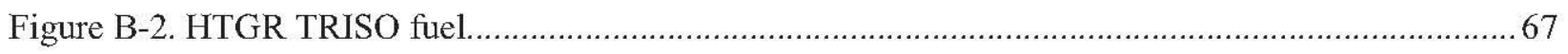

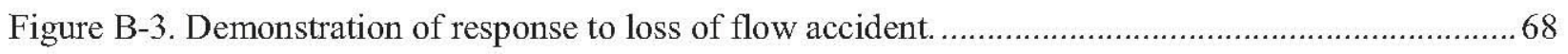

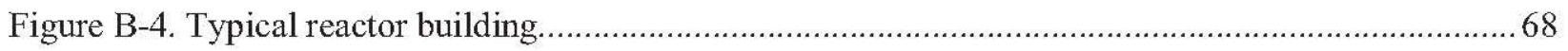

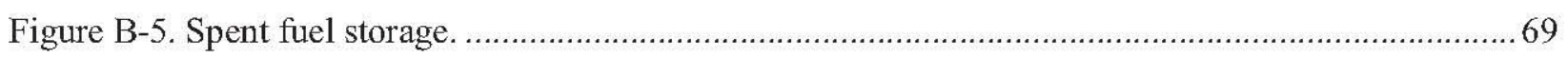

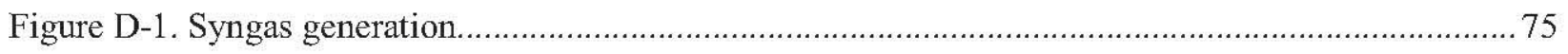

Figure D-2. Alternative syngas supply feedstocks and configurations. ......................................... 76

Figure D-3. Conventional FT Production of Diesel, Naphtha and LPG. ......................................... 77

Figure D-4. Alternative further processing of F-T naphtha to produce chemicals. .............................. 77

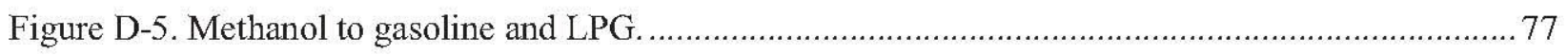

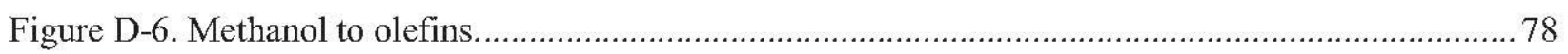


Figure D-7. Comparison of $\mathrm{CO}_{2}$ generation and the potential for capture in coal to liquids process alternatives.

Figure D-8. Conventional CTL using the traditional Fischer Tropsch process. ............................... 80

Figure D-9. CTL process incorporating HTGR and HTSE technologies. .................................. 80

Figure D-10.CTL FT process using conventional SMR for hydrogen supply................................ 81

Figure D-11. CTL FT process using HTGR incorporated SMR for hydrogen supply. ....................... 81

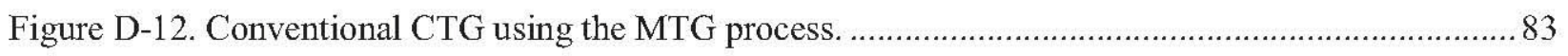

Figure D-13. CTG process applying HTGR and HTSE technologies. ...................................... 84

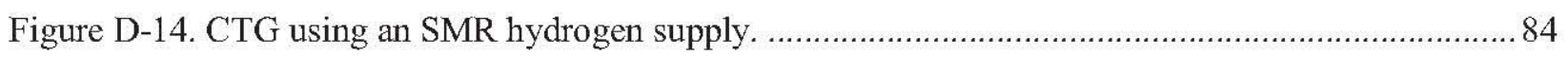

Figure D-15. CTG using an SMR with HTGR hydrogen supply. ......................................... 85

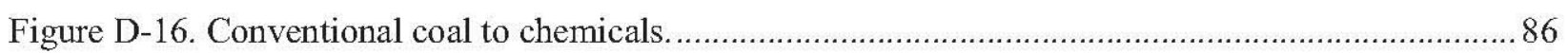

Figure D-17. Coal to chemicals process incorporating HTGR and HTSE technologies. ...................... 87

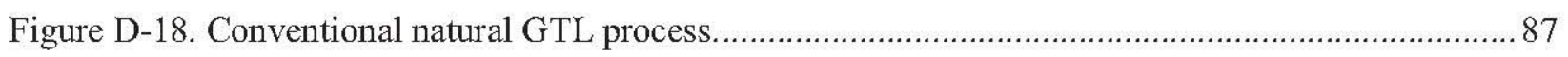

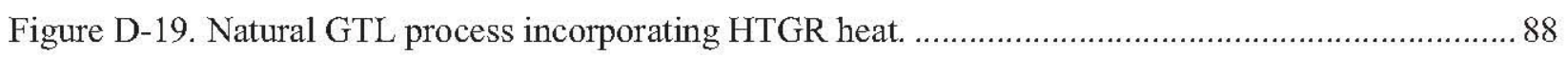

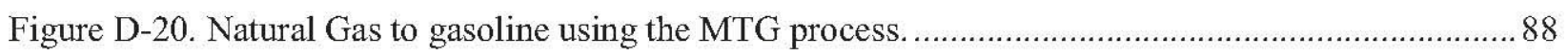

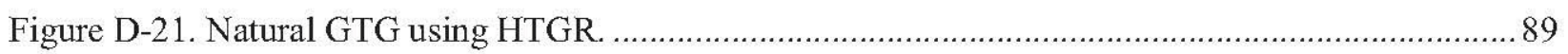

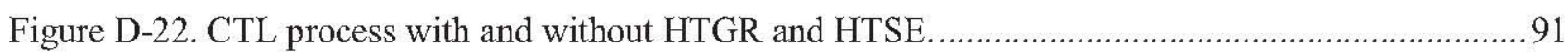

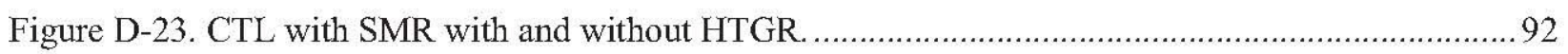

Figure D-24. CTG process with and without HTGR and HTSE. ...........................................93

Figure D-25. CTG with SMR hydrogen supply and with HTGR heat. ......................................94

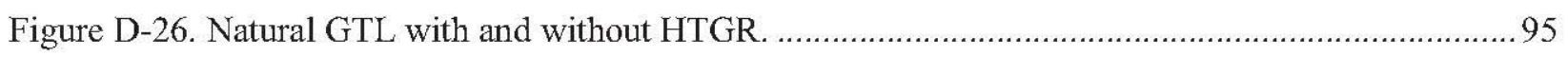

Figure D-27. GTG without and with incorporation of HTGR heat and electricity..........................96

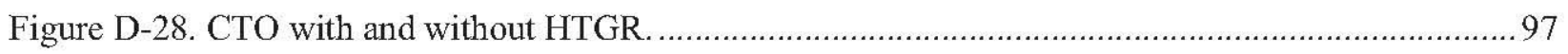

Figure D-29. Expansion of the CTL process to producing chemicals from naphtha...........................98

Figure D-30. History of natural gas prices to industrial consumers, January 2001 through February 2012 .

Figure E-1. Comparison of the production costs of conventional carbon conversion processes with the production cost of diesel refined from crude oil vs. the price of crude oil.

Figure E-2. EIA projections of the potential range of crude oil prices from the present through 2035.

Figure E-3. Production costs of conventional and nuclear incorporated coal and natural GTG processes compared with the production cost of gasoline refined from crude oil vs. the price of crude oil.

Figure E-4. Comparison of production costs for alternative carbon conversion processes. 109

Figure E-5. HTSE hydrogen production cost versus cost of electricity. 109

Figure E-6. Projections on long term price of natural gas. 110 
Figure E-7. Comparison of United States with International natural gas prices in $2010 \ldots \ldots \ldots \ldots \ldots \ldots \ldots \ldots 111$

Figure E-8. Total capital investment for candidate process plants. ........................................... 113

Figure E-9. Comparison of costs of electricity generation for several technologies. .........................114

Figure E-10. Effect of variations in key parameters on diesel pricing for conventional CTL

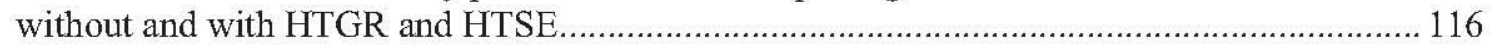

Figure E-11. Effect of variations in key parameters on diesel pricing for CTL with SMR without

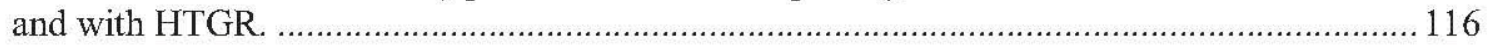

Figure E-12 Results of Monte Carlo analysis of parameter variations on the probability of diesel productions costs using the CTL with SMR process conclusions on economics.................. 117

Figure E-13. SMR hydrogen production costs versus. cost of natural gas and $\mathrm{CO}_{2}$ with sequestration.

Figure E-14. SMR hydrogen production cost versus cost of natural gas and $\mathrm{CO}_{2}$ without sequestration......

Figure F-1. Summary of the results of the survey of the PACRO site.

Figure F-2. Potential site for the carbon conversion plant.

Figure F-3. Geological characterization.

Figure F-4. Conventional CTG plant with SMR hydrogen supply.

Figure F-5. CTG plant with an HTGR supplying heat and electricity to the SMR hydrogen supply.

Figure F-6. CTG plant performance characteristics.

Figure F-7. Notional plan view of fully deployed CTG plant

Figure F-8. Paducah CTG plant with SMR and HTGR fully deployed.

Figure F-9. CTG plant w/SMR first phase deployment.

Figure F-10. Annual and accumulative funding requirements.

Figure F-11. Jobs during construction of Paducah process plant

Figure F-12. Paducah plant project accumulative cash flow.

Figure F-13. HTGR technology development projected schedule.

Figure F-14. Paducah HTGR plant deployment.

Figure F-15. Annual and accumulative funding required for deployment of the Paducah HTGR plant.

Figure F-16. Jobs during deployment of the Paducah HTGR plant. 146

Figure F-17. Sensitivity of selling price of gasoline to variations in key economic parameters. 147

Figure F-18. Combined effect of parameter uncertainties on gasoline production cost. 148

Figure F-19. Coal production in Kentucky 1994-2010. 149

Figure F-20. Carbon conversion industry deployment schedule. 150

Figure F-21. Natural gas and coal production sites in Kentucky. 151

Figure F-22. Distributed approach to deployment of a carbon conversion industry. 151 
Figure F-23. Kentucky's electricity generation sources transformation objective. ............................. 152

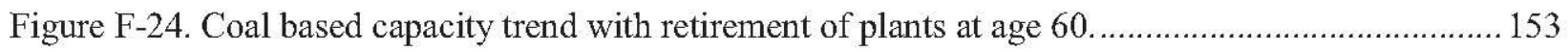

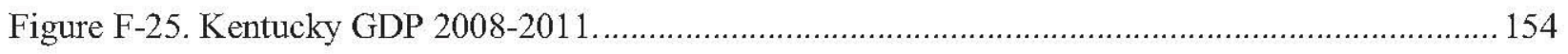

Figure F-26. Components of GDP change in Kentucky 2010 to 2011 ........................................ 154

Figure F-27. Carbon conversion deployment expenditure profile. ........................................ 156

Figure F-28. Carbon conversion industry annual coal and natural gas consumption. ........................ 156

Figure F-29. Natural gas production and interstate receipts. ................................................... 157

Figure F-30. Carbon conversion industry annual revenues and contribution to Kentucky GDP............ 157

Figure F-31. Schedule for integration of HTGR technology into the carbon conversion industry.......... 158

Figure F-32. Expenditure profile for integration of HTGR technology into the Kentucky carbon

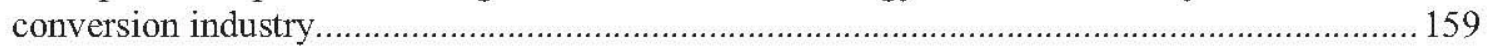

Figure F-33. Electrical capacity additions integrating HTGR into the carbon conversion industry........ 159

Figure F-34. Retained upgraded coal plants after retirement of selected plants. .............................. 161

Figure F-35. Transformation of electricity generation sources................................................... 162

Figure F-36. Generation technologies mix during transformation of the Kentucky electricity

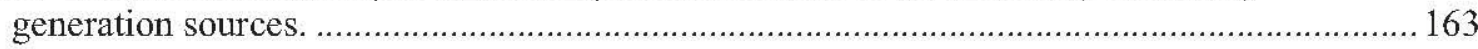

Figure F-37. Estimated costs of the Kentucky electricity generation technologies transformation......... 164

Figure F-38. Estimate of electricity generation cost increases from electricity generation

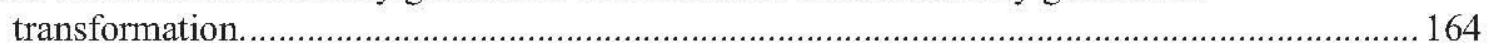

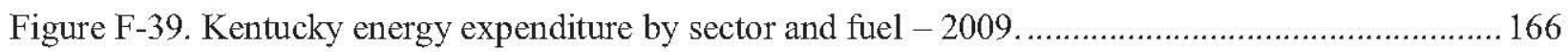

Figure F-40. Contributions of carbon conversion industry and transformation of electricity

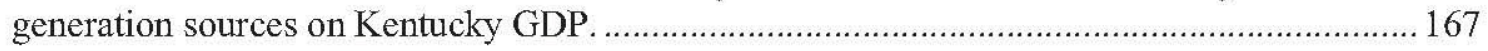

Figure G-1. Haldor Topsoe Convective Reformer (HTCR) design. .......................................... 170

Figure G-2. Haldor Topsoe Exchange Reformer (HTER) internals being installed at Sasol facility....... 171

\section{TABLES}

Table 3-1. Carbon conversion alternatives evaluated. .11

Table A-1. Composition of the available purchase area labor pool in target sectors:..........................6 62

Table D.1. Carbon conversion alternatives evaluated............................................................................. 78

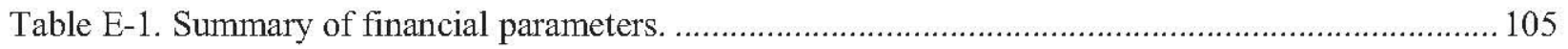

Table E-2. Variations for conventional CTL processes without HTGR and HTSE technologies. ...........115

Table E-3. Variations for CTL processes with HTGR and HTSE Technologies ...............................115

Table F-1. USEC Site Paducah, KY (PACRO Site Bank Assessment) .......................................... 125

Table F-2. Summary of economic analysis of Reference Paducah plant.......................................... 146

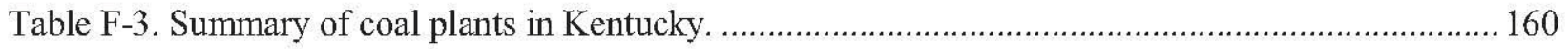




\section{ACRONYMS}

CCS carbon capture and sequestration

CTG coal to gasoline

CTL coal to liquids

CTO coal to olefins

DCL direct coal liquefaction

DOE Department of Energy

EIA Energy Information Administration

EOR enhanced oil recovery

EPA Environmental Protection Agency

FT Fischer-Tropsch

GAV gross added value

GDP gross domestic product

GTG gas to gasoline

GTL gas to liquids

HTGR high temperature gas-cooled reactor

HTSE high temperature steam electrolysis

INL Idaho National Laboratory

LPG liquid petroleum gas

LWR light water reactor

MTG methanol to gasoline

NGCC natural gas combined cycle

NGNP Next Generation Nuclear Plant

PACRO Paducah Area Community Reuse Organization

PGDP Paducah Gaseous Diffusion Plant

SMLWR small modular light water reactor

SMR steam methane reforming

TVA Tennessee Valley Authority

WGSR water gas shift reaction 
INL/EXT-12-26710

November 2012

$\mathrm{xviii}$ 


\section{DEVELOPMENT APPROACHES AND PATH FORWARD}

Important opportunities exist for the energy future of Kentucky that will:

- Sustain and possibly grow its coal and natural gas industries

- Add substantive value to its indigenous coal and natural gas resources

- Reduce dramatically the environmental effect of energy production and power generation capability

- Add substantive opportunities to develop an advanced manufacturing industry in the Commonwealth

- Increase the Commonwealth's gross domestic product (GDP).

These can be achieved through development of a carbon conversion industry for the transformation of coal and natural gas to synthetic transportation fuels, chemical feedstock and chemicals that are the building blocks for the chemical industry. Over the longer term, environmentally clean nuclear energy (e.g., high temperature gas-cooled reactors [HTGRs]) can provide the substantial energy needs of a carbon conversion industry and be part of the diverse mix of replacement technologies for the current fleet of ageing coal-fired electric power generating stations.

\subsection{Energy Development Approaches for Kentucky}

The opportunities for Kentucky's energy future can be achieved through the following:

- Strengthening the coal and natural gas economy in Kentucky by building a carbon conversion industry - A carbon conversion industry will add substantive value to Kentucky's major indigenous resource - coal. Carbon conversion will produce high value synthetic transportation fuels and chemicals that form the building blocks for the chemical industry. Over the longer term, environmentally responsible nuclear energy (e.g., HTGRs) can provide the substantial energy needs of the carbon conversion industry and help stabilize volatile energy prices.

- Developing a viable economic future for the highly trained and experienced workforce in the Paducah area - The phased construction of a coal conversion facility in Paducah is an important part of the implementation of a carbon conversion industry throughout the Commonwealth and provides both short and long term opportunities for utilizing the experienced workforce and strengthening the regional economy.

- Ensuring continued reliable and affordable sources of energy for Kentucky's industries and populace by diversifying the technologies for generating electric power - Anticipated increased environmental requirements necessitate looking at alternative forms of energy production, and in particular electric power generation. A diverse mix of power generation technologies (e.g., nuclear energy, clean coal and natural gas technologies) is warranted considering the uncertainties inherent in predicting future energy resources and demand.

As part of ongoing activities to address these goals, the Kentucky Energy and Environment Cabinet participated in a collaborative evaluation of energy development opportunities with the NGNP Industry Alliance (an industry consortium), and the Department of Energy's (DOE's) Idaho National Laboratory (INL). This report summarizes the results of these evaluations to identify:

- Technically and economically viable approaches to increase the value added to the economy associated with the extraction and processing of indigenous resources (coal and natural gas).

- Opportunities for application of nuclear energy technologies as part of the overall energy mix with emphasis on integration of HTGR technology. The HTGR technology and other forms of nuclear energy provide an option that is environmentally clean and provides stable, competitive energy prices. 
- Industrial infrastructure capabilities and needs that support the long term energy future.

\subsection{Conclusions}

This evaluation concludes that a viable option for the Commonwealth of Kentucky is development of a carbon conversion industry that uses a variety of processes for conversion of coal to synthetic transportation fuels, chemical feedstock and commodity chemicals. This option provides substantive increases in the value-added to indigenous resources, with a commensurate contribution to the Commonwealth's GDP. This report focuses on evaluating a new industry in Kentucky around its largest indigenous resource - coal. This new industry offers the opportunity for conversion of coal to other hydrocarbon forms that can be used for transportation and manufacturing in Kentucky and exported for both domestic and international use.

The most attractive approach is to adopt a phased approach with industry building one or more initial coal conversion process plants that represent a viable business case, and over the longer term adding process plants as needed to maintain and grow the Commonwealth's economy. Additionally, as advanced nuclear energy technology (e.g., HTGR technology) becomes commercially available it will be integrated for process operations to take advantage of it as an economic, long term, high availability energy supply with no greenhouse gas emissions at a stable price.

The report suggests that Kentucky's entry into the carbon conversion industry include two coal to liquids (CTL) facilities - one for the high sulfur coal in western Kentucky and one for the low sulfur coal in eastern Kentucky. The western Kentucky facility, suggested to be located in Paducah, addresses a short-term goal of developing a viable economic future for the highly trained and experienced workforce in the Paducah area. Today that work force supports, and is supported by, the operations of DOE's Paducah Gaseous Diffusion Plant (PGDP) that could cease enrichment operations as early as May 2013.

The other plant could be located in eastern Kentucky using the low sulfur eastern Kentucky coal as feedstock and natural gas for production of hydrogen needed in the process. This would begin to provide an internal stable market for eastern Kentucky's coal and natural gas to offset the steady reduction in its production experienced over the last decade and projected to continue because the retirement of coal based electricity generation in Kentucky and nationally; the principal market for eastern Kentucky coal. The further long term development of the carbon conversion industry in Kentucky would be focused on increasing this market to build a higher level of base consumption of coal and natural gas in eastern Kentucky.

An initial step forward in building a carbon conversion industry would be phased construction over the next decade of the two initial coal conversion facilities using conventional technologies to produce transportation fuels.. The design of these coal conversion facilities should be compatible with integration of HTGR technology in about two decades to address anticipated environmental requirements and potential volatile international energy pricing. Similar phased construction of additional coal conversion facilities could be extended over the following decade to build a substantive industry benefitting the local and Commonwealth economies.

The following results and conclusion are developed in this report:

- The technical and economic viability of carbon (coal and natural gas) conversion processes has been evaluated against a set of criteria including:

- Competitiveness in the anticipated market

- The extent to which value is added to the economy 
- The flexibility in using alternative feedstock and in the range of products that can be produced to accommodate changes in the market

- The experience base for the technology

- The ability to utilize nuclear energy and associated technologies as needed to reduce carbon and other emissions.

- Conversion of coal to synthetic transportation fuels (e.g., gasoline, diesel, liquid petroleum gas [LPG]), chemical feedstock and to building block chemicals (e.g., olefins) provides considerable improvement in the value of Kentucky's indigenous coal resource compared to contemporary uses such as electricity production or exporting coal without such processing.

- Two facilities to initiate the carbon conversion industry in Kentucky appear technically and economically viable.

- Work on such facilities could be started as early as 2013 using conventional technologies, assuming availability of necessary funding. The scale of the facilities can be approached in a modular fashion (e.g., start at $\sim 1 / 4$ of full capacity) to spread out the capital investment and confirm operational problems are identified and resolved before committing further capital. Conventional conversion technologies emit considerable quantities of $\mathrm{CO}_{2}$. Analyses have shown that a major part of these emissions can be captured to be sequestered in permanent underground storage or utilized for enhance oil recovery to the extent such a market is available. It is estimated that the market for enhanced oil recovery (EOR) is not viable over the long term; however, there are considerable underground volumes for sequestration, subject to future economic viability.

- The costs for producing the products (e.g., synthetic transportation fuels, feedstock and chemicals) using conventional technologies are expected to be competitive with products produced by processing of domestic and imported crude oil and natural gas.

- Depending on the extent of environmental restraints (e.g., through imposed costs for carbon emissions and the long term costs of sequestration), the facilities could be expanded in a phased approach by 2029 to integrate HTGR technology as the primary energy supply. This nuclear energy technology has the inherent advantages of no emissions and insensitivity to global hydrocarbon prices. Hence, choosing the appropriate conventional conversion technology and integrating with nuclear energy can lead to a coal conversion capability that has minimal carbon emissions and stable long term energy pricing.

As a separable and practical reality, the retirement over the next five decades of Kentucky's ageing coal-fired electric power generating fleet requires long range planning to ensure that the replacement power generating technologies fulfill the desired or policy-imposed environmental requirements. As described in this report, selecting a diverse set of replacement power generating technologies is warranted, considering the uncertainties inherent in predicting the future energy resources and needs, nationally and internationally. Best available information suggests that the transformation to this diverse set of technologies should initially include natural gas combined cycle (NGCC) generation, subsequently complemented by clean coal technologies and nuclear energy - the mix primarily determined by anticipated energy price trends, Kentucky's expected long term industrial base, and desired energy selfsufficiency and export posture. This diverse mix allows Kentucky and its industry to adjust to the changing global energy landscape and not find itself in an inelastic energy technology position.

A review was also performed of the energy required for uranium and uranium tailings enrichment and for decontamination and reconstitution of contaminated metal components that have been used in the gaseous diffusion enrichment processes at Paducah and Portsmouth, Ohio. The latter function could recover tons of copper, nickel and stainless steel with substantial potential value. The objective of this review was to establish if there is sufficient energy required to investigate incorporating the HTGR 
technology in all of these applications. This review concluded that the energy required for these processes is relatively small compared with the capacity of the HTGR, (e.g., 285 MW(t) for such processes compared with $600 \mathrm{MW}(\mathrm{t})$ for a single HTGR module). Accordingly, this application does not have sufficient energy requirements to justify a dedicated HTGR plant, but could be included in the demand for a plant supplying energy to a carbon conversion process plant, if the economics are viable. The viability of this application could be evaluated as part of the detailed design of a Paducah carbon conversion plant.

Additionally, broad opportunities exist for the development of the industrial infrastructure that supports the carbon conversion industry and the nuclear energy industry. Such infrastructure could include providing equipment and systems including modular assemblies for the carbon conversion and nuclear energy portions of such complexes as well as supplying materials and maintenance and outage services.

\subsection{Suggested Overall Path Forward}

- Pursue developing collaborative partnerships with industry to build the initial portions of a carbon conversion industry. It is suggested that such partnerships be based on constructing and operating at least two initial coal conversion facilities, one located in the Paducah area and one in eastern Kentucky, either in parallel or one shortly following the other. These facilities would be used for conversion of western Kentucky coals and eastern Kentucky coals, respectively. The considerable differences in the coal characteristics suggest that two separate initial process plants should be constructed, potentially based on two different carbon conversion process technologies.

These partnerships should include development of strategies for achieving these initiatives. Such strategies would address project market and transportation and distribution needs, investment structure and incentives, support of the mining industry, goals for GDP growth, desired increases in export of natural gas, coal and electricity, reductions in emissions, and tempering of increasing costs of energy. Relevant projections could include long term coal and natural gas production rates, competitive coal and natural gas pricing, existing coal-based electricity plant retirements and upgrades.

- In the planning basis for the carbon conversion industry, ensure that economically competitive and environmentally compatible process plant design configurations are chosen that support a phased approach to integrating nuclear energy as the long term source of energy.

- Discuss the Tennessee Valley Authority's (TVA) long term plans for the operation of the Shawnee Fossil Plant (net summer rating of $1206 \mathrm{MW}(\mathrm{e})$ ).

- Develop a plan for utilization of the experienced workforce in transitioning from the operation and maintenance of PGDP and decommissioning (and possible demolition) of PGDP to the construction and operation of the initial Paducah coal conversion plant module and the transition to its expanded capacity. Establish agreements-in-principle with DOE regarding use of the Federal property in Paducah.

- Prepare a plan that anticipates retirement of portions of the current coal fired power generation fleet (e.g., considering age and evolving regulations) and the deployment of a diverse set of alternative technologies including nuclear energy technologies for base load capabilities. This report provides a notional basis for such planning. An essential decision is the extent to which Kentucky and its power generating industry plan to be a net exporter of energy in the form of electricity considering tradeoffs such as investments in new generating capacity and enlarged transmission system capacity.

- Prepare a plan for industrial infrastructure development based on the needs of a growing carbon conversion industry and in the future, a nuclear energy industry. This should include regulatory and educational institution changes that will be required within the Commonwealth. 
November 2012

- Prepare an evaluation of the overall effect on the economy and demographics in Kentucky as these industrial capabilities are realized. 


\section{BACKGROUND AND REPORT STRUCTURE}

A collaborative evaluation was conducted by the Kentucky Energy and Environment Cabinet, the NGNP Industry Alliance Limited and the INL and is reported herein that examined (1) technically and economically viable approaches for increasing the value to the economy of extracting and processing indigenous resources, (2) the potential for integrating nuclear energy technology (e.g., HTGRs) in the long term mix of energy sources for Kentucky, and (3) infrastructure capabilities and needs to support Kentucky's long term energy future. Integral to these evaluations was identifying short and long term opportunities for the Paducah, Kentucky area to take advantage of the experienced workforce resources in that area due to the pending closure of the DOE uranium enrichment facility and the needs to provide a stable long term market for eastern Kentucky coal to offset continuing reductions in production due to retirements of coal based electric power plants; the principal market for this coal. The evaluation also examined long term use of HTGRs in Kentucky for base load electricity generation to augment and replace existing, ageing generation in Kentucky.

This evaluation was discussed in letters between the NGNP Industry Alliance Executive Director, Frederick Moore and the Energy and Environmental Cabinet Secretary, Dr. Leonard K. Peters, including:

- Letter from Frederick L. Moore (Alliance) to Dr. Leonard K. Peters (Secretary, Kentucky Energy and Environment Cabinet), [Follow up on results of meeting in November 2011 and provided recommended outline of collaborative evaluation], December 5, 2011

- Letter from Dr. Leonard K. Peters to Frederick L. Moore, [Agreement with pursuing a collaborative evaluation and suggesting a two stage approach], December 29, 2011

- Letter from Frederick L. Moore to Dr. Leonard K. Peters, [Provided a suggested scope, approach, schedule and participant roles for the two stage collaborative evaluation], January 13, 2012

This report summarizes the results, conclusions, and recommendations of the evaluation focused on the following:

- Technically and economically viable approaches to increase the value added to the economy associated with the extraction and processing of the indigenous resources of coal and natural gas. The primary approach adopted for the evaluation is the conversion of coal and natural gas to other hydrocarbon forms for use in transportation and manufacturing

- Opportunities for the application of nuclear energy technologies, with emphasis on HTGR technology, as a major part of the energy mix in meeting the energy needs of the Commonwealth for processing of indigenous resources and generation of electricity

- Industrial facility options for carbon conversion to be located on the current PGDP site and in eastern Kentucky. These options are intended to ultimately utilize integrated nuclear energy (HTGRs) for process heat production and electric power generation.

- Specific alternative processes for coal and natural gas conversion. Such evaluations include assessment of technical feasibility, economic viability, national policy uncertainty and regulatory risk

- Deployment strategies that:

- Use a phased approach to achieve deployment of viable processes at the earliest practical time by applying primarily conventional processes. A phased approach spreads out capital investment and minimizes project risk

- Facilitate the integration of nuclear energy technologies for environmental and economic considerations over the long term 
- Maintain flexibility to adapt to new processing developments and evolving government policies and regulations, prices of energy, prices of feedstock, and Commonwealth objectives.

- Kentucky's electric power generation industry, within the Commonwealth and adjacent states, and investigate apparent options for diversifying electric power generation to include nuclear energy/HTGRs

- Alternative potential business cases including various products, including electric power, to be produced

- Conditions for use of current government property and adjacent properties as required for a commercial business venture

- Availability of indigenous resources and industrial infrastructure that enable conclusions affecting the preceding (e.g., skilled manpower, water, electric power, coal, natural gas, rail and road transportation)

- Possible options for infrastructure development to support an emerging nuclear energy industry within Kentucky and elsewhere, (e.g., nuclear equipment manufacture; nuclear fuels fabrication)

The rest of this report is structured as follows:

Section 3-Results and Conclusions: Detailed discussion of the results and conclusions regarding the technologies and phased approaches to developing a carbon conversion industry, the sources of energy for that industry and the long term transition to a diverse electricity generation capability

Section 4 -Infrastructure Development Opportunities: Characterization of the equipment, material, construction and operating labor and maintenance services that are required for successful deployment of the carbon conversion process that can provide opportunities and potential economic benefit from expansion of existing or development of new infrastructure and industries within the Commonwealth to support the expansion and operation of these process plants.

The following appendices provide important background information in support of this evaluation:

Appendix A, Evaluation Team and Summary of Paducah area characteristics

Appendix B, High Temperature Gas-cooled Technology and Safety Basis

Appendix C, NGNP Industry Alliance Limited

Appendix D, Process Alternatives Functional and Performance Characteristics

Appendix E, Process Alternatives Economic Analyses

Appendix F, Deployment Strategies

Appendix G, Steam Methane Reformer Modification. 


\section{RESULTS AND CONCLUSIONS}

\subsection{General}

Several investigations were performed to identify and formulate carbon conversion development opportunities for expanding the market and increasing the value of the indigenous coal and natural gas resources in Kentucky through the deployment of carbon conversion processes and integration of nuclear energy to satisfy energy needs in the Commonwealth. These investigations (1) identified carbon conversion processes that match up with the characteristics of the coal and natural gas in Kentucky and the market for the products from these processes, (2) evaluated the technical and economic viability of each of the processes, (3) established the role of nuclear energy with emphasis on HTGR technology as incorporated in the carbon conversion processes and as an alternative for coal based electricity generation, and (4) identified the alternatives that meet the objectives of this collaborative effort and are technically and economically viable

An important opportunity exists for the Commonwealth of Kentucky to develop and deploy a carbon conversion industry using coal and, where viable, natural gas as feedstock for the production of synthetic transportation fuels, chemical feedstock and chemicals. A notional strategy for developing a carbon conversion industry is described herein to provide perspective on the elements that need to be addressed and the scope, costs and schedule required. This deployment strategy includes two principal initiatives. The first addresses the deployment of a carbon conversion process plant using western Kentucky coal in the Paducah area to initiate development of a carbon conversion industry to take advantage of the experienced workforce resources in that area that will be available when enrichment operations cease at DOE's PGDP. The second is a parallel plan to deploy plants that emphasize use of eastern Kentucky coal to forestall a continuing reduction in the production of coal from this area due to retirement of coal based electricity in Kentucky and throughout the United States, and the installation of emissions control equipment on other plants such that the low sulfur coal produced in eastern Kentucky is no longer required.

Analyses of this notional carbon conversion industry conclude that its deployment is technically feasible, can produce fuels and chemicals at a production cost competitive with similar products from traditional industries, and can generate returns on investment at these production costs that are expected to be consistent with industry objectives. Further, such a carbon conversion industry adds substantive value to the Kentucky economy beyond the cost of the coal and natural gas as feedstock through conversion to higher value products for use within Kentucky and for national and international export. Deployment of this industry will better retain the value of these indigenous resources within Kentucky, have significant impact on the local economies of Paducah and eastern Kentucky and increase the contribution of mining and processing these resources to the Kentucky GDP.

Over the longer term, nuclear energy provides an important option to address the energy needs of a growing carbon conversion industry and as part of a diverse mix of energy production technologies to replace coal-fired electric power generation facilities being retired due to age and potentially uneconomical upgrades to satisfy ever more demanding environmental requirements. Nuclear energy provides a long term, environmentally clean source of energy at a stable price that is competitive with other alternatives. The HTGR technology is best suited for the high temperature process heat needs of a carbon conversion industry and provides high efficiency and competitive generation costs for electric power generation. 
INL/EXT-12-26710

November 2012

\subsection{Comparison with Kentucky's Long Term Energy Plan}

The options evaluated herein, including transformation of the electric generation industry, support the objectives of the energy development plans proposed for Kentucky in Governor Beshear's 7 point strategy in "Intelligent Energy Choices for Kentucky's Future," Commonwealth of Kentucky, November 2008. The following strategies of this plan are addressed herein:

- Strategy 4: Develop a CTL industry in Kentucky to replace petroleum-based liquids

- Strategy 5: Implement a major and comprehensive effort to increase gas supplies, including coalto-gas in Kentucky

- Strategy 6: Initiate aggressive carbon capture and sequestration (CCS) projects for coal-generated electricity in Kentucky

- Strategy 7: Examine the use of nuclear power for electricity generation in Kentucky

The strategic plan calls for diversification across the electric power generation sector so that the anticipated growth in the need for electricity by 2025 can be met while at the same time reducing greenhouse gas emissions to a point $50 \%$ lower than they would be under a business-as-usual scenario, in fact, $20 \%$ lower than 1990 emissions levels.

The goals and actions of Strategy 4 are particularly pertinent and parallel the results, conclusions and recommendations herein, to wit:

\section{Strategy 4, Develop a CTL Industry in Kentucky to Replace Petroleum-Based Liquids}

Energy independence and economic security are major objectives of this plan for Kentucky and for the United States. Volatile petroleum prices beyond our control promise to rise again as the economy recovers. The United States imports $60 \%$ of its petroleum, largely from unstable regions in the Middle East and South America. But, Kentucky has abundant coal resources and is the third largest coal producer in the United States. The high emissions of carbon dioxide into the environment must be addressed now, as the United States moves toward federal mandates and penalties for coalfired power generation. Kentucky can diversify ultimate coal utilization, producing cleaner and more efficient energy for state and domestic use. Coal-to-liquid and coal-to-gas Technologies can replace petroleum-based liquids and imported natural gas, respectively.

\section{Goal}

Kentucky will develop a CTL industry that will use 50 million tons of coal per year to produce four billion gallons of liquid fuel per year by 2025.

With its vast coal resources, proven support from elected officials, and dedicated research and development program, Kentucky is uniquely positioned to develop a CTL industry that can serve as an engine for economic growth, while helping to reduce our dependence on foreign oil. The actions in Strategy 4 further support the implementation of the state's alternative transportation fuel standard.

\section{Actions to Achieve the Goal}

1. Kentucky will sanction two 500 million gallon per year (approximately 35,000 barrels per day) CTL fuel facilities in both 2013 and 2014, and then two additional 480 million-gallon per year CTL fuel facilities by 2018, and two more by 2025, for a total of eight new CTL facilities.

\footnotetext{
b The following text through the "Actions to Achieve the Goal" are taken directly from "Intelligent Energy Choices for
} Kentucky's Future," Commonwealth of Kentucky, November 2008. 
INL/EXT-12-26710

November 2012

2. To ensure that trained personnel are available to staff increased coal consumption required by the CTL industry, Kentucky's Energy and Environmental Cabinet will work with the Community and Technical College System to identify appropriate training programs. To achieve the required employment levels, increased training capabilities should be available within the next three years.

3. Kentucky will evaluate its current coal mining capabilities to ensure that it can achieve the necessary levels of coal production to support both coal-fired electricity generation and the development of a CTL industry in the near-term.

The following present the results of the evaluations that parallel these goals and actions including:

- The functional and performance characteristics and economics of the alternative processes that could be applied in developing the carbon conversion industry.

- The specific processes used to demonstrate a carbon conversion industry development and the strategy for siting plants in Paducah and in eastern Kentucky

- The application of HTGR nuclear energy technology to reduce emissions and stabilize energy costs in the carbon conversion industry and as part of the installation of new generation to replace retired coal based generation

- The transformation of the electricity generation sources in Kentucky over the longer term in accordance with Commonwealth objectives

- Assessment of the impact of these activities on the local Paducah and eastern Kentucky economies and the Kentucky GDP.

\subsection{Process Alternatives}

Table 3-1 summarizes the attributes and nomenclature for the several carbon conversion processes evaluated in this effort. 
Table 3-1. Carbon conversion alternatives evaluated.

\begin{tabular}{|c|c|}
\hline Acronym & Process \\
\hline \multicolumn{2}{|c|}{ Coal to liquids $(C T L)^{1, \mathrm{c}}$ - producing diesel, naphtha and liquefied petroleum gas } \\
\hline CTL & Conventional CTL using the Fischer-Tropsch (FT) process \\
\hline CTL w/SMR & $\begin{array}{l}\text { Conventional CTL with steam methane reforming (SMR) supplying hydrogen } \\
\text { to the coal gasifier }\end{array}$ \\
\hline CTL w/SMR \& HTGR & $\begin{array}{l}\text { CTL with SMR (CTL w/SMR) with HTGR supplying heat and electricity to } \\
\text { the steam methane reformers }\end{array}$ \\
\hline $\begin{array}{l}\text { CTL w/HTGR \& } \\
\text { HTSE }\end{array}$ & $\begin{array}{l}\text { CTL with HTGR and high temperature steam electrolysis (HTSE) supplying } \\
\text { hydrogen to the coal gasifier }\end{array}$ \\
\hline \multicolumn{2}{|c|}{ Natural gas to liquids $(G T L)^{4}$-producing diesel, naphtha and liquefied petroleum gas } \\
\hline GTL & Conventional natural GTL using the FT process \\
\hline GTL w/HTGR & 1 GTL with HTGR supplying heat to the primary reformer \\
\hline \multicolumn{2}{|c|}{ Natural gas to gasoline (GTG) ${ }^{2}$ - producing gasoline and liquefied petroleum gas } \\
\hline GTG & Conventional natural GTG using the methanol to gasoline (MTG) process \\
\hline GTG w/HTGR & GTG with H0TGR supplying heat to the primary reformer \\
\hline \multicolumn{2}{|c|}{ Coal to gasoline $(C T G)^{5}$ - producing gasoline and liquefied petroleum gas } \\
\hline CTG & Conventional CTG using MTG process \\
\hline CTG w/SMR & Conventional CTG with SMR supplying hydrogen to the coal gasifier \\
\hline CTG w/SMR \& HTGR & $\begin{array}{l}\text { CTG with SMR (CTG w/SMR) with HTGR supplying heat and electricity to } \\
\text { the steam methane reformers }\end{array}$ \\
\hline $\begin{array}{l}\text { CTG w/HTGR \& } \\
\text { HTSE }\end{array}$ & CTG with HTGR and HTSE supplying hydrogen to the coal gasifier \\
\hline \multicolumn{2}{|c|}{ Coal to chemicals ${ }^{3}$-including olefins such as ethylene and propylene } \\
\hline CTO & Conventional coal to olefins (CTO) \\
\hline $\begin{array}{l}\text { CTO w/HTGR \& } \\
\text { HTSE }\end{array}$ & CTO with HTGR and HTSE supplying hydrogen to the coal gasifier \\
\hline \multicolumn{2}{|c|}{ Direct coal liquefaction (DCL) - producing diesel, naphtha and liquefied petroleum gas } \\
\hline DCL & DCL based on Bergius-Pier process \\
\hline
\end{tabular}

\subsubsection{Syngas Generation}

All of the processes listed in Table 3-1 involve conversion of coal and/or natural gas into some combination of diesel, naphtha, LPG, gasoline and commodity chemicals (e.g., ethylene and propylene). In all cases, except for the direct coal liquefaction (DCL) process, the first step in the process is the conversion of the feedstock to synthetic gas composed of a specific ratio of $\mathrm{H}_{2}$ and $\mathrm{CO}$, see Figure 3-1. With coal as the feedstock the synthetic gas is produced in a gasifier at high temperature.

In the coal gasification process the coal is burned in the gasifier generating $\mathrm{CO}$ and hydrogen among other tramp constituents in the coal and slag. There are several types of gasifiers commercially available; for the purposes of this evaluation a dry-fed gasifier similar to those supplied by Uhde and Shell was used. ${ }^{4}$ There is insufficient hydrogen in the coal to achieve the required ratio of $\mathrm{H}_{2}$ to $\mathrm{CO}$ in the syngas;

c All of the INL references in this report as well as other documentation of interest to the subjects of carbon conversion and the HTGR can be retrieved from the INL Website https:/inlportal.inl.gov/vhtrinformation. 
hence, another supply of hydrogen is required. In most commercial gasifiers this is done by injecting steam and using the water gas shift reaction (WGSR) to produce the hydrogen; $\mathrm{CO}+\mathrm{H}_{2} \mathrm{O} \gg \mathrm{CO}_{2}+\mathrm{H}_{2}$. This reaction is a major source of $\mathrm{CO}_{2}$ generation in the coal gasification process.

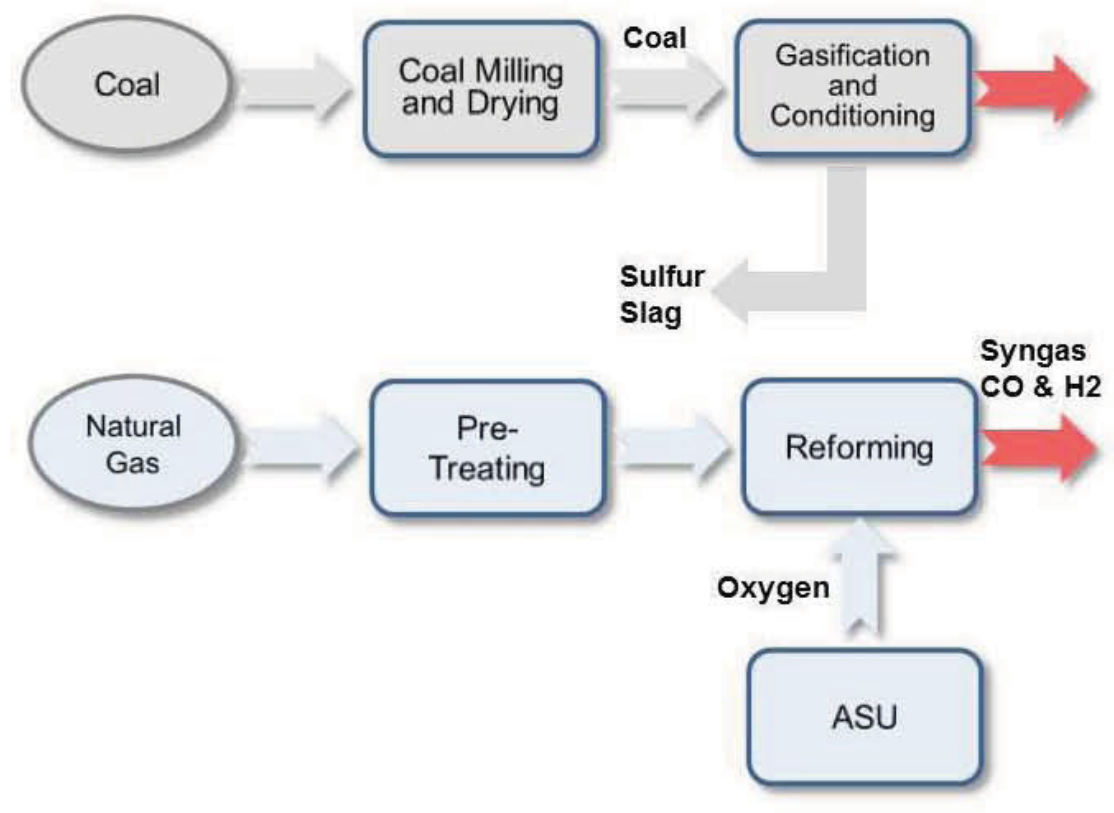

Figure 3-1. Syngas generation.

For natural gas feedstock the syngas is produced through a reforming process splitting the carbon and hydrogen in the gas and adding oxygen to produce the $\mathrm{H}_{2}$ and $\mathrm{CO}$ components of the syngas. In this case there is sufficient hydrogen in the natural gas to obtain the required ratio of $\mathrm{H}_{2}$ to $\mathrm{CO}$. This is an endothermic process and the heat is supplied by burning some of the natural gas. Burning natural gas for heat for this process is a major source of $\mathrm{CO}_{2}$ generation.

The quantities of $\mathrm{CO}_{2}$ produced in the coal gasification process are significantly higher than that for the natural gas reformer. In both cases, however, the majority of the $\mathrm{CO}_{2}$ generated in these processes can be captured, compressed and transported for geologic sequestration or EOR. However, capture is costly and there are important regulatory and liability uncertainties regarding the risks of geologic sequestration that must resolved to offer a credible assignment of cost. Further, there is insufficient capacity in EOR to make that a viable long term disposal pathway. See Section 3.1.7 and Appendix D.3 for more discussion on sequestration and EOR. Pending government regulation of $\mathrm{CO}_{2}$ emissions also make release economically unattractive. Accordingly, there is advantage to reducing the amount of $\mathrm{CO}_{2}$ generated in the syngas processes. Figure 3-2 shows four approaches evaluated herein.

Figure 3-2 shows three different configurations for providing an external supply of hydrogen to the coal gasifier as a substitute for WGSR to produce the required $\mathrm{H}_{2}$ to $\mathrm{CO}$ ratio, as follows:

- Steam methane reforming (SMR): A common process used in the United States to produce hydrogen from natural gas and water. This process is used throughout the petro-chemical industry with good success. Use of SMR reduces the $\mathrm{CO}_{2}$ generated in the process by $\sim 60 \%$ compared to a process using WGSR to produce hydrogen.

- SMR with HTGR heat: Conventional SMR burns some of the natural gas to supply the heat required for the endothermic reaction. This and the reaction itself produce about 9 tons of $\mathrm{CO}_{2}$ for every ton of hydrogen produced. Adding high temperature heat from the HTGR reduces $\mathrm{CO}_{2}$ generation by $83 \%$ 
compared to a process using WGSR to produce hydrogen and also generates about $15 \%$ more hydrogen for the same feed rate of natural gas.

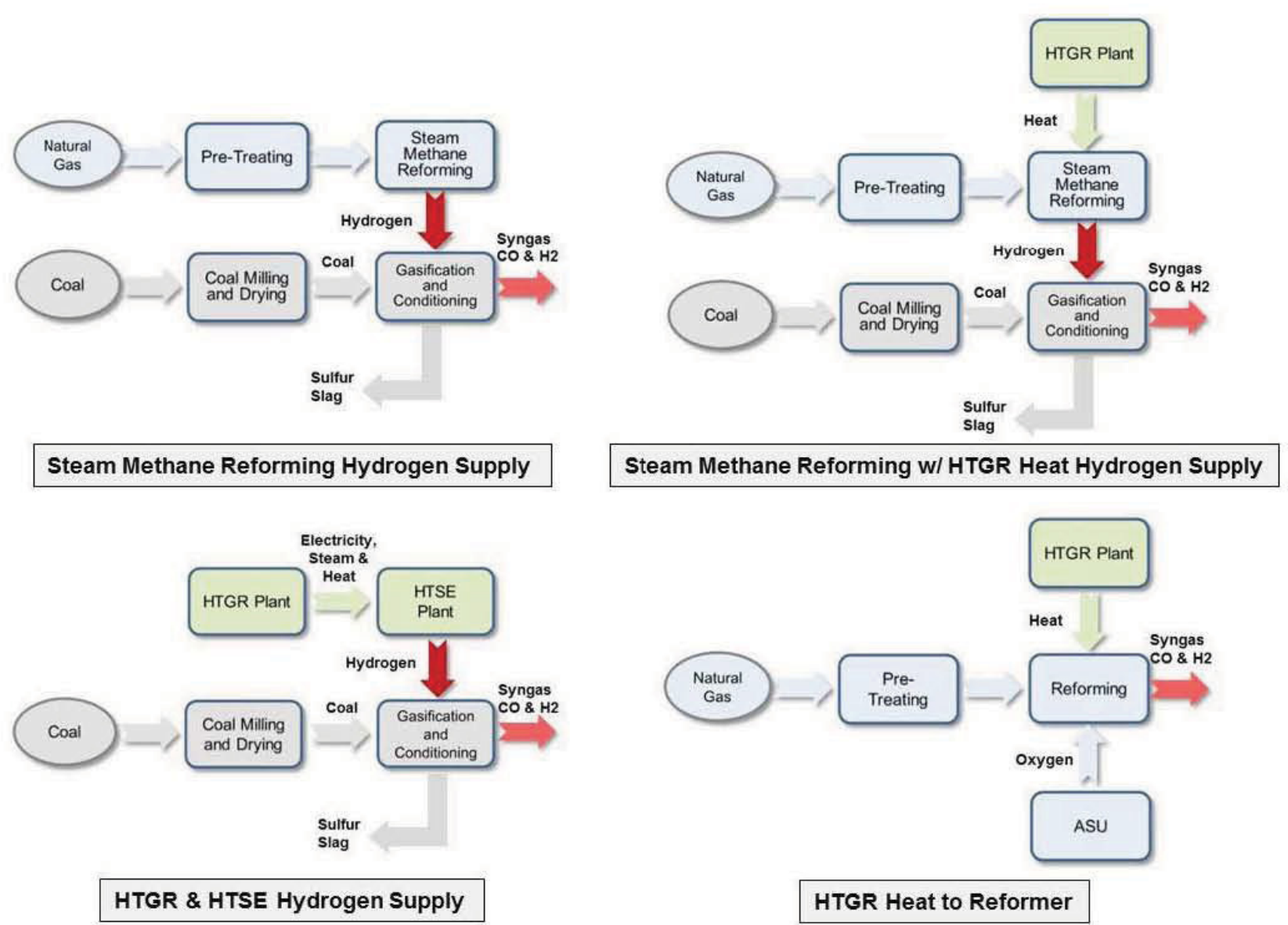

Figure 3-2. Alternative syngas supply feed stocks and configurations.

- HTGR and HTSE: The HTGR supplies heat and electricity to the high temperature steam electrolysis (HTSE) process to produce hydrogen with no $\mathrm{CO}_{2}$ emissions. This is the most effective process, reducing $\mathrm{CO}_{2}$ emissions by more than $90 \%$ in the gasification process compared to a process using WGSR.

The fourth configuration shown in Figure 3-2 describes natural gas reforming, wherein the addition of HTGR heat to the reformer in the natural gas to syngas process reduces the generation of $\mathrm{CO}_{2}$ by $23 \%$ and reduces the amount of natural gas required for the process by $\sim 10 \%$.

All of these methods for providing an external supply of hydrogen and heat have been evaluated for the process alternatives considered herein.

\subsubsection{Indirect Processes for Carbon Conversion}

The syngas can be used to synthesize many different products as listed in Table 3-1. Figures 3-3 through 3-6 schematically represent indirect cycles for carbon conversion that were evaluated.

- Coal and natural gas to liquids (GTL) producing diesel fuel, naphtha and LPG using the conventional Fischer-Tropsch (FT) process. 


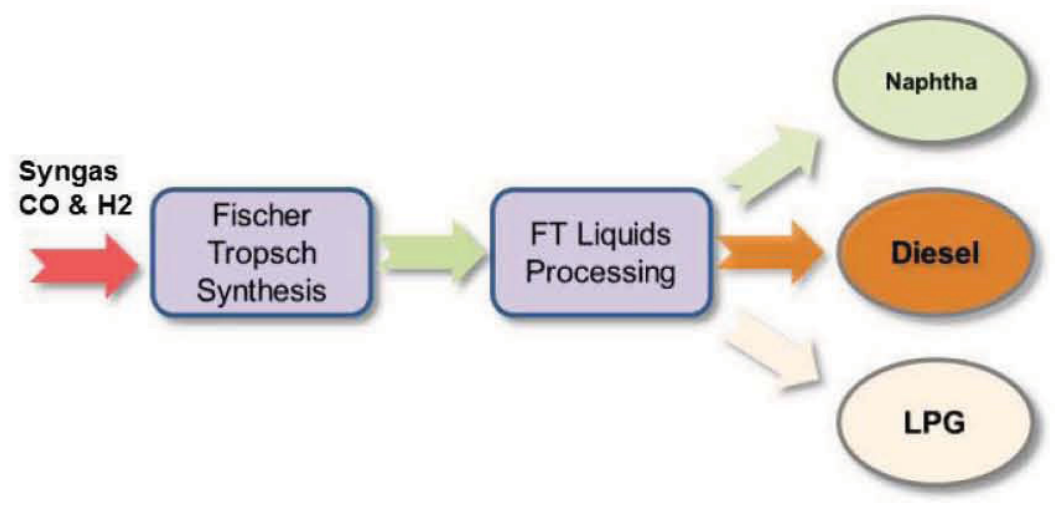

Figure 3-3. Conventional FT production of diesel, naphtha and LPG.

- A CTL alternative of converting the naphtha to higher value products including gasoline and olefins.

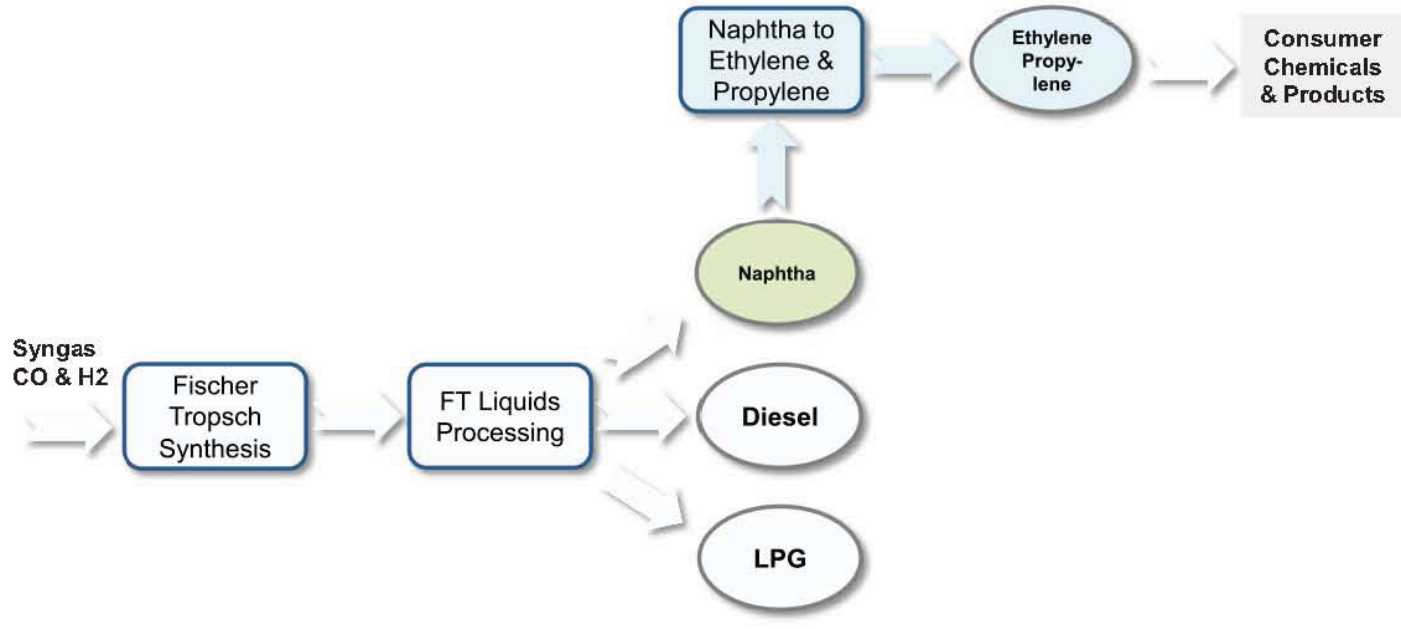

Figure 3-4. Alternative further processing of F-T naphtha to produce chemicals.

- Coal and natural gas to gasoline (GTG) using the methanol to gasoline (MTG) process.

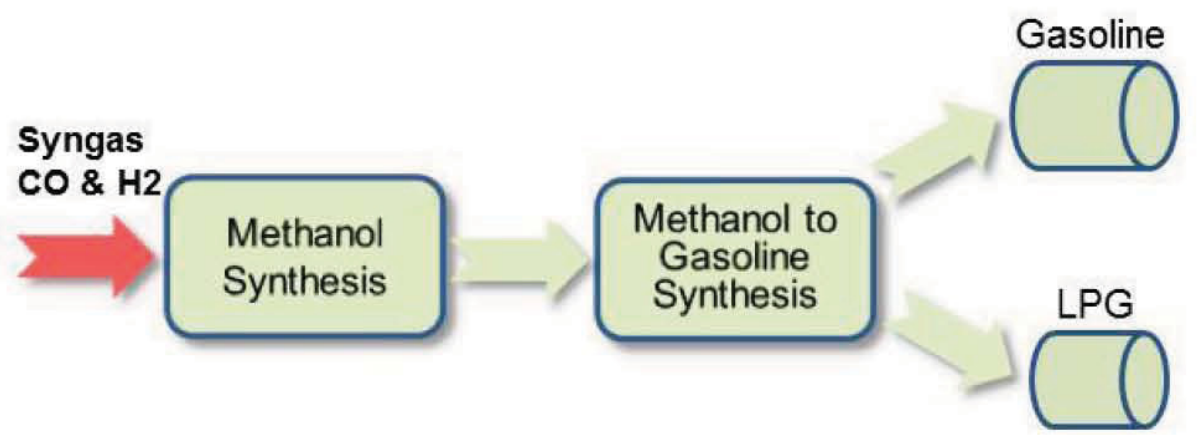

Figure 3-5. Methanol to gasoline and LPG.

- Coal to chemicals (e.g., olefins such as ethylene, propylene) using the coal to methanol to olefins (CTO) process. 


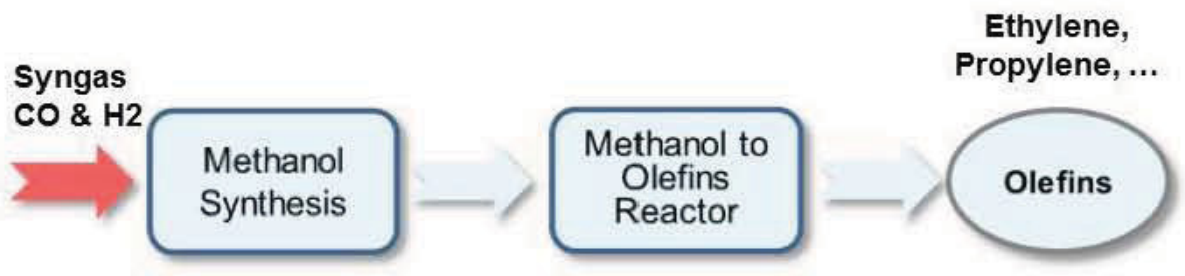

Figure 3-6. Methanol to olefins.

\subsubsection{Direct Process for Carbon Conversion}

The DCL process was developed early in the twentieth century based on research by F. Haber (University of Karlsruhe 1910), commercialized by BASF (starting in 1924 by M. Pier) based on further research work by F. Bergius (University of Hanover 1913) and applied by the Germans until the end of WWII for production of transportation fuels ${ }^{5}$. This carbon conversion technology has been the subject of potential application for coal conversion to transportation fuels by National Energy Technology Laboratory and others for several decades. ${ }^{6,7,8,9,10,11}$ A DCL plant is currently successfully operating in Shenhua China. ${ }^{9}$ Figure 3-7 is a schematic of the process used in that plant. INL has not conducted as complete an evaluation of this process as that performed for the other alternatives. However, Reference 8 summarized a brief historical review of the development of this technology and its status in 2011 and concluded:

"Coal can play a key role in our energy future in ways that go beyond electric power generation. Clean liquid fuels from coal can become a promising option to fill in a significant and widening gap between supply and demand. Coal is an important bridge to a sustainable future. Direct coal liquefaction to produce transport fuels is technically feasible; major advances have been achieved in improving liquid yields $(\sim 4$ bbl per ton coal) and quality through laboratory $R \& D$ and pilot plants in 1980 's and 1990 's. Liquids from direct coal liquefaction are valuable feedstocks for fuels as well as chemicals and materials.

$D C L$ commercialization in Shenhua, China is a major step forward in the world. $D C L$ is still more expensive than petroleum-based processes, owing to its high capital and operating costs in the US. Studies suggest that DCL would emit significantly more $\mathrm{CO}_{2}$, so DCL plants need to incorporate carbon management strategy.

$D C L$ achieves thermal conversion efficiency of $\sim 65 \%$, but given these benefits $D C L$ technology for deployment in the US is likely not to be cost competitive with refined crude oil products based on current crude oil prices. Fundamentally more energy efficient DCL processes with high coal to oil yields that will work effectively and continuously must be commercially demonstrated."

This alternative is judged to be potentially viable, depending on successful resolution of the emissions limitations and reassessment of its competitiveness with refined products as a function of crude oil price similar to what is done for indirect processes herein. INL does not have sufficient information on the current DCL technology to complete those analyses at the time of this writing due to vendor-specific proprietary controls. It should be noted that it appears that the DCL process is particularly well suited to operation with high sulfur coal and could be applied for the Paducah plant using Western Kentucky coal but may be not be suitable for use with low sulfur eastern Kentucky coal. 


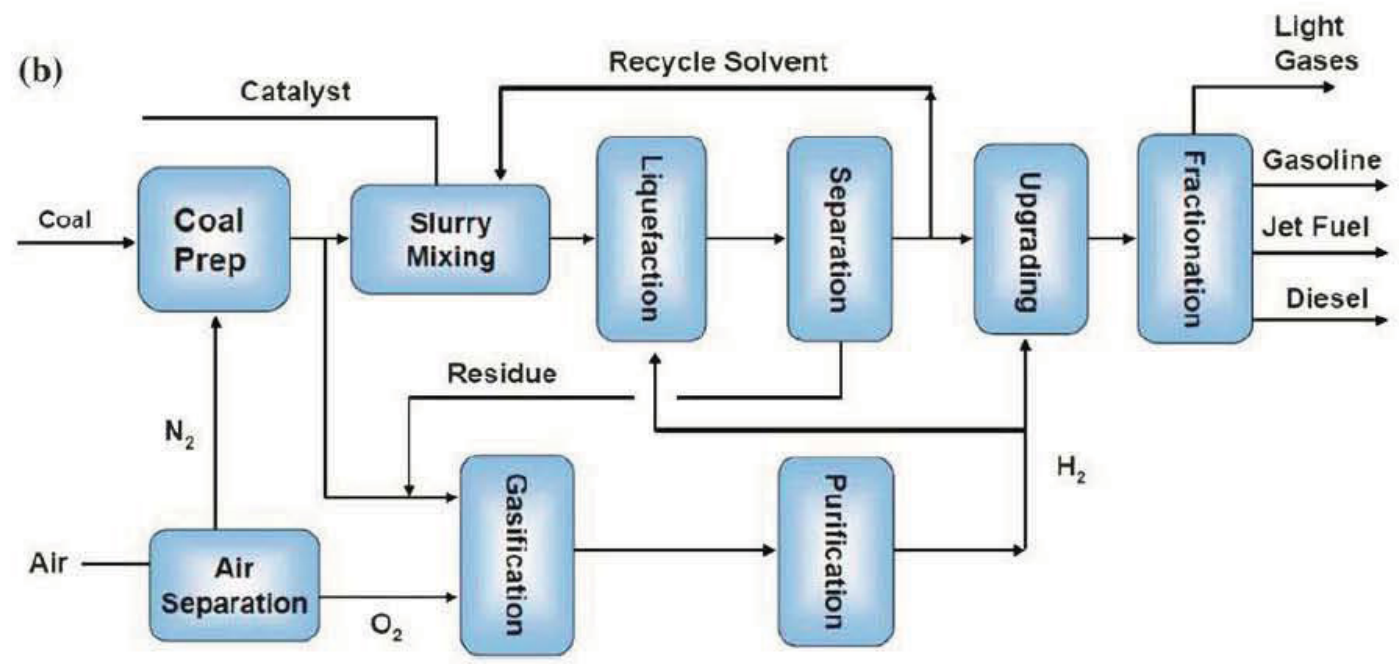

Figure 3-7. DCL conversion of CTL.

\subsubsection{Plant Capacities}

All of these processes can be deployed in facilities comprised of multiple trains or modules of 12,500 to 15,000 bpd capacities, each. For the purposes of the analyses herein total plant capacities of $\sim 50,000$ bpd to $\sim 60,000$ bpd have been considered; comprised of four modular trains each with $25 \%$ of the full plant capacity.

\subsubsection{Comparison of $\mathrm{CO}_{2}$ Emissions for Indirect Processes}

The extent of $\mathrm{CO}_{2}$ generation and emissions is a distinguishing characteristic of these processes as shown in Figure 3-8. The benefits of generation and emissions reductions through the incorporation of SMR, HTGR and HTSE technologies are apparent in this figure. This figure shows that a substantial percentage of the emissions generated by all of the processes can be captured for sequestration or EOR. However, there are substantive operational costs associated with capture and transport of these emissions that add to the production costs of these processes. The potential to reduce the generation of emissions through incorporation of these technologies is a key element in selection of the processes to be deployed to address the effects on production costs of current and potential regulations of $\mathrm{CO}_{2}$ emissions by the Environmental Protection Agency (EPA).

There is insufficient information available on the $\mathrm{CO}_{2}$ generation in modern DCL processes. As cited in the quote above successful deployment of DCL processes will require incorporation of effective carbon management processes. 


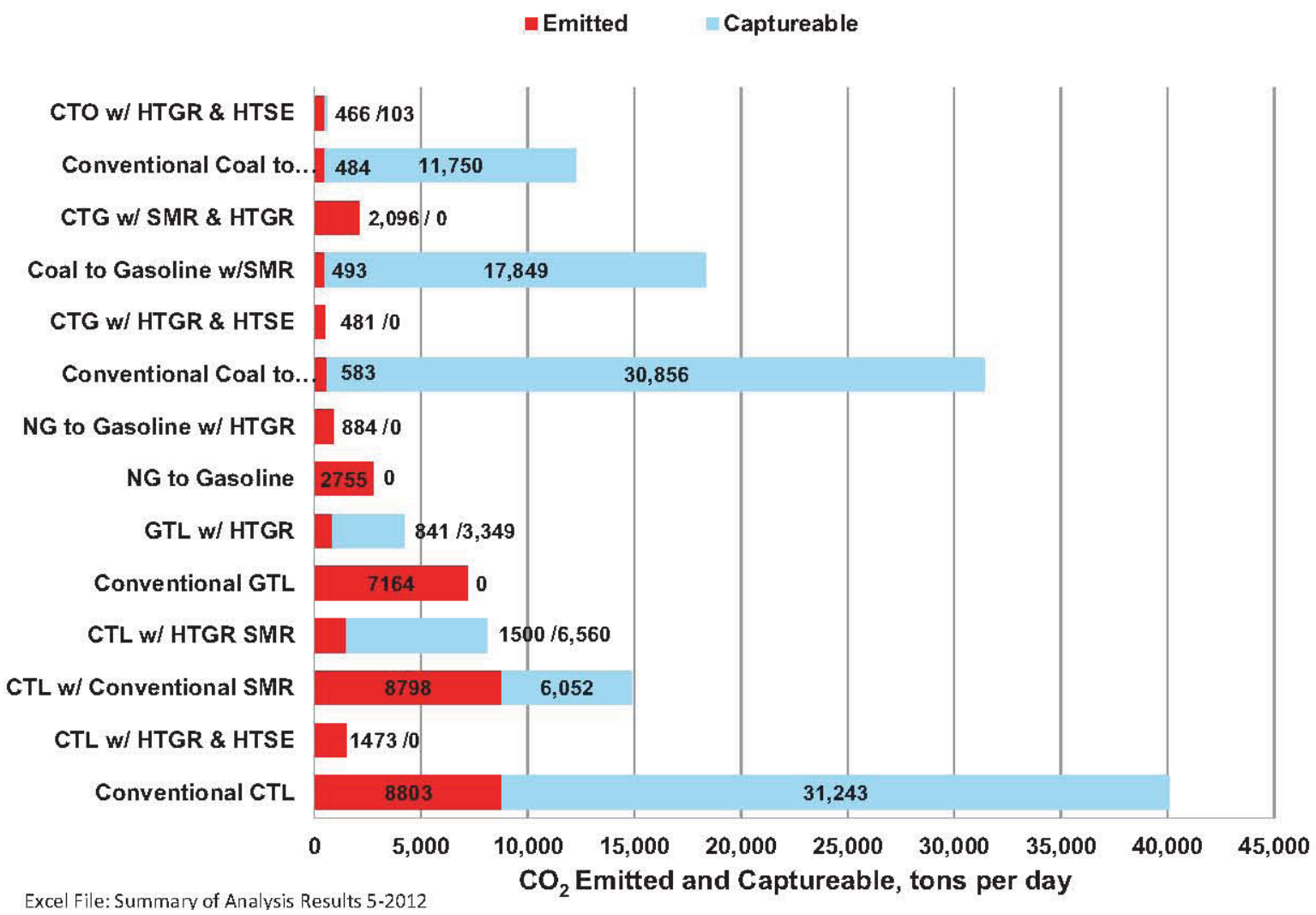

Figure 3-8. Comparison of $\mathrm{CO}_{2}$ emissions of alternative processes.

\subsubsection{Economics of the Alternative Processes}

\subsubsection{Production Costs of Synthetic Transportation Fuels}

The economic viability of the candidate processes was evaluated by comparing the calculated production costs for each process with the production costs for the products using other more traditional processes (e.g., the production cost for refining crude oil or generating chemicals from natural gas liquids). These calculations were made for consistent economic factors (e.g., return on investment, debt to equity ratio, interest rates and terms) and were made for the conventional carbon conversion processes and those in which the HTGR and, where applicable, the HTSE technologies were incorporated. These analyses are documented for each process in the references in Table 3-1. Figures 3-9 and 3-10 summarize the results of those analyses associated with the production of synthetic fuels.

Figure 3-9 summarizes the production cost of diesel fuel for the six coal and natural gas to diesel alternative processes evaluated compared with the historical costs of refining diesel from crude oil as a function of the price of crude oil. This historical data was extracted from DOE Energy Information Agency data bases for the period May 2002 through March 2012. ${ }^{12}$ The line through the data was produced using a linear regression analysis.

Figure 3-10 shows a similar comparison of the production costs for the six coal and natural GTG processes evaluated with the production costs of refining gasoline from crude oil. 


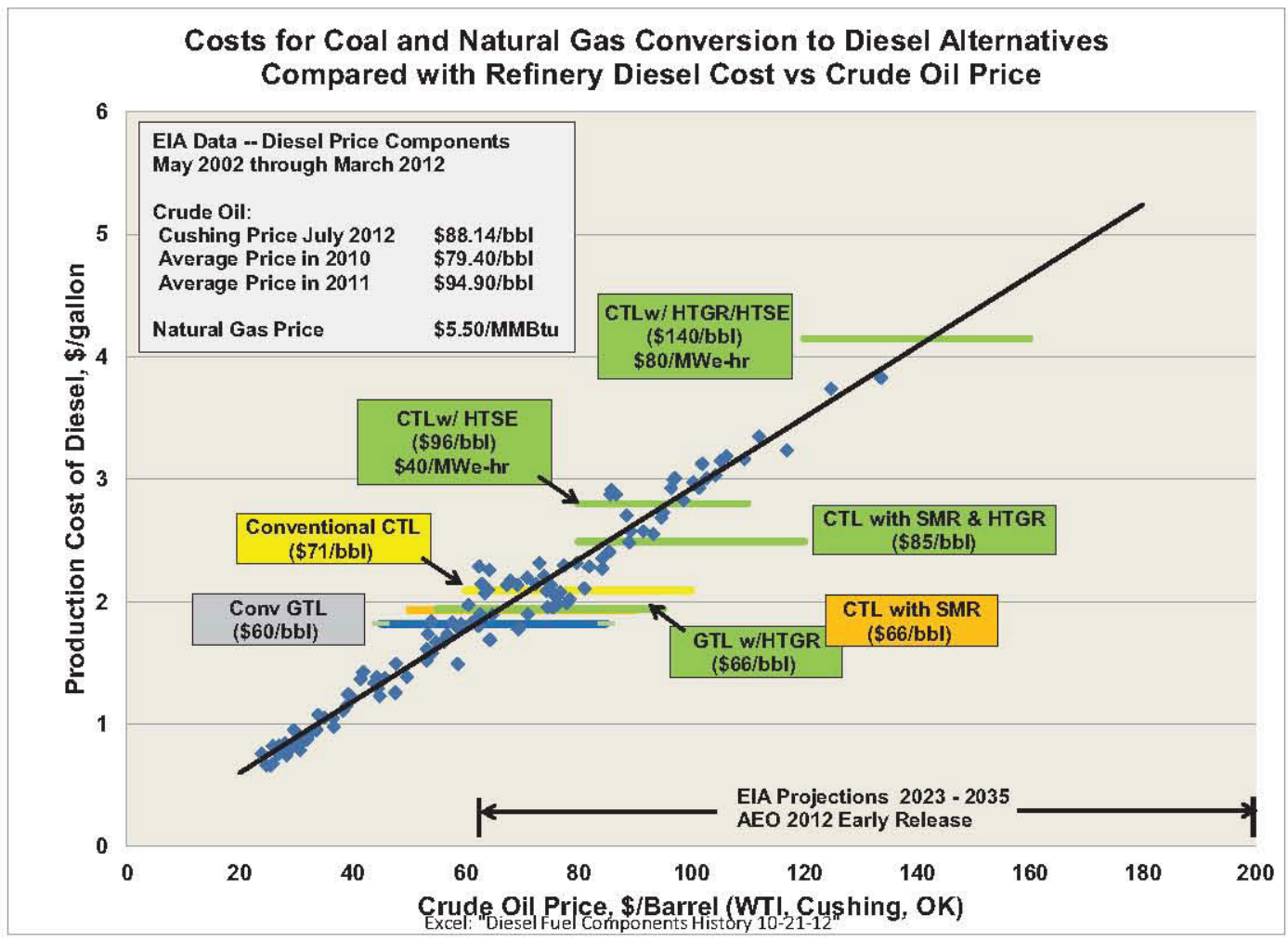

Figure 3-9. Comparison of the production costs of carbon conversion processes with the production cost of diesel refined from crude oil versus the price of crude oil.

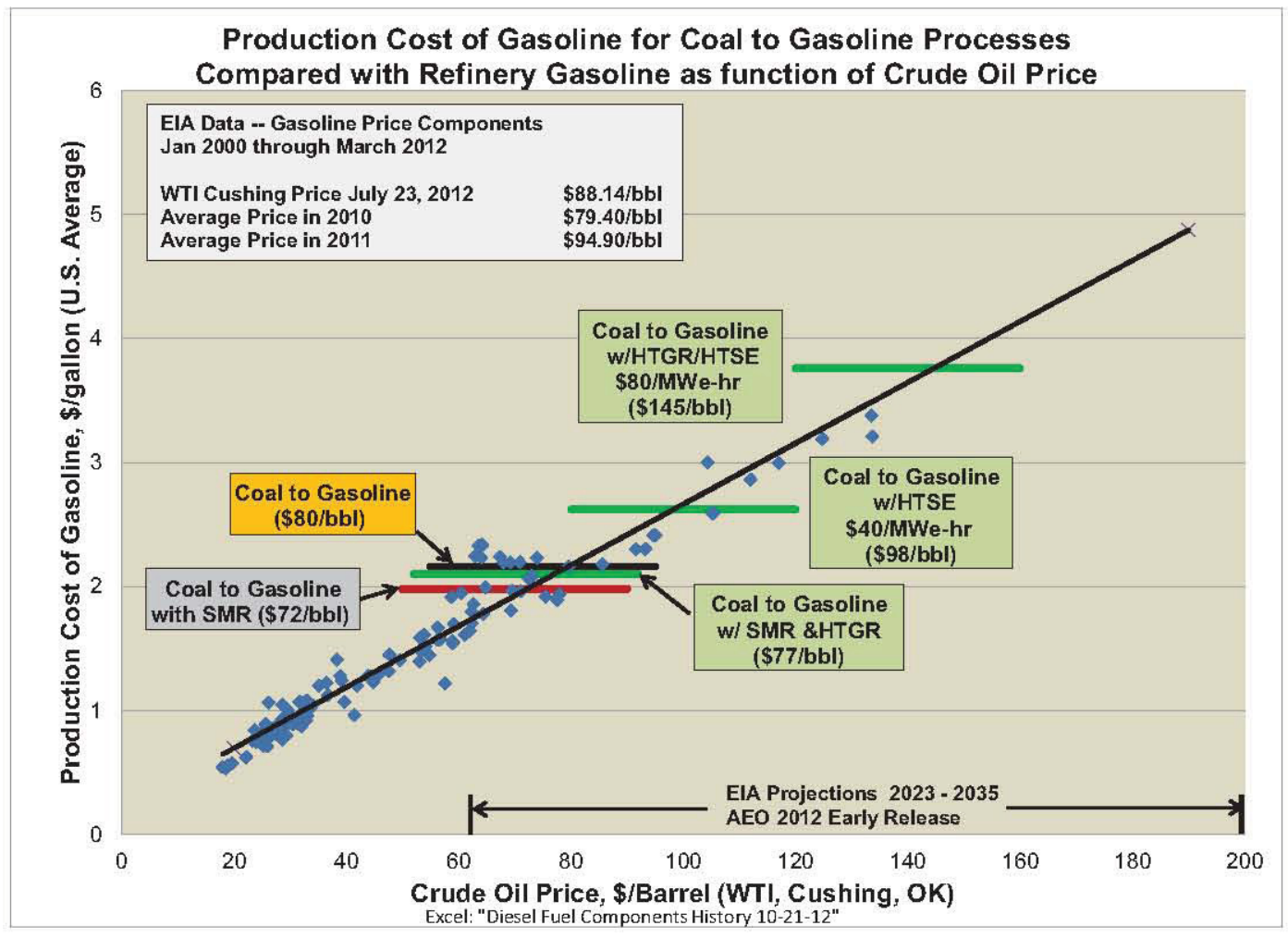

Figure 3-10. Comparison of the production costs of carbon conversion processes with the production cost of gasoline refined from crude oil versus the price of crude oil. 
Figures 3-9 and 3-10 both show Energy Information Administration (EIA) projections of the price of crude oil in the 2023 to 2035 time frame given in Figure 3-11. In all cases the projections on the costs of production for the alternatives fall within the EIA projections of crude oil prices over time (the production cost of diesel and gasoline produced using carbon conversion processes can compete with those products produced by conventional crude oil refining processes). This range is very wide, however, and all but those alternatives that use the combined HTGR and HTSE technologies for the hydrogen supply are grouped in a lower range, $\$ 58$ to $\$ 85 / \mathrm{bbl}$, that is more closely aligned with the range of variations experienced over the last five years and projected as the reference case by EIA (see Figure 3-11).

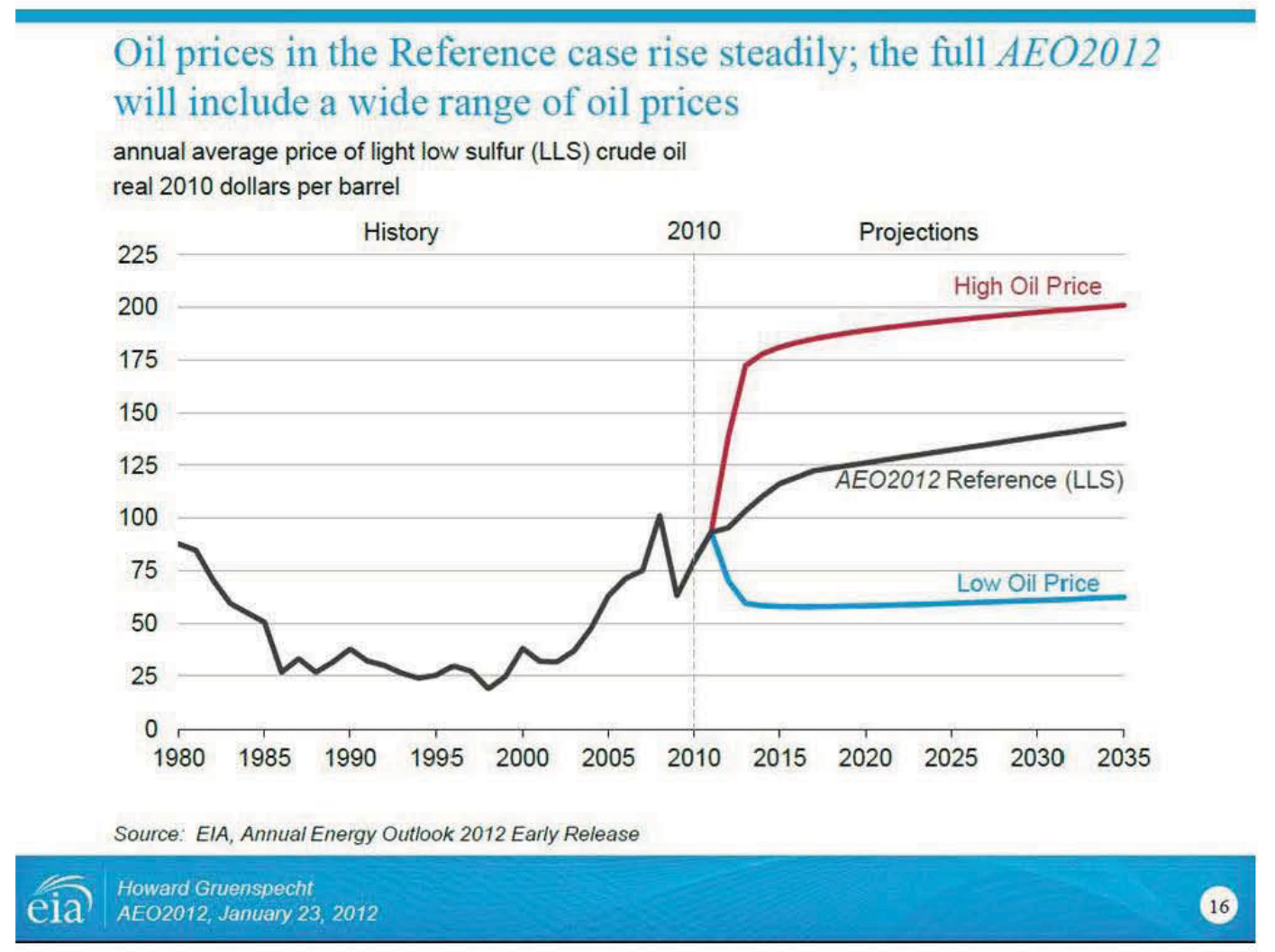

Figure 3-11. EIA projections on future crude oil prices.

Finally, Figure 3-12 compares the production costs for all of the alternatives evaluated and shows the costs of $\mathrm{CO}_{2}$ that would make the production costs for conventional processes equal to a process where $\mathrm{CO}_{2}$ reducing technologies are incorporated (HTGR and HTSE technologies). The production costs for HTGR and HTSE are shown in red bars (HTGR and HTSE) and orange bars (HTSE only). This reflects two different configurations that were evaluated for application of the HTSE technology. In the HTGR and HTSE case the HTGR provides all of the energy including electricity for operation of the HTSE process. In the HTSE only case electricity for operation of the process is provided from the grid. These applications of HTSE are discussed in the following section.

In those cases where natural gas is either the primary feedstock or used for SMR to produce hydrogen, a cost of $\$ 5.50 / \mathrm{MSCF}$ has been used. This was the average cost of natural gas to industrial users in 2009. 


\section{Comparison of Production Costs}

Prices Adjusted to Achieve 10\% IRR, 80\% Debt, 8\% Interest, 20 Year Term

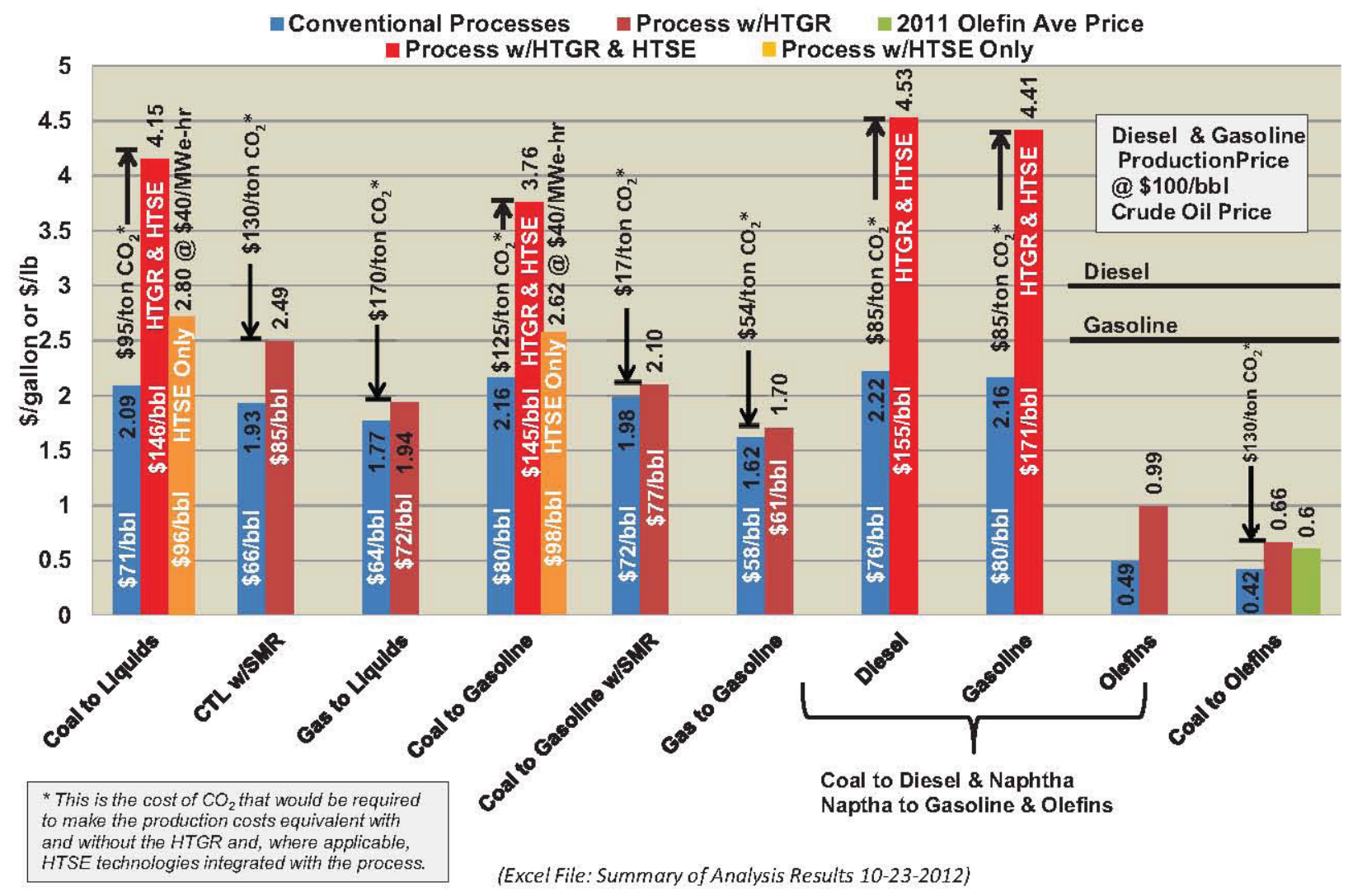

Figure 3-12. Comparison of the production costs for the alternative processes.

As shown the $\mathrm{CO}_{2}$ costs for incorporating HTGR and HTSE are high; $\$ 95$ to $\$ 125 /$ ton in the CTL and CTG processes. However, the CTG process with SMR and the HTGR supplying heat and electricity requires only a $\$ 17 /$ ton cost of $\mathrm{CO}_{2}$ to be equal to the production cost without it. The variation in the costs of $\mathrm{CO}_{2}$ to bring the two configurations into balance is a function of the reduction of $\mathrm{CO}_{2}$ achieved through use of the HTGR and HTSE technologies and the production cost of the integrated process. For example, the required costs of $\mathrm{CO}_{2}$ are high for CTL with HTGR and HTSE because the projected production cost for that case is high. In contrast the projected cost of integrating HTGR into the CTLL with SMR case is low but the required $\mathrm{CO}_{2}$ cost is high because the differential in $\mathrm{CO}_{2}$ generation between the two cases is relatively small. The low required cost of $\mathrm{CO}_{2}$ for the $\mathrm{CTG}$ with the SMR case reflects a low projected production cost for the HTGR and a substantial reduction in $\mathrm{CO}_{2}$ generation.

\subsubsection{Application of HTSE for hydrogen production}

The production costs for the processes using HTSE in Figures 3-9, 3-10 and 3-12 are shown for a range of electricity prices. The higher production costs (equivalent crude oil prices in the $\$ 140 / \mathrm{bbl}$ range) are associated with supply of electricity using the HTGR which in this configuration has an equivalent price of $\sim \$ 80 / \mathrm{MW}(\mathrm{e})$-hr. As shown in these figures, the production costs using HTSE are a strong function of the price of electricity and if electricity can be obtained in the range of $\$ 40 / \mathrm{MW}(\mathrm{e})$-hr, the production costs become more competitive with the other alternatives (equivalent crude oil prices in the $\$ 100 / \mathrm{bbl}$ range). Although the lower prices for electricity are in the range currently available to industrial users in Kentucky they are highly dependent on coal-fired generation that may not be available over the long term for the reasons cited elsewhere in this report. However, over the long term such low prices for 
electricity may be available off-peak or from generation that has been fully amortized and dedicated to the plant. In any event the factor of two reduction in electricity cost for these processes results in $\sim 30 \%$ reductions in production costs, making the application of HTSE for hydrogen production more competitive with the other processes.

It is important to note, however, that independent of costs the HTSE option for hydrogen production could become a necessary alternative to SMR if government regulation leads to restrictions on $\mathrm{CO}_{2}$ emissions and any or all of the following conditions apply: (1) restrictions prohibit most $\mathrm{CO}_{2}$ emissions, (2) EOR with sequestration is not available, and (3) costs for capture, compression and transport for geologic sequestration are prohibitive (e.g., equivalent to $\$ 100 /$ ton $\mathrm{CO}_{2}$ or more ). Section 3.1 .7 summarizes the factors that can affect the costs and the potential revenues for disposition of $\mathrm{CO}_{2}$ and the effect of these on the production costs for synthetic fuels, the availability of geologic sequestration and EOR sites in Kentucky and the liability risks associated with sequestration whether through direct injection to geologic sites or as part of EOR. These latter risks may be the most significant factor in determining whether any form of sequestration is viable, (if costs to cover liability risks become prohibitive).

If HTSE is to be a viable non-greenhouse emitting alternative for hydrogen production in the event $\mathrm{CO}_{2}$ generation costs become prohibitive the price of crude oil would need to be in the range of $\$ 100 / \mathrm{bbl}$ or higher, see Figures 3-9, 3-10 and 3-12. Since the price of crude oil is set internationally it is judged conceivable that both high crude oil prices and high costs for $\mathrm{CO}_{2}$ generation, which is a national issue, could be concurrent. For example, as discussed more in a later section of this report, legislation was introduced recently in the U.S. Senate to impose significant taxes on greenhouse gas emissions when crude oil prices were above $\$ 100 / \mathrm{bbl} /$

With overall net efficiencies at least a factor of two better than conventional low temperature electrolysis and with projected hydrogen production costs significantly lower than for alternative high temperature developmental chemical processes, such as Sulfur - Iodine, HTSE is a viable option for nonGHG emitting hydrogen production. ${ }^{13}$ Accordingly, it is recommended that Kentucky interests continue to support commercialization of the HTSE process and monitor its development so it is available if needed in the future.

The following section provides more insight into the factors and effects of variations in the prices of natural gas, costs for disposition of $\mathrm{CO}_{2}$ generated by the processes and revenues that may be realized from capture and transport of the $\mathrm{CO}_{2}$ for EOR and long-term sequestration.

\subsubsection{Effects of Variations in Natural Gas Prices and Costs of $\mathrm{CO}_{2}$ Disposition on the Economics of the Alternative processes}

The use of SMR for hydrogen production not only reduces the generation rates of $\mathrm{CO}_{2}$ but also can reduce the capital cost of coal based plants by reducing the feed rate of the coal required for the same production rate reducing the size of the expensive coal handling equipment and gasifier and the SMR configuration facilitates the integration of HTGR technology. The feasibility of using SMR for hydrogen production relies on having a long term source of natural gas. The economic viability of alternative processes using SMR also depends on several factors.. These include the cost of natural gas, the potential costs associated with $\mathrm{CO}_{2}$ generation (either a tax on emissions and/or the costs for capture and transport for geologic storage) and the potential to realize revenue from use of the $\mathrm{CO}_{2}$ for $\mathrm{EOR}$ combined with sequestration. This section discusses each of these effects and an assessment of the potential costs associated with regulation of $\mathrm{CO}_{2}$, the availability of sites for geologic and $\mathrm{EOR}$ sequestration in Kentucky, the potential liability risks associated with sequestration, and a comparison of the economic effect of potential outcomes on disposition of $\mathrm{CO}_{2}$ over a range of costs and revenues. 


\subsubsection{Effect of Natural Gas Cost Variations and $\mathrm{CO}_{2}$ Costs on Production Costs}

Figures 3-13 and 3-14 provide data for the conventional CTG process, CTG with SMR providing hydrogen for the gasification process and CTG with SMR with integrated HTGR providing the energy requirements. The figures show the variations in the production costs for these processes as a function of the price of natural gas and costs of $\mathrm{CO}_{2}$ generation. Figure 3-13 shows the results for "No cost of $\mathrm{CO}_{2}$ " and Figure 3-14 shows the results for a cost of " $\$ 50 /$ ton of $\mathrm{CO}_{2}$ ". The upper range is a notional value to illustrate the effect of either a direct tax or of the plant modifications necessary to capture, compress, transport and inject the $\mathrm{CO}_{2}$ emissions for sequestration. In the first case the production costs for the plants using SMR and natural gas for hydrogen production exceed those of a conventional CTG plant for a natural gas price of $\$ 4.30$ to $\$ 5.65 / \mathrm{MSCF}$ and above. In the second case with a cost of $\$ 50 /$ ton of $\mathrm{CO}_{2}$ the crossover point is much higher at $\sim \$ 8.00$ to $\$ 12.00$ /MSCF. These charts show that there is a choice on which process to choose depending on the perceived risks for rising natural gas prices and the potential for costs to be imposed on $\mathrm{CO}_{2}$. If the risk for the former is judged to be higher than the latter the conventional CTG process is favored. If the risk of the latter is judged to be higher or if both risks are judged significant then use of the SMR source of hydrogen and ultimately integrating the HTGR into the SMR process is favored. The potential that both risks are significant has been used for the analyses performed herein; hence, the SMR with HTGR configuration is used.

Note that comparable analyses for the CTL process obtain similar results as that for the CTG plant.

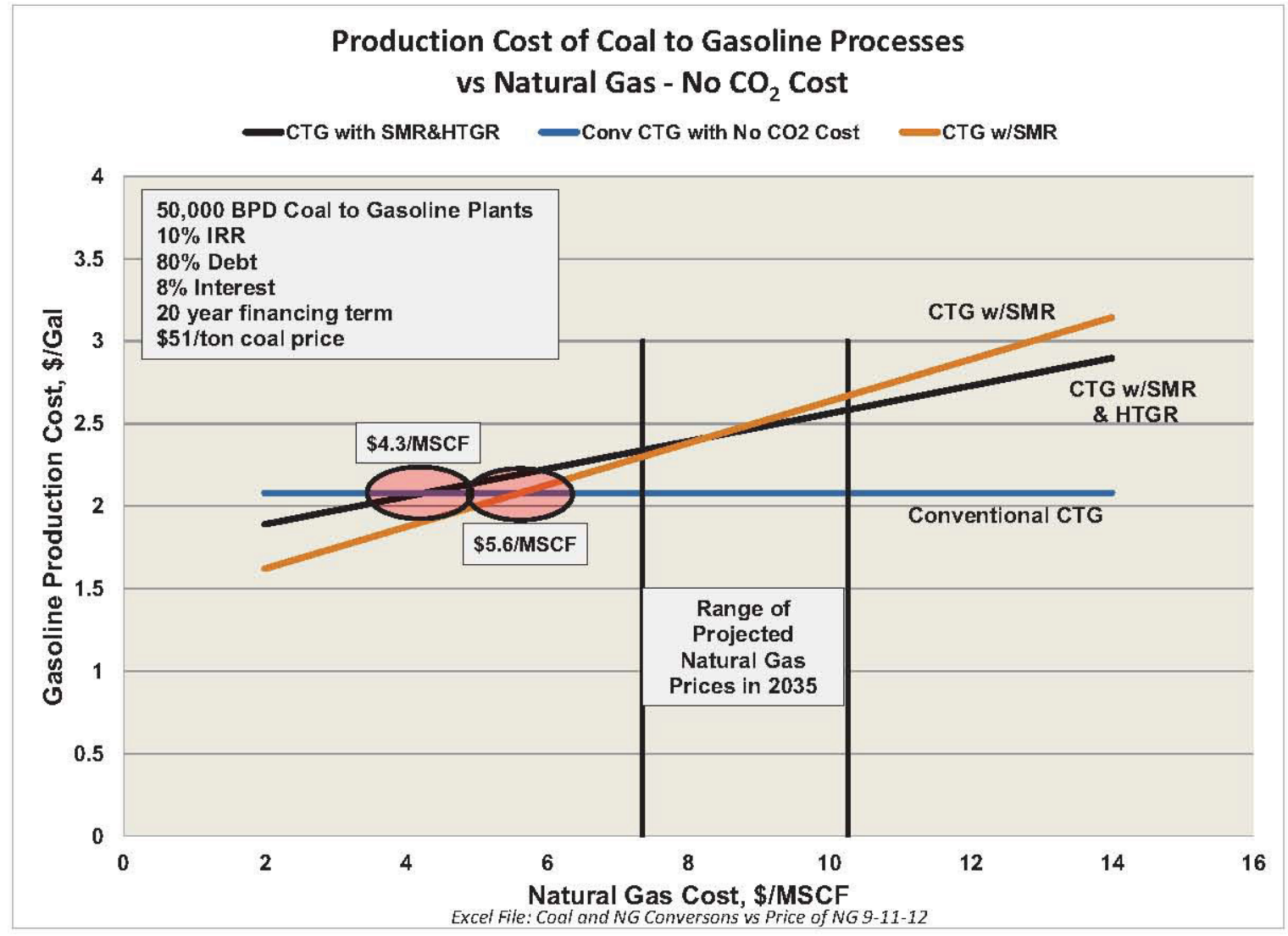

Figure 3-13. Production costs of CTG processes vs. natural gas price; no $\mathrm{CO}_{2}$ costs. 


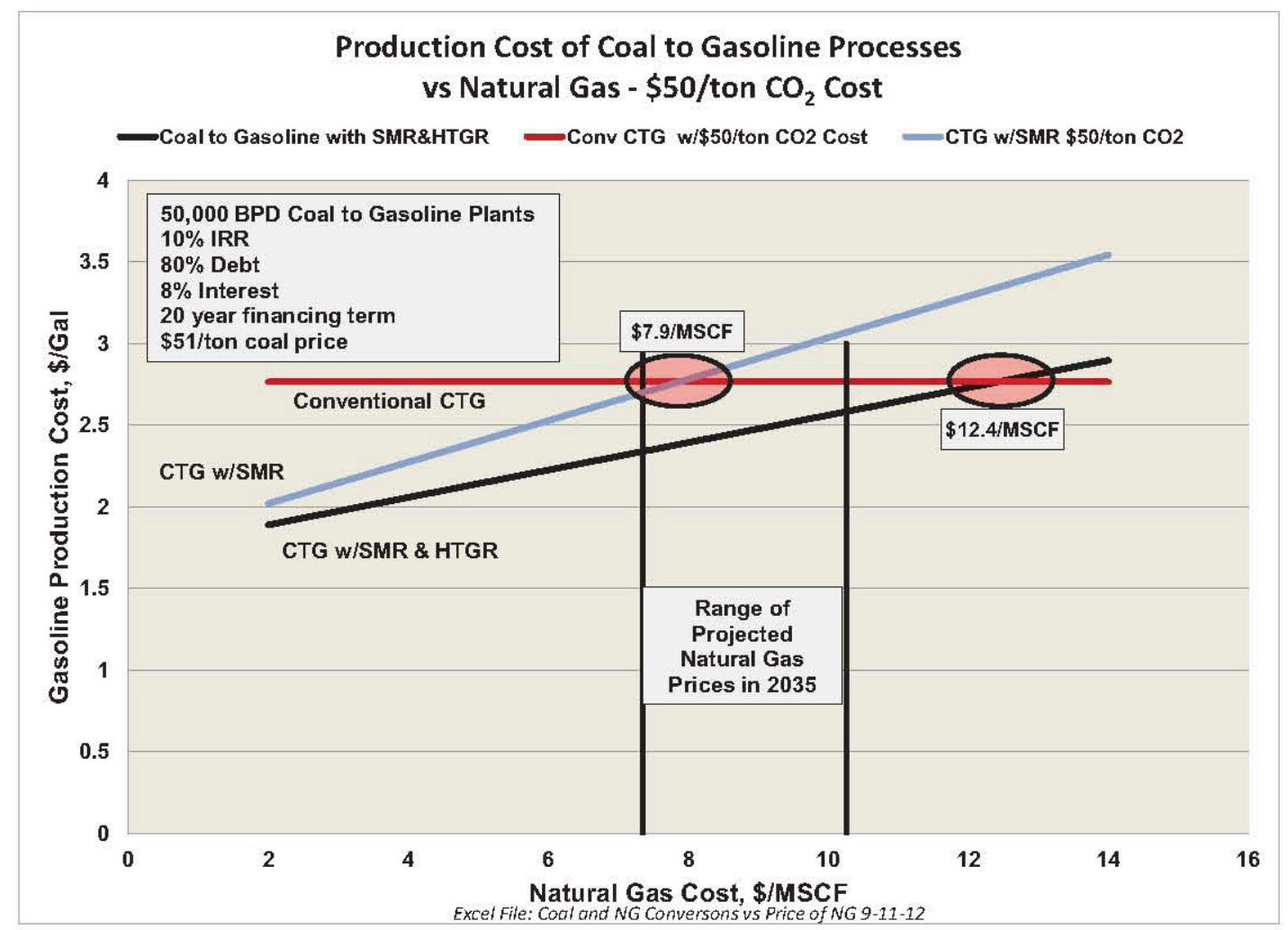

Figure 3-14. Production costs of CTG processes vs. costs of natural gas; $\$ 50 /$ ton $\mathrm{CO}_{2}$ costs.

\subsubsection{Estimating the Costs of $\mathrm{CO}_{2}$}

There is no significant commercial experience with capture and transport of $\mathrm{CO}_{2}$ from industrial processes for either long term geologic storage or for EOR as a long term storage mechanism. Accordingly, the actual costs and risks are not well defined. There is considerable literature identifying the cost factors involved for capture, transport and injection for geologic storage and for EOR that provide potential ranges of costs and revenue. The costs for transport and storage vary widely from a low value in the range of $\sim \$ 16 /$ ton $^{\mathrm{d}, 14,15,16,17,18}$, representative of a mature geologic sequestration industry, to much higher values in the range $\$ 30$ to $\$ 100 /$ ton $^{19}$ during development of the industry. There are several projects currently under way to prove these concepts and determine costs. ${ }^{20,21,22}$ Where the analyses discussed herein include costs for capture, transport and sequestration, the costs for the equipment and operations required for capture and compression are included in the model and a cost of $\sim \$ 16 /$ ton, (the long term estimate for a mature industry) is assessed for the cost of transport. ${ }^{16}$

A major uncertainty in assessing the potential costs for the disposition of $\mathrm{CO}_{2}$ is the potential for government regulation of $\mathrm{CO}_{2}$ emissions. Review of two examples is illustrative of the impact such regulation may have on these costs. The first example is the Bill introduced by Senator Bingaman that requires electric utilities to supply a certain percentage of their total annual generation from renewables (starting at $24 \%$ in 2014 and rising to $84 \%$ by 2035 ) or pay effectively a tax of $\$ 30 / \mathrm{Mw}(\mathrm{e})$-hr on the generation that is not compliant ${ }^{23}$. To put this in perspective this is a value higher than the generation costs of most existing coal-fired plants in the United States and is $\sim 30 \%$ of the average cost of electricity to consumers in the United States. In addition, the provisions assigning credits are designed to essentially eliminate coal-fired plants from the nation's generation capacity. An EIA assessment of the impact of this

d A more detailed discussion of sequestration and EOR is covered in Section D.3. 
Bill concluded that up to $94 \mathrm{GW}(\mathrm{e})$ of coal-fired generation capacity could be retired early ${ }^{24}$ and, because new non-coal-fired generation is more expensive electricity costs would increase between $5 \%$ and $30 \%$ depending on the area of the country. This legislation was not passed but is an example of the potential regulations that may be imposed on the electricity generation industry. A provision of this Bill also called for investigation of how to impose similar regulations on other industries.

Another example is the implementation of the California Cap and Trade Program in September 2012 and the first auction of greenhouse gas credits in November 2012. ${ }^{25}$ In this auction 23.6 million ton of credits were auctioned off at an average price of $\$ 10.09$. The number of credits for emissions is generous in the early years starting in 2013 but become more stringent over following years. The relatively low prices for these credits reflect the lower requirements in 2013. The futures market for the 2013 auction is currently at $\$ 14.09 .^{26}$ As the limitations on emissions increase year to year increases in the price of the credits are expected to increase. A specific reason for the increase is a year by year increase in the reserve price. The $\$ 10$ initial reserve on bids for allowances in 2012 increases each year by $5 \%$ plus the rate of inflation. In ten years the reserve price will have increased by $\sim 63 \%$ over inflation. The experience in California may portend similar actions in other States. There are also penalties that will be imposed on entities that have emissions in excess of their allowances or credits. These are not explicitly identified in the legislation but are covered by other California law and would be expected to be higher than the auction price of credits.

\subsubsection{Effect of $\mathrm{CO}_{2}$ Costs on the Production Costs of Gasoline Refined from Crude Oil}

Imposition by the government of regulations such as those currently pending by the EPA ${ }^{27}$ would result in costs for $\mathrm{CO}_{2}$ generation that would also affect the production costs for refining gasoline and diesel from crude oil. Figure 3-15 shows the effect of the $\$ 50 /$ ton cost for $\mathrm{CO}_{2}$ on the production costs of gasoline refined from crude oil as a function of the price of crude oil. Because the emissions generated in the refining processes are not high $\left(\sim 96 \mathrm{Kg} \mathrm{CO}_{2} / \mathrm{bbl}\right.$ for gasoline and $\sim 110 \mathrm{Kg} \mathrm{CO}_{2} / \mathrm{bbl}$ for Diesel $\left.{ }^{28}\right)$ the effect adds only a few cents to the production costs. Also shown on this figure are the results for varying natural gas prices from $\$ 4 / \mathrm{MSCF}$ to $\$ 10 / \mathrm{MSCF}$ and $\mathrm{CO}_{2}$ costs from $\$ 0 /$ ton to $\$ 50 /$ ton on the production costs of a natural GTG process. As shown in the preceding figures the effect of natural gas variations is larger than for $\mathrm{CO}_{2}$ costs because these processes have low $\mathrm{CO}_{2}$ generation rates. The large swing in production costs $(\$ 47 / \mathrm{bbl}$ to $\$ 100 / \mathrm{bbl}$ crude oil price equivalent) is still within the projected range of crude oil prices over the next several decades.)

The conclusion is that the imposition of a cost of $\mathrm{CO}_{2}$ in the range of $\$ 50 /$ ton would not materially affect the comparison of the production costs of the alternative processes with the production costs of products refined from crude oil as a function of the price of crude oil.

e "Materially" is used in this context to indicate that the parametric variation (e.g., the range of $\mathrm{CO}_{2} \operatorname{costs}$ from $\$ 0$ to $\$ 50 /$ ton) does not affect the conclusion. 


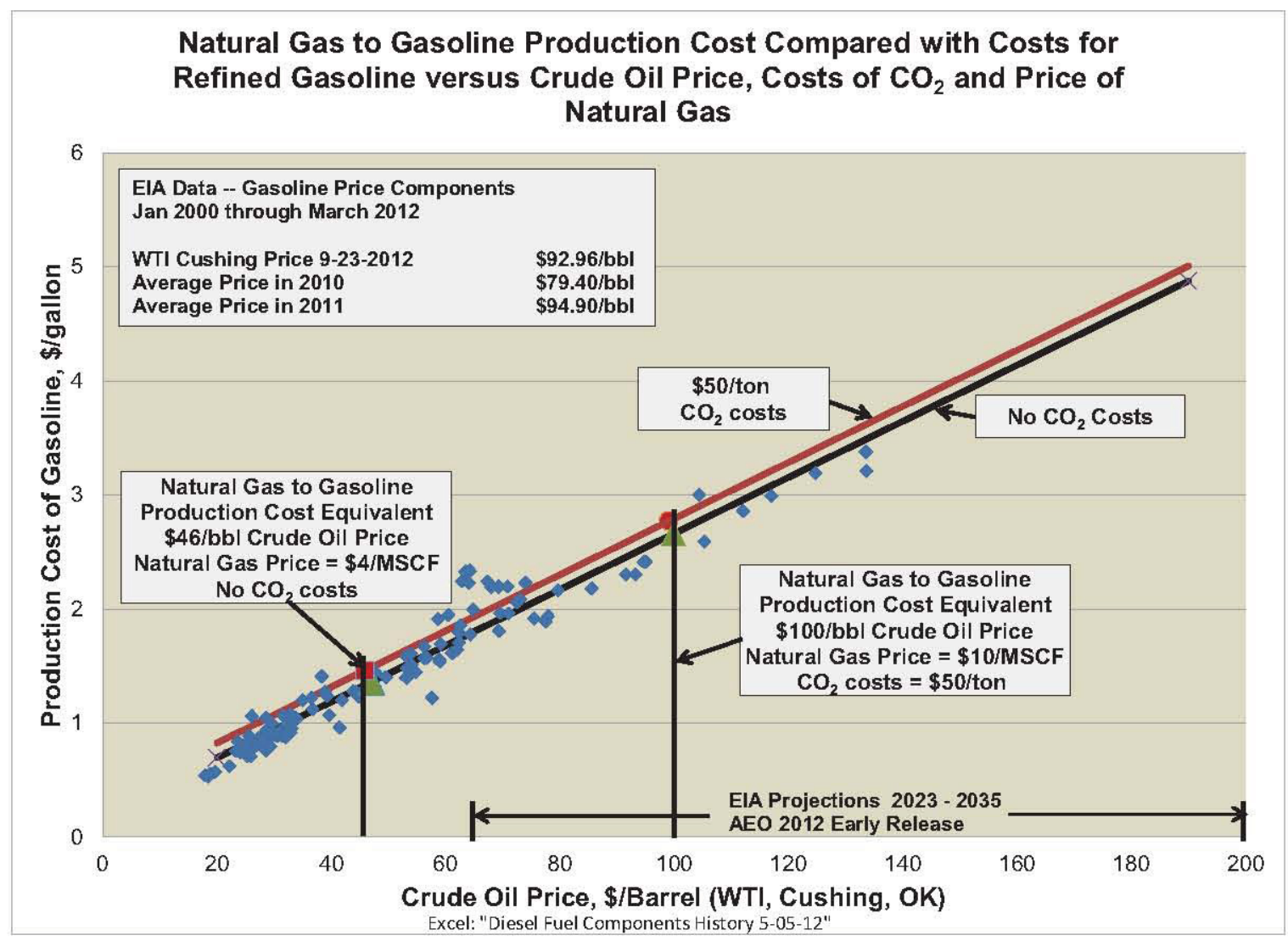

Figure 3-15. Comparison of gasoline production costs for natural GTG process with refining from crude oil as a function of the costs of natural gas, $\mathrm{CO}_{2}$ and crude oil.

\subsubsection{Use of Captured $\mathrm{CO}_{2}$ for EOR}

The prospects for capture and transport of $\mathrm{CO}_{2}$ emissions for $\mathrm{EOR}$ have also been studied on an international, national and local level ${ }^{14,17,31}$. With respect to potential revenue these reports note that the current cost for $\mathrm{CO}_{2}$ used for EOR is in the range of $\$ 20$ /ton and new sources would need to be at that level to be competitive. A value of $\$ 20 /$ ton, net of the costs of transport and injection, is used herein to investigate the effect of revenue generated from EOR on the production costs of the process alternatives.

It is noted that current processes for injection of $\mathrm{CO}_{2}$ for $\mathrm{EOR}$ do not provide permanent sequestration of the $\mathrm{CO}_{2}$. This is a necessary function of use of $\mathrm{EOR}$ for disposition of $\mathrm{CO}_{2}$ to reduce emissions to the environment. One other major factor on costs of sequestering $\mathrm{CO}_{2}$ that has not been fully developed are those associated with the regulatory process and liability exposure for release of the sequestered $\mathrm{CO}_{2}$. Those costs have not been included herein due the immaturity of these estimated costs, This issue is discussed in more detail in a following section.

\subsubsection{Availability of Geologic Sequestration and EOR Sites in Kentucky}

There is a market for $\mathrm{CO}_{2}$ for EOR throughout the United States based on Kentucky studies performed in the early $2000 \mathrm{~s}$ on the opportunities for $\mathrm{CO}_{2}$ sequestration in Kentucky identified potential sites for both EOR and geologic sequestration ${ }^{29}$. The availability of EOR sites, however, is limited with capacity less than the current emission generation rates in the Commonwealth. Quoting the report:

4. "Enhanced recovery projects designed to maximize $\mathrm{CO}_{2}$ sequestration could use approximately 20 percent of the $\mathrm{CO}_{2}$ emitted in the state." 
This conclusion is supported by the GTSP Report ${ }^{14}$ referred to above that evaluated the broad applicability and long term viability of $\mathrm{EOR}$ as a repository for excess $\mathrm{CO}_{2}$ generation and concluded:

Although gigatons of low-cost $\mathrm{CO}_{2}$ storage opportunities may be associated with value-added reservoirs in North America alone [12 gigatons in depleted oil fields with EOR potential], the long-term challenge presented by the need to stabilize atmospheric concentrations of $\mathrm{CO}_{2}$ indicates that, because the storage capacity available in oil-and gas-bearing reservoirs is dwarfed by capacity in reservoirs that do not bear saleable products, over the long term, $\mathrm{CO}_{2}$ storage in value-added reservoirs may not represent as significant a portion of total $\mathrm{CO}_{2}$ stored as is widely believed. Our research suggests that all classes of $\mathrm{CO}_{2}$ storage reservoirs are valuable and will be needed once CCS technologies begin their expected large-scale commercial deployment. ...

... there is likely some potential for very low and even negative cost (and therefore perhaps already profitable) CCS opportunities, but these opportunities represent only a small portion of the emissions mitigation potential to be exploited. Many are likely already being utilized by the marketplace, albeit often without application of $M M V$ [Measurement, Monitoring and Verification] systems, which would be required to demonstrate the long-term retention of the injected $\mathrm{CO}_{2}$ if the primary purpose of these projects was climate protection...

Deployment of multiple carbon conversion plants will be required to meet the objectives of Kentucky in advancing alternative markets and increasing the value of indigenous coal and natural gas resources. Based on these references, EOR is not a viable long term repository for $\mathrm{CO}_{2}$.

The Kentucky study of $\mathrm{CO}_{2}$ sequestration potential identified significant geologic sequestration sites. One of these sites is associated with natural gas recovery from Devonian Black Shales ${ }^{30}$. Results of evaluation of this repository concluded:

- "Estimates using the distribution of gas storage capacity of $\mathrm{CO}_{2}$ from $\mathrm{TOC}$ data indicate a sequestration capacity of 6.8 billion tonnes in the five-county area of the Big Sandy Gas Field of eastern Kentucky.

- Assuming a thickness weighted average adsorption capacity of 40 scf/ton (at 400 psia), as much as 25 billion tonnes of $\mathrm{CO}_{2}$ could be sequestered in the deeper and thicker portions of the Devonian shales in the Appalachian and Illinois Basins of Kentucky. "

This study also concluded:

"In the state's coal basins, there are an estimated 283 bcf of coalbed methane gas-in-place. For the shale and coals, using a recovery factor for natural gas of 17 percent, 5 tcf remain available for primary production and approximately 50 tcf available for enhanced recovery. $\mathrm{CO}_{2}$ sequestration in these reservoirs could result in an additional 30 bcf in annual production for natural gas in Kentucky and sequestration of 60 bcf $\mathrm{CO}_{2}$ annually. At this rate, in 10 years, as much as 31.8 million metric tons of $\mathrm{CO}_{2}$ could be sequestered."

The total potential capacity for geologic sequestration in Kentucky is, therefore, $\sim 32$ billion tonnes. Review of Figure 3-11 shows that those processes with large sequestration requirements, (those with high captureable rates; CTL, CTL w/SMR, CTG and CTO) the annual requirement ranges from $\sim 3$ to 10 million tonnes per year. In 2010 Kentucky $\mathrm{CO}_{2}$ emissions were $\sim 93$ million tonnes. Even if the majority of the current $\mathrm{CO}_{2}$ emissions were to be captured and sequestered there is still sufficient capacity to accommodate the captureable $\mathrm{CO}_{2}$ emissions from several carbon conversion plants with high $\mathrm{CO}_{2}$ generation rates. Such sequestration will require installation of transport pipelines from the plants to the sites and development of injection wells and management and monitoring equipment. 


\subsubsection{Costs to Cover Risk Factors Associated with Long Term $\mathrm{CO}_{2}$ Sequestration}

There are costs associated with CCS that have not yet been estimated with any confidence. These are the costs of regulation and of liability for ensuring the security of the sequestration. Many studies have defined the need for and recommended structures for assigning liability and several states have initiated legislation covering liability. ${ }^{31,32,33,34,35,36,37,38,39,40}$ Wyoming, Kansas and Montana legislatures, for example, have adopted liability frameworks and Texas and Illinois have initiated actions for the purposes of addressing these liability issues. Reference 35 summarizes the required structure as follows:

"Developing a framework to manage CCS project liability requires several conditions to be met: (1) responsibility should be assigned for damages from a CCS project over a defined time period; (2) funds must be available for monitoring, remediation, and damage payment throughout the CCS project life-cycle; and (3) the regulatory framework should be adaptive and incorporate site-specific data into CCS risk management. Additionally, regulatory and liability frameworks should be structured to provide incentives for good site selection and operation and an effective monitoring regime. These conditions must be met not only to manage environmental, health, and safety risks, but also to integrate CCS within a larger climate policy."

The consensus of these references is that several phases of CCS will require coverage of liability:

- Bonding and/or insurance held by the owner will be required during the period of injection

- The owner will retain liability after the last injection either for a pre-determined period or until specific performance criteria have been met (e.g., reduction or stabilization in site pressure, validation of $\mathrm{CO}_{2}$ migration models by measurement and monitoring of critical variables). Bonding and insurance will cover this period.

- There is general agreement that some form of general insurance will be required to cover the owners during these periods for major leaks or damage to property in addition to the bonds and owners general liability insurance. This would be funded by periodic payments into a fund run by a consortium of operators/owners similar to the self-insurance funds covering nuclear energy plants.

- There is also general agreement that some form of State or more likely Federal government program will be required to assume liability over the very long term. These costs could be covered by funds financed by the owners through payments based on quantities sequestered, annual fees and fees per wells. This is similar to the Trans-Alaskan Pipeline Authorization Act that covers major leaks from this pipeline on land and in the water.

Review of the literature, however, has not identified any experience with the actual costs to the owner of the facility to deal with these issues. National Energy Technology Laboratory estimated the costs for capture, transport and storage on a hypothetical basis with emphasis on the equipment and piping costs associated with getting the $\mathrm{CO}_{2}$ to the injection site. They included a $\$ 5 \mathrm{MM}$ premium for a bond to cover the operational period. This seems low when some State legislations place limits of liability of \$500MM. This cost also does not cover contributions to governmental or consortium funds to cover long term storage liability. It is judged that these costs may be substantial additions to the injection cost; potentially comparable to those cited for capture, compression and transport. The analyses performed herein do not include these costs explicitly; the $\$ 50 /$ ton cost used as a notional upper bound may or may not be sufficient to cover them. Confidence on the magnitude of these costs will become apparent once regulations are in place and actual sequestration is initiated. 


\subsubsection{Summary of Costs and EOR Revenue on Gasoline Production Costs}

Figure 3-16 and Figure 3-17 compare the production costs for conversion of CTG for ranges of costs of $\mathrm{CO}_{2}$ and for revenues derived from EOR for the conventional process and for that process using SMR for hydrogen production. In both figures the costs for $\mathrm{CO}_{2}$ cover three cases; (1) no costs, (2) costs for capture, transport and long term geologic sequestration ranging from $\sim \$ 16 /$ ton to $\sim \$ 32 /$ ton, and (3) emitting all $\mathrm{CO}_{2}$ with imposed taxes on these emissions ranging from $\$ 20$ /ton to $\$ 50 /$ ton. In both figures the revenue from $E O R$ ranges from $\$ 15 /$ ton to $\$ 20 /$ ton. These ranges are notional since no definitive values are available and are used only to illustrate these effects. The equivalent cost of crude oil shown on these figures was calculated using the linear relationships between the production cost of gasoline refined from crude oil as a function of crude oil price and $\mathrm{CO}_{2}$ costs shown in Figure 3-15.

The following observations result from comparing the two figures:

- The effects of variations in $\mathrm{CO}_{2}$ costs and revenue are more pronounced for the conventional case because of its higher rate of $\mathrm{CO}_{2}$ generation.

- The effect of revenue generation from EOR is relatively small on production costs in either case with the change from $\$ 15 /$ ton to $\$ 20 /$ ton; production cost increases varying from $\sim 5 \%$ to $10 \%$ and $\$ 5$ to $\$ 6 / \mathrm{bbl}$ variations in equivalent crude oil price

- The effect of $\mathrm{CO}_{2}$ costs are more pronounced varying from a $10 \%$ increase in production costs at the lower end of the cost range ( $\$ 16$ to $\$ 20 /$ ton) to $20 \%$ to $30 \%$ at the upper end of the range ( $\$ 32 /$ ton to $\$ 50 /$ ton). Variations in equivalent crude oil price are shown to be up to $\$ 20 / \mathrm{bbl}$.

- Unless the taxes on $\mathrm{CO}_{2}$ emissions are low, $\left(\$ 20 /\right.$ ton or lower) emitting all $\mathrm{CO}_{2}$ generated is not economically viable.

\section{Conventional Coal to Gasoline Conversion Effect of $\mathrm{CO}_{2}$ Disposition on Production Costs}

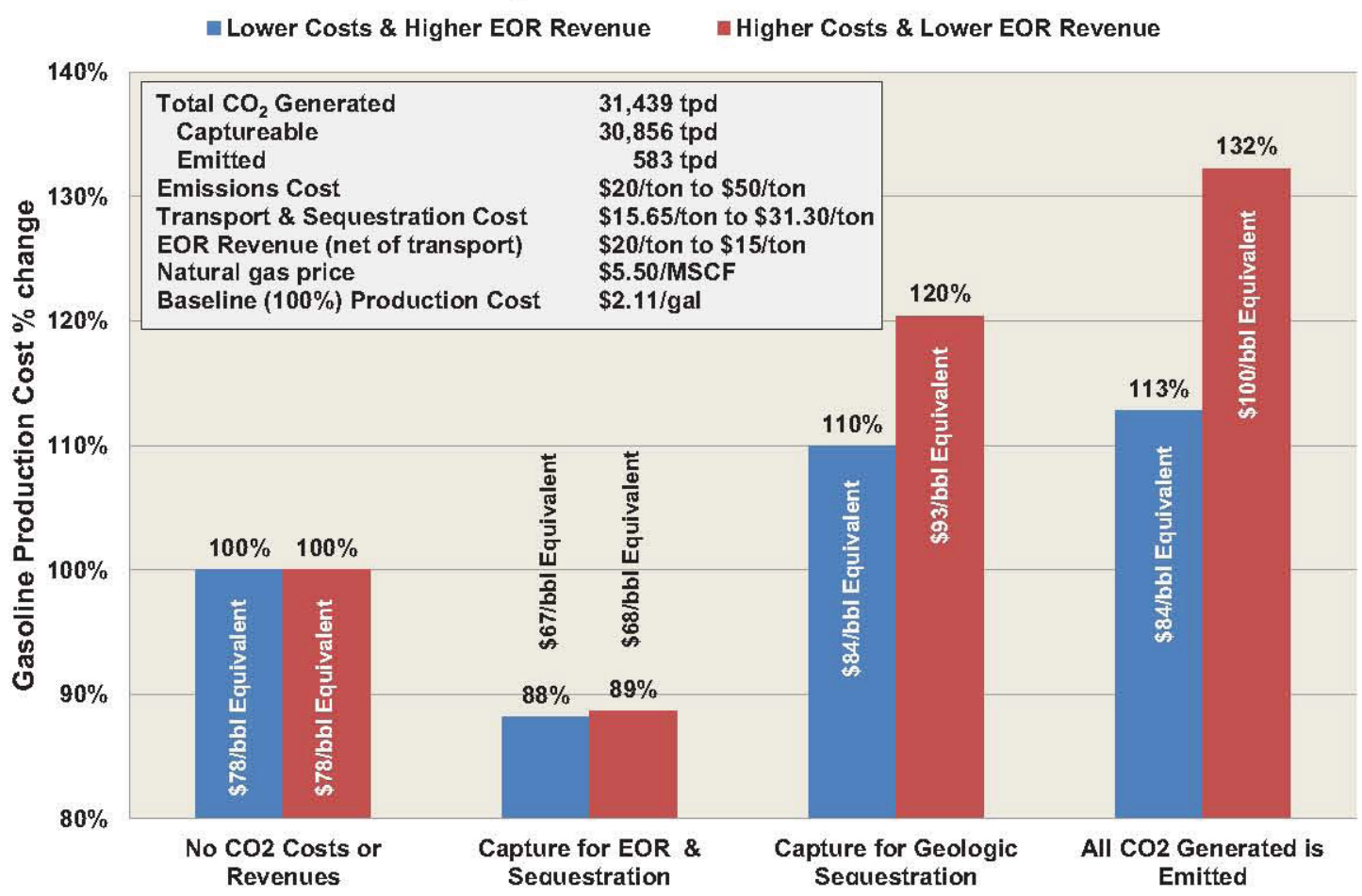

Figure 3-16. Effect of $\mathrm{CO}_{2}$ disposition on gasoline production costs for the conventional CTG process. 


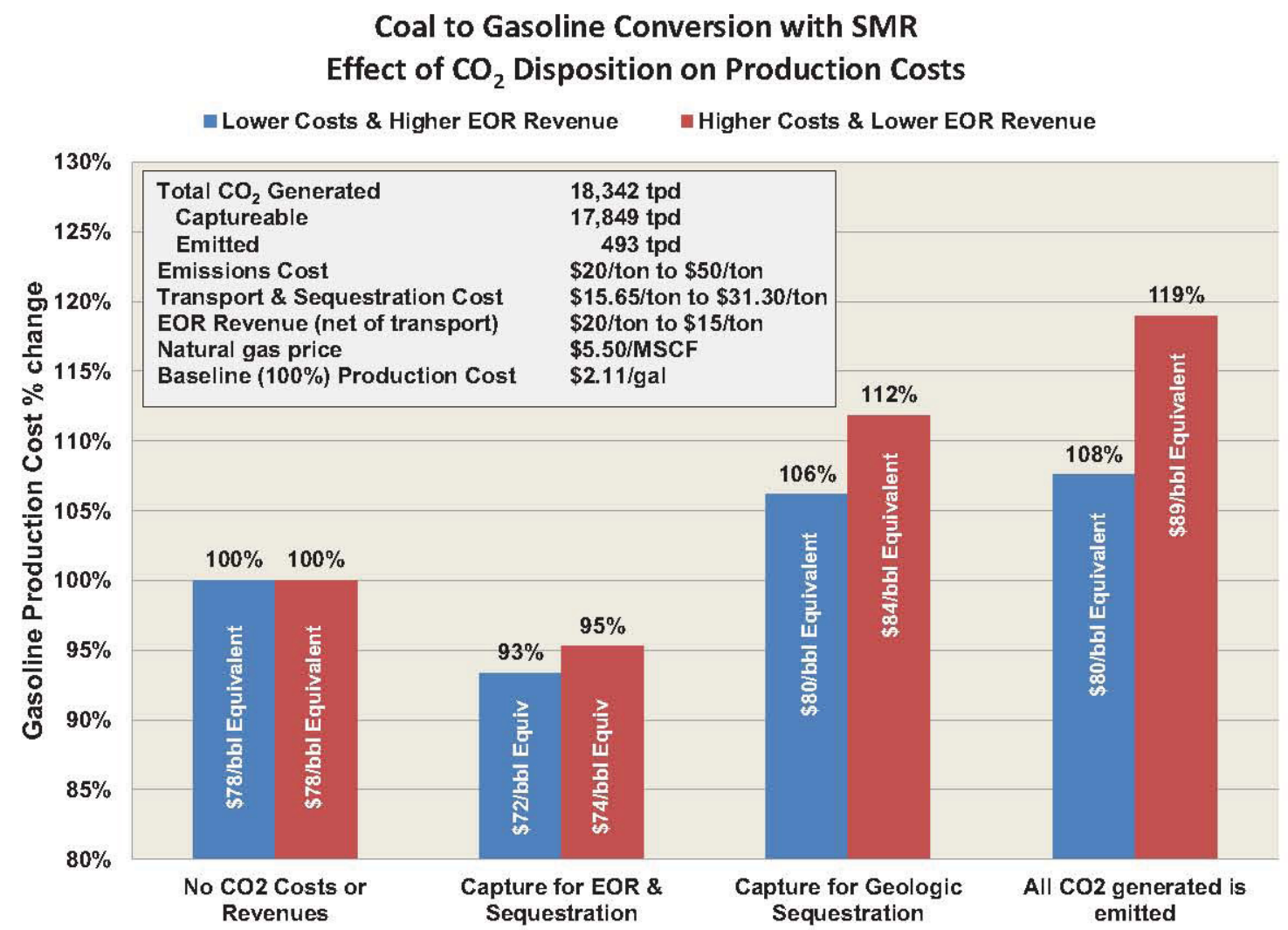

Figure 3-17. Effect of $\mathrm{CO}_{2}$ disposition on gasoline production costs for the CTG process with SMR.

\subsection{Notional Selection of the Processes for Evaluating Deployment of a Carbon Conversion Industry in Kentucky}

\subsubsection{Selection of the Initial Carbon Conversion Process}

For the purposes of evaluating the general business economics, effects on the economy of Kentucky, nominal schedule, and potential integration with HTGR technology, CTG and LPG plants using the MTG process have been notionally selected for examining deployment in Paducah and for the first plant (EK-1) in eastern Kentucky. Figure 3-18 is a high level schematic of this process. As noted previously, this process plant concept would use an external supply of hydrogen from a steam methane reformer for use in the gasification process and the gasifier concept modeled for this evaluation is representative of the dryfed designs offered by Shell and Uhde. ${ }^{7}$

Clearly the selection of the specific process(es) used in these initial plants and in the deployment of a broader carbon conversion industry within Kentucky would be the responsibility of the owners of the plants. These selections would be made after consideration of several factors including market conditions, energy costs, (e.g., crude oil, coal, natural gas), plant costs, financing, site characteristics including feedstock supply, infrastructure, distribution network, etc. The evaluations summarized herein provide some insight into the influence of these factors on the selection of a process.

The specific functional, performance and economic characteristics of all of the carbon conversion processes evaluated are summarized in Appendices D and E. 


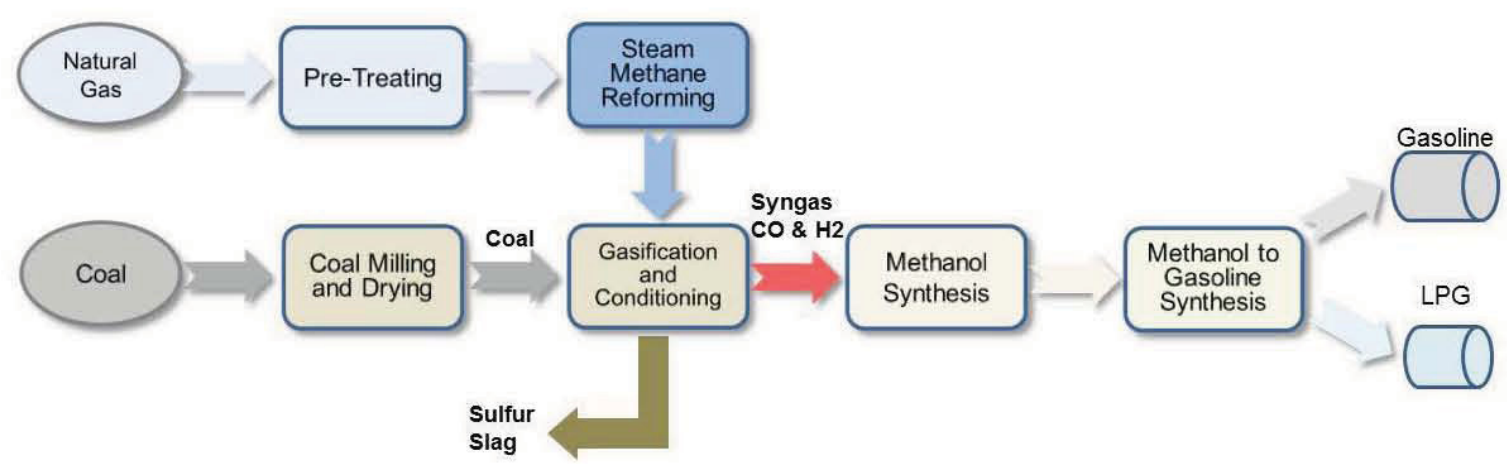

Figure 3-18. Coal to MTG and LPG process.

The bases for notionally selecting the indirect coal to MTG and LPG process for Paducah and EK-1 include the following:

- Gasoline and LPG are high value products with mature national and international markets

- As shown in Figure 3-10 the calculated costs for production of gasoline and LPG using this process are competitive with their production costs from crude oil using conventional refining techniques at crude oil prices in the range of $\$ 75 / \mathrm{bbl}$ and above. This price of crude oil is in the lower end of projections of the future price of crude oil in the 2023 to 2035 time frame as shown Figure 3-11.

- The coal to MTG process uses conventional technology, commercially available equipment, and deployment could be initiated as soon as Project funding is available. There are several plants using this concept under construction or planned in the United States.; three of which are in Kentucky.

${ }^{41,42,43}$ Some other plants that originally were going to use coal as the feedstock have switched to natural gas due to its current low $\operatorname{cost}^{44}$ but could be converted to use coal at a later date as natural gas prices rise.

- The use of a SMR hydrogen supply has the advantage of reduced $\mathrm{CO}_{2}$ emissions when compared with those of a traditional plant design that uses the water shift reaction for hydrogen generation, and facilitates later modification of the hydrogen supply to use HTGR and, if applicable, HTSE technologies when they are proved to be economically viable.

- The methanol process can also be used to produce chemicals used as building blocks in the chemical industry (see Figure 3-6) providing flexibility to maintain plant economic viability in changing market conditions.

\subsubsection{Integrating the HTGR Technology}

The HTGR is particularly well suited to integration with the carbon conversion processes because it operates in a temperature range $\left(700\right.$ to $\left.850^{\circ} \mathrm{C}\right)$ similar to the temperatures at which many of the processes operate. It also has a very high margin of safety that permits its collocation with the processes (see Appendix B). The high operating temperature of the HTGR also results in much higher net efficiencies in the generation of electricity when compared with light water reactor (LWR) technologies. Accordingly, it is particularly well suited for providing heat and electricity to a steam methane reformer. In combination with the High Steam Electrolysis (HTSE) technology it can also provide emission free hydrogen in place of the steam methane reformers. Figure 3-2 shows these two alternative applications of the HTGR and HTSE technologies. In the first HTGR heat is used in the SMR process reducing the natural gas fired in the process thereby reducing $\mathrm{CO}_{2}$ emissions by over $90 \%$ of conventional processes. The second shows the use of HTGR and HTSE technology for the production of hydrogen; essentially eliminating $\mathrm{CO}_{2}$ emissions from the gasification process. This latter application eliminates the use of natural gas in the 
process removing the potential impact of volatility in the prices of natural gas on the economics of the process as shown in Figures 3-9 and 3-10.

A DCL process also requires addition of hydrogen and traditionally uses SMR as the supply. The HTGR and HTSE technologies could also be directly adapted to this type coal conversion process in a manner similar to that shown in Figure 3-2.

The ready adaptability of these plant configurations to application of non-emitting HTGR and HTSE technologies provides the ability to apply these technologies as needed to respond to governmental actions on emissions regulation or taxation, in addition to market changes, (e.g., rapid increases in the costs of the natural gas feedstock to the SMR process).

Based on current planning the HTGR and HTSE technologies are expected to be commercially available in the late-2020s time frame. It is recommended that the progress in development of these technologies be supported and monitored by Kentucky interests to support making a decision in the early to mid-2020s on adapting these technologies to the process plant. For the purposes of analysis it has been assumed that a decision to incorporate the HTGR and potentially the HTSE technology into the carbon conversion plants would be made in 2023. It is projected that three years of design, planning and permitting effort will be required prior to initiating construction of the HTGR, and if applicable, the HTSE plant. Full deployment of this plant and its integration with the process plant would be done in a four phase schedule that would take $\sim$ seven years to complete. Based on a schedule that maintains an achievable funding level and begins plant construction in 2025 , this deployment would be complete by the end of 2032.

\subsubsection{Notional Plant Performance, Costs and Revenues}

\subsubsection{Initial Plants Capacities and Deployment Schedules}

An ultimate plant capacity of 67,000 bpd of gasoline ( $58 \mathrm{Kbpd}$ ) and LPG ( $9 \mathrm{Kbpd}$ ) has been used for the Paducah and EK-1 plants. The strategy for deployment of each of these plants involves four phases of initial construction of conventional process modules of $25 \%$ of full capacity each, $(\sim 17,000 \mathrm{bpd}$ each $)$. The deployment of the first module would include final design work for the full plant site, initiation of long term procurement, site preparation, construction and commissioning of the first module and one year of operation before initiating subsequent deployment of the remaining three modules to iron out design and operating problems. To facilitate the deployment of the EK-1 plant its schedule has been delayed from that of the Paducah plant by one year. The experience in planning and construction of the Paducah plant will be useful in developing the processes and infrastructure necessary to deploy EK-1. A preliminary schedule for this phased deployment indicates that the Paducah plant could be operating at full capacity in 2020 if the deployment Project were initiated in early 2013 ; shortly followed by EK-1 at full capacity in 2021. The first Paducah module would begin operation in 2018. Note that the schedule for EK-1 to reach full capacity could be shortened to correspond with Paducah if it does not include the one year operation of the first module before commissioning of the second. This may be achievable if the first module operation at Paducah does not identify any major problems. Also, if different coal conversion technology is used for the Paducah application and the eastern Kentucky application, then the plants could readily be implemented in parallel.

Appendix F provides detail of the deployment strategy and economics for these plants. Note that the development of this strategy has used the same CTG process for the Paducah and EK-1 plants. This does not have to be the case. For example, a DCL process producing diesel, naphtha and LPG may be more suited for use in Paducah using the higher sulfur coal of Western Kentucky. The indirect CTL process may be preferred for all four plants in the eastern Kentucky area. As noted previously the selection of the 
processes for each plant will be the purview of the owners. The use of the CTG process for both of these plants is notional to support completing the analyses performed herein.

\subsubsection{Initial CTG Plants Revenues and Benefit to Kentucky Economy}

Conversion of the indigenous coal resources to gasoline, LPG or chemicals in the carbon conversion industry would provide a substantial increase in the value of this resource to the economies of Paducah, eastern Kentucky and the Commonwealth. Use of indigenous natural gas in the SMR process also provides an internal market and can support increased production of this commodity. The products of the plant increase the value of the coal and natural gas due to the increased revenues for the higher prices of the products. The value multipliers can range from 5 to 40 times the retail value of the coal and natural gas depending on the price assigned to the coal, natural gas and the products, (e.g., diesel fuel, gasoline, chemicals). It is estimated that a full scale CTG plant will generate revenue of $\sim \$ 2 B(2011 \$)$ per annum assuming a sales price equal to the average wholesale price of gasoline and LPG from crude oil refineries, (price at the gate) in 2010 and 2011.

Construction of the initial CTG plants and their operation will also create jobs and have economic benefit to Kentucky. As cited in the preceding the construction of the conventional plant is projected to extend over seven years. The total cost is estimated to be in the range of $\sim \$ 7$ billion per plant.

Construction of each plant will require a total of $\sim 31,000$ man-years over this seven year period with an average workforce of $\sim 4,400$ per year and a peak of $\sim 9,300$ in year five. The addition of HTGR plants would extend over another seven years at a cost of $\sim \$ 6$ billion, and require an additional 15,000 manyears of effort with an average workforce of $\sim 2000$ per year for each plant. The process plants are expected to employ 400 each and each HTGR plant an additional 400 personnel.

At this level of activity and expenditure the Paducah plant would provide a substantial step toward offsetting the economic loss due to closure of the DOE PGDP and help sustain the Paducah economy over the $\sim 14$ years of construction and the longer term operation of the process and HTGR plants. EK-1 would have similar impact on the economy of eastern Kentucky with emphasis on stemming the reduction in coal production.

Appendix F provides more details of the economics of these plants.

The following section discusses the siting of the Paducah plant. Siting of the eastern Kentucky plants is beyond the scope of this report. Appendix F discusses the specific characteristics that are required for siting a carbon conversion plant in eastern Kentucky.

\subsubsection{Notional Siting of the Paducah Plant}

In 2009, the Paducah Area Community Reuse Organization (PACRO) completed a thorough survey of a site adjacent to the PGDP, including an environmental report, to determine the suitability of that site for locating an energy project. ${ }^{45}$ This survey was performed as part of a wider survey of Kentucky to identify sites suitable for industrial development. ${ }^{46}$ Review of the PACRO report and further evaluations of the site as part of this collaborative effort concluded that it has the necessary infrastructure and labor force for design, construction and operation and for shipping of products from the process plant. Figure 319 is an excerpt from the PACRO report showing the site. As also shown on this figure it would be necessary to expand this site in order to accommodate the projected size of the reference plant $(\sim 1000$ acres). Accordingly, the original PACRO site which included $\sim 500$ acres was increased by expanding into the DOE owned area and the Western Kentucky Wildlife Management Area west of the original site Discussions with Kentucky interests (see Appendix A) confirmed that this is a viable approach to increase the size of the site. 


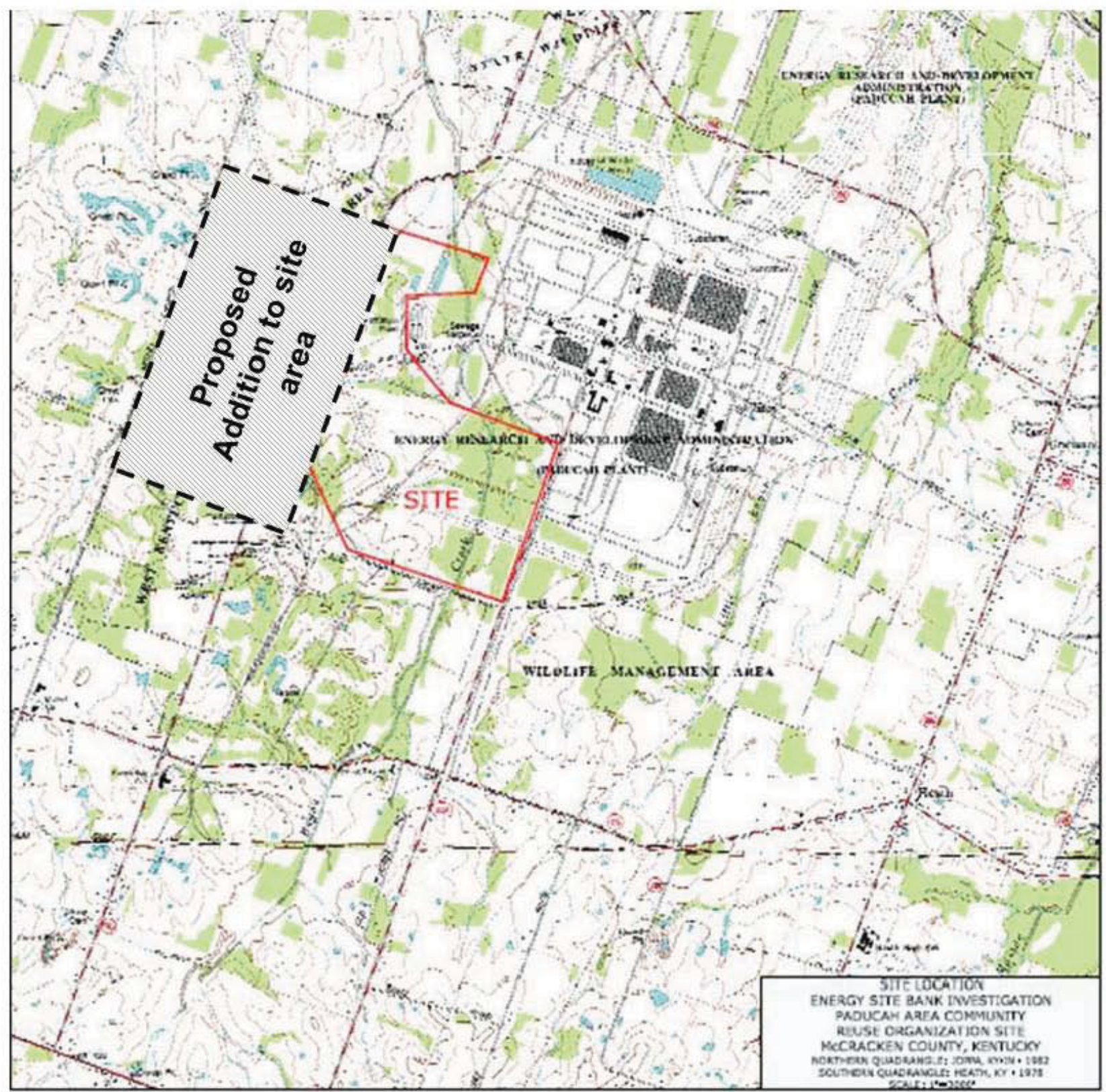

Figure 3-19. Potential sife for the Paducah carbon conversion plant.

Figure 3-20 is a notional layout of the complete coal to MTG plant and the HTGR plant (shown in phantom) that would located on the PACRO site in Paducah. The plant covers approximately $75 \%$ of the 1000 acres identified for the plant leaving some room for future expansion if the market conditions are favorable for such expansion. 


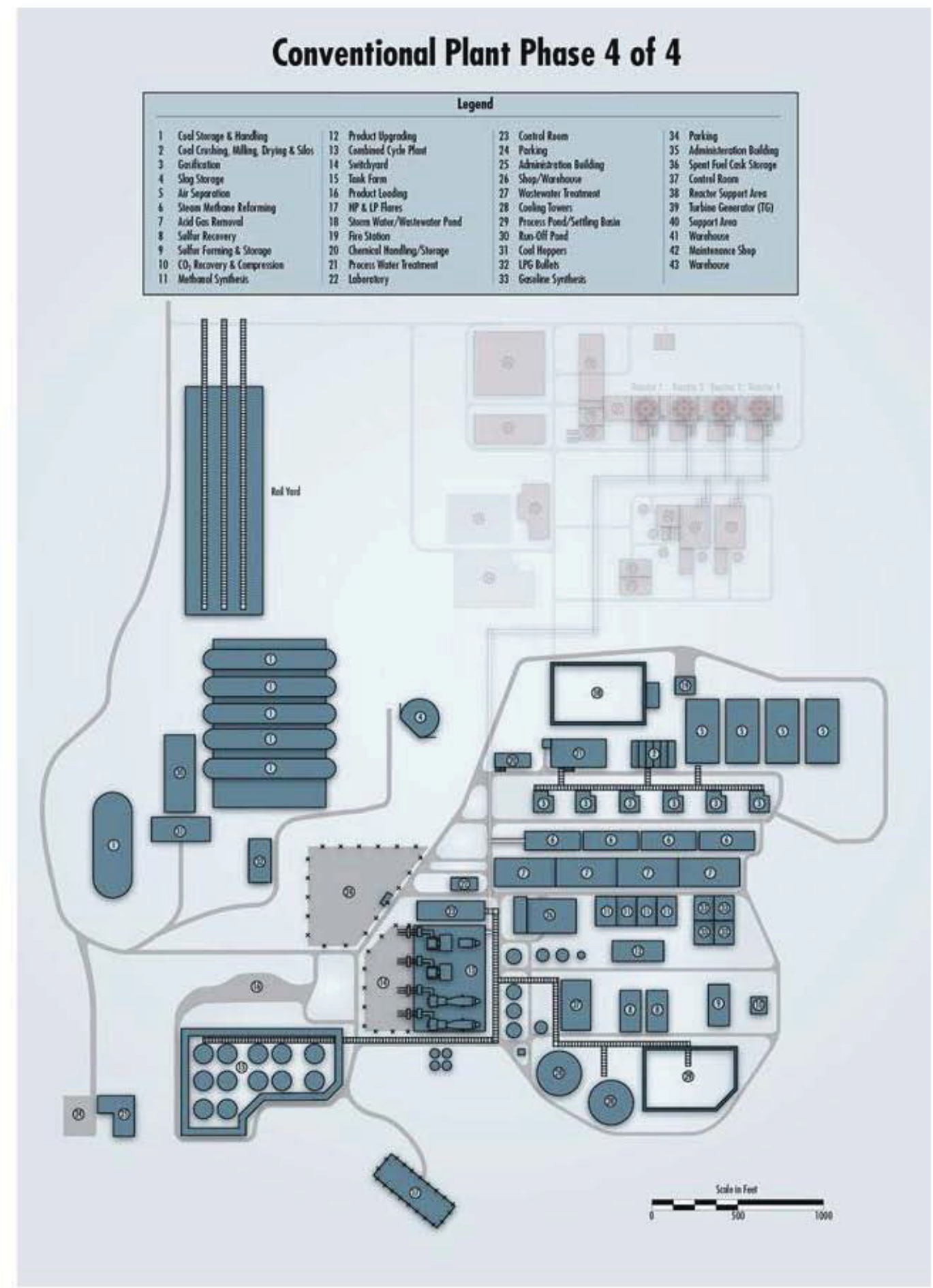

Figure 3-20. Notional tayout of coal to MTG and HTGR plants. 


\subsection{Deployment of the Carbon Conversion Industry}

\subsubsection{Objectives of Deploying the Carbon Conversion Industry}

The Paducah and EK-1 plants could be the first in deployment of a carbon conversion industry comprised of several additional carbon conversion plants within Kentucky. An objective of deploying this industry is to provide long term internal markets for Kentucky coal and natural gas. Figure 3-21 shows that total production of coal in Kentucky has been declining for more than 15 years; the principal reduction has been in production in eastern Kentucky while the production in Western Kentucky has been relatively stable. This reduction in eastern Kentucky coal production is due to retirement of coal-based electricity generation and addition of emissions control equipment to coal plants so they no longer need to use the low sulfur eastern Kentucky coal. This trend of decreasing coal production is expected to continue due to current and pending EPA regulations on toxic chemical and $\mathrm{CO}_{2}$ emissions. ${ }^{47,48}$

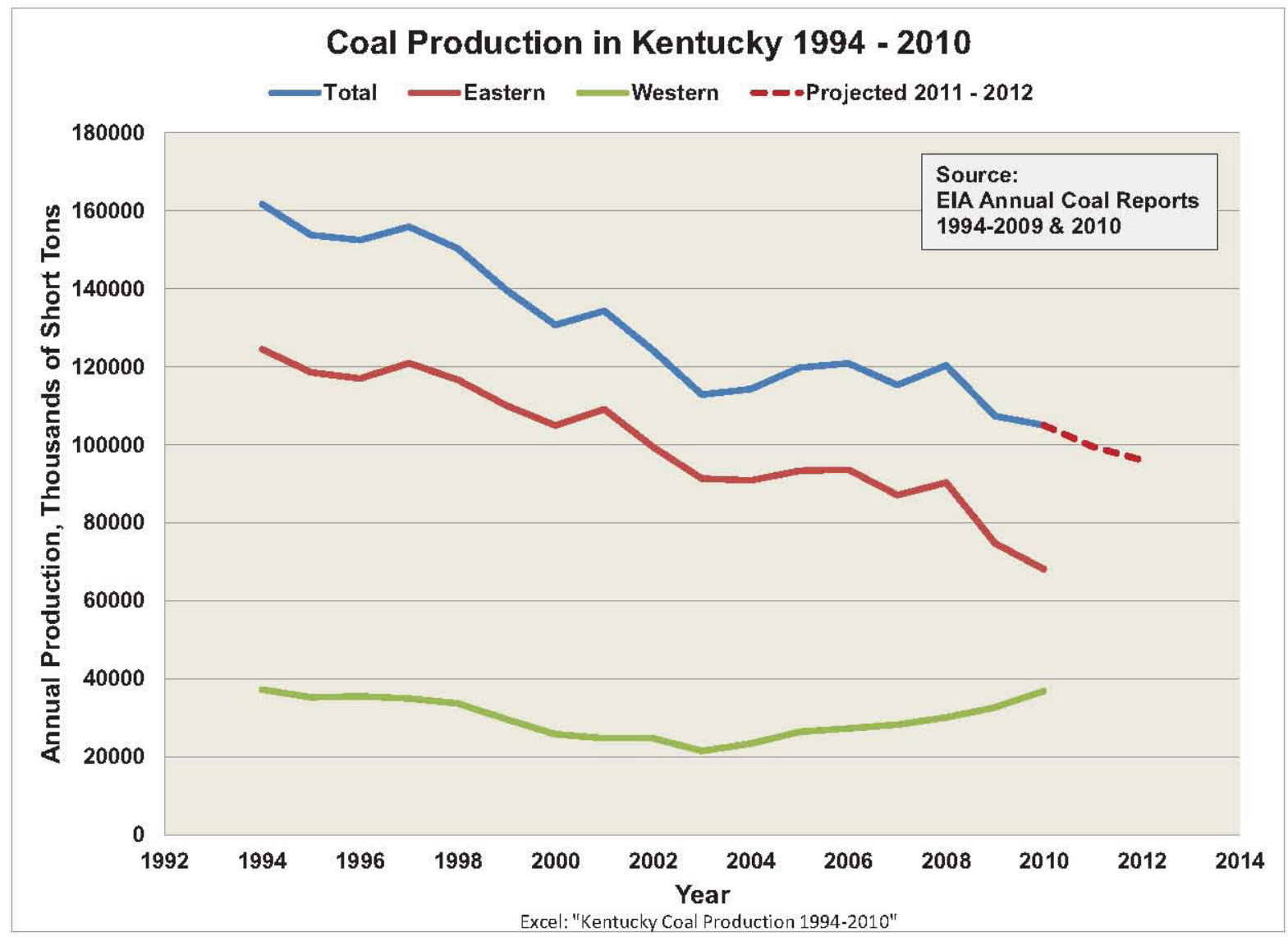

Figure 3-21. Coal production in Kentucky 1994-2011.

Figure 3-22 shows the history of production of natural gas in Kentucky and Interstate Receipts of Natural Gas for 1987-2010. Although production increased rapidly in the 2007 to 2010 time frame the rate of production is still more than a factor of ten(10) less than the Interstate Receipts. In addition over this time frame the prices of natural gas have fallen substantially (e.g., from $\sim \$ 8 / \mathrm{MSCF}$ in 2008 to lows in the $\$ 2 / \mathrm{MSCF}$ in 2012) because of the new gas shale plays. Natural gas futures on the commodities market indicate that the prices will remain low in the $\$ 4 / \mathrm{MSCF}$ or less range for at least the next decade. 


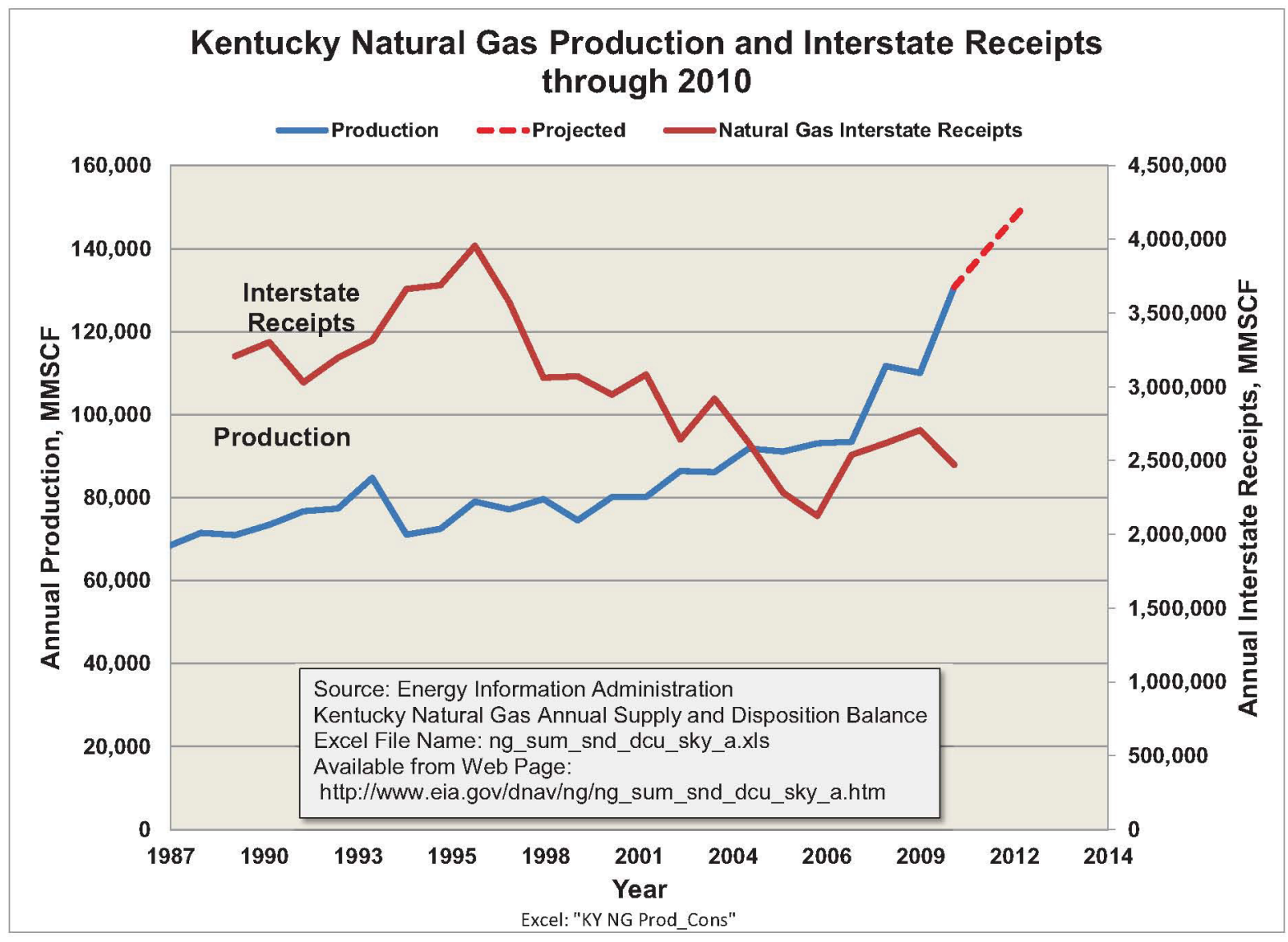

Figure 3-22. Kentucky natural gas production and interstate receipts.

The reductions in coal production and in the price of natural gas have substantial impact on the tax revenues to the Commonwealth. The Commonwealth receives a severance tax on the coal and natural gas of $4.5 \%$ of the sales price. Kentucky coal has a historical value in the $\$ 50 /$ ton range. Accordingly, a million tons has a severance tax value of $\$ 2.25 \mathrm{MM}$. The 28 million ton annual reduction in coal production 2002 to 2012 has reduced Commonwealth tax revenues by $\sim \$ 65 \mathrm{MM}$. Similarly the $\sim \$ 4 / \mathrm{MSCF}$ reduction in natural gas prices over the last 4 years has reduced revenues on internal production by $\sim$ \$20MM even with the increase in internal production. This reduction in tax revenue and the negative impact on the local economies provide incentives for taking action to stem these losses.

A goal of developing a new market for eastern Kentucky coal of at least 14 million tons per year within the next 10 to 15 years has been cited by the Kentucky Energy and Environment Cabinet. ${ }^{49}$ This is less than the 50 million tons per year cited in the Kentucky energy development Strategy 4 discussed previously but is judged to be a level of production that is achievable in the short term and sufficient to address the short term economic impact of reducing production of eastern Kentucky coal if no action is taken. The schedule for deploying the carbon conversion industry that consumes at least 14 million tons of coal annually projects full scale capacity on-line by the end of 2023 if action is taken to begin its development in 2013; a ten year period. This is consistent with the schedule in Strategy 4 called for development of the industry by 2025 .

The CTG plant described as a notional alternative for deployment in Paducah and for EK-1 consumes $\sim 12,000$ tpd or $\sim 3.5 \mathrm{MMtpy}$ of coal assuming an $80 \%$ capacity factor. The addition of a CTL plant producing diesel, naphtha and LPG of 50,000 bpd capacity would consume an additional 7,720 tpd per 
plant or $2.25 \mathrm{MM}$ tpy of coal at an $80 \%$ eapacity factor. Accordingly, deployment of the Paducah and EK-1 CT G plarts arid thro additional CTL plarts would consume 14.5 MMTpy of coal.

These plants would be expected to use Steam Methane Reforning as the hydrogen supply using ratural gas as the fedstock. At full eapacity these five plarits would ecrisume 400 billion cubic feet of ratural gas arrmally. This rate is about thre times the production rate in Keritucky in 20 lo. Sirles most of the ratural gas is produced in eastern Kentueky deployment of these plants would have the added benefit of substantially incteasing the demand for eastem Kentucky natural ges as well as coal

\subsubsection{Cafoon Conversion industry Degloyment Schedive}

For the purposes of analysis the notional earbon conversion flest has been defined as comprising two CTG and throe CTL plants. As noted cre CT G plant would be sited in Padueah and one as EK-l in eastem Kentucky. The three CTL plants would also be sited in eastern Kentucky. It was beyond the scope of this report to identify the spetifie sites in easterr Kenturky, however, preferred sites would be near a coal mine mouth and natural gas well s. Based on Kentucky Geological Survey data such sites appear to be plentiful in easten Kentutky; ses Figure 3-23.
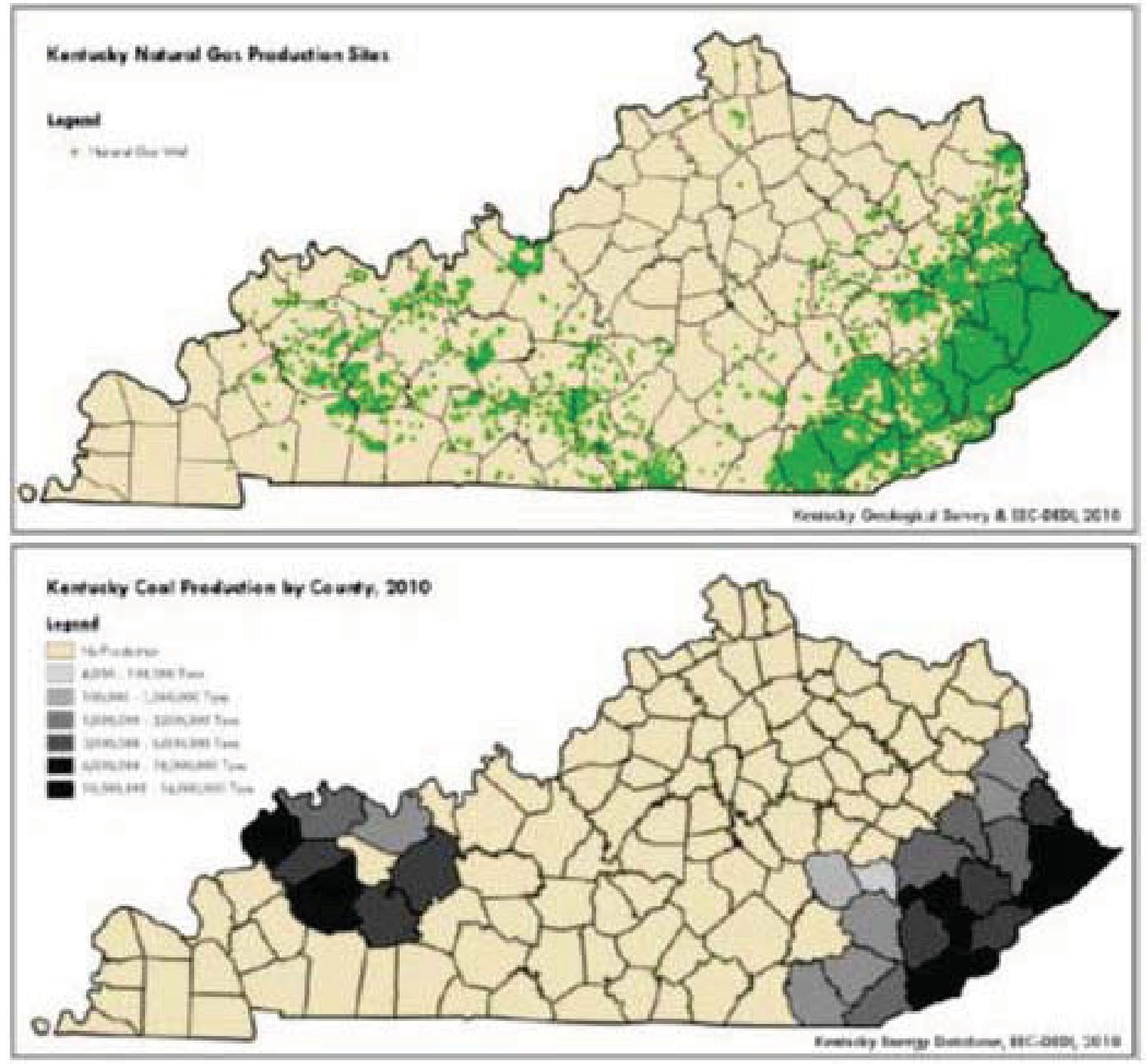

Figure 2-23. Cool mine and natural gas well jocations in Kentucky. 
Figure 3-24 shows the schedule for deployment of the carbon conversion industry. As discussed EK-1 would be constructed in parallel with the Paducah plant and reach full capacity one year after Paducah reaches full capacity. The other three CTL plants (EK-2, 3, and 4) would follow in one year increments. This is judged to be an aggressive schedule, but reaches the cited goal for consumption of eastern Kentucky coal and natural gas in a timely manner; (within the 10 year period cited by the Kentucky Energy and Environment Cabinet). As discussed for the Paducah plant deployment it is assumed that HTGR technology will be integrated into the processes of these plants providing heat and electricity when commercialized. This integration will reduce $\mathrm{CO}_{2}$ emissions to lower levels and will provide a stable energy price over the longer term. These HTGR plants will also be sized to supply electricity to the regional grid to replace coal based generation as those plants are retired due to age or EPA regulations. The addition of the HTGRs to the process plants reduces the quantities of natural gas consumed. This is reflected in the reduction of natural gas consumption shown in Figure 3-25 in the 2029 to 2034 time frame.

\begin{tabular}{|c|c|c|c|c|c|c|c|c|c|c|c|c|c|c|c|}
\hline Activity & 10 & 11 & 12 & 13 & 14 & 15 & 16 & 17 & 18 & 19 & 20 & 21 & 22 & 23 & 24 \\
\hline Carbon Conversion Ind & & & & & & & & & & & & & & & \\
\hline Paducah CTL Plant & & & & ב- & & & & & & Z & & & & & \\
\hline EKY Plant 1 & & & & & & & & & & & & & & & \\
\hline EKY Plant 2 & & & & & & & & E & & & & & & & \\
\hline EKY Plant 3 & & & & & & & & & & & & & & & \\
\hline EKY Plant 4 & & & & & & & & & & & & & & & \\
\hline
\end{tabular}

Figure 3-24. Carbon conversion industry deployment by calendar year.

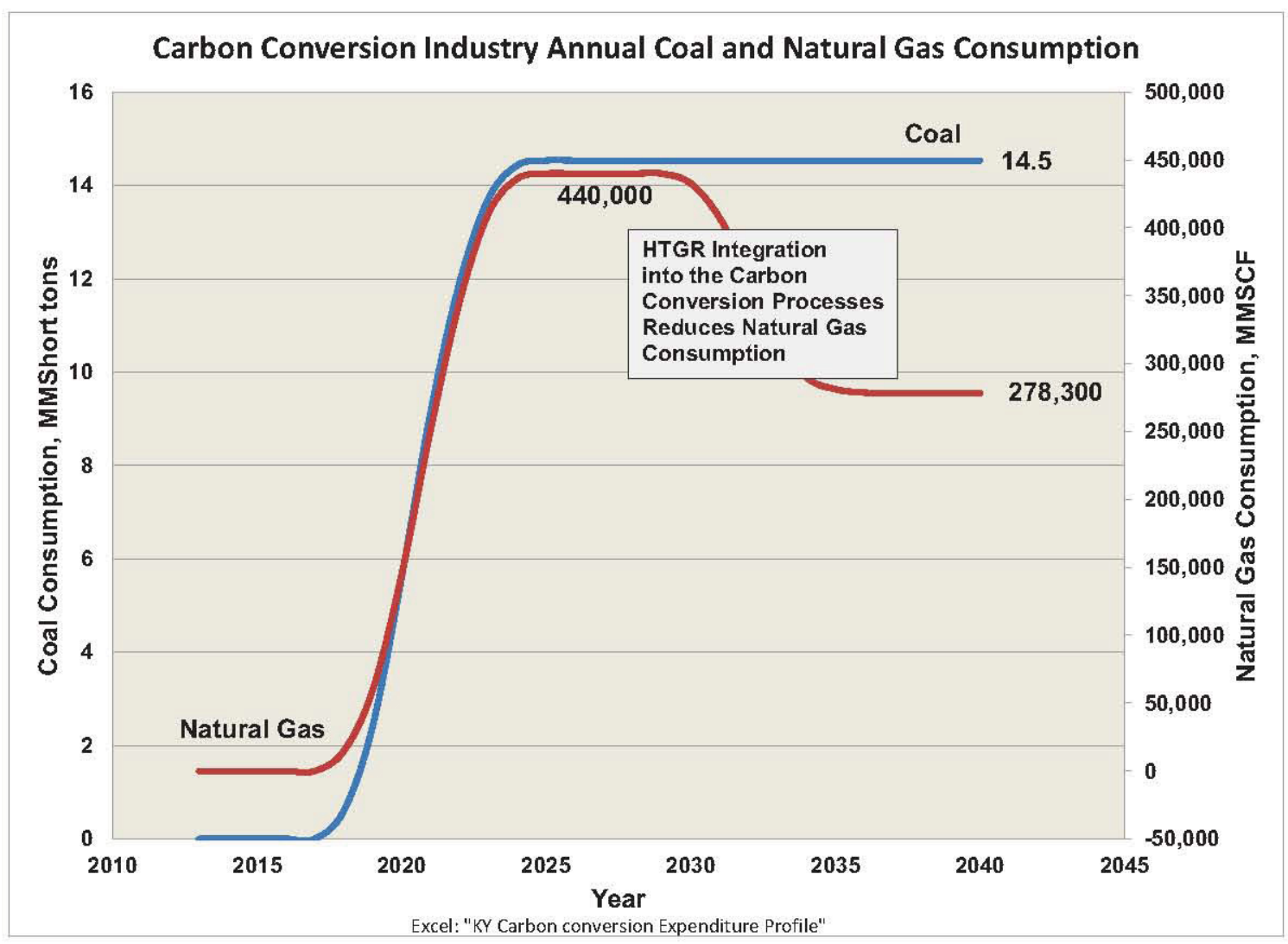

Figure 3-25. Carbon conversion industry coal and natural gas consumption. 


\subsubsection{Carbon Conversion Industry Revenues and Contribution to the Kentucky GDP}

The production of synthetic fuels by these plants will also increase the value of the coal and natural gas they consume. Based on average costs in 2011 of refining these fuels from crude oil these plants when operating at full capacity are projected to generate $\$ 11.8 \mathrm{~B}(2011 \$)$ per year. This is projected to translate into an $\$ 8.5 \mathrm{~B}$ contribution to the Kentucky GDP or $\sim 5 \%$ of the 2011 GDP as shown in Figure 3-26.

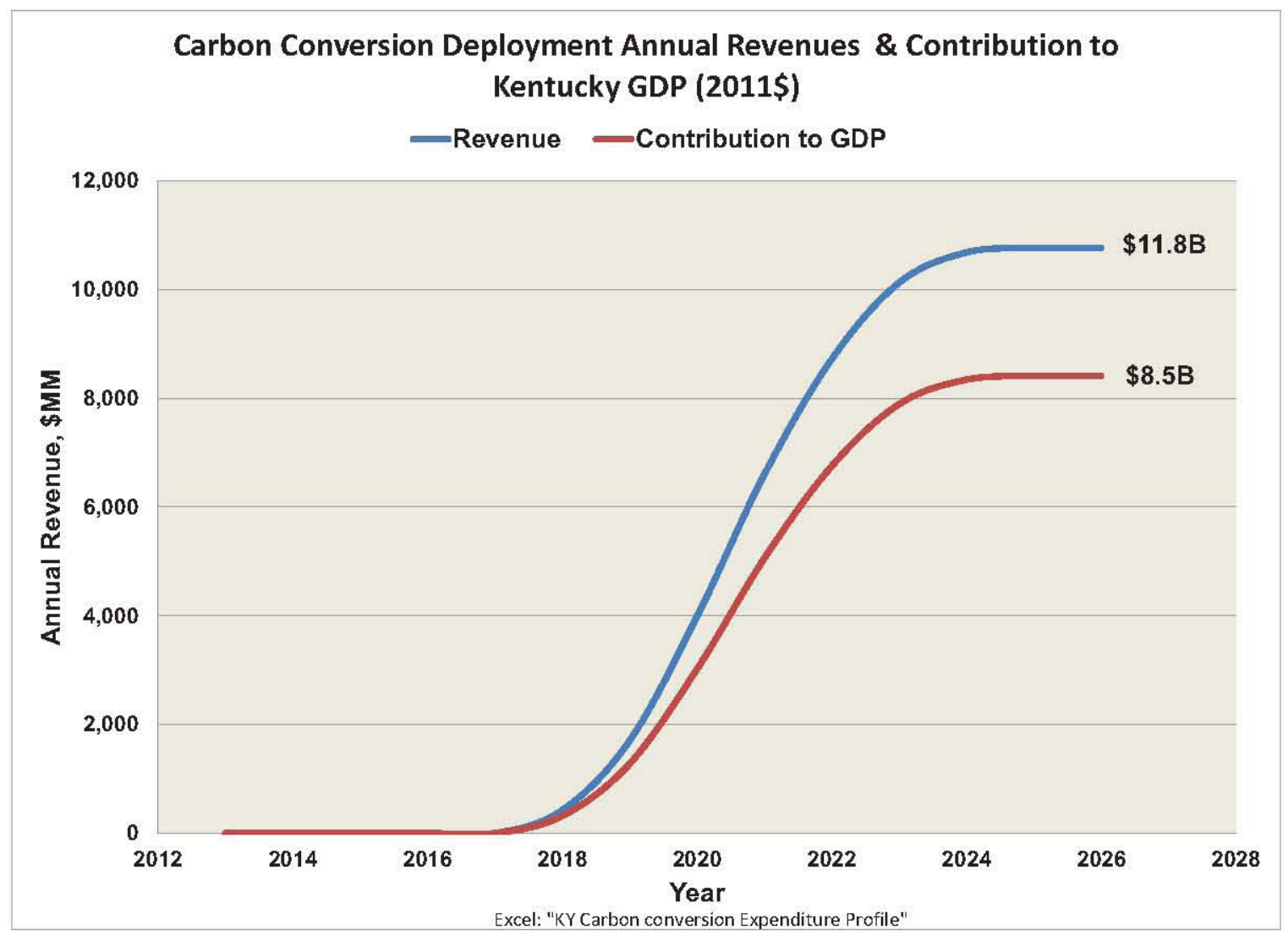

Figure 3-26. Carbon conversion industry deployment annual revenues and contributions to Kentucky GDP.

The expenditures during deployment of the carbon conversion industry and integration of the HTGR technology into the carbon conversion processes would be large and would also add to the Kentucky GDP during the periods of construction. Figure 3-27 shows the expenditures and the projected contributions to the Kentucky GDP over the 2013 through 2040 time frame. The peak contributions to the GDP are in the $\$ 3$ to $\$ 4 \mathrm{~B}(2011 \$)$ range or $\sim 2 \%$ of the 2011 GDP. Please note that manufacture of major equipment that constitutes about $30 \%$ of the capital costs in building a major process plant has been assumed to occur outside of Kentucky, hence not contributing to the GDP. Depending on the extent an industrial manufacturing capability exists or will be developed in Kentucky, the contribution to Kentucky's economy and the GDP can be further increased by up to $\$ 1 \mathrm{~B}$.

Although these are relatively modest contributors to the Kentucky GDP the contribution from the long term revenue from the carbon conversion plants is $\sim 1-1 / 2$ times the total mining contribution to the GDP in 2011. The periods of construction not only add to the GDP but do so while providing jobs. The plants also provide jobs in Paducah and eastern Kentucky while operating; 1,000 personnel per plant when the HTGR is fully integrated. Therefore, the deployment of this industry presents a significant step toward offsetting the projected reductions in coal production in eastern Kentucky in addition to the 


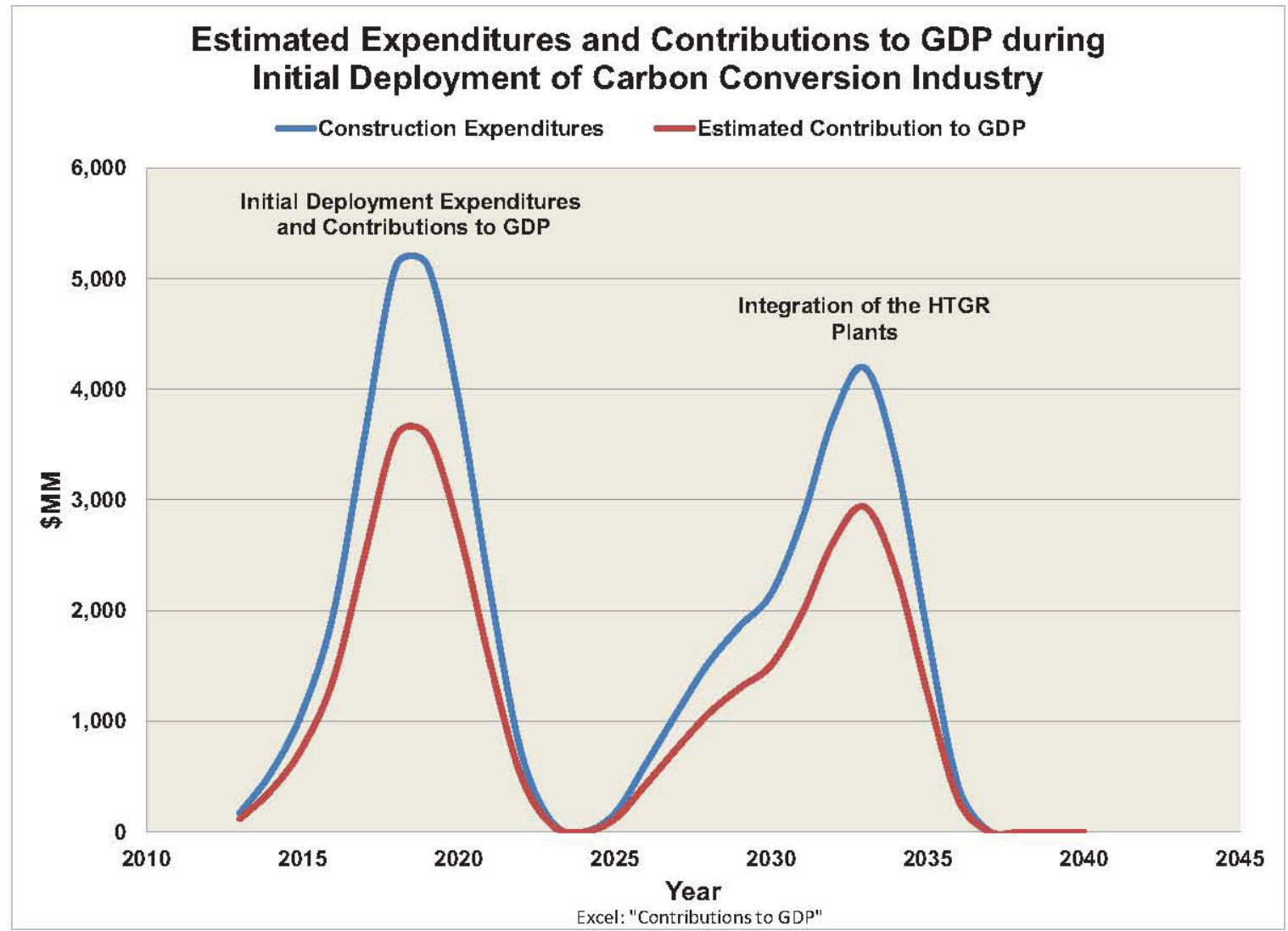

Figure 3-27. Estimated expenditures and contributions to GDP during initial deployment of carbon conversion industry.

economic loss from the closing of the Paducah PGDP. It should be noted that the economic multiplier effects of business growth (e.g., real estate, retail sales growth) that accompanies such industry development has not been included.

\subsubsection{A Distributed Configuration for the Carbon Conversion Industry}

Production and transport of finished products from eastern Kentucky may not be practical depending on the infrastructure and terrain at the plant sites. For this reason or for other reasons such as to facilitate product distribution, a distributed approach to deployment of the facilities that will make up the carbon conversion industry may be warranted. Figure 3-28 illustrates this approach. The mine mouth plants would produce synthesis gas which would then be piped to other locations that would process that gas to produce synthetic fuels and/or chemicals. These facilities would be located in areas that have favorable infrastructure to support construction and operation of these plants and locations that facilitate distribution of the finished products within the Commonwealth, nationally and internationally. 
INL/EXT-12-26710

November 2012

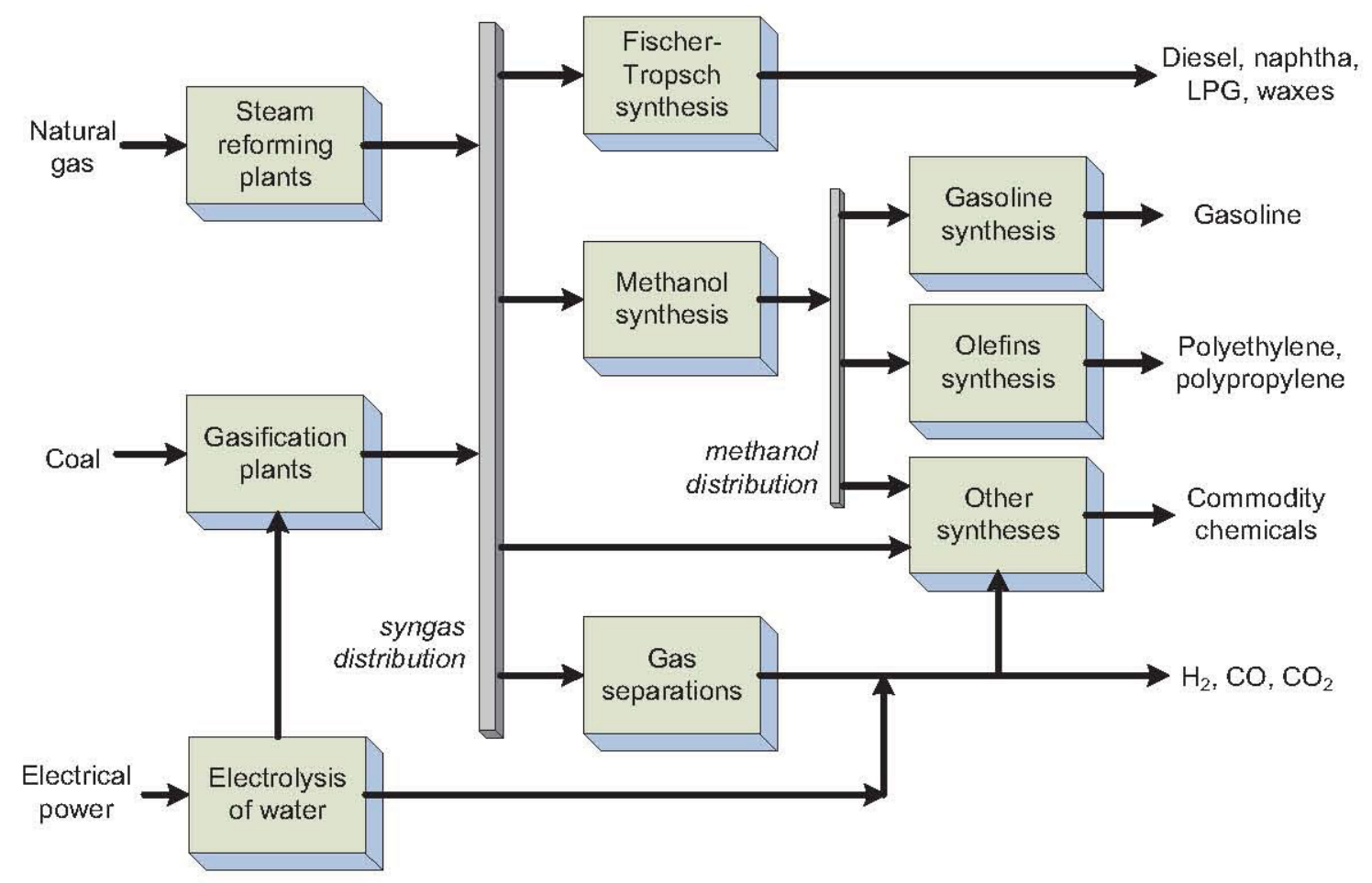

Figure 3-28. Distributed approach to deployment of a carbon conversion industry.

\subsection{Transformation of Kentucky Electricity Generation Industry}

\subsubsection{Electricity Generation Transformation Objectives}

Over $90 \%$ of electricity in Kentucky is generated using coal. The current and pending EPA regulations on mercury and toxic chemicals require the installation of expensive emissions control equipment that is not economically viable on some Kentucky plants leading to the potential for their earlier retirement than might otherwise be expected. ${ }^{50,51}$ There are also pending EPA regulations on $\mathrm{CO}_{2}$ emissions that currently apply to new plants. It is uncertain whether the EPA intends on applying these or similar regulations to existing plants. Discussions of industry and environmental groups seem to indicate that there is an expectation that this will occur. ${ }^{52}$

It remains unclear what EPA intends to do to address $\mathrm{CO}_{2}$ emissions from existing plants. Jackson [EPA Administrator] told reporters Tuesday that EPA has no plans to propose an NSPS for existing plants, despite the fact that the December 2010 settlement [that resolves a lawsuit filed by states and environmental groups], required EPA to propose NSPS for new, modified and existing plants at the same time. Industry sources are skeptical of Jackson's assertions.

"We have little confidence that the administration will adhere to this view, particularly after the election is over," Segal [Executive director of the Electric Reliability Coordinating Council, a utility coalition] said.

David Doniger, policy director of the climate and clean air program at the Natural Resources Defense Council, said NRDC and other parties to the 
settlement agreement are continuing disctssions with EPA on how to regulate existing soupces.

"Existing power plants are not covered by this standard but the Clean Air Act regtives EPA to follow to with requirements for those soupces, too, "Doniger said. "The proposal acknowledges this responsibility.

"The settlement disctssions continte, and we look forward to peaching an agreement with EPA on a schedule for completing the standard for new soupces and developing standards for existing sourtes."

If implemented these regulations could also lead to early retirement of those plants that have become marginally economic or uneconomic due to the regulatory impositions. These retirements in addition to normal retirements due to age and obsolescence require addition of new generation technologies. The new technologies must also be consistent with regulations on $\mathrm{CO}_{2}$ and other $\mathrm{GHG}$ emissions.

The Commonwealth's goal of transforming the electricity generation technologies in Kentucky from one dominated by coal to diverse sounes with improved emissions characteristics was outlined by the Secretary of the Kentucky Energy and Environment Cabinet in a presentation to the National Governor's Association. ${ }^{53}$ This is shown in Figure 3-29. As shown this trans formation would ideally occur over a twenty year period resulting in a mix of electricity sources with coal, coal with CCS and nuclear contributing $\sim 29 \%$ each of the total Kentucky grid capacity and petroleum, natural gas, biomass and renewables contributing the $\sim 10 \%$ balance. Since this objective transformation was developed in the 2007-2008 time frame it did not take into account the recent reductions in natural gas prices resulting from the large number of gas shale plays. The potential effect of these low gas prices on the actual transformation is discussed in the next section.

\section{Kentucky's Strategic Energy Direction}

\section{Diversifying Electricity Portfolio}

\section{Kentucky's Electricity Generation Sources}

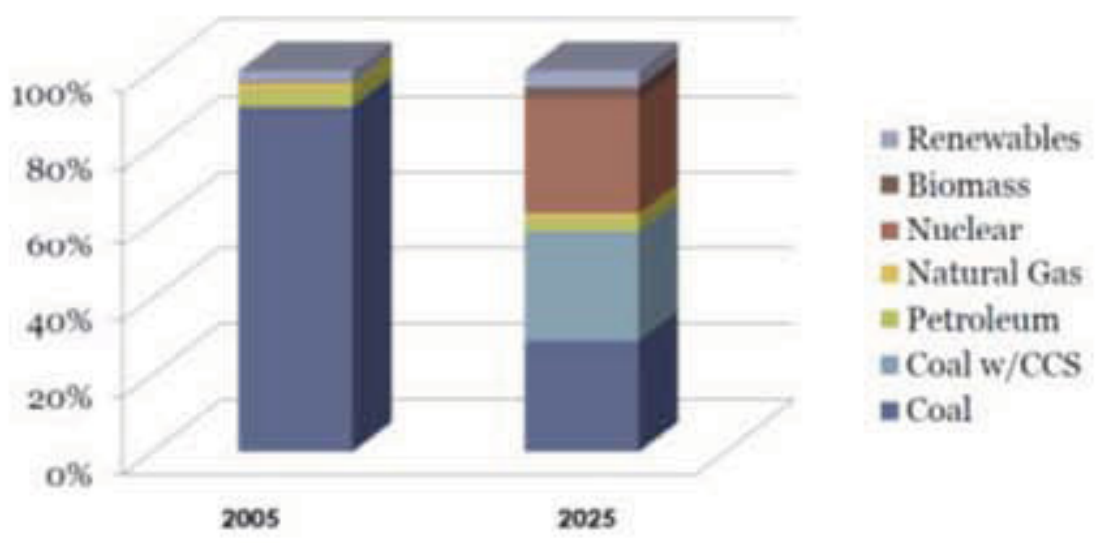

Figure 3-29. Electricity generation transfomation strategic goal. 
Including coal-fired plants as a primary constituent of the final mix of generation will necessitate addition of emissions control equipment to existing plants and new plants for continued operation over the long term. Review of the existing fleet of coal plants shows that the average age of these plants is almost 40 years and the newer plants will reach 60 years of age in the mid-2020s. Additionally, if the EPA extends regulation of $\mathrm{CO}_{2}$ to existing plants it may not be practical or economic to modify existing plants to meet these regulations. It may be necessary, therefore, to replace all existing plants as part of this transformation. The strategy developed herein, however, assumes that a substantial number of the existing coal plants can be modified and retained for long term operation.

\subsubsection{Electricity Generation Transformation Strategy}

The strategy for meeting the objectives of transforming the electricity generation to the mix shown in Figure 3-29 is developed in detail in Appendix F and is shown in Figure 3-30. This strategy includes three principal generation technologies; the upgrade of existing coal plants with emissions control equipment and addition of new plants using coal with CCS and nuclear energy technologies. The Commonwealth's long term objective does not include substantial renewable, petroleum and natural gas generation.

With respect to addition of nuclear generation it is assumed that a mix of LWR and HTGR technologies would be deployed. The LWR technologies could include large plants similar to those currently in operation and small modular LWR (SMLWR) plants. The modular characteristics of the SMLWR may be an advantage compared with large LWR plants in siting where transmission capacity is limited. This is also an advantage of the modular HTGR technology. There is considerable uncertainty in the schedule for commercialization of the SMLWR technology so it may not be available as an alternative to the large LWRs when nuclear technology is needed in the transformation. The transformation strategy is configured to be consistent with the schedule for retirement of existing generation due either to age or EPA regulations and with the deployment of the carbon conversion industry which includes addition of HTGR electricity generation as this technology is integrated into the processes. (The assumed mix of nuclear energy technologies does not strongly affect the economic results that follow.)

Figure 3-30 shows the annual change in the sources of generation to achieve the Commonwealth's goal of shifting from the original coal based generation to the new mix of generation with lower emissions and varied technologies. It will be noted in review of this figure that the transformation cannot be practically achieved in 20 years. Also note a significant deployment of natural gas generation to fulfill the transformation requirements is necessary as an interim step to reaching the Commonwealth's final goal, with that goal being achieved in 2040 rather than 2025 as suggested in Figure 3-29.

The 27-year period is required to be consistent with the expected retirements of existing plants (as shown in Figure 3-30) and the expected schedule for commercialization of the Coal with CCS and HTGR technologies in the early-to-late 2020s. It has been assumed that natural gas generation will be used to substitute for retiring coal-fired generation early in the transformation to take advantage of the current low prices of natural gas that are expected to remain low for at least the next decade and the relatively low capital cost for NGCC generation. This is consistent with the overall trends in the United States wherein there has been a substantial increase in the new natural gas generation being built and planned for future replacement of coal-fired plants. The downside of maintaining a significant level of NGCC generation on the grid over the long term is the volatility of natural gas prices and the strong relation between natural gas prices and the price of electricity production of NGCC plants. It is expected that as gas shale reserves are depleted the prices will rise rapidly making NGCC generation less economic than other forms of generation. The effect of natural gas price on generation costs for NGCC plants is shown in Figure 3-31. 


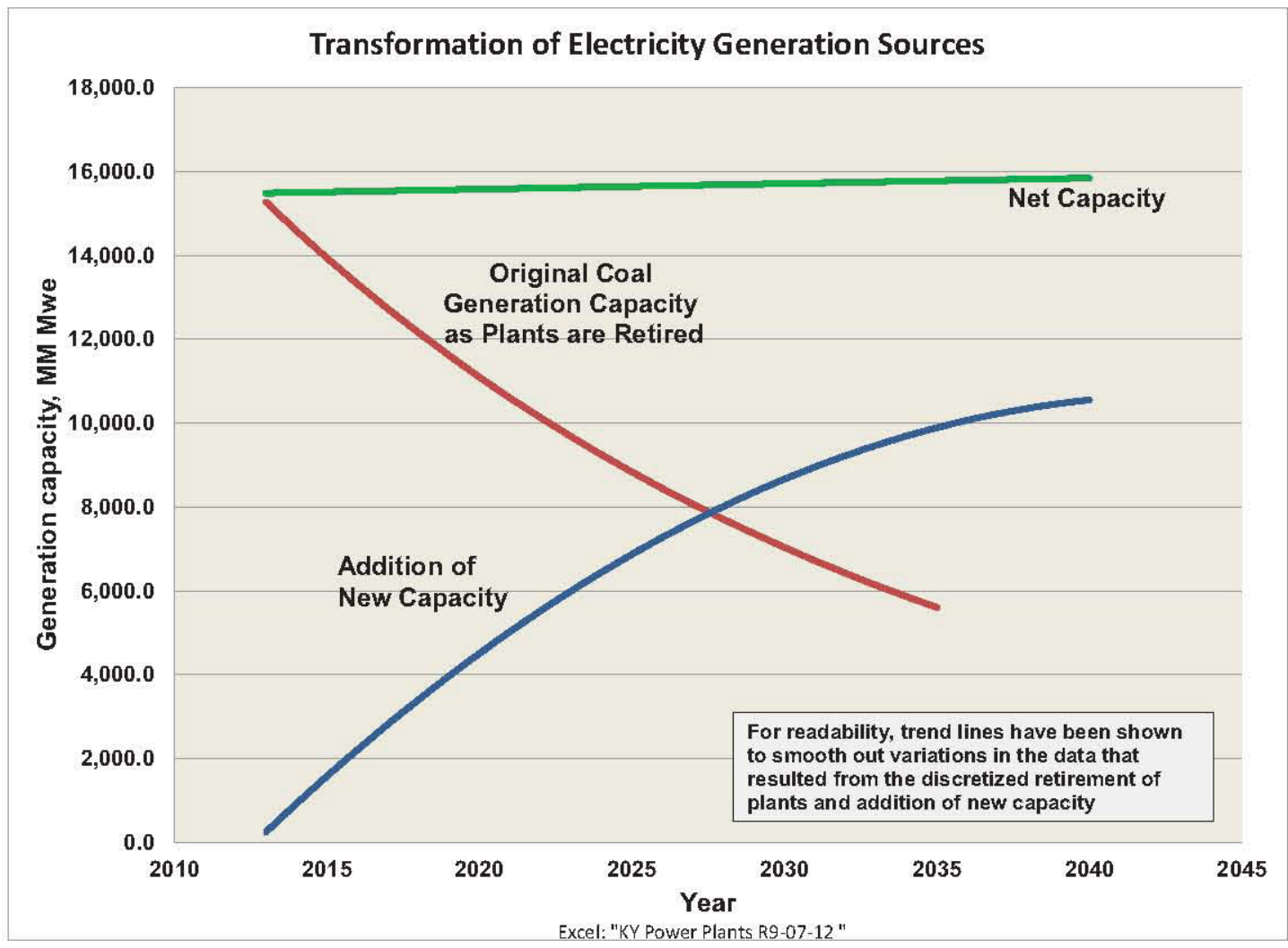

Figure 3-30. Transformation of electricity generation sources.

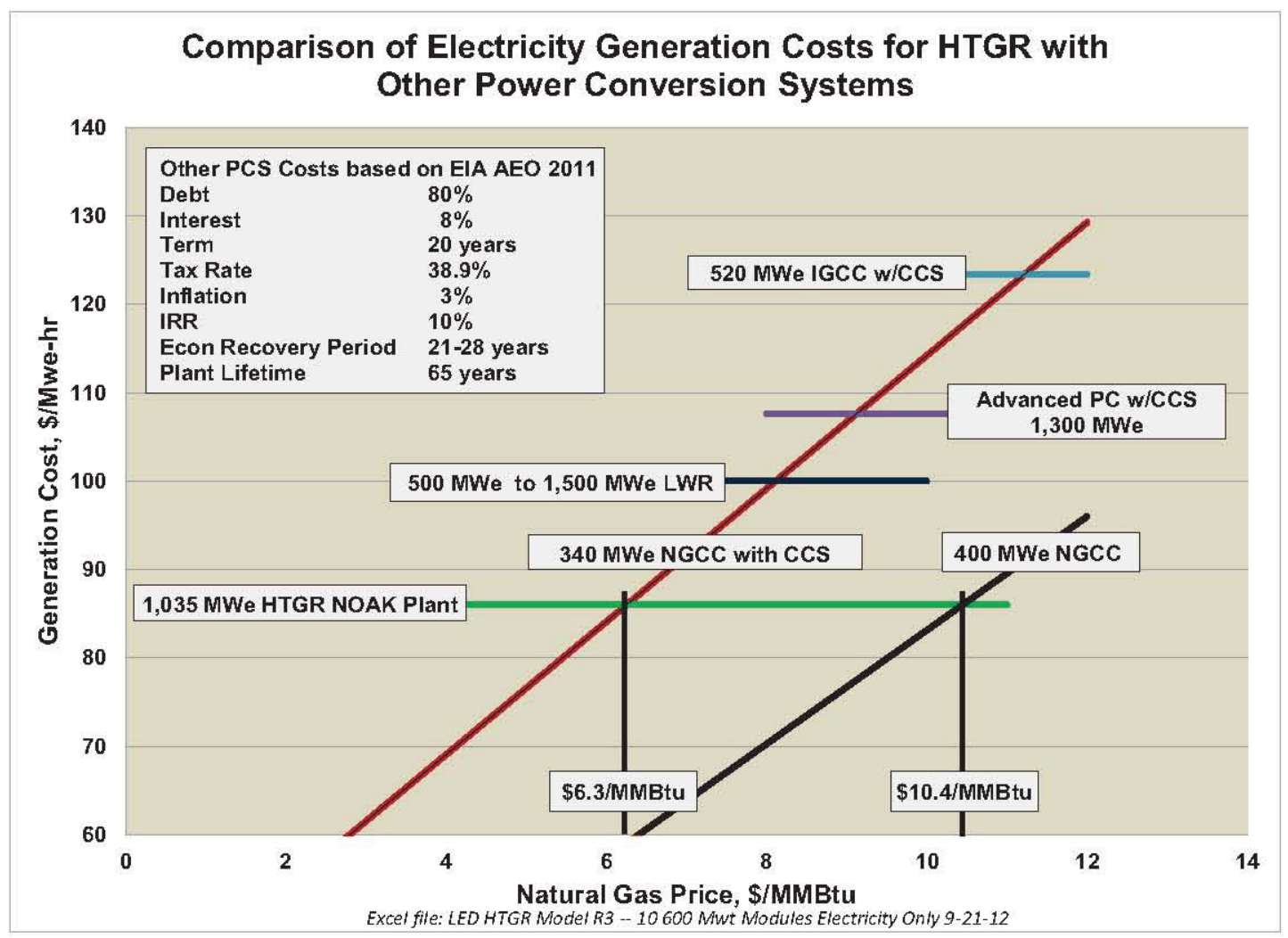

Figure 3-31. Comparison of electricity generation costs for HTGR with other power conversion systems. 
Figure 3-31 compares the costs of generation for several technologies with NGCC plants with and without CCS and with the HTGR as a function of the price of natural gas. As shown the HTGR is competitive with an NGCC plant with CCS for a natural gas price of a little higher than \$6/MMBtu and above. It is competitive with NGCC without CCS for natural gas prices near \$10/MMBtu and above. Analyses in Appendix $\mathrm{C}$ show that long term prices of natural gas are projected to be in a range that includes these values and above by 2035 . The HTGR is also competitive with other low or non-GHG emitting sources of power. It is, therefore, a very viable alternative over the longer term for replacing coal based generation in Kentucky.

Figure 3-32 illustrates the transformation of the electricity generation sources in Kentucky for the strategy developed herein. NGCC technology (without CCS) is first used to substitute for retirement of coal based generation in the 2013-2023 time frame. Coal with CCS and nuclear technologies are then brought on-line over the 2020 to 2040 time frame as they are proved technically and economically viable. The NGCC generation is phased out over this period to achieve a mix of technologies consistent with the Commonwealth's long term goal. If the costs of natural gas remain low, however, it would not be prudent to phase NGCC out of the mix but rather to reduce the amount of Coal with CCS, modifications of existing coal-fired plants or nuclear depending on the economics of each at that time.

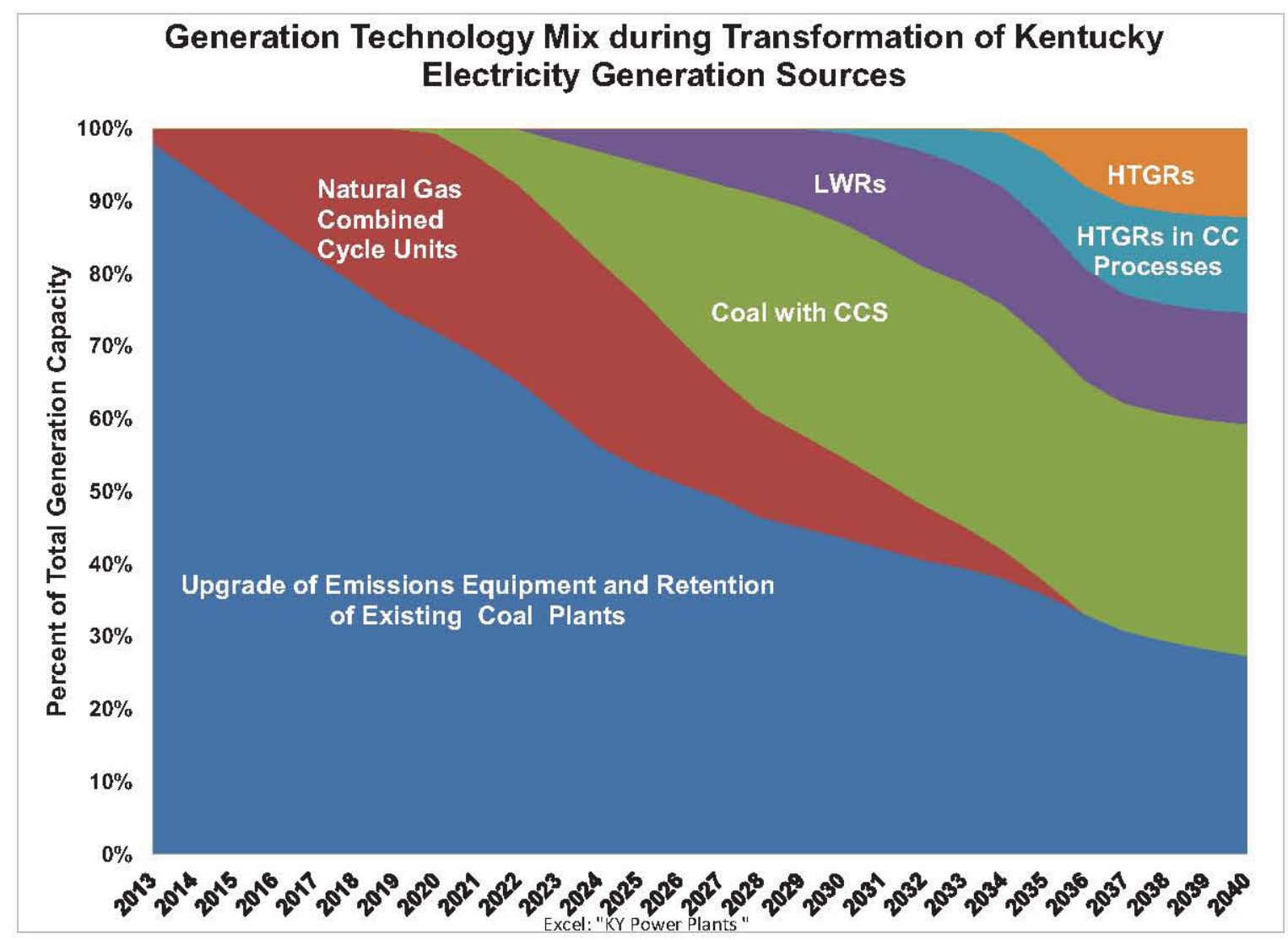

Figure 3-32. Generation technology mix during transformation of Kentucky's electricity generation sources.

Note that the HTGR technology is brought on-line both as part of integrating this technology for the supply of heat and electricity in the carbon conversion processes and as standalone electricity generators. LWRs have also be used in the transformation to substitute non-greenhouse gas emitting generation capacity for retiring coal-fired plants. Although the HTGR cost of generation is $\sim 15 \%$ less than that of light water based technologies, as shown in Figure 3-32, the light water technology is used in the earlier 
deployment of nuclear generation, (starting in the early 2020s) since the HTGR technology is projected to be available commercially in the late 2020s). If the need for integration of nuclear technology occurs later than used herein then HTGR would be a more economic addition than LWRs.

\subsubsection{Electricity Generation Transformation Costs}

Figure 3-33 shows an estimate of the capital costs for achieving this transformation in electricity generation sources and the annual contributions to the Kentucky GDP. The costs are high; averaging \$2B to $\$ 3 \mathrm{~B}$ per year with a total estimated investment of $\sim \$ 80 \mathrm{~B}$. As shown this capital investment would have a beneficial impact on the Kentucky GDP during construction and would add jobs to the localities at the construction sites. Note that manufacture of major equipment that constitutes about $30 \%$ of the capital costs in building a major generating plant has been assumed to occur outside of Kentucky, hence not contributing to the GDP. Depending on the extent an industrial manufacturing capability exists or will be developed in Kentucky, the contribution to Kentucky's economy and the GDP can be further increased.

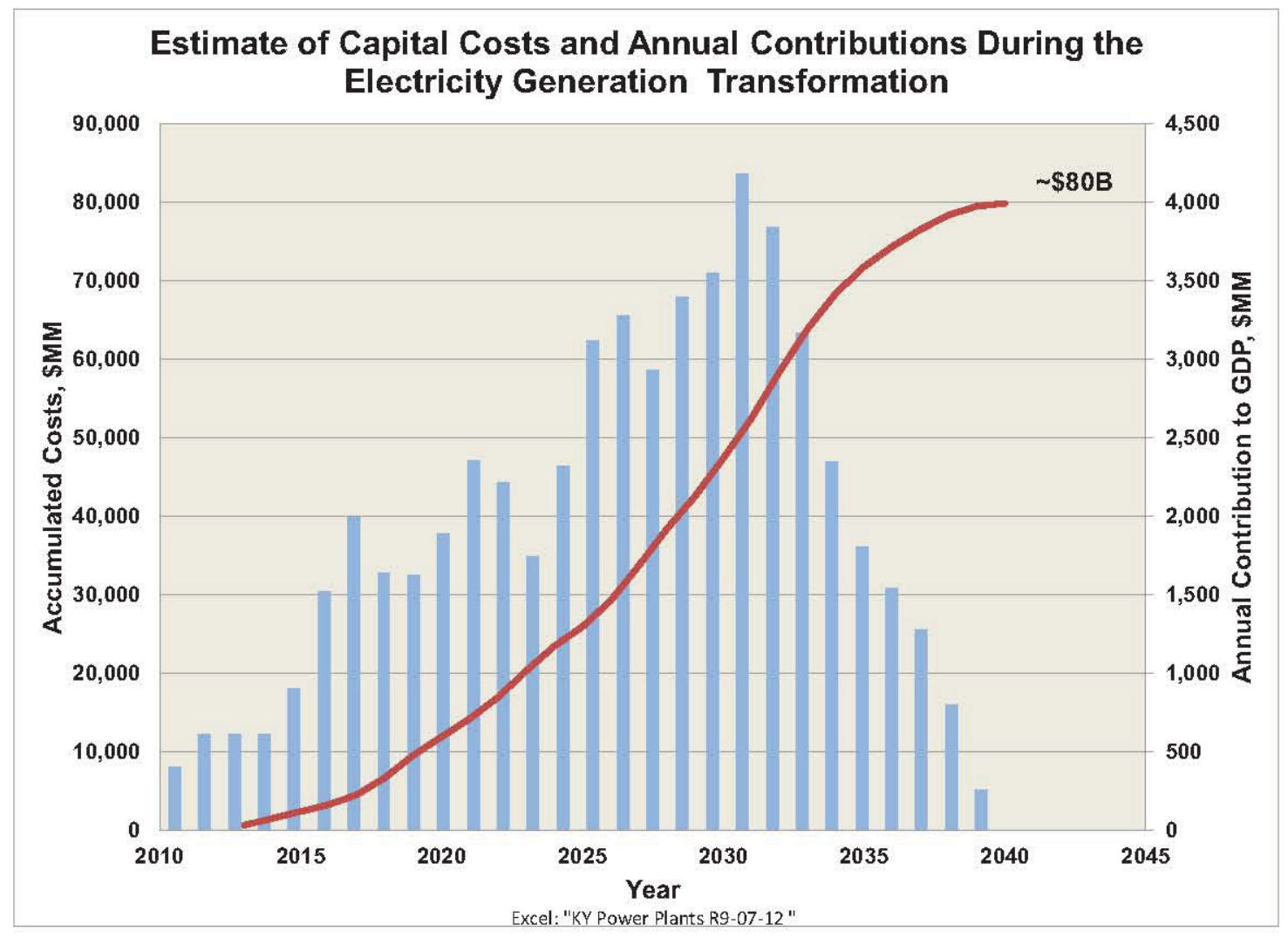

Figure 3-33. Estimate of capital cost and annual contributions during the electricity generation transformation.

Replacement of the current low cost coal based generation can be expected to increase the average cost of power generation in Kentucky by more than a factor of two; the increase as the transformation proceeds is shown in Figure 3-34. This increase is typical irrespective of the mix of generating technologies due to capital investment that must be made either in new generation or for back-fitting additional emission controls. This will have some impact on the competitiveness of exporting power from Kentucky that has not been quantified in this report, and is a strong function of the extent to which Kentucky plans to be a net exporter of electric power. More importantly, there may be a disproportionate effect on large industrial customers, the net effect of which will be dependent on some combination of power costs, labor costs and incentives offered in states and locales that may compete for such industry. 


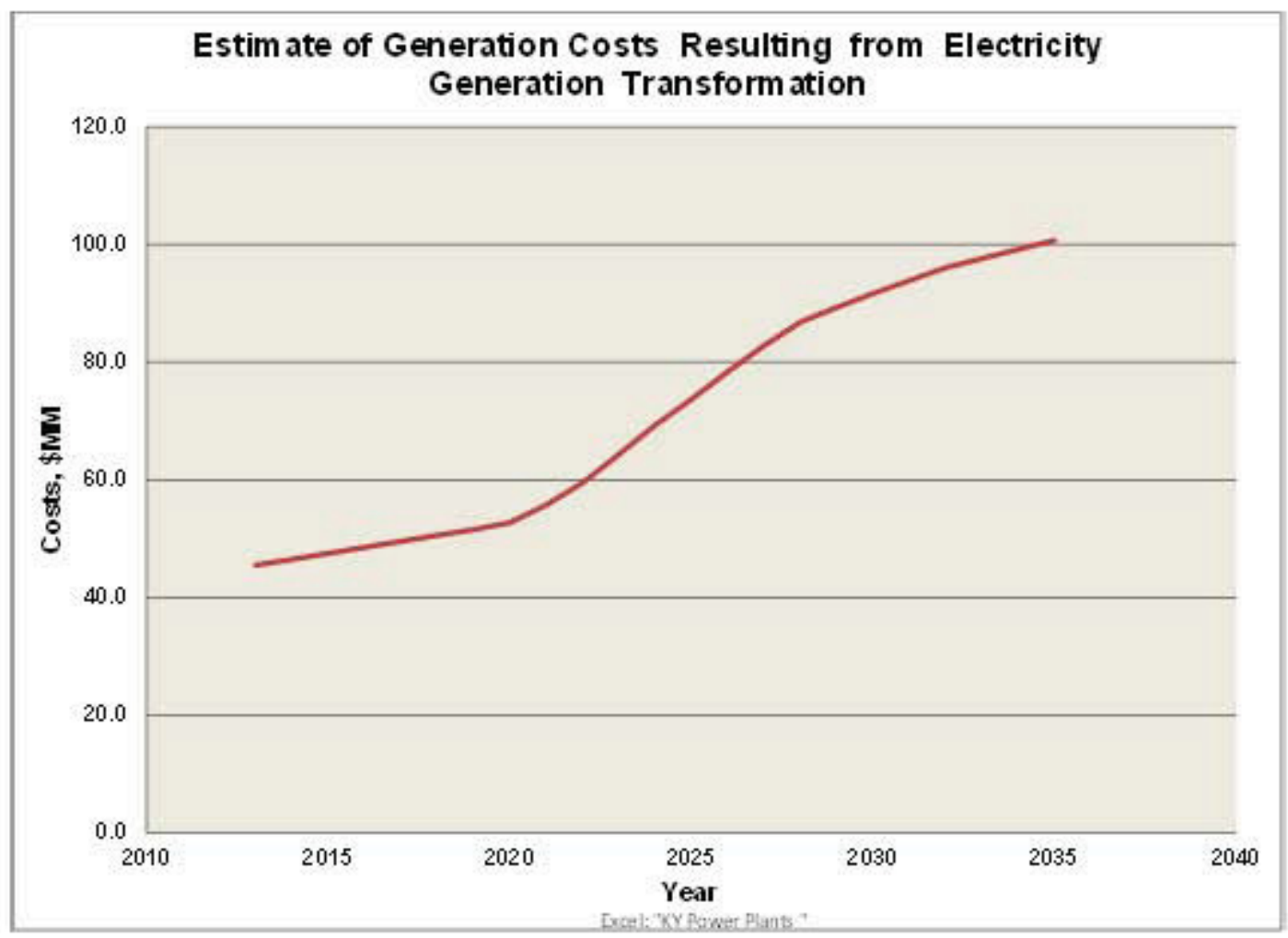

Figure 3-34. Estimate of increase in generation costs resuting from electricity generation transfomation.

It should be stated that the electricity transformation strategy was developed herein for the purposes of analysis and to provide a perspective on the potential costs, schedule and technologies involved in making this transformation. The decision on making shifts in generation technologies will be the responsibility of the electric plant owners. The decisions will reflect the status of government regulations, market conditions, technologies' economics, Commonwealth goals and a wealth of other factors that will change in their nature and influence over time.

\subsubsection{4 $\mathrm{CO}_{2}$ Emissions Reductions Resulting from Electric Power industry Transformation}

An important outcome of the transformation of the electricity generation sources is a net reduction in the $\mathrm{CO}_{2}$ emissions associated with electricity generation in Kentucky. The reductions accrue from retirement of existing coal based plants that have the highest emission characteristics of the alternative generation technologies ( 0.97 million metric tons of $\mathrm{CO}_{2}$ per billion kilowatt hour generated (mt/Bkwe-hr)) and replacing them with lower emission technologies, (e.g., natural gas (0.4 mt/Bkwe-hr)) and with technologies that have no emissions, (e.g., nuclear). There are important uncertainties due to backfit costs and technology development that will determine whether the existing coal fired power plants will be upgraded to meet current EPA regulations on toxic chemical emissions and/or retrofitted with $\mathrm{CCS}$ equipment to limit $\mathrm{CO}_{2}$ emissions. The latter retrofit would be required only if the EPA decides to apply $\mathrm{CO}_{2}$ emission regulations on existing plants as discussed above. Accordingly, two conditions have been analyzed. The first completes the analysis with no CCS equipment on the retained plants; the second includes the effect of CCS. The results of these analyses are summarized in Figure 3-35. As shown the addition of CCS equipment to the retained plants has a significant effect; increasing the reductions in emissions by almost a factor of two (2). Such equipment would be added if government actions either regulate or tax $\mathrm{CO}_{2}$ emissions. It is would likely not be installed if they do not because of its high costs. 


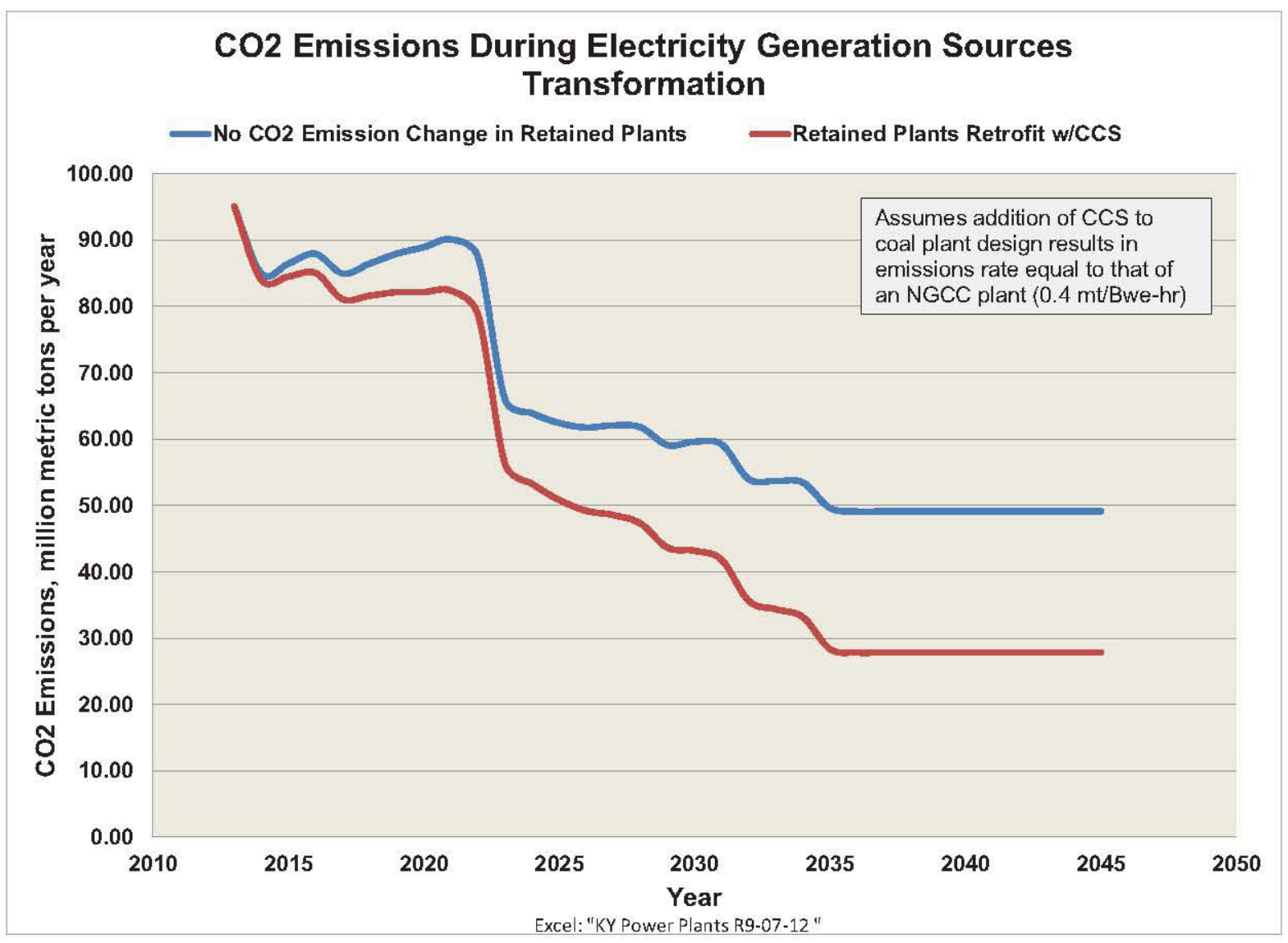

Figure 3-35. $\mathrm{CO}_{2}$ emissions during the electricity generation sources transformation.

There is also uncertainty in how effective CCS will be in reducing the emissions from existing coal plants and new plants originally installed with it. Based on the current pending regulations on emissions of $\mathrm{CO}_{2}$ for new generating plants, (emissions can be no higher than a well operating NGCC plant, $0.4 \mathrm{mt} / \mathrm{Bkwe}-\mathrm{hr}$ ) these analyses have been performed using that value for the emission rates of plants with CCS. In any event the reductions projected for the notional strategy developed herein are substantively addressing one of the primary objectives of the Kentucky Energy Policy.

\subsection{Composite Effect of Developing a Carbon Conversion Industry and the Electric Power Industry Transformation}

As shown in previous discussions the deployment of a notional carbon conversion industry would have a positive effect on the Kentucky economy by providing a continuing demand for indigenous coal and natural gas resources and increasing the value of these resources by transforming them into high value products. The investment in constructing the facilities that would make up this industry would also add value to the GDP during construction and the construction activity and operation of the facilities will provide jobs. The same is true of the investment required to transform the electricity generation sources in Kentucky. During construction of the new generation and upgrade of the emissions control equipment of the retained generation the investment would add value to the GDP and would create jobs on the plant sites. Figure 3-36 shows the projected contributions from these two initiatives and the total annual contribution to the GDP in 2011\$. In 2011 the mining industry contributed $\sim 3 \%$ of the total Kentucky GDP or about $\$ 5 \mathrm{~B}$. At the peak of construction the deployment of the carbon conversion industry and the transformation of the electric generation industry will be in the order of $\$ 12 \mathrm{~B}(2011 \$)$ or more than twice 


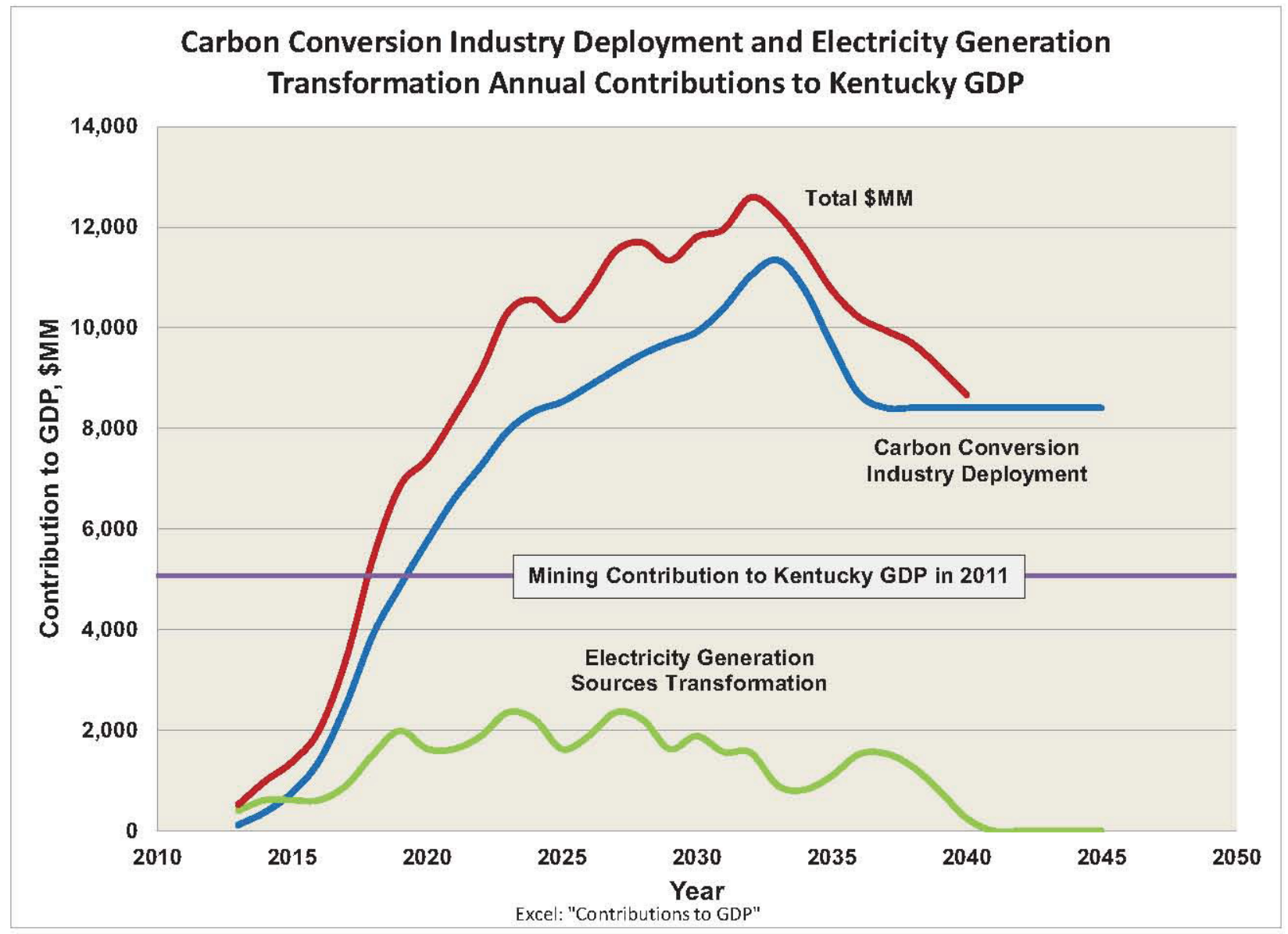

Figure 3-36. Contributions of carbon conversion industry and electricity generation transformation to the Kentucky GDP.

that of the mining contribution in 2011. Once the carbon conversion industry is fully deployed it will add $\sim \$ 8.5 \mathrm{~B}$ to the annual GDP or $70 \%$ more than the mining industry contributed in 2011 . These are substantive contributions on a real dollar basis and support the Commonwealth objectives of revitalizing the coal and natural gas production industry in eastern Kentucky and providing a viable sustainable mix of electricity generation over the long term. Also, it should be noted that the economic multiplier effects of business growth (e.g., real estate, retail sales growth) that accompanies such industry development and transformation has not been included.

An important consideration in evaluating the long term effect is that this report does not attempt to quantify the extent to which the carbon conversion industry may continue to grow beyond the notional assumptions evaluated. As an example, if the carbon conversion industry were continue to grow to utilize the entire current coal production in Kentucky, the effect on the GDP would be an order of magnitude larger. Long term planning in the Commonwealth would be well advised to include such considerations in evaluating the overall benefit to Kentucky of developing and growing such industry. 


\subsection{Path Forward}

The following actions are recommended to support deployment of the Paducah and EK-1 coal conversion plants, the carbon conversion industry and the transformation of the Kentucky electricity generation sources.

1. Pursue developing collaborative partnerships with industry to build the initial portions of a carbon conversion industry. It is suggested that such partnerships be based on constructing and operating at least two initial coal conversion facilities, one located in the Paducah area and one in eastern Kentucky, either in parallel or one shortly following the other. These facilities would be used for conversion of western Kentucky coals and eastern Kentucky coals, respectively. The considerable differences in the coal characteristics suggest that two separate initial process plants should be constructed, potentially based on two different carbon conversion process technologies.

These partnerships should include development of strategies for achieving these initiatives. Such strategies would address project market and transportation and distribution needs, investment structure and incentives, support of the mining industry, goals for GDP growth, desired increases in export of natural gas, coal and electricity, reductions in emissions, and tempering of increasing costs of energy. Relevant projections could include long term coal and natural gas production rates, competitive coal and natural gas pricing, existing coal-based electricity plant retirements and upgrades.

2. Confirm that there can be a sufficient supply of indigenous natural gas to support carbon conversion processes that use SMR for hydrogen production.

3. In the planning basis for the carbon conversion industry, ensure that process plant design configurations are chosen that support a phased approach to integrating nuclear energy as the long term source of energy.

4. Determine the long term plans for operation of the TVA's Shawnee Fossil Plant (net summer rating of $1,206 \mathrm{MW}(\mathrm{e}))$.

5. Develop a plan for utilization of the experienced workforce in transitioning from the operation and maintenance of PGDP and decommissioning (and possible demolition) of PGDP to the construction and operation of the initial Paducah coal conversion plant module and the transition to its expanded capacity. Establish agreements-in-principle with DOE regarding use of the Federal property in Paducah.

6. Prepare a plan that anticipates retirement of portions of the current coal fired power generation fleet (e.g., considering age and evolving regulations) and the deployment of a diverse set of alternative technologies including nuclear energy technologies for base load capabilities. This report provides a notional basis for such planning. An essential decision is the extent to which Kentucky and its power generating industry plan to be a net exporter of energy in the form of electricity considering tradeoffs such as investments in new generating capacity and enlarged transmission system capacity.

7. Prepare a plan for industrial infrastructure development based on the needs of a growing carbon conversion industry and in the future, a nuclear energy industry. This should include regulatory and educational institution changes that will be required within the Commonwealth.

8. Prepare an evaluation of the overall effect on the economy and demographics in Kentucky as these industrial capabilities are realized. 


\section{INFRASTRUCTURE DEVELOPMENT}

There are multiple needs and opportunities for infrastructure expansion and development to support deployment of a carbon conversion industry incorporating nuclear energy technology and transforming the electric power industry in the Commonwealth. Important examples include:

- Industrial equipment manufacturing capabilities ranging from large pressure vessel material forging and fabrication to digital electronics

- Transportation and distribution capabilities for the feedstock and products produced in the carbon conversion industry

- Education and training capabilities to develop and maintain a technically competent workforce

The extent to which these capabilities are, or become, indigenous to Kentucky is directly a function of the character, size and pace at which a carbon conversion industry is developed and the electric power industry is transformed. Further, whether these infrastructure capabilities are indigenous will reflect the incentives offered industry to invest in industrial facilities and the education system in Kentucky. Hence, no attempt is made in this report to quantify the effect of such infrastructure expansion and development on the economy of Kentucky. However, to provide some perspective, if the industrial equipment manufacturing capability needed to accomplish the notional scope of a carbon conversion industry and transform the electric power industry, there would be a greater than $30 \%$ increase in the contribution to the GDP compared to that shown in Section 3 (the economic analyses in this report are based on equipment manufacture occurring outside of Kentucky).

Each of the areas is addressed in brief in the following.

\subsection{Industrial Equipment Manufacturing}

The following summarizes the features of the key equipment and components for the notional carbon conversion industry and transformation of the electric power industry and the nature of support that is required for their design, construction and operation. There is no attempt in the following to estimate the potential market in each of the following areas; that will be dependent on the strategy used for deployment of the industry. As discussed previously equipment and material costs comprise about $50 \%$ of the plant costs. For the deployment of the Paducah process and HTGR plant this amounts to about $\sim \$ 500$ million per year during construction. Larger scale expansion of carbon conversion facilities and/or HTGR electricity plants throughout KY would result in much larger annual expenditures. These expenditures for new plants combined with maintaining the plants would require a significant support infrastructure.

\subsubsection{Process Plant Vessels}

In general, the largest pieces of equipment in a synthetic fuels plant are the FT reactor and the gasifier. Of these, the FT reactor designs are the largest. Sasol's Oryx GTL plant in Qatar currently includes the largest FT reactors built to date. Each reactor was designed to produce $17,000 \mathrm{bpd}$ of FT liquids. To achieve this capacity, each reactor is 10 meters in diameter by 60 meters tall. Approximate weight of each reactor is 2,100 tons. Figure 4-1 shows one of the Oryx plant FT reactors during fabrication. 


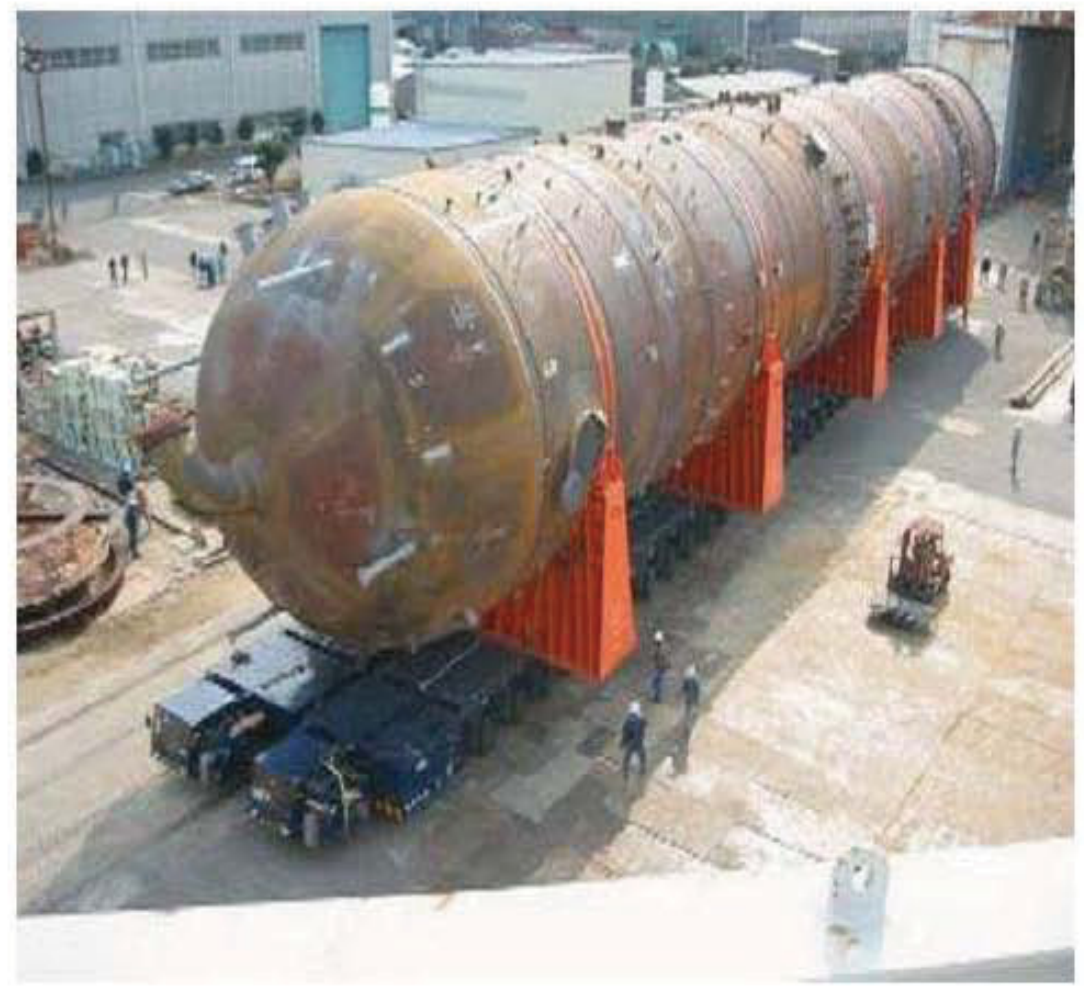

Figure 4-1. Oryx Plant Fischer-Tropsch Reactor.

Gasifiers can also be quite large. The GE (Texaco) gasifier installed at Tampa Electric's Polk Power station can process 2,200 ton/day of coal. This gasifier is approximately 4 meters in diameter. The radiant gas cooler downstream of the gasifier is even larger with a diameter of nearly 5 meters and a height of 30 meters. Weight of the syngas cooler and gasifier combined are around 900 tons. Shell's gasifier designs are similarly large. The NUON Power Buggenum plant in the Netherlands utilizes a Shell gasifier and can process between 2,000 to 2,500 ton/day of coal This gasifier has a diameter between 5 to 6 meters and a height of 50 meters. The syngas cooler is also very large with a diameter of 4 meters and a height of 64 meters. Figure 4-2 shows the membrane wall under construction for such a gasifier (picture taken from a Shell presentation courtesy of Babcock Borsig Espana, Bilbao, Spain).

With a capacity of nearly 4,000 ton/day of coal throughput, the gasifiers assumed in the INL models are larger than the Polk and Buggenum gasifiers.

In the CTG and CTC processes, the gasoline and olefin synthesis reactors are designed modularly; hence, reasonable sizes for these reactors are maintained by using multiple trains. Methanol synthesis reactors can also be quite large; however, it is possible to keep the diameter of the methanol synthesis reactor at or below a 6 meter inside diameter and still achieve a production rate of 5,000 tons/day of methanol. This is true for many commercial methanol reactor designs: Lurgi tubular packed bed reactor, ICI quench reactor, Casale mixed flow reactor, and other common designs. In the CTG process models developed herein there are 15 major pumps. In addition to these pumps, numerous other smaller pumps will be required to support the major processing units of the plant. Some other large pumps will also be required to support the utility systems. In many critical applications, it will be necessary to install spare pumps to minimize unplanned down time for the plant. Hence, the number of actual pumps in the plant could easily exceed ten times the number of pumps included in the process models developed as part of this study. 


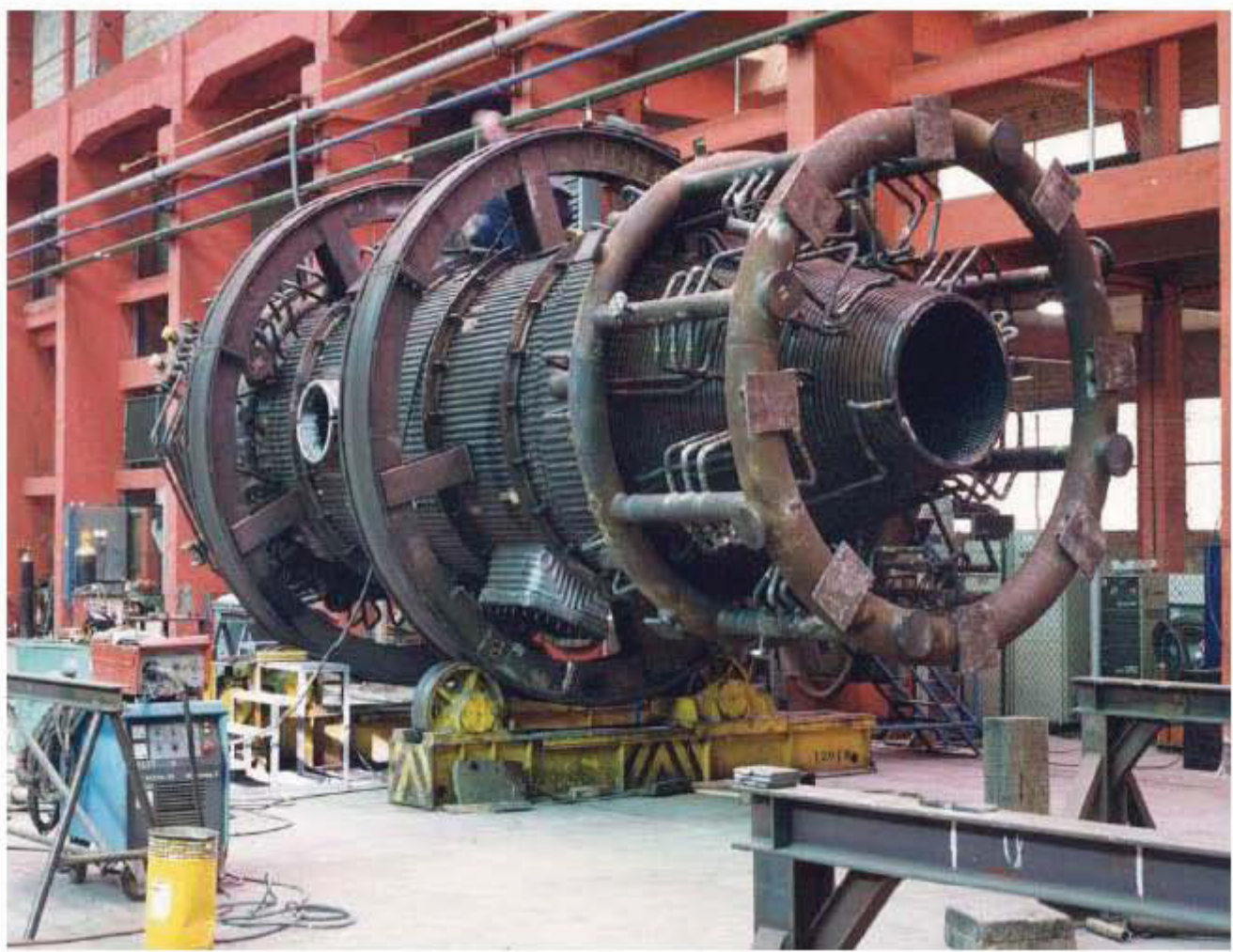

Figure 4-2. Shell gasifier membrane walf.

\subsubsection{Process Plant Pumps, Valves, Piping}

Piping and valves account for a significant fraction of the cost of a synthetic fuels or chemical plant. Typically these costs can tange from 18 to $61 \%$ of the freight-on-board equipment cost, which would normally represent about 7 to $15 \%$ of the installed plant cost. Therefore, the cost associated with piping and valves for such a plant are obviously significant.

\subsubsection{HTGR Major Components}

$75 \%$ of the equipment cost of a HTGR plant is made up of the following components and systems in the order of their relative costs:

- Reactor Building

- Reactor Vessel

- Reactor Initial Core

- Reactor Metallic Internals

- Reactor Graphite Internals

- Reactor Cavity Cooling System

- Core Refueling Equipment

- Heat Rejection System

- Heat Transport System

- Power Conversion System 
The primary system vessels which include the reactor vessel, the crossover vessel and the heat transport system vessel are among the more costly items in the plant. They are also heavy and large and not transportable by rail or road, so unless the plant is located on a major waterway the vessels will be fabricated on or near the plant site. The development of the remote fabrication facility and its operation during construction of the plant is a significant opportunity for a local qualified vessel manufacturer.

Each of the systems is comprised of many valves, blowers (circulators) and pumps that represent a significant fraction of their costs similar to that cited for the process plants.

Additionally, depending on the extent of commitment to nuclear energy, the infrastructure for fabrication of nuclear fuel is an important part of supporting the operation of these plants with expected 80 to 100 year lifetimes. Nuclear energy plant refueling occurs at one year to 18 month intervals.

\subsection{Transport and Distribution Systems}

As the carbon conversion industry is developed, it is important to evaluate the most important markets and the means of transporting the feedstock (coal and natural gas) and transporting and distributing the products, whether by waterways, truck, rail or pipeline. Further, if a distributed configuration for a carbon conversion industry should evolve as described in section 3.3.1.4, a system of pipelines will be required that interconnect the process plants producing synthesis gas and the various process plants that produce synthetic fuels and chemicals.

At the outset, a notional initial coal conversion plant located in Paducah could utilize existing waterway, rail and truck transport infrastructure. As a coal conversion industry expands, existing infrastructure is anticipated to be inadequate and planning for production, transport and distribution needs to be accomplished in an integrated manner, with necessary participation by the investing industries and consideration of necessary incentives for investment in an anticipatory manner.

Further, as the electric power generating industry is transformed, the electric transmission system will need modification and enhancement depending on the specific types and location of the new generating plants, and the extent of electric power export that is planned.

\subsection{Education and Training}

A well-educated and trained, technically competent workforce is essential to the successful development of a carbon conversion industry and transformation of the electric power industry to include diverse generating sources. In brief:

- Designing, licensing/permitting and maintaining these industries will require university educated engineering and scientific personnel at both the bachelors and graduate levels

- Construction will require crafts personnel trained and experienced in trades such as welding, pipe fitting, electrical and computer systems

- Plant operations and maintenance will require technician-level training in the respective technologies (e.g., chemical processes; nuclear energy systems; computer systems)

The companies that will invest in, develop and build the process plants and power generation plants could be expected to initially import the management and senior technology personnel. However, typical experience is that the bulk of the industrial workforce for construction, operations and maintenance will need to be developed from within the indigenous population. The specific case of a notional coal conversion facility in Paducah can make important use of the existing technically capable and experienced workforce that today operates the PGDP - but this is most likely the exception. 


\section{REFERENCES}

1. TEV-672, "HTGR Integration - Coal and Gas to Liquids Production," Rev 3, Idaho National Laboratory, April 27, 2012.

2. TEV-667, "Nuclear-Integrated Methanol-to-Gasoline Production Analysis," Rev. 2, May 15, 2010.

3. TEV-1567, "Nuclear Integrated Methanol-to-Olefins Production Analysis," July 20, 2012.

4. Shell, "The Shell Coal Gasification Process for the U.S. Industry," Gasification Technologies Conference, Washington D.C.,October, 2004; and Shell, "Shell Coal Gasification Process Using Low Rank Coal," Gasification Technologies Conference,San Francisco, CA, October 2005.

5. h-tec Energy Technology Projects, "Technology Fact Sheet," Bergius-Pier Process (1) 1924-1945," April 2006.

6. Sivakumar Vasireddy, Bryan Morreale, Anthony Cugini, Chunshan Song, and James J. Spivey, "Clean liquid fuels from direct coal liquefaction: chemistry, catalysis, technological status and challenges," Energy and Environmental Science, Received 27 May 2010, Accepted 1st September 2010 .

7. American Fuels Coalition, "Chinese Direct Coal Liquefaction Project Profitable (Reuters)," posted on September 8, 2011.

8. Ken K. Robinson, "Reaction Engineering of Direct Coal Liquefaction," Energies 2009, Vol. 2, pp. 976-1006; doi:10.3390/en20400976, Received: 14 October 2009, Accepted: 23 October 2009/Published: 29 October 2009.

9. Gasifipedia, Applications of Gasification - Coal-to-Liquids, Direct Liquefaction Processes, NETL, U.S. Department of Energy.

10. Green Car Congress: "Headwaters Inc and Axens Form Direct Coal Liquefaction Alliance," January 21,2010

11. West Virginia Coal Association Chevron Improves Direct Coal Liquefaction| Research \& Development, United States Patent: 4379744, March 26, 2012.

12. “DOE, Energy Information Agency,” Annual Energy Outlook 2012, April 2012.

13. R. Varrin, et al., NGNP Hydrogen Technology Down-Selection Results of the Independent Review Team (IRT) Evaluation, R-6917-00-01, Rev. 0, July 31, 2009.

14. J. J. Dooley, R. T. Dahowski, C. L. Davidson, On the Long-Term Average Cost of $\mathrm{CO}_{2}$ Transport and Storage, PNNL-17389, March 2008, Prepared for the U.S. Department of Energy under Contract DEAC05-76RL01830.

15. J. J. Dooley (Lead Author), R. T. Dahowski, C. L. Davidson, M. A. Wise, N. Gupta, S. H. Kim, E. L. Malone, Carbon Dioxide Capture and Geologic Storage, A Core Element of a Global Energy Technology Strategy to Address Climate Change, A Technology Report from the Second Phase of the Global Energy Technology Strategy Program, April 2006.

16. "The Cost of Carbon Dioxide Capture and Storage in Geologic Formations," Program Facts, US. Department of Energy, Fossil Energy, National Energy Technology Laboratory. 
17. Special Report on Carbon Capture and Storage, Intergovernmental Program on Climate Change, 2005.

18. $\mathrm{CO}_{2}$ Capture and Storage, Technology Brief E14, IEA, Energy Technology Systems Analysis Programme, October 2010.

19. Geologic $\mathrm{CO}_{2}$ Sequestration Technology and Cost Analysis, TECHNICAL SUPPORT DOCUMENT, U.S. Environmental Protection Agency, June 2008.

20. First Commercial-Scale CCS Project Launched In Oil Sands, Thursday, September 6, 2012, The Energy Daily.

21. "In Alabama, going after oil with a coal plant's $\mathrm{CO}_{2}$," Inside Energy, September 10, 2012.

22. "Carbon injections could revive Midwestern oil fields," Inside Energy, May 21, 2012.

23. Clean Energy Standard Act of 2012, 112th Congress, 2nd Session.

24. EIA, Analysis of Clean Air Standard Act of 2012, May 2012.

25. Adopt Subchapter 10 Climate Change, Article 5, Sections 95800 to 96023, Title 17, California Code of Regulations, to read as follows: Article 5, "California Cap on Greenhouse Gas Emissions and Market-based Compliance Mechanisms."

26. BNEF Lowers California Carbon Price Forecasts After First Sale, Bloomberg, 11-20-12.

27. Section 202 of the CAA, "GHGs from stationary sources are currently controlled under the authority of Part C of Title I of the Act."

28. DOE/NETL 2009/1346, "Development of Baseline Data and Analysis of Life Cycle Greenhouse Gas Emissions for Petroleum-Based Fuels."

29. Brandon Nuttall, "CO2 Sequestration Opportunities in Kentucky", supported by U.S. Department of Energy, National Energy Technology Lab Carbon Sequestration Program and the Kentucky Office of Energy Policy.

30. Brandon Nuttall, Jim Drahovzal, Cortland Eble, R. Marc Bustin, "Analysis of the Devonian Black Shale in Kentucky for Potential Carbon Dioxide Sequestration and Enhanced Natural Gas Production", this project was funded by the National Energy Technology Laboratory of the U.S. Department of Energy, contract: DE-FC26-02NT41442.

31. Allan Ingelson, Anne Kleffner, and Norma Nielson, "Long-Term Liability for Carbon Capture and Storage in Depleted North American Oil and Gas Reservoirs - A Comparative Analysis," University of Calgary, Energy Law Journal, Vol 31, No. 43, 2010.

32. Semere Solomon, Beate Kristiansen, Aage Stangeland, Tore A. Torp, Olav Kårstad, "A Proposal of Regulatory Framework for Carbon Dioxide Storage in Geological Formations," January, 2007, The Bellona Foundation, Oslo, Norway and Statoil Research Centre, Trondheim, Norway. Prepared for International Risk Governance Council Workshop, March 15-16, 2007, Washington, D.C.

33. M. A. de Figueiredo, "The Liability of Carbon Dioxide Storage," MIT, Energy Delta Institute, Energy Business School, February 2007. 
34. Alexandra B. Klass, Elizabeth J. Wilson, "Climate Change and Carbon Sequestration: Assessing a Liability Regime for Long-Term Storage of Carbon Dioxide," University of Minnesota, Emory Law Journal, Vol 58, 2008.

35. Elizabeth J. Wilson (University of Minnesota) and Mark A. de Figueiredo (MIT), The Impact of Liability on the Adoption and Diffusion of Carbon Capture and Sequestration Technologies.

36. EPI, Analysis of Liability Regimes for Carbon Capture and Sequestration: A Review For Policymakers, Energy Policy Institute, Center for Advanced Energy Studies, December 2011.

37. Topic Paper \#17, "Carbon Capture and, Sequestration (CCS)," Working Document of the National Petroleum Council Global Oil \& Gas Study, made available July 18, 2007.

38. IEA, Expert Workshop on Financing Carbon Capture and Storage, Barriers and Solutions, International Energy Agency, Greenhouse Gas R\&D Programme, Report Number 2007/9, July 2007.

39. IEA,"Carbon Capture and Storage," Legal and Regulatory Review, Edition 2, International Energy Agency, May 2011.

40. "Estimating Carbon Dioxide Transport and Storage Costs," Quality Guidelines, for Energy System Studies, DOE/NETL-2010/1447, March 2010.

41. Secure Energy Paducah Gasification Plant, Commonwealth of Kentucky, Division for Air Quality, Permit Application Summary Form, Completed by: Philip T. Jarboe, P.E., 4/14/2011.

42. Chisolm Energy, LLC, Commonwealth of Kentucky, Division for Air Quality, Permit Application Summary Form, Completed by: Andrew True, 4/20/2011.

43. Buffalo Creek Energy, LLC, Commonwealth of Kentucky, Division for Air Quality, Permit Application Summary Form, Completed by: Andrew True, P.E., 4/21/2011.

44. While DKRW plans Wyoming coal-to-gasoline plant, other firms switch to natural gas, By JEREMY FUGLEBERG Star-Tribune energy reporter, trib.com, Posted: Sunday, March 25, 2012 9:00 am.

45. Energy Project Site Suitability, Paducah Area Community Reuse, Organization Site, McCracken County, 2009, Department of Energy Development and Independence.

46. Kentucky Alternative Energy Site Bank Evaluation ,Department for Energy Development \& Independence, Energy and Environment Cabinet, Commonwealth of Kentucky, Prepared by Smith Management Group, PON 21270800010168 1, June 2009.

47. EPA, National Emission Standards for Hazardous Air Pollutants for Major Sources: Industrial, Commercial, and Institutional Boilers and Process Heaters: Final Rule, 76 FR 15608\& 76 FR 155543/21/11 (so-called Boiler MACT Rule).

48. PPL Kentucky Utilities Hit Market Power Bump In Coal-To-Gas Transition, Energy Daily, May 8, 2012, Vol 40, No 89.

49. Discussions with Kentucky Interests participating in this collaborative evaluation, see Appendix A.

50. Three Kentucky coal plants to retire due to EPA rules, New York|Fri Sep 16, 2011 3:34pm EDT, (Reuters) - "Kentucky power companies Louisville Gas and Electric ( $L G \& E)$ and Kentucky Utilities $(K U)$ said new, stricter, federal environmental regulations will force them to retire three older, coalfired power plants." 
51. A.E.P. Backs Down on Coal Plant Retrofit, By ERIC LIPTON, Green, A blog about the environment, May 30, 2012, 4:42 pm, "American Electric Power conceded defeat on Wednesday, at least temporarily, in its push to save Big Sandy, its 49-year-old coal-burning plant in eastern Kentucky, surprising state officials there by withdrawing its $\$ 1$ billion plan to retrofit the power plant so that it can meet tough new federal environmental regulations."

52. "EPA Targets Coal With Proposed Carbon Limits For New Power Plants," March 28, 2012, Energy Daily, Vol 40, No 61.

53. Kentucky Energy Plan: Purpose, Process and Status, Dr. Len Peters, Kentucky Energy and Environment Cabinet, presentation to National Governors Association, Energy Advisor Policy Institute. 


\section{Appendix A}

\section{Evaluation Team and Summary of Paducah Area Characteristics}




\title{
Appendix A \\ Evaluation Team and Summary of Paducah Area Characteristics
}

\author{
Deployment Energy Opportunities for Kentucky

$\begin{array}{ll}\text { Don Newell } & \text { KY Energy and Environment Cabinet } \\ \text { Mark Keef } & \text { USEC } \\ \text { John Anderson } & \text { PADD } \\ \text { Chad Chanceller } & \text { Paducah Economic Development } \\ \text { Charlie Martin } & \text { Paducah Economic Development }\end{array}$

A-1. Kentucky Evaluation Team Members

The following lists the Kentucky members of the team performing the evaluation of Energy

\section{A-2. A Summary of Paducah Area Characteristics Supporting Energy Development Opportunities}

\section{A-2.1 Introduction}

There are two imperatives which led to this study: First, in order to secure a source of reliable, ultralow polluting power (both electricity and heat) the United States needs to pursue development of the Next Generation Nuclear Power Plant (NGNP). Second, the Commonwealth of Kentucky needs to find a replacement for the Paducah, Kentucky, Gaseous Diffusion Plant (PGDP). It has been producing enriched uranium since 1952, but is scheduled to go out of service in May, 2013.

To support PGDP, Paducah has developed a workforce that is highly trained and experienced in nuclear and heavy industry. In order to maintain this workforce and the high level of economic activity in the Paducah area, the Kentucky Energy and Environment Cabinet has been actively seeking a high tech replacement for PGDP. An ideal application would be one that furthers Kentucky's involvement in the nuclear field and helps to support Kentucky's energy and environmental protection goals. This study, which examines the use of a nuclear facility to power an industrial application such as a coal conversion process, reprocessing of spent nuclear fuel, or reclamation of radioactively contaminated metals, would fulfill all of those goals.

Paducah, located in the Purchase Area of western Kentucky, has much to offer independent of the PGDP nuclear facility. The following sections outline both the nuclear/industrial assets available in the region, and the amenities available in the Purchase Area.

\section{A-2.2 Paducah Gaseous Diffusion Plant}

The heart of the industrial capability in the Paducah area is the PGDP. PGDP was constructed to enrich uranium for use in nuclear weapons and later began supplying enriched uranium to the commercial nuclear industry. The original facilities are still in operation, albeit with substantial upgrading and refurbishment. The plant is situated on a 3,556-acre parcel of DOE-owned property in McCracken County in western Kentucky, approximately ten miles west of the city of Paducah and three miles south of the 
Ohio River. The primary operations associated with the enrichment process are located on approximately 650 acres within the plant area. Of the remaining DOE-owned acreage, 1,986 acres are leased to the Kentucky Department for Fish and Wildlife Resources as part of the West Kentucky Wildlife Management Area.

The infrastructure built to support the enrichment process is significant and will support various industrial endeavors. This infrastructure includes an onsite steam plant, a water treatment facility, a sewage treatment facility, and an electrical distribution system.

The plant raw water supply is taken from the Ohio River. A portion of this supply is treated at the C611 Water Treatment Facility to provide potable water to the entire plant site. In additional to the removal of sediment and softening treatment that all water receives, the sanitary stream is sand-filtered and postchlorinated in accordance with the requirements of the Kentucky Division of Water and the Safe Drinking Water Act. The maximum site capacity for treatment is about 30 million gallons per day (mgd) of treated water.

The PGDP sanitary sewage treatment system consists of a collection system with four lift stations that collect sanitary waste from most buildings and convey it to the C-615 Sewage Treatment Facility. The C615 Sewage Treatment Facility has a design capacity of 500,000 gallons per day (gpd) and currently operates at approximately $325,000 \mathrm{gpd}$. The C-615 Sewage Treatment Facility uses primary and secondary treatment. Anaerobic digestion is provided in a heated digester and aerobic digestion by means of a trickling filter.

The existing steam plant system uses three boilers. Two boilers burn pulverized low-sulfur coal with hot side electrostatic precipitators for emissions control. One boiler is fired with natural gas or fuel oil. The steam generating capacity is about 300,000 pounds per hour (lb/hour) at $100 \mathrm{psig}$, saturated. The primary steam line from the plant is 12 inches in diameter and located above ground.

The closest natural gas line on the plant site is an ATMOS Energy 6 inch line located at C-600. Propane use at the plant site is limited and is supplied by small tanks for each particular user.

Electrical power is supplied to the plant site primarily by two local utility companies: Electric Energy, Inc. (EEI) of Joppa, Illinois, which is located approximately seven miles from the plant site, and Tennessee Valley Authority's (TVA) Shawnee Fossil Plant, which is 3.5 miles northeast of the plant. EEI operates a coal-fired generating station. TVA also operates a coal fired generating station and is the primary power supply for current operations. EEI and TVA have supply capacities of 1086 megawatts (MW) and $1200 \mathrm{MW}$, respectively. Additionally, Kentucky Utilities Companies supplies one transmission tie line, which connects to a small switching station in Paducah, Kentucky.

There are six dedicated $161 \mathrm{kV}$ transmission lines to the site from the EEI plant and another ten 161 $\mathrm{kV}$ lines from the TVA Shawnee power plant. The EEI and TVA lines are completely independent and fed from opposite directions. All lines from both supplies are tied into utility grid networks, providing access to other remote power generating locations (nuclear, fossil fuel and hydroelectric). These 16 lines supply power to the plant through four switchyards and a distribution voltage of 13.8 kilovolt $(\mathrm{kV})$.

The Paducah site is located in an area with an established transportation network. It is served by three east-west interstates and highways - Interstate 24, U.S. Highway 60 and U.S, Highway 62, one northsouth highway - U.S. Highway 45; and numerous state and county roads. It is also near the planned corridors of I-69 and I-66. The main plant access road begins at Highway 60 and runs north to the south (main) entrance to the plant.

The area is also served by two major rail systems - Burlington Northern Santa Fe and CSX - and two regional rail systems - $\mathrm{CN}$ and Paducah and Louisville. Rail-highway services are provided by three 
carriers with regional hubs at Paducah. Rail spur service is available when entering the plant on the west side and extends to several locations within the plant.

The Ohio River is located approximately three miles north of the proposed site. Barge service is available through the Riverport Authority on the Ohio River in Paducah, Kentucky. The terminal has onsite rail and truck service. It has three deck facilities and capacity for four barges. Other terminals are available in Cairo, Illinois; Mound City, Illinois; Metropolis, Illinois; and Ledbetter, Kentucky. Other navigable waterways in the area are the Cumberland, Tennessee, and Mississippi rivers.

Air service to the site is provided by the nearby Barkley Regional Airport, which is located within ten miles south-southeast of the proposed site.

\section{A-2.3 Purchase Area Characteristics}

The Purchase Area of western Kentucky encompasses a 2,392 square mile area at the confluence of the Mississippi, Ohio, and Tennessee Rivers. With a labor pool of 211,822 (Wadley-Donovan GrowthTech, LLC: 07-08-2011) it is a center of economic activity impacting the rest of the state's economy. The region contains one of Mid-America's most heavily traveled north-south interstates (I-24), the Paducah Gaseous Diffusion Plant (PGDP), the DUF6 Plant located at the PGDP site, a vast chemical complex located in Marshall County, the electrical generators located at Kentucky Dam, and the TVA Shawnee Steam Plant which generates 7.5 billion Kilowatt hours of electricity and houses an electrical grid which handles a large portion of the nation's power.

The quality of life in the Purchase Region has matured to a level that enhances the competitive recruitment of a talented workforce as shown in Table A-1. Paducah offers music, art, and festivals yearround. The Artist Relocation Program, The National Quilt Museum and Luther F. Carson Four Rivers Center are venues which keep the city vibrant. A full symphony orchestra adds to the rhythm. Indoor tennis and golf complexes keep people in the swing. An equestrian stable offers riding lessons and competitive instruction. Golf courses abound, and national fishing tournaments lure the best anglers in the world.

Table A-1. Composition of the avallable purchase area labor pool in target sectors:

\begin{tabular}{|l|c|c|c|c|c|c|c|c|}
\hline & $\begin{array}{c}\text { Nonmetallic } \\
\text { Materials }\end{array}$ & Chemicals & $\begin{array}{c}\text { Primary } \\
\text { metals \& } \\
\text { fabrication }\end{array}$ & $\begin{array}{c}\text { Transportation } \\
\text { Equipment } \\
\text { manufacturing }\end{array}$ & $\begin{array}{c}\text { Alternative } \\
\text { energy }\end{array}$ & $\begin{array}{c}\text { Logistics/ } \\
\text { distribution }\end{array}$ & $\begin{array}{c}\text { Food \& } \\
\text { beverage } \\
\text { processing }\end{array}$ & $\begin{array}{c}\text { Medical } \\
\text { supplies } \\
\text { devices }\end{array}$ \\
\hline Female & $31 \%$ & $35 \%$ & $17 \%$ & $22 \%$ & $19 \%$ & $24 \%$ & $35 \%$ & $43 \%$ \\
\hline Male & $69 \%$ & $65 \%$ & $83 \%$ & $78 \%$ & $81 \%$ & $76 \%$ & $65 \%$ & $57 \%$ \\
\hline $\begin{array}{l}\text { Most significant source of education and training } \\
\text { 4-year } \\
\text { degree or } \\
\text { higher }\end{array}$ & $6.0 \%$ & $22.8 \%$ & $8.1 \%$ & $19.7 \%$ & $21.2 \%$ & $5.5 \%$ & $4.4 \%$ & $16.2 \%$ \\
\hline $\begin{array}{l}\text { Vocational } \\
\text { or 2-year } \\
\text { degree }\end{array}$ & $1.4 \%$ & $6.0 \%$ & $1.5 \%$ & $6.0 \%$ & $8.7 \%$ & $4.1 \%$ & $0.9 \%$ & $2.6 \%$ \\
\hline $\begin{array}{l}\text { On-the-job } \\
\text { training or } \\
\text { prior } \\
\text { experience }\end{array}$ & $92.6 \%$ & $71.2 \%$ & $90.4 \%$ & $74.3 \%$ & $70.1 \%$ & $90.4 \%$ & $94.8 \%$ & $81.2 \%$ \\
\hline
\end{tabular}


The region is home to numerous institutions of higher education, including a branch of Murray State University, a branch of the University of Kentucky's School of Engineering, and the West Kentucky Community and Technical College. Those institutions have a total enrollment of 10,000 students. West Kentucky Community and Technical College (WKCTC) Emerging Technology Center affords substantial room and training equipment for robotics, automated machining, computer modeling and other high-tech systems. The Emerging Technology Center also houses University of Kentucky College of Engineering research, largely financed with grants and contracts from private companies and government agencies. The Emerging Technology Center is structured to provide training for existing technologies and work with business/industry in designing programs for specific skill sets.

Barkley Regional Airport offers daily flights to Chicago's O'Hara Airport, making air travel out of Paducah affordable and convenient due to competitive pricing and eliminating the drive to larger airports. The region also provides historically impressive links to the nation's inland waterways, interstate highway system and rail system (five Class I railroads operate in the Purchase Area) that provide convenient connections to the nation's largest markets. The Purchase Area is a day's drive or less from $2 / 3$ of the nation's population. 
INL/EXT-12-26710

November 2012 


\section{Appendix B}

\section{High Temperature Gas-cooled Reactor Technology and Safety Basis}




\section{Appendix B \\ High Temperature Gas-cooled Reactor Technology and Safety Basis}

\section{B-1. NUCLEAR HEAT SUPPLY SYSTEM}

The high temperature gas-cooled reactor (HTGR) is helium cooled, with a graphite moderated reactor core and robust ceramic fuel. The HTGR nuclear heat supply system (NHSS) is comprised of three major components: the helium cooled nuclear reactor, a heat transport system, and a cross vessel that routes the helium between the reactor and the heat transport system. The NHSS supplies energy in the form of steam and/or high-temperature fluid that can be used for the generation of high efficiency electricity and to support a wide range of industrial processes.

The NHSS design is modular with module ratings from 200 to $625 \mathrm{MW}(\mathrm{t})$, reactor outlet temperatures from 700 to $850^{\circ} \mathrm{C}$ and heat transport systems that provide steam and/or high temperature fluids. The range of power ratings, temperatures and heat transport system configurations provides flexibility in adapting the modules to the specific application.

As shown Figure B-1, the three major components are enclosed in metallic pressure vessels that make up the primary helium circuit. Under normal operating conditions helium flow is maintained by the main circulator and heat is transferred from the reactor to the heat transport system (shown as the steam generator in Figure B-1) and then to an energy conversion system (e.g., a steam turbine generator) that interfaces with the

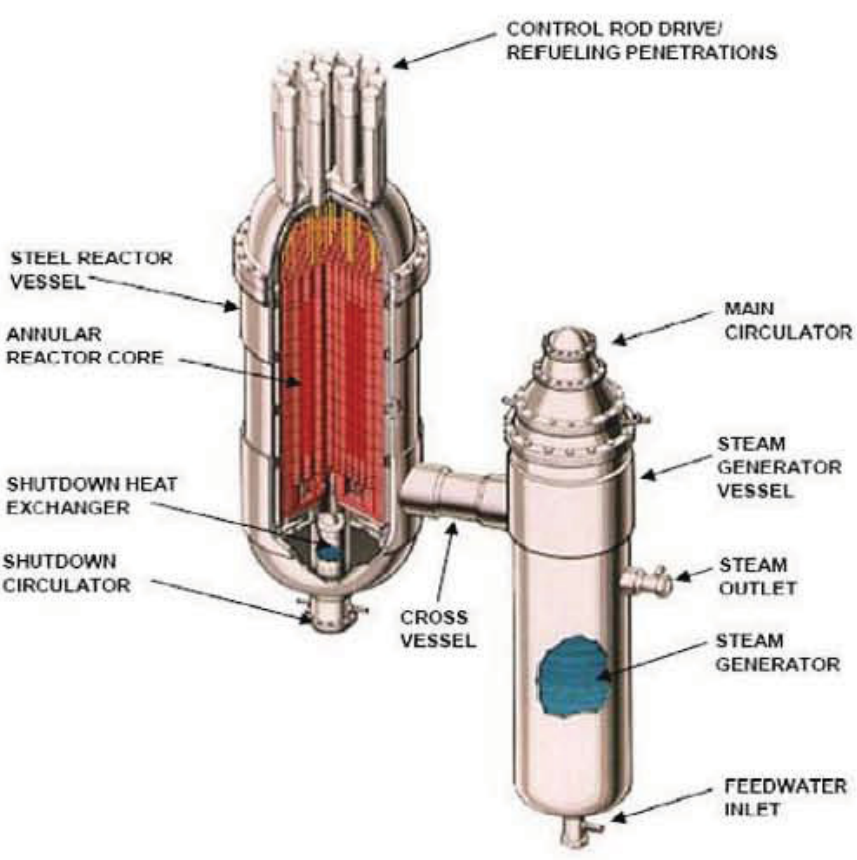

Figure B-1. HTGR and HTS. industrial process and/or the electrical grid.

When the reactor and plant are shut down for maintenance or refueling, reactor temperature is maintained by the shutdown cooling system. In the event the heat transport system or shutdown cooling system are not operational (e.g., on loss of all electrical power), reactor temperature is maintained via a radial conduction path through the reactor pressure vessel to an annular cavity formed between the reactor pressure vessel and the reactor building structure (silo) - the so-called reactor cavity. This cavity can be actively cooled or cooled by natural circulation. In the event neither of these reactor cavity cooling mechanisms is operational, conduction through the reactor building structure to the ground is sufficient to maintain reactor temperatures within acceptable limits.

Several different plant configurations have been developed as part of the Idaho National Laboratory (INL) Next Generation Nuclear Plant (NGNP) Project and in prior work conducted by the Department of Energy (DOE). These are described in References 1 thru $6 .^{12,3,4,5,6}$ 


\section{B-2. HTGR SAFETY BASIS}

The principal design objective of the NHSS is to ensure that there is no intemal or extemal event that. could lead to substantive release of radioactive material beyond the boundaries of the plant and endanger the safety of the public. This reduces the conplexity and extent of emergency planning and response and facilitates use of the HTGR technology in industrial applications.

This objective is met by provision of multiple barriers to the release of radioactive material from the plant that provide retention of those materials, thereby mesting associated regulatory requirements and assuring the protection of public health and safety and the environment under all nomal, abnormal, and accident contitions, whether affected by intemal (e.g., loss of all electrical power, a leak in a steam generator tube) or extemal events (e.g., earthquakes, flooding, tornadoes). These barriers include:

- A robust carbon-based fuel structure that forms the principal barrier to release and transport radioactive material. As shown in Figure B-2, the fiel is made up of minute ( $\sim 1 \mathrm{~mm}$ iliameter) particles comprised of multiple ceramic layers surrounding the uranium based kemels. These ceramic layers are designed to retain the products of nuclear fission and limit release to the fuel elements and the helium coolant.

- Distribution and containment of the firel particles in firel elements (compacts or spheres) of carbon based material.

- Enclosure of the fuel elements in a large graphite core.

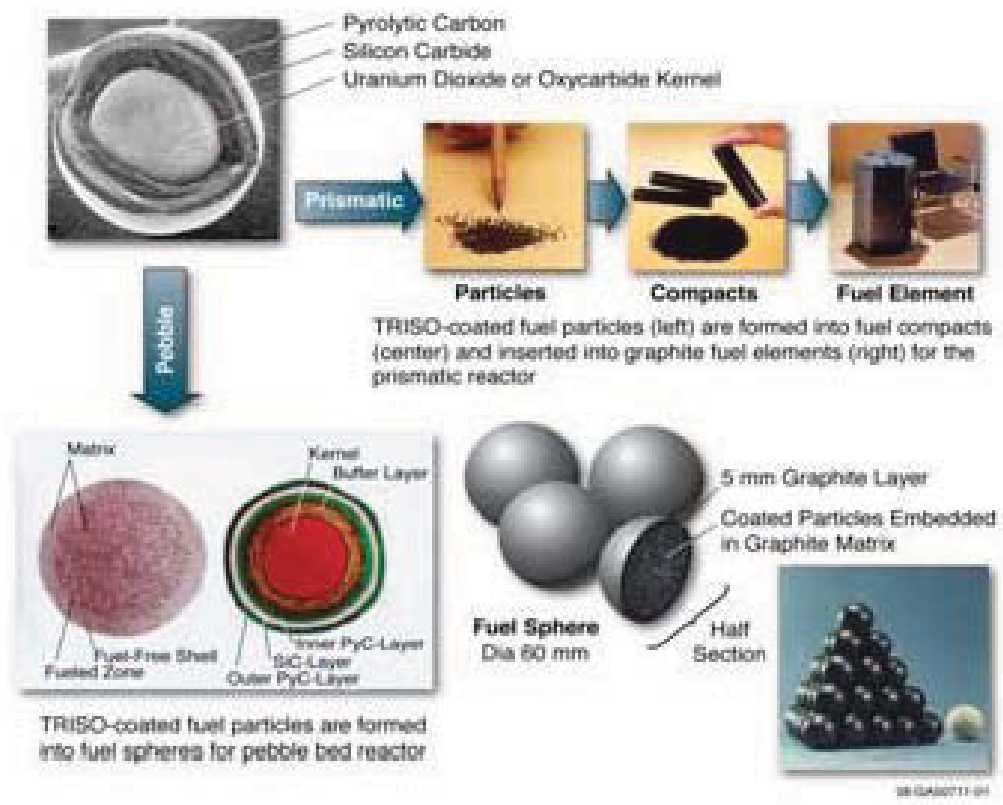

Figure B-2. HTGR TRISO fuel.

- Enclosure of the core structure and the helium coolant system in American Society of Mechanical Engineers (ASME) Nuclear Grade metallic vessels meeting ASME Code requirements for nuclear components.

- Enclosure of the NHSS vessels in a robust underground reactor builing.

Additional reactor characteristics that prevent release of radioactive materials include:

- Extreme high temperature capability of the ceramic coated and carbon-based fiel and core structure.

- No metal or water in the fuel and core structure that can, in combination, chemically react to form hytrogen or increase pressure.

- Plant design features limitintrusion of air or water so that the reactor remains shutdown and containment of ratioactive materials is maintained.

- Chemically inert helium coolant.

- Inherent nuclear and heat transfer properties of the reactor design that are continuously functional to ensure that the fuel temperatures remain within acceptable limits under all conditions. 
- Inherent properties of the reactor core that regulate nuclear power so no electrical power, coolant flow, or any other active systems or operator actions are required to limit nuclear power levels and fuel temperatures under any condition (see Figures B-3 and B-4).

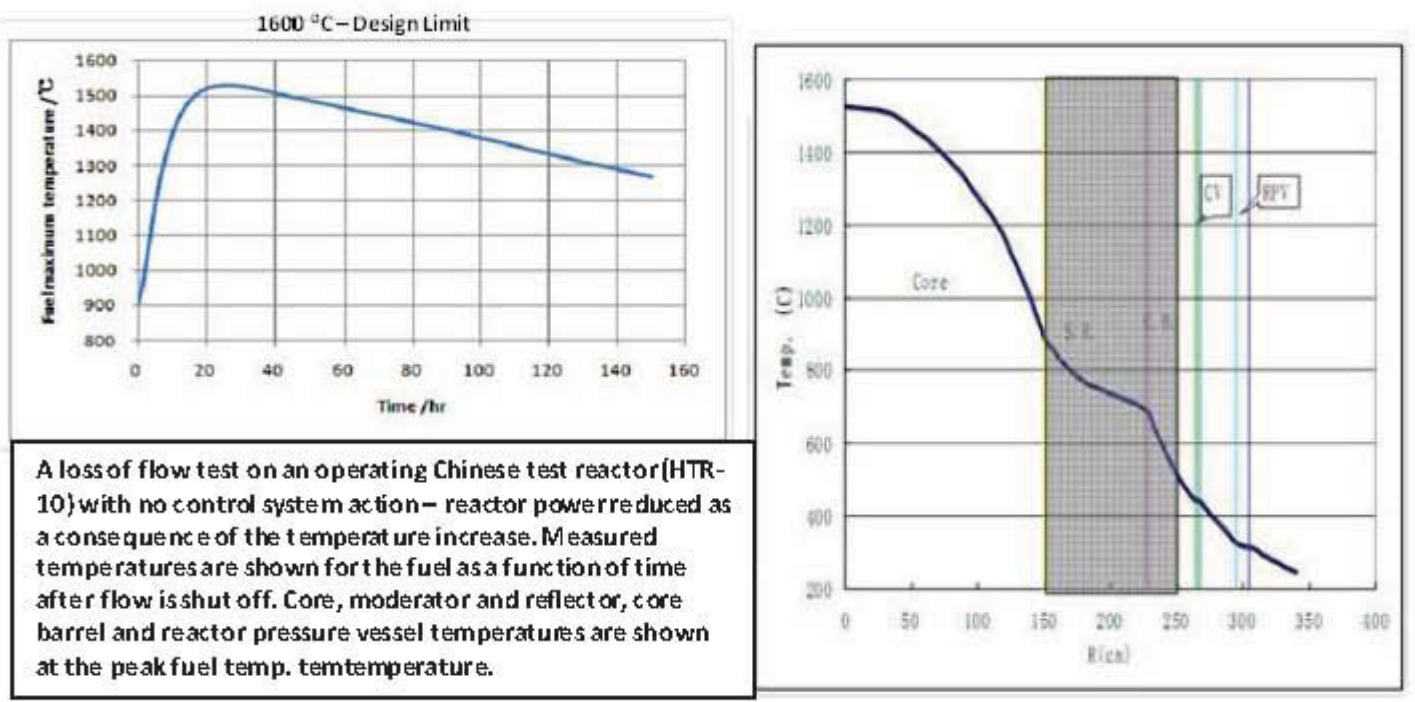

Figure B-3. Demonstration of response to loss of flow accident.

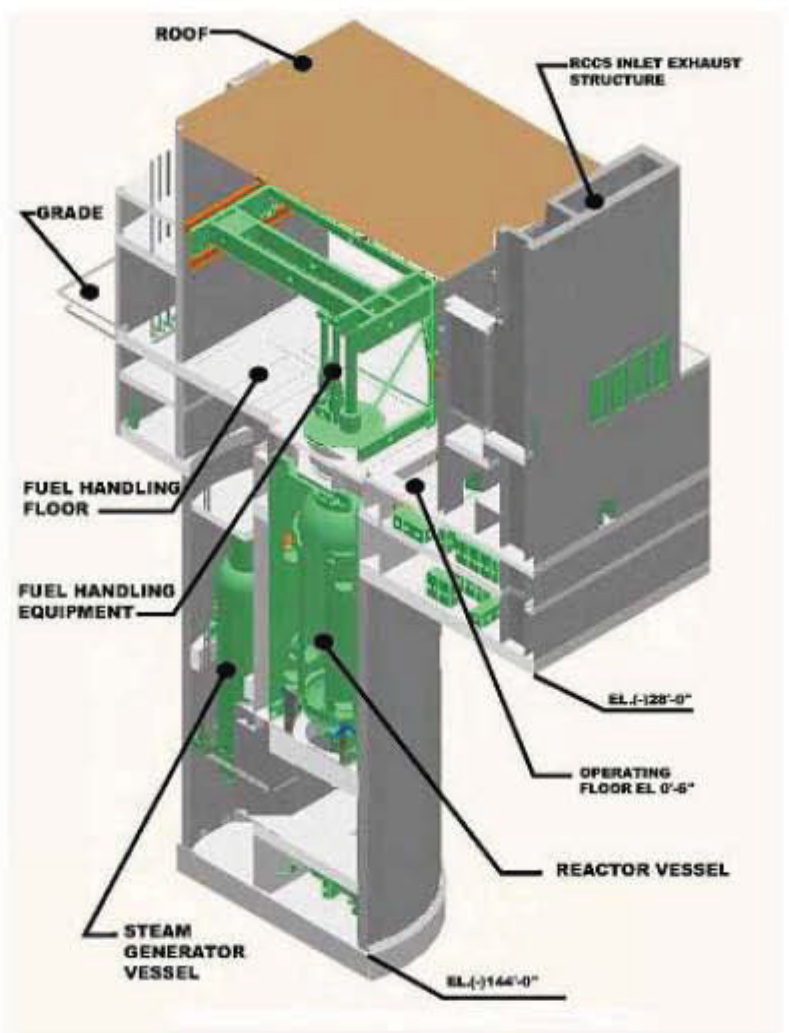

Figure B-4. Typical reactor building.

- Reactors and heat transport systems are located underground in reinforced concrete silos reducing response to earthquakes and providing a natural heat transfer path from the core, through the reactor pressure vessel, into the silo, and ultimately to the passive reactor cavity cooling system under loss of 
all forced cooling conditions. If the reactor cavity cooling system is unavallable, heat tranfer to the pround is sufficient to maintain fuel termpratures in the axceptable range.

- The praphite core has the ability to absorb large quantities of heat. It takes hours or days to reach peak accident temperatures, independent of whether active cooling systerrs are working or not.

- The heat tranfer path from the core to the reactor cavity cooling systern and to the ground is continuwely furctional, making it available independent of the plant condition.

\section{B-3. SPENT AND USED FUEL STORAGE}

- Spent and used fuel is stored in casks or tanks in underground vaults that can becooled by naturally circulating air as shown in Figure B-5.

- Active systerrs are not required to maintain acceptable temperatures of stored spent or used (defined as not completely ured but removed from the cone for mainterance) fuel becmes of low retained enemy and roburt carbon based fued material.

- Carbon based material ured for the fued and fuel elements ficilitates long temn stable storage

\section{B-4. STATUS AND PATH FORWARD}

The design of the NGNP HTGR Dernonstration Plant has not progressed beyond the pre-conceptual design work completed in FY 2007 and the bepinning of conceptual desipn work perfoned by

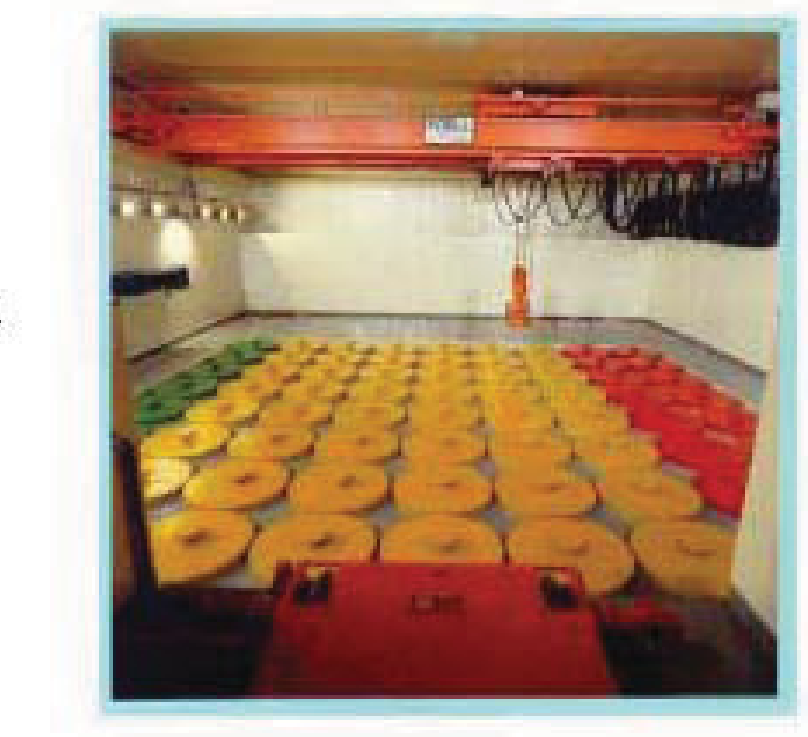

Figure B-5. Spenf fuel storage. General Atomics for the DOEE in FY 2010. Desipn work was halted by the DOEE in early 2008 in anticipation of iritiation of the public-private partuaship. This partuership has not been formed and is not likely to be fomed, if at all, until late 2012 .

The safety basis of the HTGR has been developed and described in detail in several white papers submitted to the Nuxlear Regulatory Commiscion for review. These white papers cover the elemerts described above and the mechanims that are being exsuted to confinm thair performance over all possible nomal, abnomal, and accident conditions. The following documents provide design descriptions for HTGR plants and the safety basis of the HTGR tochology. 


\section{B-5. REFERENCES}

1 Next Generation Nuclear Plant Pre-Conceptual Design Report, INL/EXT-07-12967, Revision 1, November 2007.

2 General Atomics document NGNP-R00016, "Next Generation Nuclear Plant (NGNP) Prismatic HTGR Conceptual Design Project, Conceptual Design Report - Steam Cycle Modular Helium Reactor (SC-MHR) Demonstration Plant," Revision 1, July 15, 2011.

3 AREVA NP Inc. document 12-914697-000, "Pebble Bed Reactor Plant Design Description," January $31,2011$.

4 AREVA NP Inc. document 12-9151714-000, "Pebble Bed Reactor Technology Readiness Study," January 31, 2011.

5 AREVA NP Inc. document 12-9149863-000, "Pebble Bed Reactor Scoping Safety Study," January 31, 2011SC-MHR Conceptual Design Report.

6 Basis for NGNP Reactor Design Down-Selection, INL/EXT-10-19565, August 2010. 


\section{Appendix C}

\section{NGNP Industry Alliance, Ltd.}




\title{
Appendix C NGNP Industry Alliance, Ltd.
}

\begin{abstract}
ABOUT NGNP
Member comparies have foined in this alliance with the prinary purpose to peomote the developenent and commercialization of High-Temperature Gas-Cooled Reactor (HTGR) technologies, Our alilance teptesents, the interests and views of our members that Intend to mutualy suppott and direct peoject plans to dosign, butd, operate and use the HIGR tochnology. We provide a forum and focus to communicate industry needs ard requirements and work in concert with the tdaho fiational Laborafary and others to seek out and promote indusissal uses for HIGR technologies within the Uniled States, North Ametica and other continents around the world

HTGR fechnolegy offers a major opportunity to stabilize histcaicaly volgite prices for premium fosst fuals and provide a new energy option to provide high temperature process hest for indusirlal applications, Stabilizing energy costs will encourage a teturn of process industry faclities to the U.S. from offishore locations where lower and more stably poiced fuels and feedstocks have beon awailable. As conventional fossil fuel supplies become more limited in the future due to supply or tegulatory restrictions, HiTGRs peomise to provide new sources of hydrogen and ways to shift chemical and fuets production to new foedstocks with roduced green house gas (GHG) emissions.

Commercialization of HTGR technology is essential to the National Inteests in achieving the evolving envinonmentel and energy policy goais. HTGR technology offers benefits including: 1) Reduced GHG through large scale displacement of premium fossit fueli in a wide range of industilal and commercial appications; 2) Reduced retance on impcried of and gas supplies as industry fuels; 31 Extending life of domestic ofl and natural gas supplies as strateglc atsets for transportation fuels urtil alternatives become viable technically and economically: 4) Sustainable expansion of Amencan Industrial munufactuting capobilates foc energy Intensive industriest and 5) Job creation within the U.S. wupplyng materials and equipenent to construct and operate HIGR based industral infrastruchute.
\end{abstract}

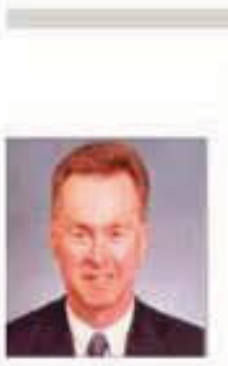

\section{NGNP Industry Alliance Officers}

Donald Halter, Executive Director f executivedirectoringnpalliance.org Don is currently Manager of Business Development for Conocoptillips. He has over 32 years of global energy industry expertence with commercial and operating background in crude oit, nafual gas, refined peoducts. heavy ol, biofuets, coal, LPG, heary oil and management consulting. Mr. Halfer holds a B.A. in Economics ficm the State University of New York, Geneseo and a Master of Business Administration, Finance from fhe Whartor School, University of Aennsylvania the has held a Commoday futures fiading Commission Series 3 license for futures and options trading (linactive status).

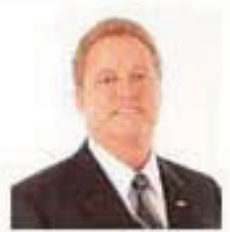

Jeff Jarrell, Vice-Chair (Executive Director-Elect) vicechainangnpalliance.org Jeff is currently the Technology Center Ditector for Energy \& Climate Change at The Dow Chemical Company. In his tole, he is responsible for out Energy Systema Technology Center and Dow's Global Introvernent Organizations - managing enesgy process safety requinements, techinical support of plart//ite energy operations, tochnology development and capital projocts implementation in energy-elated lecthologies. M. Jarrell has worked for Dow for 30 years, 25 df those years in manufacturing and engineering. He has been a part of Dows's loadonhly foams for 14 years and thas been supervising projoct and oporatlonal foams for the past 23 years. Jef hoids a Bachelors of Science degree in Chemical Engeneering from Texas Tech Untwersty.

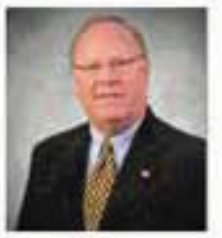

John Mahoney, Secretary-Treasurer I secrelary@ngnpalliance,org

John Mahoney has more than 30 years of experience in the commerclal energy bisiness in managetial and technical positions. In his cutront position at the Entorgy Nucloar fleet headquarters is in business development and project management woikhg with companies and entilies globally in the development of nuclear energy opportunitien. Mahoney holds a Bachelor of Science degree in bustiness administration from Nortiwood University and a Master of Science degree $\mathrm{h}$ business from Troy Uniwersity. He is contiled by the Project Managemen Institule as a project managoment peofessional and is President Emerlus of the Central Mississippl PMI Chapter. Mahoney is an officet of the Mistissippl Section of the American Nuclear Society and was elected in 2011 to the ANS Executlive Commitioe of the Human Factors. Instrumentation and Controls Diviston fot a 3-year serm.

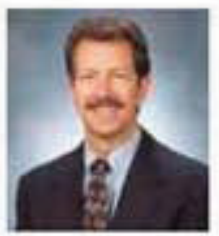

Fred Moore, Executive Director-Emerifus l executivedirectorGingnpalliance.org Fred Moore is the Global Director of Monufactuling \& Technology for the Energy business in Dow, At Dow, he is responsible for the safe and relibile production of power, team, and other untitiles for Dow grobally, which represents mote than 10 \% of Dow's asset base. In his Technology tole, he is responvible for developenent support and application of Enengy tochnology globally and with Dow's major joint ventutes. Fred holds a tischolor of Science in Envitonmental Engineeting freen Purdue University. He was the Alliance executive directoe from June 2010 to Juna 2012 and remains a voling member of the Exocutive Commiltee in his capacity. 


\section{Appendix D}

\section{Process Alternatives Functional and Performance Characteristics}




\section{Appendix D \\ Process Alternatives Functional and Performance Characteristics}

\section{D-1. INTRODUCTION}

In $2011 \sim 45 \%$ of the electricity consumed in the United States was generated from coal fired power plants. Importantly, over $90 \%$ of the electricity consumed in Kentucky in 2011 was generated using coal. The future of this application of coal energy is not certain, however, because of existing and potential federal policy and regulations on mining practices, emissions from the burning of coal, the disposal of coal based waste and transport ${ }^{1}$. Since coal is an indigenous resource and factor in the Kentucky economy it is imperative that alternative applications for coal be identified and deployed as the more traditional uses are reduced. A further objective in defining and developing alternative applications is to increase the contribution made to Kentucky's economy by the extraction and use of coal.

Markets exist for synthetic transportation fuels, (e.g., diesel, gasoline) and commodity chemicals, (e.g., ethylene, propylene) that can be produced using technically and economically viable carbon conversion processes using coal and natural gas as feedstock. These processes provide (1) additional uses and markets for the indigenous coal and natural gas resources of Kentucky and (2) the opportunity to increase the value of these resources by converting them to higher value products; a benefit to the Kentucky economy.

Processes for the conversion of coal to synthetic transportation fuels were developed by the Germans to support their campaigns during World Wars I and II. South Africa has used these processes for decades. Conversion of coal to chemicals has been extant in the United States for decades, (e.g., Eastman Chemical) and is being exploited in large scale in China. However, these traditional processes have been characterized by large scale emissions of greenhouse gases, (e.g., $\mathrm{CO}_{2}$ ) that have made them environmentally challenging and would be subject to the same regulations that are causing the early retirement of coal fired power plants. Fortunately, modern carbon conversion processes provide means to minimize and control these emissions to reduce their environmental impact through carbon capture for enhanced oil recovery (EOR) or sequestration. Incorporation of non-emitting nuclear energy supplies such as the HTGR and the nonemitting high temperature steam electrolysis (HTSE) supply of hydrogen results in further reductions making these processes even more viable from an environmental perspective.

Natural gas is also a viable feedstock for conversion to transportation fuels, (e.g., major oil companies are developing natural gas to gasoline (GTG) plants in Louisiana and elsewhere ${ }^{2}$ ) and is the primary feedstock for chemical production. The natural gas resources in Kentucky are also considered for conversion either as the primary feedstock or in combination with coal.

The following sections describe the alternative carbon conversion processes covered in this study and characterize their functional and performance characteristics. 


\section{D-2. CARBON CONVERSION ALTERNATIVES}

\section{D-2.1 Syngas Generation}

The carbon (coal and natural gas) conversion processes evaluated include those producing some combination of diesel, naphtha, LPG, gasoline and commodity chemicals, (e.g., ethylene and propylene). In all cases the first step in these processes is the conversion of the feedstock to synthetic gas composed of a specific ratio of $\mathrm{CO}$ and $\mathrm{H}_{2}$; see Figure D-1. With coal as the feedstock the Syngas is produced in a gasifier. There are several types of gasifiers commercially available; for the purposes of this evaluation a dry-fed gasifier similar to those supplied by Uhde and Shell ${ }^{4}$ was used. ${ }^{\mathrm{f}}$

In the coal gasification process the coal is burned generating $\mathrm{CO}$ and hydrogen among other tramp constituents in the coal and slag. There is insufficient hydrogen in the coal to achieve the required ratio of $\mathrm{CO}$ to $\mathrm{H}_{2}$ in the syngas; another supply of hydrogen is required. In most commercial gasifiers this is done by injecting steam and using the water shift reaction to produce the hydrogen; $\mathrm{CO}+\mathrm{H}_{2} \mathrm{O} \gg \mathrm{CO}_{2}+\mathrm{H}_{2}$. This is a major source of $\mathrm{CO}_{2}$ in this process.

For natural gas feedstock the syngas is produced through a reforming process splitting the carbon and hydrogen in the gas and adding oxygen to produce the $\mathrm{CO}$ and $\mathrm{H}_{2}$ components of the syngas. In this case there is sufficient hydrogen in the natural gas to obtain the required ratio of $\mathrm{CO}$ to $\mathrm{H}_{2}$. This is an endothermic process and the heat is supplied by burning some of the natural gas. This is a major source of $\mathrm{CO}_{2}$ in this process.

The quantities of $\mathrm{CO}_{2}$ produced in the coal gasification process are significantly higher than that for the natural gas reformer. In both cases, however, the majority of the $\mathrm{CO}_{2}$ generated in these processes can be captured, compressed and transported for sequestration or EOR. This is costly, there is uncertainty in the viability of sequestration as a method for disposing of this $\mathrm{CO}_{2}$ and there is insufficient capacity in EOR to make that a viable long term repository. Pending government regulation of $\mathrm{CO}_{2}$ emissions also make release an untenable option. Accordingly, there is advantage to reducing the amount of $\mathrm{CO}_{2}$ generated in the syngas processes. Figure D-2, Alternative Syngas Supply Feedstocks and Configurations shows four approaches that are evaluated herein.

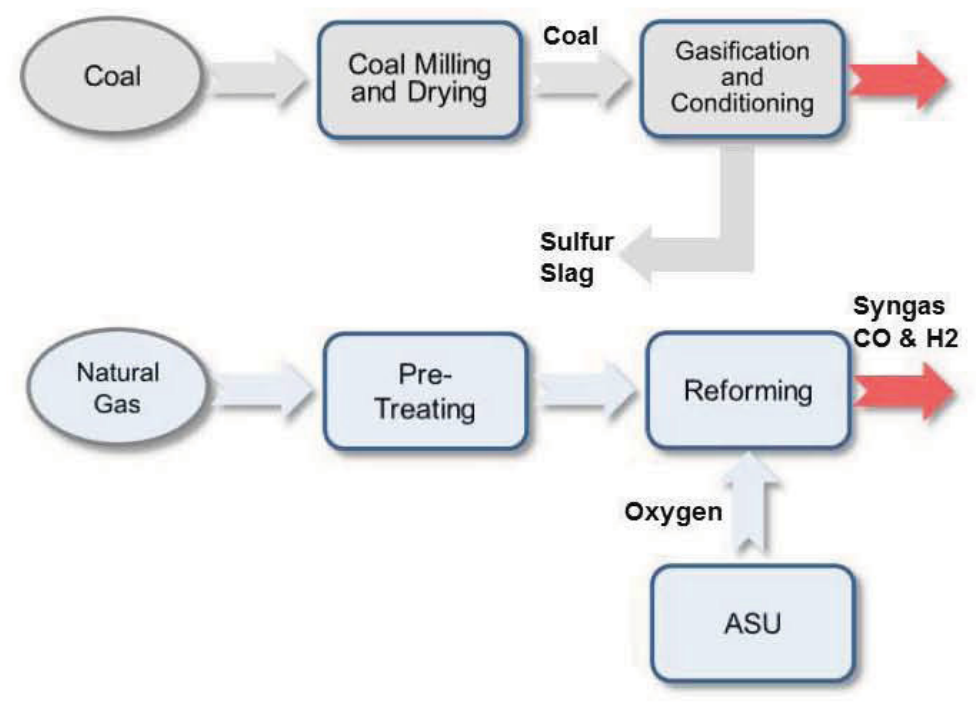

Figure D-1. Syngas generation.

f. There is an alternative process for direct production of synthetic transportation fuels using coal liquefaction reactor developed originally by the Germans and being promoted by KBR. This is also being considered but its evaluation is in an early stage. 


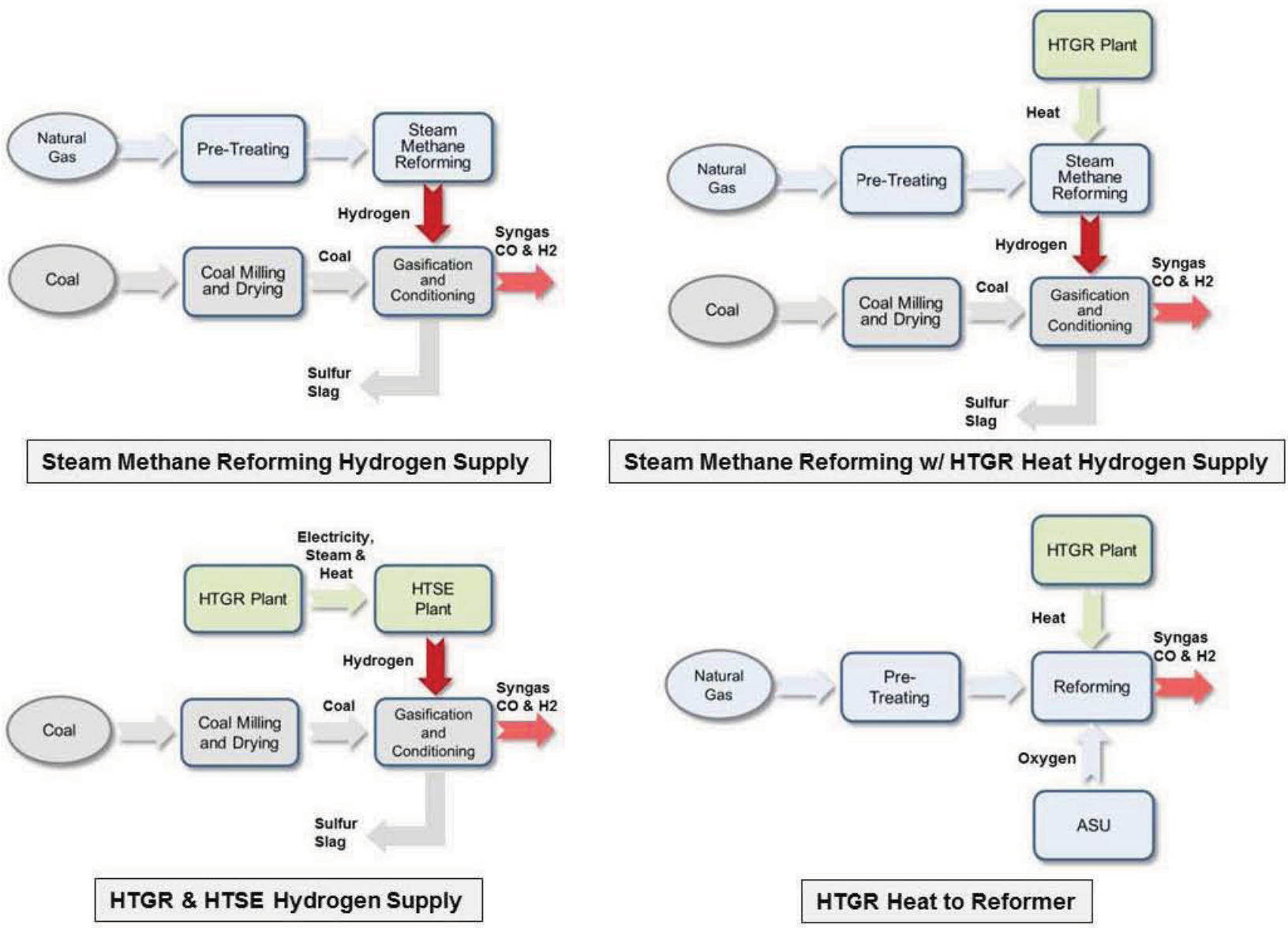

Figure D-2. Alternative syngas supply feedstocks and configurations.

Referring to Figure D-2, three different configurations are shown for providing an external supply of hydrogen to the coal gasifier as a substitute for the water shift reaction to produce the required $\mathrm{CO}$ to $\mathrm{H}_{2}$ ratio.

- Steam methane reforming (SMR); A common process used in the United States to produce hydrogen from natural gas and water. These components are used throughout the petro-chemical industry with good success.

- Steam Methane Reforming with HTGR heat; conventional SMR burns some of the natural gas to supply the heat required for the endothermic reaction. This and the reaction itself produces about 9 tons of $\mathrm{CO}_{2}$ for every ton of hydrogen produced. Adding high temperature heat from the HTGR reduces this by 7.5 tons per ton ( $83 \%$ reduction) and also generates about $15 \%$ more hydrogen for the same feed rate of natural gas.

- HTGR and HTSE; the HTGR supplies heat and electricity to the HTSE process to produce hydrogen with no $\mathrm{CO}_{2}$ emissions. This is the most effective process for reducing $\mathrm{CO}_{2}$ emissions in the gasification process.

Natural Gas Reforming, the addition of HTGR heat to the reformer in the natural gas to syngas process reduces the generation of $\mathrm{CO}_{2}$ by $23 \%$ and reduces the amount of natural gas required for the process.

All of these methods for providing an external supply of hydrogen and heat have been evaluated for the process alternatives considered herein. 


\section{D-2.2 Syngas Conversion}

The Syngas can be used to synthesize many different products. In the evaluations reported herein the following processes were analyzed:

- Coal and Natural GTL producing diesel fuel, naphtha and liquid petroleum gas (LPG) using the conventional Fischer-Tropsch (FT) process.

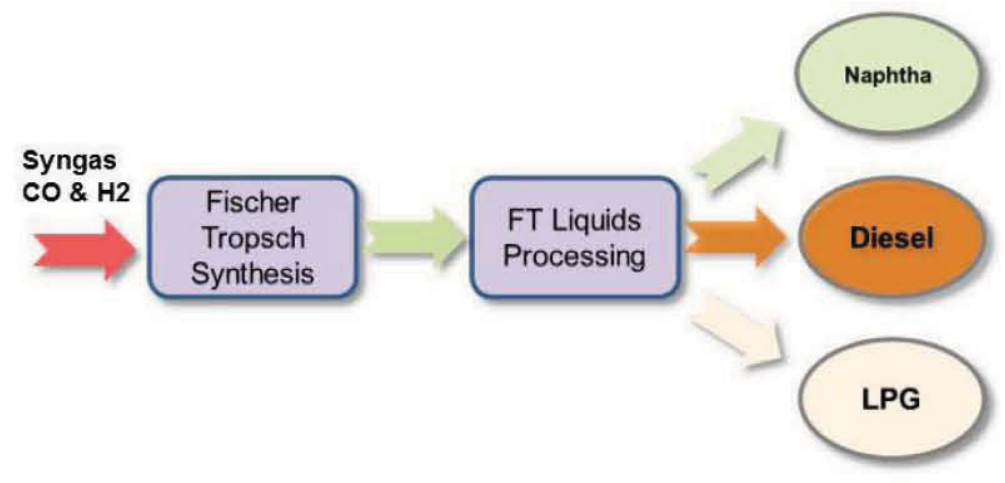

Figure D-3. Conventional FT Production of Diesel, Naphtha and LPG.

- A CTL alternative of converting the naphtha to higher value products including gasoline and olefins was also evaluated.

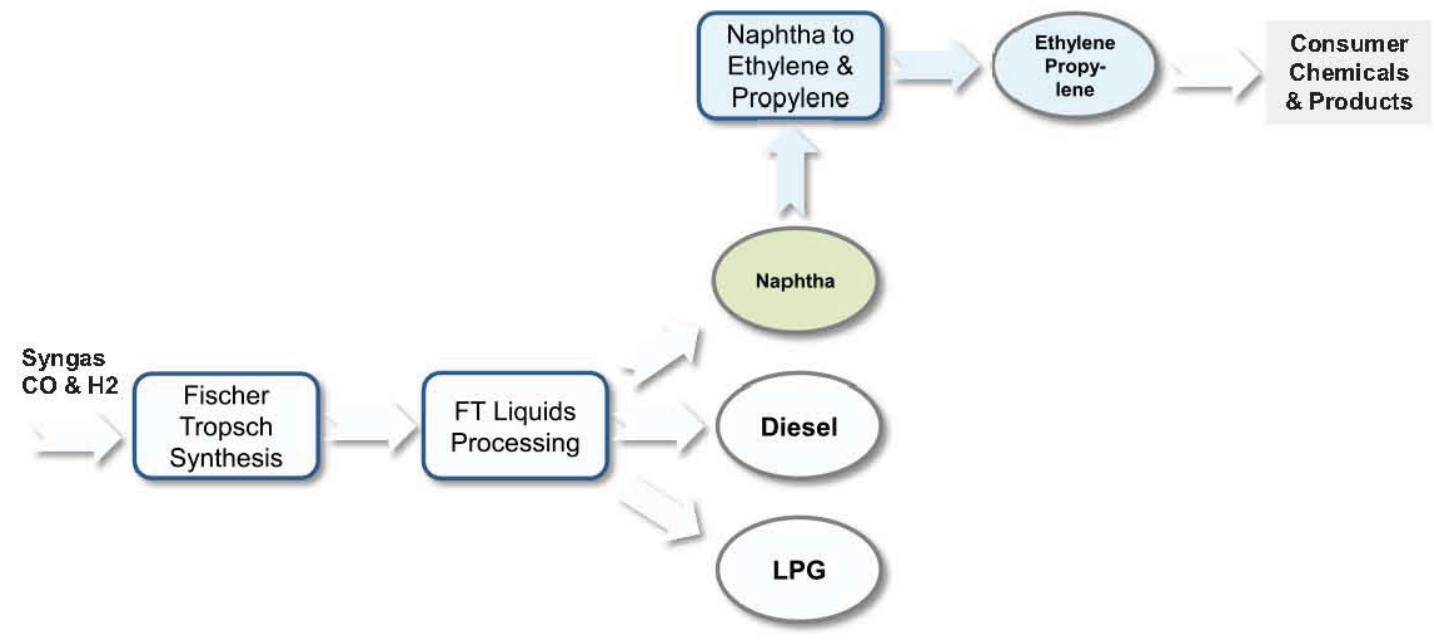

Figure D-4. Alternative further processing of F-T naphtha to produce chemicals.

- Coal and Natural GTL using the methanol to gasoline (MTG) process

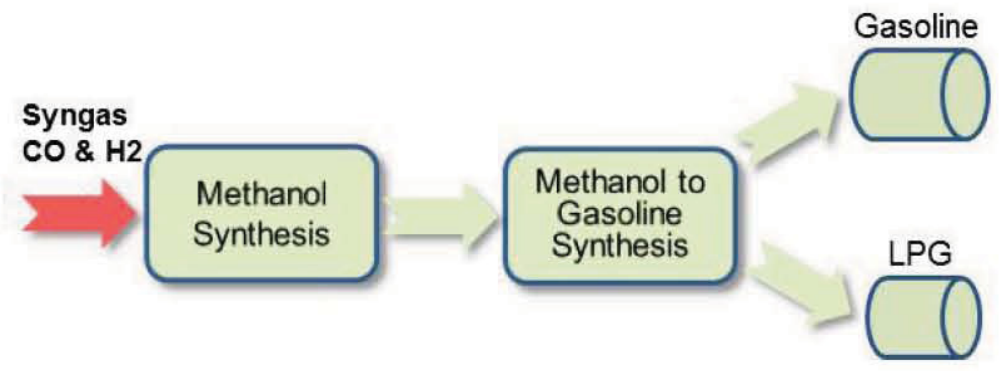

Figure D-5. Methanol to gasoline and LPG. 
- Coal to chemicals (e.g., olefins such as ethylene, propylene) using the coal to methanol to olefins (CTO) process

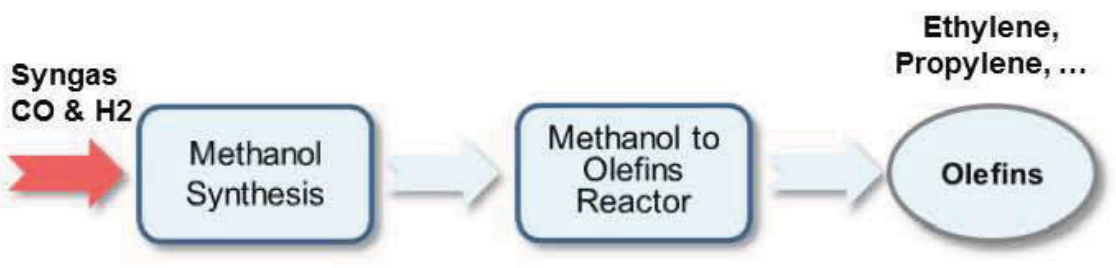

Figure D-6. Methanol to olefins.

A total of 16 process configurations were evaluated. For the purposes of discussion and to distinguish the processes, the processes that use current technologies are designated as "Conventional". The configurations that apply HTGR and HTSE technologies are described as "incorporating HTGR and, where applicable, HTSE technologies". The processes evaluated are listed in Table D.1.

Table D.1. Carbon conversion alternatives evaluated.

\begin{tabular}{|l|l|}
\hline CTL & $\begin{array}{l}\text { Conventional CTL using the FT process producing diesel, naphtha and liquefied } \\
\text { petroleum gas }\end{array}$ \\
\hline CTL w/SMR & Conventional CTL with SMR supplying hydrogen to the coal gasifier \\
\hline CTL w/SMR \& HTGR & CTL w/SMR with HTGR supplying heat and electricity to the steam methane reformers \\
\hline CTL w/HTGR \& HTSE & CTL with HTGR and HTSE supplying hydrogen to the coal gasifier \\
\hline GTL & $\begin{array}{l}\text { Conventional natural GTL using the FT process producing diesel, naphtha and liquefied } \\
\text { petroleum gas }\end{array}$ \\
\hline GTL w/HTGR & Natural GTL with HTGR supplying heat to the primary reformer \\
\hline GTG & $\begin{array}{l}\text { Conventional natural GTG using the MTG process producing gasoline and liquefied } \\
\text { petroleum gas }\end{array}$ \\
\hline GTG w/HTGR & Natural GTG with HTGR supplying heat to the primary reformer \\
\hline CTG & Conventional CTG using MTG producing gasoline and liquefied petroleum gas \\
\hline CTG w/SMR & Conventional CTG with SMR supplying hydrogen to the coal gasifier \\
\hline CTG w/SMR \& HTGR & CTG w/SMR with HTGR supplying heat and electricity to the steam methane reformers \\
\hline CTG w/HTGR \& HTSE & CTG with HTGR and HTSE supplying hydrogen to the coal gasifier \\
\hline CTO & Conventional CTO, olefins such as ethylene and propylene \\
\hline CTO w/HTGR \& HTSE & CTO with HTGR and HTSE supplying hydrogen to the coal gasifier \\
\hline
\end{tabular}

Modifications of the traditional processes developed as part of this evaluation are in the gasification and reforming stages. These include the use, for example, of SMR or HTGR and HTSE for hydrogen production as a substitute for the traditional water-shift reaction in the CTL process. The advantage of these substitutions is a significant reduction in the quantities of $\mathrm{CO}_{2}$ produced and emitted in the gasification and reforming stages. As also shown the HTGR technology is incorporated into the processes in these stages supplying heat and electricity as well as hydrogen.

Figure D-7 illustrates the advantages in emissions reductions that result from the use of SMR and HTGR/HTSE for hydrogen generation in the alternative processes. For example in the CTL process, the use of SMR reduces the total $\mathrm{CO}_{2}$ generated by $\sim 60 \%$ whereas full use of the HTGR/HTSE technology offers reductions $>90 \%$. 


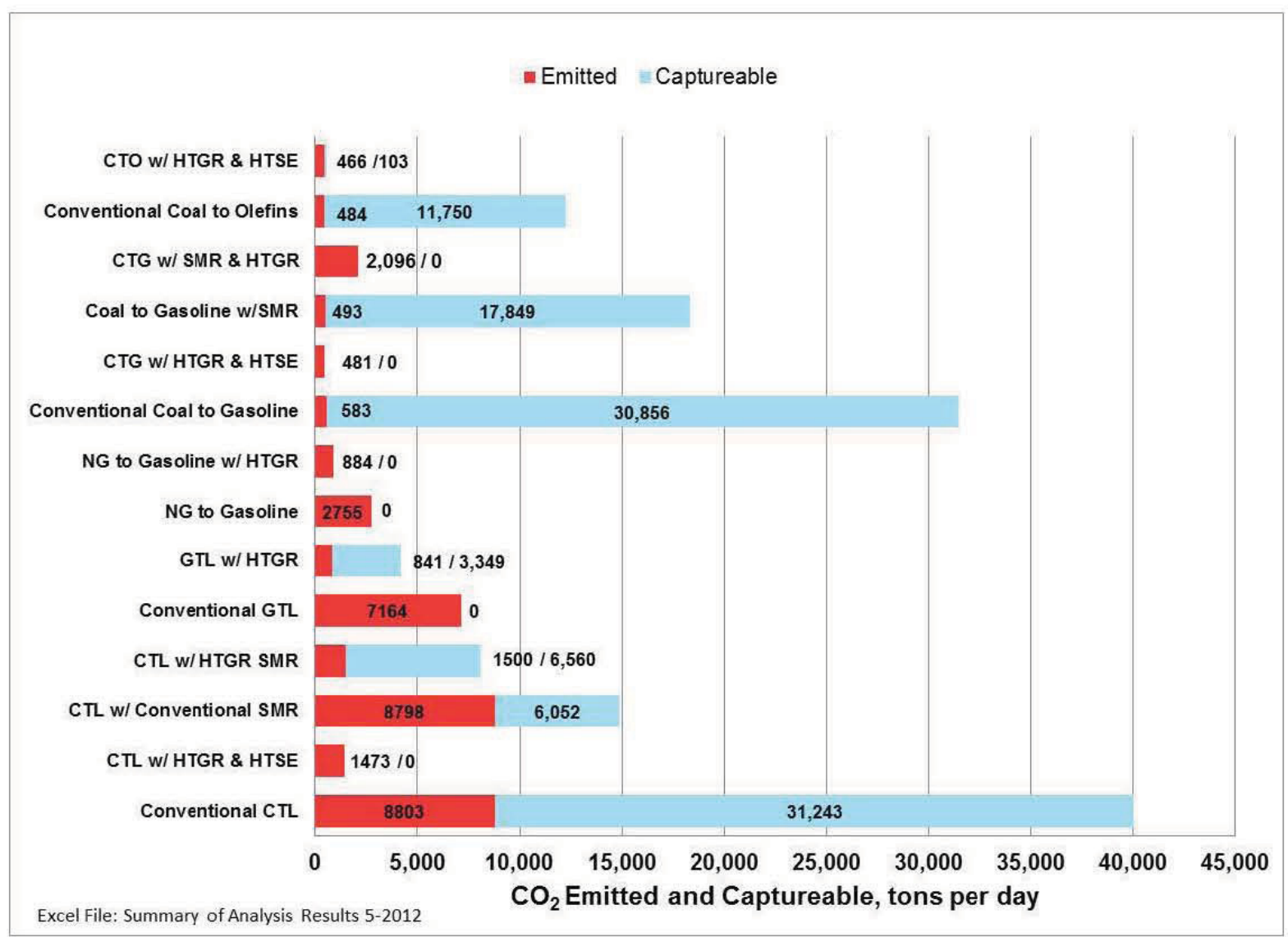

Figure D-7. Comparison of $\mathrm{CO}_{2}$ generation and the potential for capture in coal to liquids process alternatives.

\section{D-2.3 Aspen Models}

Detailed development of each of the processes evaluated in this study is documented in INL technical evaluation reports listed in Appendix $G$ of this report. In all cases detailed models of the processes in the conventional configurations and with HTGR and HTSE incorporated configurations were developed in Aspen+(C) to establish their performance characteristics. The following discusses the characteristics and bases of the process models used in this evaluation.

\section{D-2.3.1 Coal to Liquids}

Figures D-8 and D-9 are schematics of the models of the Conventional and HTGR/HTSE incorporated coal to liquids (CTL) plant using the traditional FT process. Figures D-10 and D-11 show schematics of these models for the CTL processes in which SMR is used to provide hydrogen, including that configuration with the HTGR providing heat to the SMR process. Each of the blocks in these figures represent very detailed Aspen+C models that INL has developed over several years to support these analyses. These are typical of the models used in the evaluations herein ${ }^{3}$. 
INL/EXT-12-26710

November 2012

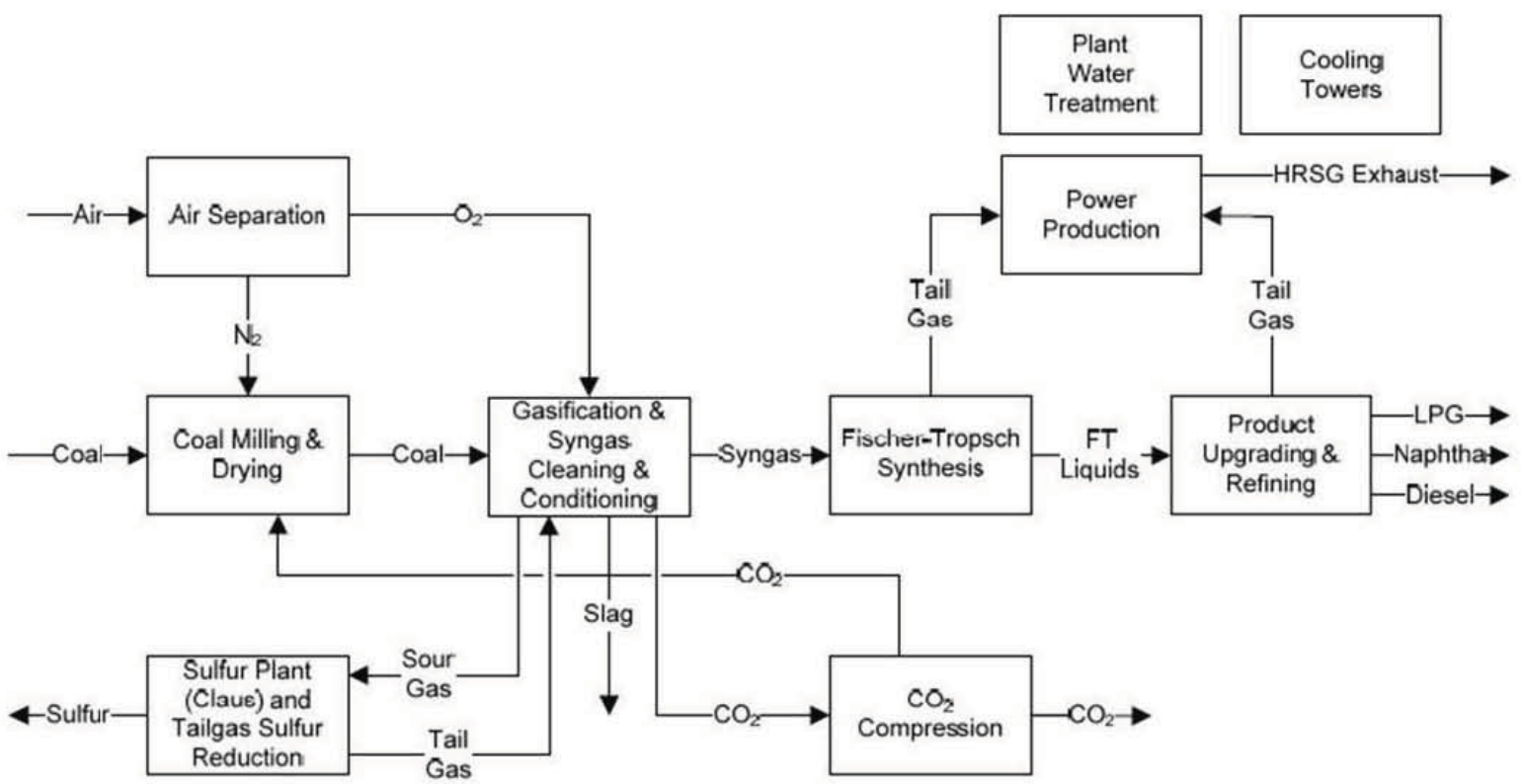

Figure D-8. Conventional CTL using the traditional Fischer Tropsch process.

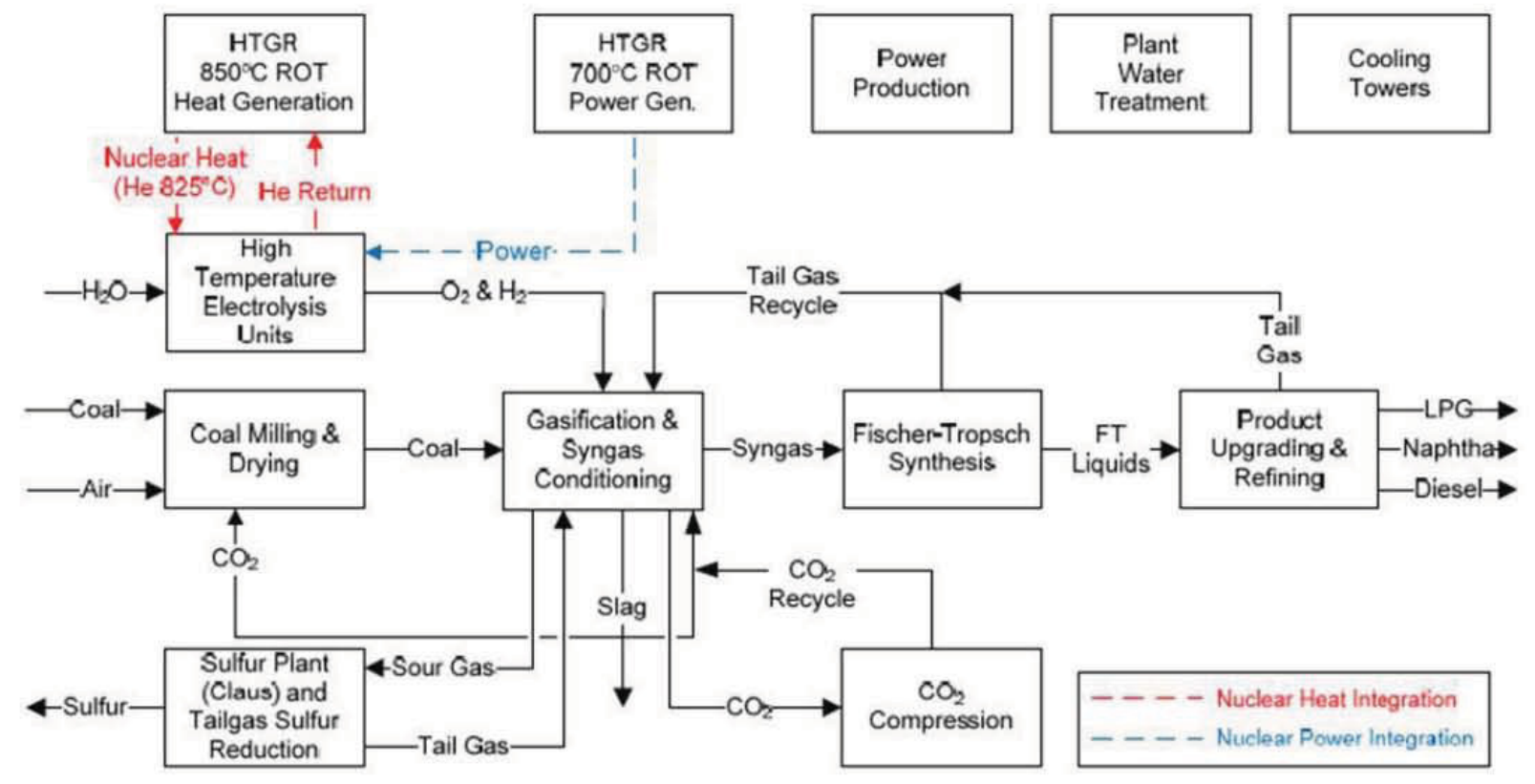

Figure D-9. CTL process incorporating HTGR and HTSE technologies. 
INL/EXT-12-26710

November 2012

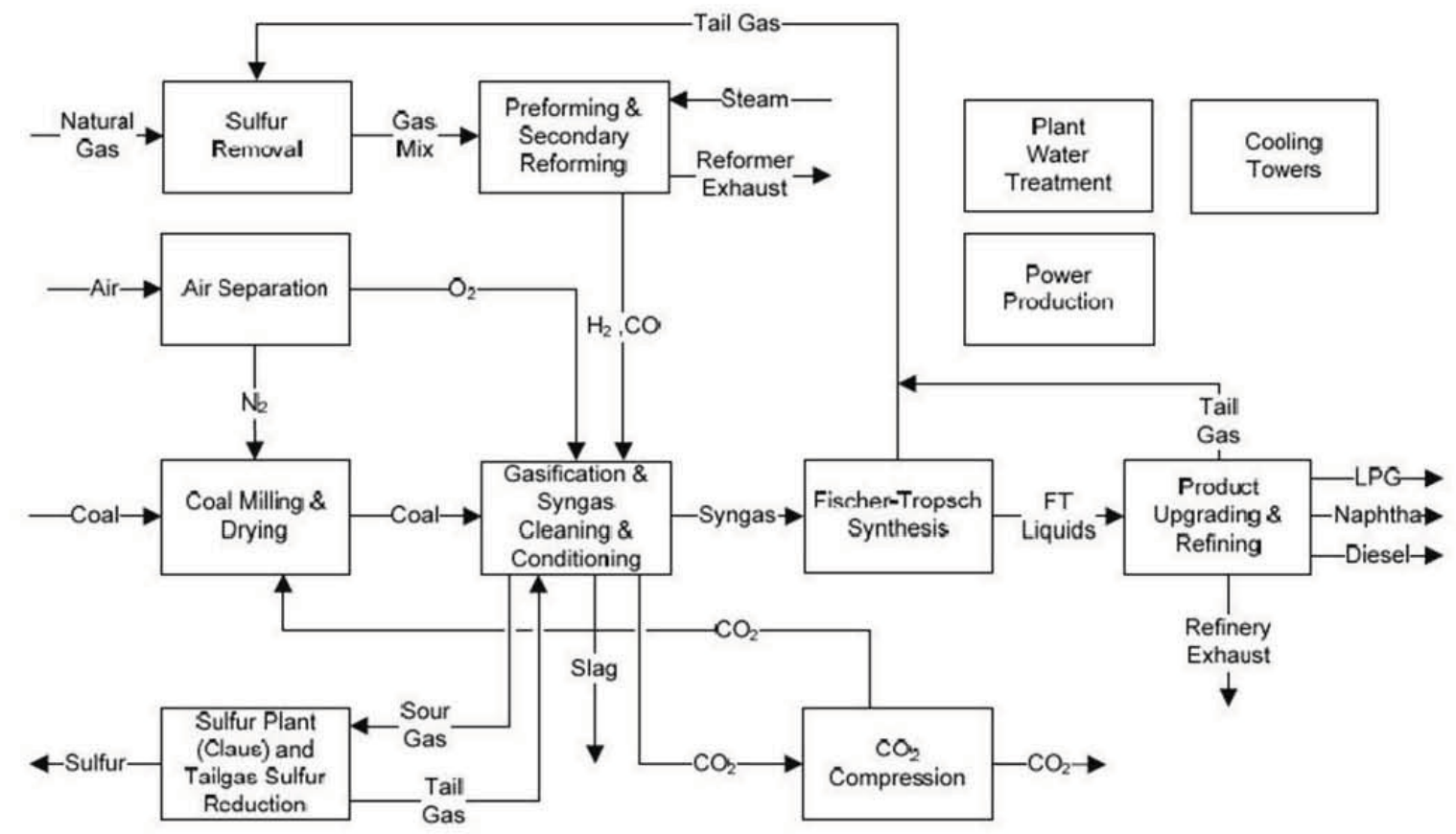

Figure D-10.CTL FT process using conventional SMR for hydrogen supply.

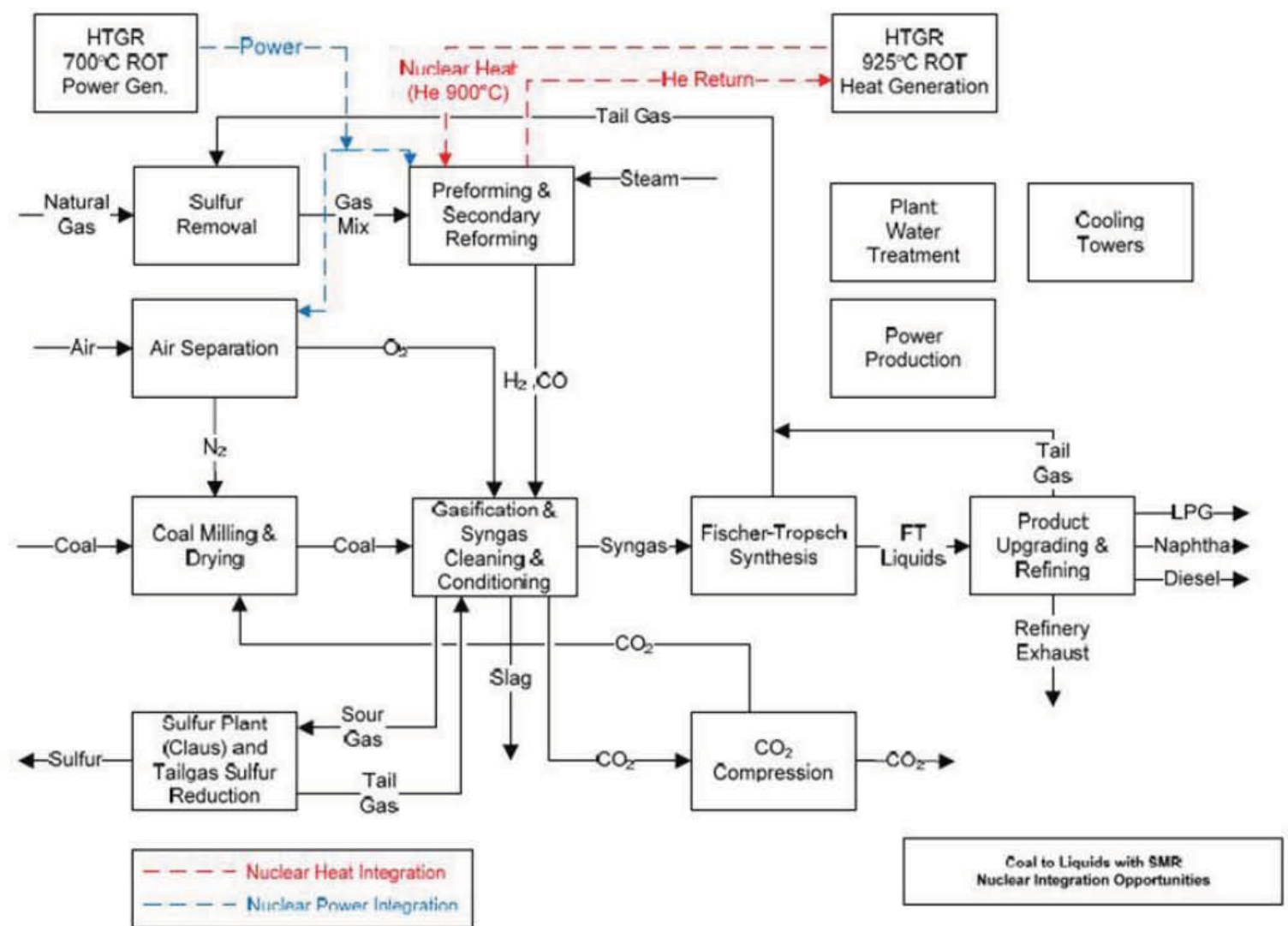

Figure D-11. CTL FT process using HTGR incorporated SMR for hydrogen supply. 
Each of the coal-based models relies on gasification to convert coal into synthesis gas. Gasification is a mature technology which has been used to produce gas for lighting and heat since the early $19^{\text {th }}$ century. Although the discovery of natural gas in the late $19^{\text {th }}$ century displaced coal gasification for these applications, coal gasification technology has continued to evolve. Entrained flow gasification represents the state-of-the-art today, with several commercial vendors offering such designs. GE and ConocoPhillips currently market slurry-fed entrained-flow gasifiers, while Shell, Uhde, and Siemens offer dry-fed entrained-flow gasifiers. The Aspen $+C$ gasification models selected for use in this study are representative of the dry-fed designs offered by Shell and Uhde.

The Conventional CTL process, Figure D-8, uses the water shift reaction to produce the additional hydrogen needed in the coal gasification process to develop the hydrogen to $\mathrm{CO}$ ratio required for the FT reaction. The water shift reaction is one of the largest sources of the large quantity of $\mathrm{CO}_{2}$ generated in this process, see Figure D-7. The integration of the HTGR and HTSE technologies, Figure D-9, provides an external source of hydrogen eliminating the need for the water shift reaction and the $\mathrm{CO}_{2}$ associated with that reaction. The HTGR also supplies electricity required for operation of the process permitting recycle of tail gases that are used in the Conventional process for electricity generation. This eliminates the other large source of $\mathrm{CO}_{2}$ generation in the Conventional process. As shown in Figure D-7, the integration of the HTGR and HTSE technologies in the CTL process reduces $\mathrm{CO}_{2}$ generation by over $95 \%$.

Figures D-10 and D-11 show alternative configurations using SMR for supplying hydrogen to the CTL process as a substitute for the water shift reaction. Steam methane reforming is the most widely used technology in the world today for production of hydrogen. Hence, it is a critical technology supporting an array of processes from ammonia production to petroleum refining. Many variations of the technology have been commercialized, such as autothermal reforming. In these studies, hydrogen production is modeled using conventional SMR. In conventional SMR using natural gas as the feedstock some of the natural gas is burned to produce the temperatures required in the endothermic reforming process. Figure D-10. When the HTGR technology is applied to the process, Figure D-11, the heat for reforming is provided by hot gas from the HTGR as well as electricity for operation of the ASU and SMR plants. As shown in Figure D-7, use of conventional SMR in place of the water gas shift reaction reduces $\mathrm{CO}_{2}$ generation in the conventional CTL process by more than $60 \%$ and the use of HTGR results in a further reduction of more than $90 \%$.

For syngas purification in all processes, only mature, commercial technologies were selected. In the SMR scenarios, sulfur was removed prior to reforming using a standard zinc oxide sorbent. In the gasification scenarios, sulfur was removed using Rectisol solvent in an absorber/stripper configuration, and captured sulfur was further processed using a Claus and SCOT process. In the gasification processes, Rectisol was also used to capture $\mathrm{CO}_{2}$ from the process gas. In some of the SMR scenarios, $\mathrm{CO}_{2}$ was captured using a Fluor propylene carbonate solvent. Hydrogen separation in all scenarios was accomplished using pressure swing adsorption (PSA). All of these technologies have broad commercial application and are considered mature.

In the CTL processes and in the Gas to Liquids (GTL) process shown later, purified syngas was converted to diesel, naphtha, and LPG using the FT process. The FT process was commercialized by Germany prior to WWII, and was used to produce fuels for use in both war machinery and automobiles. The FT process was later implemented by Sasol in South Africa in 1952. Today this technology is used to produce most of that country's diesel fuel. In the early years of FT commercialization, iron-based catalysts were primarily used. More recently, cobalt-based catalysts have also been developed and used commercially for FT synthesis. In the technical evaluations considered in this study, a cobalt-based catalyst was modeled. 


\section{D-2.3.2 Coal to Gasoline and Coal to Chemicals}

In the coal to gasoline (CTG) and coal to chemicals (CTC) scenarios considered in this study, methanol is produced as an intermediate product ${ }^{4,5}$ Figure D-12 and Figure D-13 are schematics of the CTG Conventional process, and the HTGR/HTSE incorporated configuration supplying hydrogen, using the MTG process. Figure D-14 and Figure D-15 are schematics of the CTG process using SMR for the hydrogen supply and HTGR supplying heat and electricity to the SMR process.

Figures Figure D-16 and Figure D-17 are similar schematics for the CTC process.

These processes use gasification processes similar to those described for the CTL processes but the synthesis gas is used to produce methanol suited for processing into gasoline and chemicals.

Figure D-13 and Figure D-15 show the processes incorporating the HTGR and HTSE technologies to supply hydrogen and electricity similar to that discussed for the CTL processes. As discussed in the preceding section this external source of hydrogen and electricity provides more than $90 \%$ reduction in $\mathrm{CO}_{2}$ generation in these processes.

In Figure D-15 the HTGR is supplying heat and electricity to the SMR plant to substitute for the burning of natural gas, similar to that for the CTL w/SMR configuration discussed previously. In this case the $\mathrm{CO}_{2}$ generation is also reduced by $\sim 90 \%$.

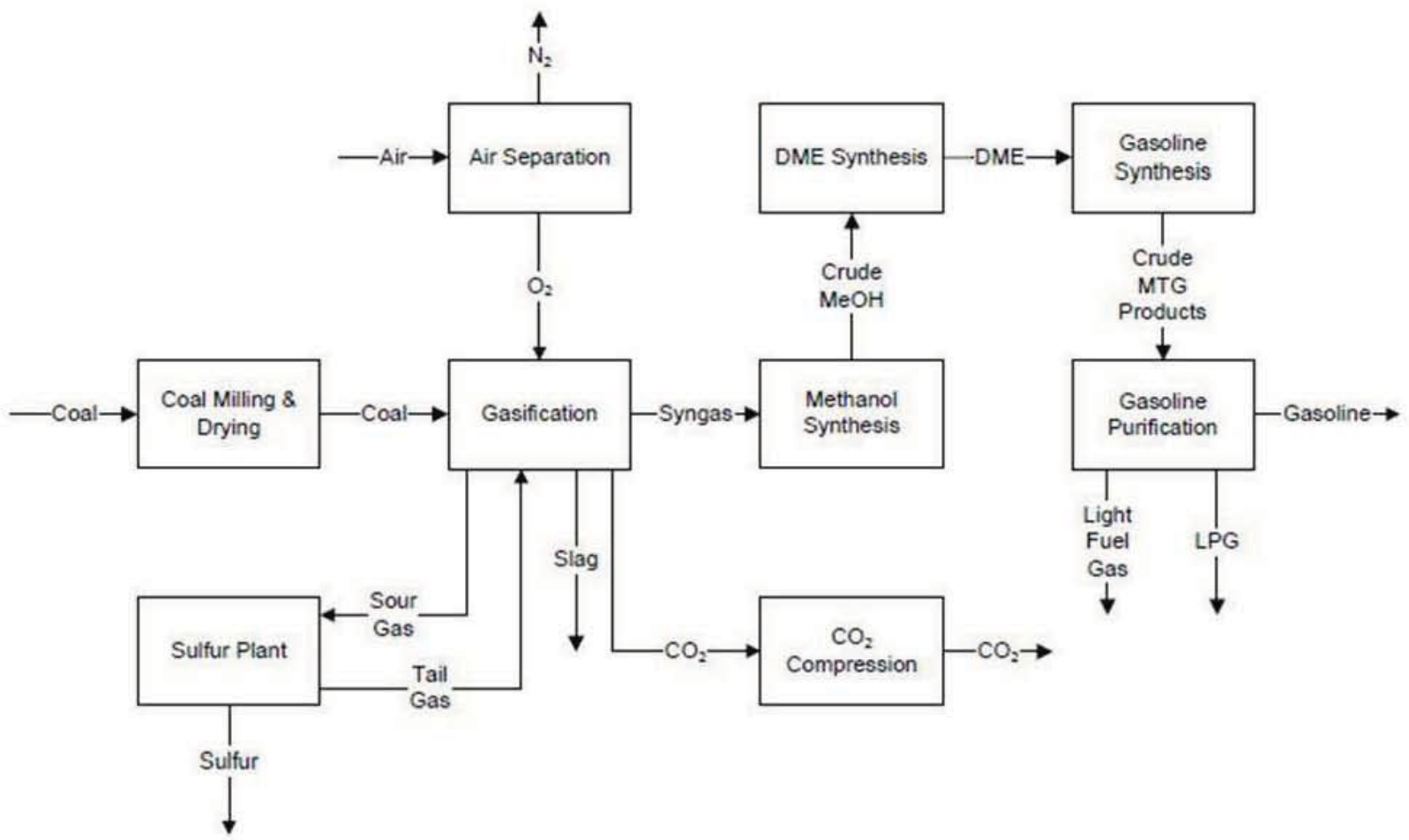

Figure D-12. Conventional CTG using the MTG process. 
INL/EXT-12-26710

November 2012

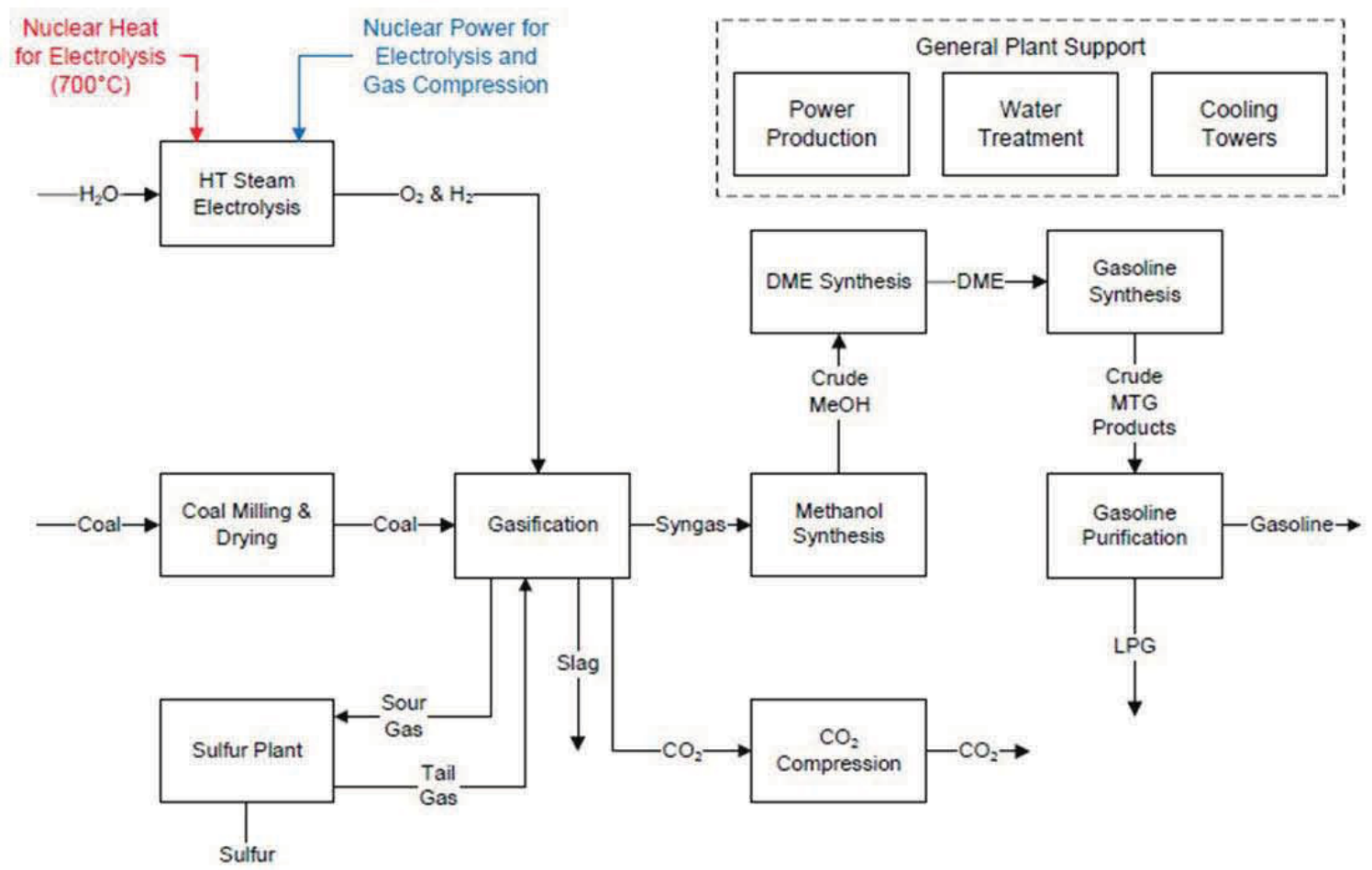

Figure D-13. CTG process applying HTGR and HTSE technologies.

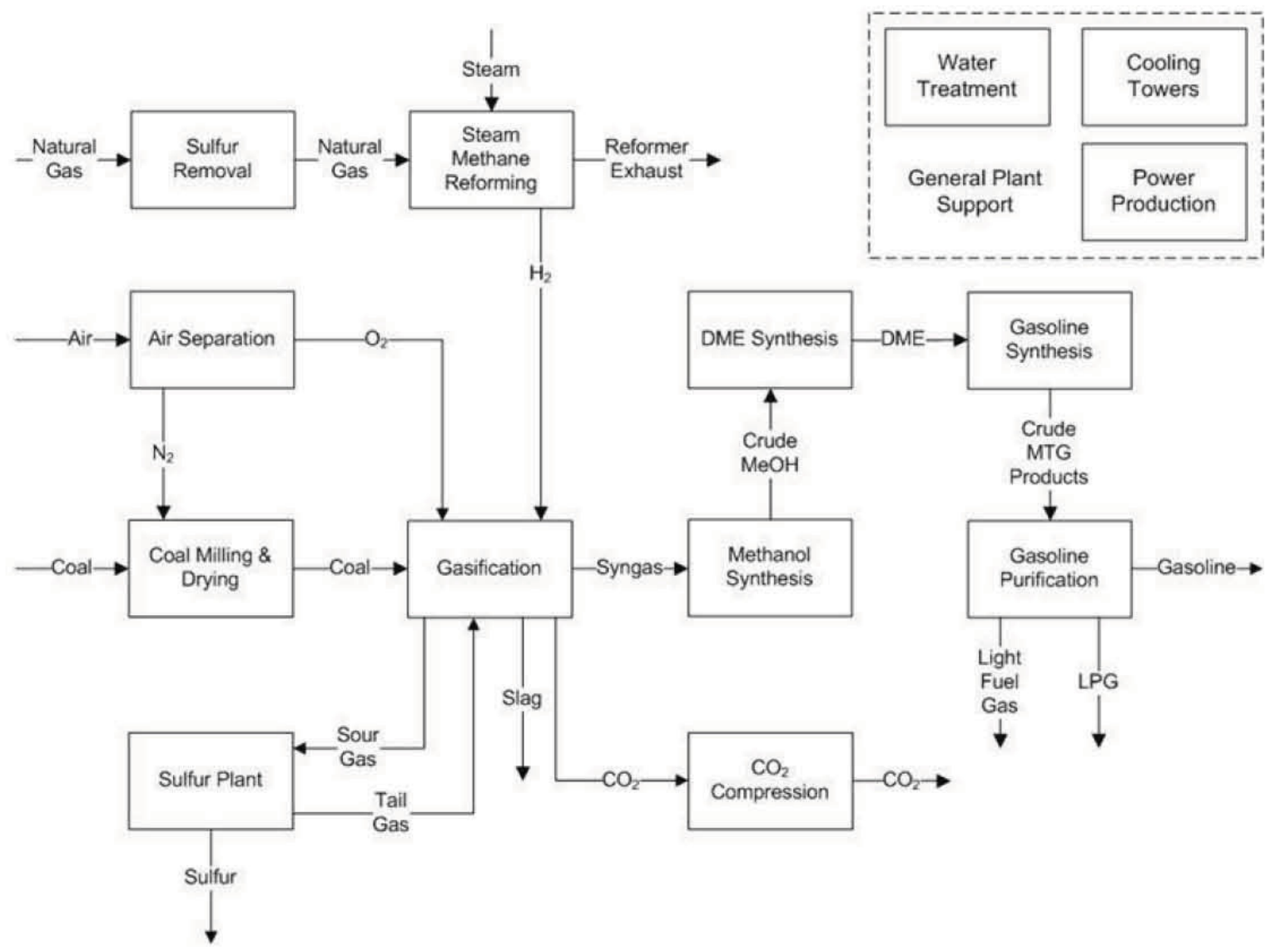

Figure D-14. CTG using an SMR hydrogen supply. 


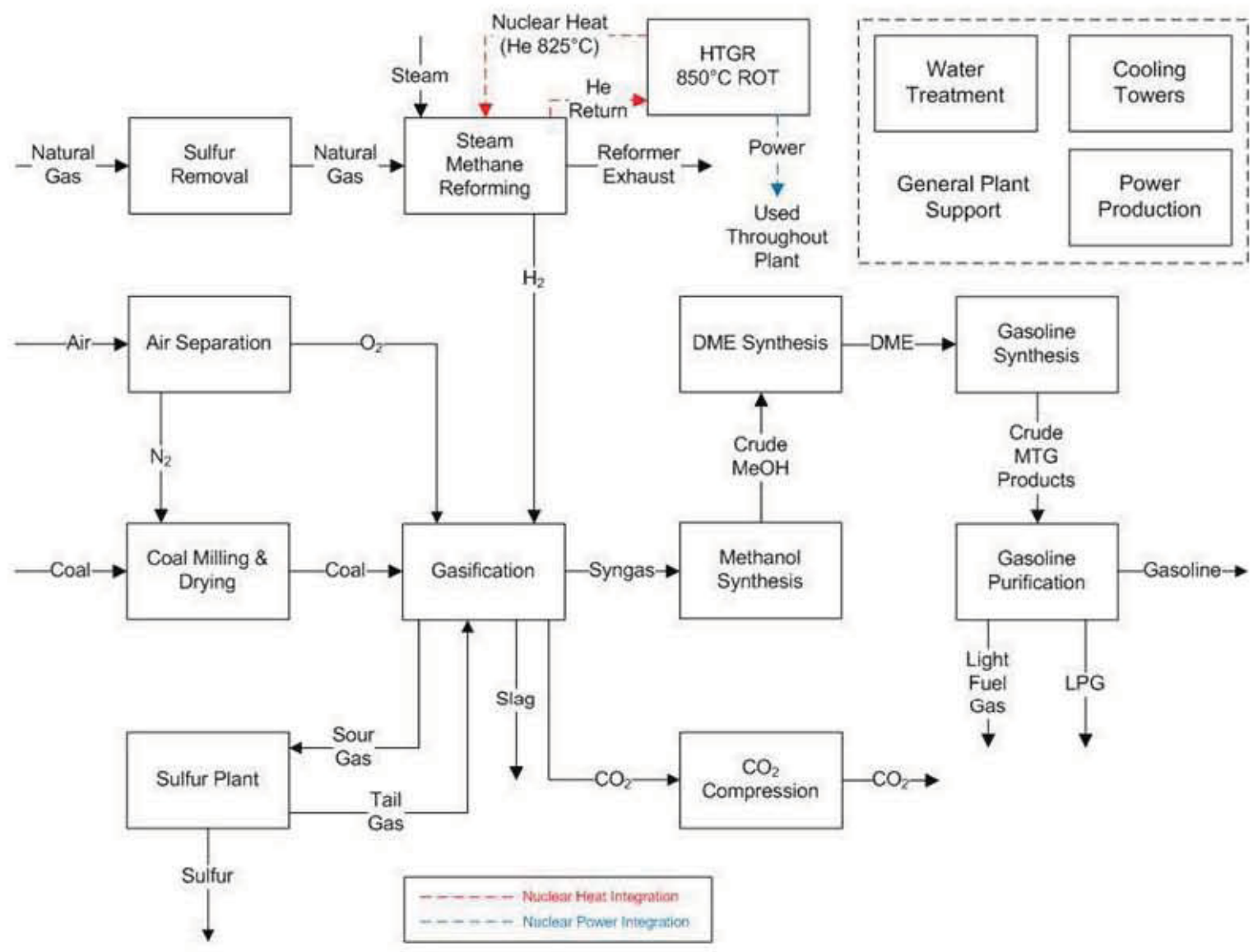

Figure D-15. CTG using an SMR with HTGR hydrogen supply.

Synthetic methanol production is well developed, with the first plant beginning production in 1923 at BASF's plant in Leuna, Germany. Refinements to that process were developed by ICI in the 1960s, thus allowing synthesis to be performed at much lower pressures. The ICI process and its derivatives are still widely used today, although significant improvements in energy utilization have been realized. In the CTG scenario, methanol is further converted to dimethyl ether and then to gasoline using a zeolite catalyst. For the evaluations in this study, ExxonMobil's methanol-to-gasoline (MTG) process was selected. This technology was first demonstrated on a commercial scale as a partnership between ExxonMobil and the New Zealand government ${ }^{6}$. The plant began operation in 1985 and ran for approximately 10 years; production rate of the plant was 14,500 barrels per day of gasoline.

There is considerable current activity in development of CTG plants:

- In June of 2009, Jincheng Anthracite Mining Group (JAMG) in Shanxi Province, China started up Phase 1 of a second generation MTG plant. ${ }^{7}$ Phase 1 of the plant development has a relatively low capacity of $2,500 \mathrm{bb} 1 /$ day. This plant was producing on-spec gasoline 60 hours after initial startup of the plant. That is fairly impressive for this type of facility. Phase 2 will expand the plant to approximately $25,000 \mathrm{bb} /$ day.

- This same technology has been selected for a synthetic fuels plant under construction by DKRW near Medicine Bow, Wyoming ${ }^{8}$. Engineering for Phase 1 (11,000 bpd) of this plant is complete, and construction is scheduled to ramp up during 2012.

- TransGas is (or was) planning a CTG plant for Mingo county, WV 
- Synthesis Energy Systems (SES) has an agreement with ExxonMobil to build up to 15 MTG plants. Their agreement was put in place in 2008. They have since teamed with CONSOL Energy, and a plant was announced for Benwood, WV.

- There are also three Conventional MTG plants that have initiated construction in Kentucky including the Secure Energy Paducah Gasification Plant on the Ohio Triple Rail Megasite near Paducah $(\sim 12,000 \mathrm{bpd})^{10}$, Chisholm Energy in Pike County $(18,000 \mathrm{bpd})^{11}$ and Buffalo Creek Energy in Pikeville $(18,000 \mathrm{bpd})^{12}$.

In reference to Figure D-16 and Figure D-17 that show the models for the chemical production scenarios in this study, methanol is converted to ethylene and propylene using a zeolite catalyst with a slightly smaller pore size than that used for gasoline production. The specific process selected in this evaluation is UOP's methanol-to-olefins (MTO) process. This process was successfully demonstrated in Norway in 1995. In 2005, UOP and Total Petrochemicals began collaboration on a process to further increase ethylene and propylene yields from the process. A demonstration unit was built and began operation in 2008 at Total's petrochemical complex in Feluy, Belgium. The first commercial plant based on this technology has been announced in China, and is targeted to start up in $2013^{13}$.

It should be noted that coal to chemicals processing has been extant in the United States for many decades; principally, by the Eastman Chemical company in Georgia.

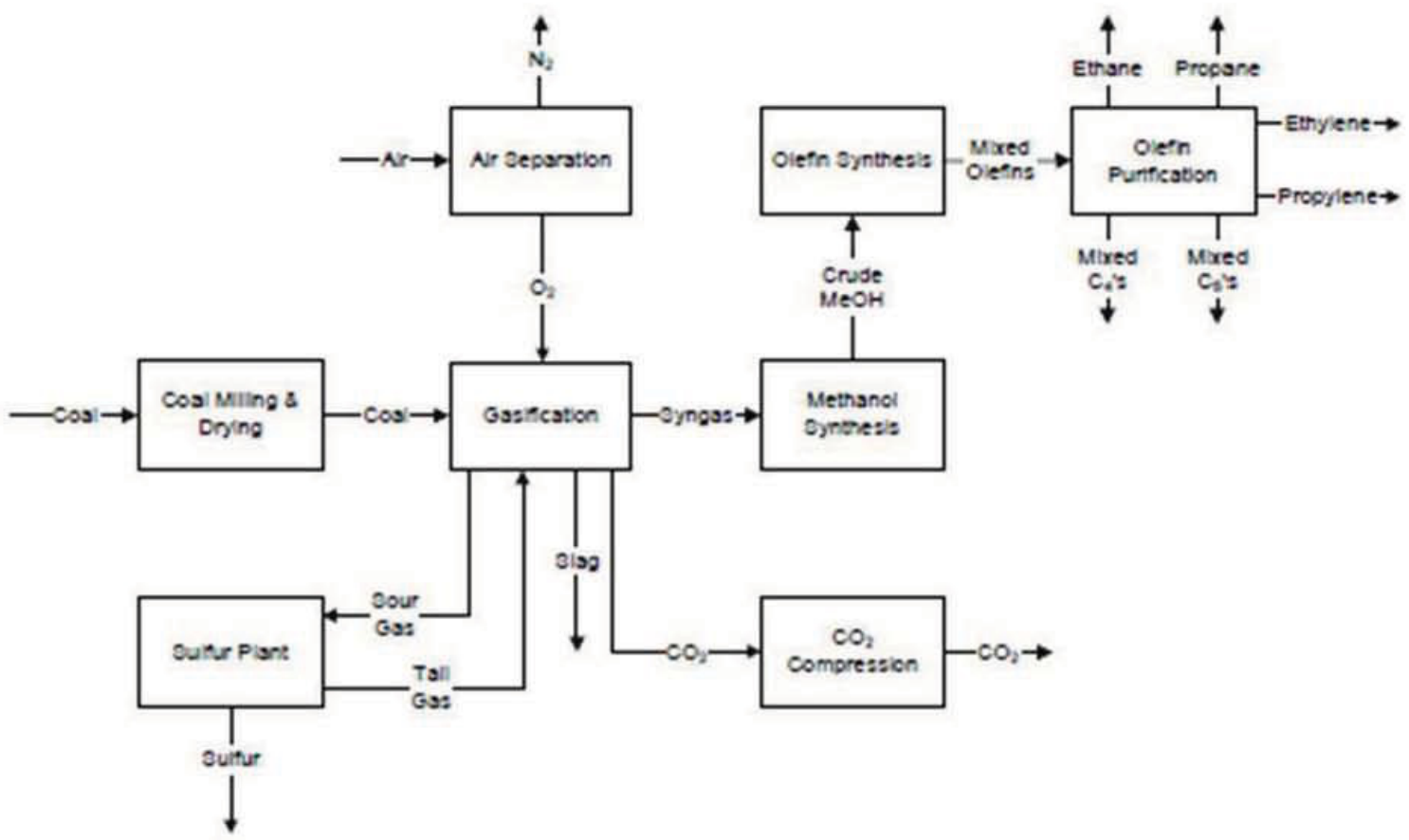

Figure D-16. Conventional coal to chemicals. 
INL/EXT-12-26710

November 2012

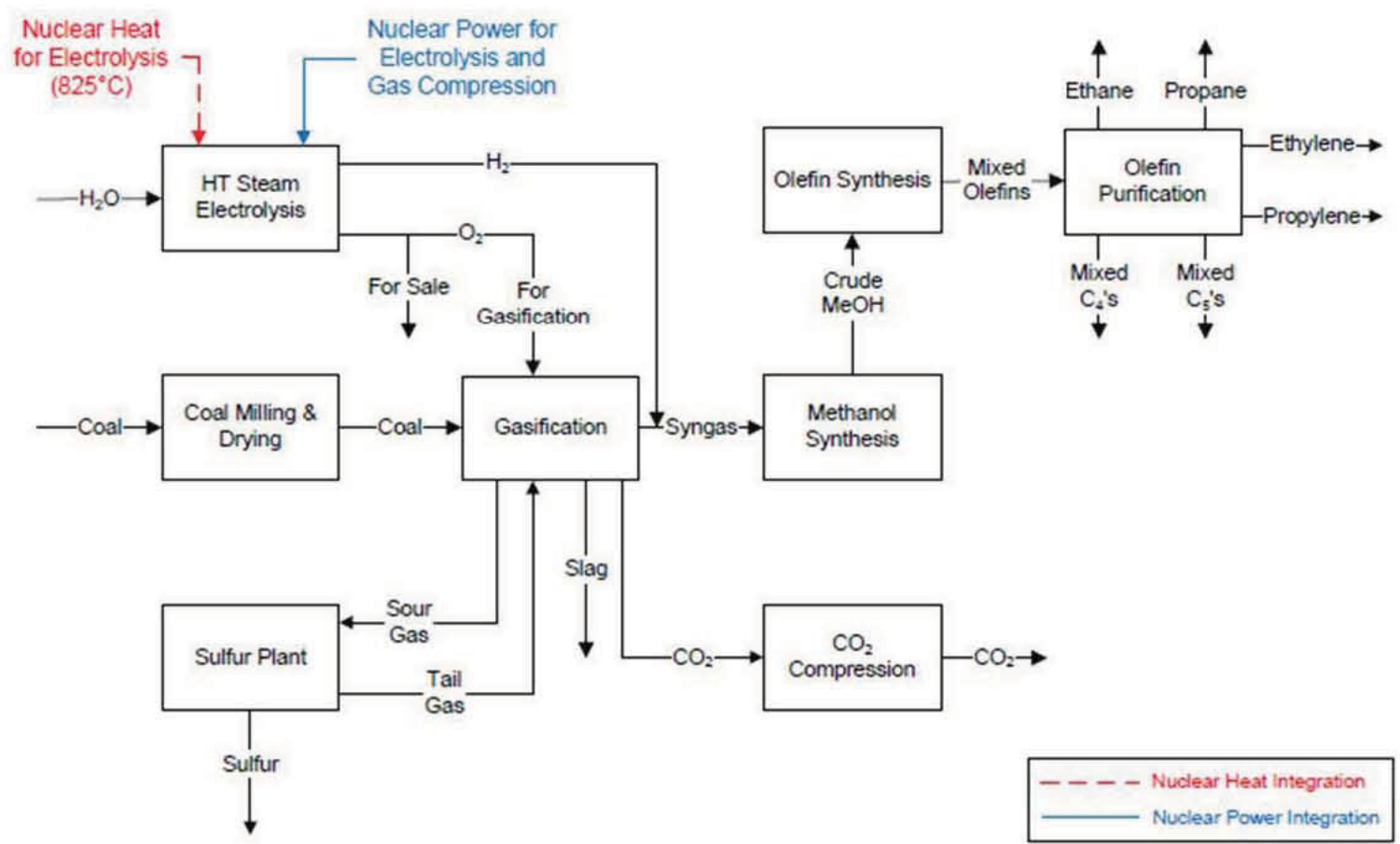

Figure D-17. Coal to chemicals process incorporating HTGR and HTSE technologies.

\section{D-2.3.3 Natural GTL and to Gasoline $e^{2,14}$}

When natural gas is chosen as the feedstock, SMR is used to convert natural gas into synthesis gas which can then be processed using FT to produce diesel, naphtha and LPG or into gasoline and LPG using the MTG process. Figure D-14 and D-15 are schematics of the Aspen+C models for the Conventional and nuclear incorporated GTL processes. Figure D-18 and Figure D-19 are schematics of the Aspen $+(\mathrm{C}$ models for the conventional and nuclear incorporated natural GTL processes.

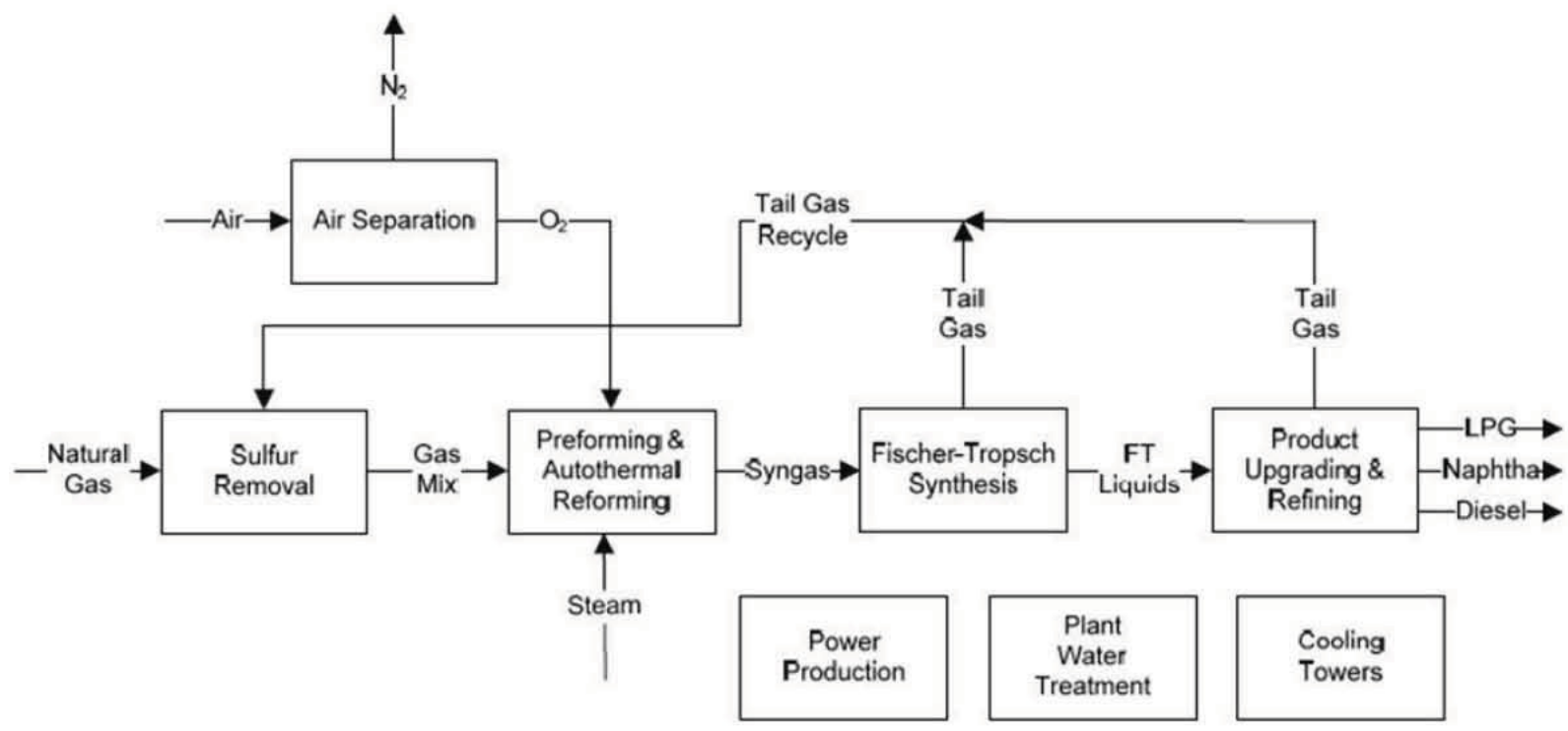

Figure D-18. Conventional natural GTL process. 
INL/EXT-12-26710

November 2012

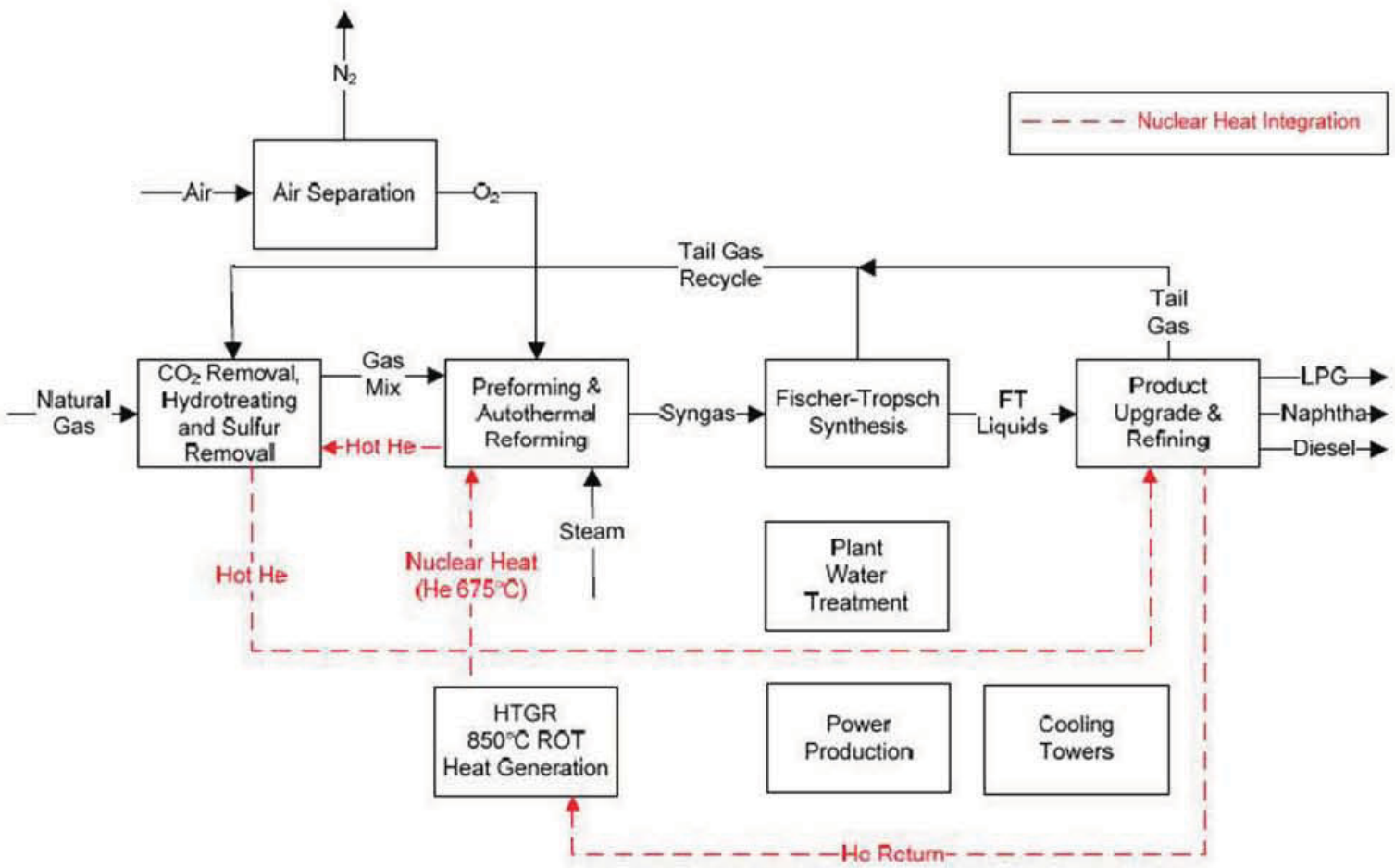

Figure D-19. Natural GTL process incorporating HTGR heat.

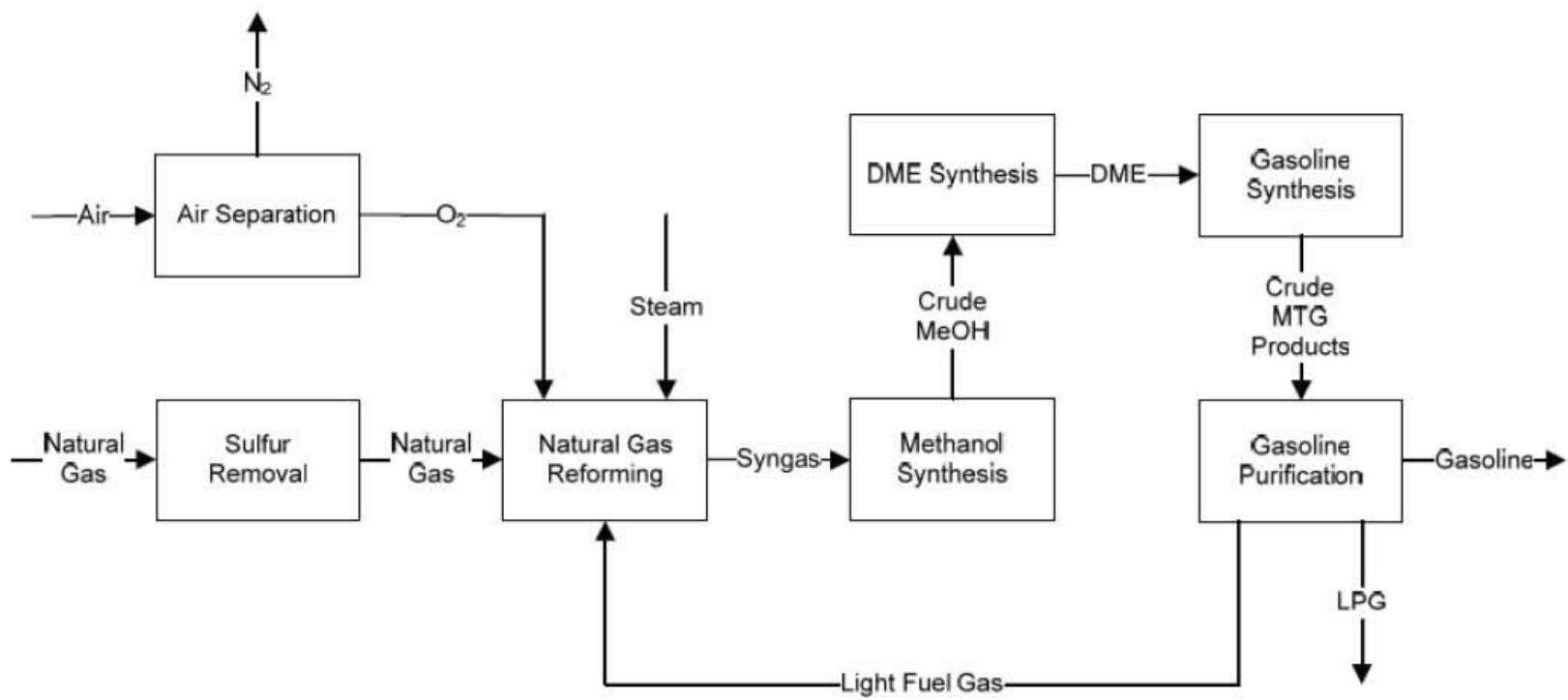

Figure D-20. Natural Gas to gasoline using the MTG process. 
INL/EXT-12-26710

November 2012
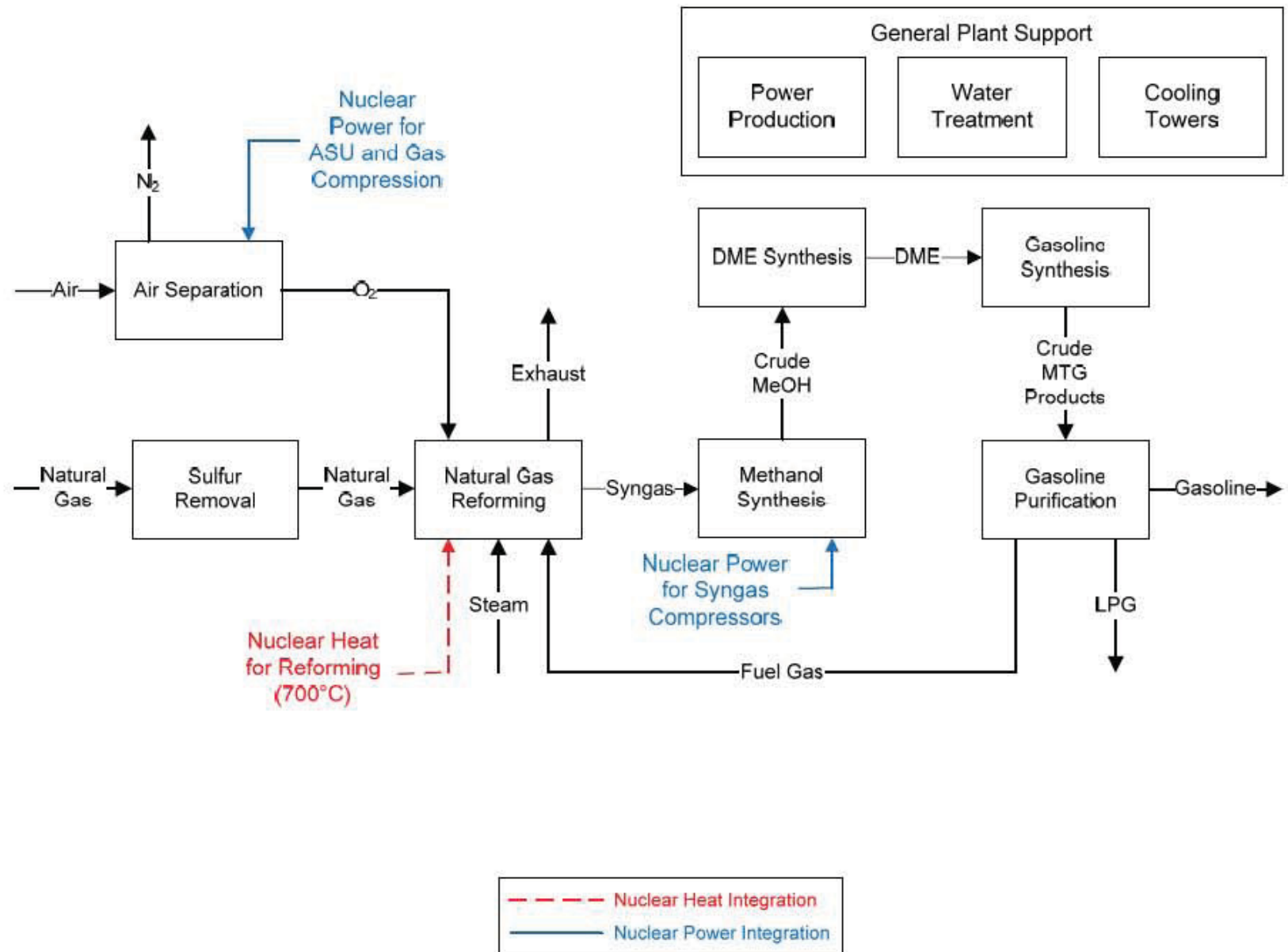

Figure D-21. Natural GTG using HTGR.

When the syngas is used to make FT liquids, autothermal reforming alone was modeled. When the syngas is used to make methanol for the natural GTG process two-step reforming was selected. In twostep reforming, an autothermal reforming stage is placed downstream of a conventional SMR stage. Selecting the appropriate reforming scenario allows great flexibility to produce a synthesis gas with the optimal $\mathrm{H}_{2} / \mathrm{CO}$ ratio for the downstream process.

As shown in Figure D-15, the HTGR provides heat in the form of high temperature helium or other chemically inert gas to offset the burning of natural gas in the Conventional process in the endothermic parts of the process. This reduces the $\mathrm{CO}_{2}$ generation by more than $40 \%$. Similarly, in Figure D-17 HTGR heat is substituted for the burning of natural gas in the reformer and for electricity to operate the process. This reduces the $\mathrm{CO}_{2}$ generation by $\sim 70 \%$.

\section{D-2.4 Performance Characteristics of the Alternatives}

The following discusses and makes brief comparisons of the performance characteristics of the carbon conversion alternatives. A 50,000 bpd plant was modeled for the processes converting coal or natural gas to transportation fuels. A 3,000 tpd plant was modeled for the coal to chemicals process. The following figures show the inputs and outputs of each of the processes; (e.g., for the CTL process the coal feed rate, water requirements, the quantities of diesel, naphtha, $\mathrm{LPG}$ and $\mathrm{CO}_{2}$ produced) and consolidated figures compare these factors for the conventional and nuclear incorporated processes. 
In addition to calculating the total amount of $\mathrm{CO}_{2}$ produced in each process, assessments were also made of the capability to capture some of that $\mathrm{CO}_{2}$ for sequestration or $\mathrm{EOR}$; the balance not captured is cited as that emitted. In the cases where sequestration is judged feasible, the equipment costs and energy requirements for capture and preparation for sequestration are estimated and included in the evaluation. An example of this effect can be seen in the summary for conventional CTL. This process generates excess electricity that can be sold to regional utilities on the grid. The amounts of that electricity are shown for the process with and without sequestration; the lower value reflecting the electricity required to capture and pressurize the $\mathrm{CO}_{2}$ for transport to the storage or EOR site. The operating costs include the costs of transporting and injecting the $\mathrm{CO}_{2}$ at the sequestration site.

\section{D-2.4.1 Conventional CTL}

- The nuclear incorporated case requires $65 \%$ less coal feed than the conventional case for the same production rate with a commensurate reduction of $96 \%$ in $\mathrm{CO}_{2}$ emissions.

- The use of HTSE for hydrogen production in the nuclear incorporated case requires the supply of over $2.4 \mathrm{GW}(\mathrm{e})$ and $\sim 700 \mathrm{MW}(\mathrm{t})$ of heat. This requires the installation of $10 \mathrm{HTGR}$ plants to support the 50,000 bpd production rate.

- The nuclear incorporated configuration requires $25 \%$ less water than the conventional case

- The carbon in the natural gas supplying hydrogen in the steam methane reformer reduces the coal feed rate by $\sim 70 \%$ when compared with conventional CTL

- The rates of $\mathrm{CO}_{2}$ generation in the CTL w/SMR process are $\sim 65 \%$ lower than the conventional CTL process, but with incorporation of HTGR heat are higher than the CTL process with incorporation of HTGR and HTSE. This is primarily due to the addition of $\mathrm{CO}_{2}$ production in the SMR. In the conventional CTL process all of the excess $\mathrm{CO}_{2}$ in the gasification process can be recycled to extinction in the gasifier. The addition of the $\mathrm{CO}_{2}$ from the SMR exceeds the amount that can be recycled. Therefore, some of the captured $\mathrm{CO}_{2}$ in the CTL with SMR scenario must be sequestered, used for EOR, or emitted.

- The inputs and outputs for the conventional and the HTGR incorporated configurations are very similar; the HTGR incorporated configuration having $\sim 45 \%$ less $\mathrm{CO}_{2}$ generation 
INL/EXT-12-26710

November 2012
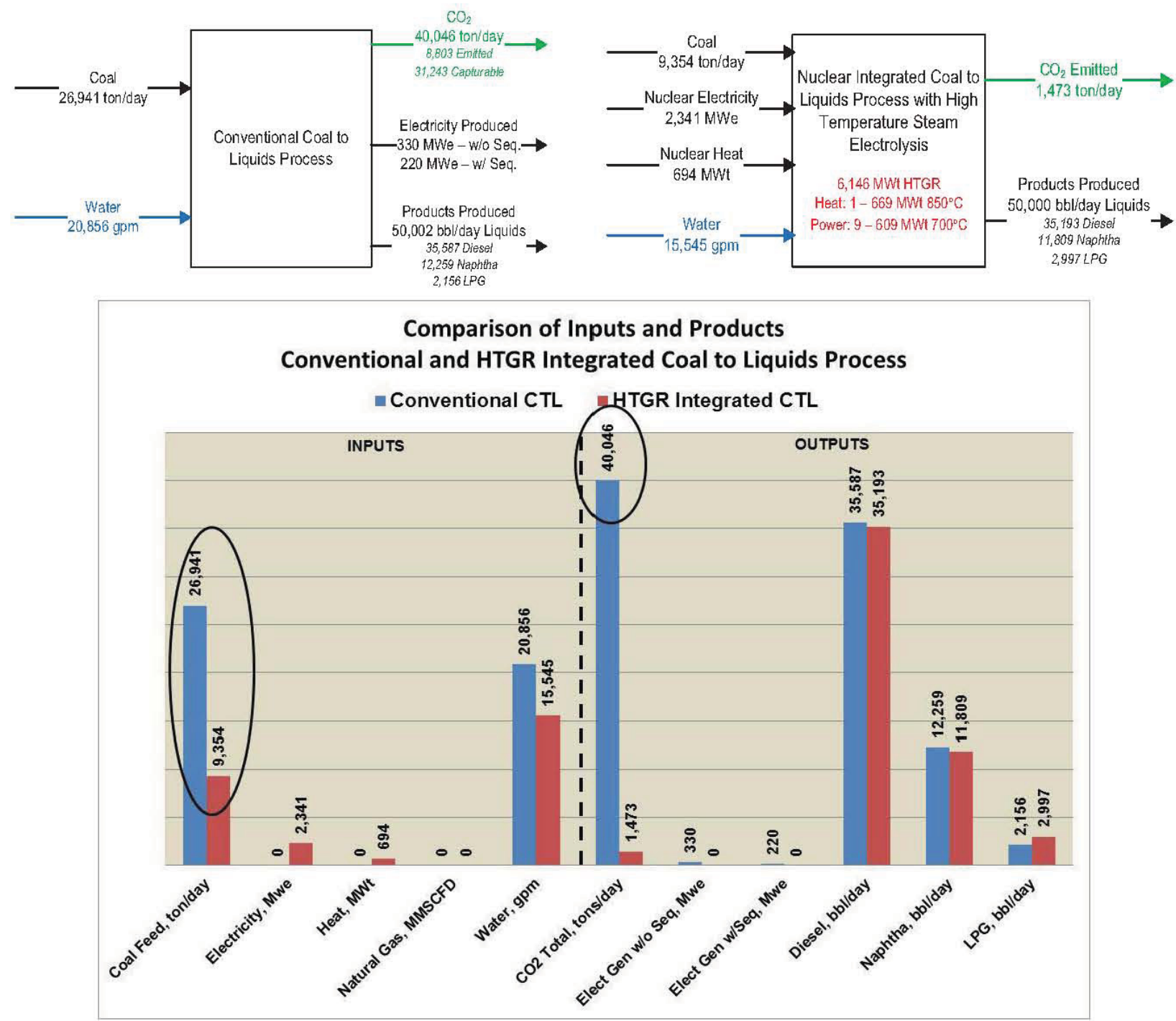

Figure D-22. CTL process with and without HTGR and HTSE.

\section{D-2.4.2 CTL with Steam Methane Reforming}


INL/EXT-12-26710

November 2012
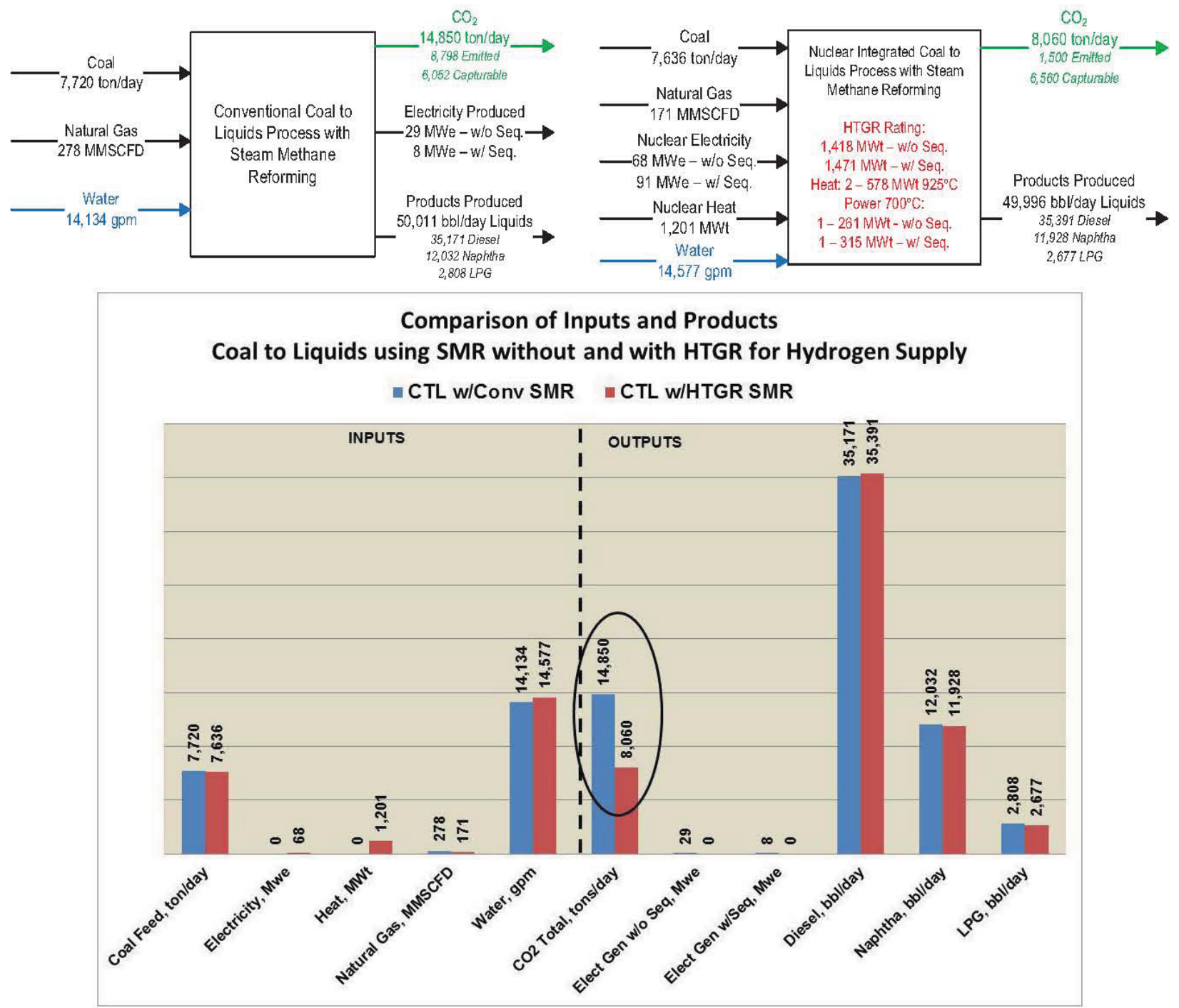

Figure D-23. CTL with SMR with and without HTGR.

\section{D-2.4.3 CTG using the MTG Process}

- Gasoline is the primary product ( $85 \%$ gasoline/15\% LPG); (e.g., when compared with CTL where the production is divided $71 \% / 24 \% / 5 \%$ Diesel/Naphtha/LPG.

- The integration of HTGR and HTSE into the process reduces the coal feed rate by $\sim 50 \%$ and $\mathrm{CO}_{2}$ generation by $>98 \%$.

The methanol process could be converted to chemical production (see Section on Coal to Chemicals, below), if the economics and the market justified this shift later in the life of the plant. 
INL/EXT-12-26710

November 2012
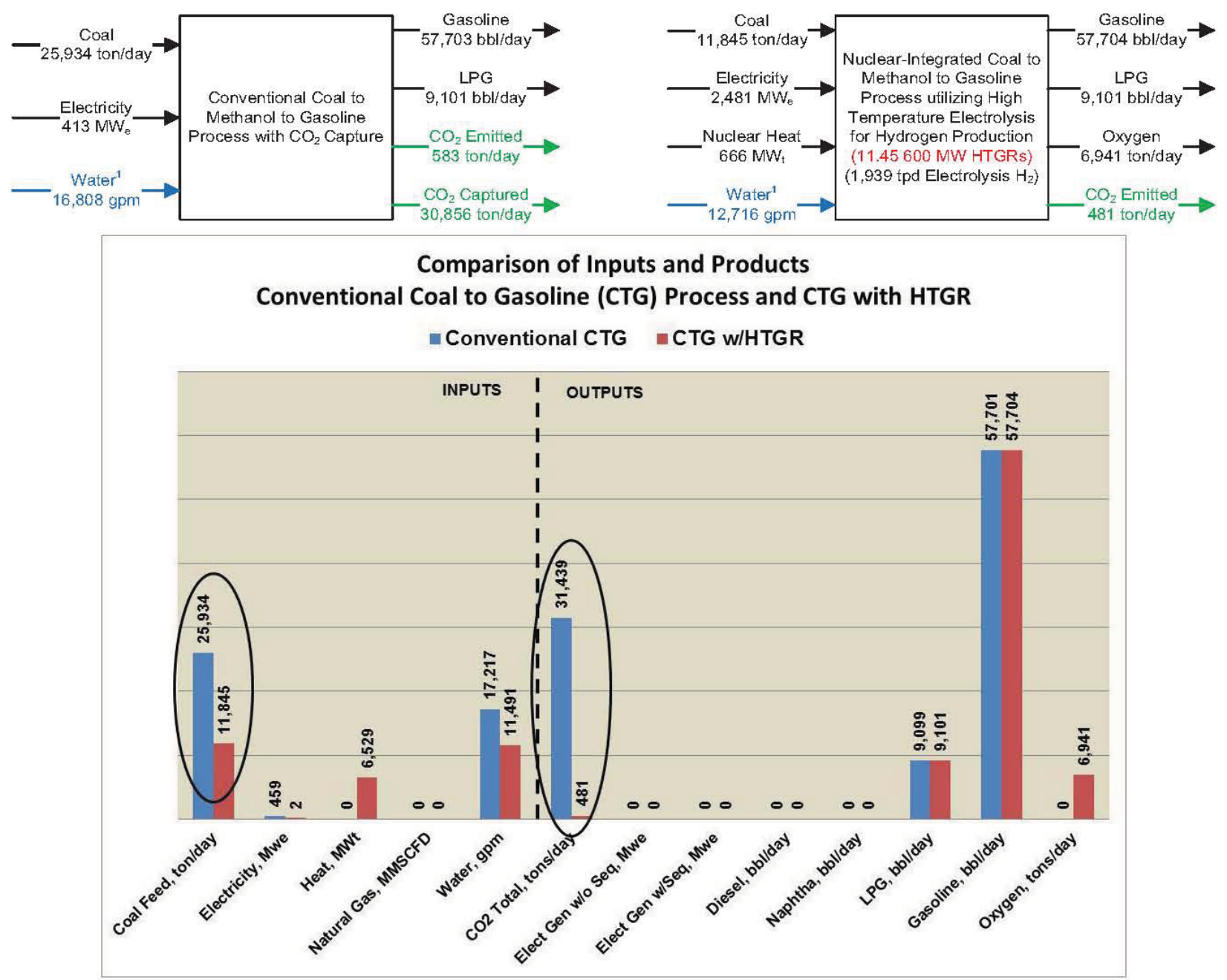

Figure D-24. CTG process with and without HTGR and HTSE. 
INL/EXT-12-26710

November 2012
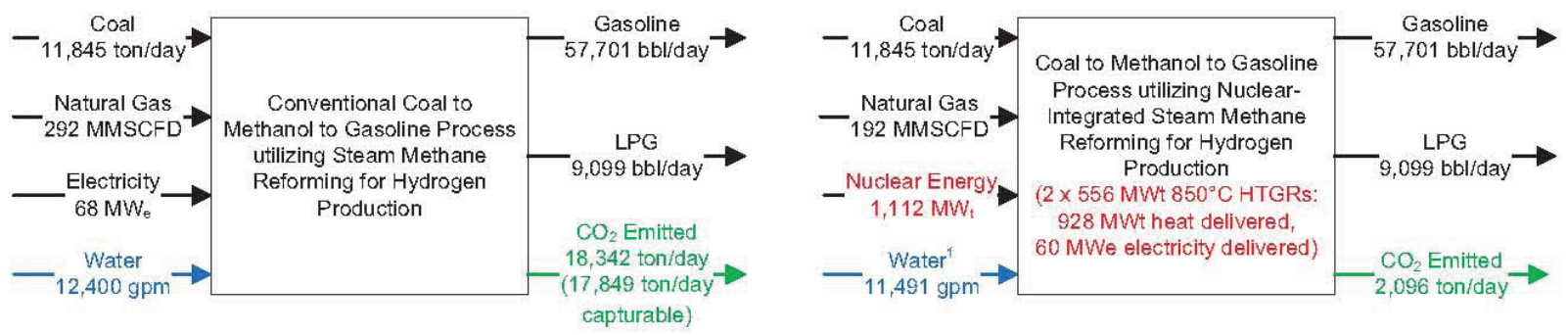

${ }^{1}$ Does not include heat rejection requirement for the nuclear or HTSE plants.

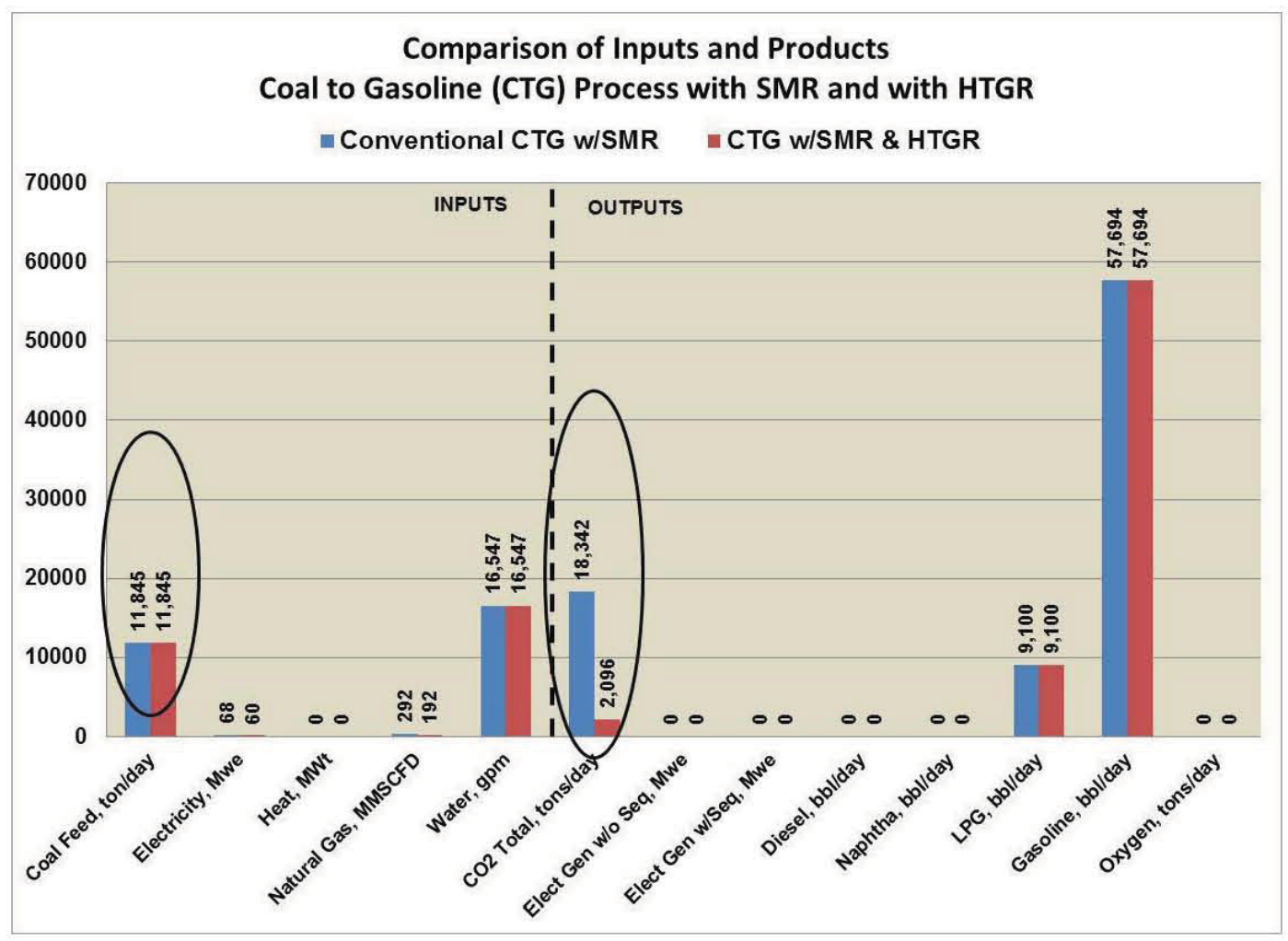

Figure D-25. CTG with SMR hydrogen supply and with HTGR heat. 


\section{D-2.4.4 Natural GTL}

There is little difference in the performance characteristics of this process without and with incorporation of HTGR heat except for a $\sim 50 \%$ reduction in $\mathrm{CO}_{2}$ generation.
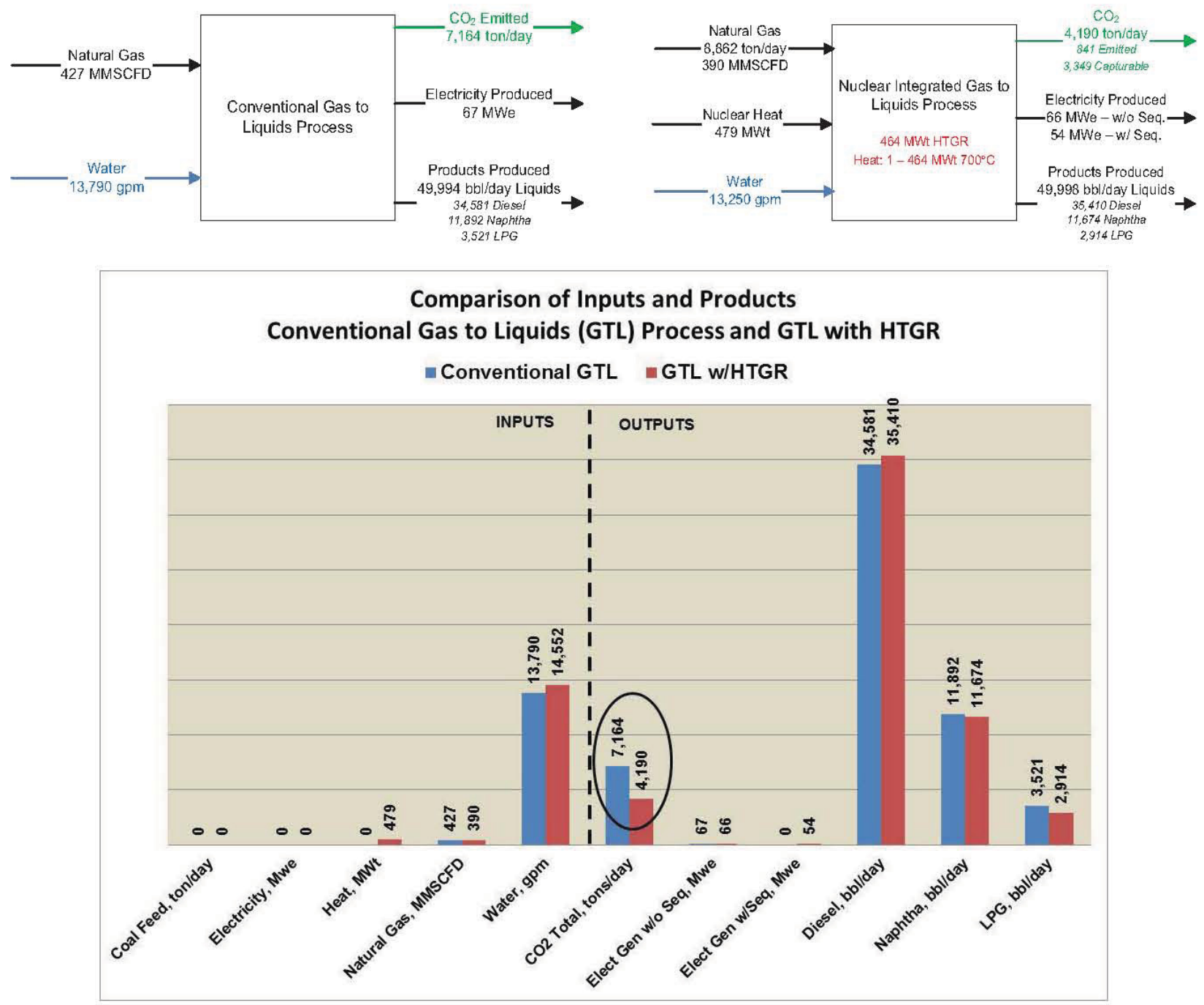

Figure D-26. Natural GTL with and without HTGR. 


\section{D-2.4.5 Natural GTL}

- There are at least two GTG plants currently in the planning and construction stages in the United States due to the current low prices of natural gas.

- This plant has low $\mathrm{CO}_{2}$ generation in the Conventional configuration but the incorporation of the HTGR heat reduces that generation by $\sim 70 \%$.

- A coal gasification unit could replace the natural gas reformers and the reformers could be converted to SMR hydrogen production with HTGR heat to convert the plant to a CTG plant if the economics make that attractive.
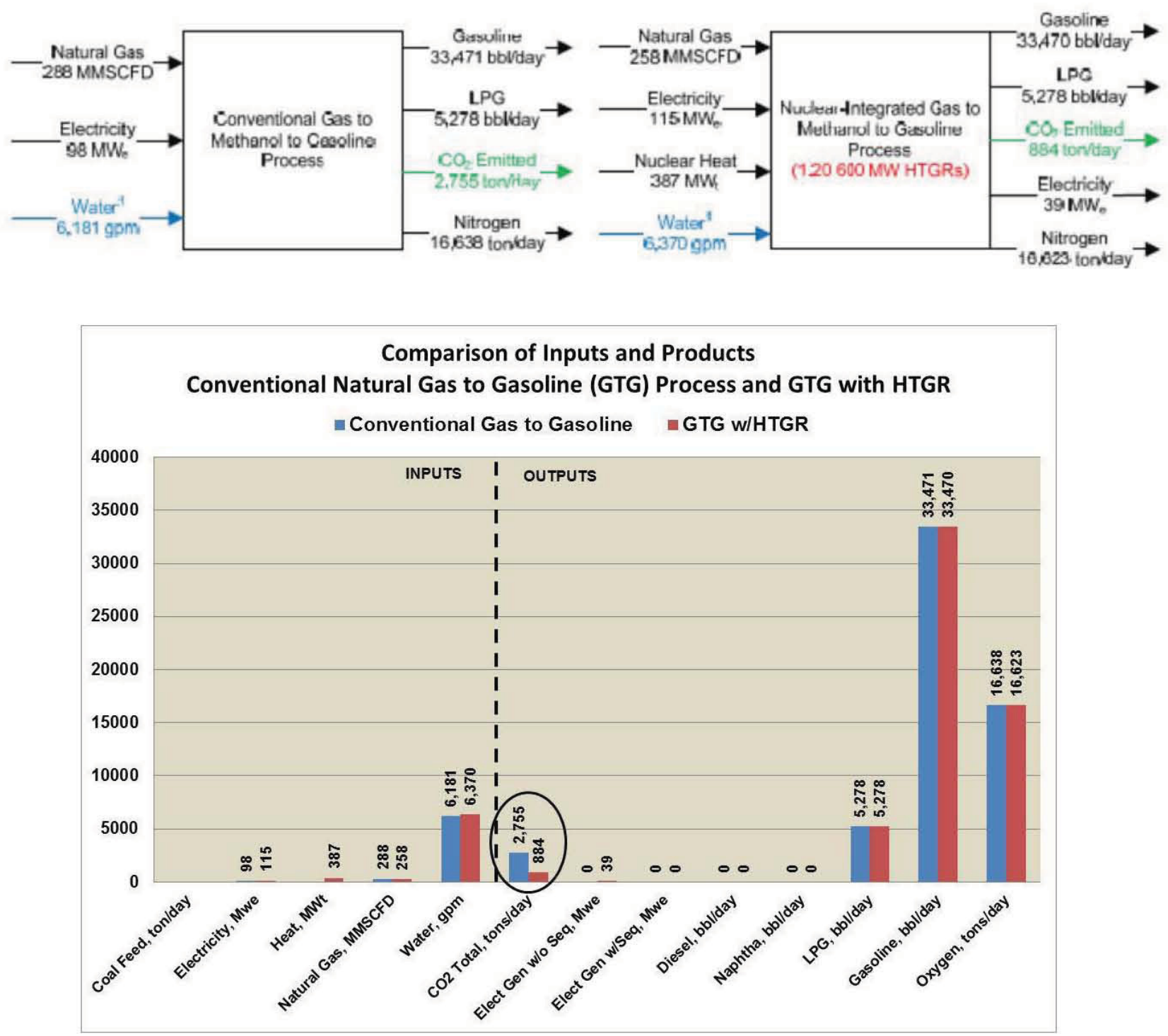

Figure D-27. GTG without and with incorporation of HTGR heat and electricity. 


\section{D-2.4.6 Coal to Chemicals}

- This process produces a large array of chemicals with good market potential.

- Integration of the HTGR technology in the process reduces the coal feed rate by $\sim 55 \%$ and the $\mathrm{CO}_{2}$ generation by $\sim 95 \%$.

- This process could evolve from an initial CTG plant using the MTG process, see discussion on the above CTG process.
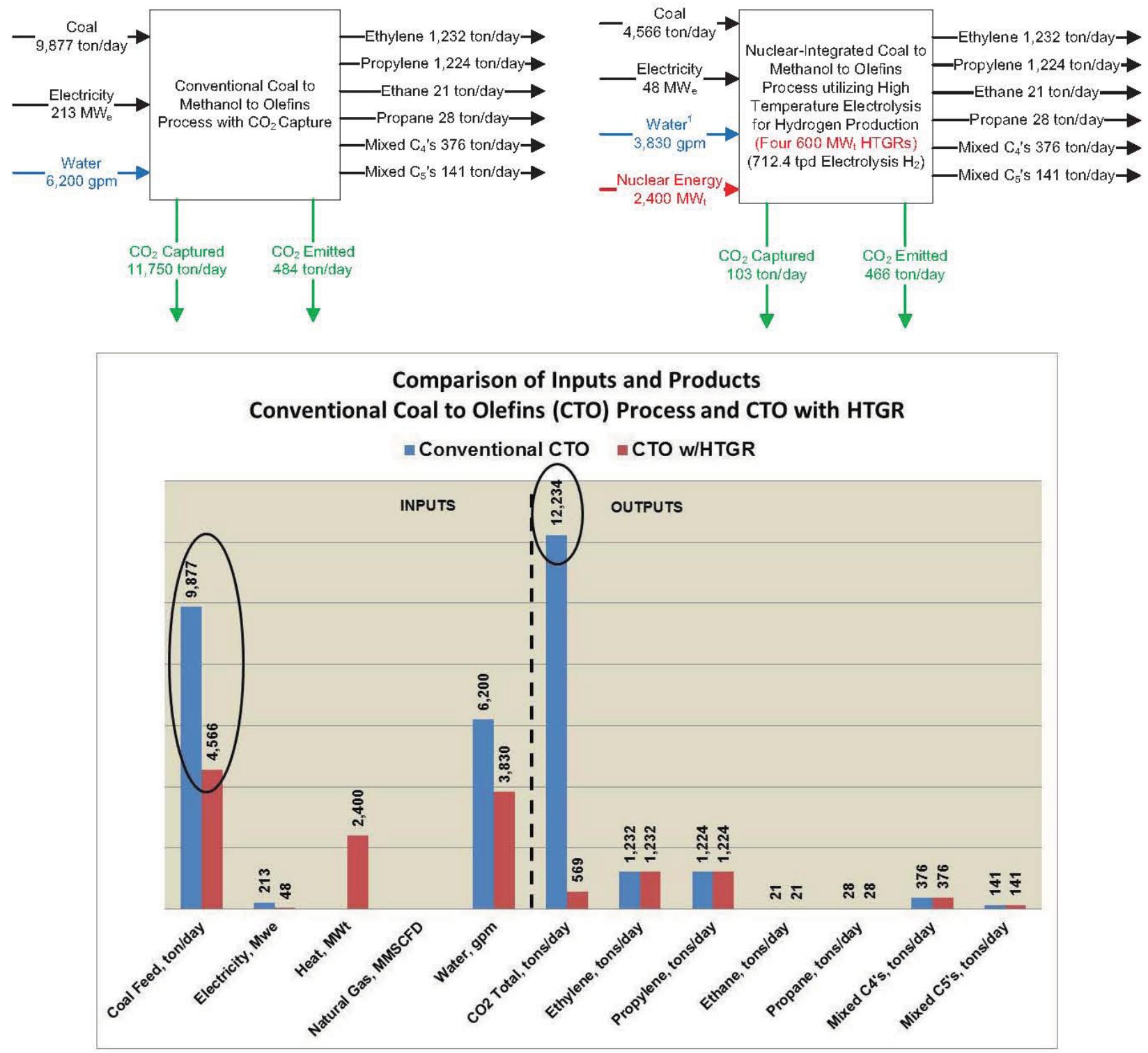

Figure D-28. CTO with and without HTGR.

\section{D-2.4.7 CTL Process with Naphtha Converted to Gasoline and Olefins}

- This is a complicated process generating a large number of products. It is a process that could evolve from an initial CTL plant if the relative prices of naphtha, gasoline and the olefins warranted adding the equipment. 
INL/EXT-12-26710

November 2012
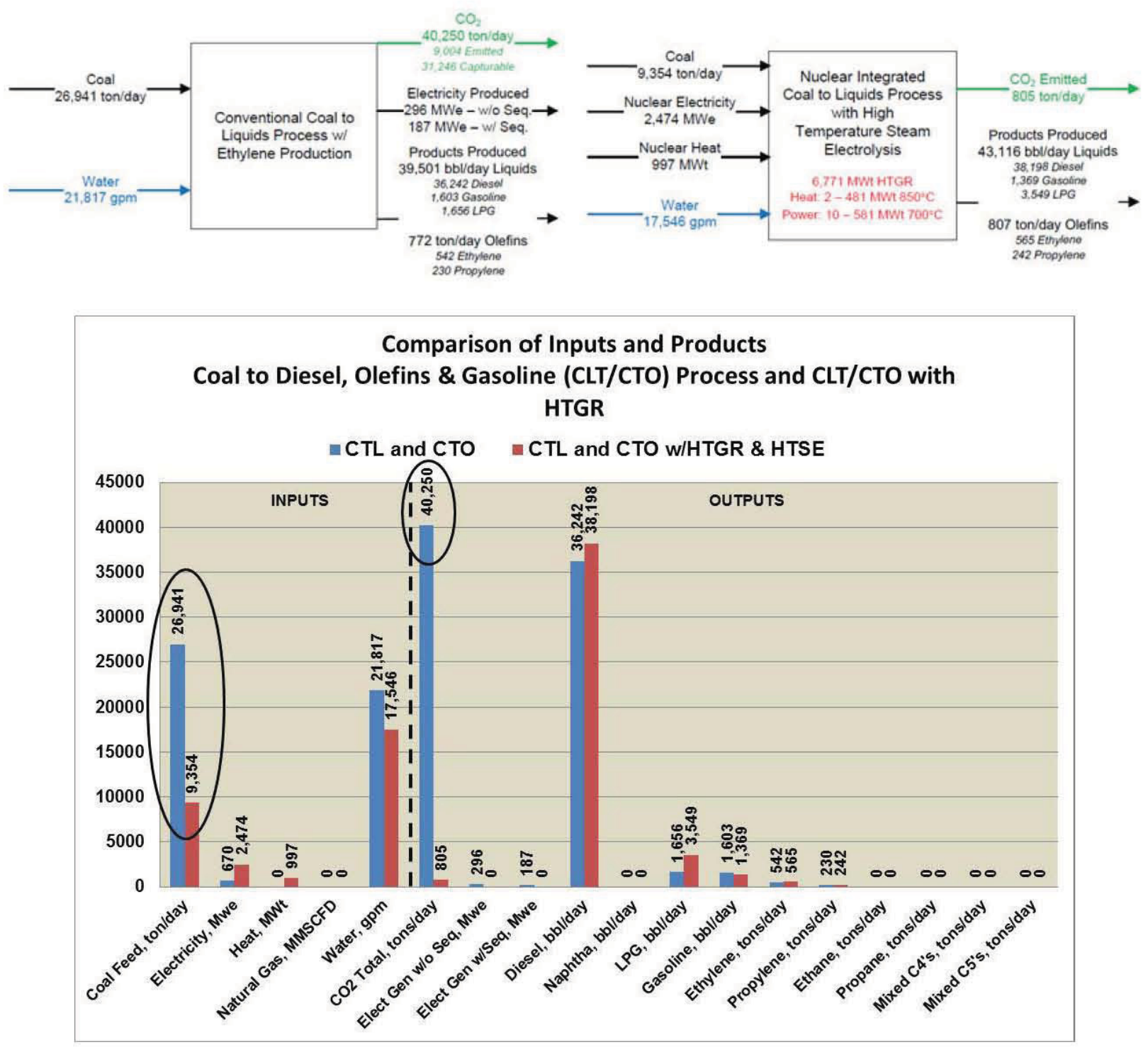

Figure D-29. Expansion of the CTL process to producing chemicals from naphtha. 


\section{D-2.5 Conclusions on the Performance Characteristics of the Alternatives}

The following conclusions are drawn from review of the data in these figures and the summary comparisons of the performance characteristics of the conventional and HTGR incorporated configurations.

1. The conventional processes utilize currently available equipment and facilities that could be deployed in a reasonable period of time - initial start of the Project to deploy a plant to initial start of plant operation in the 3 to 5 year time frame.

2. The conventional processes generate significant quantities of $\mathrm{CO}_{2}$. In most cases analyses have shown the feasibility of capturing a large percentage of that generated for sequestration or EOR. There is significant uncertainty, however, in the costs of capture and sequestration particularly at the scale required for large scale deployment of these technologies. The economic analyses conducted herein have assumed a cost of $\sim \$ 16 /$ ton of $\mathrm{CO}_{2}$ for transport and injection based on a recent Global Energy Technology Strategy Program (GTSP) report ${ }^{15}$. However, this cost is very location specific and much higher costs may arise. There is also uncertainty in the costs to cover the potential for leakage of the $\mathrm{CO}_{2}$ over the long term. The State of Wyoming, for example, has passed legislation identifying the owner of the sequestration facility as having that liability for 10 years past the date on which the last quantity of $\mathrm{CO}_{2}$ is injected into the storage facility. After that the State transfers the liability to the Federal Government.

3. There is a market for the $\mathrm{CO}_{2}$ for EOR throughout the United States based on Kentucky studies performed in the early $2000 \mathrm{~s}$ on the opportunities for $\mathrm{CO}_{2}$ Sequestration in KY identified potential sites for both EOR and sequestration ${ }^{16}$. The availability of EOR sites, however, is limited with capacity less than the current emission generation rates in the Commonwealth. Quoting the report:

4. "Enhanced recovery projects designed to maximize $\mathrm{CO}_{2}$ sequestration could use approximately $20 \%$ of the $\mathrm{CO}_{2}$ emitted in the state."

5. This conclusion is supported by the GTSP report that evaluated the broad applicability and long term viability of EOR as a repository for excess $\mathrm{CO}_{2}$ generation and concluded:

Although gigatons of low-cost $\mathrm{CO}_{2}$ storage opportunities may be associated with value-added reservoirs in North America alone 112 gigatons in depleted oil fields with EOR potential], the long-term challenge presented by the need to stabilize atmospheric concentrations of $\mathrm{CO}_{2}$ indicates that, because the storage capacity available in oil-and gas-bearing reservoirs is dwarfed by capacity in reservoirs that do not bear saleable products, over the long term, $\mathrm{CO}_{2}$ storage in valueadded reservoirs may not represent as significant a portion of total $\mathrm{CO}_{2}$ stored as is widely believed. Our research suggests that all classes of $\mathrm{CO}_{2}$ storage reservoirs are valuable and will be needed once CCS technologies begin their expected large-scale commercial deployment. ...

... there is likely some potential for very low and even negative cost (and therefore perhaps already profitable) CCS opportunities, but these opportunities represent only a small portion of the emissions mitigation potential to be exploited. Many are likely already being utilized by the marketplace, albeit often without application of MMV [Measurement, Monitoring and Verification] systems, which would be required to demonstrate the long-term retention of the injected $\mathrm{CO}_{2}$ if the primary purpose of these projects was climate protection... 
Significant deployment of these carbon conversion plants will be required to meet the objectives of $\mathrm{KY}$ in advancing alternative markets and increasing the value of indigenous coal and natural gas resources. EOR is, therefore, not a viable long term repository for $\mathrm{CO}_{2}$ generation from the conventional plants.

6. The Kentucky study of $\mathrm{CO}_{2}$ Sequestration Potential study also identified significant sequestration sites. One of these is as part of natural gas recovery from Devonian Black Shales ${ }^{17}$. Results of evaluation of this repository concluded:

- "Estimates using the distribution of gas storage capacity of $\mathrm{CO}_{2}$ from $\mathrm{TOC}$ data indicate a sequestration capacity of 6.8 billion tonnes in the five-county area of the Big Sandy Gas Field of eastern Kentucky.

- Assuming a thickness weighted average adsorption capacity of $40 \mathrm{scf} / \mathrm{ton}$ (at $400 \mathrm{psia}$ ), as much as 25 billion tonnes of $\mathrm{CO}_{2}$ could be sequestered in the deeper and thicker portions of the Devonian Shales in the Appalachian and Illinois Basins of Kentucky. "

7. This study also concluded:

"In the state's coal basins, there are an estimated 283 bcf of coalbed methane gas-in-place. For the shale and coals, using a recovery factor for natural gas of 17 percent, 5 tcf remain available for primary production and approximately 50 tcf available for enhanced recovery. $\mathrm{CO}_{2}$ sequestration in these reservoirs could result in an additional 30 bcf in annual production for natural gas in Kentucky and sequestration of 60 bcf $\mathrm{CO}_{2}$ annually. At this rate, in 10 years, as much as 31.8 million metric tons of $\mathrm{CO}_{2}$ could be sequestered."

8. The total potential capacity for sequestration in $\mathrm{KY}$ is, therefore, $\sim 32$ billion tonnes. Review of Figure D-7shows that those processes with large sequestration requirements, (those with high captureable rates; CTL, CTL w/SMR, CTG and CTO) the annual requirement ranges from $\sim 3$ to 10 million tonnes per year. In 2010 Kentucky $\mathrm{CO}_{2}$ emissions were $\sim 93$ million tonnes. Even if the majority of the current $\mathrm{CO}_{2}$ emissions were to be captured and sequestered there is still sufficient capacity to accommodate the captureable $\mathrm{CO}_{2}$ emissions from several carbon conversion plants with high $\mathrm{CO}_{2}$ generation rates.

9. Incorporation of the HTGR and HTSE technologies has the advantage of making significant reductions in the $\mathrm{CO}_{2}$ generation of the carbon conversion processes reducing the long term concern with disposition of the $\mathrm{CO}_{2}$. The HTGR energy also has a very stable price. The price of uranium has less than a $10 \%$ impact on the cost of energy production. This shelters the carbon conversion plant operating costs from the high variability of natural prices that have been experienced in the United States over the last few decades as shown in Figure D-30 


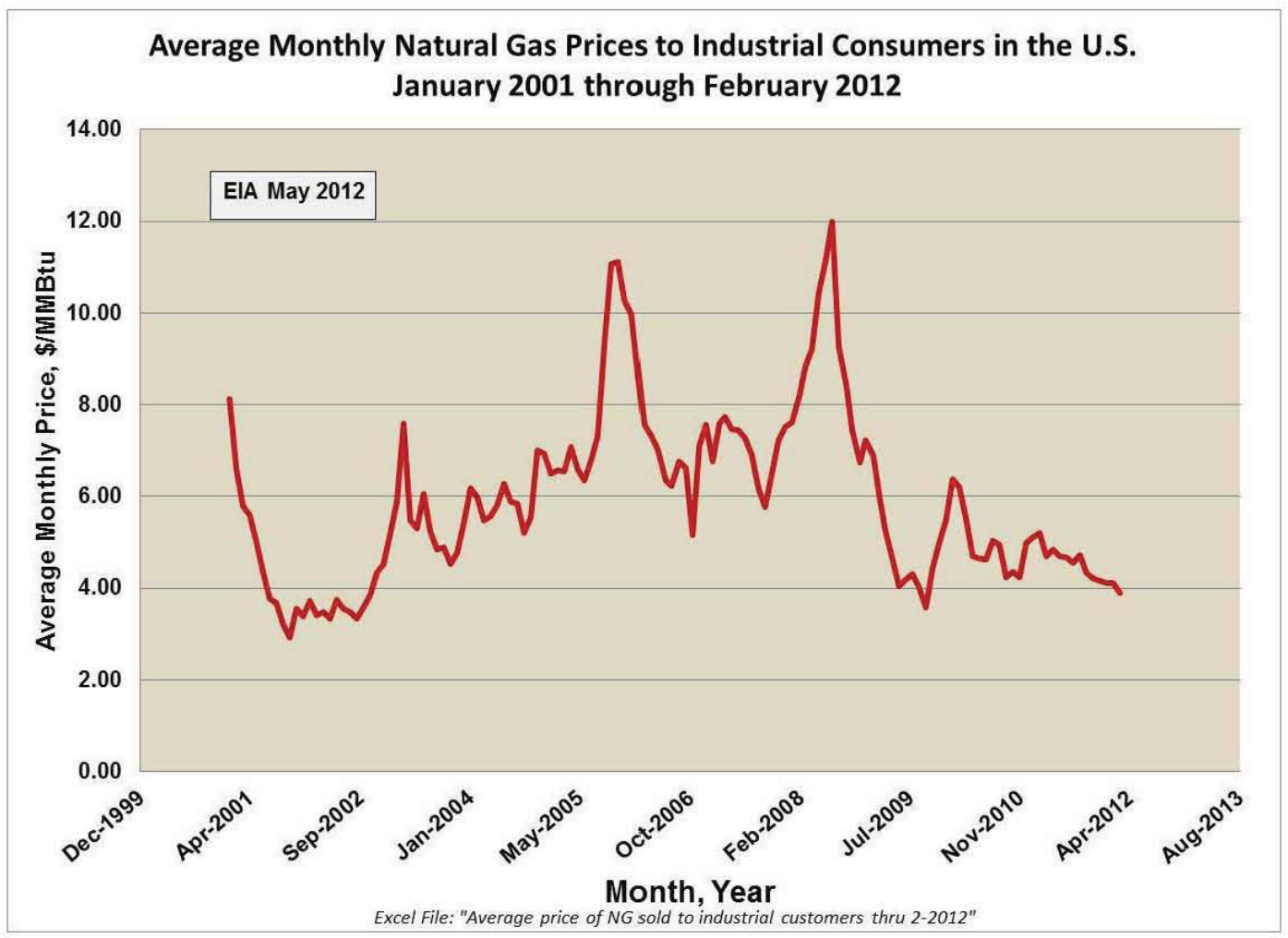

Figure D-30. History of natural gas prices to industrial consumers, January 2001 through February 2012.

10. Incorporation of the HTGR and/or HTSE technology into these processes requires completion of the development of these technologies and of the interfacing equipment, (e.g., the HTGR interface with the Steam Methane Reforming process for hydrogen production). This integration would take place in the longer term 15 to 20 years out. The strategy for deployment considers that the process selected for deployment in the shorter term (e.g., 2013-2028) can be re-configured over the longer term (2028 and beyond) to react to changes in the market or feedstock and to be compatible with incorporation of the HTGR and the HTSE technologies as they are proved technically and economically viable. ${ }^{\mathrm{g}}$

\section{D-2.6 References}

1 Air pollution: Companies, regulators struggle to understand EPA requirements on mines -07/31/2012 - www.eenews.net.

2 http://online.wsj.com/article/SB10001424052702304072004577323770856080102.html and http://www.sasol.com/sasol_internet/downloads/SASOL_GTL_Brochure_1332426778928.pdf and "North America's Syngas Boom”, Nitrogen \& Syngas, July-Aug 2012.

3 INL 2012, HTGR Integration - Coal and Gas to Liquids Production, TEV-672, Rev 3, April 27, 2012.

4 INL 2010, Nuclear-Integrated, Methanol-to Gasoline, Production Analysis, TEV-667, Rev 2, $05 / 15 / 2010$.

5 INL 2012, Nuclear Integrated Methanol to Olefins Production Analysis, TEV 1567, July 2012.

g Appendix F develops the deployment strategies considered in this evaluation more fully depicting potential deployment activities in the short term and long term periods. 
6 New Zealand Institute of Chemistry, 1996, "The Production of Methanol and Gasoline," http://nzic.org.nz/ChemProcesses/energy/7D.pdf, 2008, April 26, 2010.

7 Chinese MTG Plant -- www.worldfuels.com/wfExtract/exports/Content/33fead92---fc2d---447d--bc2e---3e95a8ff6e12.html.

8 DKRW Plant -- http://www.uwyo.edu/eori/ffiles/co2conference11/bob\%20$\% 20$ wyoming $\% 20$ eor $\% 20$ conference $\% 20$ medicine $\% 20$ bow $\% 20$ update $\% 207.13 .2011 \% 20 \mathrm{v} \% 201.0 . p$ df, The permit application is here: http://deq.state.wy.us/out/downloads/MBFP_ISA_Permit_Application_09-17-07_Final.pdf.

9 TransGas Plant -- http://www.uhde.eu/press/press-releases/singleview/archive/2011/may/09/article/transgas-coal-to-gasoline-complex-begins-construction.html.

10 Secure Energy Paducah Gasification Plant, Commonwealth of Kentucky, Division for Air Quality, PERMIT APPLICATION SUMMARY FORM, Completed by: Philip T. Jarboe, P.E., 4/14/2011.

11 Chisolm Energy, LLC, Commonwealth of Kentucky, Division for Air Quality, PERMIT APPLICATION SUMMARY FORM, Completed by: Andrew True, 4/20/2011.

12 Buffalo Creek Energy, LLC, Commonwealth of Kentucky, Division for Air Quality, PERMIT APPLICATION SUMMARY FORM, Completed by: Andrew True, P.E., 4/21/2011.

13 China Coal to Chemicals Plant http://chinaplas.info/archives/1960.html; http://www.platts.com/RSSFeedDetailedNews/RSSFeed/Petrochemicals/7937988; http://honeywell.com/News/Pages/Honeywell-UOP\%E2\%80\%99s-Advanced-Methanol-To-OlefinsTechnology-Selected-In-China-To-Produce-Chemical-Products.aspx.

14 INL 2010, Nuclear Integrated Natural Gas to Gasoline Production Analysis, TEV-xxx, yyy.

15 JJ Dooley (Lead Author), RT Dahowski, CL Davidson, MA Wise, N Gupta, SH Kim, EL Malone, "Carbon Dioxide Capture and Geologic Storage, A Core Element of a Global Energy Technology Strategy to Address Climate Change", A Technology Report from the Second Phase of the Global Energy Technology Strategy Program, April 2006.

16 Brandon Nuttall, "CO2 Sequestration Opportunities in Kentucky", supported by U.S. Department of Energy, National Energy Technology Lab Carbon Sequestration Program and the Kentucky Office of Energy Policy.

17 Brandon Nuttall, Jim Drahovzal, Cortland Eble, R. Marc Bustin, "Analysis of the Devonian Black Shale in Kentucky for Potential Carbon Dioxide Sequestration and Enhanced Natural Gas Production", this project was funded by the National Energy Technology Laboratory of the U.S. Department of Energy, contract: DE-FC26-02NT41442. 


\section{Appendix E}

\section{Economic Analyses}




\section{Appendix E Economic Analyses}

\section{E-1. DESCRIPTION OF THE ECONOMIC MODEL}

\section{E-1.1 Methods}

The INL NGNP Project has developed a detailed discounted cash flow economics model for the purposes of analyzing the economic viability of applying the HTGR technology as a high temperature energy supply in industrial applications including the generation of electricity. ${ }^{3}$ The technical evaluation reports listed in Appendix D summarize the results of applying this model to compare the economics of the HTGR incorporated processes with the conventional processes considered herein. In this regard, the metrics used for these comparisons are the costs of the products of each process that are calculated to achieve a required return on investment. The economic model includes correlations on the overnight direct and indirect costs, including owners cost and contingency, for industrial, HTGR, power conversion and HTSE plants versus the size and operating characteristics of these plants, (e.g., as a function of the process and the production rate for a CTL plant, the operating temperature and electricity and steam generation rate for an HTGR plant with, for example, a sub-critical Rankine cycle power conversion system, the hydrogen production rate for an HTSE plant). Typical construction periods and spending profiles are applied for calculation of interest during construction and the debt ratio is applied to allocate the cash flow during construction between debt and equity. Phased construction and start of operation for modular expansion of plants can be accommodated in developing the annual cash flows, for example, when parts of the plant are operating and generating revenue while other parts are still under construction. The model will account for the effects on capacity factor of the plant due to planned and unplanned shutdowns, (e.g., turnarounds in a petro-chemical plant, refueling of a nuclear plant).

There are several options for the calculations performed in the model. An internal rate of return for the project ${ }^{\mathrm{h}}$ can be calculated for a given set of product prices or an iteration can be performed on the products pricing to achieve a given internal rate of return. In the case where an HTGR plant is incorporated with the process, the calculation of return can be made for the industrial and HTGR plants separately or as an integrated entity. This permits evaluating conditions where there are separate owners of the plants and different financial parameters are used for each plant.

\section{E-1.2 Financial Parameters}

The financial parameters used by the model include the following. The values shown are those used for the evaluations described herein:

The analyses discussed herein were all performed for the set of financial parameters listed above to support comparison of the economics of each process. These parameters were recommended by the NGNP Industry Alliance, Ltd for evaluation of nth-of-a-kind HTGR applications. It should be noted that the economic analyses reported in the INL technical reports listed in Appendix D were performed for different financial parameters than those listed so the results in those reports are slightly different than those reported herein.

h In this context "project" refers to the full scope of the plant design, procurement and construction, financing, operation and, where applicable, decommissioning and disassembly. 
Table E-1. Summary of financial parameters.

\begin{tabular}{|ll|}
\hline \multicolumn{1}{|c|}{ Item } & Value \\
\hline Debt to Equity Ratio & $80 \%$ \\
\hline Interest During Construction & $8 \%$ \\
\hline Financing Interest & $8 \%$ \\
\hline Financing Term & 20 years \\
\hline Required Internal Rate of Return & $10 \%$ \\
\hline Effective Tax Rate & $38.9 \%$ \\
\hline Depreciation Rate & MACRS, 15 years \\
\hline
\end{tabular}

\section{E-1.3 Costs for $\mathrm{CO}_{2}$ and its Disposition}

The model also has provision to account for any operating costs associated with the production of $\mathrm{CO}_{2}$ from the processes. These costs could arise from taxes on emissions of $\mathrm{CO}_{2}$ to the environment or for capture of $\mathrm{CO}_{2}$ for sequestration or EOR. In the latter case if capture of $\mathrm{CO}_{2}$ is included in the plant, costs for the equipment necessary for capture are included in the overnight costs of the plant and the costs for the electricity required to operate that equipment is included in the operating costs of the plant. The costs for transport and injection of the $\mathrm{CO}_{2}$ are also included in the operating costs. If it is assumed that there is a cost associated with emissions of $\mathrm{CO}_{2}$ these costs are also included in the operating costs.

There is considerable uncertainty in what the costs of emissions and sequestration may be. Accordingly, analyses were performed with and without these costs. In the case where analyses were performed including costs for $\mathrm{CO}_{2}$, as shown in the other sections of this report, the $\mathrm{CO}_{2}$ was sub-divided into a fraction that could be captured and transported for sequestration or EOR and the balance that could not be captured and would be emitted to the environment. The costs for transport and sequestration were obtained from a GTSP study ${ }^{2}$. The costs for emission were varied over a wide range, (e.g., $\$ 0 /$ ton to $\$ 200 /$ ton ) to determine its impact on the required product pricing. Sensitivity analyses were also performed to determine the effect of applying capture and sequestration (CCS) and not applying CCS with variations in the cost of the additional emissions. The results of these sensitivity analyses are discussed below.

\section{E-1.4 Sensitivity Analyses}

The model has provisions for performing analyses to establish the sensitivity of results to variations in inputs, such as the costs of $\mathrm{CO}_{2}, \mathrm{CCS}$ and emissions, capital cost, debt ratio, internal rate of return, etc. The results of these analyses are presented in tornado charts. Examples of these charts are shown below for the carbon conversion alternatives. It is also possible to perform Monte Carlo analyses for the same variations in input values to develop a probability distribution for the product pricing that represents the composite effect of these variations. A typical chart is shown below for the CTL process with SMR.

\section{E-2. Results of Economic Analyses}

\section{E-2.1.1 Short and Long Term Deployment Time Frames}

The potential for deployment of carbon conversion technologies has been evaluated over short term and long term time frames. The short term covers the period 2013 through 2029; the longer term 2029 and beyond. The carbon conversion technologies considered for deployment in the short term are designated as "Conventional" and, in general, are non-developmental with current and historical operating 
experience. The incorporation of the HTGR and HTSE technologies would be over the longer term subject to demonstration of their technical and economic viability.

\section{E-2.1.2 Carbon to Transportation Fuel Conversions}

Figure E-1 shows the results of evaluating the economics of the Conventional carbon conversion processes for the production of diesel fuel. Since the majority of diesel fuel is produced by refining crude oil and the price of refined diesel oil is a strong function of the price of crude oil, the economic viability of the carbon conversion processes is estimated by comparing the production cost of diesel produced using these processes against that refined from crude oil as a function of the price of crude oil. The correlation of the price of refined diesel with the price of crude oil shown in Figure E-1 was developed using historical data supplied by the DOE Energy Information Agency. ${ }^{1}$ Also shown on this figure is the range of Energy Information Administration (EIA) projections on the price of crude oil through $2035 .{ }^{14}$ Figure E-2 shows these projections and their wide range of uncertainty.

Figure E-1 shows the projected production costs and the equivalent cost per barrel of crude oil for refined diesel for the conventional coal and natural gas to diesel processes and for those processes integrated with HTGR and HTSE technologies. The HTGR and HTSE technologies are shown for several different configurations:

- The HTGR supplying heat and electricity to the SMR process producing hydrogen to be used in coal gasification to achieve the required $\mathrm{H}_{2}$ to $\mathrm{CO}$ ratio in the synthesis gas (CTL with SMR and HTGR).

- The HTGR supplying heat to the primary natural gas reformer as a substitute for burning the natural gas in that stage of reforming (GTL w/HTGR)

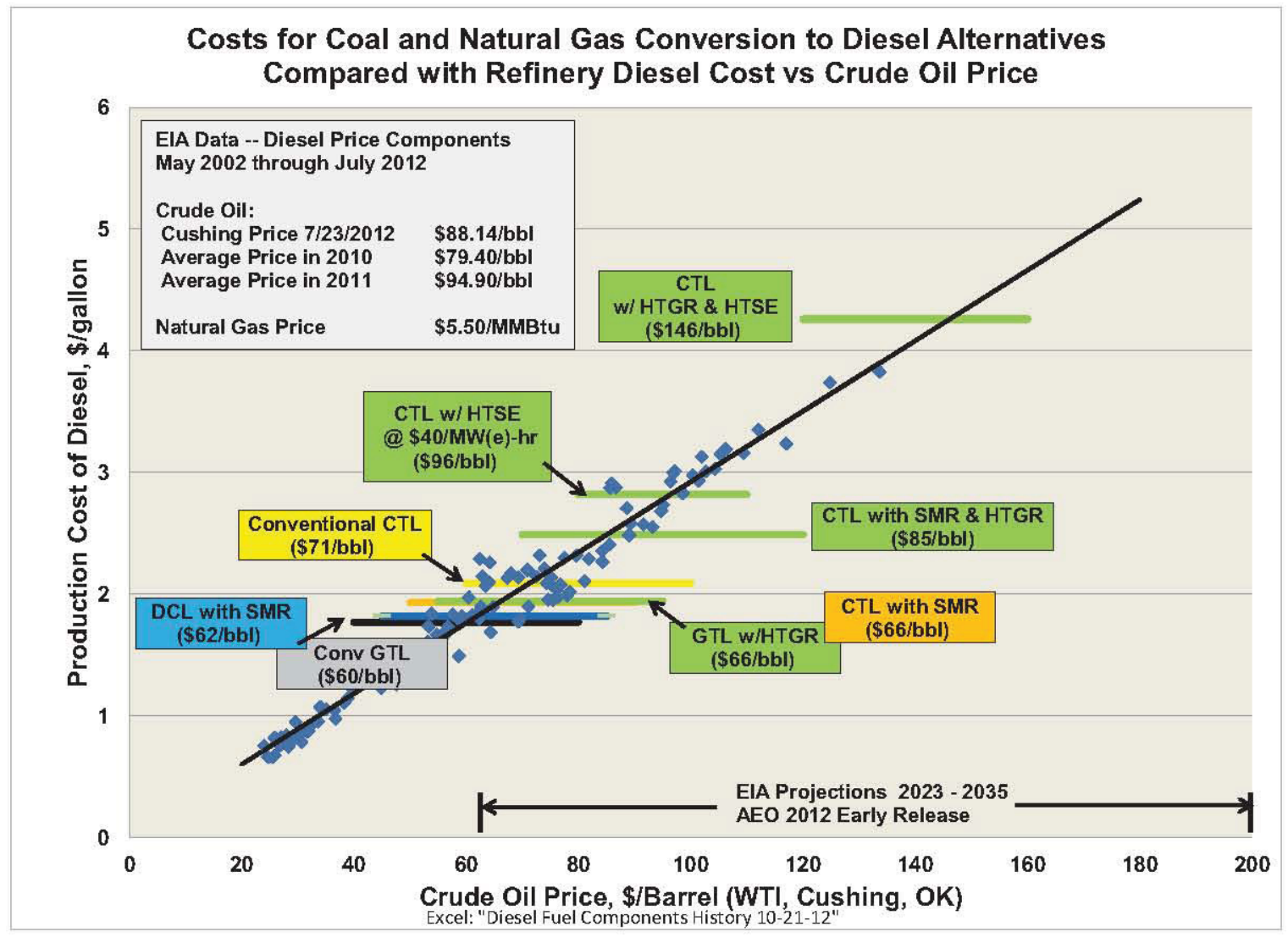

Figure E-1. Comparison of the production costs of conventional carbon conversion processes with the production cost of diesel refined from crude oil vs. the price of crude oil. 


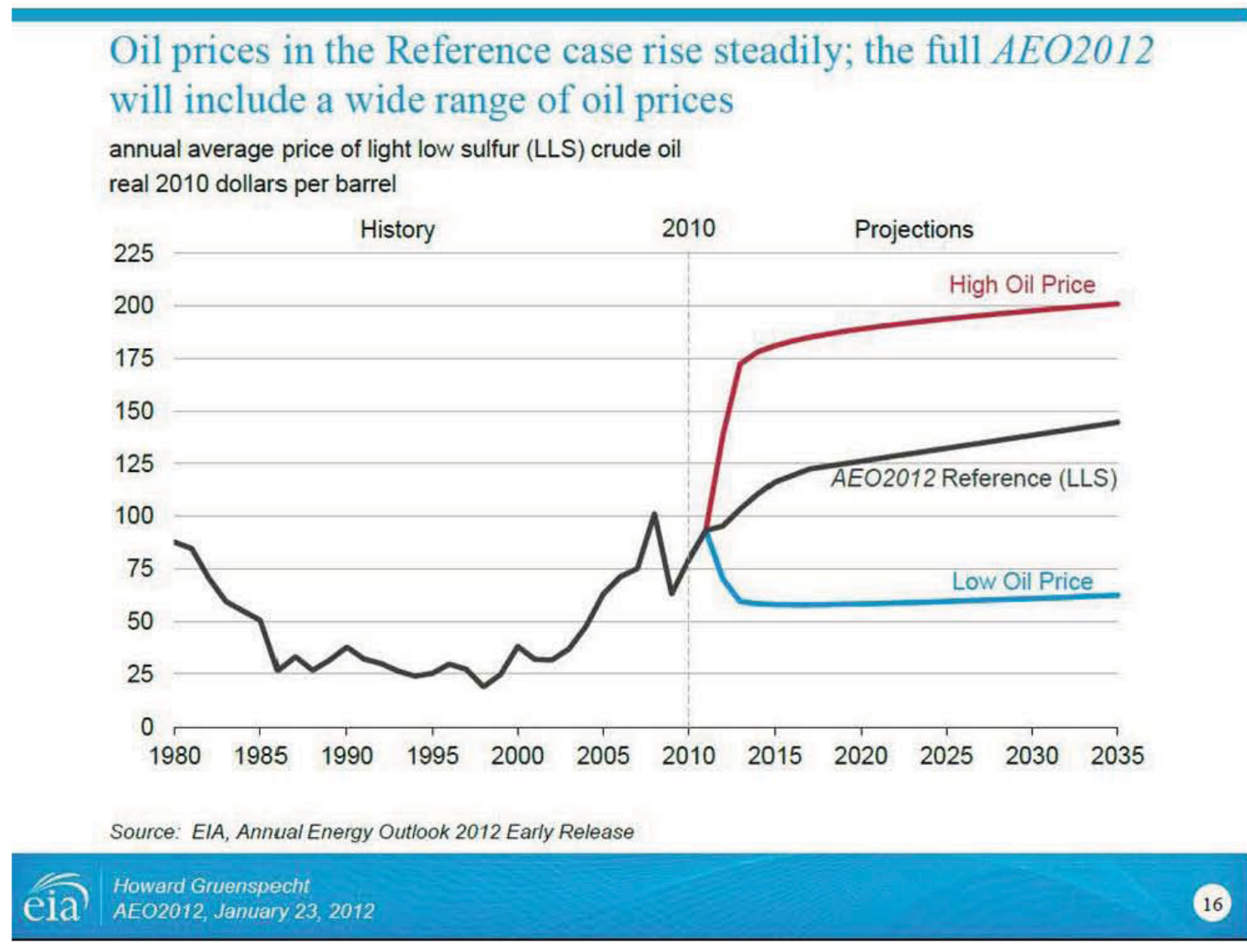

Figure E-2. ElA projections of the potential range of crude oil prices from the present through 2035.

- The HTGR supplying electricity to HTSE supplying hydrogen to the gasification process instead of the SMR (CTL w/HTGR and HTSE)

- HTSE supplying hydrogen to the coal gasification process and obtaining electricity for a source other than an HTGR (CTLw/HTSE@\$40/Mw(e)-hr)

As shown all of the processes except the CTL w/HTGR and HTSE have production costs that are grouped in the lower half of the projections of crude oil prices; $\$ 60$ to $\$ 96 / \mathrm{bbl}$. However, the production costs for the CTL w/HTGR and HTSE is still within the upper range of the EIA projections

Figure E-3 is a similar figure showing the results of evaluating the coal and natural gas to gasoline (GTG) MTG processes with the correlation of gasoline price with crude oil price. As cited for the correlation of diesel production cost versus crude oil price, this correlation was also developed from EIA data. The same variations in the use of the HTGR and HTSE technologies are shown in this figure. All but the CTG w/HTGR and HTSE processes have equivalent costs of crude oil grouped in the lower half of the EIA long term price projections; $\$ 56$ to $\$ 96 / \mathrm{bbl}$ ). Again the CTG w/HTGR and HTSE production costs are in the range of refined diesel production costs for EIA projections of crude oil prices.

As shown in these figures the production costs estimated for the conventional carbon conversion processes are competitive with the production cost of diesel and gasoline refined from crude oil for the lower half of the EIA projections for the price of crude oil from the present through 2035 ( $\$ 60$ to $\$ 145 / \mathrm{bbl})$. 


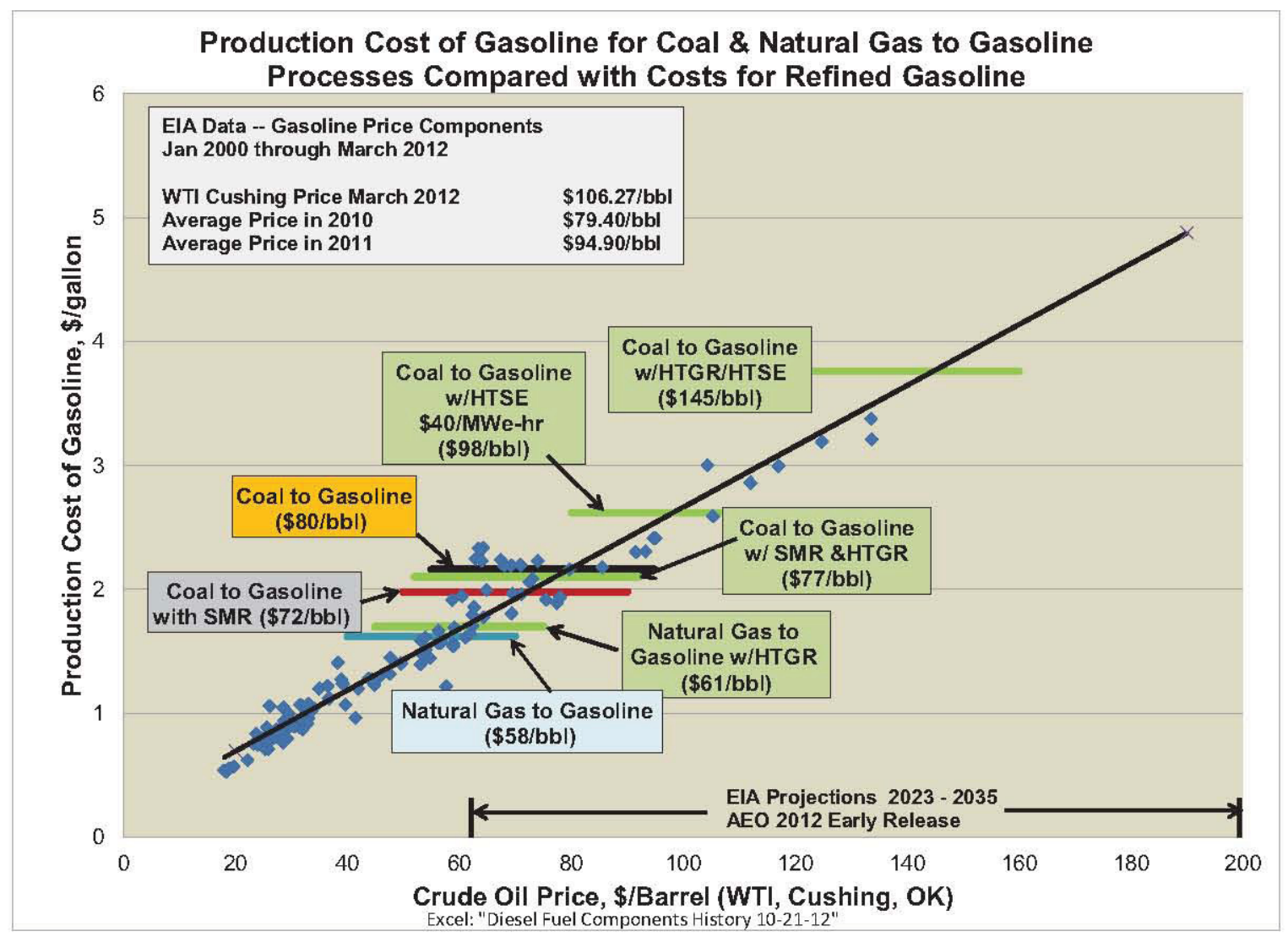

Figure E-3. Production costs of conventional and nuclear incorporated coal and natural GTG processes compared with the production cost of gasoline refined from crude oil vs. the price of crude oil.

Figure E-4 consolidates the results of the economic evaluations of all of the carbon conversion processes comparing the production costs of the conventional with the HTGR/HTSE incorporated cases and the costs of $\mathrm{CO}_{2}$ emissions that would be required to raise the conventional process costs equal to the nuclear incorporated process; a range of $\$ 17 /$ ton to $\$ 170 /$ ton. As shown, all of the candidate processes except for those incorporating the HTGR and HTSE technologies have production costs lower than the production costs of diesel and gasoline at $\$ 100$ /crude oil price.

The $\mathrm{CO}_{2}$ cost required to bring the production costs for the conventional processes in line with those for the nuclear incorporated case as shown in Figure E-5 vary considerably for several reasons. In those cases where the conventional process generates large quantities of $\mathrm{CO}_{2}$ (e.g., CTL) the effect of $\mathrm{CO}_{2}$ costs on production costs are higher than for those processes where the generation of $\mathrm{CO}_{2}$ is lower (e.g., CTL w/SMR, GTL and MTG). Secondly, for those cases using HTSE the cost of hydrogen produced by HTSE is a strong function of the cost of electricity as shown in Figure E-4 and Figure E-5. The economic evaluations performed for the case where the HTGR supplies electricity to the HTSE process, (red bars in Figure E-4) used a conservative model of the HTGR with an equivalent electricity cost of $\sim \$ 80 / \mathrm{MW}(\mathrm{e})$-hr and an equivalent hydrogen production cost $\sim \$ 3 / \mathrm{kg}$. For an electricity cost in the $\$ 40 \mathrm{MW}(\mathrm{e})$ - $\mathrm{hr}$ range which is typical of the cost to industrial users in Wyoming the equivalent hydrogen production cost would be $\sim \$ 1.6 / \mathrm{kg}$. For comparison the production cost of hydrogen using SMR with a natural gas price of $\$ 6.50 / \mathrm{MSCF}$ is $\sim \$ 1.9 / \mathrm{kg}$. As shown in Figure E-4 (orange bars) for the case where the cost of electricity is in this range the production costs using HTSE only are more competitive with the other processes. This issue is discussed further in the conclusions below. 


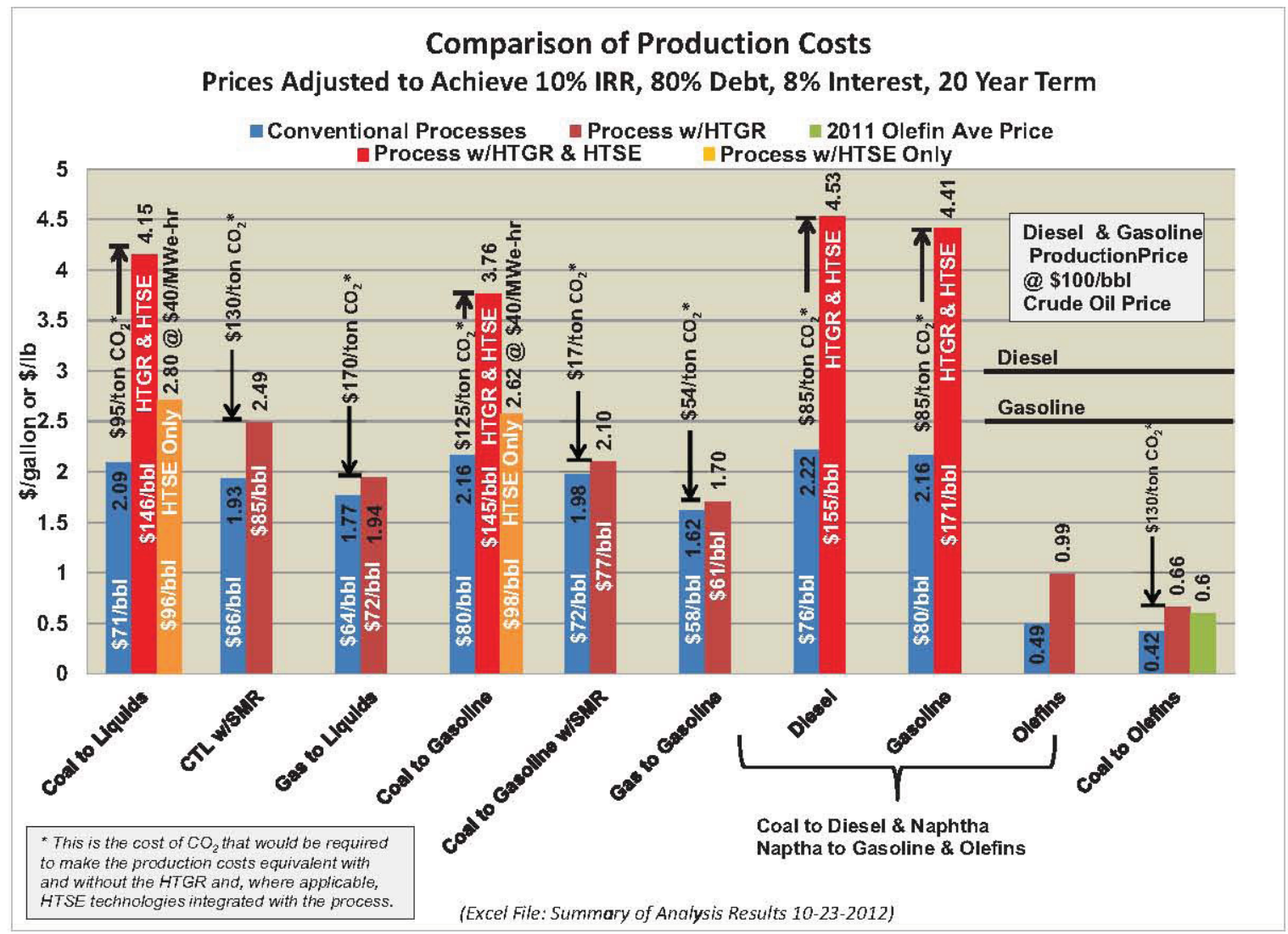

Figure E-4. Comparison of production costs for alternative carbon conversion processes.

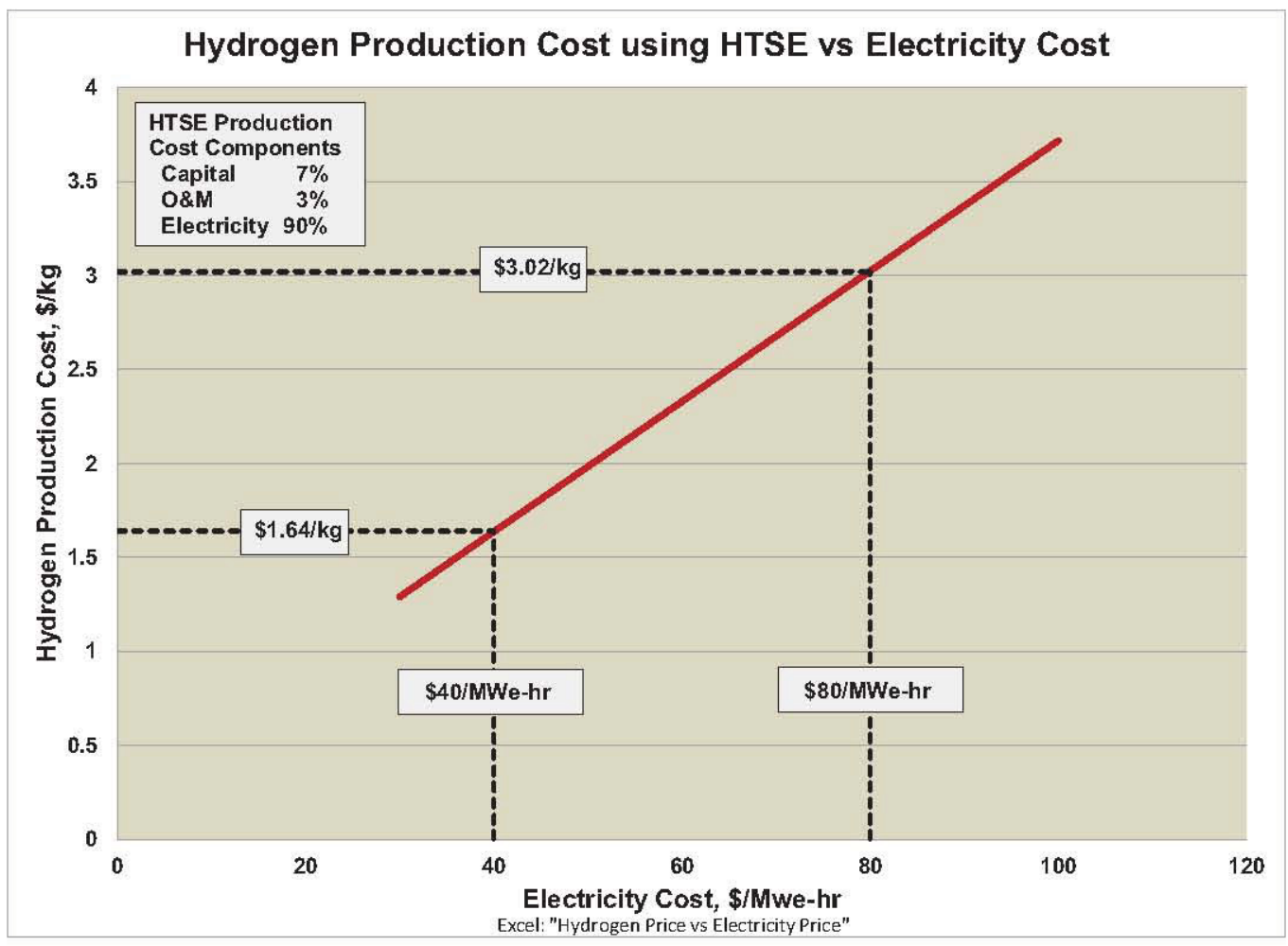

Figure E-5. HTSE hydrogen production cost versus cost of electricity. 


\section{E-2.2 Carbon to Chemicals Conversion}

The comparison of the costs for chemical production using the Conventional and nuclear incorporated processes is also shown on Figure E-4 along with the current price of Ethylene. For the purposes of the discussion Ethylene is used as representative of the full range of chemicals produced in these processes. As shown, the current price of Ethylene lies about half way between the costs estimated for the Conventional and nuclear incorporated cases.

\section{E-2.3 Projections on Natural Gas Long Term Prices}

Since most chemical production in the United States uses natural gas as the feedstock, the price of Ethylene shown in Figure E-4 reflects the current low price for natural gas. There are, however, several factors that may result in an increase in natural gas prices over the next two decades. Figure E-6 summarizes the effect of these factors. The curve extending from 2010 to 2035 and bracketed by the dotted lines reflects estimates by the EIA in the initial release of the 2012 Annual Energy Outlook (AEO) on the potential increase in natural gas prices over this time frame and the uncertainty in those prices at that time ( $2011 \$)$. The range of potential prices in 2035 projected by ELA ( $\$ 5.35$ to $\$ 9.26 / \mathrm{MMBtu})$ is based on their assessment of the uncertainty in the quantities of gas shale reserves and the large variation in the economics of extracting gas from the shale in the several locations currently being produced.

There are other factors, however, that can affect this uncertainty range and were not considered in this EIA assessment. Examples of the multiple articles and studies assessing the effects of these factors are provided in References 5 through 9.

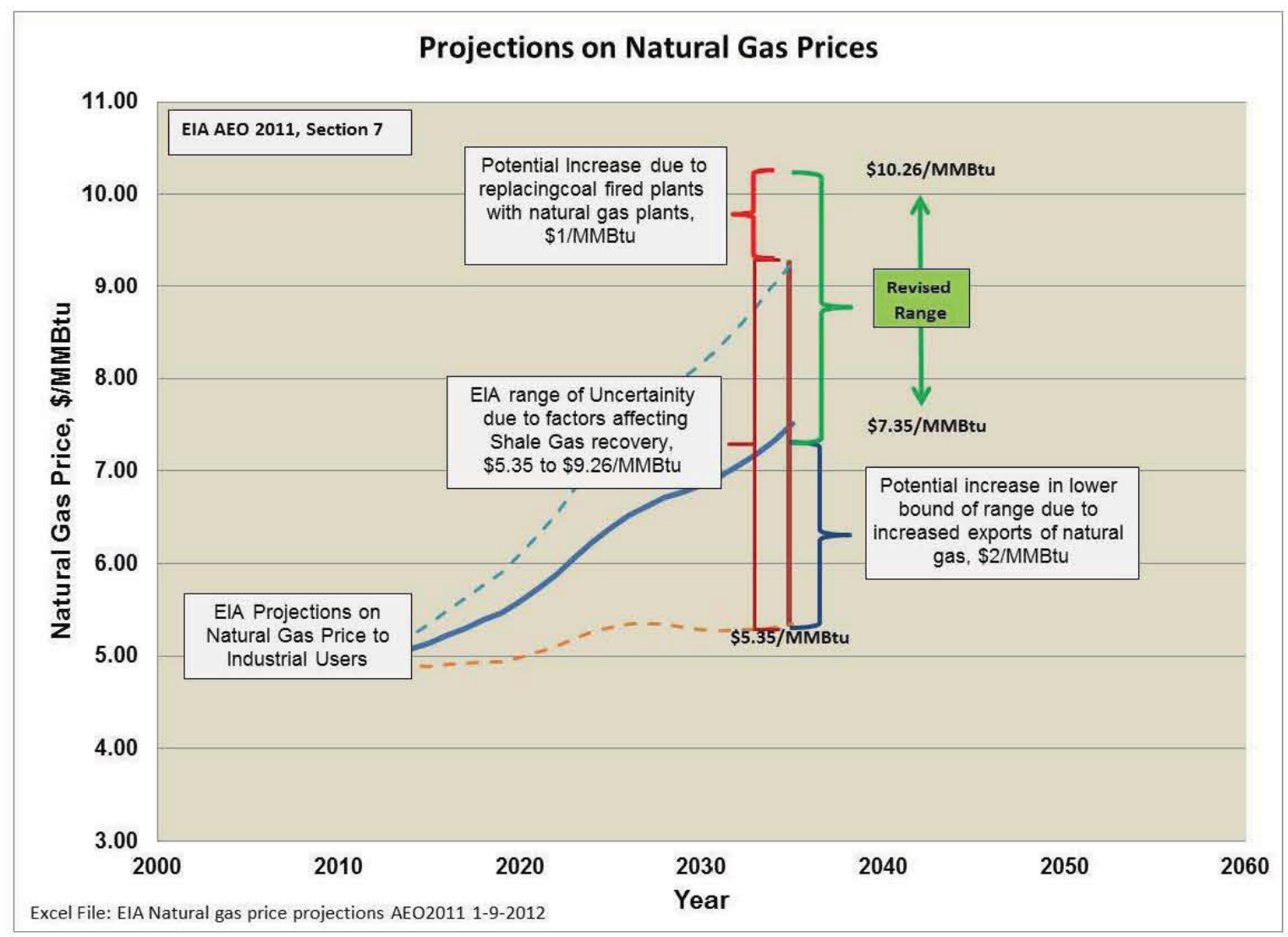

Figure E-6. Projections on long term price of natural gas. 
The low price of natural gas in the U.S. coupled with the high price of natural gas outside the United States (see Figure E-7) presents an arbitrage opportunity through export. At the time of this writing at least seven of the nine major LNG terminals in the United States have submitted requests to become exporters and two of these had received approval. The amount of natural gas that will be exported and the effect of this export on natural gas prices in the United States is uncertain. Review of the literature shows a wide range of conclusions on this subject. On average an effect of $\$ 2 / \mathrm{MMBtu}$ is judged possible. As shown in Figure E-7 this factor has been applied to the lower end of the range of uncertainty because prices in the United States must remain low to make export economically viable (with an addition of $\$ 2$ to \$3/MMBtu for compression and shipping).

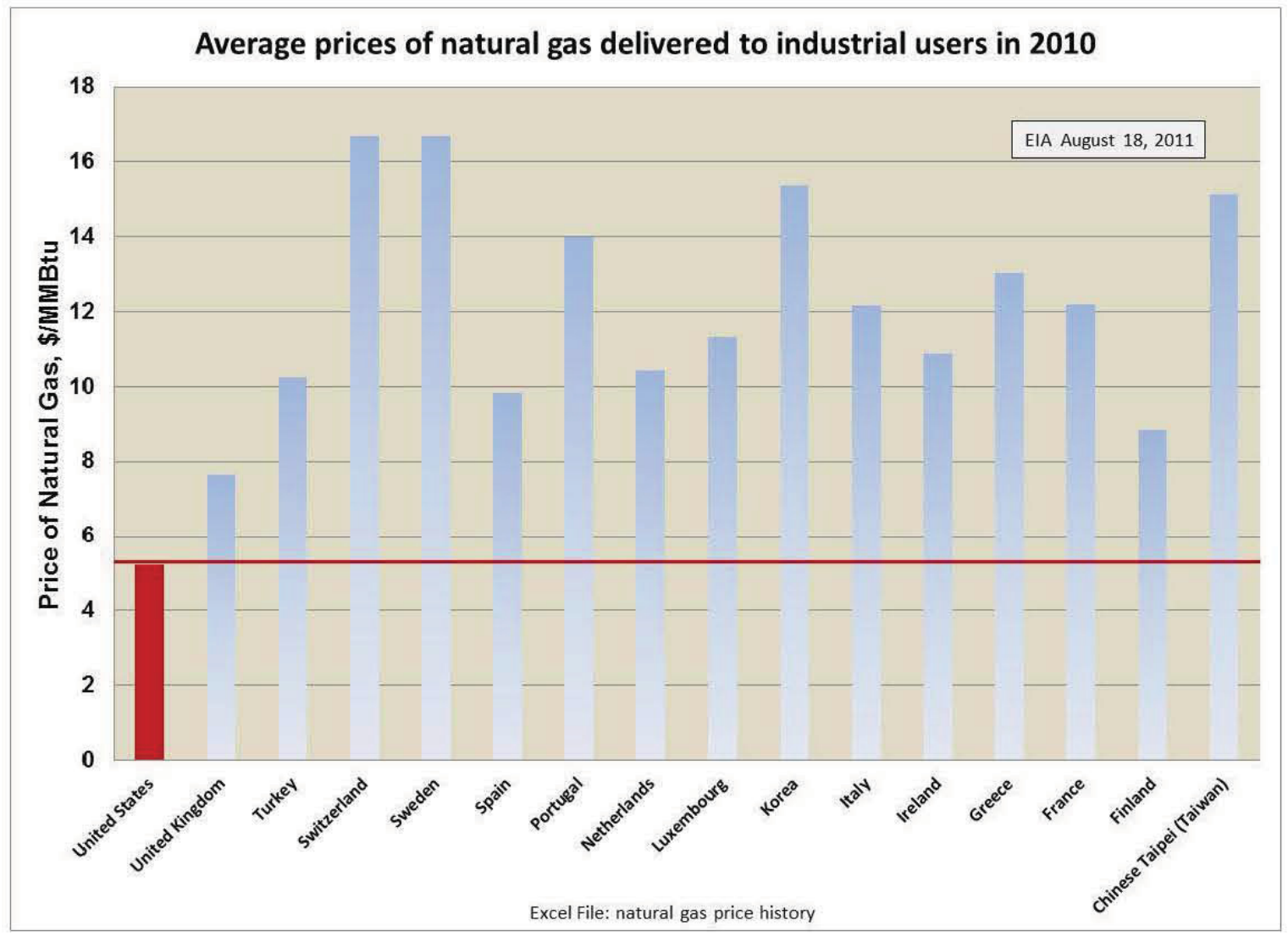

Figure E-7. Comparison of United States with International natural gas prices in 2010 .

The other factor potentially affecting natural gas prices over the long term as shown in Figure E-6 is the potential for expanded use of natural gas for the generation of electricity. This has been occurring at a rapid rate because of the low price of natural gas and the increase in EPA regulation on emissions that has resulted in the actual and projected early retirement of coal fired power plants. Again there is considerable uncertainty in this effect but a conservative estimate of a $\$ 1 / \mathrm{MMBtu}$ effect is judged to be reasonable.

This latter effect is assumed to affect the upper range of the natural gas pricing for the following reason. As low natural gas prices make this technology viable as a substitute for the generation lost due to retirement of coal fired plants the percentage of the electricity generation infrastructure in the United States based on natural gas will obviously become higher. As natural gas prices increase due to the several factors discussed herein there will come a price at which natural gas generation is not the most economic compared with alternatives, (e.g., the HTGR or other nuclear based technologies). This price will be lower if there are governmental actions that result in costs for $\mathrm{CO}_{2}, \mathrm{CCS}$ or emissions. It will not, however, be economic at that time to replace the natural gas infrastructure over a short term because of 
the significant investment required. This will result in the continued use of the natural gas technologies for electricity, even in the face of rising natural gas prices, for some period until retirement of that infrastructure becomes economic.

Based on this analysis the range of the potential price of natural gas in 2035 is projected to be $\$ 7.35$ to $\$ 10.26 / \mathrm{MMBtu}$ (2011\$). This would have the effect of at least doubling the cost of chemicals produced by natural gas raising the price of Ethylene to the range of $\$ 1.20 / \mathrm{lb}$. On this basis both the Conventional and the nuclear incorporated case would be competitive. The application of the nuclear technologies would depend on the economics and governmental regulations on carbon. $\mathrm{A} \mathrm{CO}_{2}$ cost of $\sim \$ 130 /$ ton or a prohibition on the release of $\mathrm{CO}_{2}$ would be required to bring the costs of the Conventional up to the projected costs of the nuclear incorporated process.

\section{E-2.3.1 Maximum Production Capability}

In 2010 Kentucky produced $~ 100$ million short tons of coal. Review of the functional performance data for typical coal conversion plants in Appendix D shows that feed rates for coal conversion to gasoline, diesel and chemicals are in the range of $\sim 10,000$ to 26,000 tons/day for conventional processes and $\sim 4,500$ to 12,000 tons per day for nuclear integrated processes. Those processes with the lower generation rates of $\mathrm{CO}_{2}$ production are those using SMR for hydrogen generation with coal feed rates in the 10,000 tpd range. If all of the coal produced by Kentucky in 2010 were to be consumed by plants at the rate of $10,000 \mathrm{tpd}$, and these plants operated at an $80 \%$ capacity factor 31 plants would be required. It has been estimated that a plant could be constructed in 5 years. A compressed schedule of deployment would commission a new plant every 18 months. On this basis the 31 plants could be on-line in $\sim 52$ years. At $\$ 5 \mathrm{~B}(2011 \$)$ per plant the total cost would be $\sim$ \$150B (2011\$). These plants would produce $\sim 1.6$ million barrel per day of refined product. At average wholesale prices for gasoline and diesel in $2011(\sim 2 / \mathrm{gal})$ these plants would generate revenue of $\sim \$ 43 \mathrm{~B}(2011 \$$ ) per year; $\sim 26 \%$ of the Kentucky GDP in 2011.

About $67 \%$ of a barrel of crude produces diesel and gasoline, (see figure to the right). The 1.6 million barrels of diesel and gasoline produced using all of the Kentucky coal would be equivalent to 2.3 million bpd of crude oil. This would be equivalent to more than $50 \%$ of the crude oil imported from OPEC in 2011.

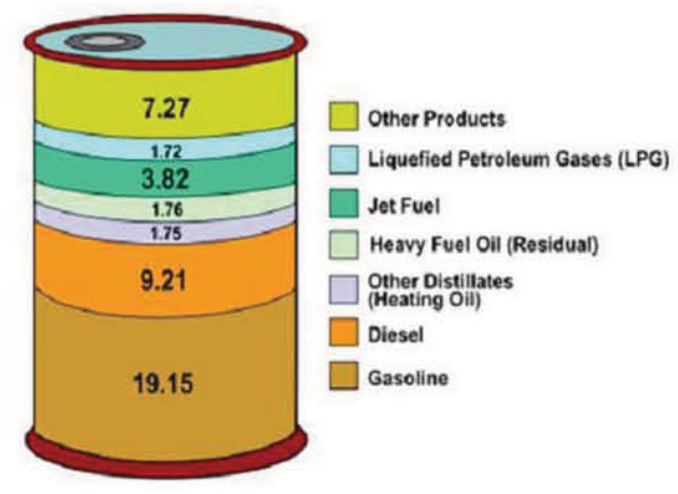

A more modest deployment of five plants was used to develop the strategy for addressing the immediate objectives of deploying a major industry in the Paducah area to offset the cessation of enrichment at the U.S. DOE Paducah Gaseous Diffusion Plant (PGDP) and providing an internal market for coal and natural gas to stem the reductions in their production from eastern Kentucky.

\section{E-2.4 Capital Costs}

Figure E-8 summarizes and compares the estimated total capital investment required for the candidate process plants (2011\$). These estimates were developed from determining the costs for the plant equipment with the design and performance characteristics developed in the Aspen+ analyses with additional factors for design, installation and contingency. Costs were also estimated for plant engineering, permitting, site preparation, project and construction management, labor, startup and testing and plant commissioning. Operating costs were also developed from the bottoms up using industry experience on staffing, outage costs and materials and services as determined in the Aspen + analyses. 


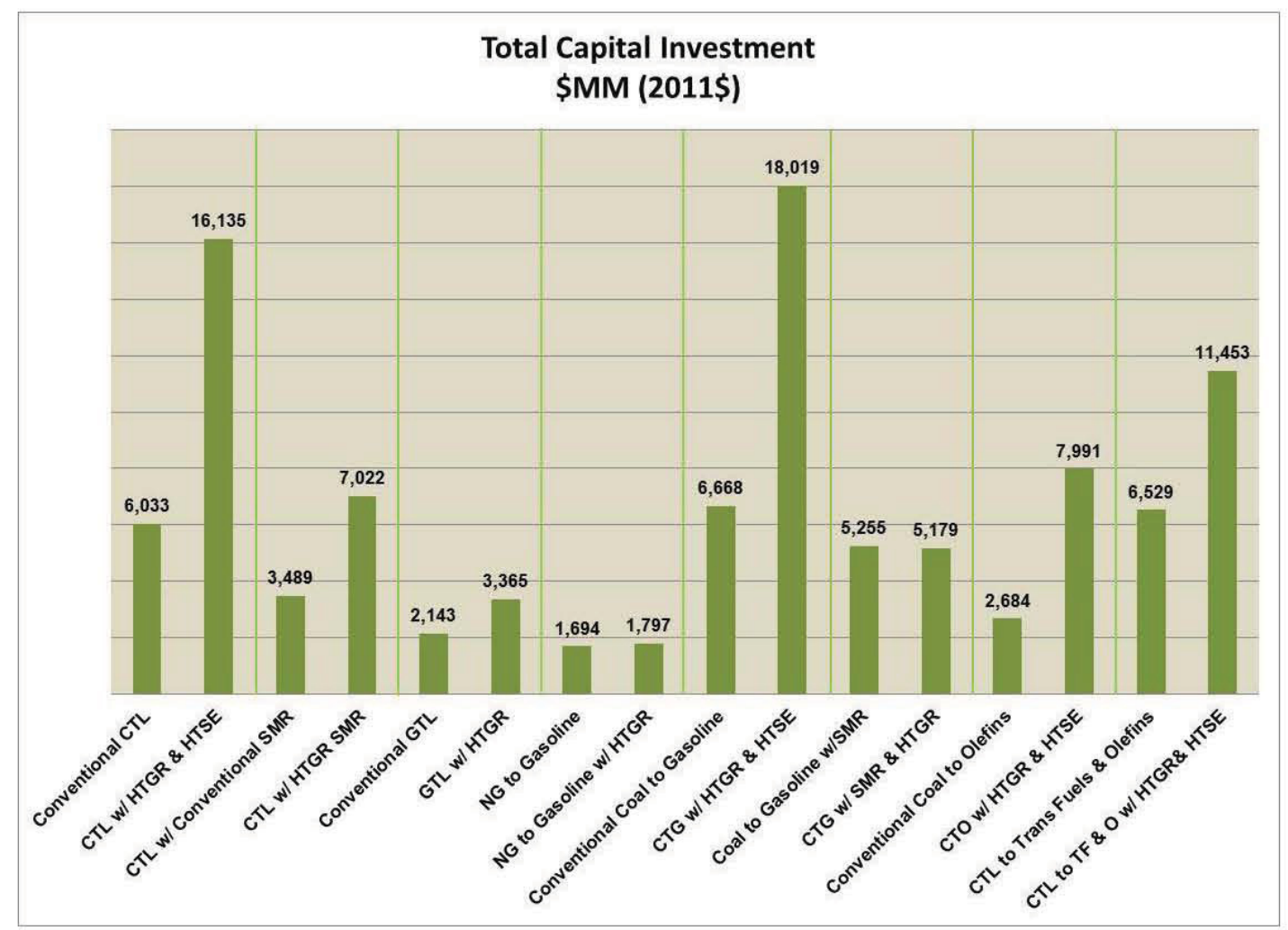

Figure E-8. Total capital investment for candidate process plants.

The capital and operating costs for the HTGR and HTSE plants are based on the module sizes, number of modules, operating conditions and power conversion system design using correlations developed as part of the INL NGNP Project ${ }^{11}$.

As shown the natural gas plants have lower capital requirements than the coal plants due to lower costs for the steam reformers used in the gas plants vice the large gasifiers of the coal plants. The addition of the HTGR/HTSE technologies adds significant capital costs to the plant. This is reflected in the figures in the preceding that show those processes having higher production costs that, in the case of those processes utilizing HTSE, would be non-competitive in today's markets. In all cases the capital expenditures are large providing incentive for the modularized phased approach that is proposed for deploying these plants to reduce the annual expenditure rate to a manageable level.

\section{E-2.5 Electricity Generation}

The high operating temperatures of the HTGR support electricity generation at high net efficiencies. Depending on the Power Conversion System selected net efficiencies in the range of $40 \%$ to $50 \%$ are achievable. These are higher than net efficiencies achievable with traditional light water (LWR) technologies that operate at lower temperatures and typically have net efficiencies of $\sim 33 \%$. The improved net efficiencies result in lower per unit costs for electricity generated by the HTGR than for LWRs including Integrated Small Modular LWRs (ISMLWR $<300 \mathrm{MW}(\mathrm{e})$ ) and the larger traditional LWRs (up to $1500 \mathrm{MW}(\mathrm{e})$ ). As is true of other nuclear technologies the HTGR generates electricity with essentially no greenhouse gas emissions. This makes it an attractive alternative in the event of governmental action to regulate these emissions.

Figure E-9 compares the costs of generation for the HTGR with other generating technologies that have no or low emission characteristics. In addition to LWRs projected costs for an Integrated 
Gasification Combined Cycle (IGCC) plant fueled by coal, a pulverized coal and an Advanced Natural Gas Combined Cycle (NGCC) plant, all with carbon capture and sequestration (CCS), are shown. Also shown is the range of projected natural gas prices in 2035 developed in the prior discussion. As shown in Figure E-9 the HTGR cost of generation is lower than projected for the LWR, the IGCC with CCS, the PC with CCS and for the Advanced NGCC with CCS plant at natural gas prices above \$5.5/MMBtu.

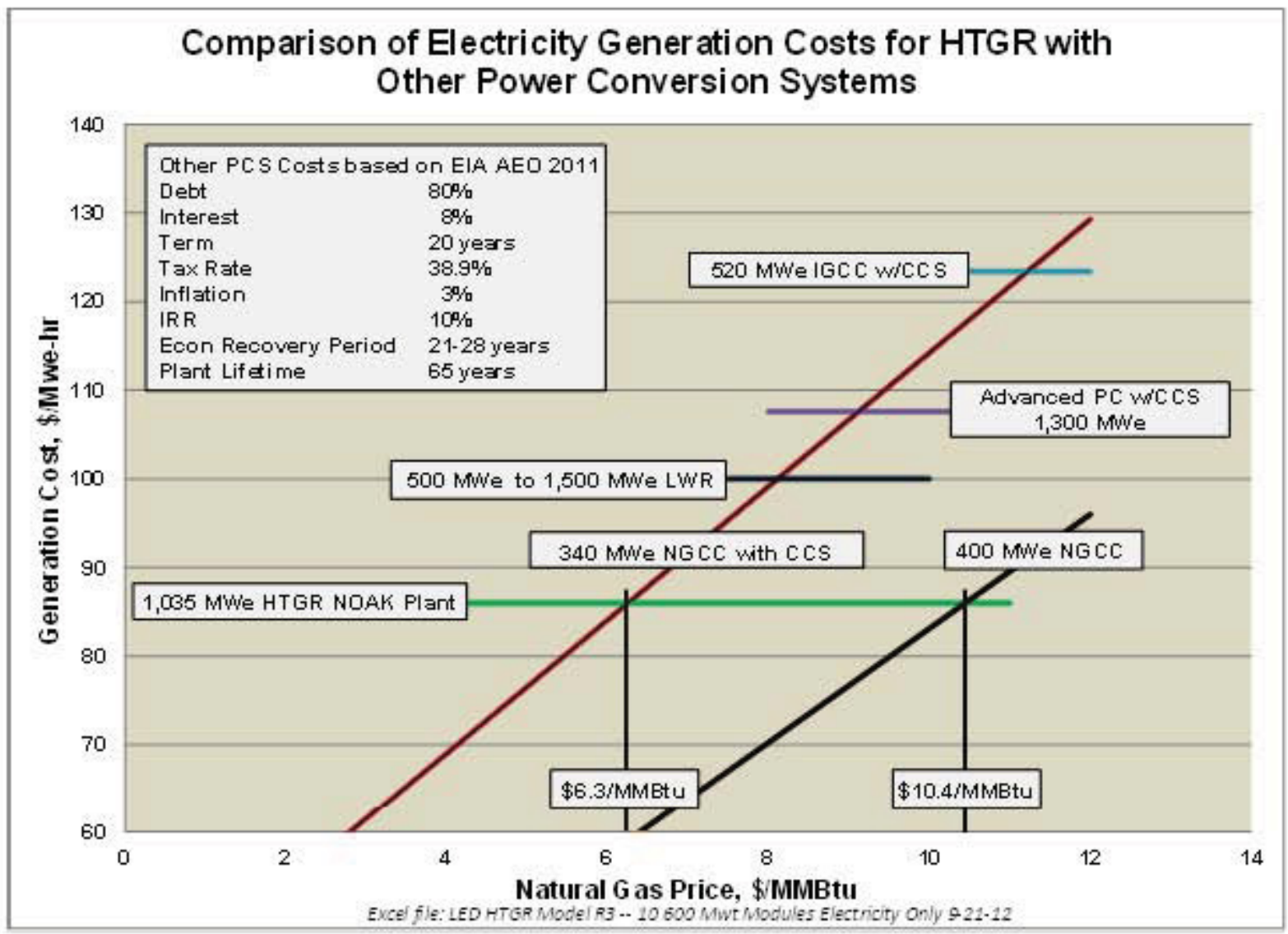

Figure E-9. Comparison of costs of electricity generation for several technologies.

\section{E-2.6 Sensitivity Analyses}

Figures E-10 and E-11 summarize in the form of Tomado charts the sensitivity of the calculated production cost of Diesel for the CTL process with and without the use of SMR for the production of hydrogen and with and without incorporation of the HTGR and HTSE technologies. The sensitivity of the calculated production costs is calculated for the variations listed in Tables E-2 and E-3.

The Tornado charts are organized to show the variations in the order of their impact from highest to lowest. It should be noted that the results show the effect of individual variations in each parameter while the others are held at the baseline value. Accordingly, these results are not additive. 
Table E-2. Variations for conventional CTL processes without HTGR and HTSE technologies.

\begin{tabular}{|c|c|c|c|}
\hline Item & Lower Value & Baseline Value ${ }^{\mathrm{i}}$ & Upper Value \\
\hline \multirow{3}{*}{$\mathrm{CO}_{2}$ Sequestration and Taxation } & None & No Sequestration & $\begin{array}{l}\text { No Sequestration } \\
\text { with } \$ 50 / \text { ton Tax }\end{array}$ \\
\hline & None & No Sequestration & $\begin{array}{l}\text { Sequestration with } \\
\$ 50 \text { /ton Tax }\end{array}$ \\
\hline & None & No Sequestration & Sequestration \\
\hline Natural Gas Price & $\$ 4.50 / \mathrm{MSCF}$ & $\$ 5.50 / \mathrm{MSCF}$ & $\$ 12.00 / \mathrm{MSCF}$ \\
\hline Internal Rate of Return & $10 \%$ & $12 \%$ & $15 \%$ \\
\hline Debt to Equity Ratio & $80 \%$ & $50 \%$ & $20 \%$ \\
\hline Economic Recovery Period & 40 years & 30 years & 20 years \\
\hline Financing Interest & $6 \%$ & $8 \%$ & $10 \%$ \\
\hline Financing Term & 10 years & 15 years & 20 years \\
\hline Construction Period & 24 months & 36 months & 48 months \\
\hline Total Capital Investment & $100 \%$ & $100 \%$ & $100 \%$ \\
\hline
\end{tabular}

Table E-3. Variations for CTL processes with HTGR and HTSE Technologies

\begin{tabular}{|llll|}
\hline \multicolumn{1}{c}{ Item } & \multicolumn{1}{c|}{ Lower Value } & Baseline Value & Upper Value \\
\hline Internal Rate of Return & $10 \%$ & $12 \%$ & $15 \%$ \\
\hline Debt to Equity Ratio & $80 \%$ & $50 \%$ & $20 \%$ \\
\hline Economic Recovery Period & 40 years & 30 years & 20 years \\
\hline Financing Interest & $6 \%$ & $8 \%$ & $10 \%$ \\
\hline Financing Term & 10 years & 15 years & 20 years \\
\hline Construction Period & 24 months & 36 months & 48 months \\
\hline Total Capital Investment & $85 \%$ & $100 \%$ & $125 \%$ \\
\hline Refueling Period & 24 months & 18 months & 12 months \\
\hline Staffing Plan & None & Vendor & INL \\
\hline
\end{tabular}

Figure E-12 shows the results of applying the ranges of parameter variations listed above for the Conventional CTL with SMR case in a Monte Carlo analysis of the cost of diesel. This shows the combined effects of these variations in the form of a probability distribution on the cost. As shown the $2 \sigma$ range for the cost spans from a low of $\$ 1.78 / \mathrm{gal}$ to a high of $\$ 2.86 / \mathrm{gal}$. This wide range reflects the large uncertainty in the input values.

i Note that these baseline values are different from the parameters listed in the prior Tables were used to perform the economic analyses as discussed in the preceding sections. As cited in discussion of these Tables those values were recommended for use in these analyses by the NGNP Industry Alliance, Ltd. The Baseline values and variations used in the sensitivity studies summarized in Figures $\mathrm{j}$ and $\mathrm{k}$ were selected to bound the expected range of the parameters evaluated.

j The INL Economic Model has two variations in the staffing plan for the HTGR plant; one that was generated from HTGR Supplier data developed by the INL NGNP Project and an INL plan that was developed from review of existing LWR plant staffing and adapting that data to the specific characteristics of the HTGR modular design. The INL staffing plan projects a much higher number than the Vendor plan 382 personnel for the first module and 71 for each additional module versus 165 personnel for the first module and 25 for each additional module. 


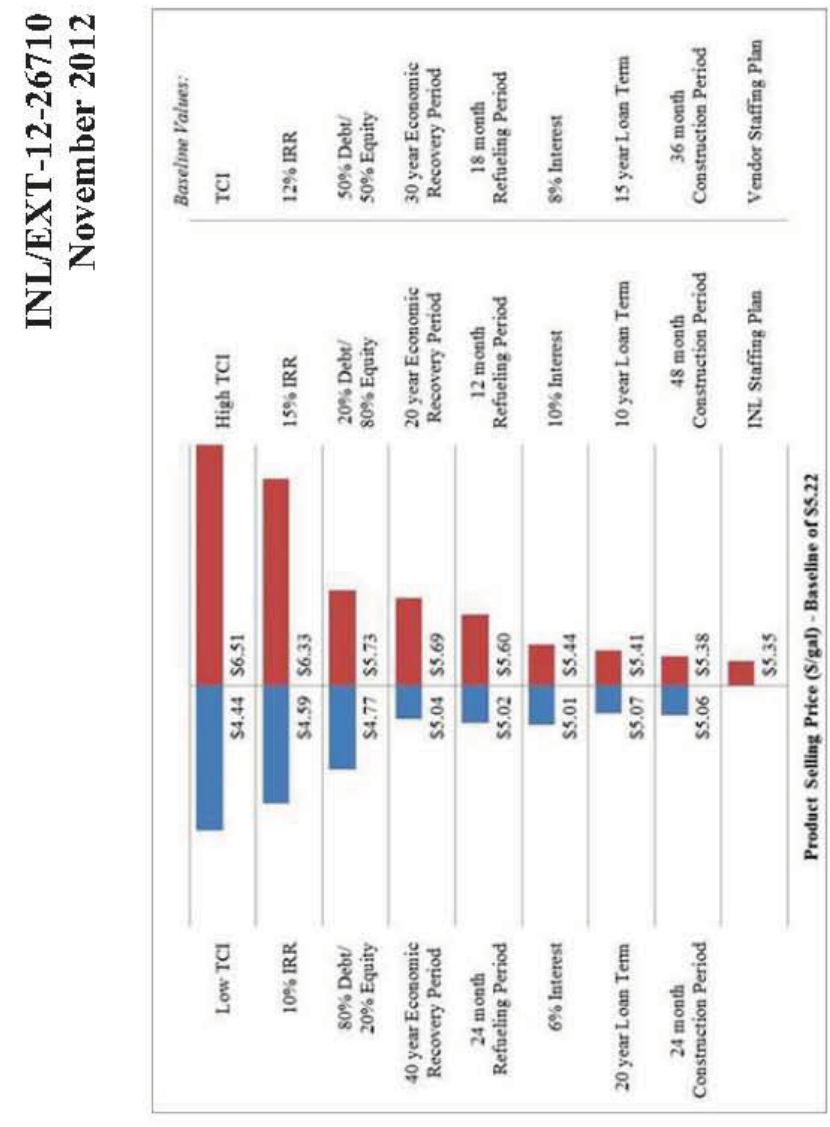

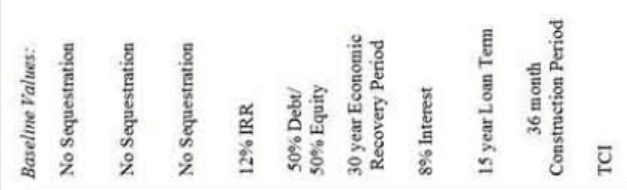

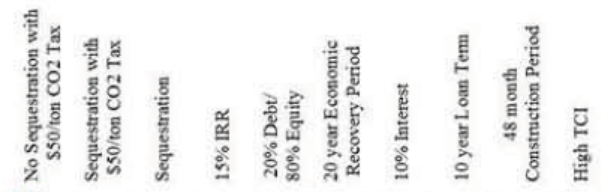

में वें के

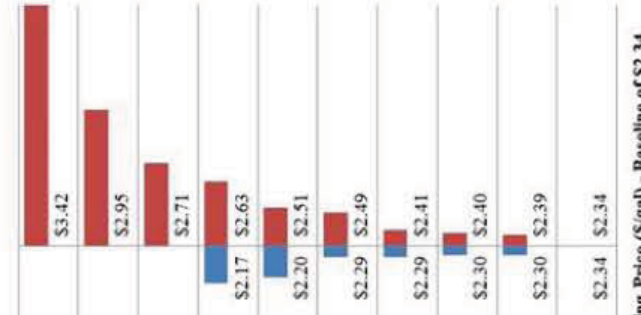

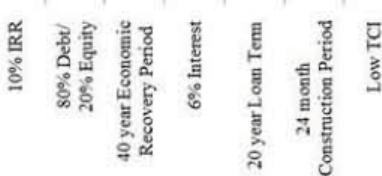
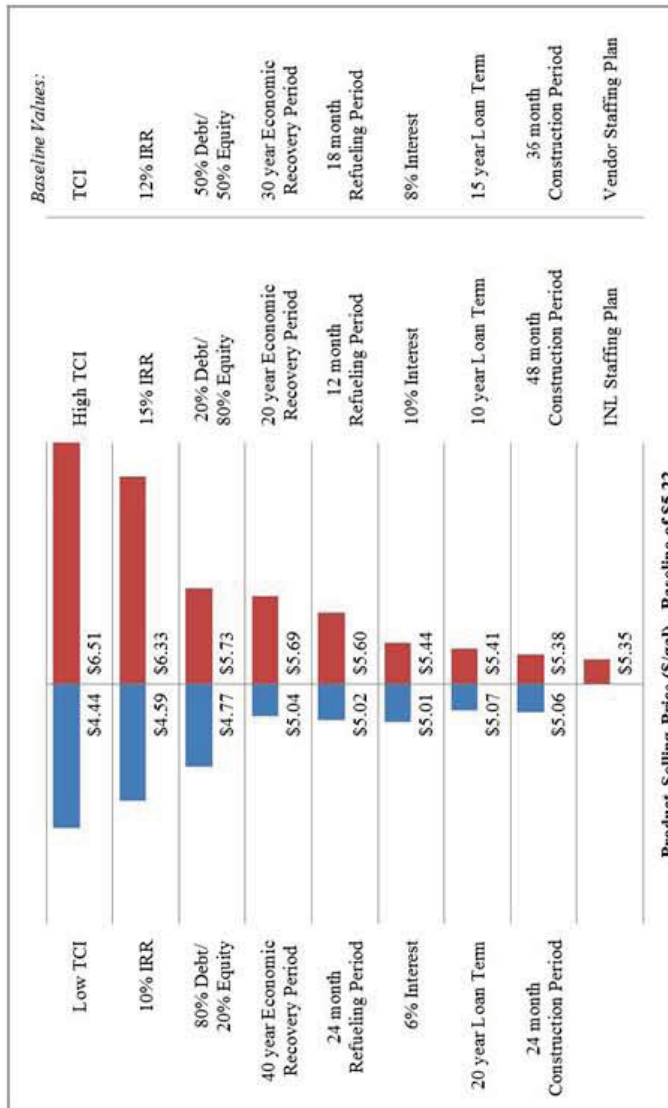

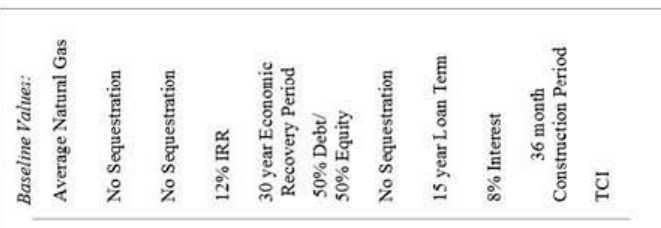

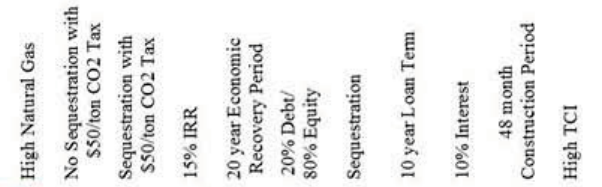

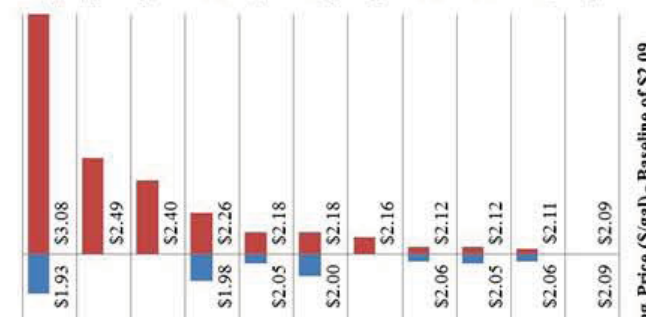

$\underline{1}$ 


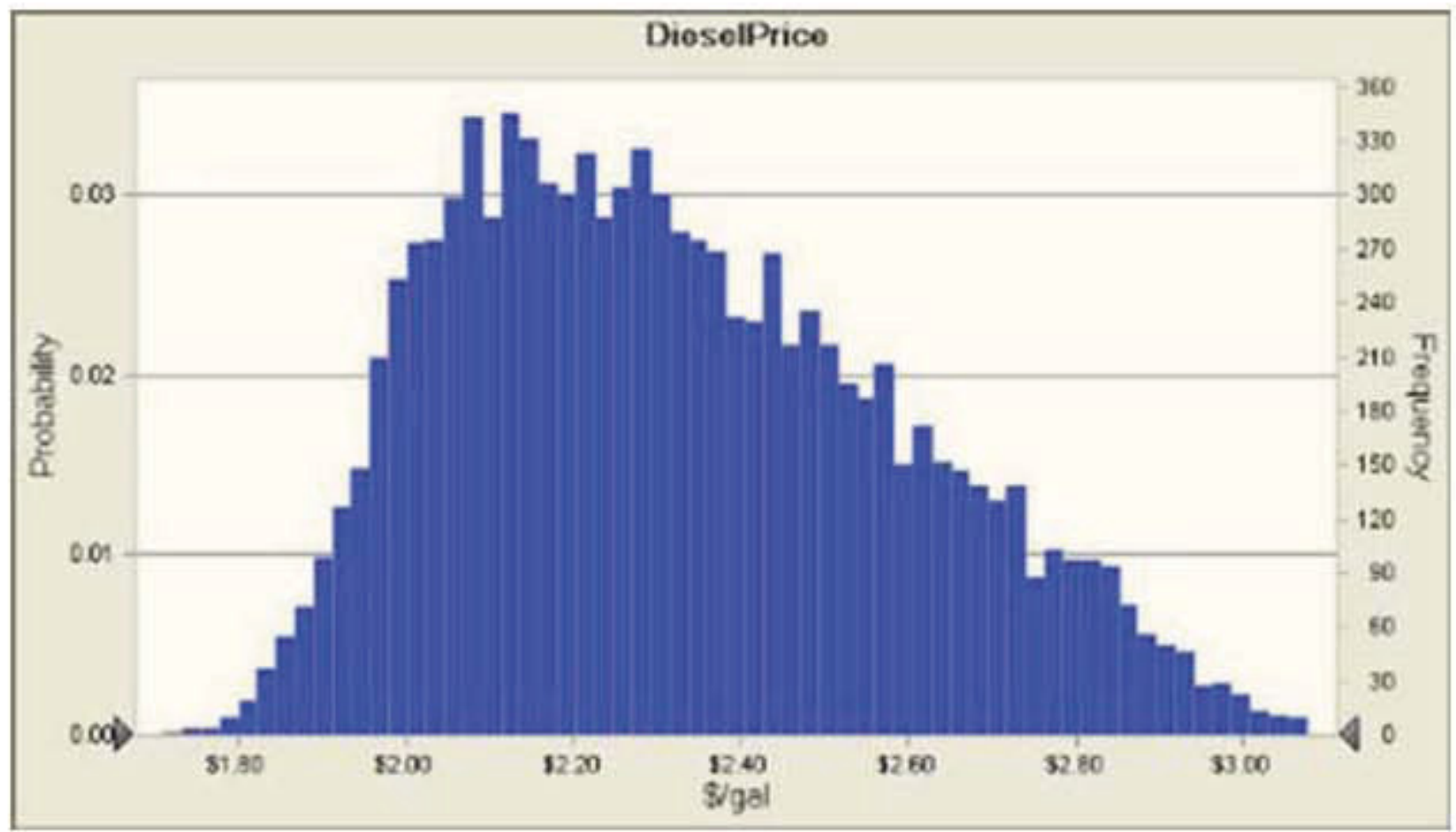

Statistics:
Trials
Mean
Median
Mode
Standard Deviation
Variance
Skewness
Kurtosis
Coeff. of Variability
Minimum
Maximum
Range Width
Mean Std. Error

Forecast values
10,000
$\$ 2.32$
$\$ 2.29$
-
$\$ 0.27$
$\$ 0.07$
0.4395
2.49
0.1153
$\$ 1.71$
$\$ 3.20$
$\$ 1.49$
$\$ 0.00$

Figure E-12 Results of Monte Carlo analysis of parameter variations on the probability of dfesel productions costs using the CTL with SURR process conclusions on economics.

1. The conventional processes are competitive with the market prices of transportation fuels and primary chemicals at the time of this writing. This conclusion supports the strategy of beginning the steps required to deploy a process as soon as practical.

2. The economics of incorporating HTGR technology to supply heat in the CTL w/SMR and the GTL processes are the more favorable of the nuclear incorporation alternatives. These processes can benefit from the zero $\mathrm{CO}_{2}$ emissions and the stable energy cost characteristics of the HTGR technology.

3. The economics of using the HTGR technology for electricity generation are very favorable even at the time of this writing where the costs of natural gas are low. In February 2012, the price of natural gas delivered to industrial customers in the United States averaged a little less than 
$\$ 4 / \mathrm{MMBtu}$ but ranged from a low of $\$ 2.80 / \mathrm{MMBtu}$ to a high $>\$ 11 / \mathrm{MMBtu}$ in the continental United States. As was shown in Figure E-11 generation of electricity using the HTGR is very competitive with other forms of non- or low $\mathrm{CO}_{2}$ emitting baseload technologies including NGCC in the upper level of this range. As shown in Figure E-11 it will be competitive with the alternative no or low- $\mathrm{CO}_{2}$ emitting technologies for natural gas prices projected in 2035 .

4. The economics of incorporating the HTGR and HTSE technologies in the CTL, CTO and MTG processes as discussed above do not appear favorable. The unfavorable economics stem from the high cost of hydrogen produced using the HTSE process. There are two primary factors in the HTSE costs; the costs of the plant that accounts for $\sim 13 \%$ of the operating costs and the costs of the electricity to operate the unit that accounts for the balance. As demonstrated above if electricity can be obtained at costs in the $\$ 45 / \mathrm{MW}(\mathrm{e})$-hr range, such as is the case in Kentucky, then it is possible to produce hydrogen in the $\$ 2 / \mathrm{kg}$ range based on the current design characteristics of the HTSE plant.

5. The principal process used to produce hydrogen in the United States is steam methane reforming (SMR) using natural gas as the feed stock. The principal factor in the cost of hydrogen produced using SMR is the cost of natural gas. If the government imposes taxes or regulation on the emissions of $\mathrm{CO}_{2}$, that would also increase the cost of the hydrogen. The SMR process generates $\sim 9$ tons of $\mathrm{CO}_{2}$ for every ton of hydrogen produced. Figures E-13 and E-14 show the effect of varying natural gas and $\mathrm{CO}_{2}$ costs on the cost of hydrogen produced using SMR. Figure E-13 is for the case where the $\mathrm{CO}_{2}$ is captured and sequestered. Figure E-14 is without any capture and sequestration. The $\$ 2 / \mathrm{kg}$ cost line is highlighted on both figures.

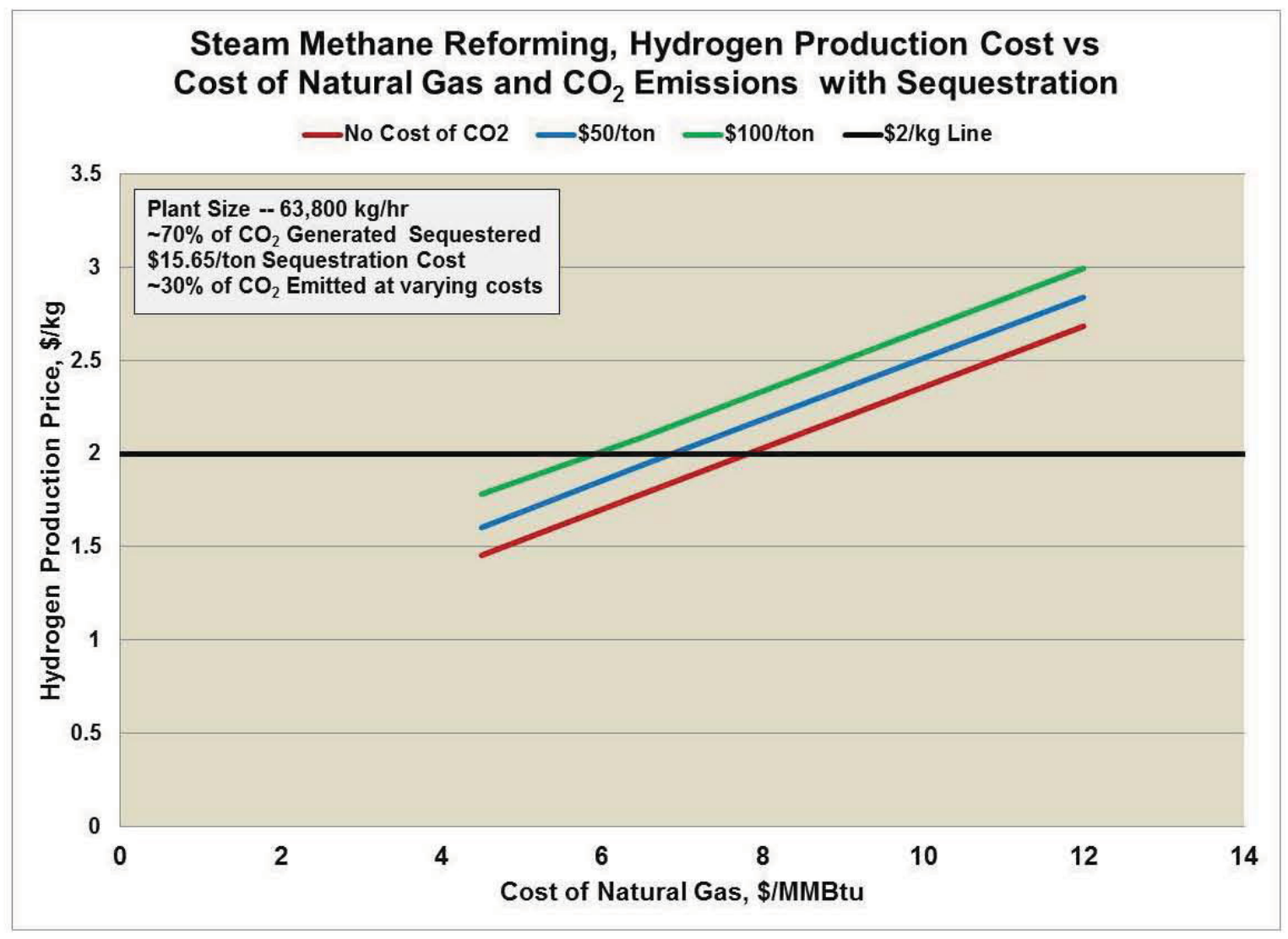

Figure E-13. SMR hydrogen production costs versus. cost of natural gas and $\mathrm{CO}_{2}$ with sequestration. 


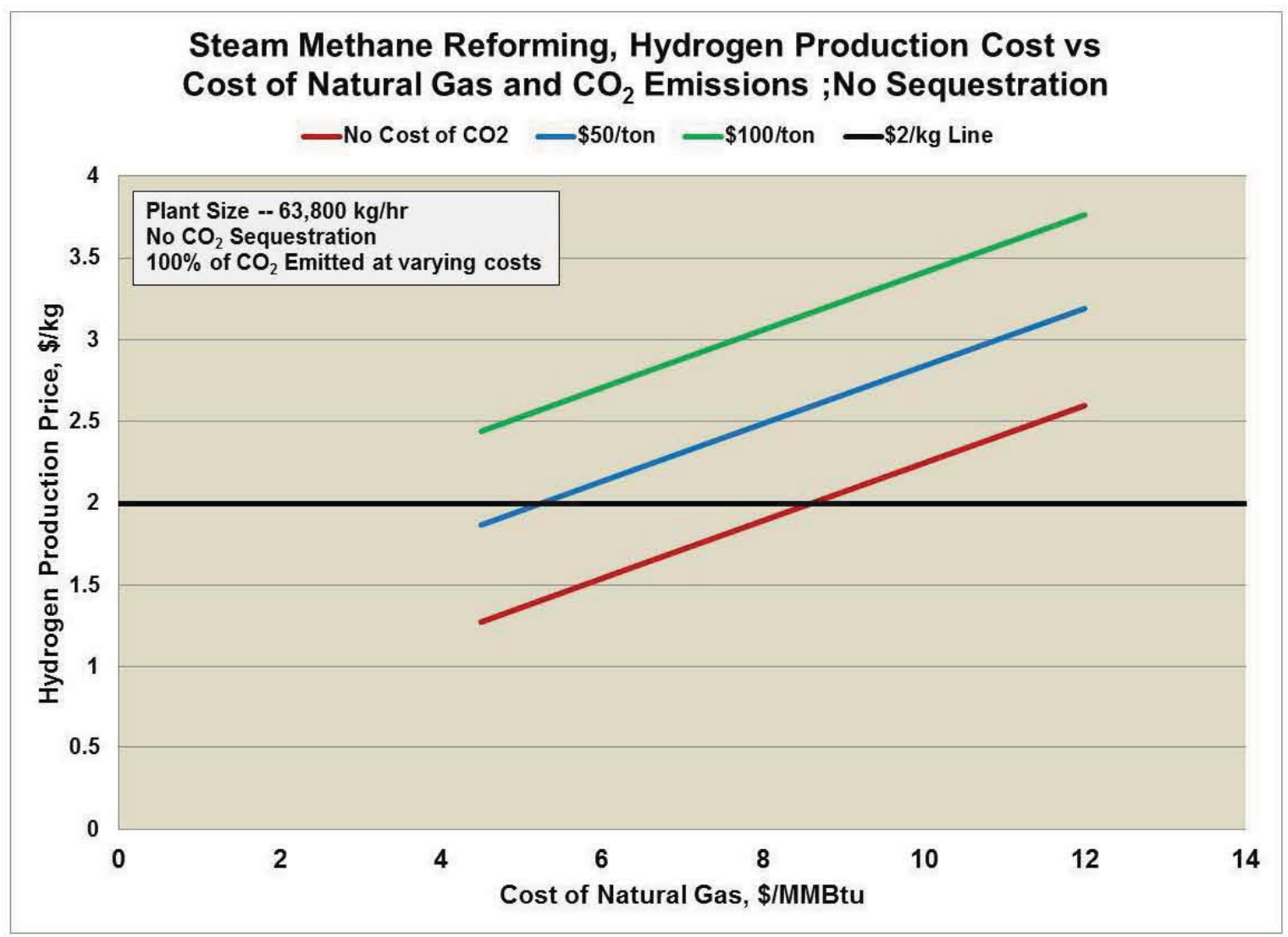

Figure E-14. SMR hydrogen production cost versus cost of natural gas and $\mathrm{CO}_{2}$ without sequestration.

As shown for the sequestration case, the $\$ 2 / \mathrm{kg}$ line is crossed at natural gas costs in the range of $\$ 6 / \mathrm{MMBtu}$ to $\$ 8 / \mathrm{MMBtu}$ for $\mathrm{CO}_{2}$ emission costs in the range of $\$ 0 /$ ton to $\$ 100 /$ ton. Note that in this case $70 \%$ of the $\mathrm{CO}_{2}$ is assumed to be transported and sequestered at a cost of $\$ 15.65 /$ ton. There is considerable uncertainty in this cost and it could be much higher which would shift the crossing of the $\$ 2 / \mathrm{kg}$ line to a much lower range of natural gas costs.

As shown for the no sequestration case, the $\$ 2 / \mathrm{kg}$ line is crossed at natural gas costs in the range $\$ 5$ to $\$ 8.50 / \mathrm{MMBtu}$ for $\mathrm{CO}_{2}$ costs between $\$ 0 /$ ton and $\$ 50 /$ ton. At the higher cost of $\mathrm{CO}_{2}$ emissions the line would be crossed in the range of $\$ 2 / \mathrm{MMBtu}$.

At the projected lower limit of the projected long term price of \$7.35/MMBtu (Figure E-7) the HTSE process could be competitive with SMR assuming current estimates of construction and operating costs prevail as the process is developed further. Improvements in those costs would reduce the costs of natural gas and $\mathrm{CO}_{2}$ at which HTSE becomes competitive.

6. The development of the HTGR is proceeding with the initial startup of the first demonstration module currently planned for the 2025 time frame. As the development progresses better estimates of the costs of construction and operation will be developed. As the cost estimates become more refined they will add to the confidence in updates to the economic analysis of these processes using these estimates.

7. Similarly, development of the HTSE process is progressing with efforts currently in progress to optimize the process and the plant configuration to minimize production costs.

8. The Kentucky interests should support the development of both of these technologies and monitor the progress of their development to ensure that they are available in the long term for meeting 
the energy needs of the Commonwealth with environmentally beneficial technologies at stable long term costs. This becomes more important as government regulation on emissions expand reducing the viability of applying coal in its traditional role of electricity generation. The HTGR technology projects to be very competitive in that role and depending on the nature of the emissions regulations can also be competitive in the conversion of coal and natural gas to transportation fuels and/or chemicals.

\section{E-3. References}

1. INL EXT-11-24143 and INL INL-12-24572

2. JJ Dooley (Lead Author), RT Dahowski, CL Davidson, MA Wise, N Gupta, SH Kim, EL Malone, "Carbon Dioxide Capture and Geologic Storage, A Core Element of a Global Energy Technology Strategy to Address Climate Change", A Technology Report from the Second Phase of the Global Energy Technology Strategy Program.

3. EIA, Annual Energy Outlook 2012 (Early Release April 2012 and June 25, 2012 Release).

4. EIA, Annual Energy Outlook 2012 Early Release.

5. Navigant Consulting, Market Analysis for Sabine Pass LNG Export Project, FERC Docket Nos. CP04-47, CP05-396, PF10-24, August 23, 2010.

6. LNG exports could drive up low gas prices, EIA says, Platts, January 23, 2012, "With US natural gas prices at 10-year lows, the Energy Information Administration confirmed last week that prices could rise by more than $50 \%$ if domestic companies are allowed to export large volumes of fuel-as liquefied natural gas - to foreign countries."

7. Natural Gas vs. Oil and Coal, Excerpt from Powers Energy Investor, February 1, 2011 Issue, Bill Powers, "One of the biggest anomalies in the North American natural gas market over the past year has been how disconnected natural gas prices have become from those of its close substitues - oil and coal. The historical relationship between the price of natural gas and oil, which has averaged 10:1 over the past two decades, has now moved to approximately $20: 1 . "$

8. Richard Finger, We're Headed To $\$ 8$ Natural Gas, So combine 13 year low gas rig counts, declining production levels with resultant ultralow storage injections, shut in gas production, faster than anticipated shale well declines, persistent switching from oil and coal to cheaper and cleaner gas alternatives...Then consider unending hotter than normal summer temperatures, continued greater than normal nuclear plant outages, a hurricane or two that knocks out Gulf of Mexico natural gas production for a week or two, and a La Nina induced cold winter... any one of these can light the fuse that pushes the tenuous supply/demand balance into cardiac arrest. That's the chain and it's going to lead us to $\$ 8.00 \mathrm{mcf}$ natural gas by the approaching winter."EIA, Effect of Increasing Natural Gas Exports and Domestic Energy Market, January 2012, "Increased natural gas exports lead to higher domestic natural gas prices, increased domestic natural gas production, reduced domestic natural gas consumption, and increased natural gas imports from Canada via pipeline."

10. NERA Economic Consulting, Proposed CATR + MACT, prepared for the American Coalition for Clean Coal Electricity, May 2011 (DRAFT).

11. INL, "Assessment of High Temperature Gas-Cooled Reactor (HTGR) Capital and Operating Costs, TEV-1196, 04/29/2011. 
Appendix F

\section{Deployment Strategies}




\section{Appendix F Deployment Strategies}

\section{F-1. SUMMARY OF APPROACH}

The evaluation of deployment strategies for carbon conversion in Kentucky includes review of siting considerations, the availability of natural gas in addition to coal, the potential market for products of carbon conversion and their relative value multipliers, the flexibility in re-configuring the initial process to take advantage of changes in the market and incorporation of the HTGR and HTSE technologies as they become commercially available. In this regard the deployment strategy discussed herein includes two phases. The first phase covers the 2013 thru 2028 time frame with deployment of a conventional plant as soon as practical. The second phase covers 2028 and on and would incorporate HTGR and where applicable HTSE technology when it has been proved technically and economically viable.

\section{F-1.1 Site Selection}

A principal objective of this evaluation is to identify a process for deployment at or near the existing DOE Paducah Gas Diffusion Plant (PGDP) currently operated by the United States Enrichment Company (USEC). This plant is coming to the end of its life and could cease enrichment activities as early as May 2013. This plant has been one of the primary resources for the enrichment of uranium for use in the current fleet of light water reactors (LWRs) in the United States. The gas diffusion process used in this plant requires considerable energy and is not competitive with the centrifuge processes being implemented in other enrichment plants ${ }^{k}$. This plant is a major employer in the Paducah area, $(\sim 3,000$ employees) and a major contributor to the Paducah area economy. Accordingly, the objective of siting a large scale carbon conversion plant in the area is intended to offset the loss of this employer.

\section{F-1.2 PACRO Site}

In 2009 the Paducah Area Community Reuse Organization (PACRO) completed a thorough survey of a site adjacent to the PGDP, including an environmental report, to determine the suitability of that site for locating an energy project. This was completed in conjunction with a Kentucky wide survey to identify locations throughout the Commonwealth that could support major industrial development and/or the siting of nuclear and renewable power generation plants. ${ }^{\mathrm{m}}$ Figure F-1 summarizes the results of the PACRO site. As shown, the survey concluded:

- Alternative Energy Development Suitability: Based upon developed criteria and scoring, this facility is best suited for the development of a biomass or CTG/CTL facility. Additionally, current operations make this site amenable to a nuclear facility. (Criteria and scoring does not necessarily guarantee site success).

- Nuclear: $72 \%$ - Established gaseous diffusion plant adjacent to proposed site location; however, foundation concerns would need to be addressed prior to development.

- Wind: Wind speed inadequate to develop a utility scale facility

k National Enrichment Facility, Hobbs, New Mexico.

1 Paducah Area Community Reuse Organization, McCracken County Energy Project Site Suitability, 2009, Department of Energy Development and Independence, Energy and Environment Cabinet Commonwealth of Kentucky.

m Kentucky Alternative Energy Site Bank Evaluation, June 2009, PON 212708000101681 Department for Energy Development \& Independence, Energy and Environment Cabinet, Commonwealth of Kentucky, Prepared by Smith Management Group, 1405 Mercer. 


\section{Paducah Area Development Community Reuse Site McCracken County, Kentucky

Ownership:

The U.S. Department of Energy owns the property in surface, and mineral is controlled

\section{Alternative Energy Development Suitability:}

Based upon developed criteria and scoring, this facility is best suited for the development of a biomass or CTG/CTL faciity. Additionally, current operations make this site amenable to a nuclear facility.

(Criteria and scoring does not necessarily guarantee site success)

Nuclear: $72 \%$ - Established gaseous diffusion plant adjacent to proposed site location; however, foundation concems would need to be addressed prior to development.

Wind: Wind speed inadequate to develop a utility scale facility

Solar. $59 \%$ - Average drect normal solar radiation is $4.3 \mathrm{kWh} / \mathrm{m}^{2} / \mathrm{day}$

Biomass: $83 \%$ - Avalable biomass in McCracken and its surrounding Counties is greater than 1,000,000 tonnes per year CTLCTG: $79 \%$ - Avalable coal from the Westem Kentucky Coal Field within delivery distance and adequate acoess to rail and potential for barge transportation.

Utilities

- Potable Water - Available at adjacent Paducah Gaseous Diffusion Plant (PGDP)

- Electric - The TVA Shawnee Plant and EE Joppa Steam Plant both supply adequate power to the PGDP facility

- Gas - 6-inch Atmos Energy natural gas pipeline north of site

- Broadband - Currently in service at PGDP faclity

- Sewer - Installed at PGDP facility

Iransportation:

- Rail - Illinois Central, P\& L - Spur located acjacent to site

- Road-Local roads near perimeter of site: SR 1321, SR 725, SR 995 and SR 1154: Interstate 24 and US 60 within $5-10$ miles of site

- Barge - Potential for barge access on Ohio River

- Airport Proximity - Barkley Regional Aiport +i5.0-miles

Water Availability:

- Water Supply - Ohio River is the primary source and water is pumped to the PGDP facility to meet a capacty of 30 MGD; Existing water intake is near the TVA Shawnee Steam Plant

Available Workforce:

- >100,000 potential workers within McCracken County and neighboring areas

Site Considerations:

- Agreement between DOE and KYY Dept of Fish and Wildifie allows for development of surrounding land if necessary, site potential $>1,000$ acres

- Zoning is for heavy industrial; former operations include munitions plant and adjacent facility is a gaseous diffusion plant

- Wetlands - Freshwater wetlands documented on property, up to $50 \%$; wetlands delineation study necessary
- Floodplains - Not wthin 100-year floodplain; some areas associated wth PGDP facility not mapped

- Water Resources - Discharge to Bayou Creek Creek, an impaired stream

- Adequate coal supply available to the site

- Poor geological assets and moderate-to-high seismic risk will require special attention to foundation design

- Site does not contain active, inactive or abandoned ollgas wels

Environmental Assets:

- T\&E-Not likely, further investigation required

- Cuitural Resources - Further investigation required for PGDP building complex (1852. 1973), no documented National Register properties within one mile

- Class I Visibility - Property located $>125$-miles west of Mammoth Cave

- Public Access Areas - Ft. Massac (IL) is 7-miles from site

- Non-Attainment $\rightarrow 75$ miles from Randolph County, IL, a non-attainment area

- Detailed Site Report for Siting Study performed in 2007 for DOE

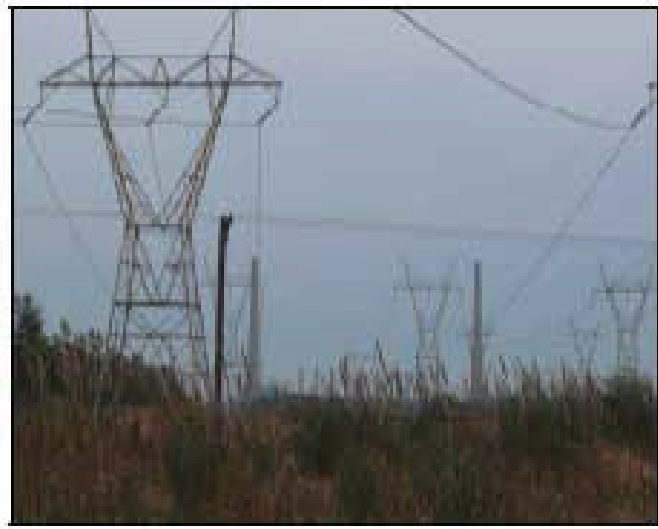

Figure F-1. Summary of the results of the survey of the PACRO site.

- Solar: 59\% Average tirect nomal solarratiation is $4.3 \mathrm{kWh} / \mathrm{m} 2 /$ day

- Biomass: $83 \%$ Available biomass in McCracken and its surrounding Counties is greater than $1,000,000$ tonnes per year 
- CTL/CTG: $79 \%$ - Available coal from the Western Kentucky Coal Field within delivery distance and adequate access to rail and potential for barge transportation.

Accordingly, the site is judged to be acceptable for a carbon conversion facility with a nuclear component.

Figure F-2 shows the location of the specific area that was evaluated. As shown it is adjacent to the PGDP but still within the boundaries of the DOE owned area. Table F-1 is a filled in data collection form for this site that was prepared as part of this study to support evaluation of potential sites for a carbon conversion plant. Review of this table shows that the site selected by PACRO satisfies the criteria for siting a carbon conversion plant except for the size of the site. The PACRO site covers $\sim 560$ acres whereas it is judged that a large scale plant (e.g., 50,000 bpd fuels production or 3,000 tpd chemicals production) will require up to 1,000 acres. Discussions with PACRO noted that it would be possible to extend the site into the area West of the original site. This extension is shown as the shaded area in Figure F-2.

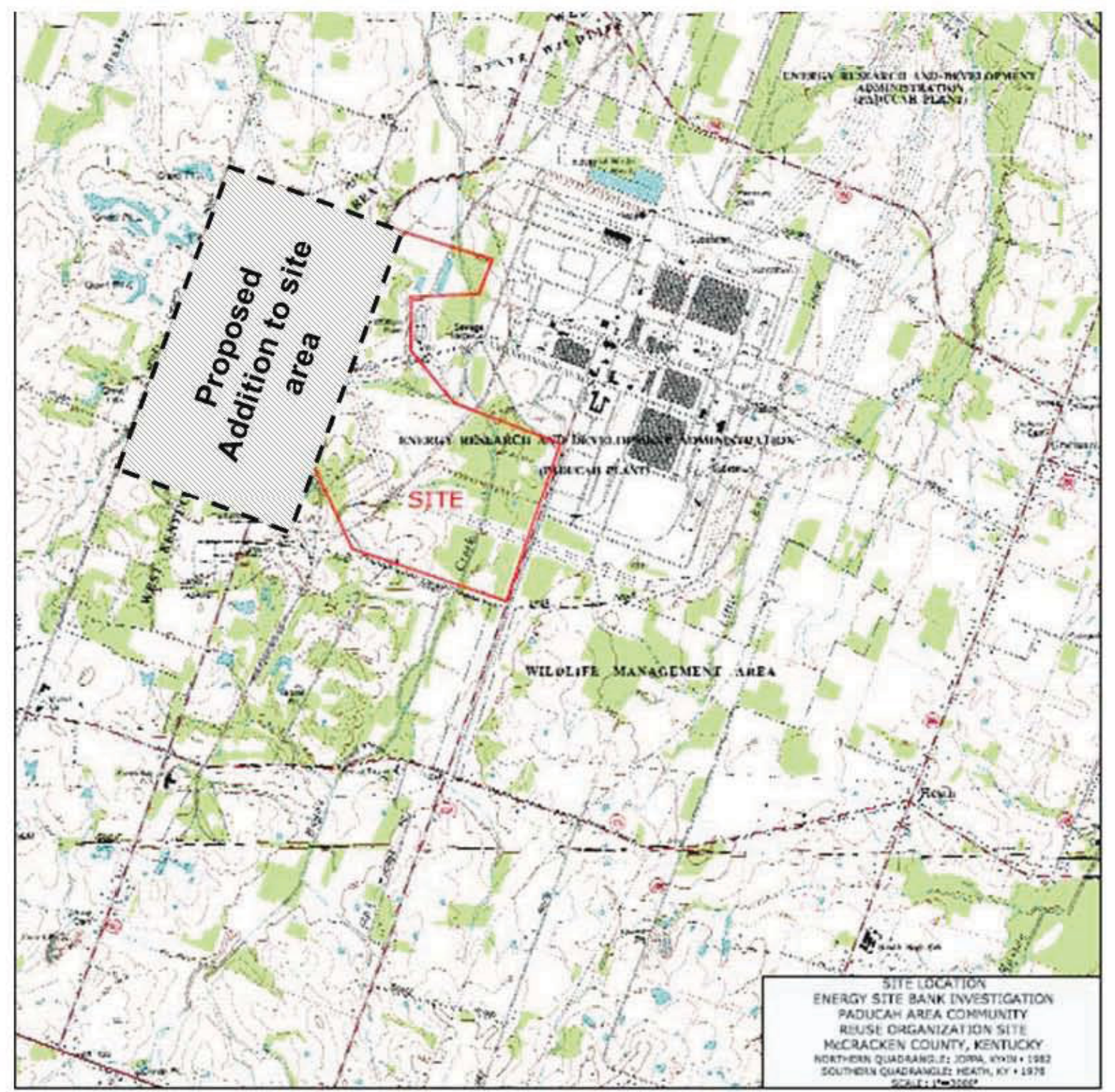

Figure F-2. Potential site for the carbon conversion plant. 


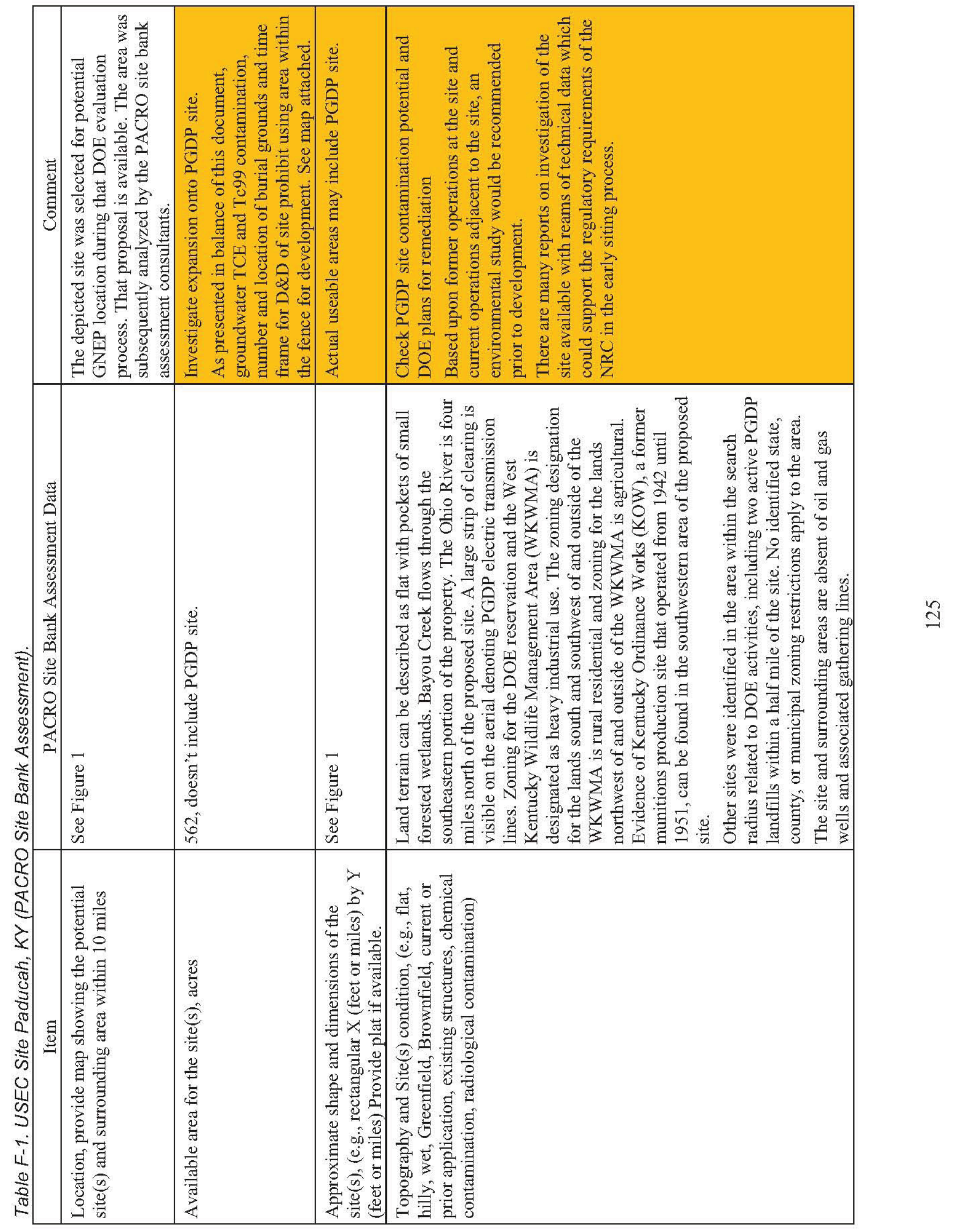




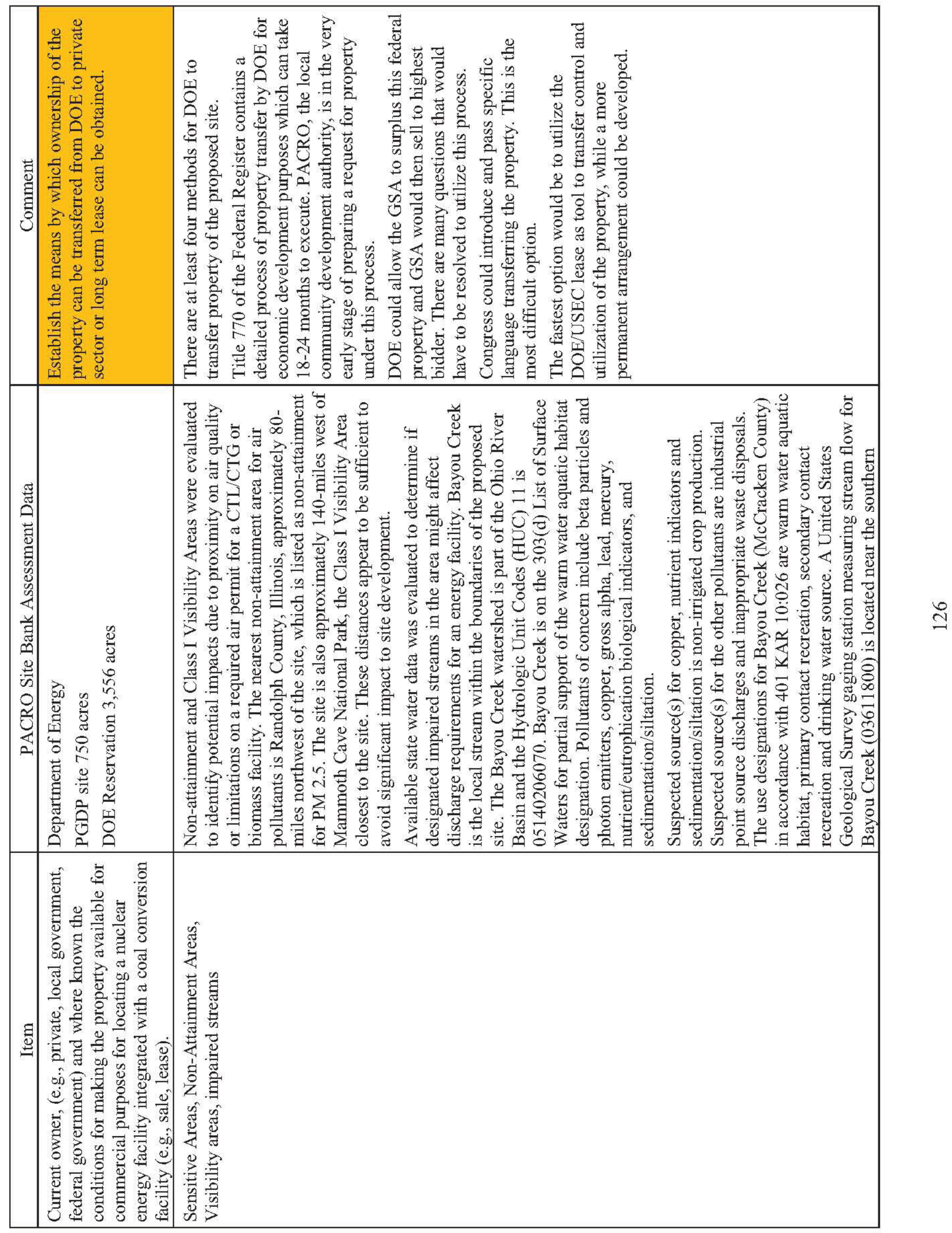




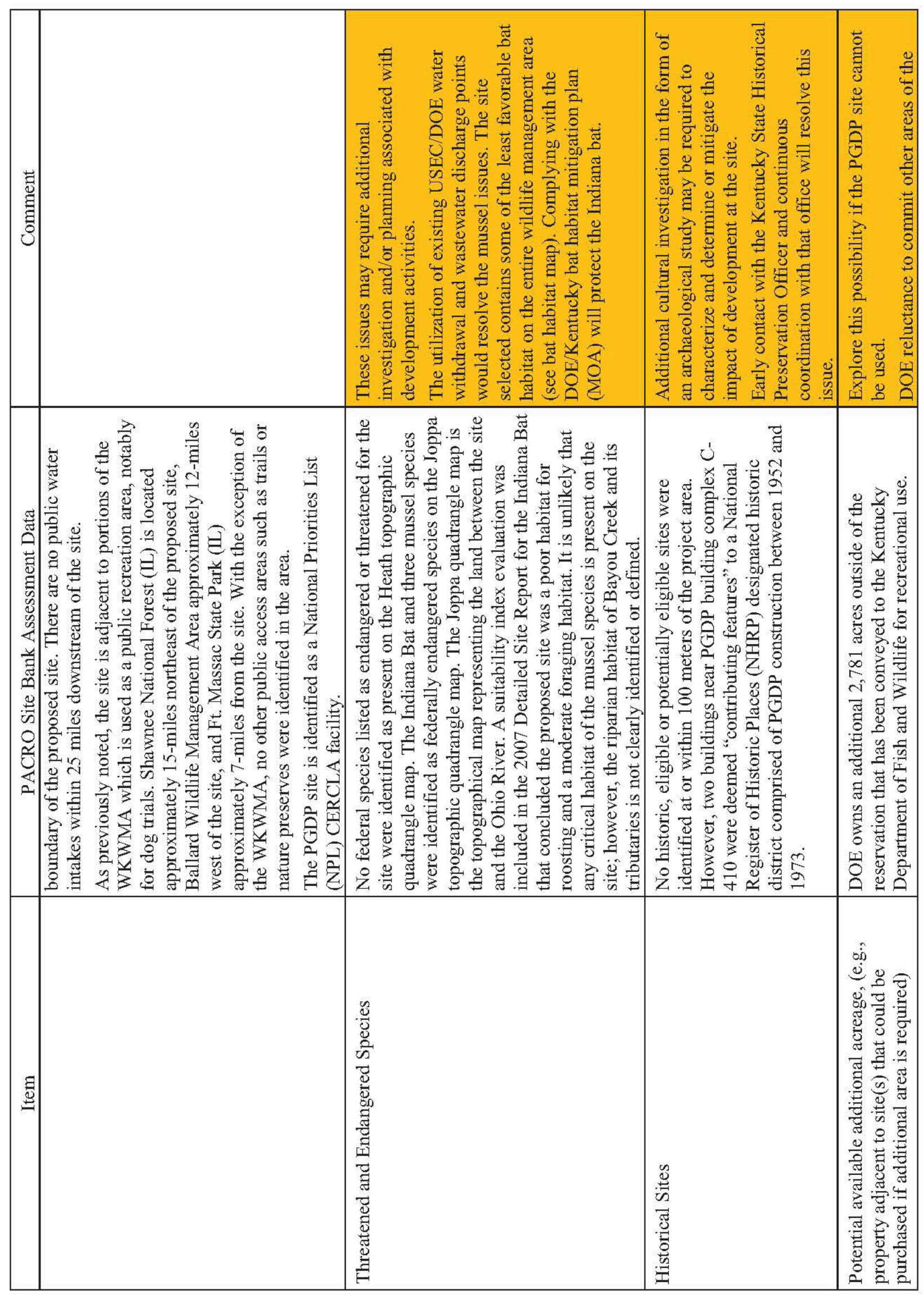




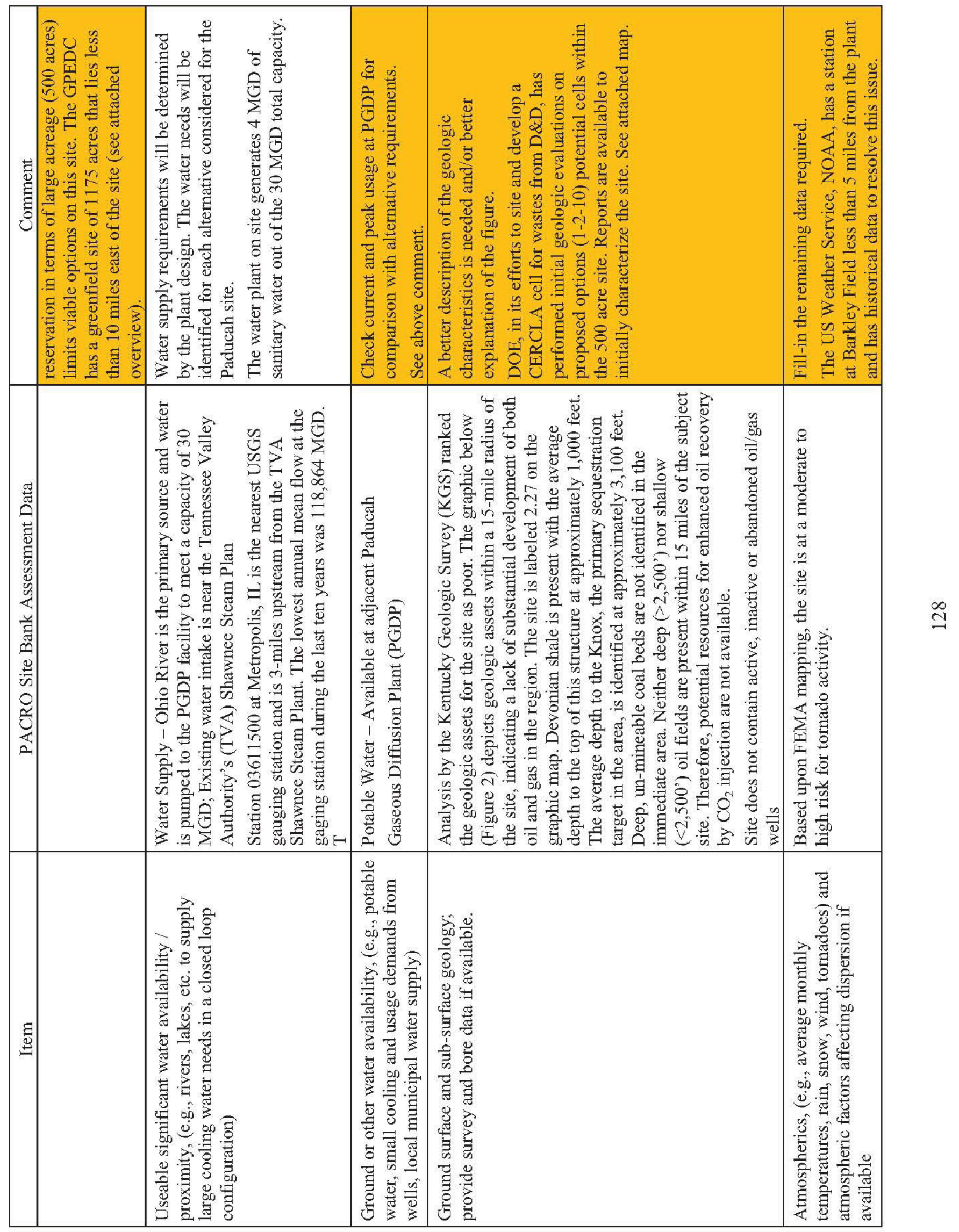




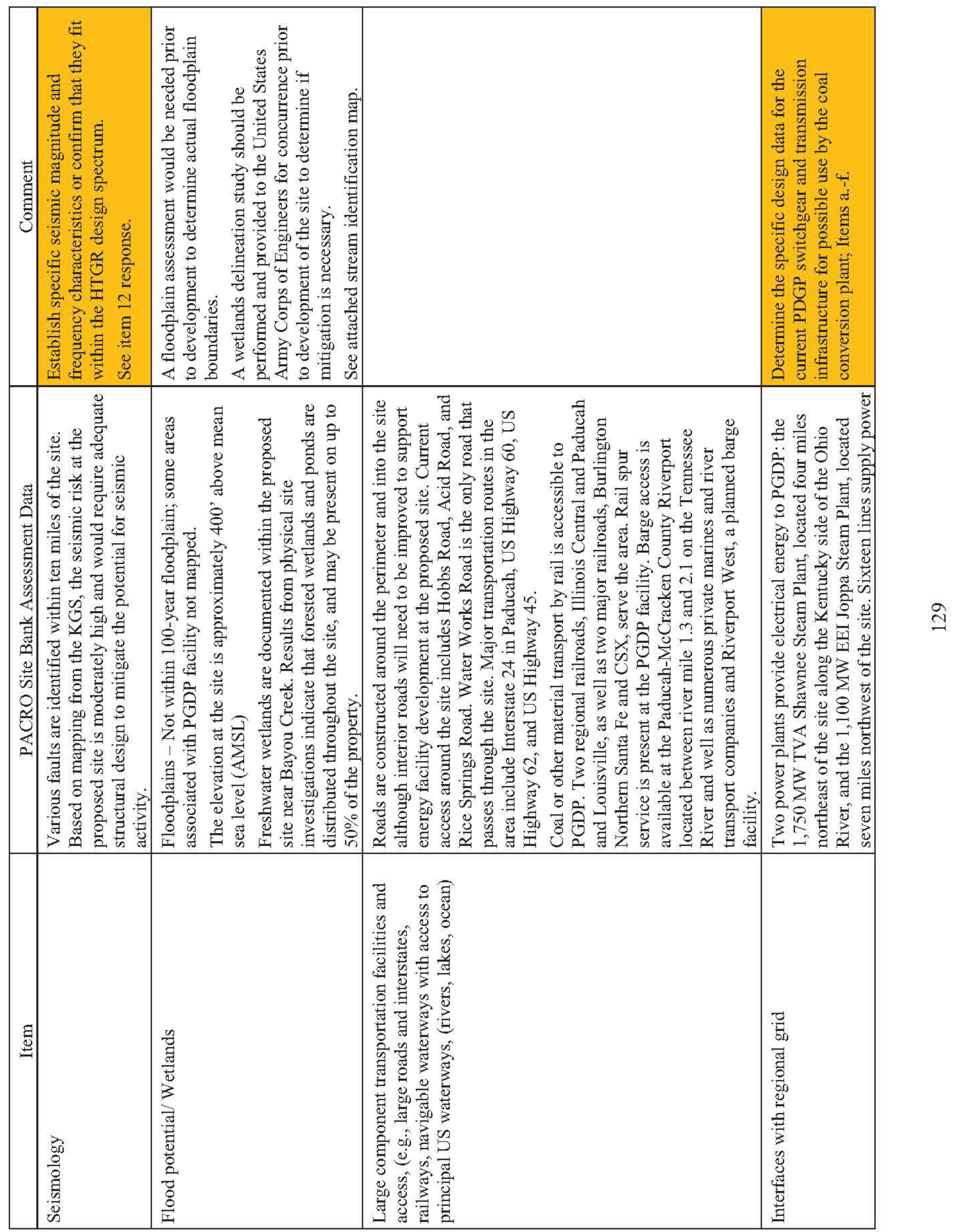




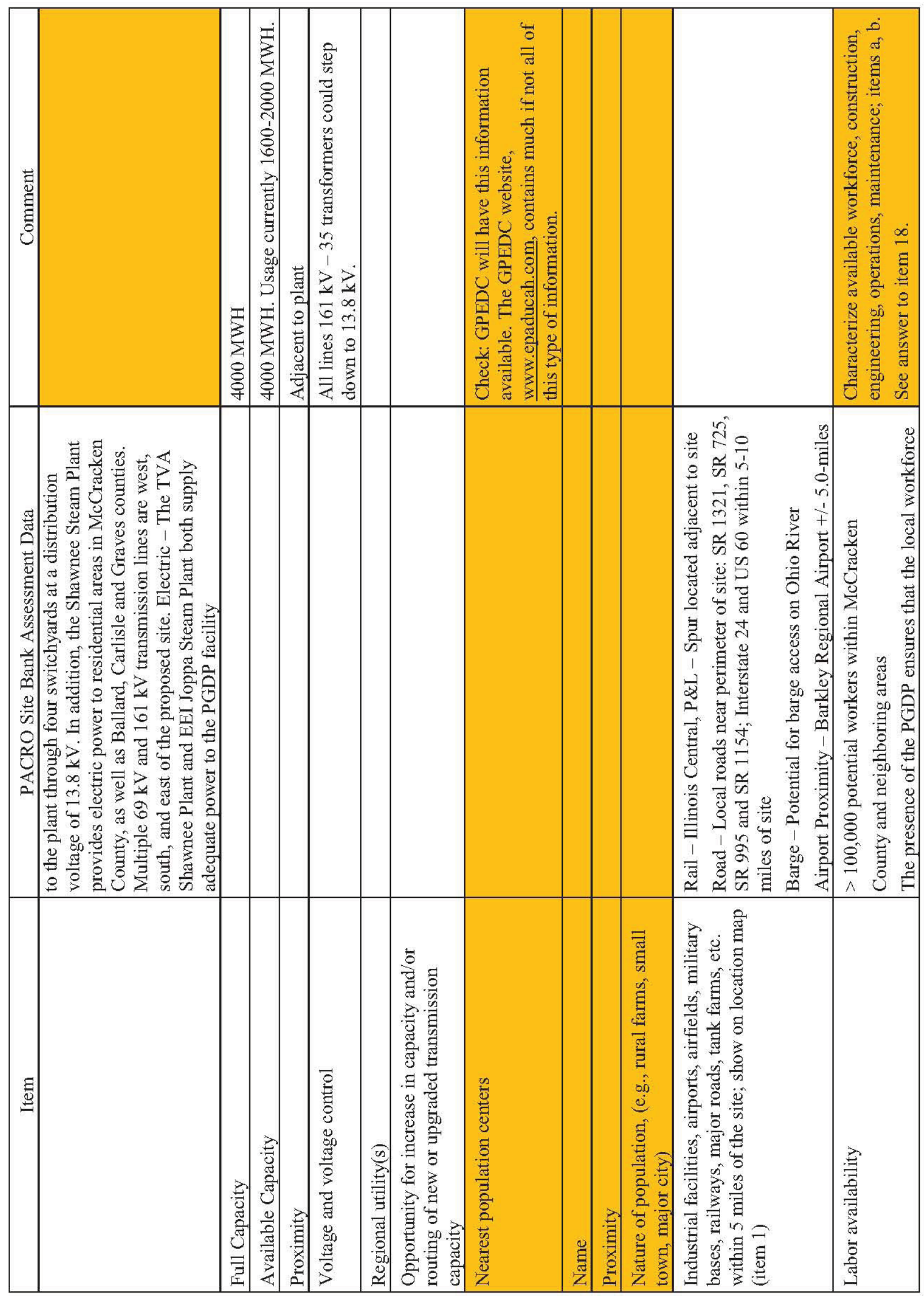




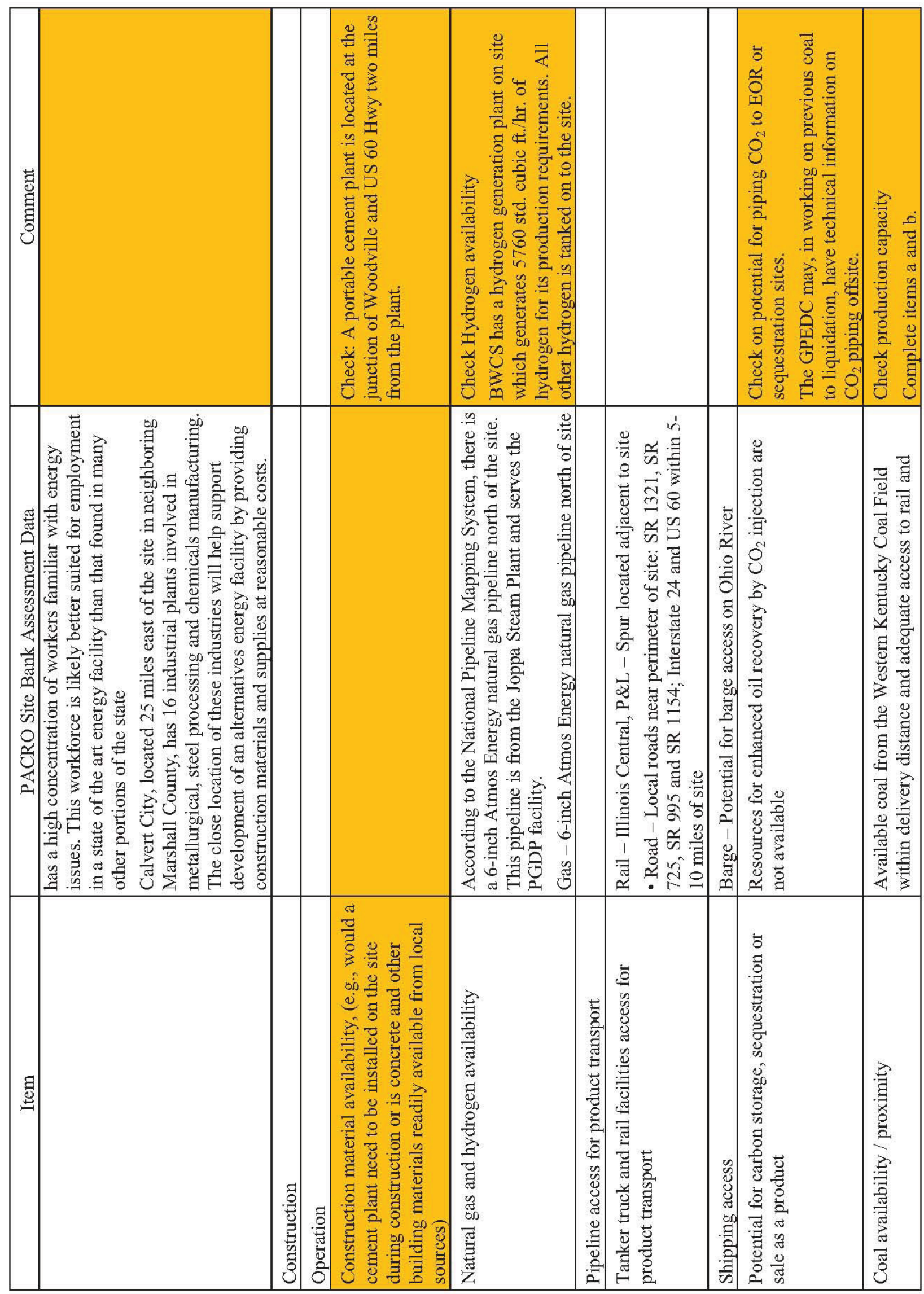



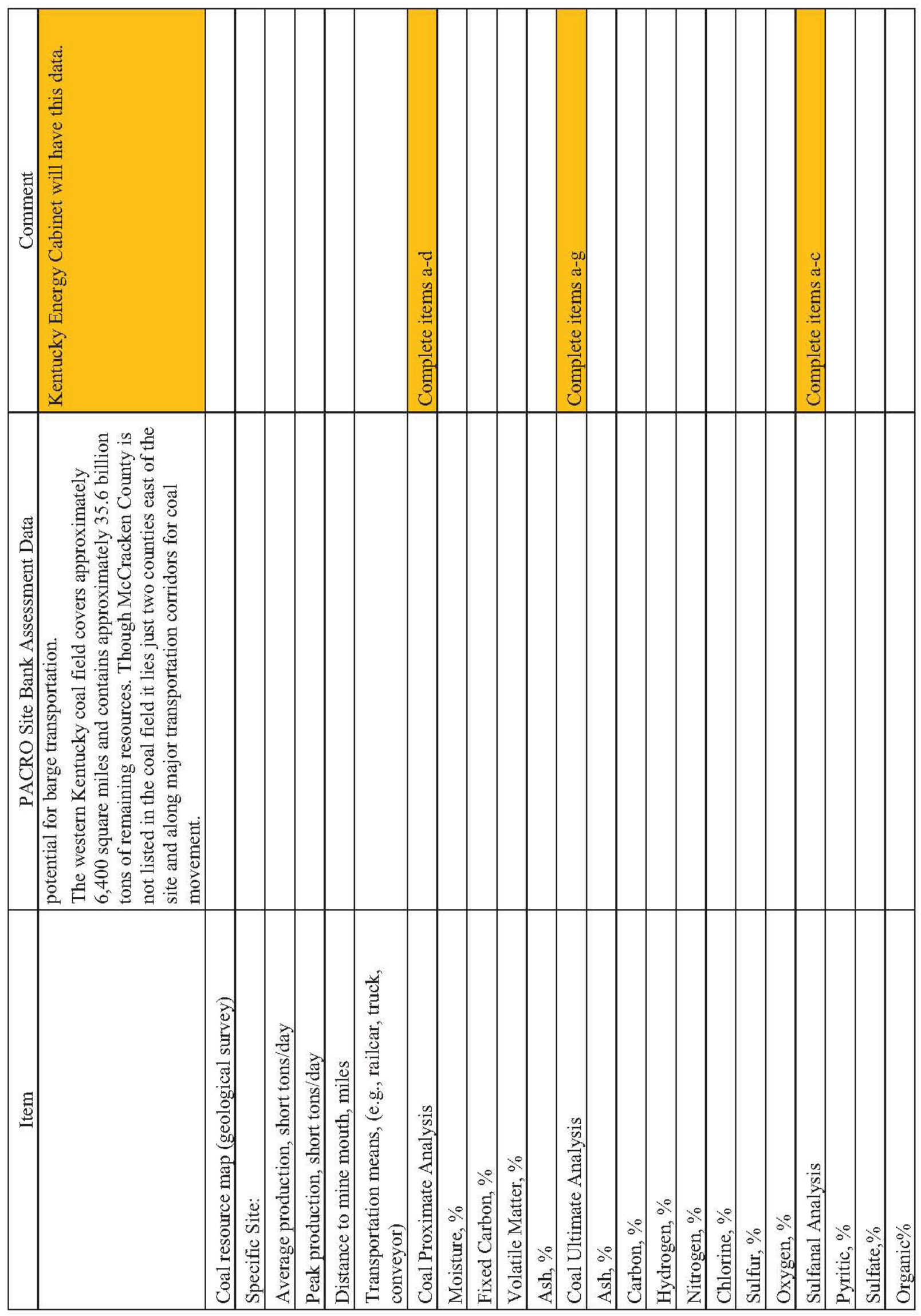


\section{F-1.3 Ohio River Triple Rail Megasite}

Paducah Economic Development is promoting a 2000 acre site Northeast of the PGDP on the Ohio River for large scale industrial development. This site has access to rail, major roads and the Ohio River, see Figure F-3. It is understood that a large coal storage and transport facility and an $\sim 23,000 \mathrm{bpd}$ coal to liquids (CTL) plant are currently planned for the site. The coal facility will feed the CTL plant and could supply a similar facility at the PGDP plant. The proposed CTL plant is the Secure Energy Paducah Gasification Plant and has obtained the necessary permits for and has initiated limited construction at the time of this writing. [refs on Secure Energy Plant]

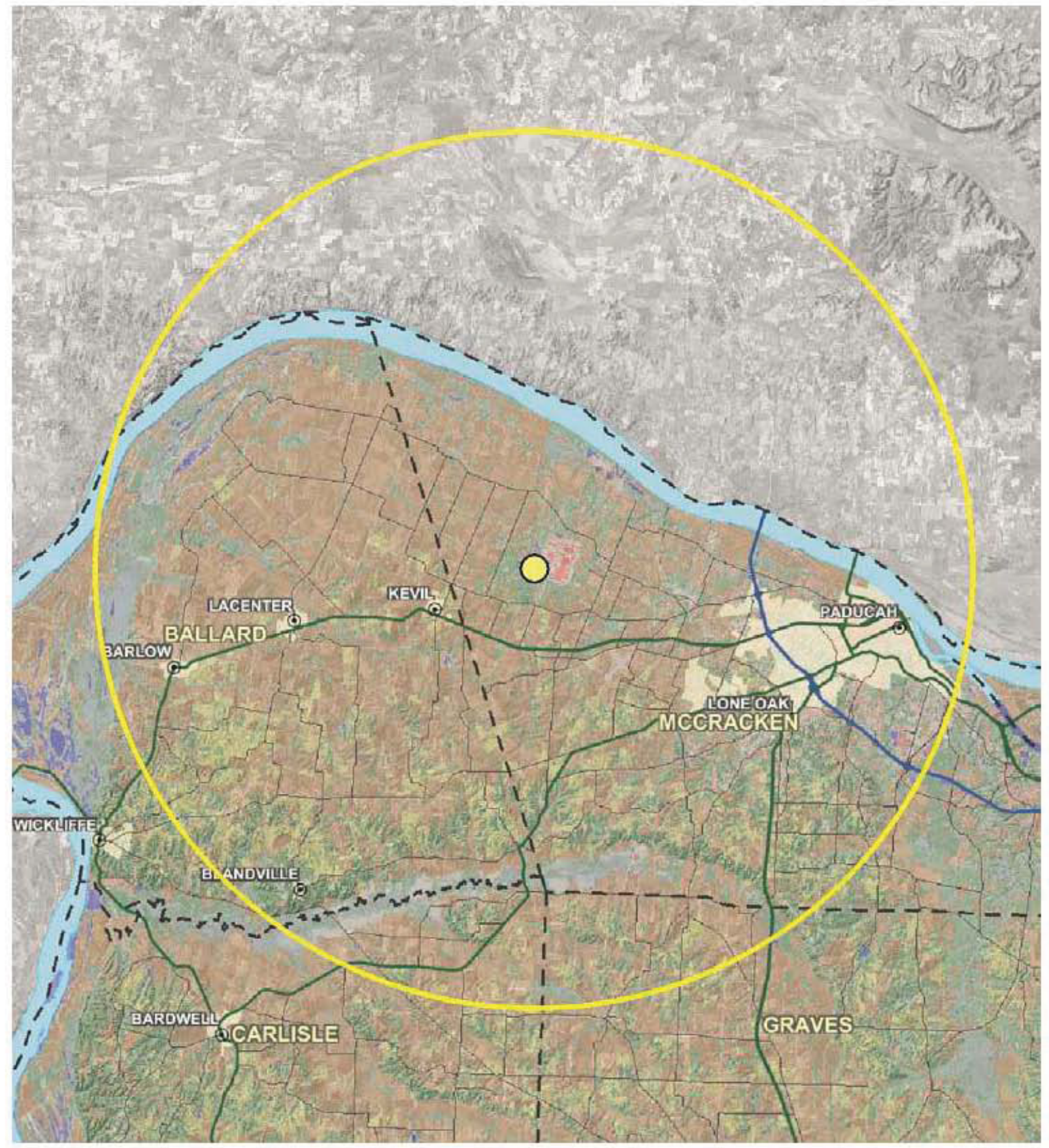

Figure F-3. Geological characterization. 
The Ohio River Triple Rail Megasite is adjacent to the Tennessee Valley Authority's (TVA) coal fired Shawnee power plant that provides the electrical power to the PGDP. This plant accounts for a large percentage of the TVA revenue. It is uncertain how long TVA intends to continue operation of this plant. This may provide an opportunity to site a natural gas fired plant in the short term either on this site or the PACRO site to provide the needed power for the Megasite and PACRO development. This plant could be converted over the longer term to an HTGR based plant when that technology is commercialized.

\section{F-2. PROCESS DEPLOYMENT}

The principal objectives of the strategy are to deploy a carbon conversion plant as soon as possible producing liquid fuels competitive with conventional fuels and/or chemicals with a long term objective of incorporating the HTGR and, where applicable, the HTSE technologies to achieve a process with minimal greenhouse gas emissions and stable operating costs. This minimizes the time to begin to take advantage of the benefits of the plant, meeting the principal short term objectives with the objective of incorporating nuclear technology in supplying the energy needs of $\mathrm{KY}$ in view.

\section{F-2.1 First phase Deployment (2013-2028)}

\section{F-2.1.1 Process Plant Module Size}

Construction and commissioning of the Conventional process plant in the first phase of deployment will be done in four unit increments or modules. This approach is taken to reduce the annual capital funding requirements by spreading implementation to full capacity over a longer period and thereby facilitate financing. Modularization is also the key to early and phased development by using the first increment to prove the principle, iron out fabrication, construction and operating problems and begin operation to generate revenue as soon as possible. A review was made to determine the factors that affect the smallest module capacity that is viable using commercially available equipment. The following summarizes the results of that review for plants using the Fischer-Tropsch (FT) and methanol processes.

For a Fischer Tropsch process, the size of a single project phase may be dictated by the capacity of any of the following plant sections: gasification, FT synthesis, or air separation. In many cases, the size of the FT reactor may be the limiting factor. The largest single slurry bubble column FT reactor in operation today has a capacity of $\sim 17,000$ bpd. Based on INL's conventional CTL model, a plant of this size would require a feed rate of 9,160 ton/day of Illinois $\# 6$ coal. After drying the coal to $6 \%$ moisture, the corresponding feed rate of dry coal would be 8,410 ton/day. This slightly exceeds the nameplate capacity for two large-scale Shell coal gasifiers $(\sim 4,000$ ton/day of dried coal each). Hence, if the FT reactor is turned down or scaled down slightly to match the capacity of two gasifiers, the plant capacity would be approximately $16,000 \mathrm{bpd}$. The oxygen requirement for a $16,000 \mathrm{bpd}$ plant would be $6,080 \mathrm{ton} / \mathrm{day}$. This exceeds the capacity of a world-scale single-train air separation unit (3,900 tonne/day or 4,300 ton/day). If the plant is further scaled back to require only a single air separation unit of this size, the resulting plant capacity would be $11,300 \mathrm{bpd}$. Obviously these values will be influenced by the specific gasifier and FT reactor designs selected, but the minimal reasonable size for a single module of a large FT project appears to be between 11,000 and $17,000 \mathrm{bpd}$.

A similar analysis also applies to a gasoline plant using the MTG process. The MTG reactors are considerably smaller than the large FT reactors used in Sasol's Oryx GTL plant; hence, multiple methanol-to-gasoline conversion reactors would be required for a plant of that size $(34,000 \mathrm{bpd})$. However, the size for a project phase could be limited by the size of a single methanol train. In recent years, 5,000 tonne/day (5,500 ton/day) single-train methanol plants have been built. Designs for a singletrain 10,000 tonne/day (11,000 ton/day) have also been proposed and designed. Based on INL's

conventional coal-to-methanol-to-gasoline model, a single 5,000 tonne/day methanol train could produce 
18,400 bpd total gasoline and liquid petroleum gas (LPG). These plants would also require air separation units as with the F-T plants. Hence, the minimal reasonable size for a single module of a large MTG plant appears to be between 11,000 and $18,000 \mathrm{bpd}$.

For the purposes of this study the module size for an F-T plant is assumed to be $12,500 \mathrm{bpd}$; four modules supporting the goal of ultimately deploying a plant with 50,000 bpd capacity. For a coal to gasoline or chemicals plant using methanol reactors the module capacity is assumed to be 17,000 bpd; four modules achieving $\sim 67,000 \mathrm{bpd}$ of production assumed in the $\mathrm{INL}$ analyses.

\section{F-2.1.2 Reference Plant Design and Deployment}

A coal to gasoline plant has been selected for the purposes of analyzing its deployment on the Paducah site. It would have a maximum production capacity of 67,000 bpd inclusive of $62,000 \mathrm{bpd}$ of gasoline and $5,000 \mathrm{bpd}$ of LPG. The plant would be comprised of four identical modules of $25 \%$ capacity each. These modules would be independent of each other so could be constructed, operated and maintained independently.

Figure $\mathrm{F}-4$ is a flow sheet for the coal to gasoline (CTG) process showing the principal components that would be deployed as part of the initial plant. This process uses a steam methane re former (SMR) to supply hydrogen to the gasification process. This supply is used in lieu of the water shift reaction that is typically used to supply hydrogen within the gasifier. The use of the SMR reduces the generation of $\mathrm{CO}_{2}$ by $70 \%$ over the traditional process and also facilitates incorporation of the HTGR technology which reduces the $\mathrm{CO}_{2}$ emissions to less than $40 \%$ of the conventional case. Figure $\mathrm{F}-5$ shows the flow sheet with the HTGR integrated into the process.

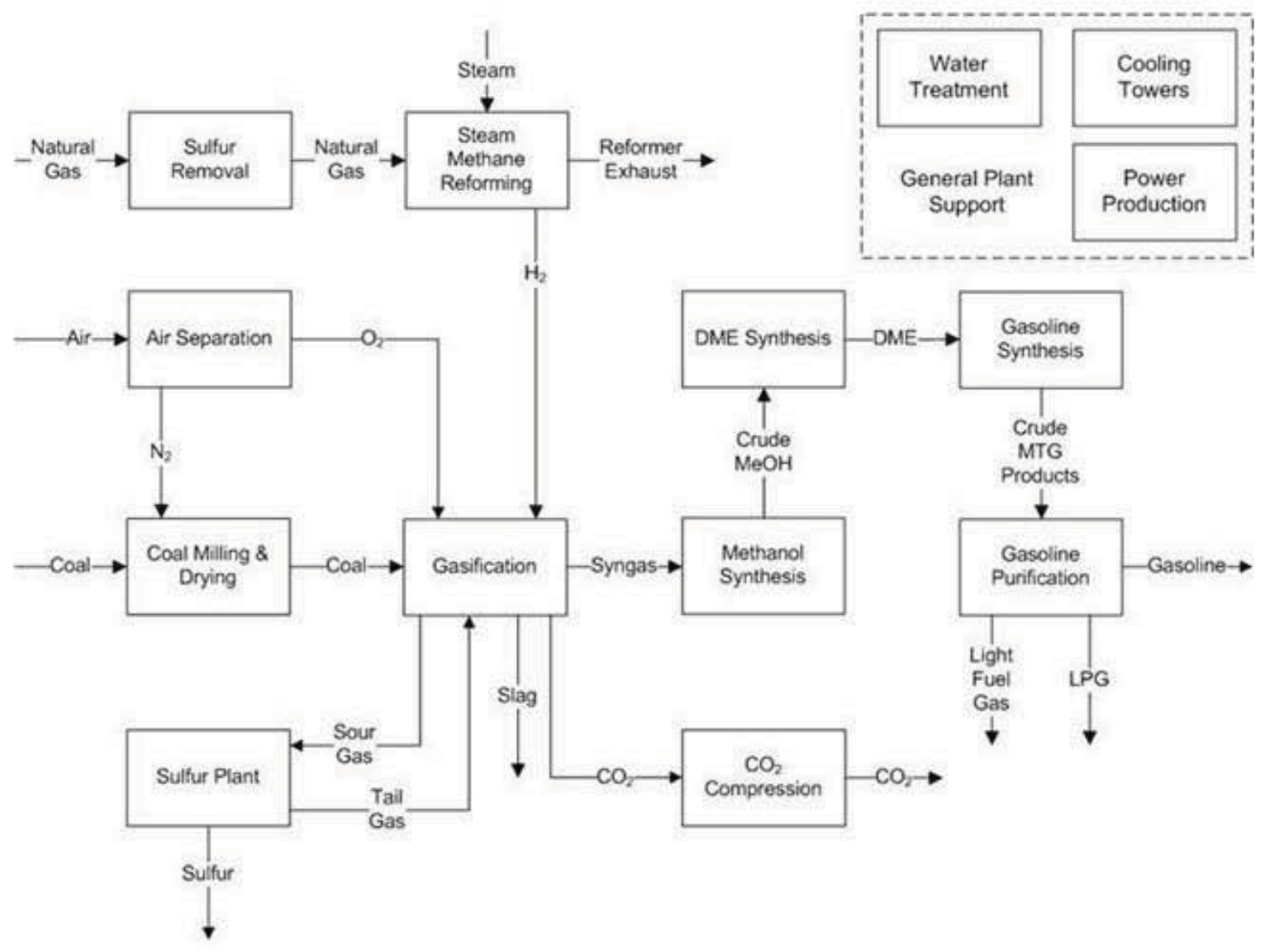

Figure $F 4$. Conventional CTG plant with SMR hydrogen supply. 


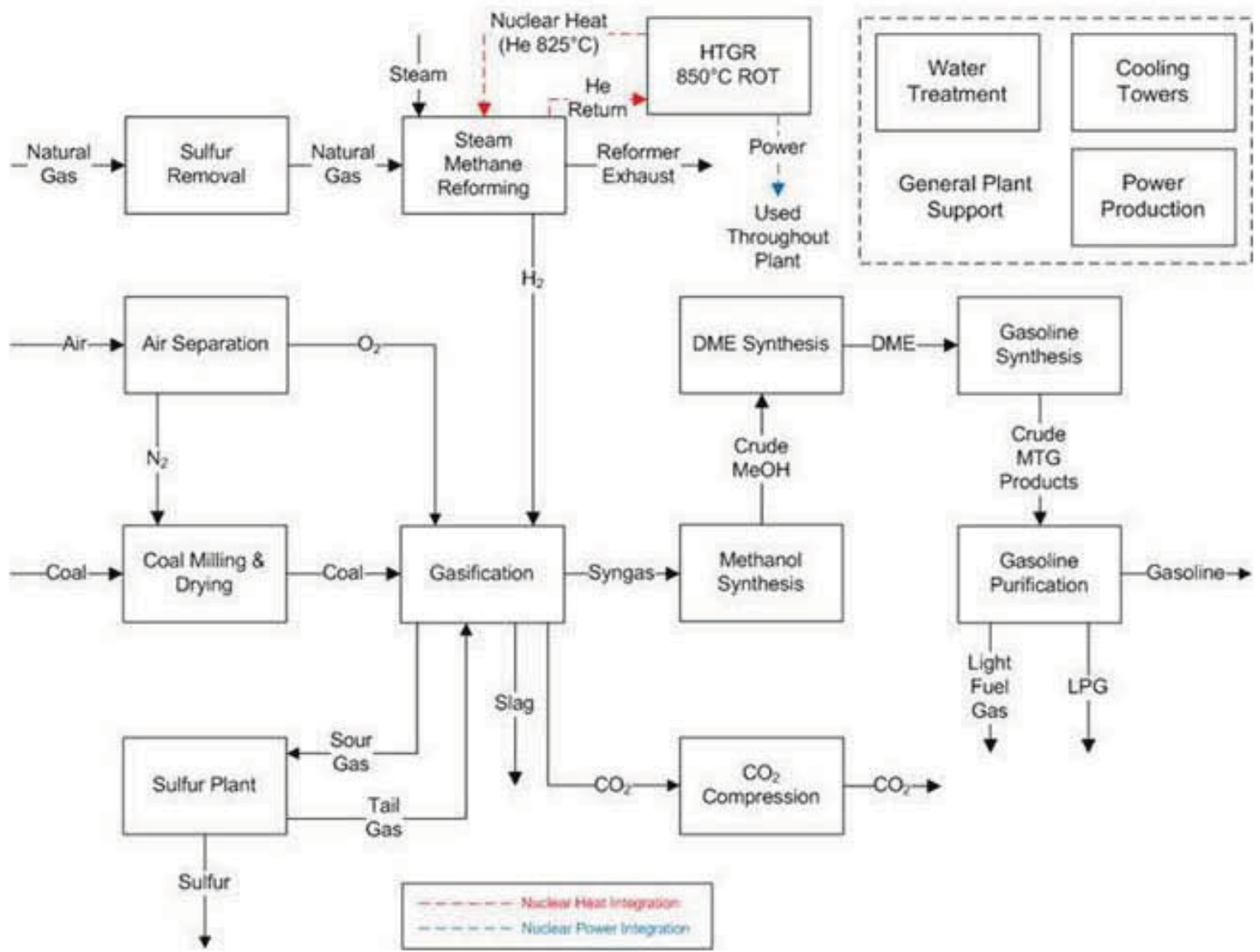

Figure F-5. CTG plant with an HTGR supplying heat and electricity to the SMR hydrogen supply.

Figure F-6 summarizes the performance characteristics of this plant; comparing the performance of the conventional plant with the HTGR integrated plant. As noted previously the significant additional reduction in $\mathrm{CO}_{2}$ emissions is shown.

Review of Figure F-6 shows that in addition to the 12,000 tpd ( $3.5 \mathrm{MMtpd}$ per year at $80 \%$ capacity factor) of coal consumed by this plant it consumes $\sim 200$ to $\sim 300$ MMSCFD (58.4 to 87.6 billion cubic feet per year at $80 \%$ capacity factor) of natural gas supplied to the steam methane reformer. The latter range depends on whether the HTGR has been integrated into the process; its integration lowers the amount of natural gas feed. These usages represent $~ 3 \%$ of the total production of coal, $8 \%$ of the total consumption of coal, 45 to $67 \%$ of the total production of natural gas and $25 \%$ to $38 \%$ of the total consumption of natural gas in Kentucky in 2010. Accordingly, this single plant provides a significant internal market for these indigenous resources. 

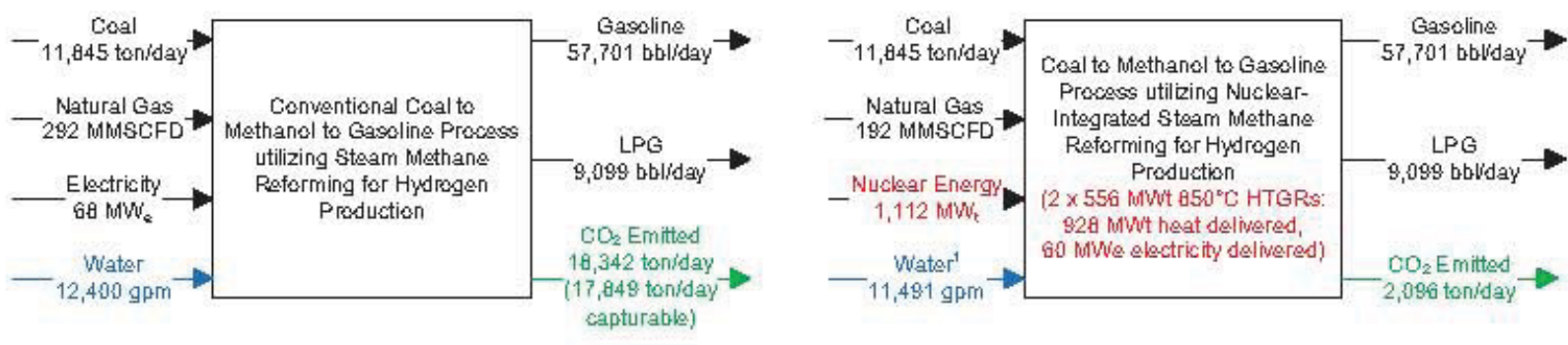

${ }^{1}$ Does not include heat rejection requirement for the nuclear or HTSE plants.

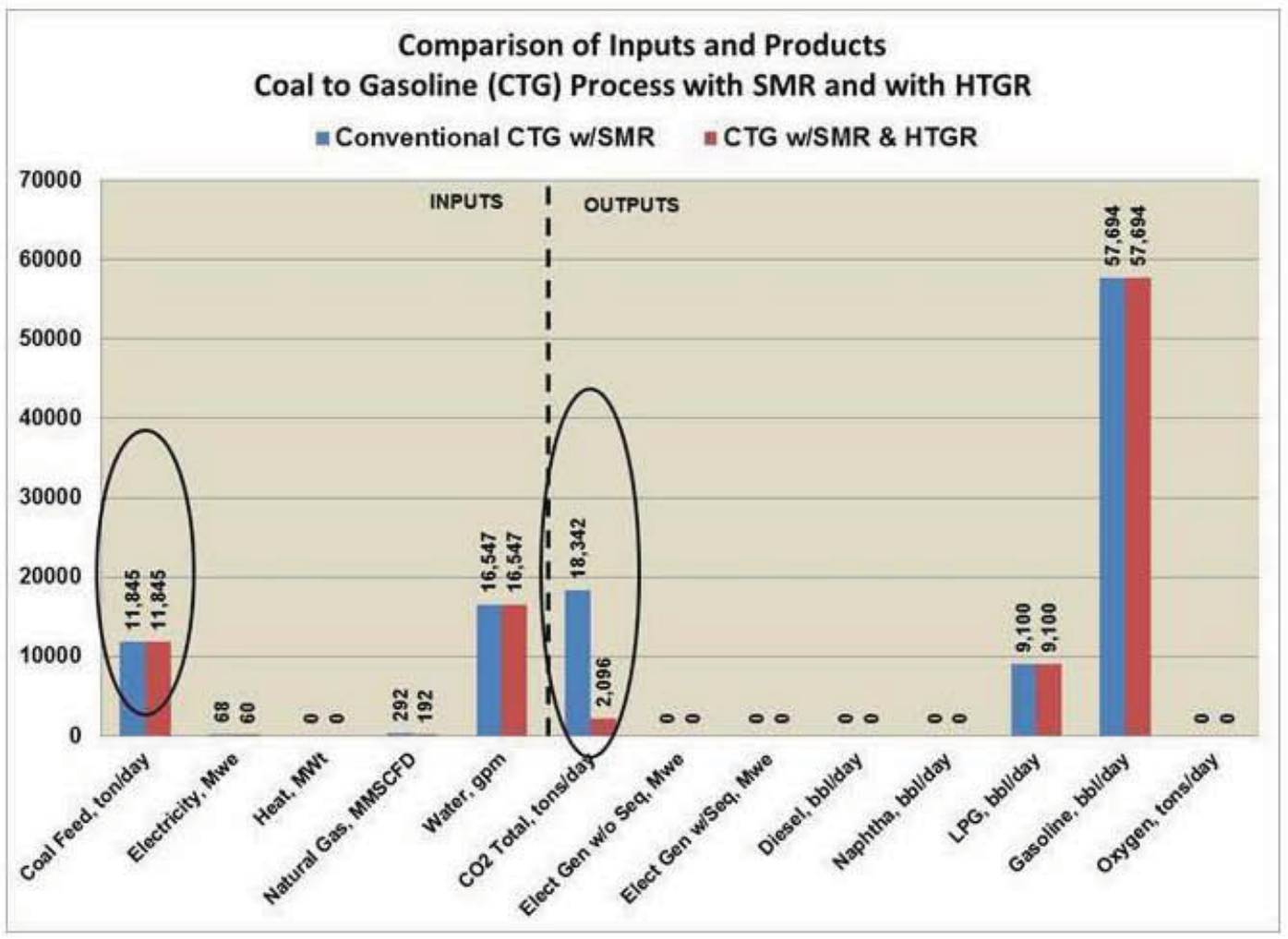

Figure F-6. CTG plant performance characteristics.

Figure F-7 is a notional depiction of the plant view of this plant when fully developed. The required area for the plant when fully deployed is one mile long by $2 / 3$ of a mile wide, not including the rail spur, comprising a total area of $\sim 430$ acres. Since this would take up the full acreage of the original site proposed by PACRO the addition of acreage cited previously is needed to accommodate the addition of the HTGR plant with additional electricity generation capacity. It is emphasized that this is a notional layout derived from multiple and existing and planned coal conversion facilities and does not represent any specific facility. The actual plant component selections and layout would be part of the plant design process.

The HTGR plant shown in phantom on Figure F-7 is a 4-600 MW(t) module plant supplying -930 $\mathrm{MW}(\mathrm{t})$ of heat and $60 \mathrm{MW}(\mathrm{e})$ to the process and $\sim 550 \mathrm{MW}(\mathrm{e})$ to the regional grid. This plant would also be deployed in a phased approach by module. The deployment of this plant would not only be the first step in integrating the HTGR technology into the carbon conversion processes but would also be the first step in integrating this technology into the mix of electricity generation in Kentucky. The full scope of these integrations is discussed further in latter sections of this report. 


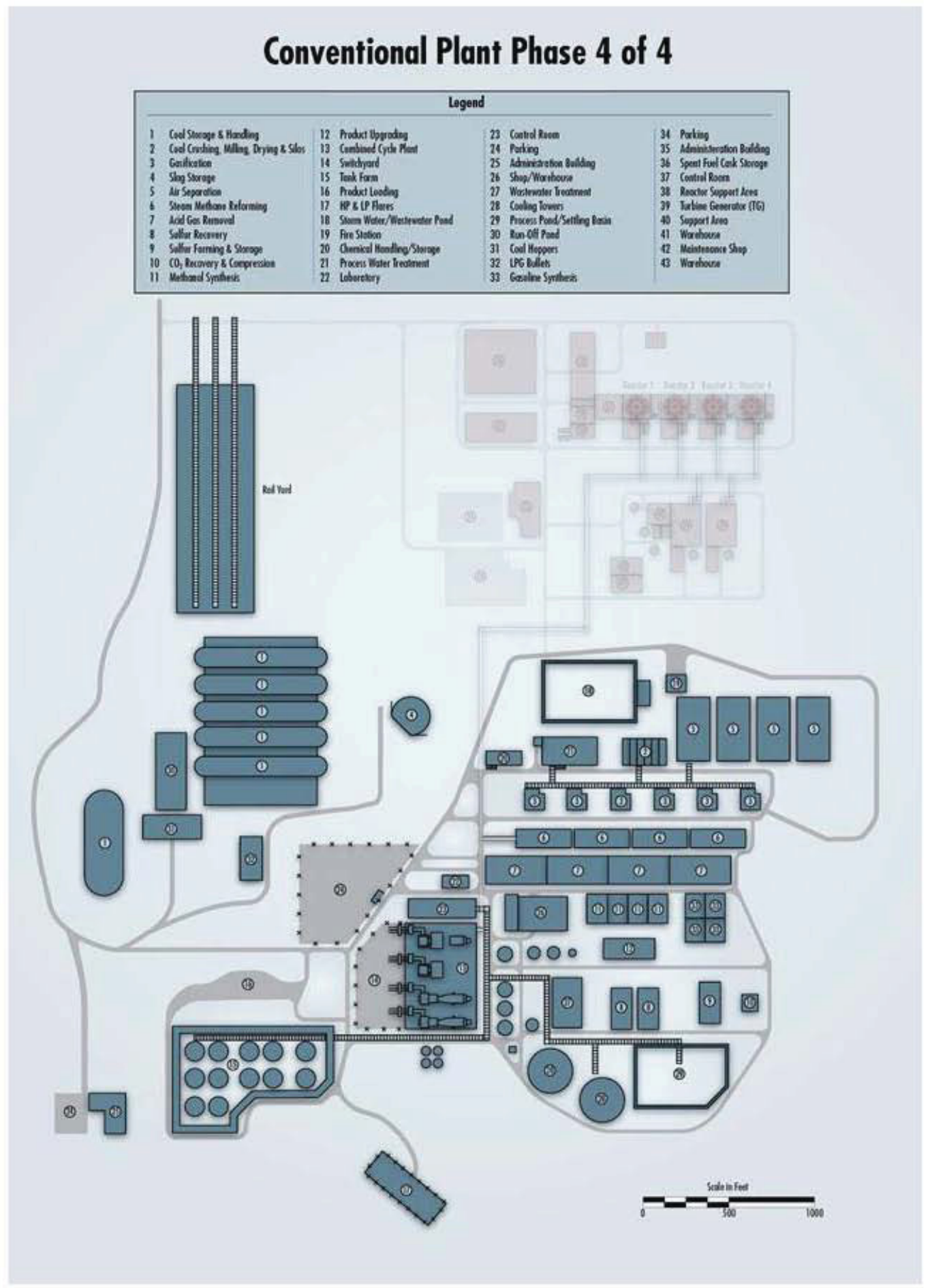

Figure F-7. Notional plan view of fulty deployed CTG plant.

Figure F-8 shows the full site deployed including the CTG and the HTGR plants. This site is one mile wide and more than a mile deep comprising $\sim 675$ acres. Placing this on the proposed 1,000 acres site near the PGDP would provide a relatively small area for further expansion if market conditions are favorable. 


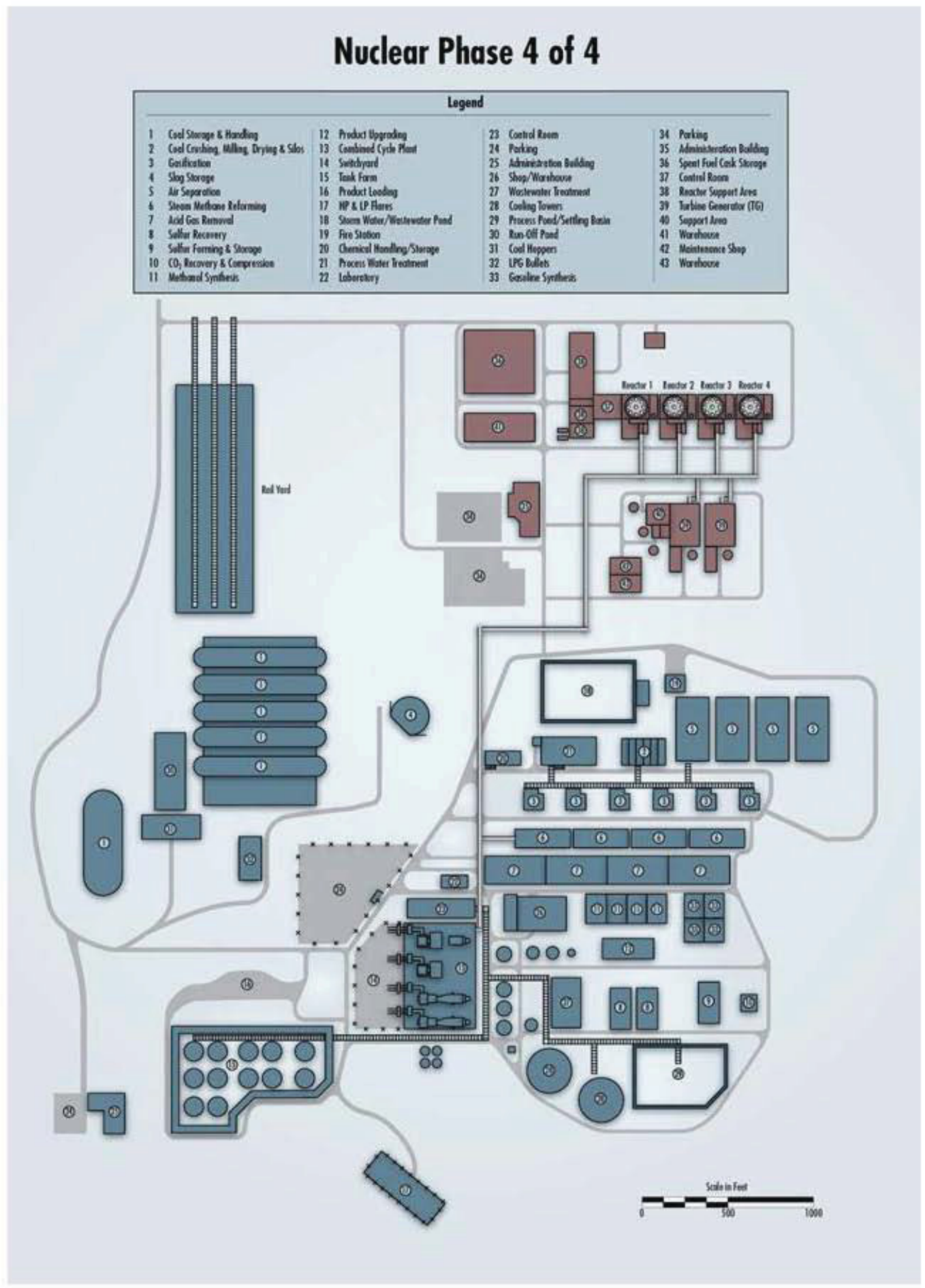

Figure F-8. Paducah CTG plant with SMR and HTGR fully deployed.

\section{F-2.1.3 Paducah Process Plant Deployment}

Figure F-9 is a notional schedule for deployment of a conventional four module 67,000 bpd CTG w/SMR plant using the methanol to gasoline (MTG) process. Figure F-9 is an estimate of the annual funding profile for this deployment schedule based on the INL estimates of the cost of this plant in $2011 \$$. For the purposes of preparing the schedule it is assumed that the Project to deploy the plant begins in 
2013. The capital investment assumes a 3\% inflation factor, a debt to equity ratio of $80 \%$, an interest rate during construction of $8 \%$, a financing interest of $8 \%$ and a financing term of 20 years. Figure F-10 shows the breakdown of annual funding by the amount financed, the required equity and the interest during construction. As shown the peak annual funding required is above $\$ 2 \mathrm{~B}$ in the $5^{\text {th }}$ year. This reflects the fact that some construction is going on with all four modules. The overlap in construction is required to complete the full project in an assumed seven year period. This large expenditure in one year may require a larger work force than can be accommodated at that selected site. Detailed discussion with an EPC is required to make a determination if the schedule should be extended to reduce the peak expenditure required in a single year. If that is the case the schedule for deployment of the $2^{\text {thd }}$ through $4^{\text {th }}$ module would also need to be extended.

The effort to deploy the first module will include items that will not be included in the effort required to construct subsequent modules, such as final design work to adapt the first and subsequent modules to the site, site preparation and long term procurement for the first and ultimately for subsequent modules. Based on prior INL experience the cost to deploy the first module will account for about $40 \%$ of the total estimated project cost, (the cost to complete the construction and commissioning of the four module plant). Some of this upfront work carries over into the cost of the second module, (e.g., long term procurement) and its cost is about $25 \%$ of the total with the third and fourth module costs covering $18 \%$ and $17 \%$ of the total cost, respectively.

The times to construct and commission the modules also vary with the first module taking an estimated 5 years; final design, permitting, early site preparation and long term procurement taking the first two years. This effort and long term procurement expenses account for about $10 \%$ of the total cost of the Project. It has been assumed that there will be a one year "shake-down" period of operation of the first module before initiating the operation of the second module. The construction period of the second module is estimated at 40 months so it begins 28 months before the end of the "shakedown" operating period of the first module. Initial operation of the third and fourth modules is then assumed to occur at 6 month intervals following initial operation of the second module. The total time from start of the Project to full deployment is 7 years.

\begin{tabular}{|c|c|c|c|c|c|c|c|c|c|c|c|}
\hline Activity & 10 & 11 & 12 & 13 & 14 & 15 & 16 & 17 & 18 & 19 & 20 \\
\hline \multicolumn{12}{|l|}{$\begin{array}{l}\text { Development \& Deployment of } 58,000 \\
\text { BPD CTG Plant w/SMR }\end{array}$} \\
\hline \multicolumn{12}{|l|}{ First Phase CTG Plant Deployment } \\
\hline \multicolumn{12}{|l|}{ Design, Permitting, Site Preparation } \\
\hline \multicolumn{12}{|l|}{ Procurement } \\
\hline \multicolumn{12}{|l|}{ Construction } \\
\hline \multicolumn{12}{|l|}{ Startup and test } \\
\hline \multicolumn{12}{|l|}{ Initiate commercial operation } \\
\hline \multicolumn{12}{|l|}{ First Module "Shakedown" Operation } \\
\hline \multicolumn{12}{|l|}{ Second Module Deployment } \\
\hline \multicolumn{12}{|l|}{ Third Module Deployment } \\
\hline \multicolumn{12}{|l|}{ Fourth Module Deployment } \\
\hline \multicolumn{12}{|l|}{ Plant Fully Operational } \\
\hline & & & & & & & & & & & \\
\hline
\end{tabular}

Figure F-9. CTG plant w/SMR first phase deployment. 


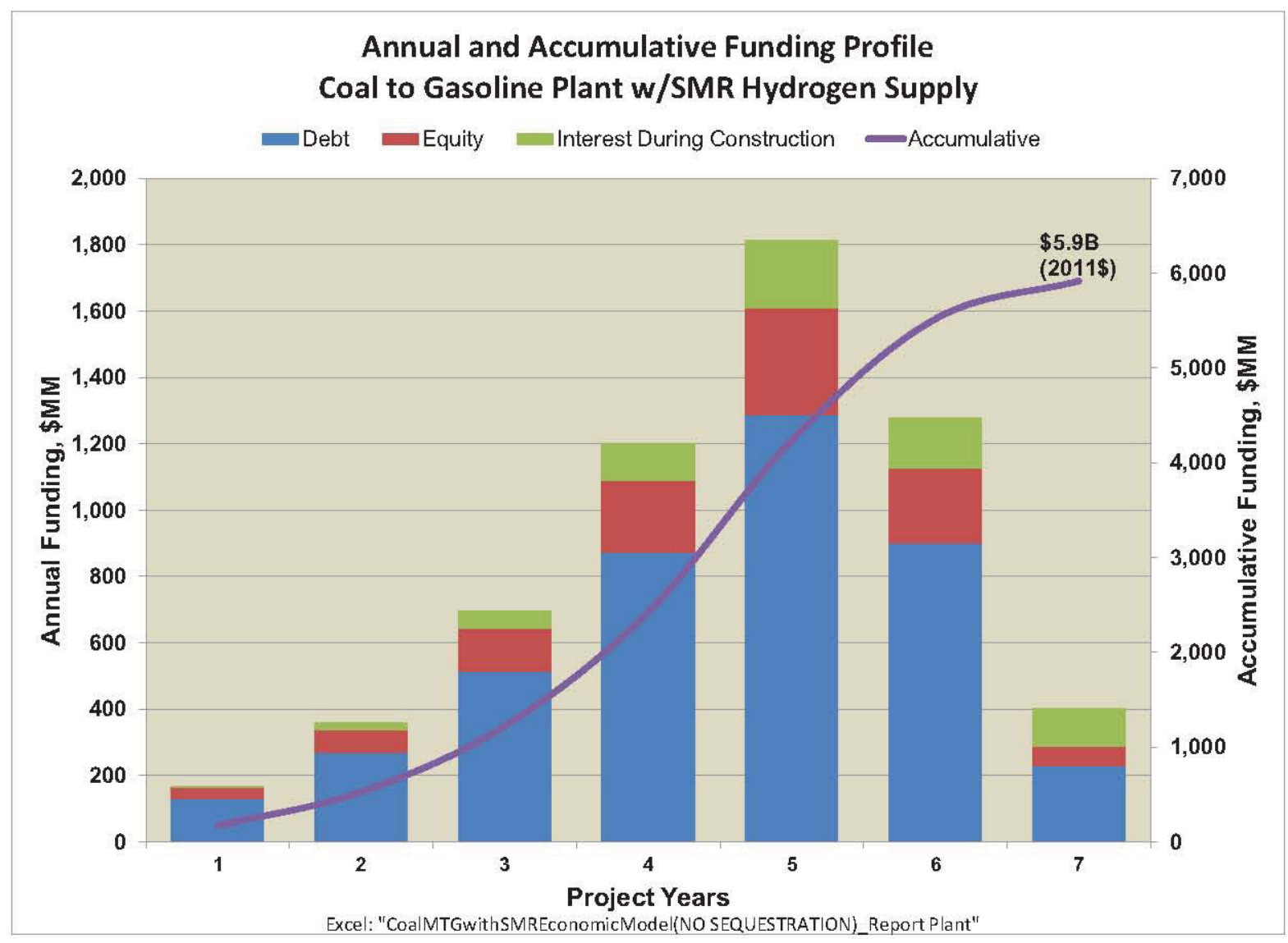

Figure F-10. Annual and accumulative funding requirements.

Figure F-11 shows the number of jobs required during the construction of the process plant. On average 4,400 personnel will be required per year with a peak of 9,300 on the $5^{\text {th }}$ year. It is judged that the Paducah area labor force will be adequate to fill the majority of these jobs. The breakdown in estimated expenditures for the plant projects that $56 \%$ of the total cost will be in labor, $30 \%$ in equipment procurement and $14 \%$ in material procurement. It is expected that the majority of labor and material will be supplied from within Kentucky and, specifically, the Paducah area. Coordination with Kentucky interests in the industrial sector would ensure that as much of the equipment procurement as possible would be from Kentucky sources. At a projected cost of $\sim \$ 7$ billion dollars (escalated cost over the construction period) this would represent a significant boost to the Kentucky economy. When fully deployed the process plant will employ $\sim 400$ with significant increases in personnel during turnarounds. 


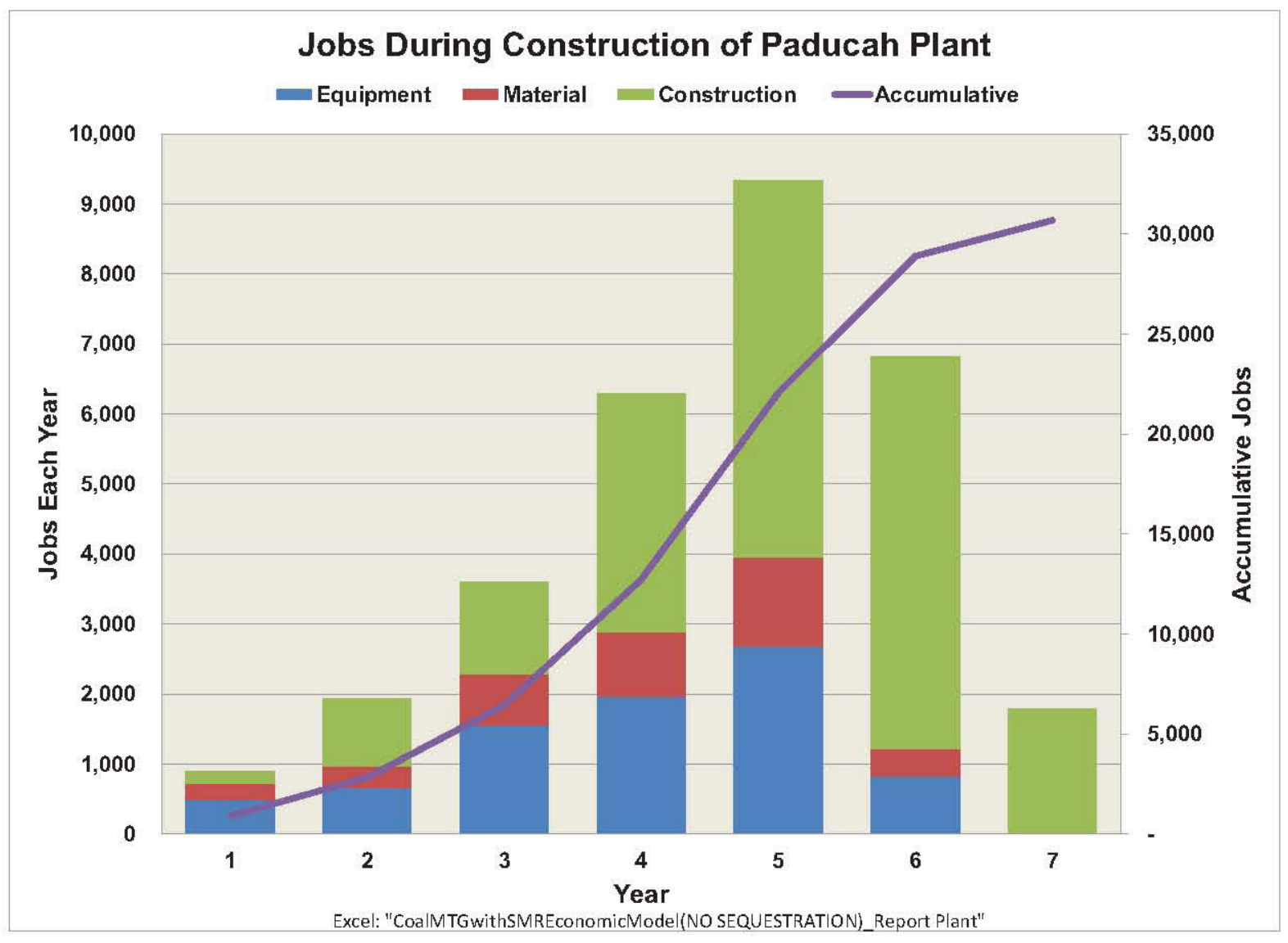

Figure F-11. Jobs during construction of Paducah process plant.

Figure F-12 shows cumulative cash flow for this plant through 2028. The product revenues are based on the prices required to achieve 10\% IRR (after tax) over the economic period of the plant; assumed to be 27 years, (the time to retire the debt). As shown the Project achieves full return of investment between 17 and 18 years from initiation. The maximum negative cash flow is $\sim \$ 2.0 \mathrm{~B}$ just as the first module is completed and begins operation. If it is necessary to extend the schedule because annual work scope is too large or the annual expenditure rate is too high the costs will increase due to inflation and the time to recover the full investment will be longer. 


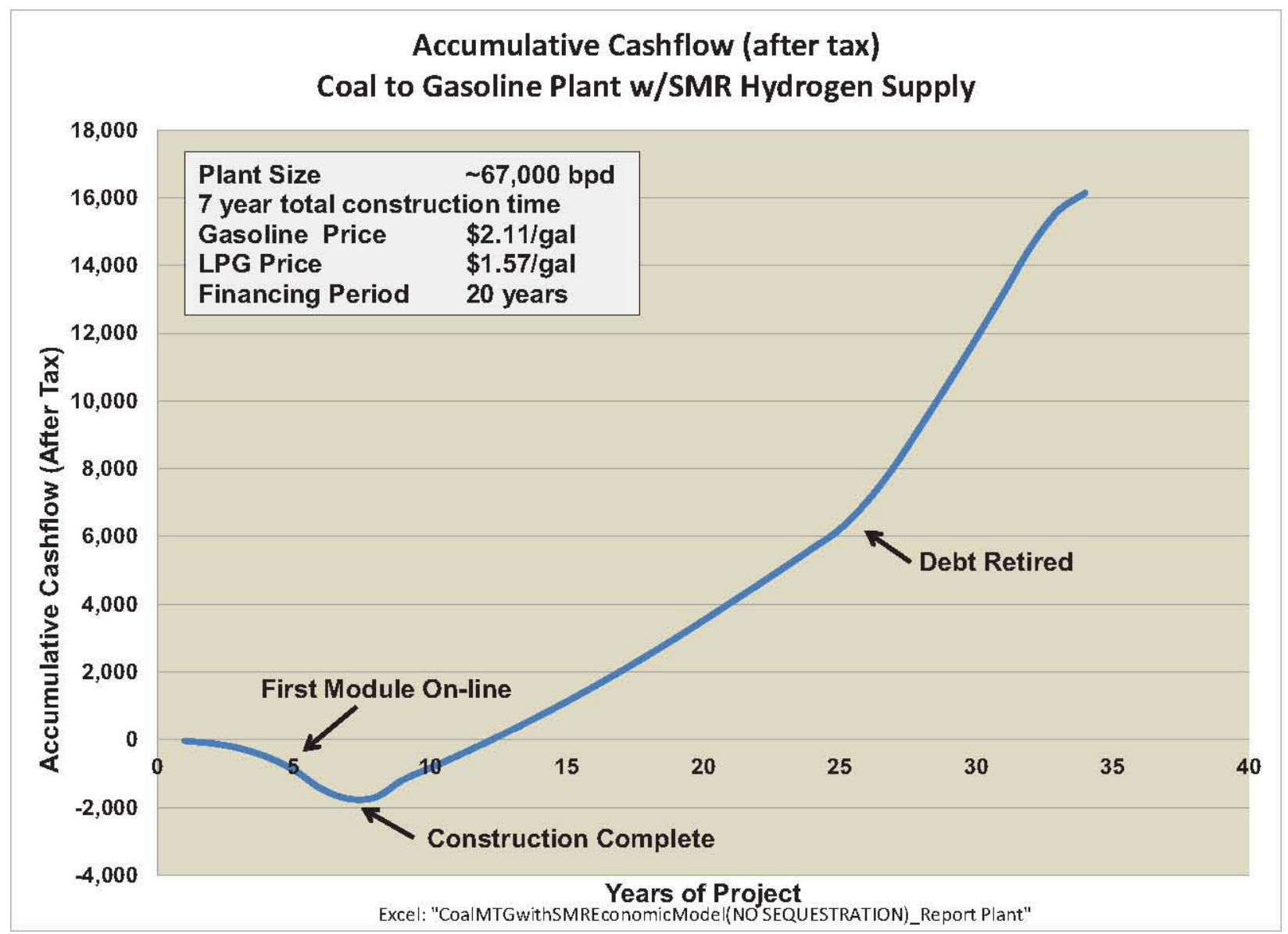

Figure F-12. Paducah plant project accumulative cash flow.

\section{F-2.1.4 Paducah HTGR Plant Deployment}

Figure F-13 shows the current projected schedule for development of the HTGR and HTSE technologies. It is anticipated that the first demonstration HTGR module and the first plant will be in an application supplying steam and electricity to an industrial facility. As shown, the full deployment of that plant is not anticipated until 2029. However, at the end of the three year initial operating period of the first module over 2025 through 2027 the performance of the technology will have been demonstrated and the open licensing issues resolved. It is expected that this will engender sufficient confidence to consider broader application of the technology. Accordingly, it is assumed that in the 2025 to 2027 time frame a decision would be made to incorporate the HTGR technology into the process plant design.

The HTSE technology may be developed and commercialized earlier than the HTGR. If it can be shown that the HTSE is an economic alternative for hydrogen production, its incorporation in the process could proceed at that time using electricity from the electrical grid. It will be necessary to monitor the progress and results of its development to make a decision on its implementation. 


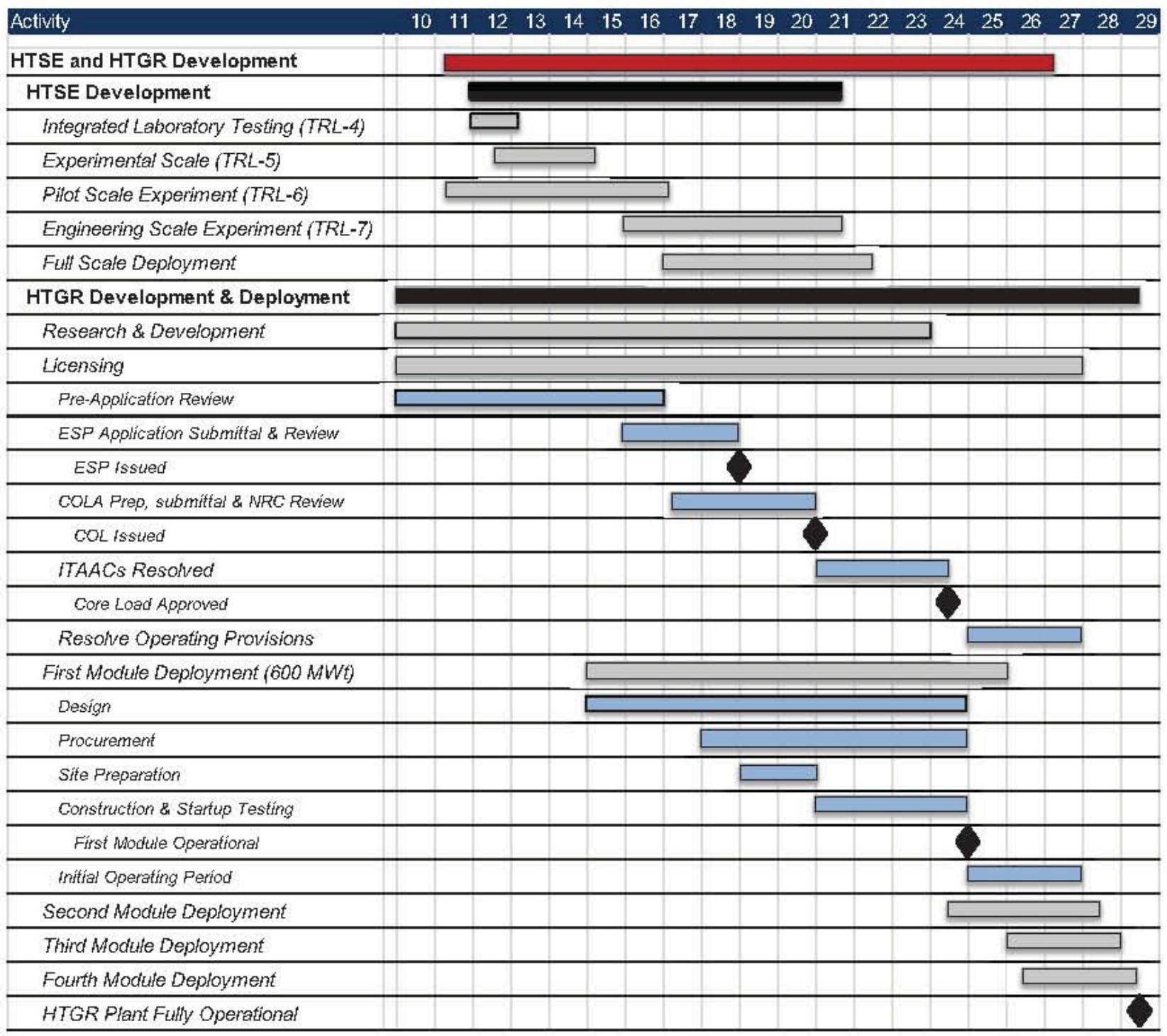

Figure F-13. HTGR technology development projected schedule.

For the purposes of this evaluation it is assumed that the application of the HTGR technology to the Paducah process plant is found to be technically and economically viable. Figure F-14 is a notional schedule for deployment of the Paducah HTGR plant. This is a 4-600 MW(t) plant supplying heat and electricity to the Paducah process and electricity to the grid. It is projected to start construction in 2025 with first module operation beginning in 2031 . This is $\sim 10$ years after the full deployment of the Paducah process plant. This is an appropriate period of operation for instituting major maintenance on the plant such as modifying the SMRs to interface with the HTGR heat supply. (Appendix G discusses the modified SMR plant). The HTGR plant will also be interfaced with the grid transmission lines at that time. The projected cost of the HTGR plant is $\sim \$ 5$ billion (2011\$) spread over 7 years of construction. The Inflated cost is estimated at $\$ 6.5$ billion including interest on debt. Figures F-15 and F-16 show the projected annual funding required to complete the plant design, licensing, equipment and material procurement, construction and commissioning of the plant and the annual and accumulative jobs developed during the deployment of this plant. During construction the site will employ 4,400 personnel on average each year and 9,300 peak in the fifth year of the project. The finished plant will employ 400 personnel. When fully deployed the Process and HTGR plant will employ at least 800 personnel. 
Paducah HTGR Plant Deployment

Licensing

Design

Procurement

1st Module Const \& Commissioning

2nd Module Const \& Commissioning

3rd Module Const \& Commissioning

4th Module Const \& Commissioning

Plant Fully Operational

Figure F-14. Paducah HTGR plant deployment.

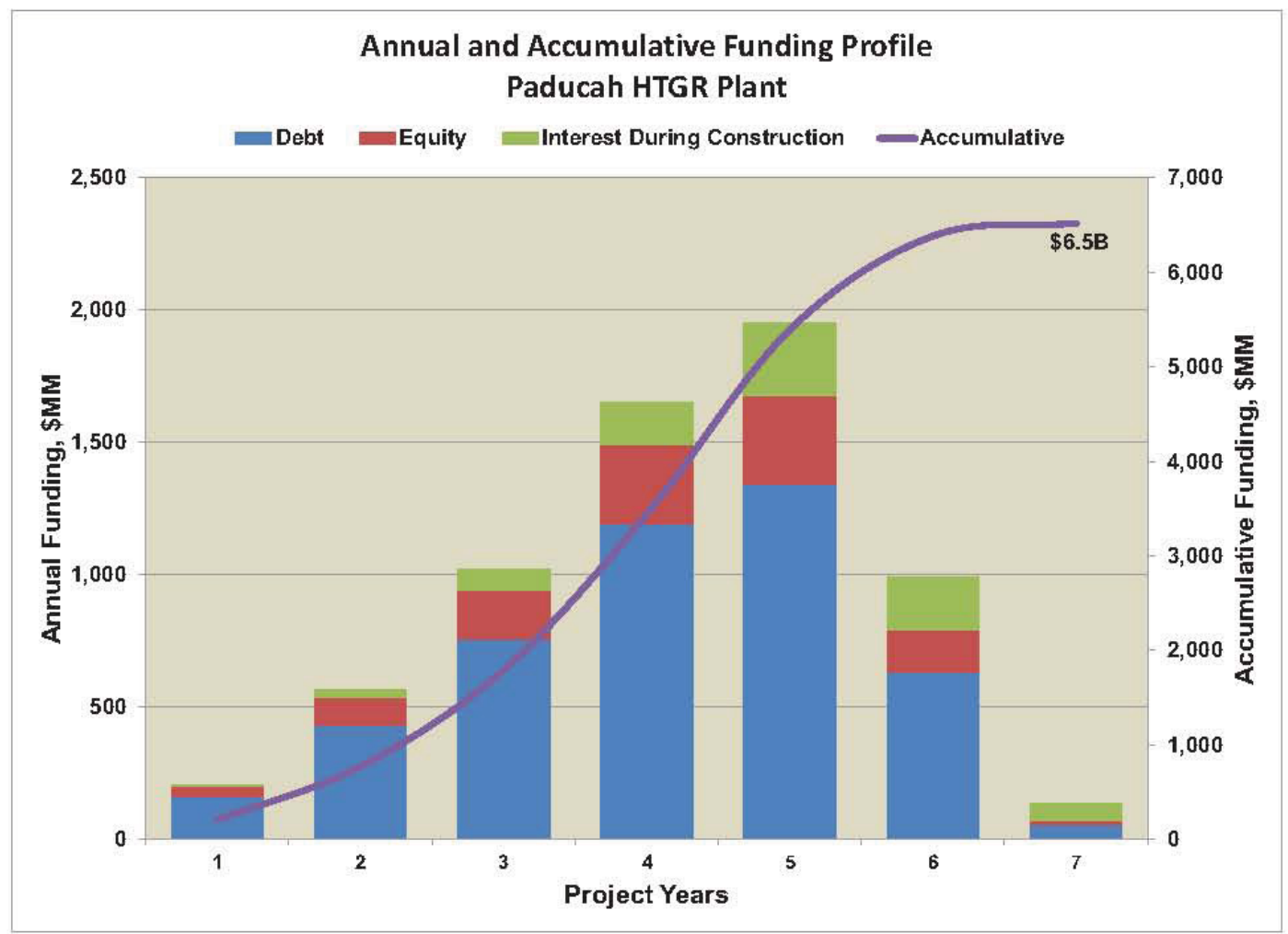

Figure F-15. Annual and accumulative funding required for deployment of the Paducah HTGR plant. 


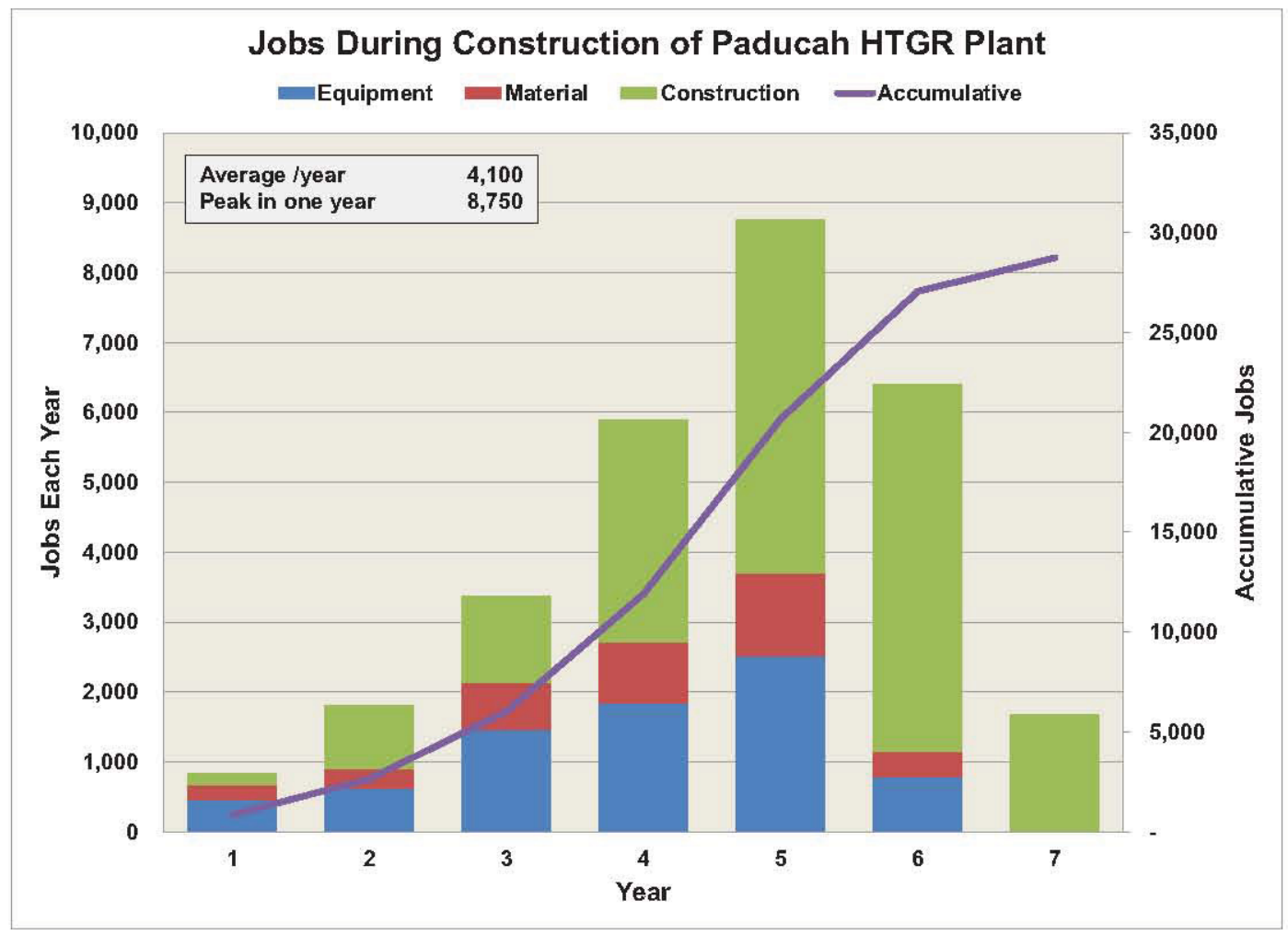

Figure F-16. Jobs during deployment of the Paducah HTGR plant.

\section{F-2.1.5 Paducah Plant Economics}

The economics of the Paducah plant are based on achieving a minimum of $10 \%$ internal rate of return on equity (IRR, after tax). It is assumed that there will be a favorable market and long term contract for the products of this plant to support obtaining financing terms of $80 \% \mathrm{debt}, 8 \%$ interest during construction, $8 \%$ interest on debt and a 20 year final debt payment period. An INL discounted cash flow analysis program ${ }^{1}$ is used to establish the minimum Production Cost of the products required to achieve the $10 \%$ return. This analysis develops annual cash flows based on the construction costs, debt ratio, interest during construction, debt payments, depreciation, operating costs, revenues and taxes. Inflation factors are applied consistent with government projections. Calculations are also made of the IRR achieved for given market prices for the products. For the purposes of the analyses herein the market prices are the average refiner wholesale prices over 2010 and 2011 as reported by the Energy Information Administration (EIA) ${ }^{2}$.

Table F-2 summarizes the results of the analyses for the reference Paducah plant:

Table F-2. Summary of economic analysis of Reference Paducah plant.

\begin{tabular}{|l|c|c|c|}
\hline \multicolumn{1}{|c|}{ Product } & $\begin{array}{c}\text { Production Costs to Achieve } \\
10 \% \text { IRR (after tax) }\end{array}$ & $\begin{array}{c}\text { Market Prices based on } \\
\text { average of } 2010 \& 2011 \\
\text { refiner wholesale prices }\end{array}$ & IRR at Market Prices \\
\hline Gasoline & $\$ 2.11 / \mathrm{gal}$ & $\$ 2.40 / \mathrm{gal}$ & \multirow{2}{*}{$16.75 \%$} \\
\hline $\mathrm{LPG}^{\mathrm{n}}$ & $\$ 1.57 / \mathrm{gal}$ & $\$ 1.57 / \mathrm{gal}$ & \\
\hline
\end{tabular}

$\mathrm{n}$ Both analyses were performed with the LPG market price. The quantity of LPG produced is less than $15 \%$ of the total production of the plant so variations in its price is not a significant factor in the economics. 
Figure F-17 shows the effects of varying the values of key parameters of the economic analyses on the calculated price of the gasoline to achieve a required IRR. These are discrete calculations varying a single parameter at a time to determine the effect of that single change while holding all other parameters constant at the baseline values. ${ }^{0}$ These results cannot be combined to determine the effect of multiple parameter changes. Figure F-18 shows the effect of combining the effects of these parameter variations on a statistical basis in a 10,000 step Monte Carlo analysis. The wide ranges of the parameter variations applied and the wide range of the results from the Monte Carlo analysis reflect the large uncertainties in the economics of this plant. These uncertainties would be reduced in the design process and it is assumed periodic re-analyses would be performed to confirm the continued economic viability of the project.

Review of Figure F-17 shows that costs of $\$ 50$ /ton of $\mathrm{CO}_{2}$ would have significant impact on the production costs of gasoline, (raises production costs by $\$ 0.40 / \mathrm{gal}$ ). These could be costs associated with capture and transport of the $\mathrm{CO}_{2}$ for sequestration to the extent possible in the process or taxes imposed by the government on emissions of $\mathrm{CO}_{2}$. Integrating the HTGR with an SMR to provide hydrogen to the coal gasifier reduces the $\mathrm{CO}_{2}$ generated by approximately a factor of ten (10) from a conventional plant significantly reducing the effect of potential costs of $\mathrm{CO}_{2}$ on production costs. It should also be pointed out the application of HTGR with HTSE for the hydrogen supply would essentially eliminate the $\mathrm{CO}_{2}$ emissions and any concern with costs associated with those emissions. The performance and economics of this application are covered in detail in Appendices D and E.

\begin{tabular}{|c|c|c|c|c|}
\hline & & & \multirow{3}{*}{$\begin{array}{l}\text { No Sequestration with } \\
\$ 50 / \text { ton CO2 Tax } \\
\text { Sequestration with } \\
\$ 50 / \text { ton CO2 Tax }\end{array}$} & \multirow{2}{*}{$\begin{array}{l}\text { Baseline Values: } \\
\text { No Sequestration }\end{array}$} \\
\hline \multirow[b]{3}{*}{$10 \% \mathrm{IRR}$} & & $\$ 2.59$ & & \\
\hline & & $\$ 2.59$ & & No Sequestration \\
\hline & $\$ 2.06$ & $\$ 2.40$ & $15 \%$ IRR & $12 \% \mathrm{IRR}$ \\
\hline $\begin{array}{l}80 \% \text { Debt/ } \\
20 \% \text { Equity }\end{array}$ & $\$ 2.09$ & $\$ 2.31$ & $\begin{array}{l}20 \% \text { Debt/ } \\
80 \% \text { Equity }\end{array}$ & $\begin{array}{l}50 \% \text { Debt/ } \\
50 \% \text { Equity }\end{array}$ \\
\hline $\begin{array}{l}40 \text { year Economic } \\
\text { Recovery Period }\end{array}$ & $\$ 2.15$ & $\$ 2.30$ & $\begin{array}{l}20 \text { year Economic } \\
\text { Recovery Period }\end{array}$ & $\begin{array}{l}30 \text { year Economic } \\
\text { Recovery Period }\end{array}$ \\
\hline 20 year Loan Term & $\$ 2.16$ & $\$ 2.23$ & 10 year Loan Term & 15 year Loan Term \\
\hline $6 \%$ Interest & $\$ 2.15$ & $\$ 2.23$ & $10 \%$ Interest & $8 \%$ Interest \\
\hline $\begin{array}{l}24 \text { month } \\
\text { Construction Period }\end{array}$ & $\$ 2.16$ & $\$ 2.22$ & $\begin{array}{l}48 \text { month } \\
\text { Construction Period }\end{array}$ & $\begin{array}{l}36 \text { month } \\
\text { Construction Period }\end{array}$ \\
\hline \multirow{3}{*}{ Low TCI } & & $\$ 2.19$ & Sequestration & No Sequestration \\
\hline & $\$ 2.19$ & $\$ 2.19$ & \multirow[t]{2}{*}{ High TCI } & \multirow[t]{2}{*}{ TCI } \\
\hline & Price & (\$/gal) & & \\
\hline
\end{tabular}

Figure F-17. Sensitivity of selling price of gasoline to variations in key economic parameters.

o Note that the Baseline product selling price $(\$ 2.19)$ is not the same as reported in Table $4.1(\$ 2.11)$. This reflects the fact that the baseline values for required IRR, debt ratio, loan term, etc. are not the same as used for the analyses supporting Table 4.1. The Baseline values cited on Figure F-17 were selected to facilitate the sensitivity analysis 


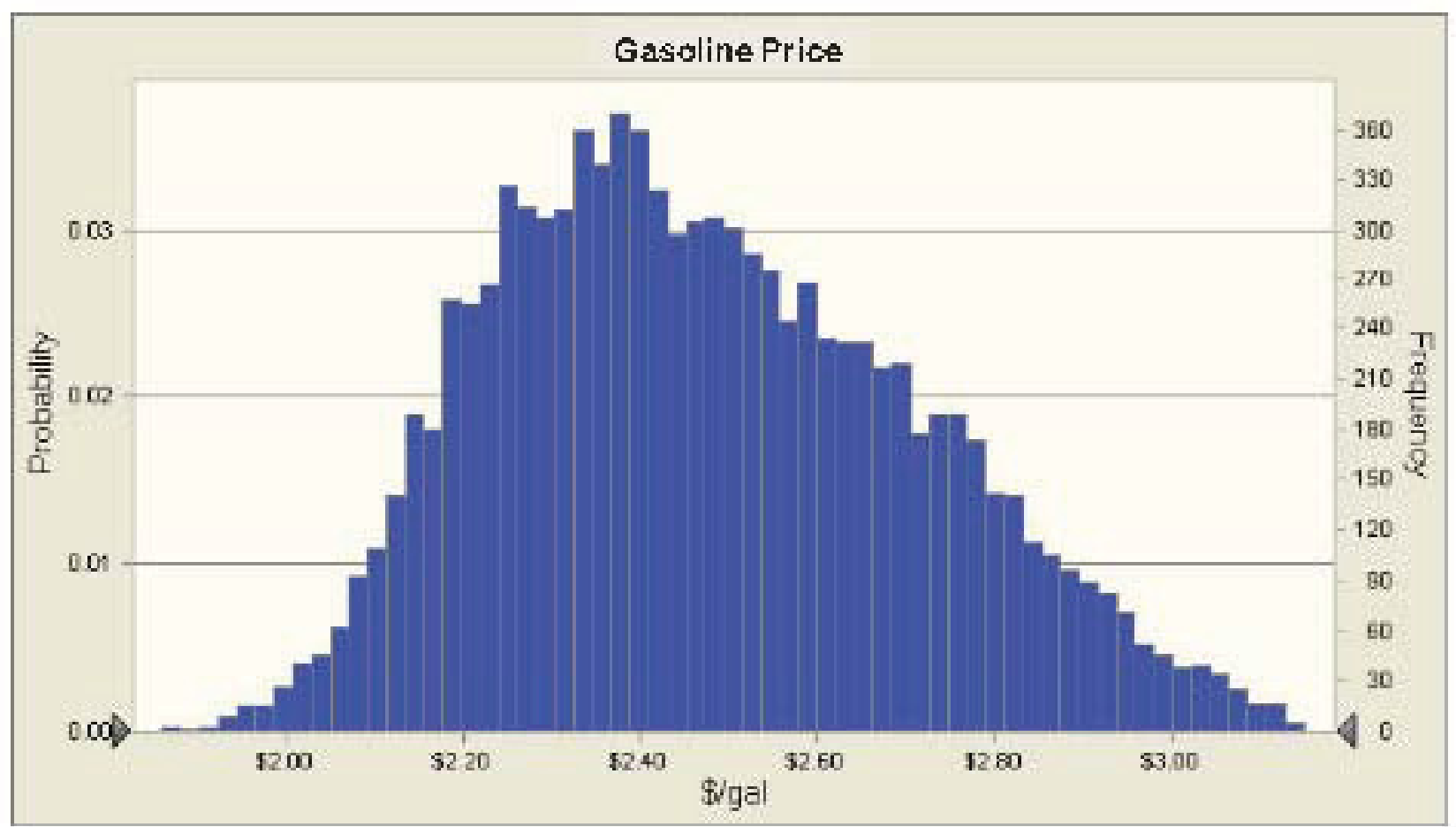

Figwe F-18. Combined effect of paramefer uncerfainfies on gasoline poducfion cosf.

Finally, the revenue that would be gererated from this single plant is $\sim 28(2011 \$)$ per year (ascuring an $80 \%$ capacity factor and the average market prices in Table F-2). This plant would consme 3.5 million tons in a year and 87 billion SCF of natural gas. At $\$ 51 /$ ton the revene is equivalent to the sale of 39 million tons of coal; a factor of ten ove the value of the coal consured. At \$5.50/MSCF the revenue is equivalent to the sale of 364 billion cubic foet of natual gas; a factor of $5-1 / 2$ ove the value of the natural gas consured. These are sipnificant adders to the value of the coal and natural pas ured in the production of these products and to the oconomy of the Commonwealth.

The rext section smumarizes the results of sirilar andyses to those tiveused in this section for deployment of the carbon comversion indurty with integration of the HTGR technology in the process plant and for elsecticity pereration. The Paducah plant representing the first of the plants doployed in development of the indurty and revicion of electricity generation mix in Kentuxky.

\section{F-2.2 Deployment of the Carbon Conversion Industry and Transformation of the Electricity Generation Sources}

\section{F-2.2.1 Introduction}

The deployment of the Paducah plant would be the first step in development of a carbon conversion industry in Kentukly produxing synthetic tansportation fuds, cherrical foedstock and chenicals from indigenous coal and natural gas resources. This industry would comprise multiple facilities engaged in the several elements of the carbon conversion processes. These include coal surply and gasification, natural gas supply and refonning, hydrogen production and supply, diesel, naphtha and LPG synthesis using the FT process, methanol synthesis, and gasoline, LPG or cherricals synthesis from methanol. Each of these steps has been discussed in preceting sections of this report; Appendices D and E discuse the fumctional and performane characteristics and econornics of the several alternatives processes involved in these steps that have been evaluated herein. 
This strategy also includes the integration of the HTGR technology into the carbon conversion processes and transformation of the Kentucky electricity generation from one dominated by coal-based technology to one comprising nuclear, (HTGR), Coal with CCS, existing coal plants with improved emissions controls and biomass along with the existing hydroelectric generation.

The following develops this strategy to provide perspective on its potential scope, costs, schedule and benefits to the Kentucky economy. The development of the actual strategy will require coordination of the several stakeholders involved in its execution and careful evaluation of the market forces, financial structures, costs, schedules, local area needs and other factors that influence the course taken. The strategy will also need re-review and modification as it progresses to address changes in the factors influencing its course. The following discussion provides insight into the scope of these initiatives and scoping estimates of their costs and benefits.

\section{F-2.2.2 Assumptions and Attributes}

The following are assumptions made in developing the deployment strategy and specific characteristics attributed to the technologies deployed.

Carbon Conversion Industry:

- The use of eastern Kentucky coal as the primary feedstock will be emphasized in selection of conversion processes in expanding the industry after Paducah with the objective of deploying plants consuming at least 14 million tons per annum. Figure F-19 shows the decline in production of eastern Kentucky coal over the last several decades. This initiative is intended to offset potentially more rapid reduction in the production of low sulfur eastem Kentucky coal due to the increased retirement of coal-based plants in the United States and the installation of emissions control equipment in other coal-based plants that no longer require low-sulfur coal to continue to operate.

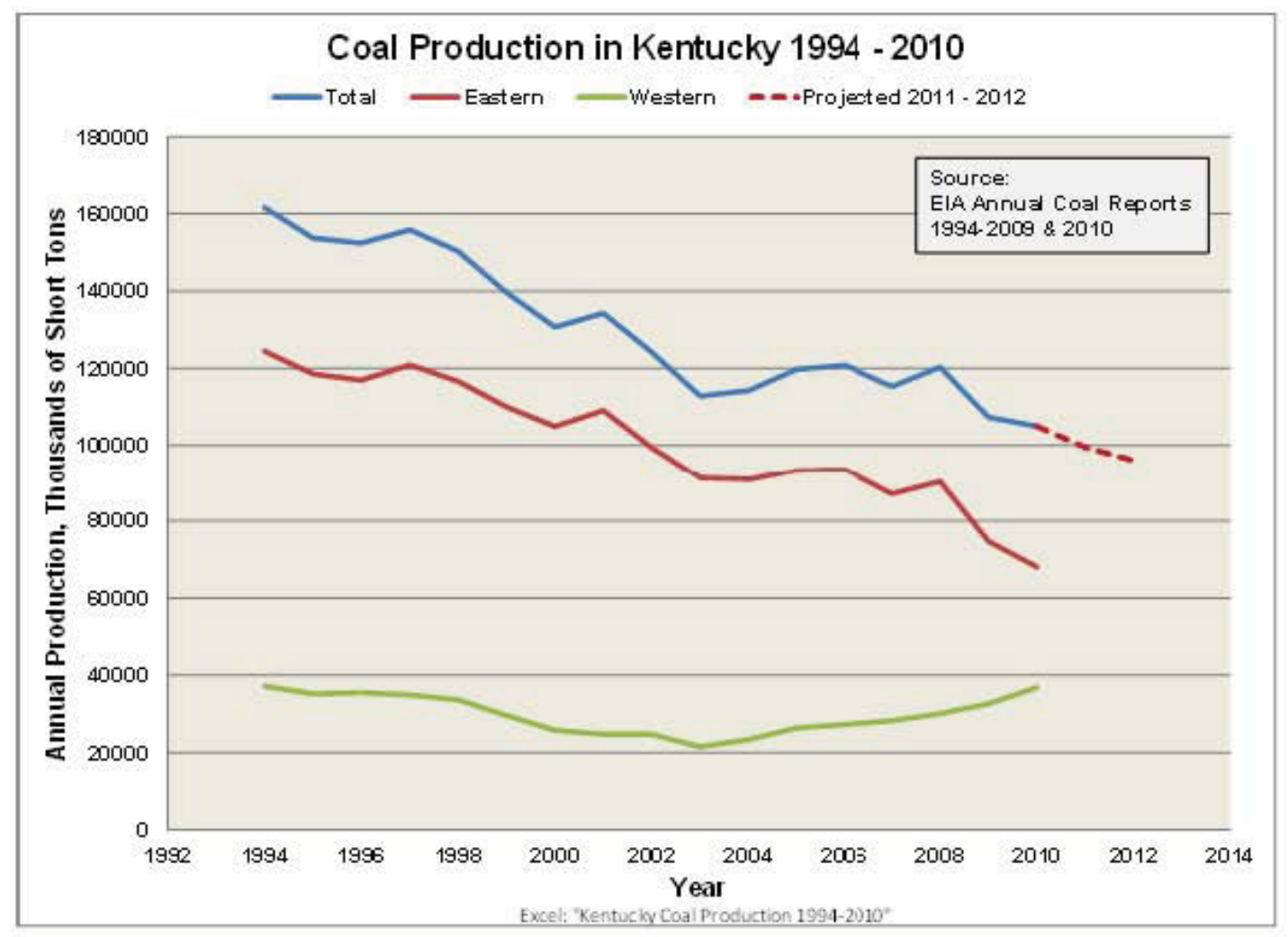

Figure F-19. Coaf production in Kentucky 1994-2010. 
- Deployment of the carbon conversion industry is assumed to result in achieving an eastern Kentucky coal consumption rate of 14 million tons per year by the end of 2023. This will require deployment of four CTL plants in eastern Kentucky. This will require overlap in the planning and construction of plants in eastern Kentucky with that of CTL plant in Paducah. For this reason the schedule for the first plant deployed in eastern Kentucky (designated EK-1) will be similar to the CTG Paducah plant but delayed by one year; the other three (designated EK-2, EK-3 and EK-4) will be CTL plants producing diesel, naphtha and LPG. All schedules begin the initiatives for deploying these plants in 2013. Accordingly, all plants will be deployed over a ten to eleven year period as shown in Figure F20.

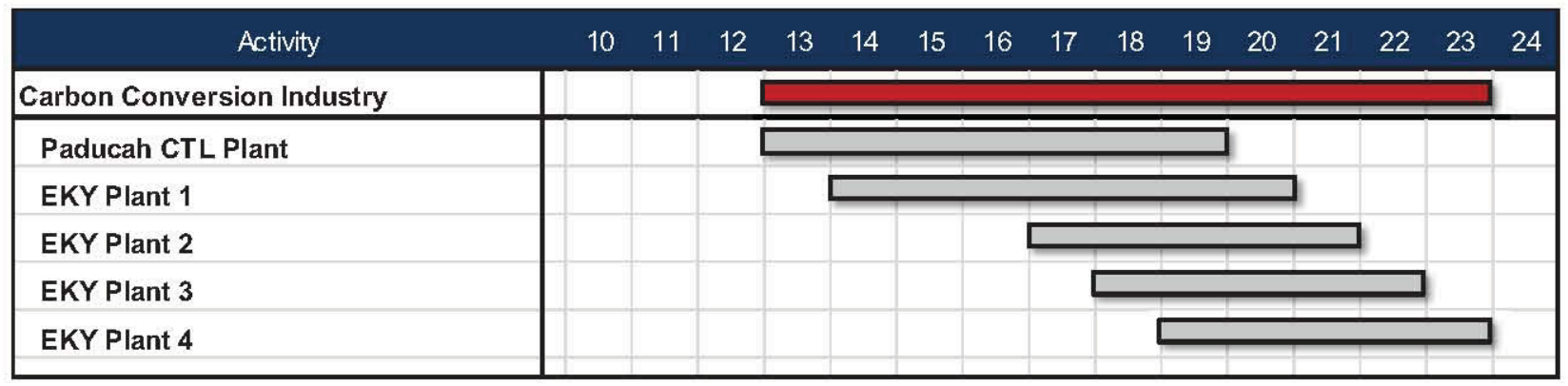

Figure F-20. Carbon conversion industry deployment schedule.

- The eastern Kentucky plants should be located close to viable supplies of coal and natural gas. The natural gas would be used to produce hydrogen for use in the coal gasification process. This will require selecting coal mine mouth sites near natural gas wells. Figure F-21 shows that the natural gas production wells and coal mines are generally co-located in eastern Kentucky so such plant sites should be readily available.

- Production and transport of finished product from eastern Kentucky may not be practical depending on the infrastructure and terrain at the plant sites. If this is the case, a distributed approach to deployment of the facilities that will make up the carbon conversion industry may be warranted. Figure F-22 illustrates this approach. The mine mouth plants would produce synthesis gas which would then be piped to other locations that would process that gas to produce synthetic fuels and/or chemicals. These facilities would be located in areas that have favorable infrastructure to support construction and operation of these plants and locations that facilitate distribution of the finished products within the Commonwealth, nationally and internationally.

- The integration of HTGR technology in the carbon conversion processes will begin in 2029 and extend over the next ten years. Over this period the original process plants will have operated for 15 to 20 years and will be ready for major maintenance that will facilitate the integration of the HTGR technology for heat and electricity supply. 

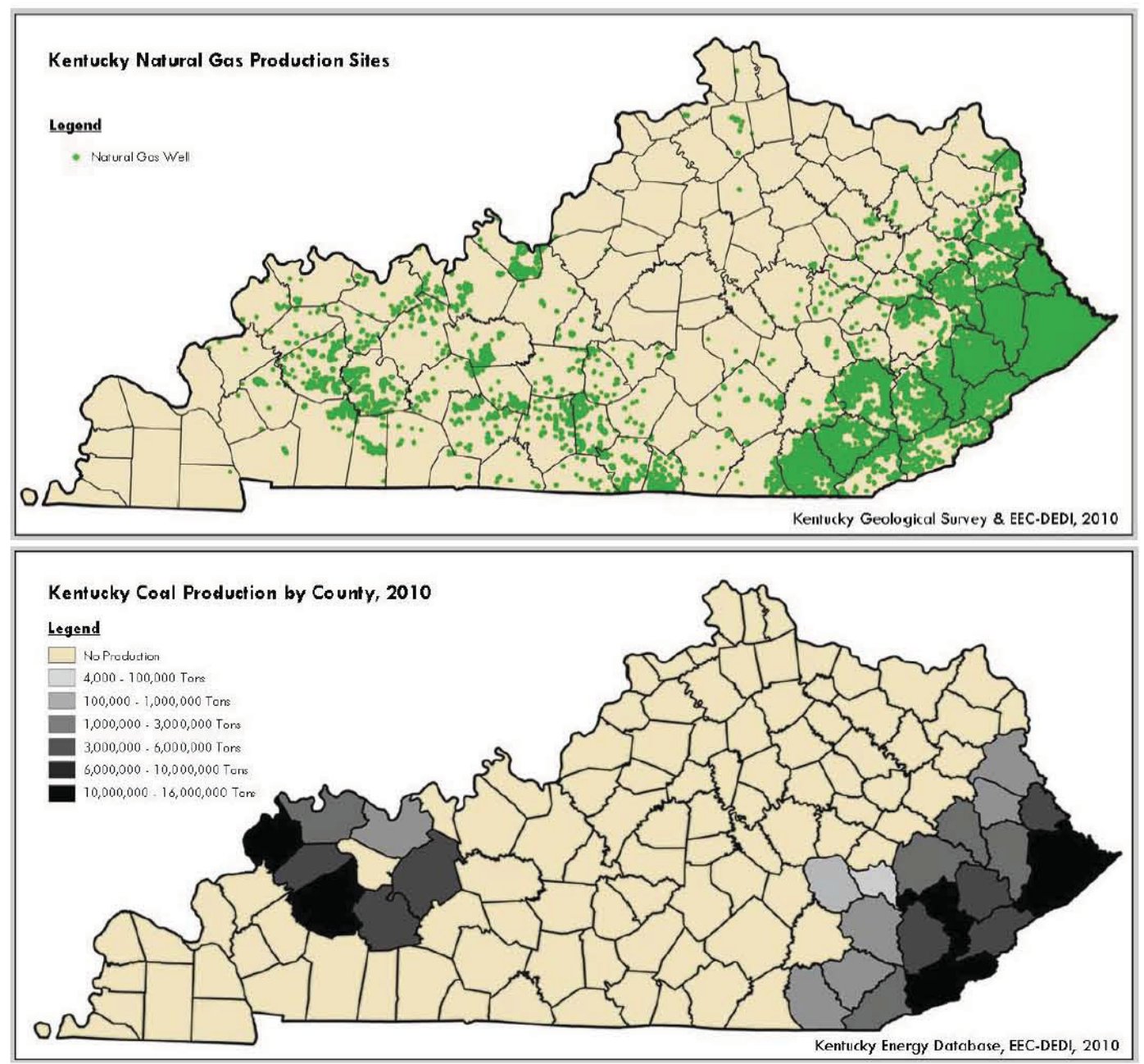

Figure F-21. Natural gas and coal production sites in Kentucky.

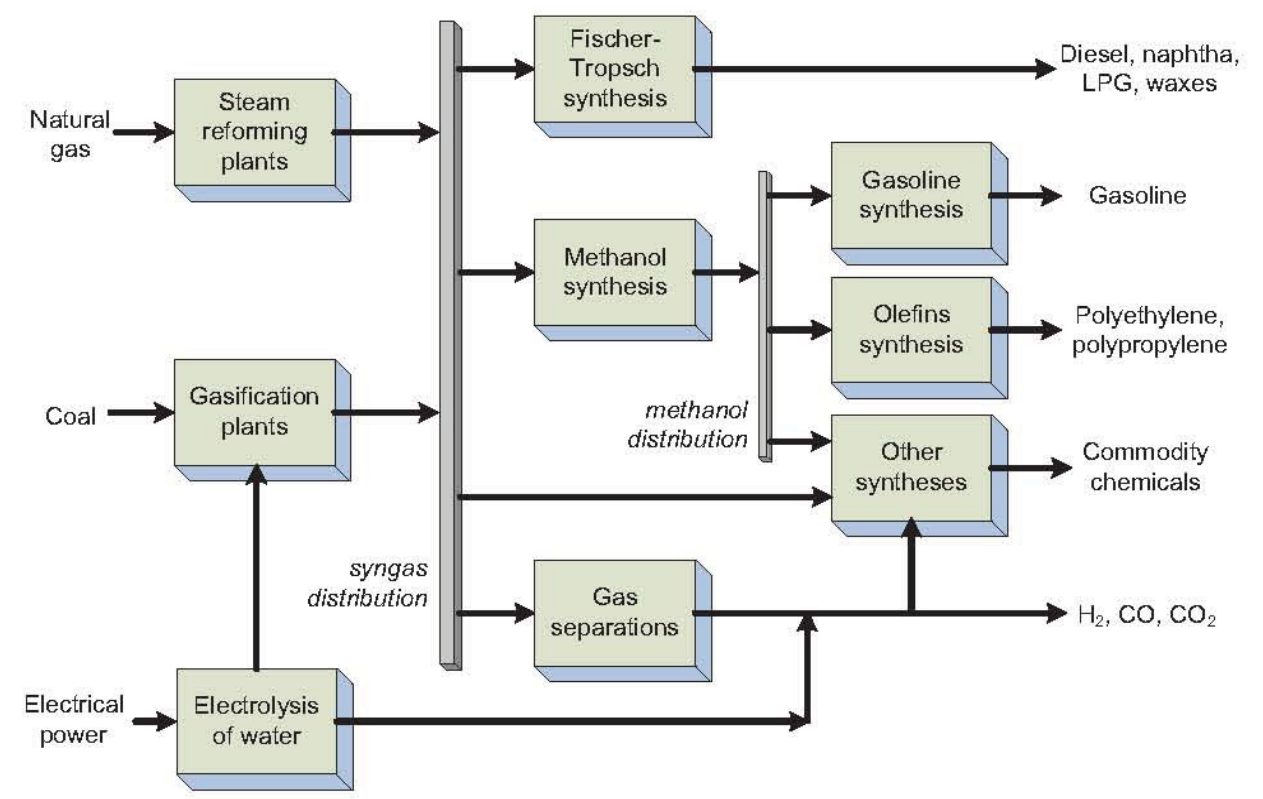

Figure F-22. Distributed approach to deployment of a carbon conversion industry. 
Electricity generation technologies transformation:

- The transformation of the electricity generation technologies in Kentucky from one dominated by coal to varied sources will be assumed to be consistent with Commonwealth goals as outlined in the Kentucky Energy and Environment Cabinet Secretary presentation to the National Governor's Association ${ }^{3}$. This is shown in Figure F-23. This transformation is expected to occur over a twenty year period resulting in a mix of electricity sources with coal, coal with CCS and nuclear contributing $\sim 29 \%$ of the capacity and petroleum, natural gas, biomass and renewables contributing the balance.

- This transformation is assumed to occur at a rate commensurate with retirement or conversion to designs with updated emission control systems of existing coal based plants based on the plants' ages. Conversion of plants will take place prior to 2016 the date when plants must have completed modifications to meet Environmental Protection Agency (EPA) regulations on mercury and other toxic chemical emissions. Addition of coal plants with CCS will occur as part of the replacement of retired plants. Figure F-24 shows what the trend in coal-based plant capacity would be in Kentucky if the existing plants were retired at age 60 . This trend and the capacity of each plant was examined in establishing those plants retiring and those that would be updated to meet EPA regulations either by addition of emissions control technologies or conversion to CCS. For the purposes of analysis is was assumed that the larger plants would be retained to achieve the $29 \%$ of existing plants shown in Figure F-24 while the smaller plants would be replaced with plants with CCS to result in the $29 \%$ of capacity for this source also shown in Figure F-23.

\section{Kentucky's Strategic Energy Direction}

- Diversifying Electricity Portfolio

\section{Kentucky's Electricity Generation Sources}

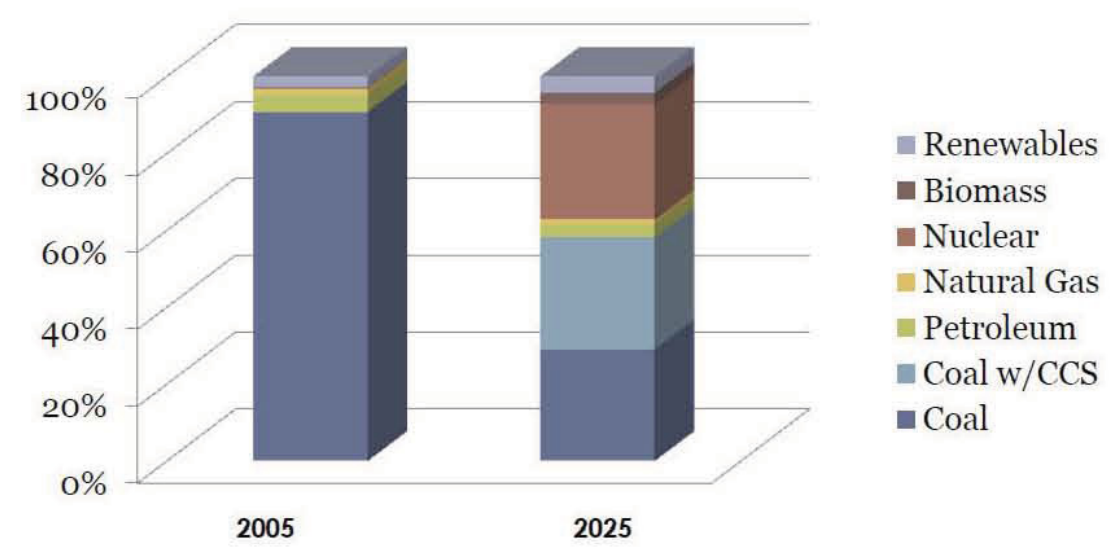

Figure F-23. Kentucky's electricity generation sources transformation objective. 


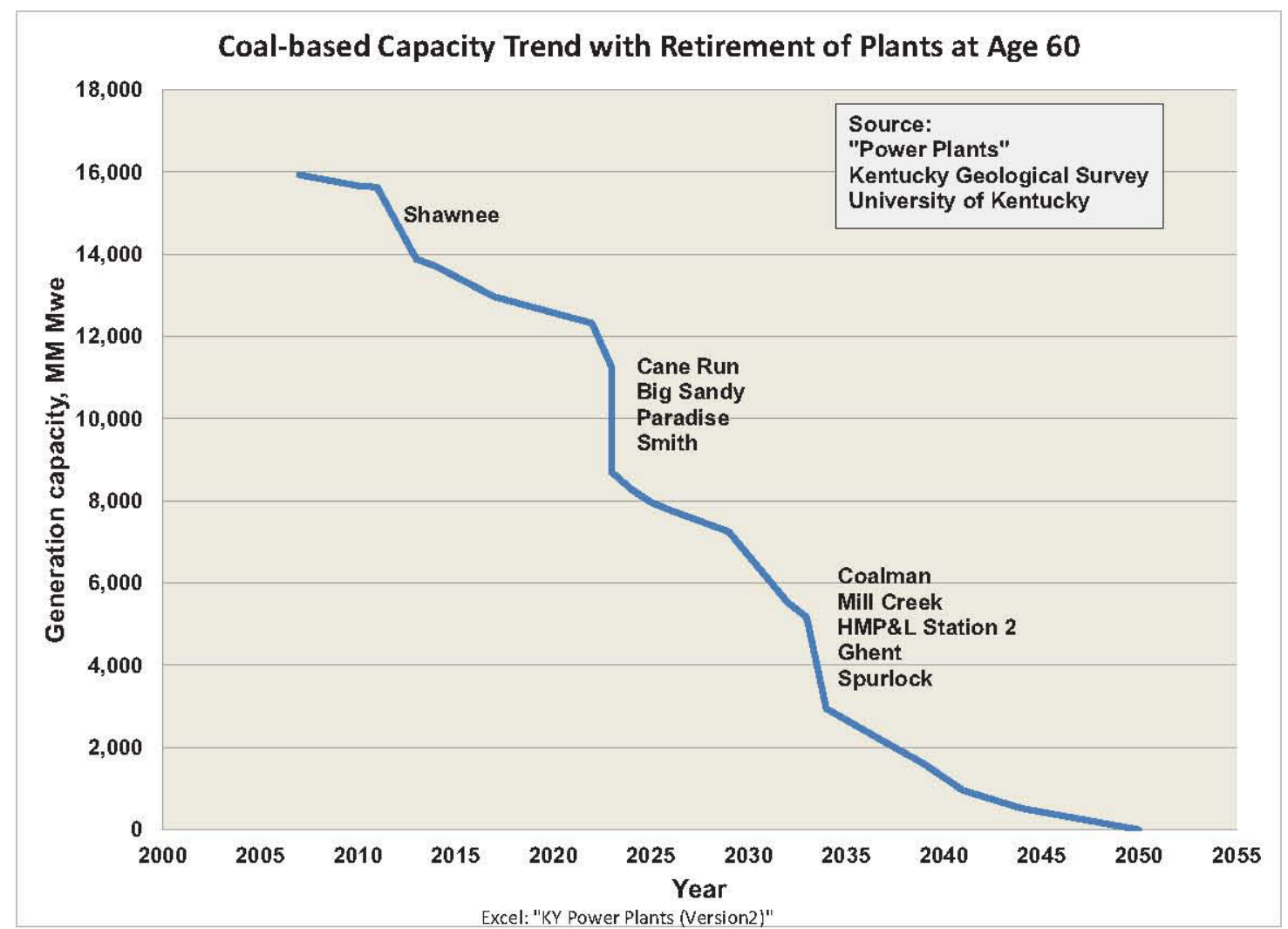

Figure F-24. Coal based capacity trend with retirement of plants at age 60.

- An objective of the deployment of a carbon conversion industry is to improve the economy of Kentucky by adding value to the indigenous coal and natural gas resources of the Commonwealth. Objectives of the transformation of the electricity generation industry are to address the aging of the existing coal-based plants, diversify the energy portfolio and reduce carbon emissions to address emerging EPA greenhouse gas emission (GHG) regulations. The expenditures in developing new generation will have a positive effect on the Kentucky economy; however, the new generation will increase the costs of electricity generation which will have a negative effect. The net effect of all of these factors on the GDP of Kentucky will be assessed as contributors on a Gross Added Value basis. Figure F-24 shows the trend in the Kentucky GDP 2008 to 2011 in real (2008\$) and current dollars. Although the GDP has increased at a healthy trend on a current dollar basis, on a real dollar basis it has been relatively flat after the dip in 2009 due to the U.S. recession. Figure F-26 shows the changes in the several contributors to the Kentucky GDP from 2010 to 2011. There was a net change of $+0.56 \%$ in the Commonwealth's GDP over this period. This shows, however, that the contribution from mining was down $\sim 0.45 \%$ and the contribution from utilities was down an additional $\sim 0.15 \%$. These trends provide additional incentive for achieving the objectives

- The gross added value (GAV) of the deployment of the carbon conversion industry to the GDP of Kentucky will include the revenue generated from the sale of the products of the industry as well as the value of the coal and natural gas supplying the process plants. This latter assumption is judged appropriate since the carbon conversion industry develops the demand for these supplies and they are not accounted in government current projections for future production. The GAV will not include intermediates that will be accounted for in other components of the GDP. These include labor, maintenance and process plant commodities such as chemicals, catalysts and other consumables.

- All calculations of GAV will be done in 2011\$. 


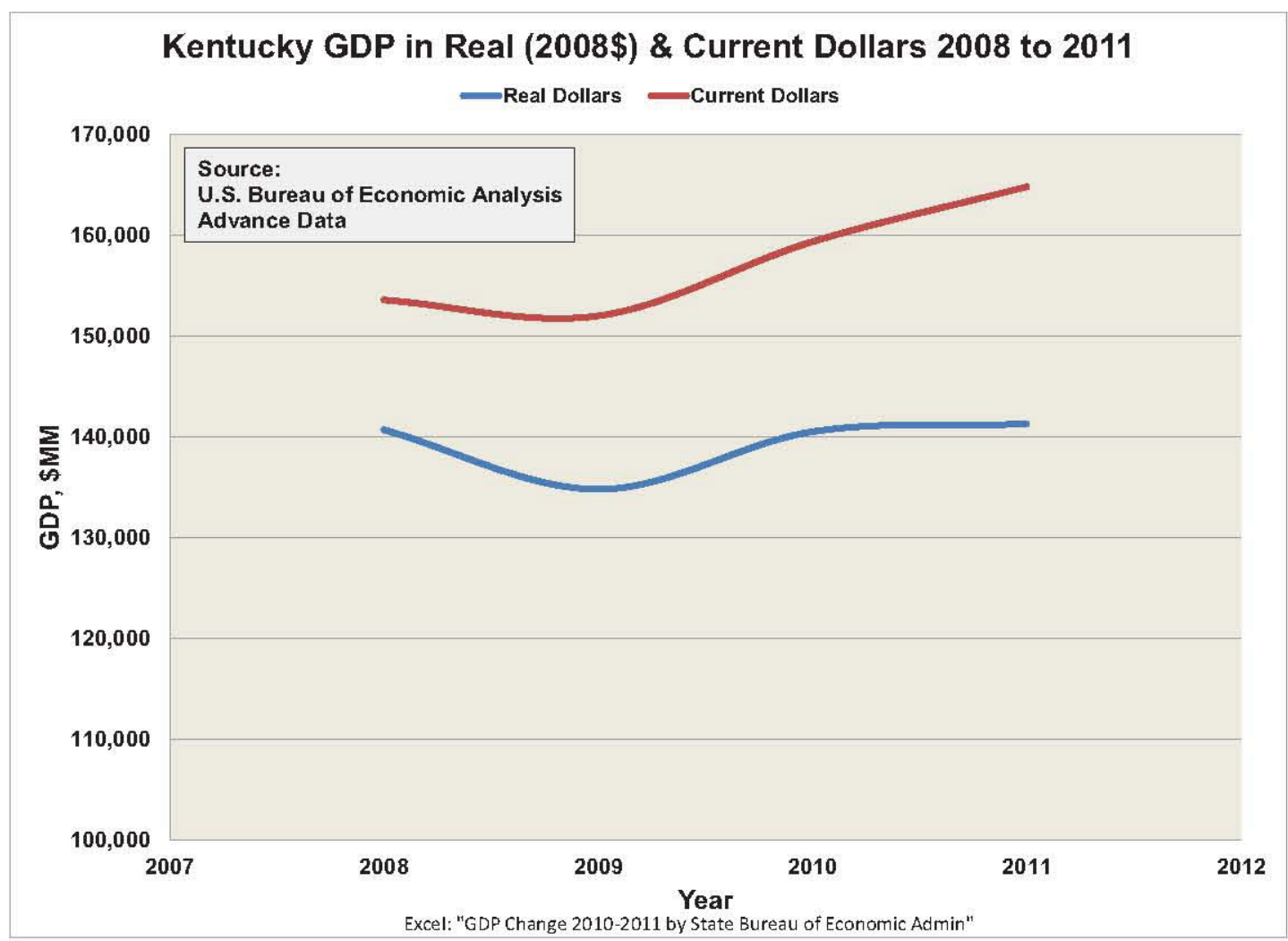

Figure F-25. Kentucky GDP 2008-2011.

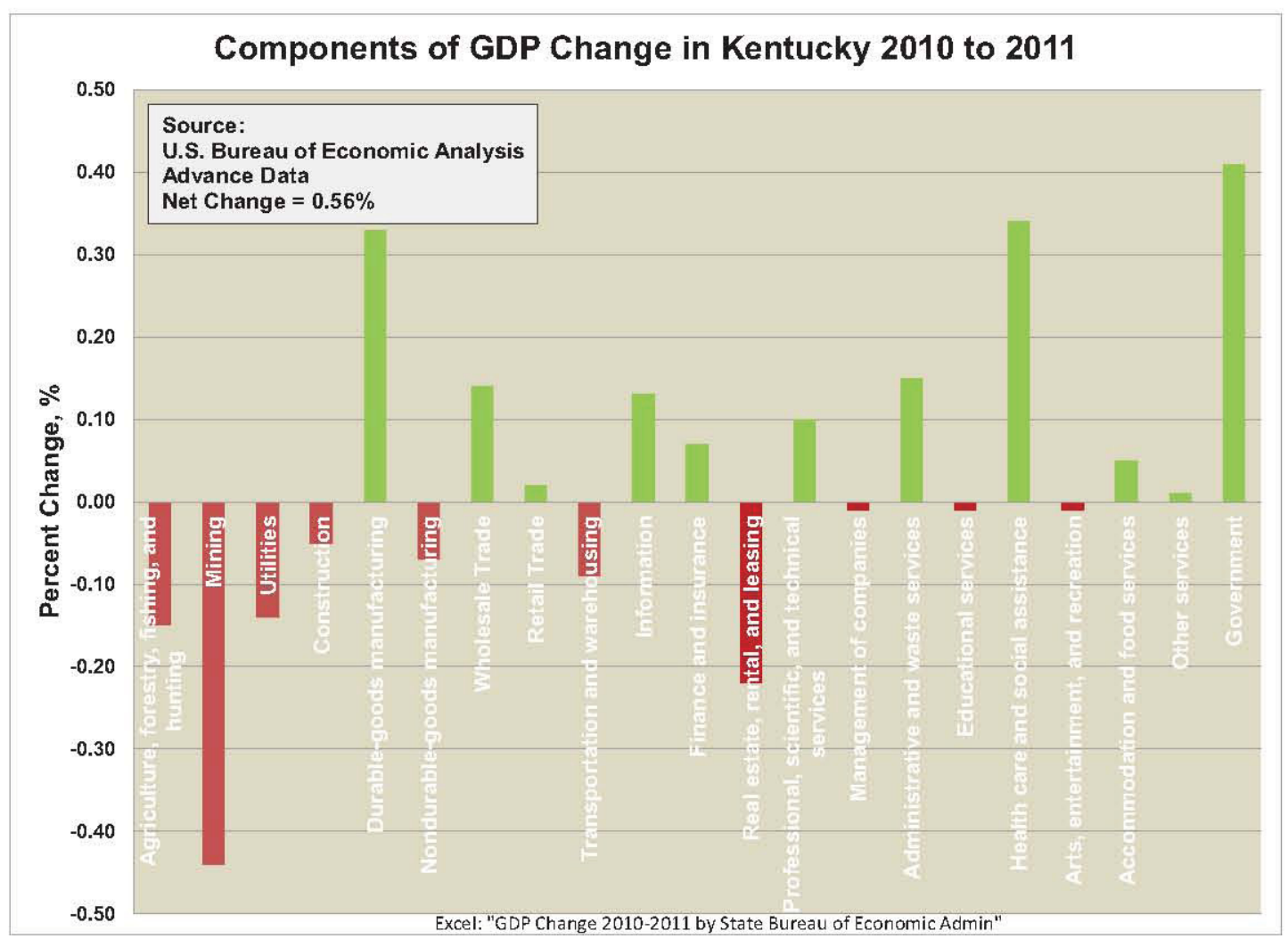

Figure F-26. Components of GDP change in Kentucky 2010 to 2011 


\section{F-2.2.3 Deployment of the Carbon Conversion Industry}

Figure F-20 showed the schedule assumed for deployment of the carbon conversion industry with a single plant in Paducah and four additional plants in eastern Kentucky. Earlier sections of the report provided the details of deploying a CTG plant in Paducah. The first plant deployed in eastern Kentucky would be similar to the Paducah plant. The other three will be coal to liquid plants producing diesel, naphtha and LPG.

As noted previously it may be necessary to deploy these plants in a distributed configuration to optimize the siting of the facilities comprising these plants to support efficient construction and operation and product distribution. For the purposes of analyses it will be assumed that the costs and schedules for deployment of these plants will be as INL has determined in their analyses of these plants as summarized in Appendices D and $\mathrm{E}$ of this report. The potential additional or lower costs for distributing the processes is judged to be within the uncertainty bounds of these analyses, see Figures F-17 and F-18.

As noted previously the first eastern Kentucky plant will be similar to the CTG plant to be deployed at Paducah with a gross output of $\sim 58,000 \mathrm{bpd}$. This plant has an estimated total capital investment requirement of $\$ 5.3 \mathrm{~B}(2011 \$)$. The remaining three will be CTL plants producing diesel, naphtha and LPG with a gross output of $\sim 50,000 \mathrm{bpd}$. These plants have estimated total capital investment requirements of $\$ 3.5(2011 \$)$. The total output of all five plants will be $\sim 266,000 \mathrm{bpd}$; the capacity of a moderately sized crude oil refinery.

Figure F-27 shows the annual and accumulative expenditure required over the deployment schedule. The peak expenditures are in the $\$ 5.0$ to $\$ 5.5 \mathrm{~B}$ range in the $6^{\text {th }}$ through $9^{\text {th }}$ years of the deployment. The average expenditure is $\sim \$ 3 \mathrm{~B}$ per year. These are significant expenditures that would be necessary to deploy this industry in a timeframe consistent with defraying the economic impact of the closure of the DOE PGDP in Paducah and increased reductions in production of eastern Kentucky coal.

Figure F-28 shows the estimated consumption of coal and natural gas as the plants are deployed and as the HTGR technology is integrated into the processes. The HTGR integration reduces the natural gas feed rate as shown on this figure. The long term annual coal consumption meets the objective of increasing consumption by at least 14 million tons annually. Figure F-29 shows the history of annual production of natural gas and interstate receipts of natural gas through 2010. The 440,000 MMSCF and $278,300 \mathrm{MMSCF}$ that will be consumed by the carbon conversion industry exceeds the 2010 production by more than a factor of two(2). These rates of consumption are, however, much smaller than the interstate receipts so can be supplied by non-Kentucky sources. In addition Figure F-29 shows that the rate of production is increasing rapidly. Also since the eastern Kentucky plants are expected to be sited near gas wells, it may be possible to increase the production from those wells to meet the process plant demands. This would be of benefit to the economies of eastern Kentucky and the Commonwealth.

Figure F-30 summarizes the estimated annual revenues and the contributions from these revenues to the Kentucky GDP that would accrue during the deployment and after full capacity of the carbon conversion industry is achieved. Full capacity and full revenue is reached with the completion and initiation of operation of the last CTL module in 2023. At that time the estimated contribution of the industry $(\$ 8.5 \mathrm{~B})$ is equivalent to that of the entire mining industry in 2010 . This revenue stream would be a significant contribution to offset the projections of reduced production of eastern Kentucky coal. 


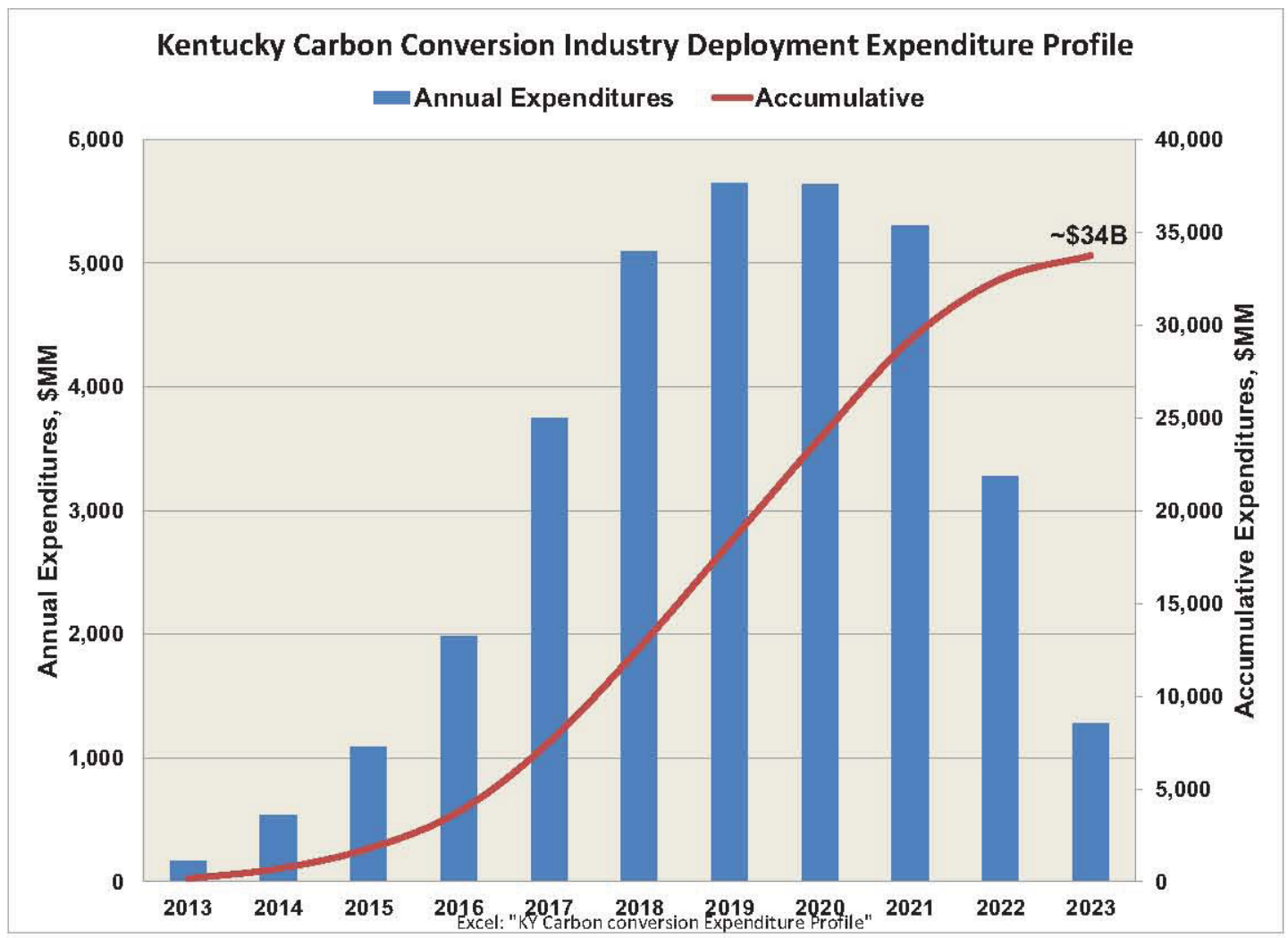

Figure F-27. Carbon conversion deployment expenditure profile.

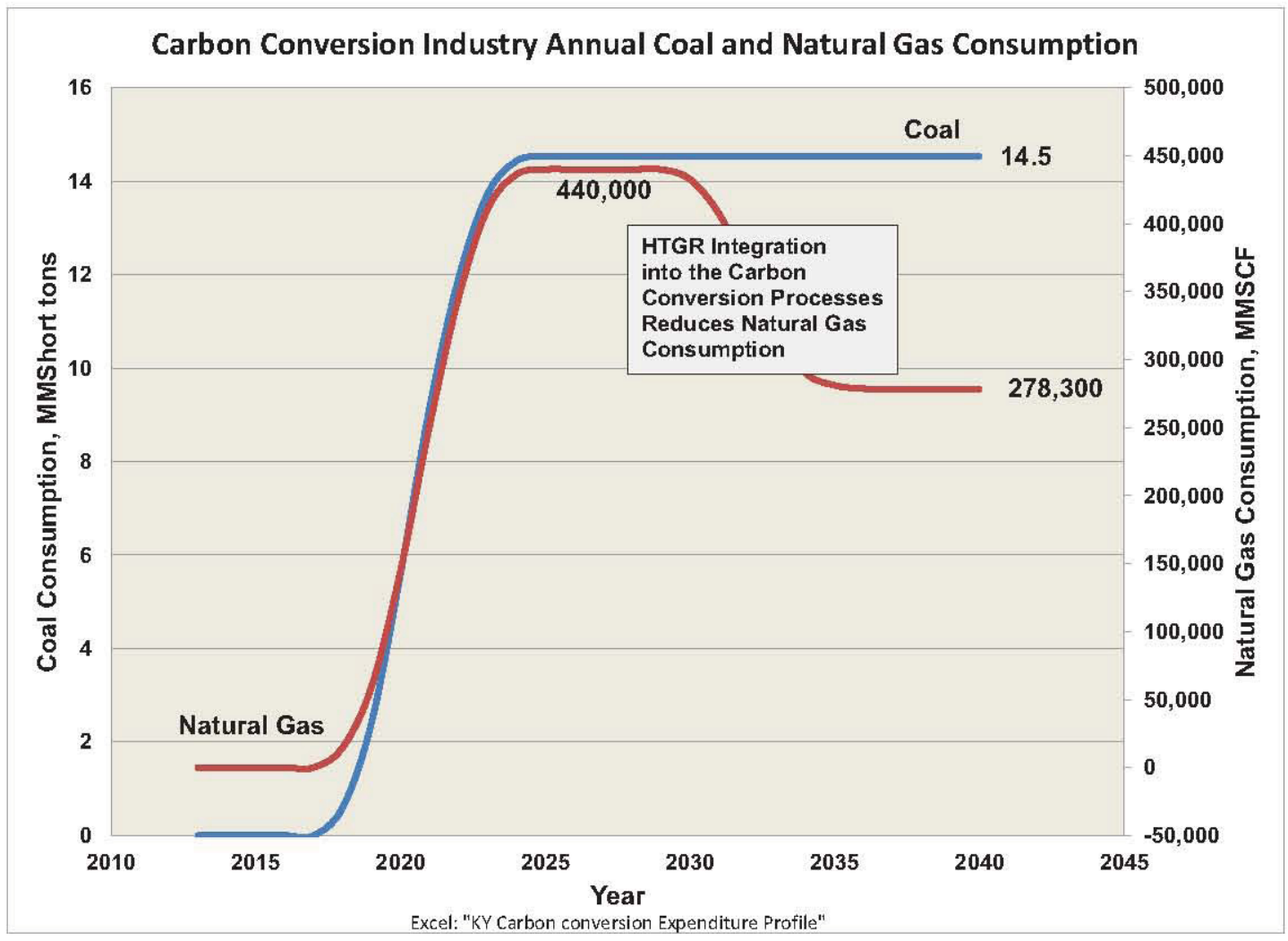

Figure F-28. Carbon conversion industry annual coal and natural gas consumption. 


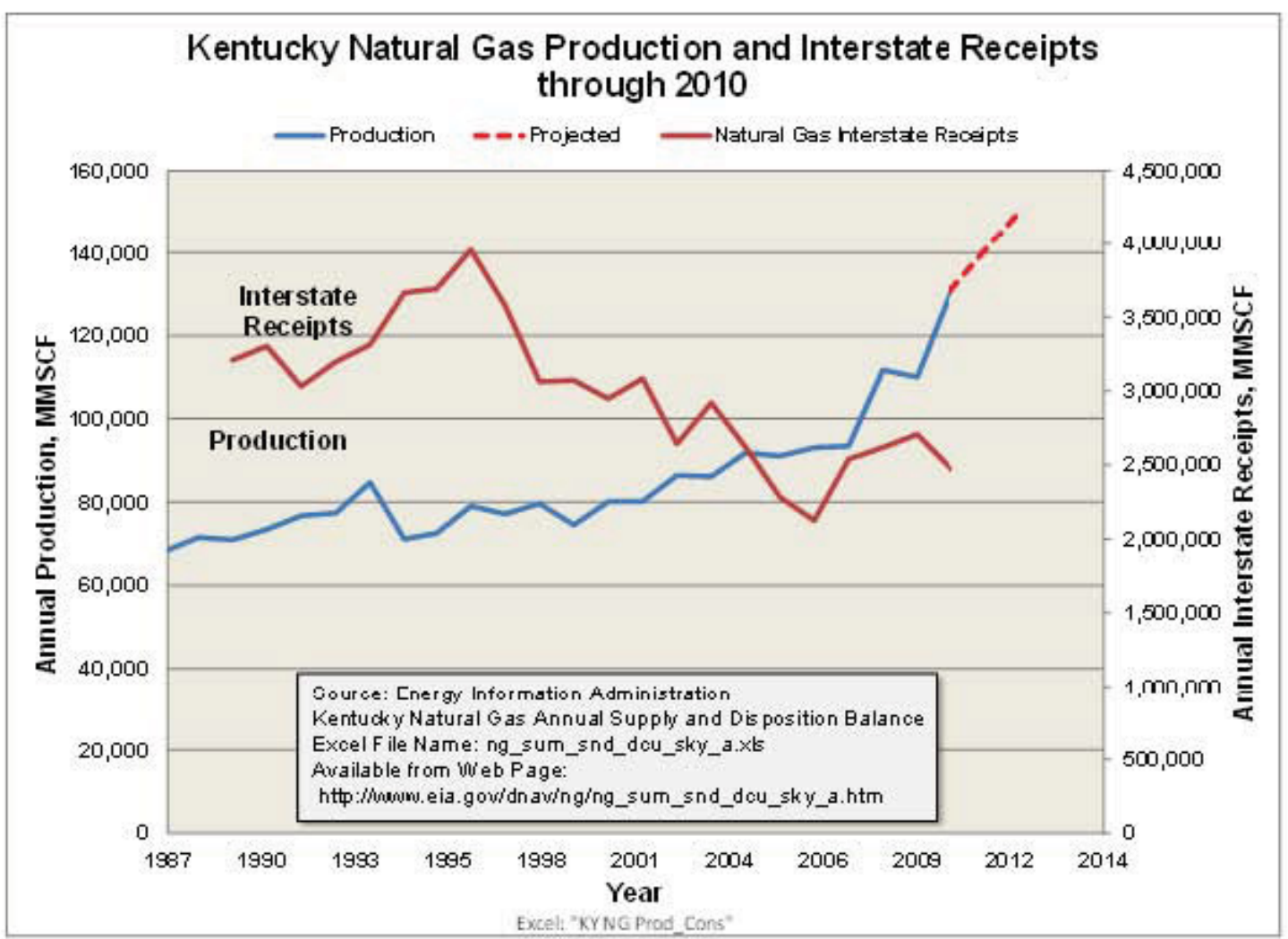

Figure F-29. Natural gas production and interstate receipts.

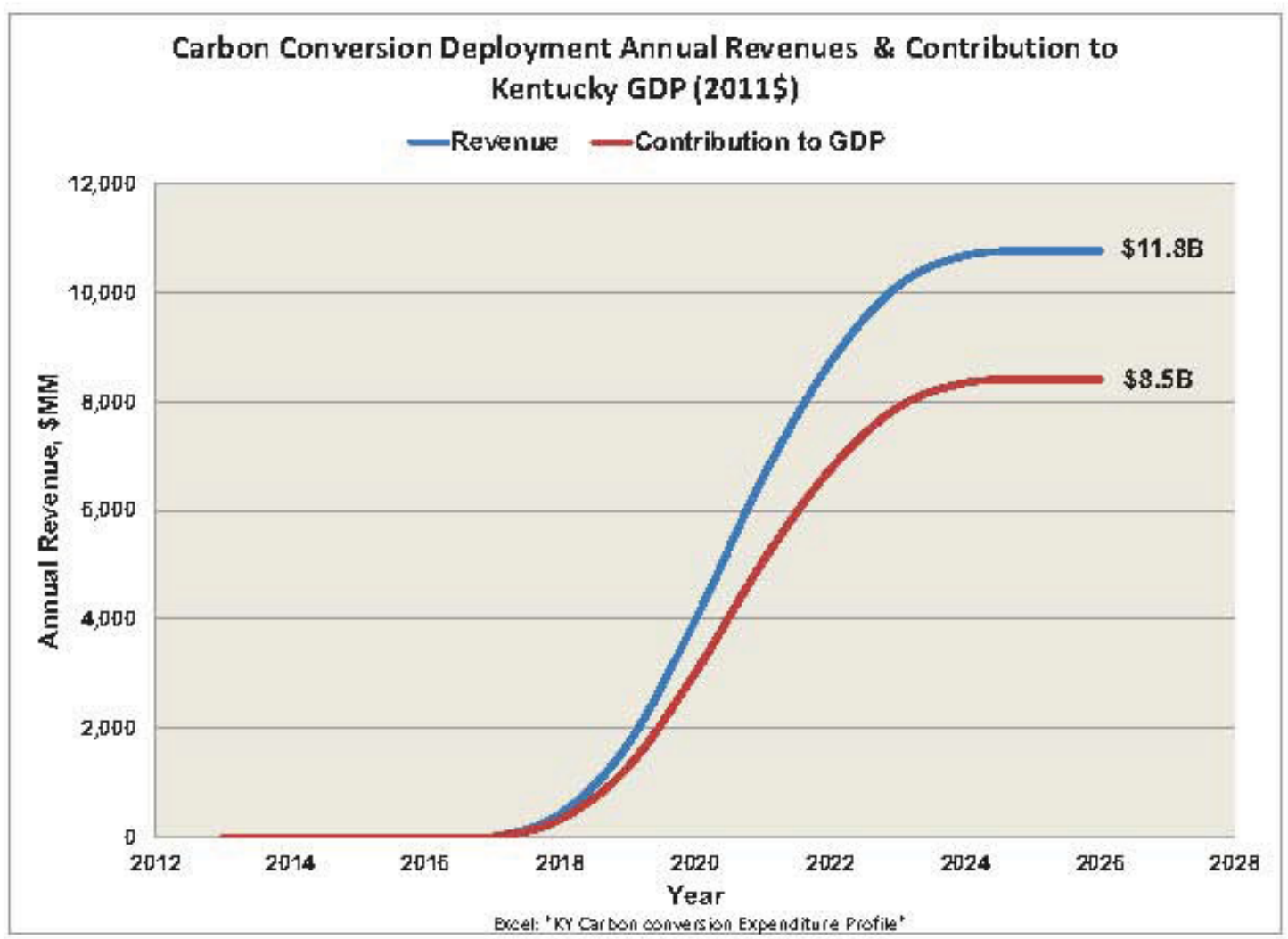

Figure F-30, Carbon conversion industry ansumal reventes and contribution to Kentucky GDP. 


\section{F-2.2.4 Integration of HTGR Technology with the Carbon Conversion Industry}

The HTGR technology should be available for integration with the carbon conversion processes beginning in 2029. This assumes that the first demonstration HTGR module has been constructed, commissioned, and completed a 3-year operating demonstration to fulfill NRC licensing requirements by the end of 2028. It has been assumed that it will take a 10 year period to fully integrate the HTGR technology into the complete carbon conversion industry as defined herein. On that basis each module within the industry would have operated for 10 to 15 years and be ready for major maintenance. Each plant will require a minimum installation of two $600 \mathrm{MW}(\mathrm{t})$ HTGR modules to provide the energy required to supply heat and electricity to the process; primarily for hydrogen production. To ensure $100 \%$ availability, however, assuming that such availability is required if any two of the energy supplied is out of service, (an N-2 criterion is applied to the energy supply) an additional two $600 \mathrm{MW}(\mathrm{t})$ modules will be supplied. The full 4-600 MW(t) module plant will be configured to be able to supply heat and electricity to the process and an additional supply of electricity to the regional grid. Accordingly, the deployment of these plants will not only support the carbon conversion industry with non-emitting sources of energy but will also support the transformation of the electricity generation industry in Kentucky.

As shown previously the preparations of the site, completion of design work, licensing, construction and commissioning of the first HTGR module in Paducah by 2029 requires that this work be initiated in 2025. The work for integrating HTGR into the first eastern Kentucky plant (EK-1) would start a year later. Subsequent integration into EK-2 through EK-4 would occur in one year increments after completion of EK-1. This sequence is shown in Figure F-31 along with the schedule for deployment of the initial set of process plants in Paducah and eastern Kentucky.

\begin{tabular}{|c|c|c|c|c|c|c|c|c|c|c|c|c|c|c|c|c|c|c|c|c|c|c|c|c|c|c|}
\hline Activity & 12 & 13 & 14 & 15 & 16 & 17 & 18 & 19 & 20 & 21 & 22 & 23 & 24 & 25 & 26 & 27 & 28 & 29 & 30 & 31 & 32 & 33 & 34 & 35 & 36 & 37 \\
\hline \multicolumn{27}{|c|}{ Carbon Conversion Industry } \\
\hline \multicolumn{27}{|l|}{ Paducah CT G Plant } \\
\hline \multicolumn{27}{|l|}{ EKYPlant 1 - CTG } \\
\hline \multicolumn{27}{|l|}{ EKYPlant 2-CTL } \\
\hline \multicolumn{27}{|l|}{ EKY Plant 3 - CTL } \\
\hline \multicolumn{27}{|l|}{ EKYPlant 4 - CTL } \\
\hline \multicolumn{27}{|l|}{ HTGR Inte gration } \\
\hline \multicolumn{27}{|l|}{ Paducah CT G Plant } \\
\hline \multicolumn{27}{|l|}{ EKY Plant 1 - CTG } \\
\hline \multicolumn{27}{|l|}{ EKY Plant 2 - CTL } \\
\hline \multicolumn{27}{|l|}{ EKY Plant 3 - CTL } \\
\hline EKY Plant 4 - CTL & & & & & & & & & & & & & & & & & & & & & & & & & & \\
\hline
\end{tabular}

Figure F-31. Schedule for integration of HTGR technology into the carbon conversion industry.

Figure F-32 summarizes the expenditure profile for integrating the HTGR into the Kentucky carbon conversion industry. As shown this scope has a total projected cost of $\sim 24 \mathrm{~B}$; similar to that for deployment of the initial plants in the industry.

Each deployment will also add HTGR electrical capacity to the Kentucky electrical grid. Figure F-33 shows the build-up in HTGR electrical capacity on the grid during the integration into the carbon conversion industry. As shown in Figure F-23 the overall goal in transforming the electricity generation sources is to have $\sim 30 \%$ nuclear capacity on the gird. Assuming a 20 GW(e) grid capacity this would require $\sim 6 \mathrm{GW}(\mathrm{e})$ of nuclear capacity. These deployments realize about a third of that goal, but do not achieve the third in the 20 years shown in Figure F-23. This is due to the delay in getting the HTGR technology available for commercial application. If the schedule for achieving a commercial HTGR plant this schedule could be accelerated the integration of this technology into the Kentucky grid would be equally accelerated. 


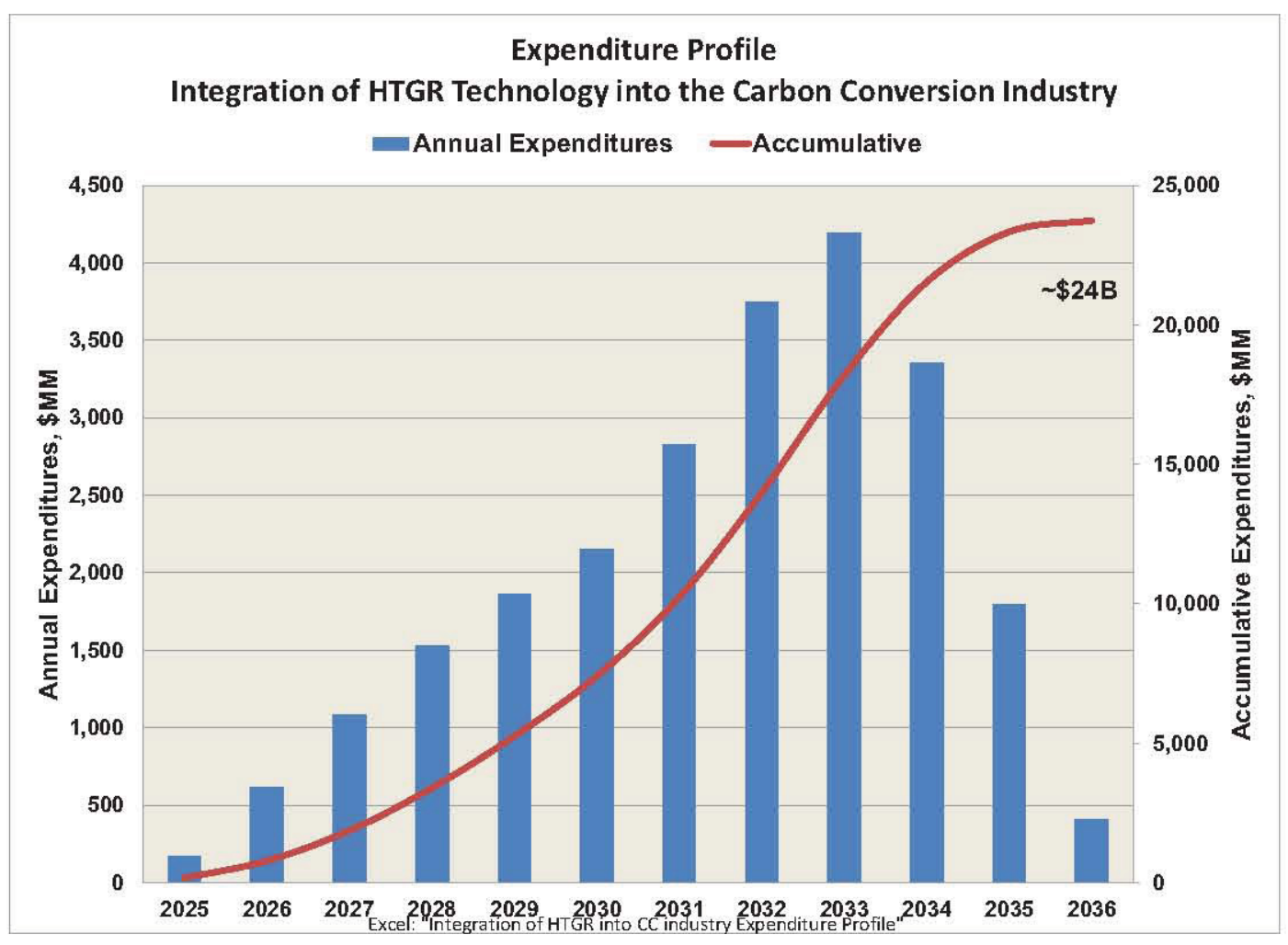

Figure F-32. Expenditure profile for integration of HTGR technology into the Kentucky carbon conversion industry.

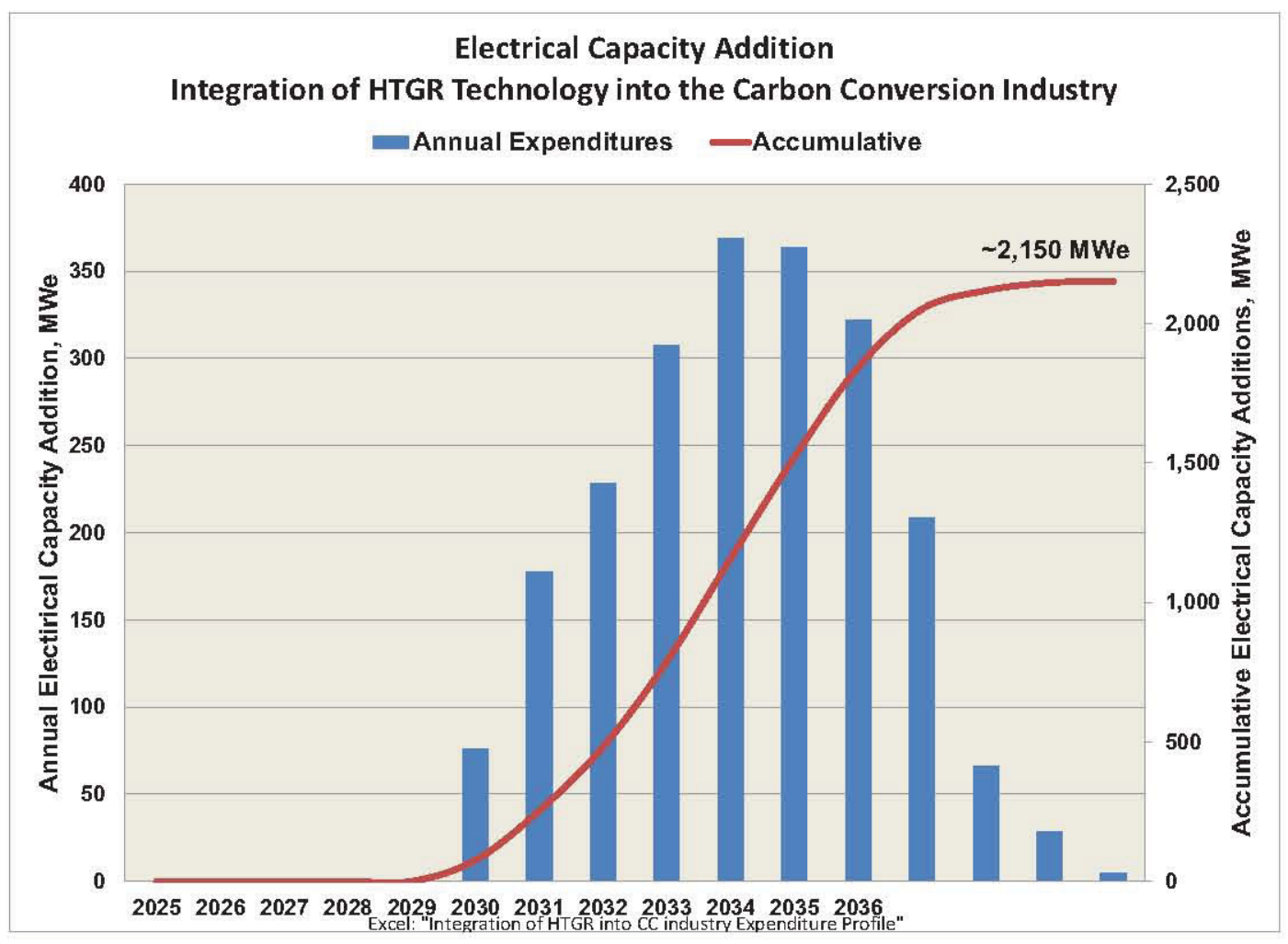

Figure F-33. Electrical capacity additions integrating HTGR into the carbon conversion industry. 
The following section discusses deployment of the variety of electricity sources required to achieve the transformation of the electrical grid as shown in Figure F-23.

\section{F-2.2.5 Electricity Generation Source Transformation}

Achieving the transformation in the electricity generation sources summarized in Figure F-23 requires retirement and/or modification of the existing coal based plants and adding new generation technologies. The final mix of generation technologies are to include primarily coal with emissions control equipment, carbon capture and sequestration (CCS), nuclear and biomass generation. The strategy summarized in Figure F-23 does not make major changes in the percentage of natural gas, petroleum, and renewables on the grid. The following discussion focuses on the scope, schedule and costs related to updating existing coal plants to meet EPA regulations to continue operating, retiring the balance of the coal plants and adding new generation.

As cited earlier and as shown in Figure F-23 the objective is to achieve a split in electricity generation of $\sim 30 \%$ in each of the existing upgraded coal plants, new coal plants with CCS and nuclear over a twenty year period. The $\sim 10 \%$ balance of the generation is comprised of new biomass, petroleum and natural gas plants. Using the current capacity of $16 \mathrm{GW}(\mathrm{e})$ total grid capacity the capacity of each of these would be $\sim 5 \mathrm{GW}(\mathrm{e})$.

Table F-3 summarizes some of the characteristics of the existing coal plants in Kentucky. Reduction of this inventory to $5 \mathrm{GW}(\mathrm{e})$ requires retiring $\sim 11 \mathrm{GW}(\mathrm{e})$ of existing plants. The highlighted columns on this table show the years in which each plant's age reaches 60 years. Figure F-23 shows the trend in remaining capacity if the plants were retired at this age. For the purposes of analysis, however, it will be assumed that those plants to be retired will be retired in an orderly progression beginning in 2013 and ending in 2035. Figure F-34 shows the remaining coal based capacity for this orderly retirement. The retained coal generation will also be updated with emission control equipment necessary to meet EPA regulations over this time frame. Based on industry literature ${ }^{4}$ a cost of $\$ 1 B$ per GW(e) is used for installation of the new emissions control equipment.

Table F-3. Summary of coal plants in Kentucky.

\begin{tabular}{|c|c|c|c|c|c|c|c|c|c|c|c|c|}
\hline Compary & Plant_Name & Plant_Type & $\begin{array}{l}\text { Initial } \\
\text { Service }\end{array}$ & Year at 60 & $\begin{array}{l}\text { Nameplate } \\
\text { _Capacity }\end{array}$ & $\begin{array}{c}\text { Generating } \\
\text { Capacity_ } \\
\text { MWY }\end{array}$ & Accum Cap & Coal_Units & Total_Units & $\begin{array}{l}\text { Last } \\
\text { Updated }\end{array}$ & $\begin{array}{c}\text { Coal } \\
\text { Consumption } \\
\text { ST }\end{array}$ & $\begin{array}{l}\text { Electric } \\
\text { Production } \\
\text { MWh }\end{array}$ \\
\hline Kentucky Utilities Co. (E.ON US) & Tyrone & Coal & 1947 & 2007 & 75 & 75 & 15,936 & 1 & 3 & 40210 & 12091 & 24047 \\
\hline Kentucky Utilities Co. (E.ON US) & Green River & Coal & 1950 & 2010 & 264 & 264 & 15,672 & 4 & 4 & 40210 & & \\
\hline Kentucky Utilities Co. (E.ON US) & Pineville & Coal & 1951 & 2011 & 38 & 38 & 15,634 & 1 & 1 & 40210 & & \\
\hline Tennessee Valley Authority & Shawnee & Coal & 1953 & 2013 & 1750 & 1750 & 13,884 & 10 & 10 & 40210 & 4082644 & 7436357 \\
\hline East KY Power Cooperative & Dale & Coal & 1954 & 2014 & 216 & 176 & 13,708 & 4 & 4 & 40210 & 389154 & 818662 \\
\hline Kentucky Utilities Co. (E.ON US) & Brown & Coal & 1957 & 2017 & 739 & 740 & 12,968 & 3 & 10 & 40210 & 1092651 & 2498989 \\
\hline Louisville Gas \& Electric (E.ON US) & Cane Run & Coal & 1962 & 2022 & 645 & 645 & 12,323 & 3 & 4 & 40210 & 1575971 & 3233873 \\
\hline American Electric Power (AEP) & Big Sandy & Coal & 1963 & 2023 & 1097 & 1060 & 11,263 & 2 & 2 & 40210 & 2507625 & 6245122 \\
\hline Tennessee Valley Authority & Paradise & Coal & 1963 & 2023 & 2558 & 2558 & 8,705 & 3 & 3 & 40210 & 6353549 & 14251654 \\
\hline Owens boro Municipal Utilities & Smith & Coal & 1964 & 2024 & 445 & 416 & 8,289 & 2 & 2 & 40210 & 1197428 & 2390873 \\
\hline East KY Power Cooperative & Cooper & Coal & 1965 & 2025 & 344 & 321 & 7,968 & 2 & 2 & 40210 & & \\
\hline Westem Kentucky Energy & Reid & Coal & 1966 & 2026 & 195 & 195 & 7,773 & 1 & 2 & 40210 & & \\
\hline Westem Kentucky Energy & Coleman & Coal & 1969 & 2029 & 521 & 521 & 7,252 & 3 & 3 & 40210 & 1278540 & 2660340 \\
\hline Louisville Gas \& Electric (E.ON US) & Mill Creek & Coal & 1972 & 2032 & 1717 & 1717 & 5,535 & 4 & 4 & 40210 & 4748412 & 10347176 \\
\hline Westem Kentucky Energy & HMP\&L Station 2 & Coal & 1973 & 2033 & 365 & 365 & 5,170 & 2 & 2 & 40210 & 751395 & 1575058 \\
\hline Kentucky Utilities Co. (E.ON US) & Ghent & Coal & 1974 & 2034 & 2226 & 2226 & 2,944 & 4 & 4 & 40210 & 5331887 & 11325017 \\
\hline East KY Power Cooperative & Spurlock & Coal & 1977 & 2037 & 1279 & 814 & 2,130 & 3 & 3 & 40210 & 3567030 & 7605669 \\
\hline Westem Kentucky Energy & Green & Coal & 1979 & 2039 & 528 & 528 & 1,602 & 2 & 2 & 40210 & 217705 & 2324793 \\
\hline Cinergy / Duke Energy & East Bend & Coal & 1981 & 2041 & 669 & 648 & 954 & 1 & 1 & 40210 & 1913481 & 4270135 \\
\hline Westem Kentucky Energy & D.B. Wils on & Coal & 1984 & 2044 & 440 & 440 & 514 & 1 & 1 & 40210 & & \\
\hline Louisville Gas \& Electric (E.ON US) & Trimble County & Coal & 1990 & 2050 & 566 & 514 & 0 & 1 & 7 & 40210 & 1409667 & 3124300 \\
\hline
\end{tabular}




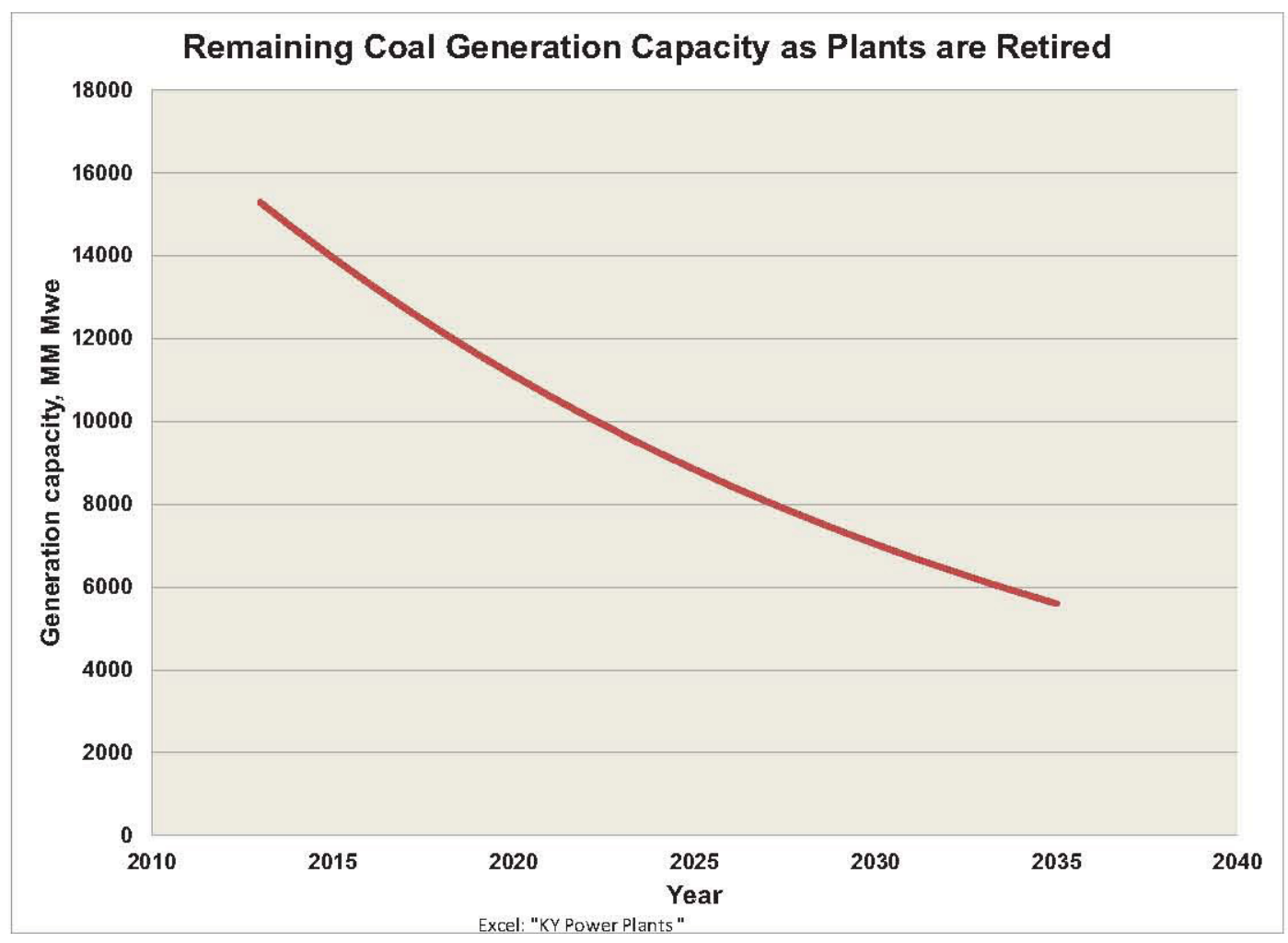

Figure F-34. Retained upgraded coal plants after retirement of selected plants.

Figure F-35 illustrates the addition of new capacity as existing coal based capacity is retired with the objective of maintaining the total grid capacity in the range of $16 \mathrm{GW}(\mathrm{e})$. The additional new capacity includes a mix of natural gas combined cycle generation in the first half of the transformation, with coal with CCS, LWR, and HTGR electricity generation completing the additions. It is necessary to include a significant capacity of natural gas generation in the earlier phase of the transformation because the other technologies are still in development and will not be available for commercial application until the mid2020 s. The natural gas generation is needed to make up for the retirements in the 2013 to mid-2020s that have already been announced ${ }^{5}$ and additional retirements that are anticipated because of the current and pending EPA regulations. ${ }^{6}$ Use of natural gas generation in this interim period is economic because of the low prices for natural gas projected over the next decade and potentially beyond, and the low capital costs for deployment. Natural gas generation is also the baseline for GHG emitting generation in pending EPA regulation on GHGs. However, over the longer term the economics of natural gas generation may not be favorable as natural gas prices rise. Accordingly, it has been assumed that it will be retired after 15 to 20 years of operation as new non-GHG emitting generation comes online. 


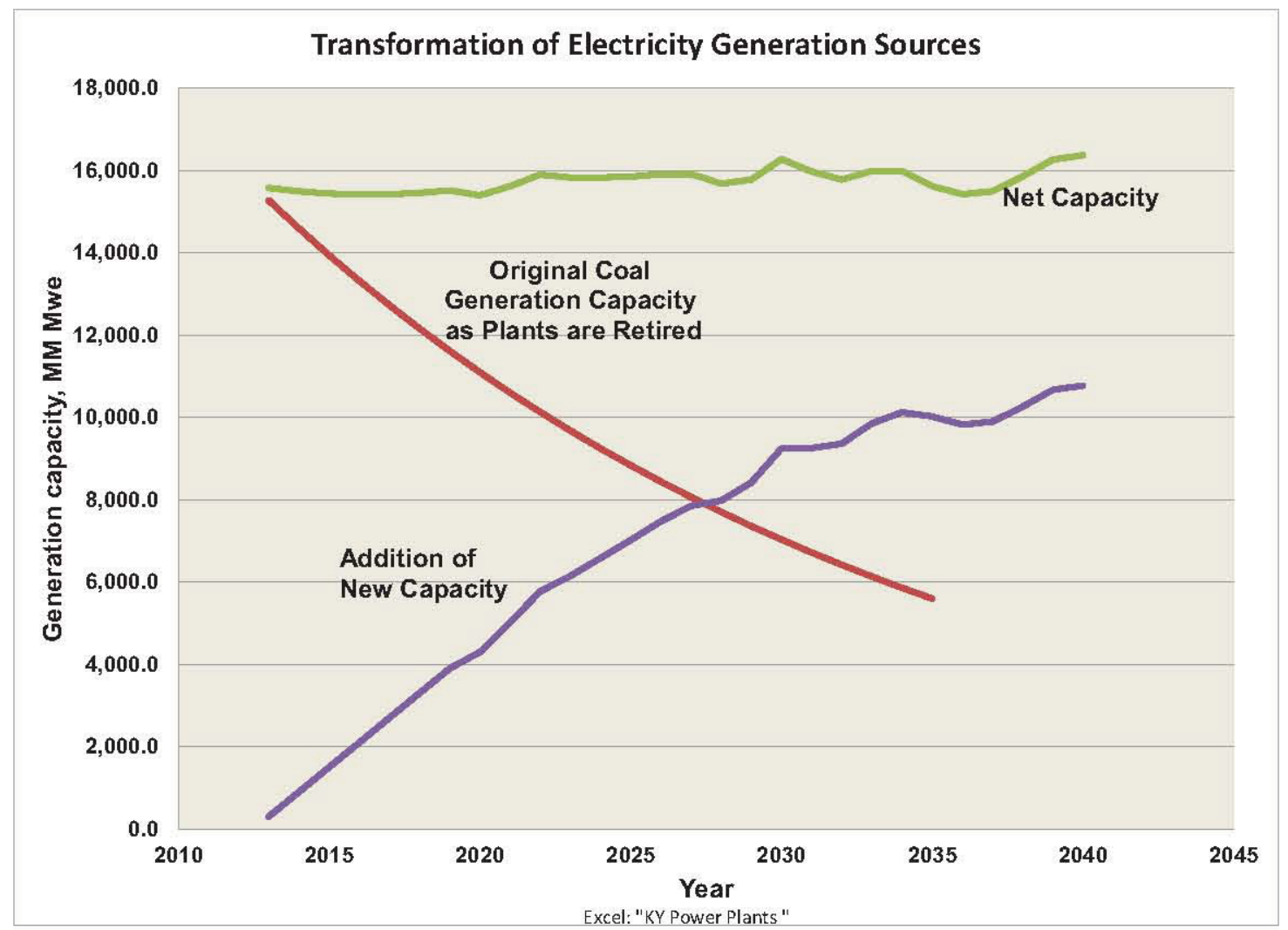

Figure F-35. Transformation of electricity generation sources.

Figure F-36 shows the shifts in the mix of generation technologies as the Kentucky grid is transformed from one dominated by coal in 2013 to the mix shown in Figure F-23. This shows the early addition of natural gas generation as coal plants are retired in the 2013-2020 time frame. In the early 2020 s coal plants with CCS (1300 MW(e) per plant) are added to the grid and the natural gas capacity is beginning to be retired. This retirement of natural gas capacity continues as the nuclear components are added to the mix. The initiation of the nuclear additions is based on current estimates of their availability for commercial application. LWRs (500 to $1500 \mathrm{MW}$ (e) per plant) are the first additions to the grid beginning in 2023 and extending through 2032. HTGRs are added in two phases. The addition during the integration of the HTGR technology into the carbon conversion processes as discussed in previous sections is the first phase. The second phase is the addition of an electricity only plant ( 1000 MW(e)) toward the end of the addition of HTGRs to the carbon conversion processes.

As shown for this notional strategy the total period for the transformation of the electricity generation technologies is 27 years; exceeding the goal of 20 years shown in Figure F-23. This longer period is consistent with the expected rate of existing coal-fired plant retirements or upgrades. If this changes the rate of additions of new technologies would be adjusted accordingly. 


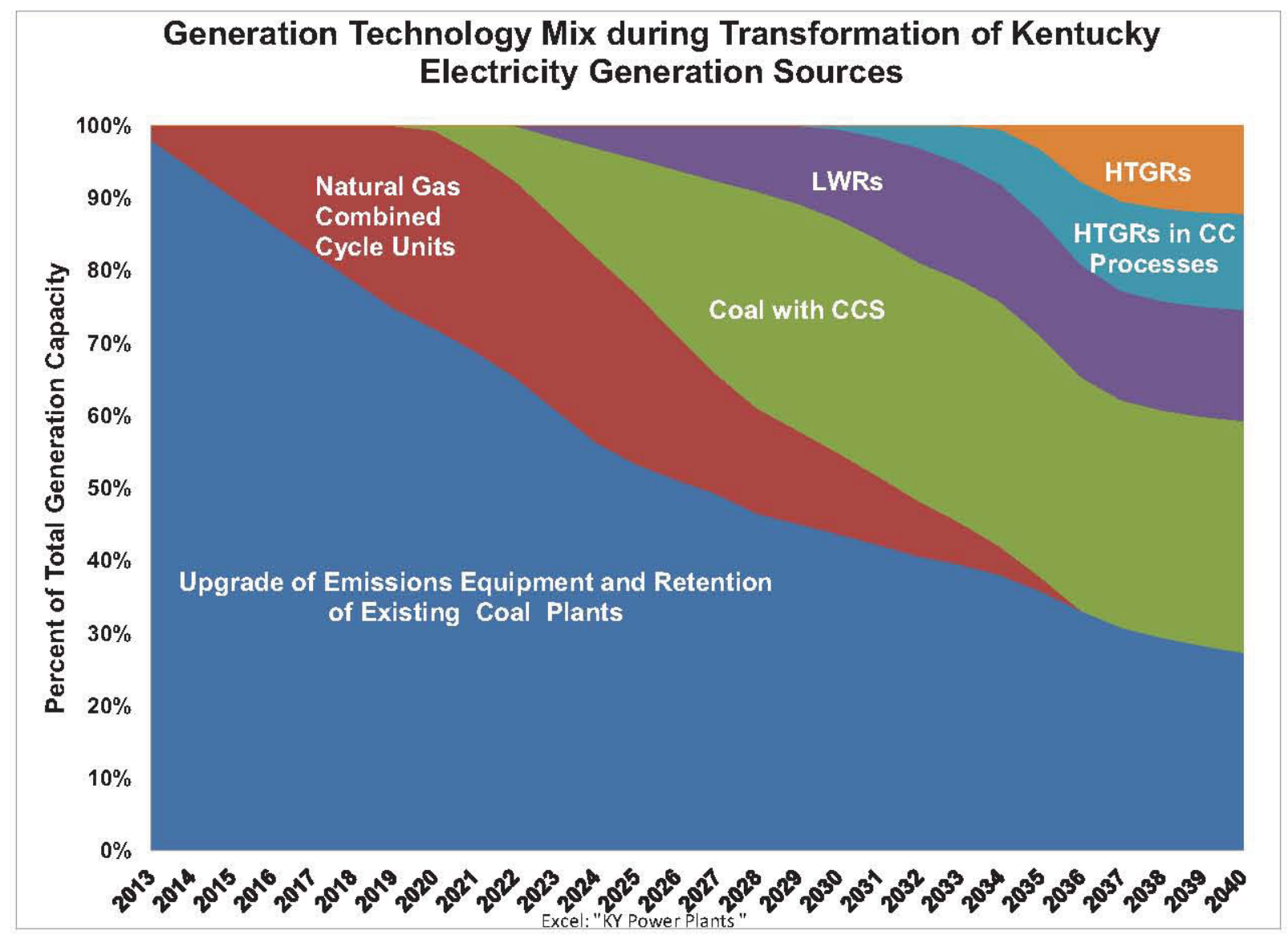

Figure F-36. Generation technologies mix during transformation of the Kentucky electricity generation sources.

Figure F-37 summarizes the estimated costs for the transformation. These costs are based on EIA estimates for the NGCC and Coal with CCS technologies and estimates developed for the LWR and HTGR technologies by the INL. The estimated costs are high, averaging $\sim \$ 3 \mathrm{~B}$ per year over the duration of the transformation. While this expenditure rate would have a positive effect on the Kentucky economy over this period because it is estimated that $\sim 70 \%$ of these expenditures would be in the form of labor and materials, the financing of such expenditures may be difficult.

In addition to the high costs the shift in electricity generation technologies will also increase the costs of electricity generation in Kentucky. The estimated costs of generation over the period of transformation are shown in Figure F-38. The added technologies have estimated generation costs significantly higher than the existing coal-fired plants. Accordingly, when complete it is estimated that the costs of generation will increase by a little more than a factor of two. This could have an adverse effect on the Kentucky economy and on the ability to export electricity outside the Commonwealth, if that were a priority. This factor is addressed in the following section of this report.

It should be emphasized that the prior discussions and estimates of costs and impacts on electricity generation in Kentucky are based on a notional strategy. The actual strategy, (e.g., the schedule of capacity retirement and plant upgrades, the selection of and schedule for addition of new generation) will be decided by the plant owners. These decisions will be highly influenced by government action on emissions regulation, long term objectives of the Commonwealth and costs. The development of the notional strategy discussed herein was completed to provide perspective on the scope and costs required to realize any significant transformation of electricity generation sources. 


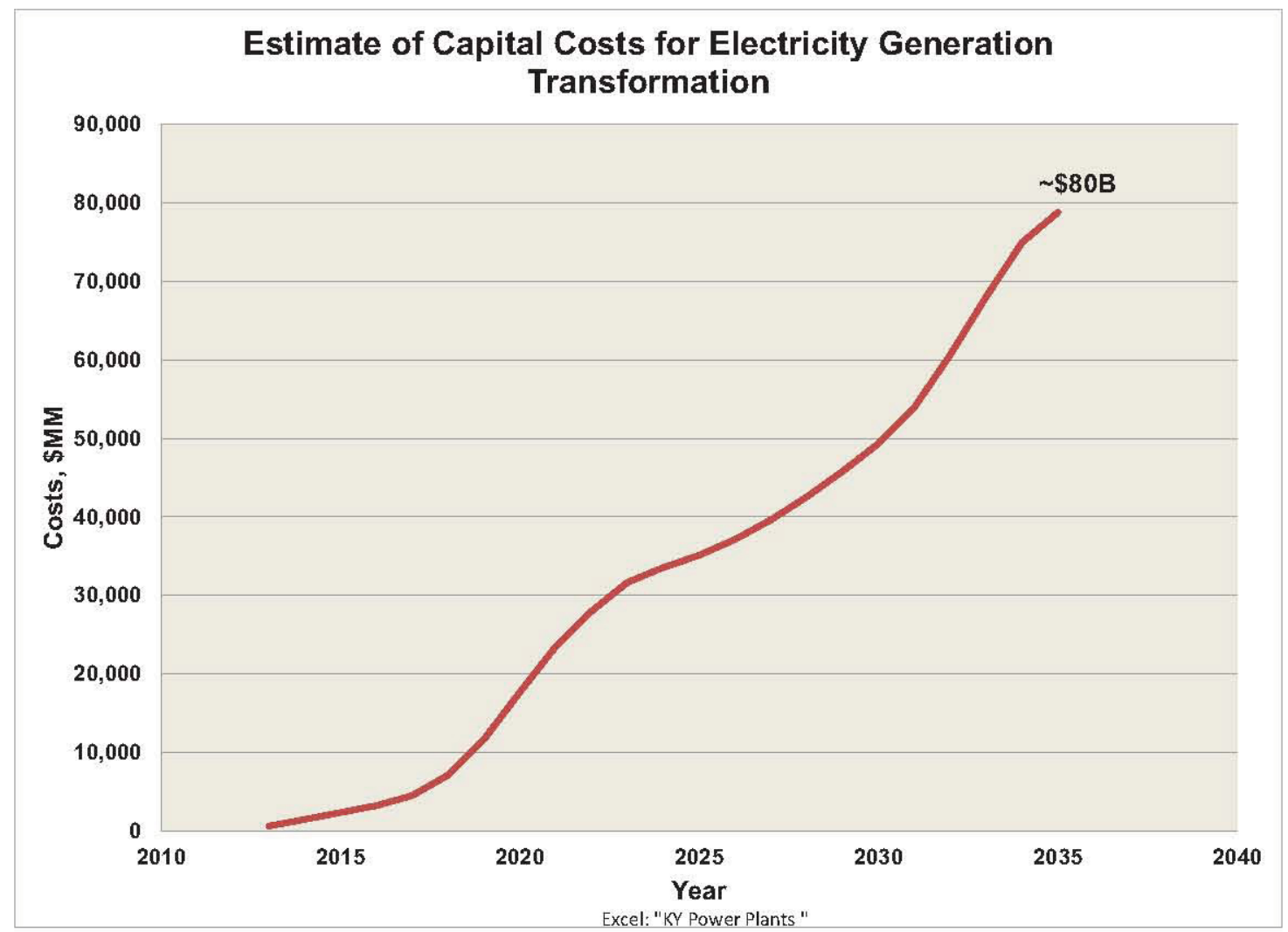

Figure F-37. Estimated costs of the Kentucky electricity generation technologies transformation.

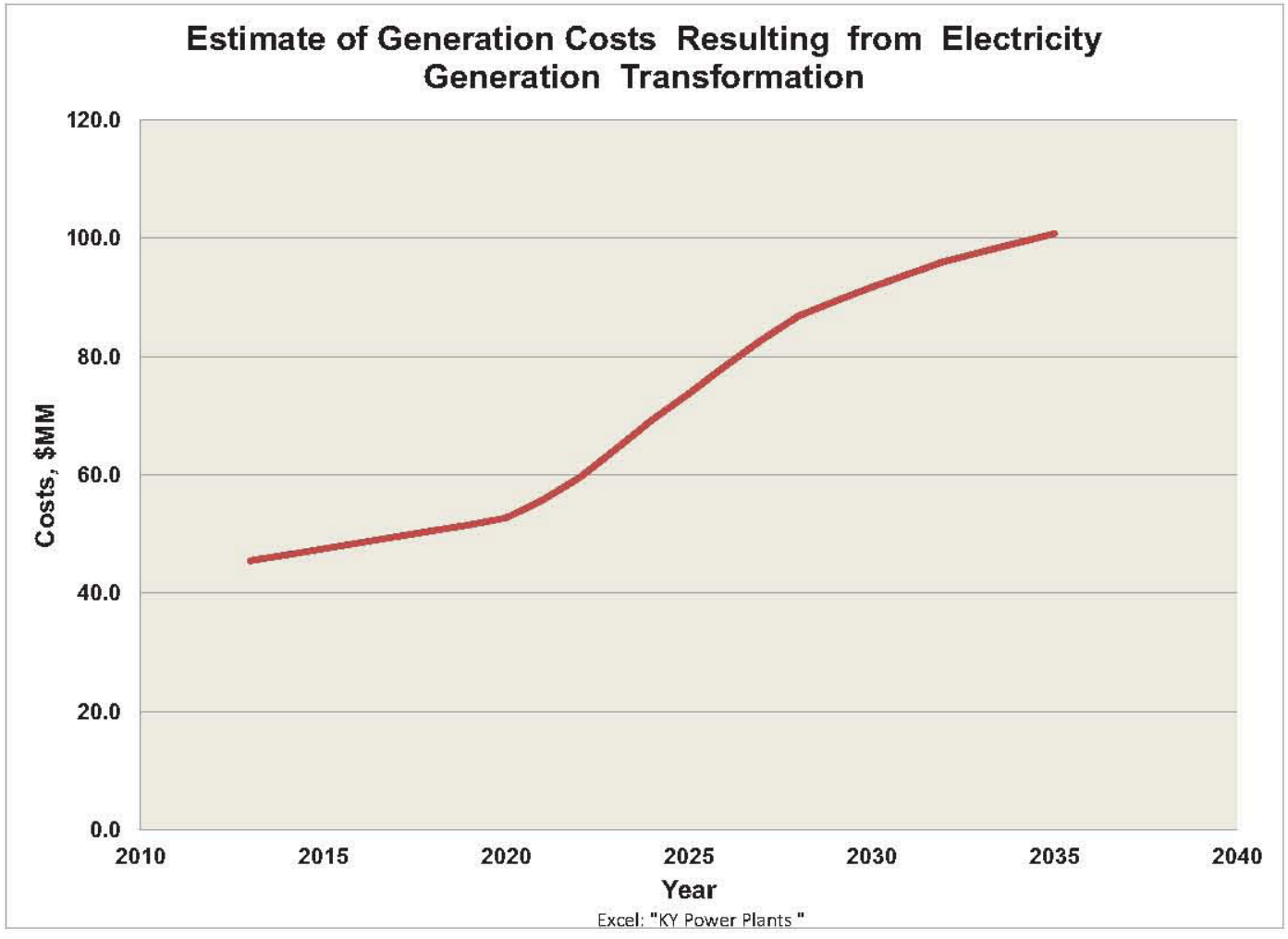

Figure F-38. Estimate of electricity generation cost increases from electricity generation transformation. 


\section{F-2.2.6 Net Effect on Kentucky GDP}

The deployment of a carbon conversion industry and the transformation of the electricity generation sources will have effect on the Kentucky economy during construction and over the longer term. The influence of these on the Kentucky real GDP ${ }^{p}$ is used as a metric to quantify their effect.

The carbon conversion industry deployment would add to the Kentucky GDP as expenditures are made during construction of the process plants and later during integration of the HTGR technology in the carbon conversion process. Over the longer term the consumption of coal and natural gas and the production and sale of synthetic fuels will be an added component to the GDP. In this regard, Figure F-10 summarized the funding profile required for deployment of the carbon conversion process plants and Figure F-32 summarized the costs for integrating the HTGR into these process plants. INL review of the elements of the costs in each of these cases shows that $\sim 70 \%$ of the costs are in the form of labor and material which would be expected to be local to Kentucky. Accordingly, it is estimated that these would be direct contributors to the Kentucky GDP during that period.

The revenues generated by the process plants will also have a direct contribution to the GDP. This is shown in Figure F-30. The contribution to the GDP from the revenues has been established by subtracting intermediate contributions to generation of the revenue that are accounted for in other elements of the GDP, (e.g., labor, commodities). The value of the coal and natural gas used in the conversion processes is included in this accounting since it is consumption directly related to these plants and is not currently accounted elsewhere.

Similarly, the expenditures during construction of new electricity generation to achieve the objective of diversifying electricity generation technologies will also add to the GDP. The estimated annual expenditures over the construction period are summarized in Figure F-37. Again 70\% of these expenditures is assumed to directly affect the GDP.

The increase in electricity generation costs due to the transformation of the electricity generation sources may have a negative effect on the GDP by increasing the costs of production in the industrial sector and costs to the residential and commercial sectors. The increases will also affect the ability to export electricity outside the Commonwealth. However, this increase in generation costs is judged to not have a significant effect on the Commonwealth's GDP over the longer term for the following reasons:

- With respect to export the percentage of generation exported from Kentucky is less than $10 \%{ }^{7}$ and, accordingly, has a very small influence on the GDP

- Figure F-39 shows the expenditure in Kentucky on energy by sector and fuel. ${ }^{7}$ Electricity accounted for $33 \%$ of energy expenditures in 2009 . The doubling of the generation costs over the period $2013-$ 2040 would increase this percentage of total energy expenditure but it is judged that the increase would not be proportional to the increase in cost because there would also likely be reduced demand. An estimate of the effect of this increase on reduced demand could be made using the correlations developed by Kentucky in Reference 8 . This paper states:

“...These electricity price elasticity coefficients suggest that given a $10 \%$ increase in the real price of electricity in Kentucky, and holding all other included factors constant:

- Commercial consumers would reduce electricity consumption by between $2.1 \%$ and $5.4 \%$

- Industrial consumers would reduce electricity consumption by between $3.4 \%$ and $12.2 \%$

p The cost analyses presented in the prior sections of this report have been based on 2011 . For the purposes of this discussion the GDP effects will be referenced to the Kentucky 2011 GDP. 

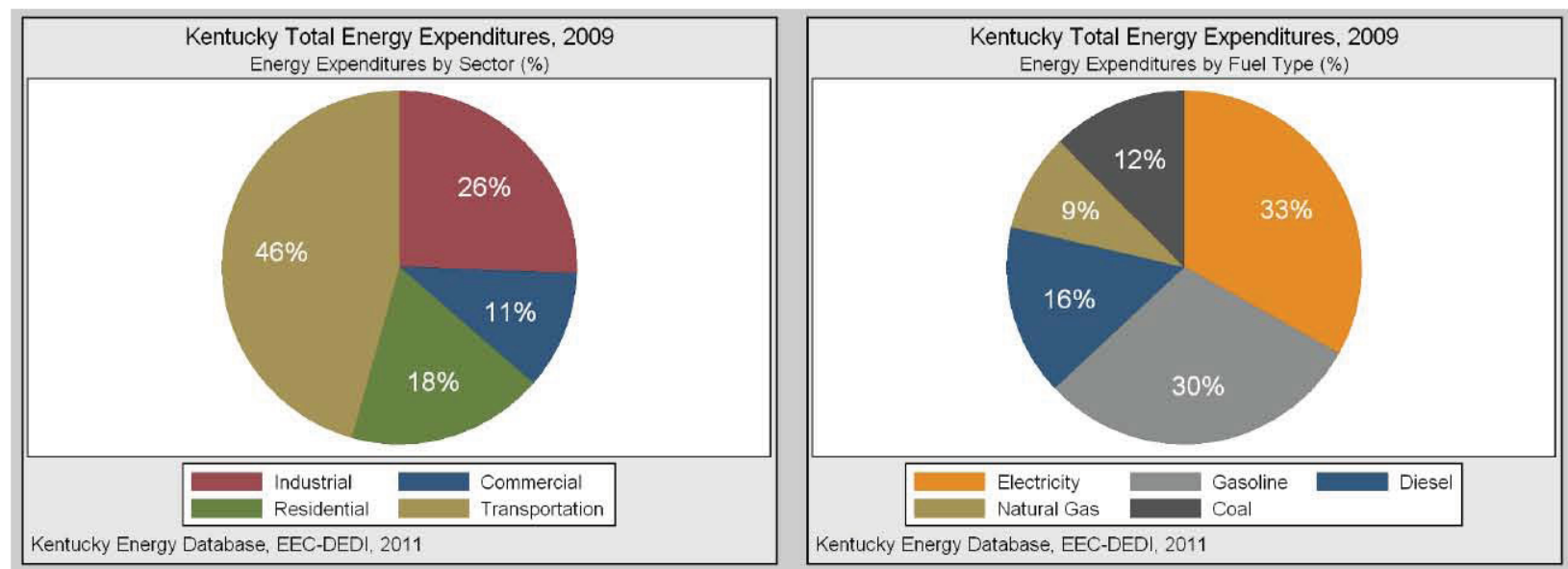

\begin{tabular}{|c|ccccc|}
\hline Sector & Million (\$ US) & Percentage & Fuel Type & Million (\$ US) & Percentage \\
\hline Total & 17,477 & $100 \%$ & Total & 17,477 & $100 \%$ \\
\hline Transportation & 7,979 & $46 \%$ & Electricity & 5,713 & $33 \%$ \\
Industrial & 4,471 & $26 \%$ & Gasoline & 5,153 & $30 \%$ \\
Residential & 3,140 & $18 \%$ & Diesel & 2,697 & $16 \%$ \\
Commercial & 1,887 & $11 \%$ & Coal & 2,123 & $12 \%$ \\
& & & Natural Gas & 1,560 & $6 \%$ \\
\hline
\end{tabular}

Figure F-39. Kentucky energy expenditure by sector and fuel - 2009.

- Residential consumers would reduce electricity consumption by between $3.1 \%$ and $8.6 \% \ldots$,

The $100 \%$ increase in electricity price projected for the full transformation of the generation sources would project decreases in demand on average between $29 \%$ and $87 \%$. This is judged to be an unreasonable expectation on reduction in demand over this long period. It also does not take into account increases in demand due to other factors such as the expansion of the economy and population in Kentucky over this period. It is judged that there will be little change in demand on a percentage basis over the period of transformation.

- The period of transformation is long resulting in a gradual increase in annual costs as shown in Figure F-39. This should allow the economy to absorb the increases without major impact.

- The increase in electricity generation costs will not be limited to Kentucky as the impact of retired coal based plants and introduction of new higher cost technologies increase the average real generation cost nationally. The projected ultimate generation costs are also in the same range as current generation costs in parts of the United States that do not have significant coal based generation, (e.g., the Northeast). Therefore, Kentucky should be able to retain its position within the national economy.

Accordingly, the effect of the projected increases in real electricity generation costs will not be considered further in the assessment of the transformation on the real GDP.

Figure F-40 shows the estimated annual contributions of the notional deployment of the carbon conversion industry and the expenditures during transformation of the electricity generation sources developed herein to the Kentucky GDP in real (2011\$) dollars. For comparison, also shown is the contribution of the mining industry to the GDP in 2011. The maximum contribution during deployment of the carbon conversion industry and transformation of the electric generation industry is $\sim \$ 12 \mathrm{~B}(2011 \$)$ or more than twice the 2011 contribution. The long term contribution from revenue of the carbon conversion 
industry is $\sim \$ 8.5 \mathrm{~B}$ (2011\$); $70 \%$ higher than the mining industry contribution in 2011. The long term carbon conversion industry will consume a minimum of $\sim 14.5$ million tons per day of primarily eastem

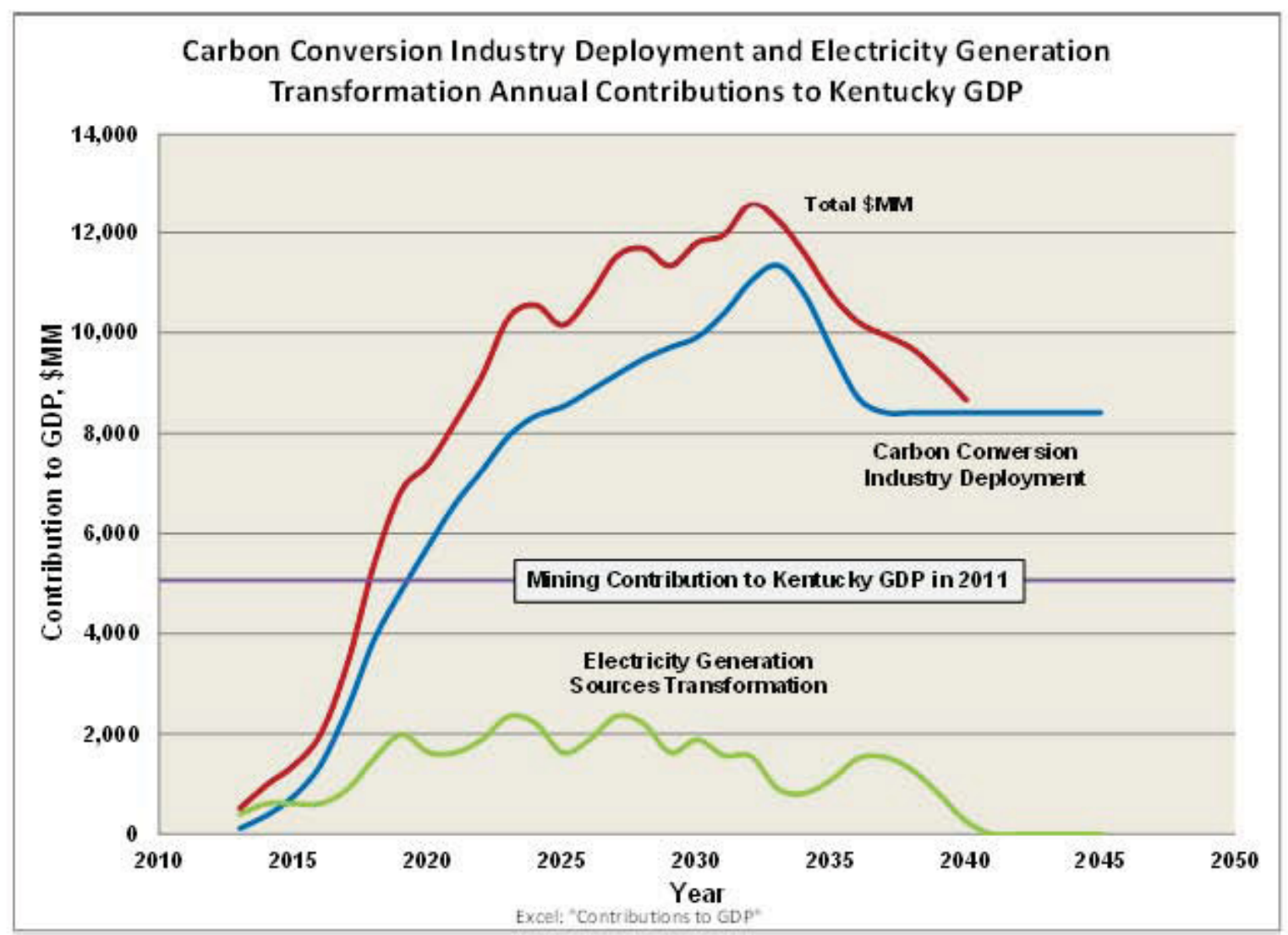

Figure F 40 . Contributions of carbon conversion industry and transformation of electricity genteration sources on Kentucky GDP.

Kentucky coal and 378,300 MMSCF per day of eastem Kentucky natural gas. Additionally, if these initiatives were started as analyzed in this report initial coal and natural gas consumption would begin in 2018 and the plants will reach full capacity in 2023. The integration of the HTGR into the process plants beginning with initial construction in 2025 adds to the GDP through 2036 . This integration also reduces $\mathrm{CO}_{2}$ emissions to manageable levels.

These are substantive contributions to the Kentucky economy on a real dollar basis and support the Commonwealth objectives of revitalizing the coal and natural gas production industry in eastern Kentucky and providing a viable sustainable mix of electricity generation over the long term. Also, it should be noted that the substantive economic multiplier effects of business growth (e.g., real estate, retail sales growth) that accompanies such industry development and transfomation has not been included. 


\section{F-3. REFERENCES}

1 INL EXT-11-24143 and INL INL-12-24572

2 EIA, Annual Energy Outlook 2012 (Early Release April 2012 and June 25, 2012 Release)

3 Kentucky Energy Plan: Purpose, Process and Status, Dr. Len Peters, Kentucky Energy and Environment Cabinet, presentation to National Governors Association, Energy Advisor Policy Institute

4 A.E.P. Backs Down on Coal Plant Retrofit, By ERIC LIPTON, Green, A blog about the environment, May 30, 2012, 4:42 pm, "American Electric Power conceded defeat on Wednesday, at least temporarily, in its push to save Big Sandy, its 49-year-old coal-burning plant in eastern Kentucky, surprising state officials there by withdrawing its $\$ 1$ billion plan to retrofit the power plant so that it can meet tough new federal environmental regulations."

5 Three Kentucky coal plants to retire due to EPA rules, NEW YORK | Fri Sep 16, 2011 3:34pm EDT, (Reuters) - "Kentucky power companies Louisville Gas and Electric ( $L G \& E)$ and Kentucky Utilities $(K U)$ said new, stricter, federal environmental regulations will force them to retire three older, coalfired power plants."

6 EPA Targets Coal With Proposed Carbon Limits For New Power Plants, March 28, 2012, ENERGY DAILY, Vol 40, No 61

72011 Energy Profile, Kentucky Department for Energy Development and Independence, Kentucky Energy and Environment Cabinet

8 Aron Patrick, et al, Modeling Electricity Price Elasticity of Demand using Heterogeneous Panel Data, Kentucky Department for Energy Development and Independence, Kentucky Energy and

Environment Cabinet in partnership with the University of Kentucky Department of Statistics, June 8, 2012 


\section{Appendix G}

\section{Steam Methane Reformer Modification}




\section{Appendix G Steam Methane Reformer Modification}

Prior to initiating the incorporation of the HTGR technology it will be necessary to revise the SMR reformer design to use the HTGR heat in a convective heat exchanger in place of the burning of natural gas and a radiant heat exchange mechanism.

In a conventional steam methane reformer, heat is transferred from the combustion gas to the reforming tubes via radiation. In the HTGR integrated steam methane reformer scenarios considered in this study, convective heat transfer will be required. Due to this difference, a redesign of the reformer will be required in order to ensure adequate heat transfer in the HTGR integrated scenario. Fortunately, significant work has already been done by industry to develop and commercialize convective steam reformers. Although the objectives in prior development of this technology have not focused on nuclear heat integration, the concepts and designs appear to be easily adaptable to using hot gas from an HTGR as the heat source. The Haldor Topsoe Convective Reformer (HTCR) was developed in the 1980's and has been in large-scale industrial operation since 1997. This technology was designed to use flue gas as the heat source, and integrates a combustor into the design. A schematic of the reformer design is shown in Figure G-1. The HTCR reactor consists of a vertical, refractory lined vessel, containing the tube bundle with several bayonet tubes. Each tube assembly is surrounded by a flue gas guiding tube, and the heat flux is adjusted by a proprietary flue gas control device. Below the vertical section is a horizontal combustion chamber containing the burner. Note that in this design, the flue gas temperature $\left(1,270^{\circ} \mathrm{C}\right)$ is significantly hotter than the gas that can be delivered by an HTGR $\left(850^{\circ} \mathrm{C}\right)$. Also, the flue gas exit temperature in this design $\left(600^{\circ} \mathrm{C}\right)$ is slightly warmer than the helium exit temperature assumed in the HTGR scenario $\left(563^{\circ} \mathrm{C}\right)$.

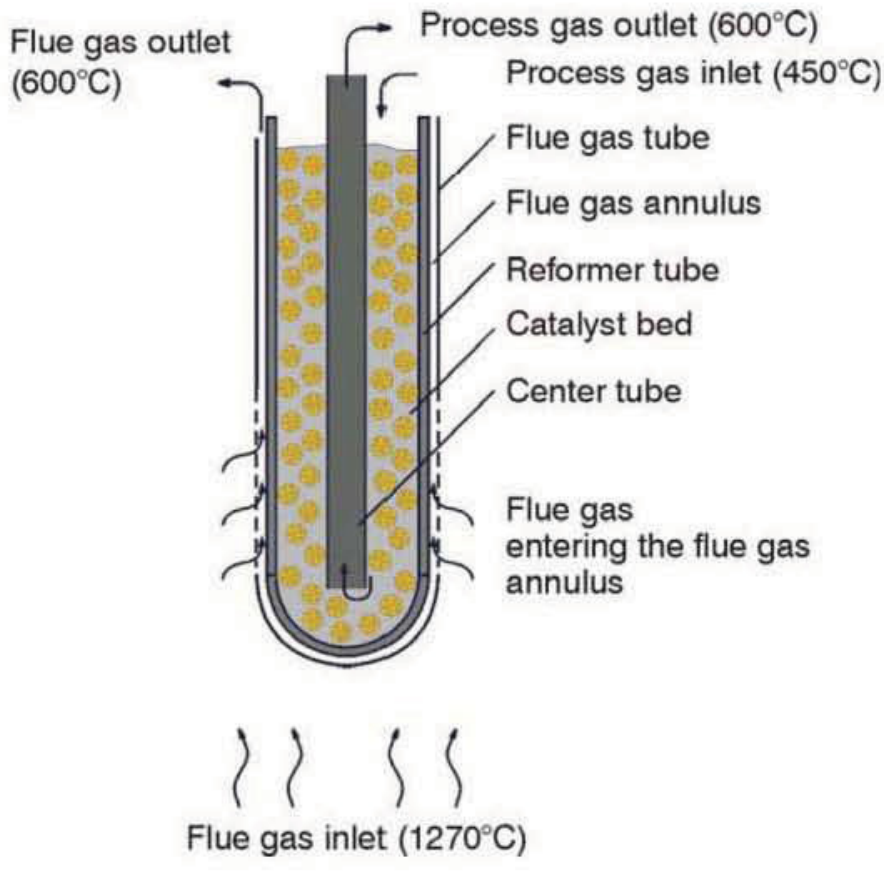

Figure G-1. Haldor Topsoe Convective Reformer (HTCR) design.

Haldor Topsoe has also developed a convective reformer that relies on process gas as the heat source. In this design, the hot gas enters the reformer at $1,040-1,050^{\circ} \mathrm{C}$. This design, known as the Haldor Topsoe Exchange Reformer (HTER), was first used on a commercial scale in 2003 at Sasol's Secunda, 
South Africa synfuels complex. A picture of the HTER internals being lifted after arrival at this site is shown in Figure G-2. One key difference between the HTER and the HTCR designs is that the HTER is designed for operation at higher pressures, which would be desirable when using an HTGR for the heat source.

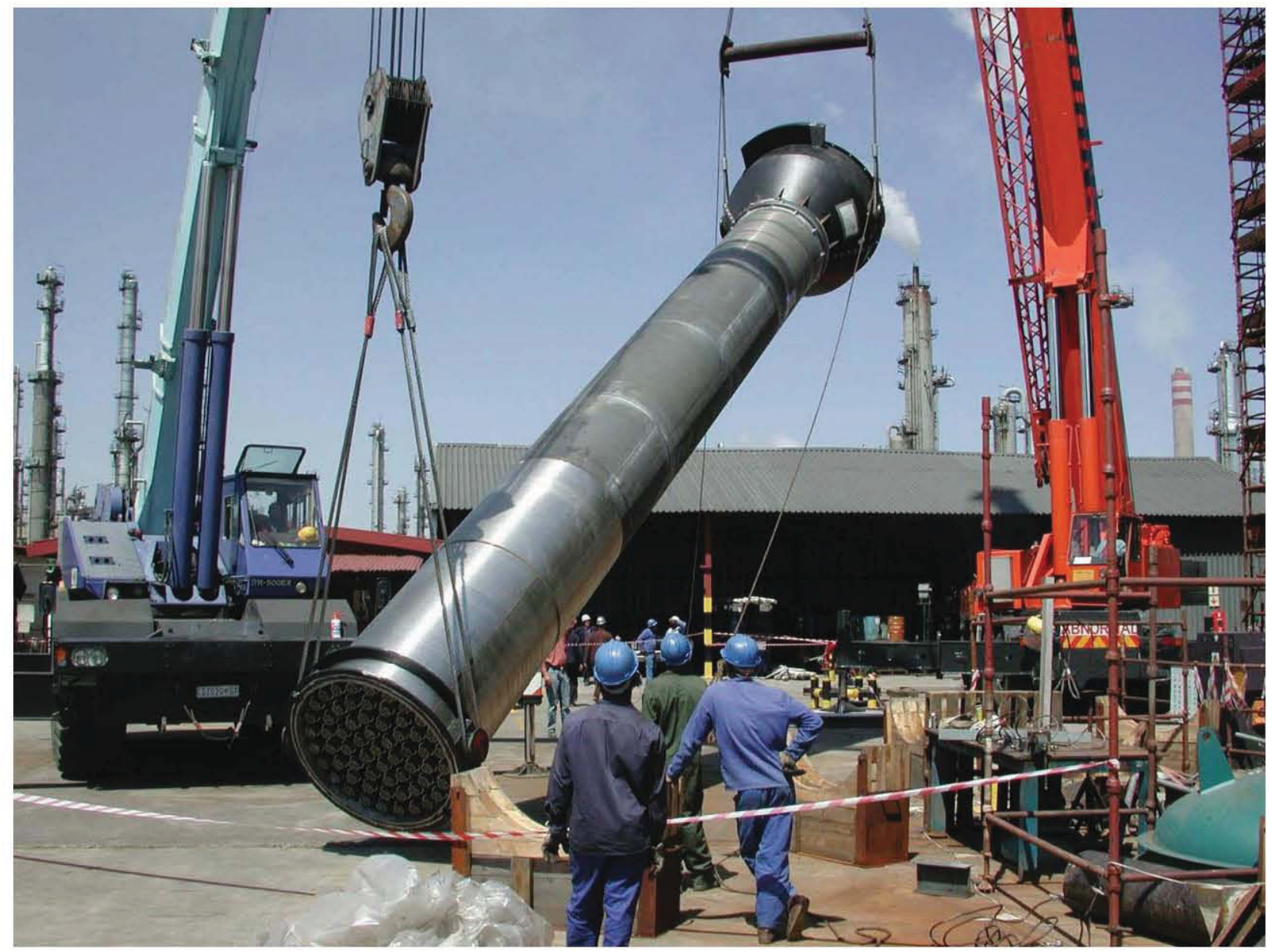

Figure G-2. Haldor Topsoe Exchange Reformer (HTER) internals being installed at Sasol facility.

Based on the commercial success of convective steam reforming in recent years, it is believed that this technology could be adapted to use an HTGR for the heat source. Due to the lower temperature of the HTGR heat compared to previously proven heat sources, it is anticipated that a somewhat larger design would be required. Development is needed to quantify this issue, identify any other potential issues, and ensure a trouble-free design. 
Attachment, NGNP Industry Alliance Limited Business Plan 


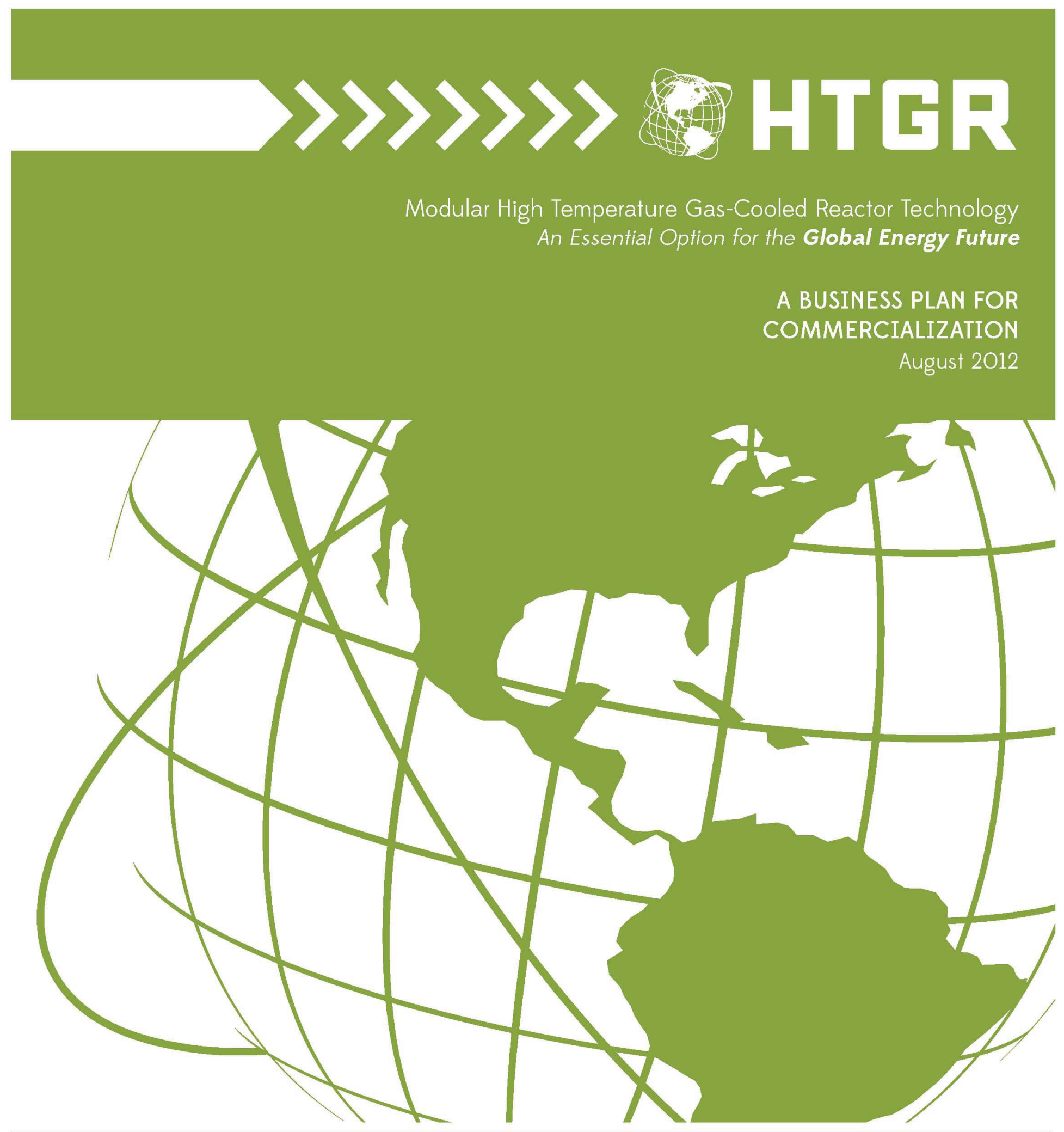

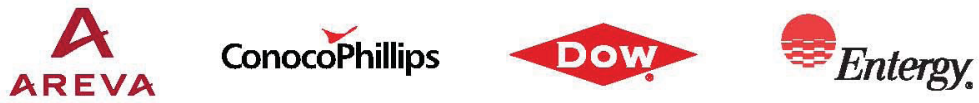

The NGNP Industry Alliance

Promoting the development and commercialization of High Temperature Gas-cooled Reactor (HTGR) technology

\section{GRAF Teclh \\ MERSEN \\ PTAC \\ SGL GROUP}

|TECHNOLOG

TOYOTANSO
(2)

Westinghouse

* US nuclesare 


\section{AN INTRODUCTION TO THE HIGH TEMPERATURE GAS-COOLED REACTOR}

A nuclear, near-zero carbon source of process heat and power for industry

The industrial sector was responsible for more than $20 \%$ of energy usage in North America and Europe in 2009 and above $25 \%$ in OECD Asia. Refining, chemical processing and iron \& steel industries rely on fossil fuel for high temperature process heat and account for over $40 \%$ of this industrial sector total.

Today, there are no other choices for lower carbon footprint pathways to provide high temperature process heat. The HTGR provides the only option on the technology horizon that addresses this industry's carbon footprint, energy security and price volatility.
The HTGR is at least $30 \%$ more efficient in the production of electric power than light water Small Modular Reactors (SMRs) and can uniquely address industrial process heat requirements. The potential market for HTGRs is at least twice that of any other proposed modular reactor - as many as 700 reactor modules in North America alone.

\section{High Temperature Gas Reactor (HTGR) - The Game Changer}

1. The design of the HTGR is intrinsically safe. Post-Fukushima, the importance of this capability is clear.

- Intrinsic safety allows co-location with new or existing industrial facilities

- There are no failure scenarios that result in any significant release of radioactive materials based upon:

o Fission products are contained within ceramic-coated fuel particles

- The reactor shuts itself down well below temperatures that can damage the ceramic fuel particles

- No heat transfer fluid (water, gas, etc.) is required for post accident cooling

o Spent fuel is air cooled without motive force required

o No motive power, electric or otherwise, or operator intervention is needed to safely shut down the reactor

2. The HTGR is the only technology on the near-term horizon capable of displacing the use of fossil fuel for electricity and high temperature process heat while emitting zero carbon.

- Supplies process heat requirements for petrochemical refining, chemical processes and extraction and upgrading of bitumen from oil sand and shale, and provides higher efficiency electrical power (more than $30 \%$ higher) and lower-cost power generation compared to SMRs

- Displaces/supplements premium fossil fuels, lowers $\mathrm{CO}_{2}$ emissions and provides stable process heat pricing as fossil fuels are fungible global commodities and pricing is tied to oil intrinsic energy parity in many parts of the world

- Allows premium fossil fuels to be used for higher-value products, such as chemical feedstocks that add multiples of GDP vs. simply burning as fuel

3. It is economically competitive with natural gas in most places of the world today without any price for carbon.

- Competes globally today for process heat and power at about \$6 per MMBTU equivalent natural gas price

- Even in North America (NA), the Alliance concludes this will be competitive in the commercialization time frame of $2025^{+}$

- The Alliance estimates that the first 25 -year build out with only a $25 \%$ market penetration in NA only will likely create more than $\$ 1$ trillion in GDP

- Creates high-paying jobs in infrastructure (large industrial forgings \& other ancillary equipment), construction and operation

- Helps assure energy security by providing long-term stable energy costs \& enabling conversion of carbon (coal, pet coke, solid waste) to synthetic fuels and chemicals via nuclear-assisted conversion processes with a minimal carbon footprint

4. The business model will likely not require loan guarantees based on large industrial end-user long-term purchase agreements and multi-investor ownership.

- The business model envisions third-party fence line commercial agreements with the process heat and power off-takers, enabling the long-term agreement to serve as collateral and eliminate the need for loan guarantees 


\section{The North American Potential Market alone is represented by:}

\section{Co-generation}

Petrochemical, Refinery, Fertilizer/Ammonia plants and others

\section{Premilinary Economics - Cogeneration}

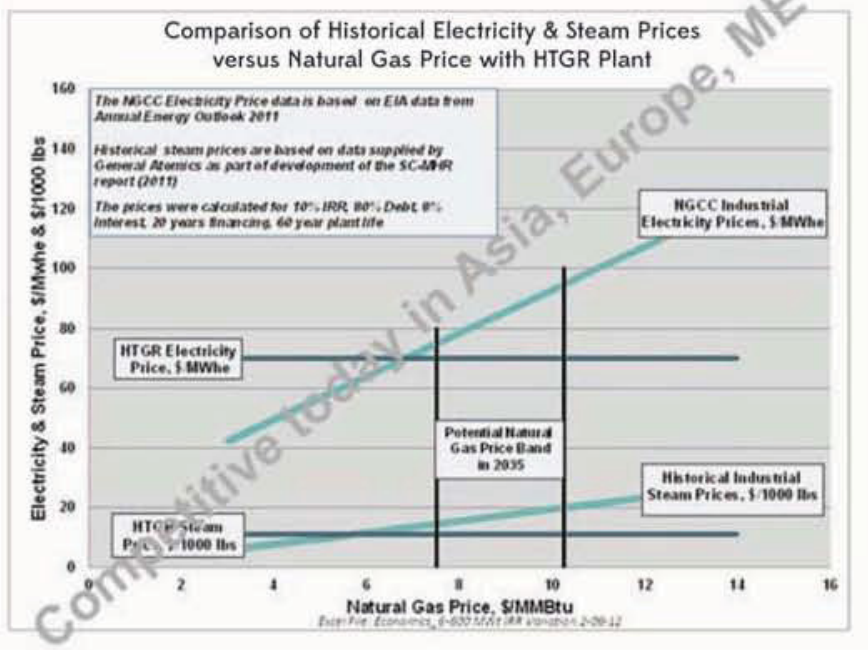

75 GWt (-125 - 600 MW' modules)

Oil Sands / Oil Shale

Steam, electricity, hydrogen \& water treatment

$18 \mathrm{GW}+(-30-600 \mathrm{MW}+$ modules)

Hydrogen Merchant Market

$36 \mathrm{GWH}(-60-600 \mathrm{MW}$ - modules)

Synthetic Fuels \& Feedstock

Steam, electricity, high temperature flids, hydrogen

$249 \mathrm{GWt}(-415$ - $600 \mathrm{MWt}$ modules $)$

IPP Supply of Electricity

110 GWt (-180 - 600 MWt modules)

\section{Fitit High Temperature Gas-Cooled Reactors (HTGRs)}

\section{A nuclear, near-zero carbon source of process heat and power for industry}

- The business model envisions many of the installations being joint venture (JV) structures with typical financing ( $80 / 20$ debt to equity) enabling many to participate in financing. A $\$ 4$ billion 4 reactor Nth of a kind installation with $4 \mathrm{JV}$ partners would only require cash infusion by the partners of $\$ 200$ million each

5. The key challenge centers not on the HTGR or its economics, rather it is the financial lift associafed with mafuring this game-changing fechnology. The fwo-decade-plus fimeframe for an inifial economic refurn on invesfment is difficult for private industry to make alone considering the business risks - parficularly those introduced by the government regulatory process.

\section{Summary}

Post-Fukushima, the HTGR brings a new level of intrinsic safely that enables its co-location with other industries and communities. It dramatically reduces $\mathrm{CO}_{2}$ emissions from petrochemical production, petroleum refining and extraction of bitumen from oil sands and shale. It is economical today in Europe, Asia and the Middle East where natural gas price is tied to oil parity. The Alliance concludes that even U.S. gas prices are likely to emerge in a range that will make this technology competitive for process heat and power in the 2020 + timeframe as utilities, transportation and natural gas compete to arbitrage the current U.S. price advantage. Further, if one envisions oil in the $\$ 130+$ per-barrel range in the 2020 + timeframe, it provides an economic approach to production of synthetic fuels from indigenous carbon sources with virtually no carbon footprint. It is the game-changing technology that can address the overarching global energy policy goals of energy and feedstock security, economic growth/GDP (jobs) and carbon footprint (climate). Based on the current trajectory, if funding were sufficient in the coming years, this technology could be deployed initially in the mid-2025 timeframe. 


\section{A BUSINESS PLAN FOR COMMERCIALIZATION}

This business plan includes the following summation:

- HTGR Technology - brief introduction to HTGR technology and its most important attributes

- Market and Economics - characterization of the potential market and the associated economics

- Investment Perspectives - why HTGR technology is a well-founded investment for industry, equity and national policy makers

- Commercialization Strategy - steps to commercialization and deployment

- Enterprise Structure - description of the major activities and organization to implement the commercialization strategy. Example investment scenarios are developed around this structure and described in more detail in the referenced Appendices

- Enterprise Risk - summary characterization of the most important risks associated with completion of the commercialization strategy

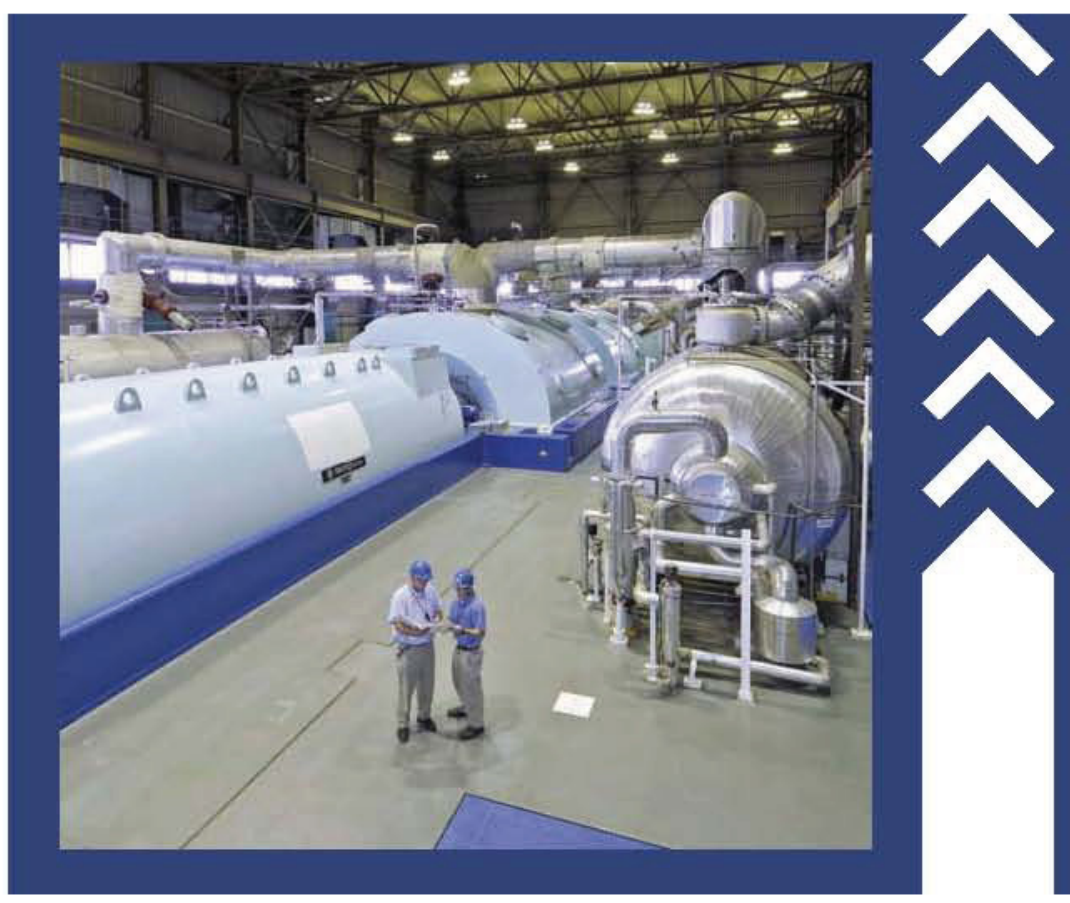

Selected topics are amplified in the Appendices, including:

- Appendix A: The Target Markets, Competition and Preliminary Economics

- Appendix B: Development Venture - completing the development for commercialization

- Appendix C: Deployment Project - constructing and operating the initial HTGR plant

\section{HTGR TECHNOLOGY}

Today, the process heat requirements for the energy-intensive industries around the globe are provided almost entirely by fossil fuels. In addition, power for these industries is provided by solid, liquid and gaseous fossil fuels. Consequently, these industries are hostage to evolving environmental concerns, unpredictable government policies, uncertainty of supply and price volatility. Modular HTGR nuclear technology provides an important option that addresses these issues head-on. It provides process heat at the temperatures needed by industry and power with competitive economics, compelling safety, and minimal environmental concerns.

For those markets that rely on premium fossil fuels, commercializing the HTGR makes available the only game-changing technology on the horizon that can address the overarching and global energy policy goals of energy and feedstock security, economic growth/GDP (jobs) and carbon footprint. In addition, trends in fossil fuel prices suggest that modular HTGR technology integrated with modified versions of conventional carbon conversion technologies provide an economic approach to production of synthetic transportation fuels, chemical feedstocks and chemicals with a minimal carbon footprint.

\section{Fulfills the Energy Needs of Energy-Intensive Industry}

A prismatic core modular HTGR with a conventional steam cycle has been selected as the reference concept for commercialization. The concept, developed by AREVA US, provides the best match to near-term energy needs with competitive economics and acceptable risks for investment readiness, while also laying the foundation for more advanced modular HTGR concepts. It is envisioned that the reference concept module will be incorporated in multi-module plants that can provide over-the-fence supplies of energy analogous in capacity and reliability to conventional combined cycle facilities used by industry. For example, a large industrial complex might typically have 4 to 6 modules for reliable process heat and power supply.

The nuclear supply system module is based on a $625 \mathrm{MW}$ thermal (MW/t) annular reactor core in a large steel reactor vessel. It is a two-loop system with the reactor connected to two parallel steam generators and helium circulators.

Ceramic-coated particle nuclear fuel is a key part of the modular HTGR concept. Each fuel particle consists of a fuel kernel surrounded by multiple ceramic-coating layers which provide the primary fission product retention barrier under all conditions. The total fuel supply includes roughly 30 billion such particles per core. As shown below, the particles 

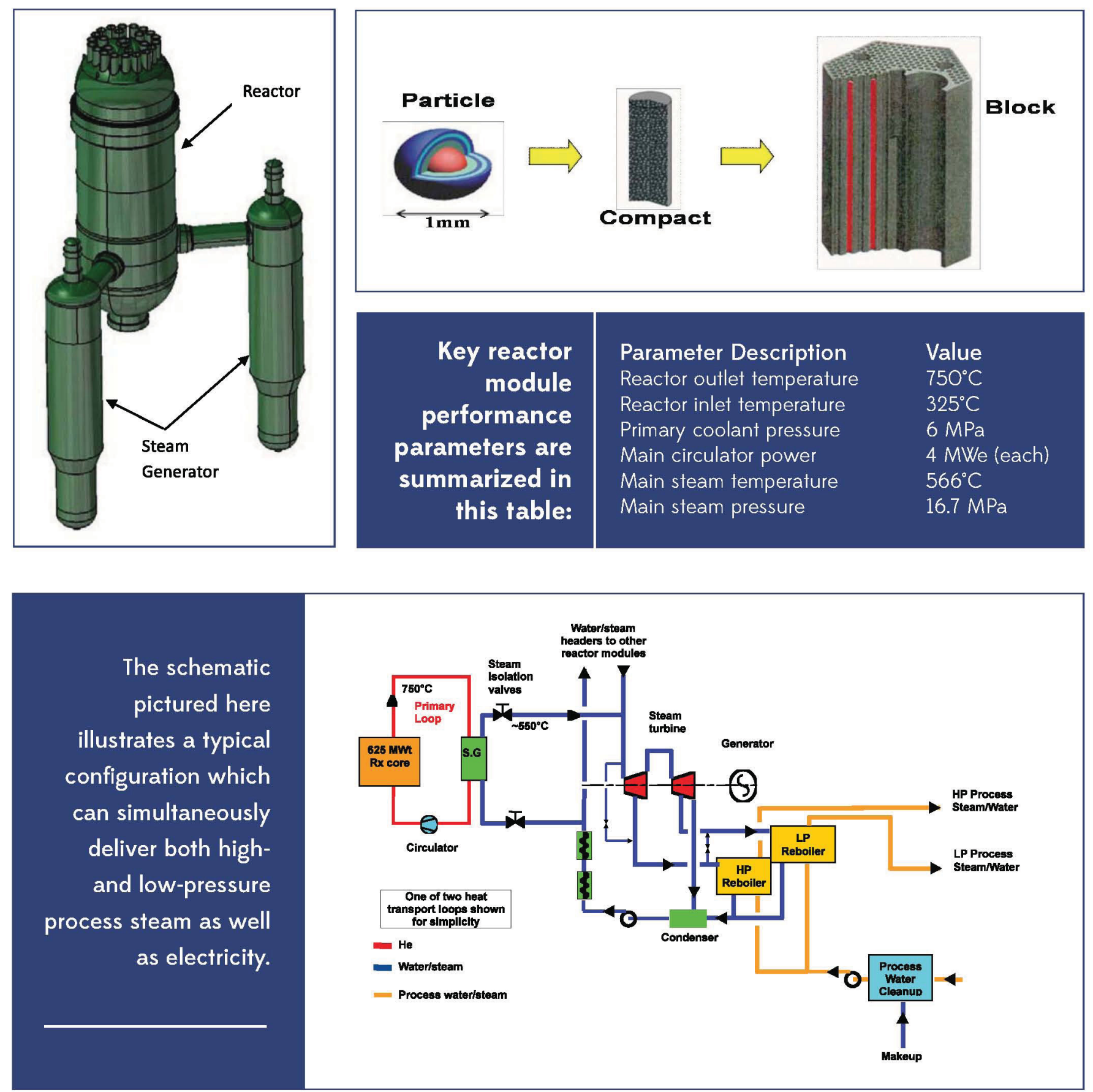

are distributed in graphitic cylindrical compacts, and the compacts are placed in holes drilled in the graphite fuel blocks. The fuel blocks are loaded into the fueled annulus of the core. The rest of the core is made up of non-fueled graphite reflector blocks, that due to its heat treatment (up to 3,000 degrees $\mathrm{C}$ ), also behaves as a ceramic. Hence the basic core structure is entirely ceramic.

Circulating helium carries the heat produced in the reactor to the steam generators to produce high temperature superheated steam. The remaining steam distribution system can be configured in a variety of different ways depending on the specific needs of each energy user.

The initial fleet will adapt multiple standard reactor modules with application-specific process steam and/or power generation modules for a range of plant sizes for the target applications discussed above. 


\section{Compelling Safety}

The superior safety characteristics of modular HTGR technology provide a nuclear energy system design that intrinsically protects the public and the environment. The safety case supports acceptable business risk for collocation at the energy end-user's facility.

The compelling safety case directly addresses extraordinary events such as interruption by natural causes (e.g., flood or earthquake), human error or equipment failure that affect the plant normal operations. Power and heat generation is managed through intrinsically self-limiting reactor shutdown without operator action and without the need for fluid management systems (e.g., water or gas) or electric power.

No explosive gases can be produced by the fuel materials or core infrastructure - the materials were selected and designed to preclude this. Used nuclear fuel from a HTGR requires no cooling water or active systems for storage or heat transfer over time, relying instead on natural convective flow of air.

The safety case has been demonstrated in the German AVR HTGR and recently in the 10 and 30 MW designs in Japan and China respectively. In those tests, the reactor was allowed to heat up to the point where it simply shut itself down.

\section{Intrinsic Nuclear Safety}

No need to evacuate or shelter the public and no threat to food or water supplies under any conditions.

Multiple assured barriers to the release of radioactive material are provided.

Reactor power levels are limited and the nuclear reactor shuts down if reactor temperatures exceed intended operating conditions.

No actions by plant personnel or backup systems are required to either ensure shutdown of the reactor or ensure cooling.

No power and no water or other cooling flid is required.

Reactor materials including the reactor fuel are chemically compatible and in combination will not react or burn to produce heat or explosive gases.

Achievable levels of air or water intrusion do not result in substantive degradation of the capability to contain radioactive materials.

Spent or used fuel is stored in casks or tanks in underground dry vaults that can be cooled by natural circulation of air and shielded by steel plugs and concrete structure.

Proximate public and industries need not shelter or evacuate for any internal or external event challenging reactor safety. This translates into a close-in siting capability needed for process steam/heat loads, plus anticipated improved public and investor acceptance.

\section{Extensive Development History}

The basis for the HTGR technology was first developed over 50 years ago in the UK, the U.S. and Germany. Seven experimental and demonstration reactors have been built world-wide, including U.S. commercial scale demonstrations of specific HTGR concepts for electric power generation at the Fort St. Vrain plant located in Colorado 1 that operated from 1976 through 1989 and the Peach Bottom Atomic Power Station, Unit 1, a 200 MWt, HTGR located in Delta, Pennsylvania, that was operated ${ }^{2}$ from June of 1967 to its final shutdown on October 31, 1974.

Current HTGR system-related development efforts exist in China, Korea, Japan and Russia, and there has been recent revived interest from the process heat industry in Europe.

Through 2011, $\$ 445$ million dollars ${ }^{3}$ has gone into confirmatory research and development for HTGR technology by the U.S. Department of Energy under the Next Generation Nuclear Plant (NGNP) program. Activities currently underway to complete qualification and codification for fuel, graphite and high temperature materials will complete in five to six years if sustainable funding is provided. These activities are being conducted at the Idaho National Laboratory (INL) and elsewhere in the national laboratory complex.

In complementary activities over the past decade, industry has invested more than a billion dollars ${ }^{4}$ in advancing design concept and pre-licensing work with the vision for completing a commercial-scale demonstration project. 


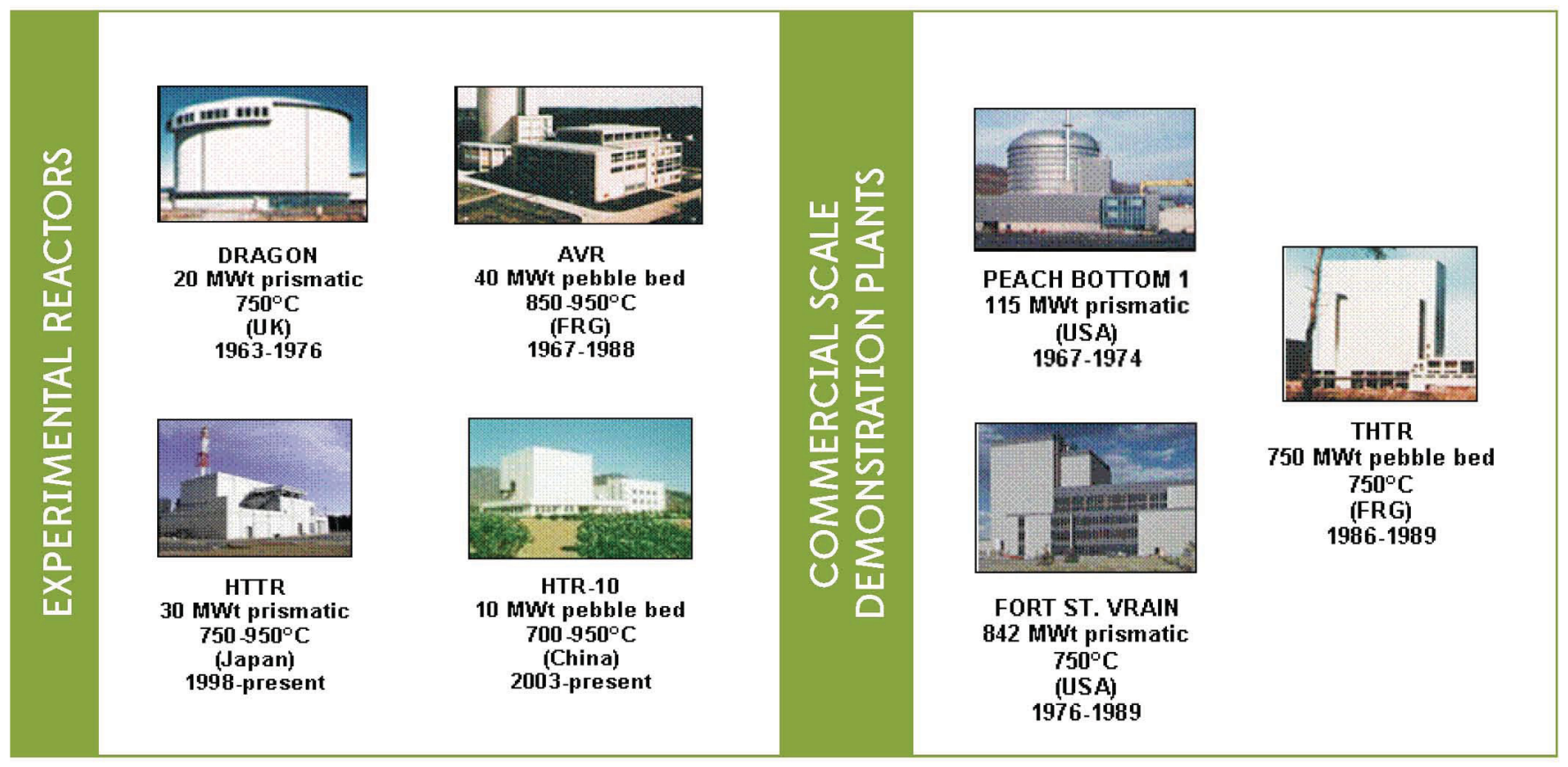

\section{MARKET AND ECONOMICS}

As described in more detail in Appendix A, substantive evaluations comparing the technology and economics of the HTGR with conventional technologies have been completed for about 20 different industrial processes including co-generation supply of steam and electricity to industrial plants, electricity generation as a merchant or regulated power generator, non-conventional oil extraction and upgrading, production of hydrogen, conversion of coal and natural gas to transportation fuels and chemical feedstock, production of ammonia and ammonia derivatives, seawater desalination, and coke and steel production. These evaluations addressed applications where the high temperature capabilities of the HTGR extend the use of nuclear energy beyond the traditional role of conventional light water reactors to supply electricity only. Based on these evaluations, and making conservative estimates regarding the extent of anticipated market penetration, the potential market in North America alone is represented by the summary in the adjacent figure.

For purposes of this business plan, the initial target market is limited to three broad market sectors: 1) delivery of high temperature process steam; 2) co-generation of process heat and electric power; and 3) power generation. This initial target market is selected based on the functional and performance capabilities of the reference concept described earlier, and assessment of preliminary economics for the associated applications. Each sector is summarized in the following with the estimated production capacity that could be installed, the cumulative contribution to the economy for the period 2025 through 2050 , and a preliminary characterization of economics.
The North American Potential Market alone (assuming conservative market penetration):

\section{Co-generation}

Petrochemical, Refinery, Fertilizer/Ammonia plants and others

75 GW† ( 125 - 600 MW† modules)

Oil Sands / Oil Shale

Steam, electricity, hydrogen \& water treatment

$18 \mathrm{GW}+$ ( 30 - $600 \mathrm{MW}+$ modules)

\section{Hydrogen Merchant Market}

$36 \mathrm{GWt}$ ( $60-600 \mathrm{MW}$ - modules)

\section{Synthetic Fuels \& Feedstock}

Steam, electricity, high temperature fluids, hydrogen $249 \mathrm{GW}+(\sim 415-600 \mathrm{MW}+$ modules $)$

IPP Supply of Electricity

$110 \mathrm{GW}+(-180-600 \mathrm{MW}+$ modules $)$

\section{Price of Carbon}

For every $\$ 10$ per ton of $\mathrm{CO}_{2}$, the cost-effectiveness of the HTGR improves by $\$ 0.50 / \mathrm{MMBTU}$ equivalent natural gas price. $\mathrm{A} \$ 50$ price per ton of $\mathrm{CO}_{2}$ improves the competiveness of the HTGR from \$6/MMBTU to \$3.50/MMBTU. 
1. Petrochemical, Chemical, Petroleum and Other Processing Facilities - These production facilities have large energy demands typically addressed via natural gas-fired on-site power generation and high temperature steam supply for combinations of process heating, mechanical drivers and direct steam injection. In support of assessing representative potential applications, a recent site-specific report, "Evaluation of Siting an HTGR Co-generation Plant on an Operating Commercial Nuclear Plant Site" 5 has been prepared by the INL with the support of Entergy Louisiana, LLC, Entergy Nuclear, Inc., and The Dow Chemical Company. This report addresses the technical feasibility and economic viability of locating an HTGR co-generation plant at the Waterford Steam Electric Station site in St. Charles Parish, Louisiana, and providing the energy needs of two nearby large petrochemical process facilities.

- Installed rating of plants for potential market ${ }^{6}-75 \mathrm{GW} / \mathrm{t}$ or -125 modules

- Cumulative contribution to the economy - $\$ 330 \mathrm{~B}$

- Competes with natural gas at an energy equivalent price of $-\$ 6 / \mathrm{MMBtu}$

2. Oil Sands Recovery Operations in Alberta, Canada - These operations have modest electrical demands for on-site generation but require large process steam loads in the form of distributed injection of steam for bitumen recovery. In support of assessing this potential application, a recent report "Integration of HGTR Technology with Oil Sands Processes" has been jointly prepared by the INL and the Petroleum Technology Alliance Canada that represents the leading petroleum companies who operate on an international scale and are heavily involved in the oil sands industry in Canada. This report addresses the technical feasibility and economic viability of using a central HTGR cogeneration plant to provide the energy needs of multiple bitumen recovery sites over a period of several decades, and upgrading the extracted bitumen to premium synthetic crude.

- Installed rating of plants for potential market ${ }^{8}-18 \mathrm{GW} t$ or -30 modules

- Cumulative contribution to the economy - \$95B

- Competes with natural gas at an energy equivalent price of $-\$ 10 / \mathrm{MMBtu}^{9}$

3. Power Generation - Adding power generation units has unique siting constraints such as geographic close-in locations to load centers, transmission capacity and/or cooling water. In addition, the modular HTGR is an ideal technology fit for replacing small to medium coal-fired plants scheduled to be retired in the timeframe of interest due to tightening environmental requirements.

- Installed rating of plants for potential market ${ }^{10}-110 \mathrm{GW} /$ or 180 modules

- Cumulative contribution to the economy $-\$ 480 B$

- Competes with natural gas at an energy equivalent price of $-\$ 6 / \mathrm{MMBtu}$

In addition to the three sectors identified above, direct heating growth applications are emerging for industrial manufacturing processes such as ethane cracking, steam methane reforming and water-to-hydrogen thermal processes for hydrogen production. These growth areas can extend the market potential for the above target applications. New market applications such as carbon conversion for production of synthetic transportation fuels and chemical feedstock are other areas that are expected to emerge prior to mid-century. In addition, a higher temperature capability can be applied to advanced energy conversion cycles for more efficient and cost-effective power generation. Serving these growth areas requires further high temperature materials qualification, development of high temperature heat exchange capability and commercialization of highly efficient hydrogen production technology. The groundwork for these growth areas has been established in previous development work by industry and the Idaho National Laboratory.

While the North American market, noted above, is very large, the global market is enormous. Appendix A provides a comprehensive evaluation of these markets, the projected prices for natural gas and oil that constitute the competition, and preliminary economics for each sector.

\section{INVESTMENT PERSPECTIVES}

For those markets that rely on premium fossil fuels, commercializing the modular HTGR provides the option to use the only game-changing technology on the horizon that can address the overarching global energy policy goals of energy and feedstock security, economic growth/GDP (jobs) and carbon footprint (climate). Further, trends in fossil fuel prices suggest that modular HTGR technology integrated with modified versions of conventional carbon conversion technologies provides an economic approach to production of synthetic transportation fuels and chemical feedstocks with a minimal carbon footprint.

Modular HTGR plants can produce competitively priced electric power and high temperature process heat/steam that assures energy security and stabilization of energy prices for about $60 \%$ of global energy needs. Of these energy 


\section{\ame Changer for Industry}

It's the only game-changing technology on the horizon that can address the overarching global energy policy goals of energy and feedstock security, economic growth/GDP (jobs) and carbon footprint (climate).

needs, over half of the associated applications have been evaluated at the conceptual level and show promising economics.

Using HTGR nuclear-produced process heat dramatically reduces $\mathrm{CO}_{2}$ emissions from petrochemical production and petroleum refining facilities. It is economically competitive today in many parts of the world where gas prices are tied to oil, such as Europe, Japan and the Middle East. Further, we conclude that even U.S. natural gas prices are likely to emerge in a range that will make this technology competitive for process heat and power in the $2 \mathrm{O}^{2} \mathrm{O}^{+}$timeframe as utilities, transportation and LNG exports compete to arbitrage the current U.S. price advantage. (See Appendix A)

Further, if we are able to envision oil in the $\$ 130^{+}$per-barrel range over the next decade and beyond, the modular HTGR technology option integrated with carbon conversion processes provides an economic approach to production of synthetic transportation fuels - and/or in a carbon emissions-constrained environment, an alternative source of chemical feedstock.

The HTGR can create an expanding marketplace beyond electricity generation and enable industrial growth that is today solely relying upon a natural gas supply. HTGR-produced energy can be a hedge that can insulate industry from energy price volatility. Unlike natural gas energy production, HTGR use is largely immune to fuel price swings where $70 \%$ of the cost is driven by the capital investment with fuel being $<20 \%$. This is entirely opposite of natural gas used for industrial process application where $-70 \%$ of the cost of energy is directly tied to the cost of fuel and the enormous volatility this brings with it.

\section{Why would an energy end-user be interested in this technology?}

Current industrial plants are using one primary source of energy, natural gas, to develop the process heat. Modular HTGR technology provides an important option based on: 1) high temperature output, 2) competitive, stable long-term energy prices and 3) intrinsic safety.

1. High Temperature Output - HTGR technology is capable of delivering process heat at the heat and pressure ranges required by manufacturing and processing plants. Reliable and sustainable supply can be offered through multiple nuclear heat supply units (multiple HTGR modules) with close to $100 \%$ availability. The output produced is several hundred degrees above what is possible with conventional light water reactor technology and is produced without $\mathrm{CO}_{2}$ emissions.

2. Competitive and Stable Long-term Energy Prices - This technology offers flexible scalable deployment, high reliability and attractive economics. It is flexible, in part, due to its relative size that is comparable to the thermal output of a conventional gas turbine, making it a like-for-like functional replacement of thermal and power needs where redundancy is also a requirement. Because HTGR nuclear fuel cost is projected to be consistent with today's commercial nuclear fuel laccounting for $<20 \%$ of total production $\cos ^{1{ }^{11}}$ ) and is purchased for multi-year capabilities, it is largely

\section{Energy Supply}

- The HTGR is competitive today in many parts of the world

- Creates a new market for nuclear energy within industrial heat applications and a brand-new energy option using indigenous carbon to produce synthetic fuels and feedstocks

- Supports requirements of industry that are not serviceable from lower temperature light water reactors

- Provides for higherefficiency power production

- Provides stable energy price uncoupled from volatile pricing for natural gas - a fungible global commodity tied to oil parity 
immune to volatility in pricing and market swings; largely in opposition to natural gas for industrial production where $-70 \%$ of the operational costs are tied to fuel.

3. Intrinsic Safety - Intrinsic safety is the entry card to co-locating near or next to any large integrated manufacturing complex. The HTGR provides a nuclear energy system design that is intrinsically safe at a size and scale that will meet the needs for commercialization and provides intrinsic safety design to protect personnel, the public and the environment. The fuel design is at the heart of the safety case and supports collocation of modular nuclear units with existing or new industrial facilities. Due to the robust fuel design, it is a candidate for close-in siting capability needed to expand the existing industrial capacities.

One only needs to survey the world today to see that, in many places, natural gas price is indexed to oil price and, even in North America, higher natural gas prices seem only logical by the mid-2O2Os based upon several important considerations: 1) Projects are underway to export U.S. liquid natural gas (LNG) by reconfiguring import terminals to export capabilities - increased demand and export will eventually result in higher U.S. prices due to international arbitrage; 2) Additional natural gas-fired base load power generation and growth in industrial use will likely create an inelastic demand and associated volatile pricing; and 3) A move to natural gas as a transportation fuel is yet another likely inelastic demand that can lead to increased price volatility over the next decade.

\section{Why would a national policy maker be interested in this technology?}

1. Growth in the Economy and Jobs - The Alliance's market analysis indicates that within the first 25 years of application in the U.S. and the Alberta oil sands industry, nearly a trillion dollars in gross domestic product could be generated. Further, the modular HTGR is particularly well suited for small to medium and developing countries, with its scalable modular deployment and superior safety characteristics that do not rely on intervention of any systems or people to safely avoid major events during operation. Altogether, this translates into profitable growth in new market sectors for the nuclear energy system and equipment suppliers, owner/operators and energy end-user industries with many thousands of highly skilled, high-paying jobs. This growth is good for industry and good for the U.S., North America and other countries that choose to participate and engage this technology. China is already underway with the deployment of their version of a modular HTGR design that may compete globally.

\section{HTGR Deployment}

- Grows the economy by introducing

opportunities to rebuild manufacturing

infrastructure in stakeholder countries

- Creates high-value technical and

manufacturing jobs and new major

export markets

- Enables companies to compete globally

in a volatile and oil-indexed energy market

- Penetration of HTGR technology to

the likely markets would conservatively

create over $\$ 1$ trillion in GDP by 2050

in North America alone
2. Energy Price Stability - The HTGR energy pricing is expected to be stable over an operational plant life of more than 60 years by virtue of the fact that $<20 \%$ of the energy cost is tied directly to the fuel raw material. By supplanting natural gas and other fossil fuels for producing heat, the modular HTGR provides insulation from energy price variability.

3. Alternative Uses for Indigenous Carbon Resources \& Improving Energy Security - HTGR technology provides an attractive path to take advantage of indigenous carbon (coal, pet coke, municipal solid waste, etc.) by gasifying the carbon with co-production of hydrogen, all using the modular HTGR technology, and ending up with chemical feedstock or transportation fuels. As an example, if you matched up about thirty one 50,000-barrelsper-day carbon conversion plants with the annual coal production output of Kentucky, you could convert that coal to transportation fuels equivalent to about one-fourth of the U.S. import demand today with minimal $\mathrm{CO}_{2}$ emissions. This improves both energy security and independence. 
4. Minimizes Carbon Emissions - Environmental factors range from incremental advantages associated with fuel utilization, waste management, land use and cooling water requirements. Unique within nuclear, the modular HTGR is the only carbon-reducing game-changing technology on the foreseeable horizon for supplanting fossil fuels in the production of high temperature process heat. The end-user community that is driving the Alliance envisions a path that would eliminate as much as $80 \%$ of its carbon footprint with this technology. Substantially lower carbon footprints cannot be achieved without bold technology advances.

5. Minimizes Water Usage - The high thermal efficiency of modular HTGR technology can make use of dry cooling as an economic alternative in those areas where water is limited.

\section{COMMERCIALIZATION STRATEGY}

The commercialization strategy is comprised of the following elements, most of which are overlapping, to achieve a commercially viable energy supply technology:

Complete the Technology Development - The development activities for the nuclear fuel, graphite structural materials, high temperature metals and composite materials, and contemporary analytical methods. The extant development activities are currently being led by the Idaho National Laboratory and have, as a foundation, the past design and qualification work that has been advanced by others on similar nuclear technologies.

Complete the Design Development - The development activities for the reference prismatic reactor concept and a Rankine cycle steam plant capable of co-generating process heat (as steam) and electricity.

Establish the Licensing and Regulatory Requirements - A licensing plan that continues the pre-application iterative process of collaboratively working with the US Nuclear Regulatory Commission (USNRC) to establish the regulatory performance and design requirements for modular HTGRs. The licensing plan will then continue into the preparation of a license application for a selected site based on the design being developed for the reference concept.

Develop the Supply Infrastructure - Establish a supply chain for nuclear fuel, graphite and other major equipment that can be matured to support construction and operation of the demonstration and follow-on plants.

Construct and Deploy the Demonstration Module and the First-of-a-Kind Plant - The demonstration will consist of the initial single reactor module to confirm technology and licensing implementation. This is then expanded to a FOAK plant comprised of multiple modules supplying energy with a compelling business case.

\section{ENTERPRISE STRUCTURE}

The NGNP Industry Alliance is leading the industry effort to commercialize modular HTGR technology and anticipates a structure for the enterprise to commercialize HTGR technology as summarized below. This structure includes enterprise activities that comprise the equity investment opportunities that are expected to realize important long-term and continuing returns as the HTGR technology is widely adopted across the globe. Each of the activities envelops some or all of the components of the commercialization strategy described above.
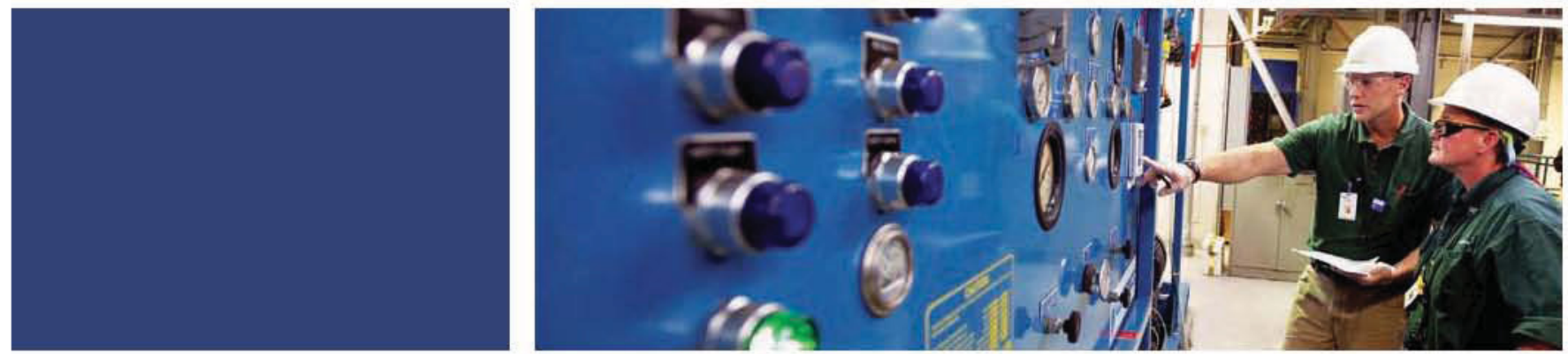


\section{Overall Structure}

1. Development Venture - A joint venture led by the Nuclear System Supplier (NSS) with the Prospective Owner entity (Owner). Equity investors are anticipated to include nuclear system suppliers, vendors of major equipment and materials, governments, industrial energy end-users and other equity investors. The NSS will lead completion of technology development, and perform design development through preliminary design. The Owner will lead completion of pre-application activities with the USNRC and lead preparation of license applications supporting the Deployment Project (e.g., an Early Site Permit application (ESP), a Construction Permit application or a combined Construction and Operating License application (COLA) ${ }^{12}$.

2. Deployment Project - A joint venture led by the Owner for procurement, construction and operation of the FOAK plant. Equity investors are anticipated to include energy producers (e.g., utilities; power-generating companies; independent power/energy producers), municipalities, architect-engineers/constructors (AE/C) and industrial energy end-users. The Owner and/or the designated Operator will lead final site and plant licensing submittals and hold the operating license; the NSS and the AE/C will complete the final design; and the AE/C will manage construction.

3. Infrastructure Framework - Activities to establish a supply chain for nuclear fuel, graphite and major equipment that can be matured to support construction and operation of the demonstration and follow-on HTGR plants. The structure of this activity will depend on the extent to which the NSS elects to be the supplier versus purchasing from others. It is anticipated that nuclear fuel production capability will be developed as part of the development venture. Initial indications are that the graphite and major equipment vendors will make the necessary investments.

4. Technology Expansion Program - Activities to pursue advanced and alternative technologies to broaden the initial market for HTGR technology. This could include technology advances such as higher temperature materials, gasto-gas heat exchangers, and a high-efficiency hydrogen production capability. Advanced HTGR plant designs will support higher temperature process heat needs and the production of hydrogen, essential to the carbon-conversion technologies. There are several carbon-conversion technologies that could be economically integrated with HTGRs. This is envisioned as a separate investment and is not integral to the initial development venture.

5. Program Direction - Activities led by the NGNP Industry Alliance to ensure appropriate direction and overall integration for commercialization of HTGR technology. The Alliance will lead an activity to mature the understanding of market opportunities and associated economics. The Alliance anticipates that membership will expand to include at least each of the entities represented in the above activities.
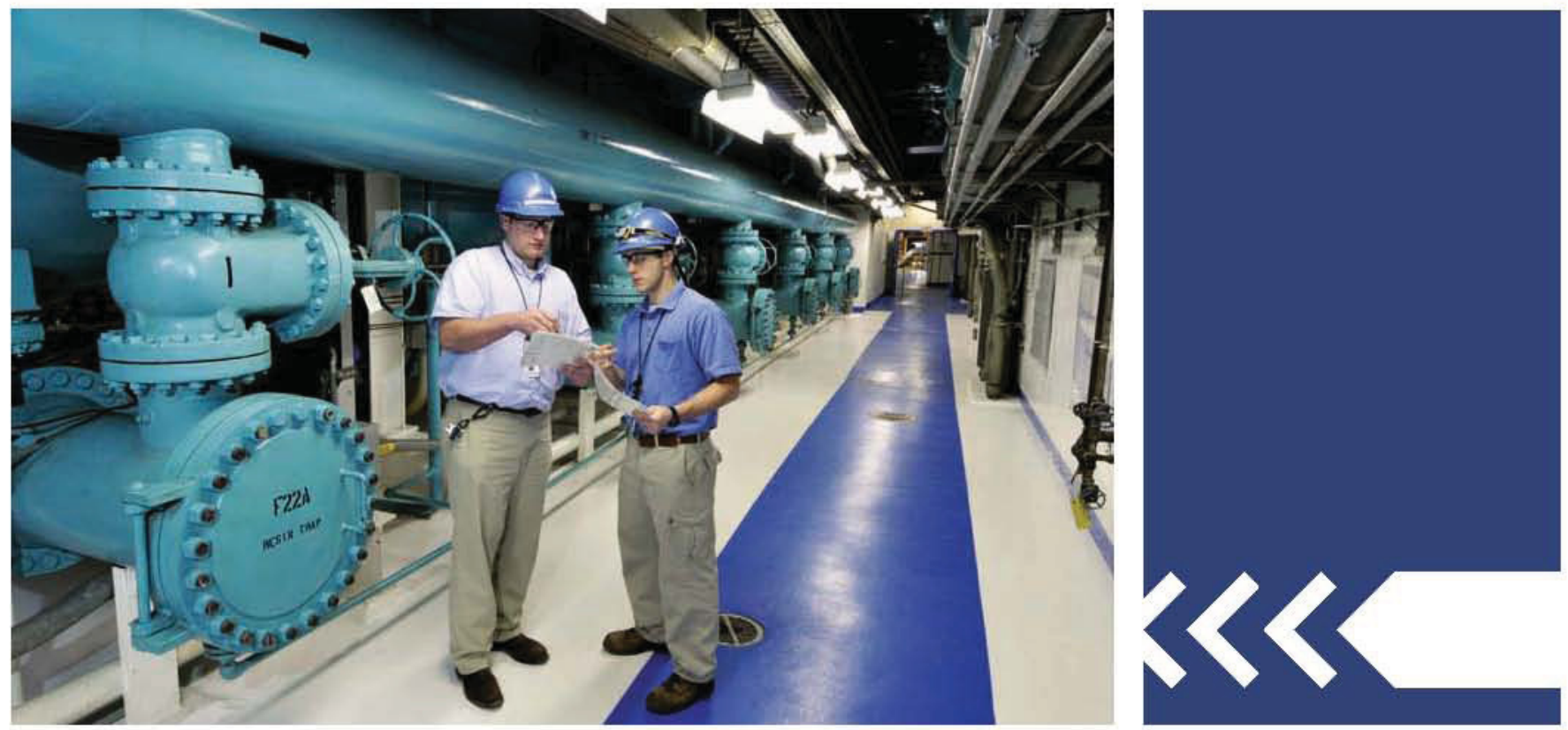


\section{Estimated Costs}

The estimated costs to complete each of the Enterprise activities are summarized as follows:

\begin{tabular}{|c|c|}
\hline Development Venture & \$ millions (2011) \\
\hline Development & 316 \\
\hline Conceptual/ Preliminary Design & 280 \\
\hline Final Design & 200 \\
\hline Licensing through preparation of application ${ }^{13}$ & 165 \\
\hline Equipment and infrastructure development & 648 \\
\hline $\begin{array}{l}\text { Inspections, Testing and Modifications } \\
\text { (Demonstration initial operations) }\end{array}$ & 75 \\
\hline Deployment Project & $\$$ millions (2011) \\
\hline Complete site-specific design & 200 \\
\hline Construction permit/license application/review & 32 \\
\hline Equipment procurement & 432 \\
\hline Construction & 625 \\
\hline Startup \& testing ${ }^{14}$ & 55 \\
\hline Initial operations ( 3 years) & 348 \\
\hline Revenue (initial 3 years) & -265 \\
\hline Infrastructure Framework & $\$$ millions (2011) \\
\hline Nuclear fuel production facility & 440 \\
\hline Graphite production facility & 150 \\
\hline $\begin{array}{l}\text { Technology Expansion Examples } \\
\text { (Future - Second-Generation Product) }\end{array}$ & $\$$ millions (2011) \\
\hline Intermediate $\mathrm{HX}$ & 100 \\
\hline Hydrogen production & 200 \\
\hline Higher temperature materials & 100 \\
\hline Program Direction & \$ millions (2011) \\
\hline Program Support & 90 \\
\hline
\end{tabular}




\section{Schedule}

A notional schedule for the Enterprise follows. This includes completing the Development Venture and the Deployment Project, as summarized earlier, that culminates in completing the first-of-a-kind HTGR technology plant.

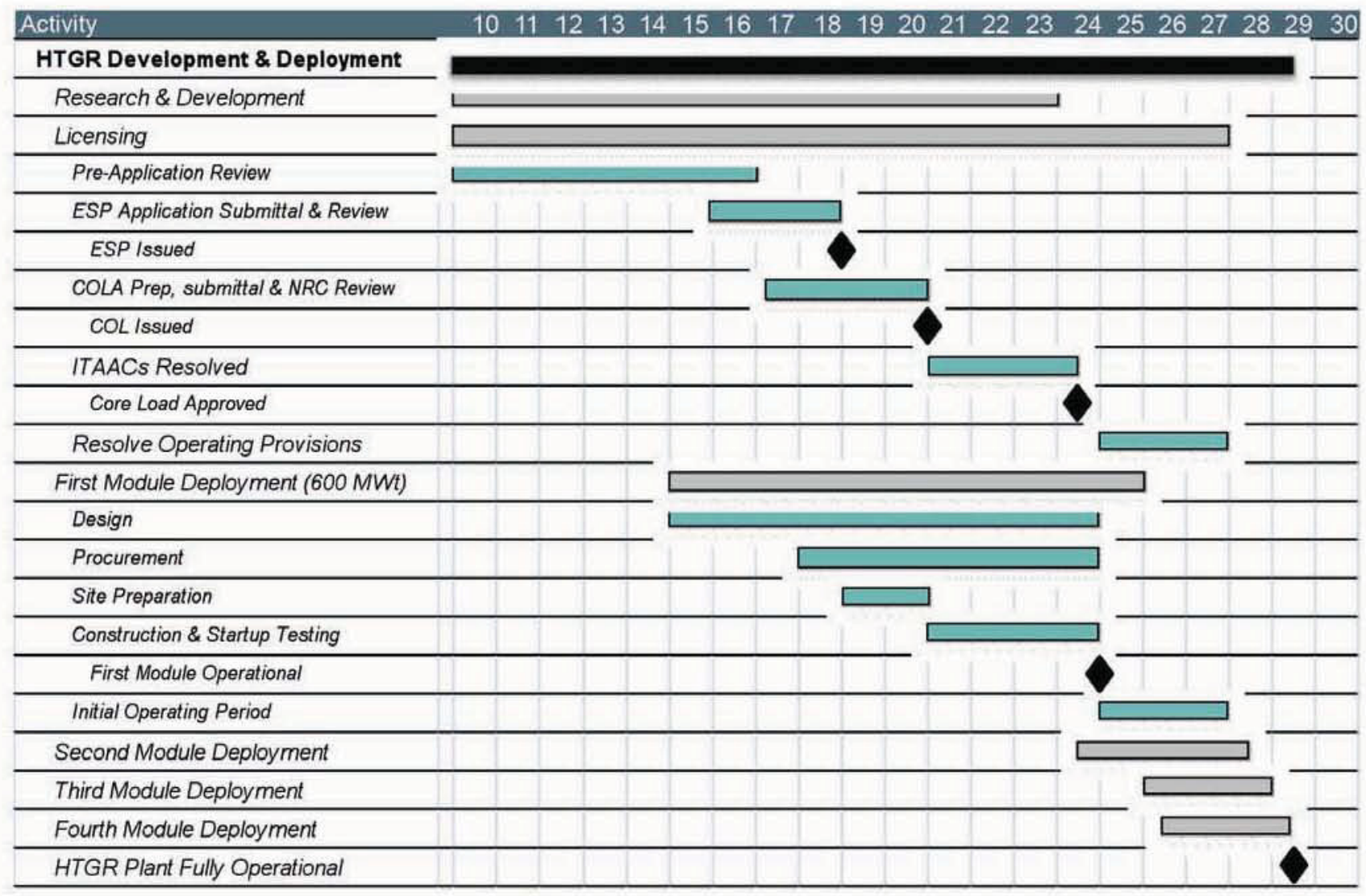

\section{Investment Opportunities}

For possible investment purposes, two areas of the Enterprise structure are developed more fully in Appendices B and C.

Development Venture - Appendix B provides a summary of possible approaches to executing the Development Venture. The Development Venture includes providing the technical foundation and regulatory framework for commercialization of modular HTGR technology and supporting the licensing and construction of the initial fleet of modular HTGRs for commercial application. A large equity investment is required for which a return will be realized following completion of several modular HTGR plants. The return is in the form of intellectual property ownership that can be realized after a build-out of less than $5 \%$ of the conservatively estimated market penetration.

Deployment Project - Appendix C provides a summary of a possible approach to executing the Deployment Project. The Deployment Project constructs and operates the demonstration module and the FOAK plant based on modular HTGR technology. Return on investment begins to be realized about eight years from initial investment and includes both revenues from operation and ownership of intellectual property associated with the techniques and experience gained in the construction and startup of the FOAK plant.

Specifics regarding breakdown of scope, the investment framework, the interaction and interdependencies of these activities, investment risk and the character of intellectual property and other return on investment are the subjects for detailed discussions with interested equity investors.

\section{ENTERPRISE RISK PERSPECTIVE}

The potential consequences for three areas of overall risk are of particular importance to the success of the Enterprise are identified below. Executing the risk mitigation activities and accommodating the residual risk are essential for success. 
1. Technology Development - These are the important technologies necessary to support initial deployment. This includes the ongoing development and design support activities such as codification in consensus technical standards and providing technical support for development of a regulatory framework via pre-application licensing activities.

Risk mitigation:

INL/EXT-11-23907, NGNP Project - 2011 Status and Path Forward, December 2011, and detailed development plan references therein. These constitute a comprehensive plan for the remaining technical development activities including codification.

Residual risk (low):

Unanticipated technical issues or untimely processing and acceptance of code cases by consensus standards committees and NRC

2. Nuclear Facility Licensing - This includes ongoing pre-licensing application interactions with the NRC directed toward developing the regulatory technical requirements and review processes applicable to HTGR technology. The development of this licensing framework for the HTGR may require important changes to existing regulatory requirements that have evolved primarily for light water reactor technology. The framework is needed for eventual certification of the HTGR reactor design as well as site licensing requirements for collocation of the reactor with industrial processes. Progress on and the credibility of this developing framework is essential to beginning detailed design work with an acceptable business risk.

Risk mitigation:

- Next Generation Nuclear Plant Licensing Strategy - a report to Congress, August 2008. This report, prepared jointly by NRC and DOE, summarizes the preferred licensing development approach and necessary NRC resources.

- PLN-32O2, NGNP Licensing Plan, June 26, 2009. A detailed implementation plan prepared by INL for DOE that is in effect until January 1, 2013.

- Entergy Licensing Plan for HTGRs - in preparation (a June 2012 draft is anticipated). This plan, effective January 1, 2013, will describe the licensing implementation approach through completion of pre-application activities, preparation of the construction permit and operating license applications and executing the license for the initial HTGR plant.

- Aggressive pre-application activities with NRC to adapt/augment current regulatory requirements for applicability to HTGR technology since 2009 are continuing.

- A licensing plan will be formulated under the development venture. This plan will enable preparation of design and licensing documents and determine the licensing application requirements ${ }^{16}$. It will provide the approach that can best share the investment risk during technology development as well as for investors in the deployment projects.

Residual risk (high):

- NRC finalization of the requirements framework will not be fully complete until an operating license is issued.

- There is exposure to public hearings during the licensing and permitting process.

3. Successful Execution of Interdependent Enterprise Activities - Success in three of the Enterprise activities is highly interdependent (i.e., Development Venture; Deployment Project; Infrastructure Framework). As a consequence, investment, execution and coordination among these activities and the involved companies and investors are paramount.

Risk mitigation

- Preparation of this Business Plan for Commercialization

- Development of prospectus for Enterprise activities that provide a conceptual approach to an investment model and characterization of alternatives for return on investment

- Contractual vehicles and business arrangements are anticipated between the companies that lead each of the Enterprise activities and describe coordination between the investment ventures

Residual risk (currently high)

- Assured funding path is not established and, therefore, investment, execution and coordination planning is not planned 


\section{THE ALLIANCE AND ITS CURRENT MEMBERS}

Member companies havejoined in this alliance with the primary purpose to promote the development and commercialization of HTGR technologies through support of, and participation in, the DOE's Next Generation Nuclear Plant (NGNP) Project. Our alliance represents the interests and views of our members that intend to mutually support and direct project plans to design, build, operate and use the HTGR technology. We provide a forum and focus to communicate industry needs and requirements and work in concert with the Idaho National Laboratory and others to seek out and promote industrial uses for HTGR technologies within the United States, North America and other continents around the world.

\section{Description}

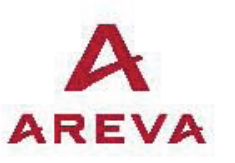

Conocơhillips
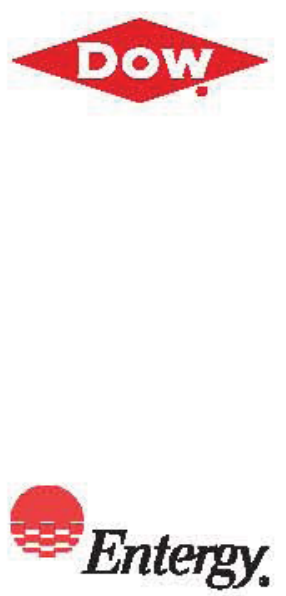

GRAF Trechlermational
AREVA supplies solutions for carbon-free power generation. Its expertise and know-how in this field are setting the standard, and its responsible development is anchored in a process of continuous improvement. As the global nuclear industry leader, AREVA's unique integrated offer to utilities covers every stage of the fuel cycle, nuclear reactor design and construction, and related services. AREVA has designed, built and operated high temperature gas-cooled reactors and is active in further development of the prismatic graphite block HTGR.

ConocoPhillips traces its beginnings to 1875 . They are one of the world's largest independent Exploration and Production companies, based on proved reserves and production of liquids and natural gas. As of May 1, 2012, the company had operations in almost 30 countries and more than 16,000 employees. Production averaged 1.62 million Barrel of Oil Equivalent (BOE) per day in 2011, and proved reserves were 8.4 billion BOE as of Dec. 31, 2011.

Dow, founded in 1897 combines the power of science and technology with the "Human Element" to passionately innovate what is essential to human progress. The Company connects chemistry and innovation with the principles of sustainability to help address many of the world's most challenging problems such as the need for clean water, renewable energy generation and conservation, and increasing agricultural productivity. Dow's diversified industry-leading portfolio of specialty chemical, advanced materials, agro-sciences and plastics businesses delivers a broad range of technology-based products and solutions.

Entergy Corporation is an integrated energy company engaged primarily in electric power production and retail distribution operations. Entergy owns and operates power plants with approximately 30,000 megawatts of electric-generating capacity, and it is the second-largest nuclear generator in the United States. Entergy delivers electricity to 2.8 million utility customers in Arkansas, Louisiana, Mississippi and Texas. Entergy has annual revenues of more than \$11 billion and approximately 15,000 employees. In 1999, as a part of the company's unregulated growth strategy, Entergy began to grow the nuclear fleet by acquiring the first of six additional operating nuclear plants that provide electric power via long-term power agreements. Entergy has been one of the fastest growing and successful nuclear companies in the nation and was recently ranked 7th in the world for nuclear electricity generation. Additionally, in 2003 a long-term management services contract was signed with Nebraska Public Power District for Entergy to support the management of the Cooper Nuclear Station in Nebraska. The Cooper contract was extended in 2010 to provide management support through 2028 . Through its TLG Services Company, Entergy also provides decommissioning services for the industry. Other management, technical and engineering services for the nuclear industry are provided by Entergy Nuclear Incorporated.

Graftech International is a global company with more than 125 years in the graphite materials industry, offering innovative solutions for the most challenging applications. Its customers are located in more than 70 countries and represent a wide range of industries and end markets, including steel manufacturing, advanced energy and latest-generation electronics. Graftech operates 19 principal manufacturing facilities on four continents and employs nearly 3,300 people. 


\section{MERSEN}

PTAC

SGL GROUP

THE CARBON COMPANY

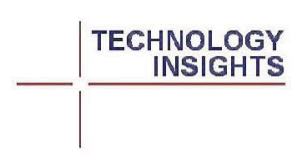

TOYO TANSO

inspiration for innovation

\section{(2) Westinghouse}

* US Nutrasafe
Mersen is a global expert in materials and equipment for extreme environments and for the safety and reliability of electrical equipment. They are focused on serving expanding markets: energy, electronics, chemicals and pharmaceuticals, transportation and process industries. Major product offerings are in: graphite anticorrosion equipment for the chemicals and pharmaceuticals industries; fuses for power semiconductors brushes and brushholders for electrical machinery; and high-temperature applications of isostatic graphite. Mersen has sales and/or manufacturing base in more than 40 countries.

The Petroleum Technology Alliance Canada (PTAC) is an association that facilitates collaborative research and technology development to improve the performance of the Canadian hydrocarbon energy industry. Members include the conventional oil and gas business - oil and gas producers, processors and transporters, high technology service and supply companies, research providers and others in specialty and expert fields directly supporting the energy industry. The purpose of PTAC is to provide a mechanism that facilitates collaboration on DEVELOPMENT to the benefit of those involved.

We are "SGL Group - The Carbon Company," one of the worldwide leading manufacturers of carbon-based products. We have an in-depth materials, production, applications and engineering expertise, a comprehensive graphite and carbon fiber-based product portfolio, and an integrated value chain from carbon fibers to composites. We operate close to our customers through a global sales network and state-of-the-art production sites in Europe, North America and Asia.

Technology Insights is a consulting firm that specializes in assessing and supporting the development and deployment of emerging technologies related to energy generation, distribution, utilization and management.

Toyo Tanso Co., LTD. produces and sells isotropic graphite, other specialized carbon products and carbon products for general industries. It also manufactures for sale composite materials made from carbon and ceramic, metal or organic materials. In addition, it produces for sale carbon electrode for fluorine electrolysis and business of surface treatment on various materials with fluorine gas.

Westinghouse Electric Company LLC is the world's pioneering nuclear energy company and is a leading supplier of nuclear plant products and technologies to utilities throughout the world. Westinghouse supplied the world's first pressurized water reactor in 1957 in Shippingport, PA, USA. Today, Westinghouse technology is the basis for approximately one-half of the world's operating nuclear plants, including 60 percent of those in the United States. Worldwide, the nearly 14,000 employees of Westinghouse Electric Company continue to pioneer value-added engineering and services creating success for our customers in their increasingly demanding markets. The four core product lines of Westinghouse - Nuclear Automation, Nuclear Fuel, Nuclear Services and Nuclear Power Plants - support this mission. Through these core businesses, Westinghouse aims to serve the needs of utility, government and industrial customers in nuclear power-related industries. Through alliances with customers, Westinghouse plays a key role in the design and implementation of integrated solutions.

Ultra Safe Nuclear Corporation (USNC) is participating in the development and commercialization of new "Ultra Safe" technology to enhance the robustness of nuclear reactors and nuclear fuels, including the Fully Ceramic Micro-encapsulated (FCM) TRISO-based fuel for LWRs. The Company provides design and analysis services for fuel, core and reactor systems on gas- and water-cooled reactors and has representation and technical contributors in the United States, Europe and Asia. 
BIBLIOGRAPHY

1. Owned and operated by Public Service Company of Colorado and granted an operating license by the Atomic Energy Commission (AEC) on December 21, 1973 (initial criticality on January 31,1974 )

2. Owned and operated by the Philadelphia Electric Company (later shortened first to PECO Energy and later to just PECO) USNRC docketed by USNRC (License No.: DPR-12 Docket No.: 50-171)

3. INL/EXT-11-23907, NGNP Project. 2011 Stafus and Path Forward, December, 2011

4. Historical investment by the industry - see Next Generation Nuclear Plant Implementation Strategy (11/30/2009 section 3.3 .1 attachment to letter to DOE Secretary Chu dated 11/30/2009 from the NGNP Industry Alliance in response to FOA DE-FOA-O000149 issued 9/18/2009)

5. Report No. INL/EXT-11-23282 (October 2011)

6. Assumes replacement of $50 \%$ of the existing co-generation facilities with ratings in excess of $900 \mathrm{MWW}$ ( 125 operating facilities) as they are retired due to increased natural gas prices and/or carbon emission costs/regulation over the period 2025-2050

7. Report No. INL/EXT-11-23239 (October 2011)

8. Assumes installation of six central energy facilities to provide the energy needs for $25 \%$ of the growth in the oil sands in-situ production that is projected over the period 2025-2050

9. $\$ 10 / M M B t u$ equivalent natural gas price (higher than previously noted $\$ 6 / M M B+u$ ) is based on a capital construction cost multiplier for the Alberta oil sands region of $-1.7 \times$

10. Assumes installation of $-45 \mathrm{GWe}$ capacity over the period $2025-2050$. This is about $10 \%$ of the nuclear electricity generation that would be required as replacement and/or alternatives to coal and natural gas based generation plants to meet emissions regulations such as those recently issued by EPA

11. Fuel cost includes: conversion $-2 \%$; fabrication $-50 \%$; waste fund $-8 \%$; enrichment $-16 \%$; uranium $-23 \%$. Ref: AREVA

12. The licensing plan prepared in the Development Venture will determine licensing requirements under USNRC Regulations 10 CFR Part 50 (Domestic Licensing of Production and Utilization Facilities) or 10CFR Part 52 (Licenses, Certifications, and Approvals for Nuclear Power Plants)

13. The licensing plan prepared in the product development venture will determine licensing requirements under USNRC Regulations 10 CFR Part 50 (Domestic Licensing of Production and Utilization Facilities) or 10CFR Part 52 (Licenses, Certifications, and Approvals for Nuclear Power Plants)

14. Design certification is planned following first plant demonstration

15. Some funds may come through government DEVELOPMENT programs

16. USNRC Regulations 10 CFR Part 50 (Domestic Licensing of Production and Utilization Facilities) or 10CFR Part 52 (Licenses, Certifications, and Approvals for Nuclear Power Plants) 


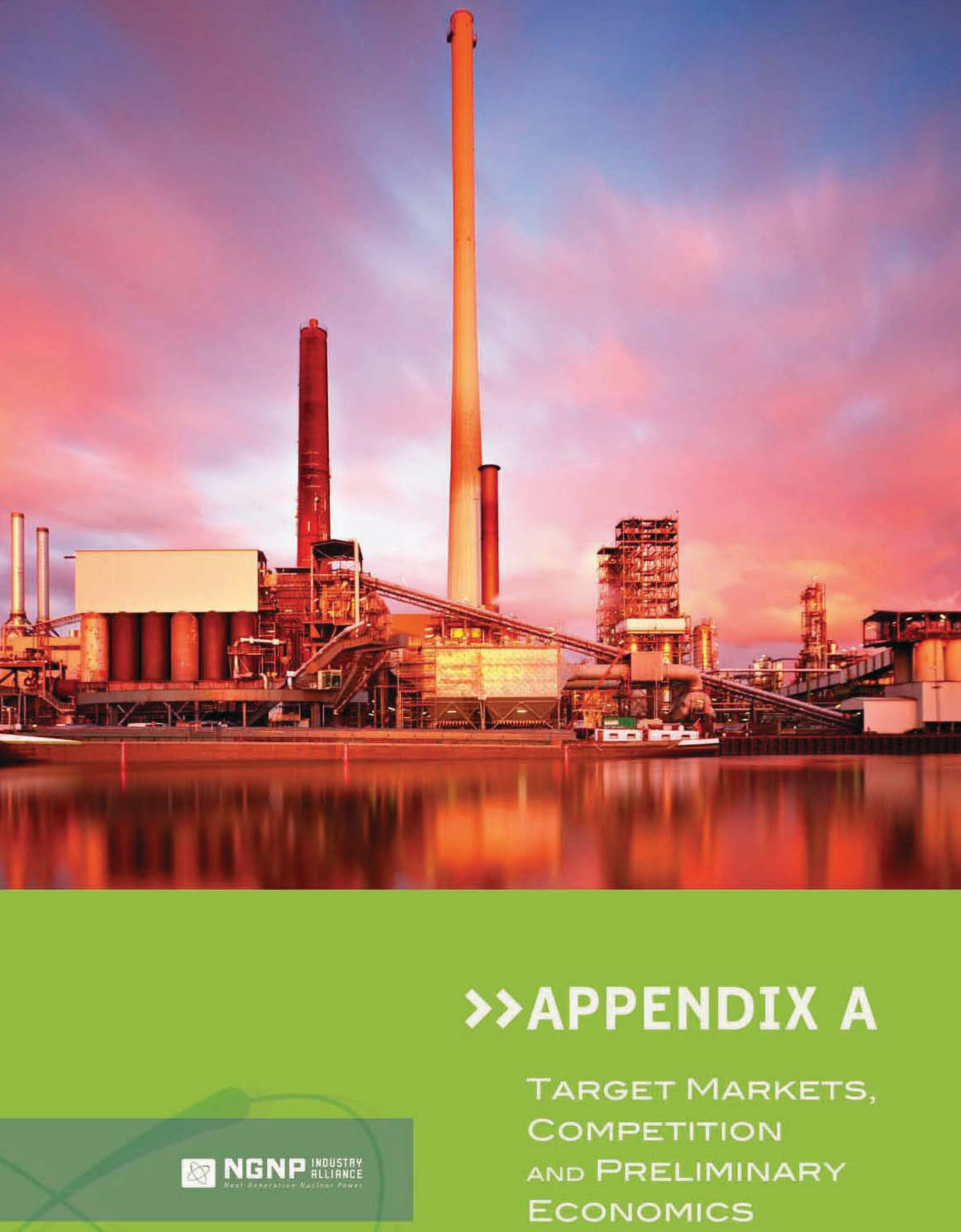




\section{APPENDIX A}

Target Markets, Competition and Preliminary Economics

\section{PREFACE}

Scoping economic analyses for potential applications in the targeted energy markets shows that industrial plants integrated with modular HTGR technology can be competitive currently (much of the world) or are expected to be competitive (North America) at the time of initial deployment ( 2025$)$.

This appendix examines the target markets for HTGRs. The discussion on natural gas price forecasting is specific to North America.

- Assesses 1) the competition based on natural gas as a source of heat and feedstock, and 2) competition of refined petroleum products with production of synthetic transportation fuels and feedstock

- Summarizes preliminary economics for HTGR technology plants compared to the competition.

Globalty, the potential market is considerably larger and current energy economics suggest that HTGR fechnology could be expected to be even more competitive as shown in the graphic to the right. Much of the rest of the world, unitike North America, has gas pricing fied to off on a BIU parity basis, and this targely sets pricing.

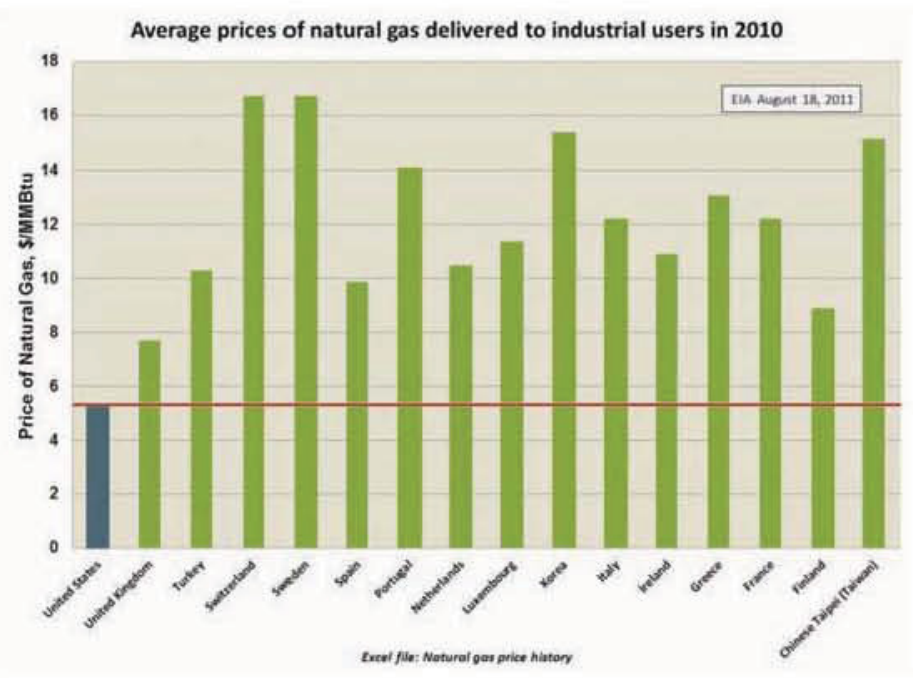

\section{THE TARGET MARKETS}

Substantive evaluations comparing the technology and economics of the HTGR technology with conventional technologies have been completed for about 20 different industrial processes including co-generation supply of steam and electricity to industrial processes, electricity generation as a merchant or regulated utility, non-conventional oil extraction and upgrading, production of hydrogen, conversion of coal and natural gas to transportation fuels and chemical feedstock, production of ammonia and ammonia derivatives, seawater desalination, and coke and steel production. ${ }^{2.6}$

These evaluations addressed applications where the high temperature capabilities of the HTGR extend the use of nuclear energy beyond the traditional role of conventional light water reactors to supply electricity, only.

Of these, the application of the HTGR technology in co-generation, oils sands operations, electricity generation, hydrogen production and carbon conversion (e.g., coal to liquids) are judged to be most viable in the initial phase of the HTGR commercialization. However, it is noted that hydrogen production and carbon conversion require the complementary commercialization of high temperature steam electrolysis to fully utilize the potential of HTGR technology.

A preliminary market study was conducted to assess the size of the potential market in terms of the number of HTGR modules (nominal $600 \mathrm{MW} / \mathrm{t}$ rating) that could be deployed in these areas over an assumed initial deployment period of 2025-2050 (see figure at right). The market penetrations projected for the first four application areas are based on the size of the current market and projections for its growth. The latter synthetic transportation fuels and chemical feedstock market would be essentially a new market with uncertain size. This market is estimated based on a goal of substantially reducing the amount of imported crude oil in the next three decades. Aside from possible policy drivers, it is estimated future crude oil prices in the range of $\$ 65$ to $\$ 200 / \mathrm{bbl}$ could provide a compelling business case for synthetic transportation fuels production using HTGR energy integrated with carbon conversion processes. The total 


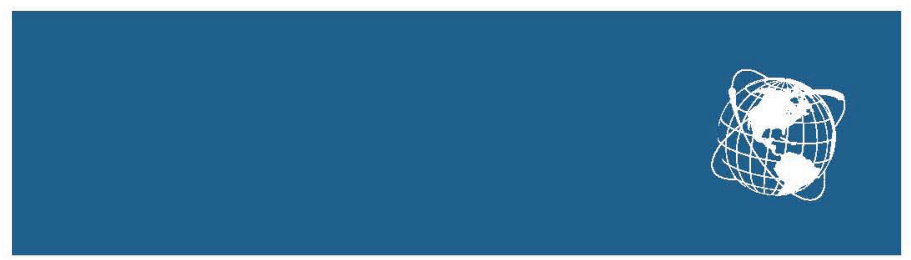

number of projected HTGR modules deployed over this period is projected somewhere between 400 and 800 ; even at the low end, this is a substantial potential market that readily justifies development and commercialization of HTGR technology.

Beyond the overall market characterization, detailed assessments have been performed for applying the HTGR technology to specific proxy industrial applications 1) for supplying steam and electricity to collocated petrochemical facilities ${ }^{d}$, 2) steam, electricity and high temperature gas to support bitumen recovery and upgrading in the Alberta, Canada, oil sandse, and 3) electricity generationf. Evaluations were performed for HTGRs integrated with multiple carbon conversion processes. Each of these evaluations compared the economics of applying the HTGR technology in these potential applications with conventional energy technologies; principally the firing of natural gas. Whereas the HTGR has very high front-end capital requirements and very low operating costs, the natural gas technologies, (e.g., gas-fired steam generators, natural gas combined cycle units) have relatively low capital costs but high operating costs; the operating costs are dominated by the cost of natural gas. The price of natural gas is, therefore, a major factor in assessing the competition. The potential for government policies that effectively establish a price on $\mathrm{CO}_{2}$ emissions is also another distinguishing factor; HTGR technology has no $\mathrm{CO}_{2}$ emissions during operation.

\section{ASSESSING THE COMPETITION}

\section{Historical and EIA Projected Natural Gas Price}

The figure at the right shows the historical prices of U.S. natural gas at the well head and delivered over the last two decades. The current low prices reflect the large potential reserves and low costs for extraction of gas from shale gas. (Note the differences in price delivered to end users versus well head price; the latter is the price quoted at Henry Hub).

The prospects for continued extraction of natural gas from shale gas in the U.S. has led the EIA to predict modest increases in natural gas prices through 2035 to a value of $\sim \$ 7 / \mathrm{MMBtu}(2009 \$)^{\mathrm{h}}$. It is of interest that current futures market for natural gas has bids in the $\$ 7.5 / \mathrm{MMBtu}$ range for December 2024 deliveries; a rate of increase in projected prices greater than predicted by the EIA'.
High Temperature Gas-cooled Reactors - Application Beyond Electricity
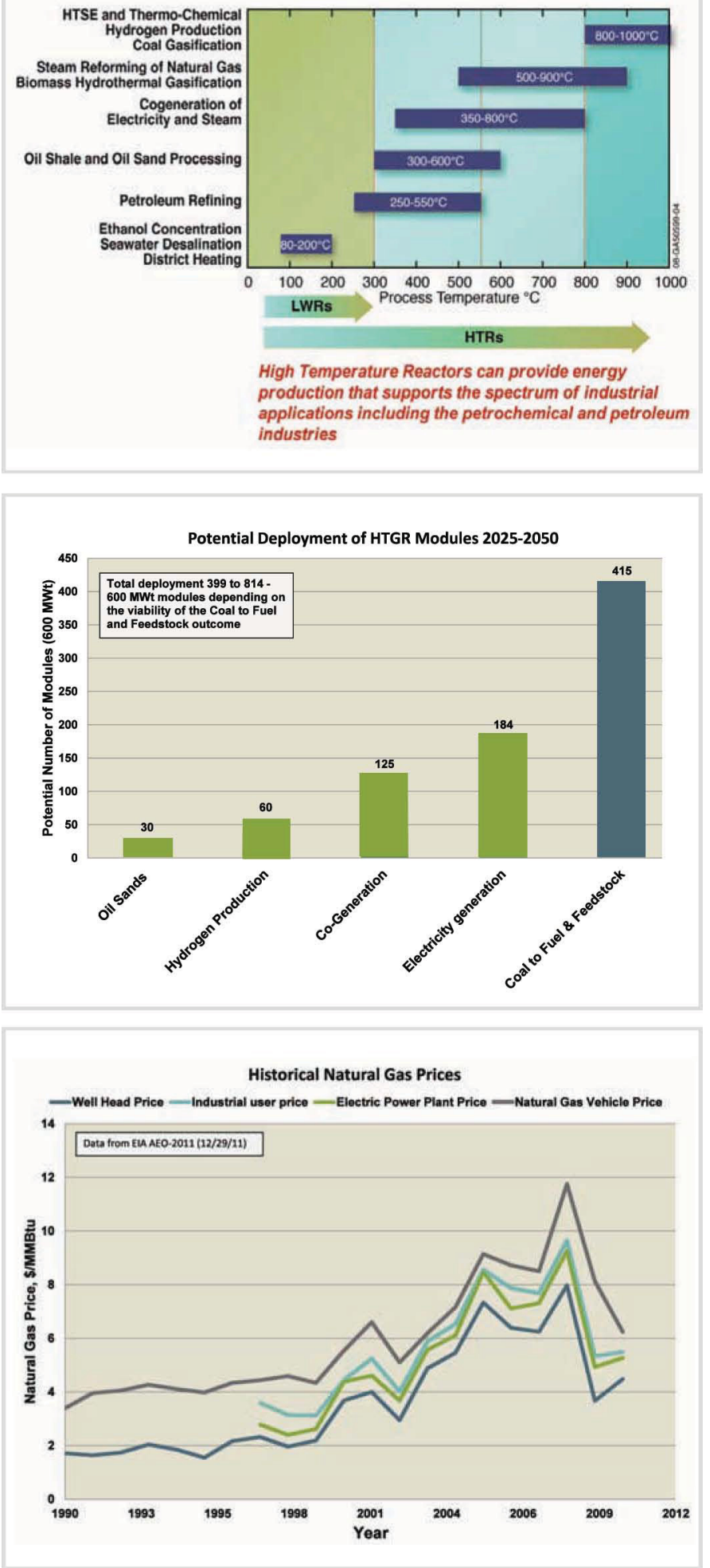


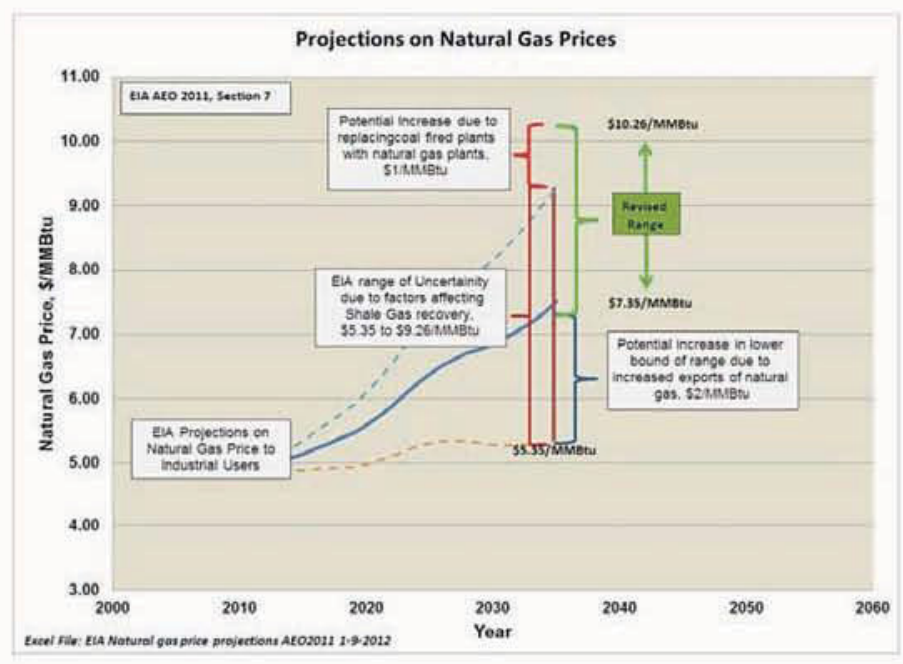

As shown in the figure to the left, the EIA has evaluated several positive and negative factors potentially affecting the size of the shale gas reserves and the long-term costs for extracting the gas that led to establishing upper and lower bounds on the price projections in 2035 with a range from $\$ 5.35 / \mathrm{MMBtu}$ to $\$ 9.26 / \mathrm{MMBtu}^{\mathrm{h}}$.

\section{Effect of Environmental Regulations on Natural Gas-Fired Electricity Generation}

There are other factors that could raise natural gas prices even if shale gas continues as a viable and economic source. These include the impact of recent EPA regulations on the emissions of mercury and other constituents (referred to as CATR + MACT regulations) on the retirement of coal-fired plants. The supposition is that the capacity of these plants will be replaced with natural gas plants. The EPA has estimated that these regulations would increase the retirements by 2016 when the regulations are fully in effect from 7GW under no regulation conditions to $9 \mathrm{GW}$ under the regulations. An industry study, however, predicts an increase of $48 \mathrm{GW}$ in retirements when the inventory of coal plants over 40 years old with poor heat rates and no current scrubber installations is considered. This study concludes that replacing these plants with natural gas plants in 2016 would increase electricity production from natural gas plants by $26 \%$, increase natural gas demand for electricity generation by $\sim 25 \%$ and increase natural gas prices by $\sim 17 \%$. The $25 \%$ increase in natural gas usage for electricity generation increases the total consumption in the U.S. by $\sim 8 \%$. The increase in natural gas price of $17 \%$ is approximately equivalent to an increase of $\$ 1 / \mathrm{MMBtu}$ in that timeframe.

\section{International Market Arbitrage}

Another significant factor is the likelihood of increased exports of natural gas from the U.S. to other countries that have significantly higher prices. As shown in the following figure, these differentials are currently over factors of three. It has been projected that recent requests for permits to convert existing LNG import facilities for export, if implemented, could result in exports amounting to $20 \%$ of current production ( 4 trillion cubic feet annually) $)^{k}$. This is twice the increase in demand projected for the early retirement of coal plants cited previously. Using that correlation between the increase in price with the increase in demand (or the decrease in supply for this case), such exports would be expected to increase the price of natural gas by about $35 \%$ or $-\$ 2 / \mathrm{MMBtu}$.

Even with the expected increase in production from the abundant shale gas, the U.S. and OECD countries in general are expected to continue to be importers of natural gast. This would also have a net effect on the prices in the U.S. No

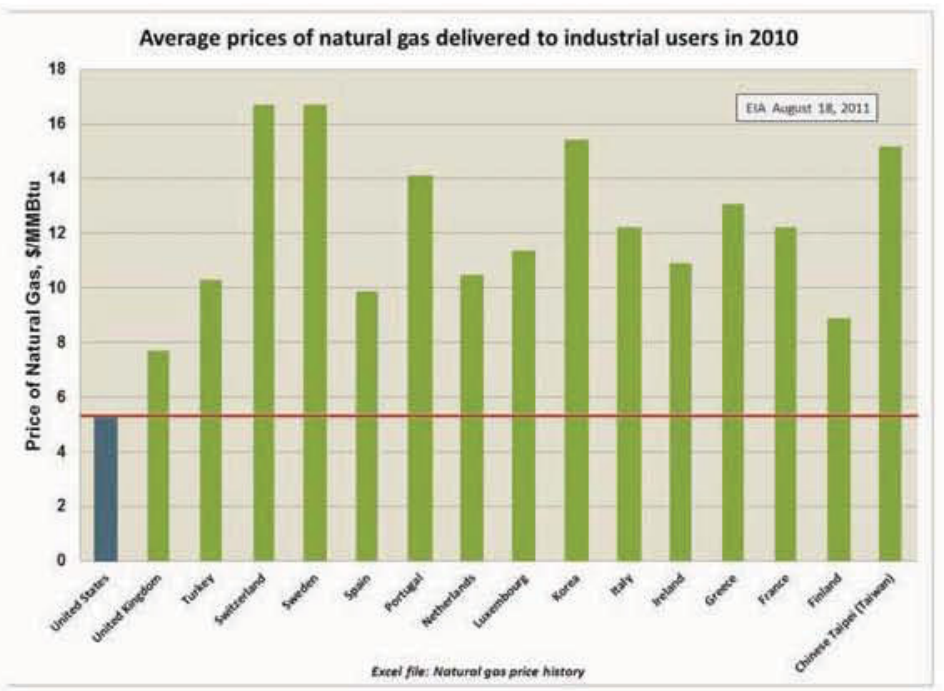
attempt has been made to address that factor in this assessment.

In summary, the EIA uncertainty band on natural gas prices in 2035 ranges from $\$ 5.35$ to $\$ 9.26 /$ MMBtu, based on potential positive and negative effects on shale gas extractions. The effect of early retirements on coal-fired plants due to EPA regulations on emissions could shift that band up to a high of $\$ 10.26 / \mathrm{MMBtu}$. Finally, increased exports of natural gas due to favorable price differentials between the US and other countries could shift the band up by another $\$ 2 / \mathrm{MMBtu}$. It is assumed that this would only affect the lower bound (from $\$ 5.35$ to $\$ 7.35 / \mathrm{MMBtu}$ ); an increase to a price in excess of $\$ 12 / \mathrm{MMBtu}$ would reduce the favorable differential that would spur increased 
exports. This leads to the revised potential range of natural gas prices of $\$ 7.35$ to $\$ 10.26 / \mathrm{MMBtu}$, delivered, as shown in the previous figure.

It should be noted that this analysis has not considered any effects of governmental actions to regulate or tax carbon dioxide emissions, i.e., establish an effective cost for carbon dioxide. Regulation would affect the ability to use natural gas technology in specific regions of the country, (e.g., similar to the attainment and non-attainment regions under the current Clean Air Act). Taxes would affect the effective price of the gas. There is too much uncertainty at the time of this writing to include these considerations on future viability of natural gas.

\section{Alternative Approaches to Assessing the Competition - Comparing Natural Gas to Oil Prices}

An alternative way of looking at projected natural gas prices is to compare the price of oil and the price of natural gas on an equivalent energy basis, i.e., projecting the price of natural gas based on the projected price of oil using a developed rationale for the ratio. Historically, this ratio has been roughly 10:1. EIA projections of oil and gas prices through 2035 are shown in the following.

These projections include a reference (best estimate) case and high and low projections around the reference case for variations in economic growth and for high and low projections in the price of oil. The projections for oil and gas prices and oil-to-gas price ratio for the variations in economic growth considered by EIA are shown, as well as similar data for the variations in oil prices.

The reference case predicts that the oil-to-natural gas price ratio that has traditionally been near 10 , but has risen recently as high as 40, will settle a little above 15 . The variations in the projected ratio due to changes in economic growth are not large.

The variations in projected oil prices from the reference case through 2035 are large; over $+\$ 50 / \mathrm{BBL}$. The projections of natural gas prices for that case do not vary significantly from the reference case. Accordingly, there are wide swings in potential oil-to-gas price ratios through 2035; leveling out between 6 and 27 depending on the scenario.

The highest price projected for natural gas is $\$ 7.5 / \mathrm{MMBtu}$ (Henry Hub), which would result in an oil-to-natural gas price ratio of $\sim 17$ in 2035 for the reference oil price $\$ 125 / \mathrm{BBL}$. In our prior analyses, we have shown that pressures on natural gas pricing due to increased usage for electricity production, increased exports and factors affecting the availability, and extraction of shale gas could increase the price in 2035 to the $\$ 10 / \mathrm{MMBtu}$ range. This would reduce the ratio to 12.5 for the reference oil price, closer to the traditional ratio of 10 .

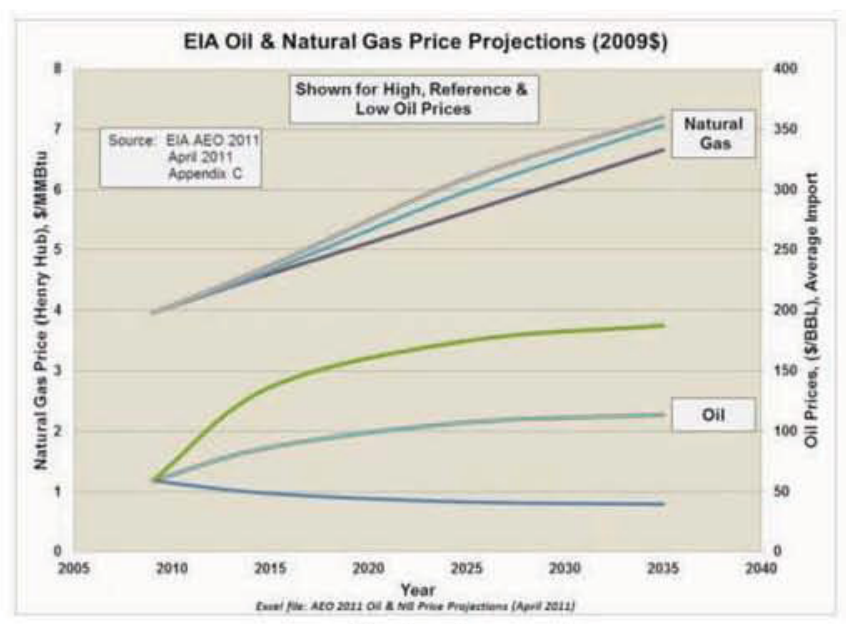

EIA Projections of Oil and Natural Gas Prices projections for variations in oil prices

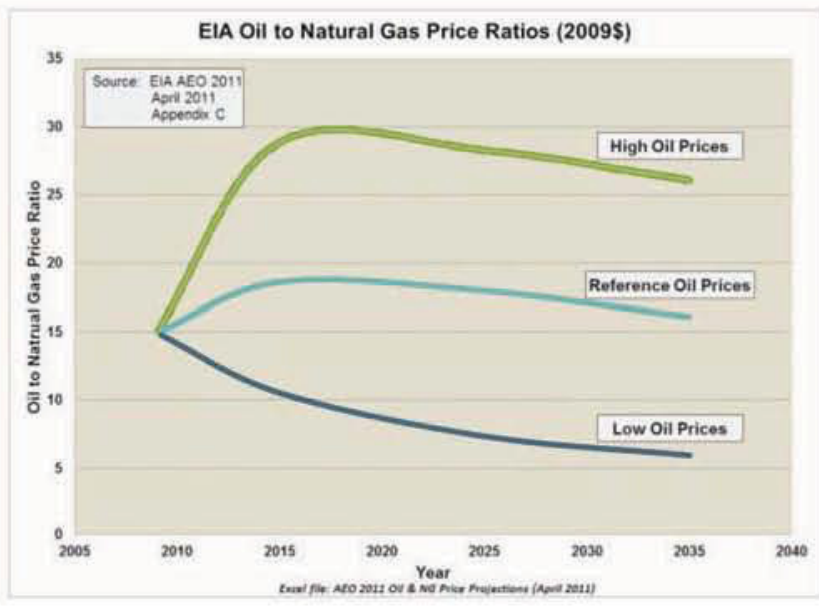

Oil to Natural Gas Price Ratios using for variations in oil prices

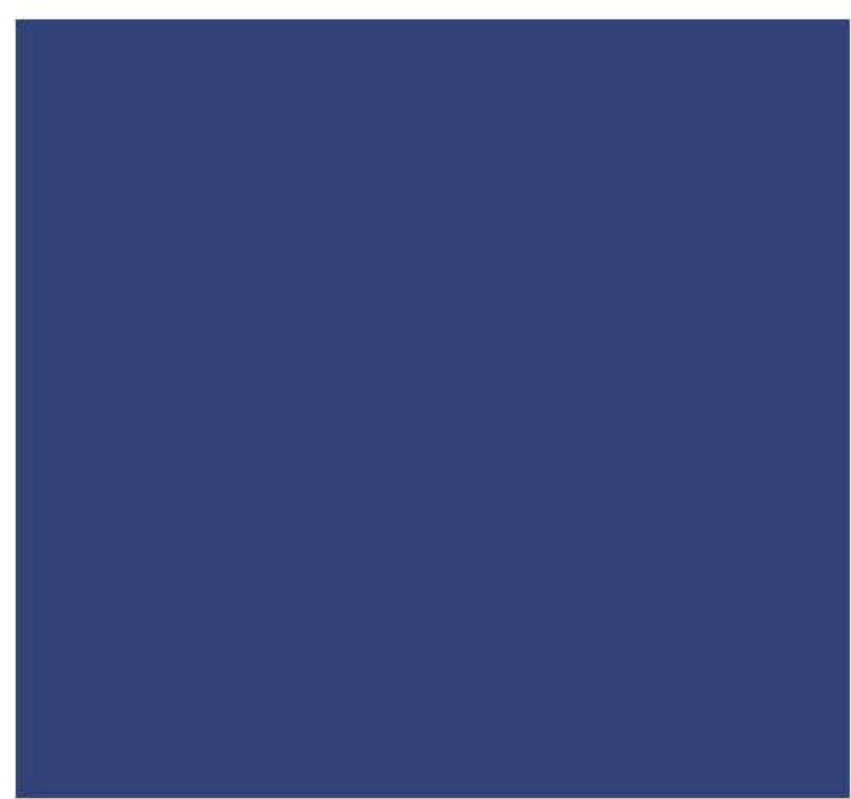


Other factors that could increase natural gas prices over the longer term include:

- Increased production by the chemical processing industries in the U.S. using higher quantities of natural gas feedstock. The high oil-to-gas price ratio improves the competitiveness of U.S. production compared with foreign companies whose price of feedstock is tied to the oil price, either because the feedstock is an oil derivative or the natural gas price is indexed to the oil price.

- Reduced shale gas production because of low natural gas prices. Shifts away from drilling for natural gas to drilling for oil have already been observed due to reduced profit margins for the latter.

- Increasing costs for transport of the natural gas from areas where it is plentiful to end users, (e.g., from Texas into the Midwest. New pipelines will be required increasing the cost of transport.

Consequently, as before, a projected upper-bound price for natural gas into the $\$ 10 / \mathrm{MMBtu}$ range in the 2035 timeframe appears reasonable.

\section{PRELIMINARY ECONOMICS FOR HTGRS COMPARED TO THE COMPETITION}

The following figures summarize the results of preliminary economic analyses for the evaluations of proxy industrial applications previously described in the market assessment. These results are based on best available information regarding the estimated all-in costs including overnight cost, financing costs, operating costs, maintenance costs and decommissioning costs. Discounted cash flow analyses have been utilized on a consistent basis using an HTGR plant with a reactor outlet temperature of $750^{\circ} \mathrm{C}$ and a Rankine cycle energy conversion plant. The results are compared to the projected range of delivered natural gas costs in 2035 as discussed above.

\section{Co-generation of Steam and Electricity for Industrial Processes}

The HTGR is competitive with natural gas technologies applied in co-generation of steam and electricity generation for delivered natural gas prices in the range of $\$ 6$ to $7 / \mathrm{MMBtu}$. Delivered natural gas prices in the U.S. to industrial users averaged $-\$ 5.5 / \mathrm{MMBtu}$ in 2010 . The projected range of delivered natural gas prices in -2035 suggests that the HTGR will be readily competitive.

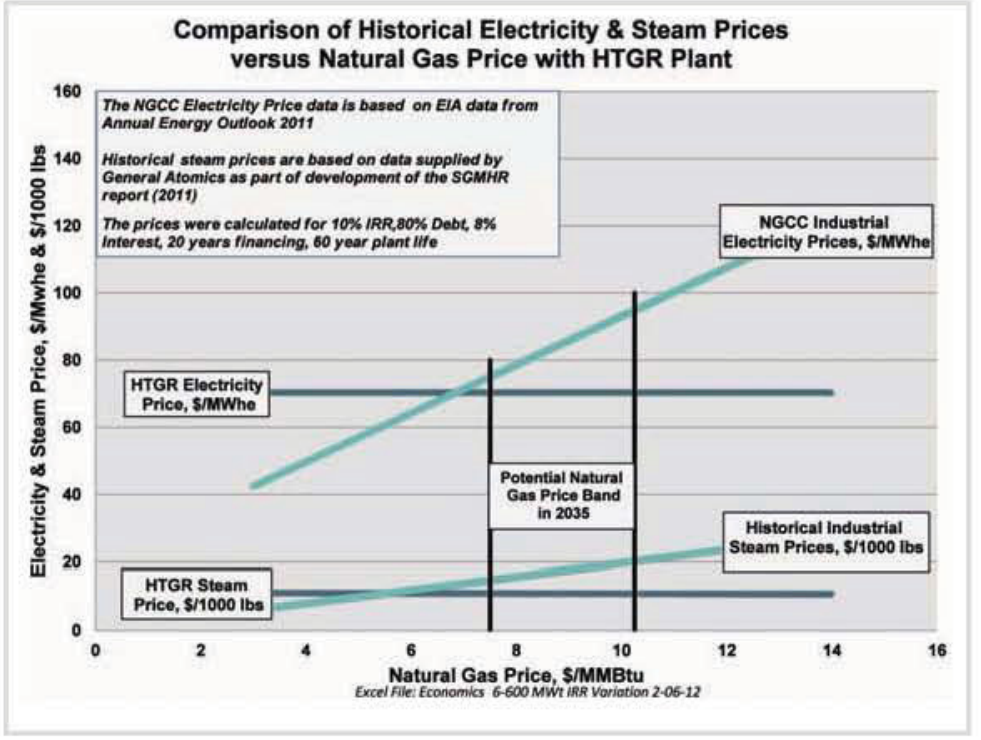

Note: A \$1O/MT tax on $\mathrm{CO}_{2}$ emissions is equivalent to an increase of $\$ 0.50 / \mathrm{MMBtu}$ Natural gas price. 


\section{Oil Sands Operations}

The results for the oil sands show that the current prices for energy in the oil sands, (i.e., $\$ 6 / \mathrm{MMBtu}$ for natural gas energy supply with no $\mathrm{CO}_{2}$ charge), are significantly lower than that projected for the HTGR central energy supply facility; about $\$ 12.5 / \mathrm{MMBtu}$. However, for the projected natural gas price band in $\sim 2035$ (mid-way in the projected deployment of the HTGR technology cited previously) of $\$ 7.50 / \mathrm{MMBtu}$ to $\$ 10.25 / \mathrm{MMBtu}$, the HTGR facility becomes more competitive. Additionally, the HTGR becomes even more competitive if regulation or a tax on $\mathrm{CO}_{2}$ emissions is imposed and/or there are reductions in the availability of the natural gas supply. A $\$ 120 /$ ton tax on $\mathrm{CO}_{2}$ would be required to make the HTGR competitive at current delivered natural gas prices ( $\$ 5 / \mathrm{MMBtu})$. However, as shown, a $\$ 40 /$ ton tax would be sufficient to make the HTGR technology competitive for a natural gas price of $\sim \$ 8 / \mathrm{MMBtu}$. Accordingly, the HTGR technology becomes much more economically attractive depending on the actual price and the effects of carbon tax or regulation in the oil sands market.

\section{Electricity Generation}

The economic results for base load electric power generation show a cost of $\sim \$ 82 / \mathrm{MW}$-hr. Comparing this with an advanced natural gas-combined cycle plant with carbon capture and storage/sequestration suggests that the HTGR could be competitive for delivered natural gas prices greater than about $\$ 5.6 / \mathrm{MMB}$.
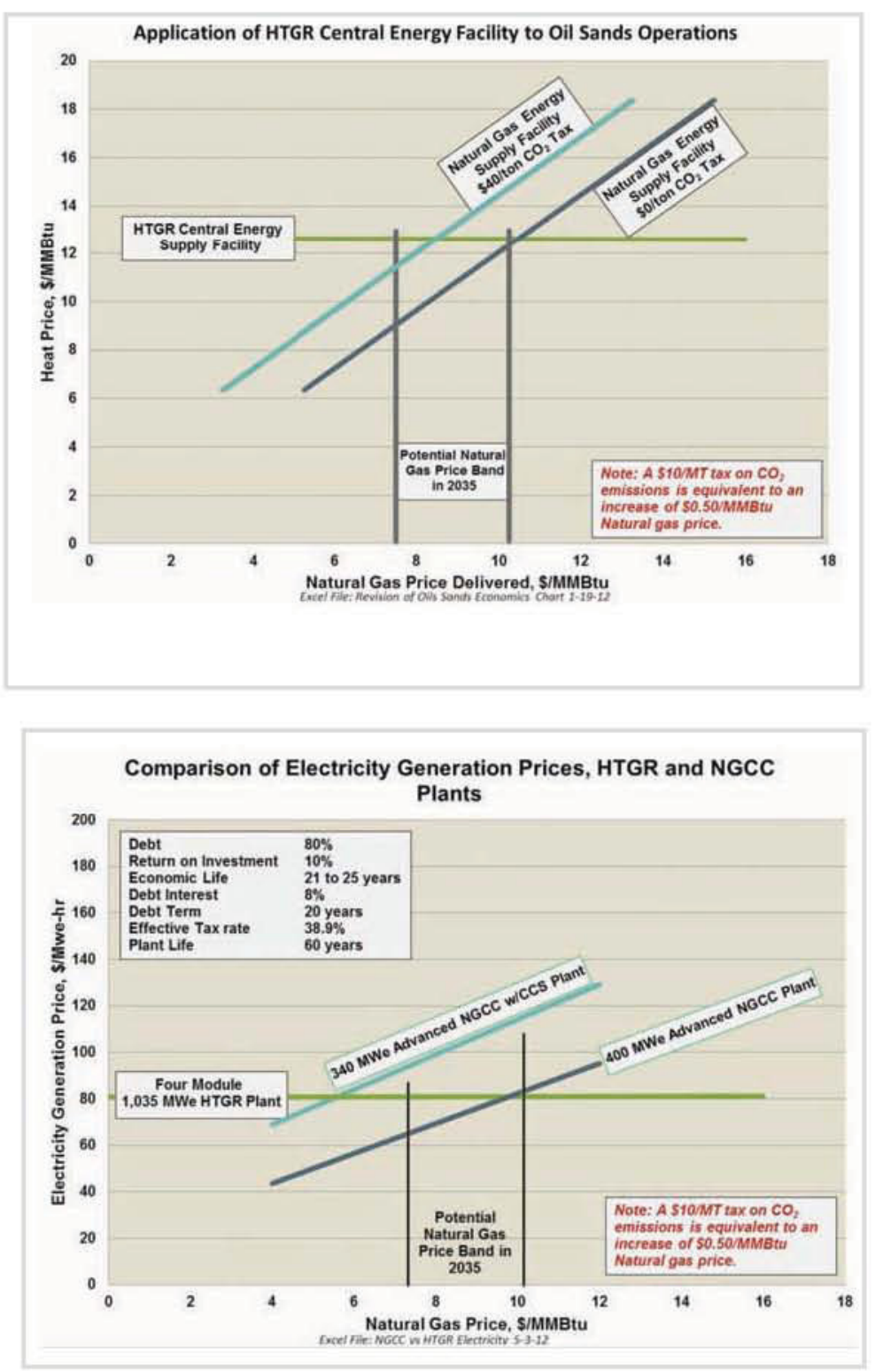
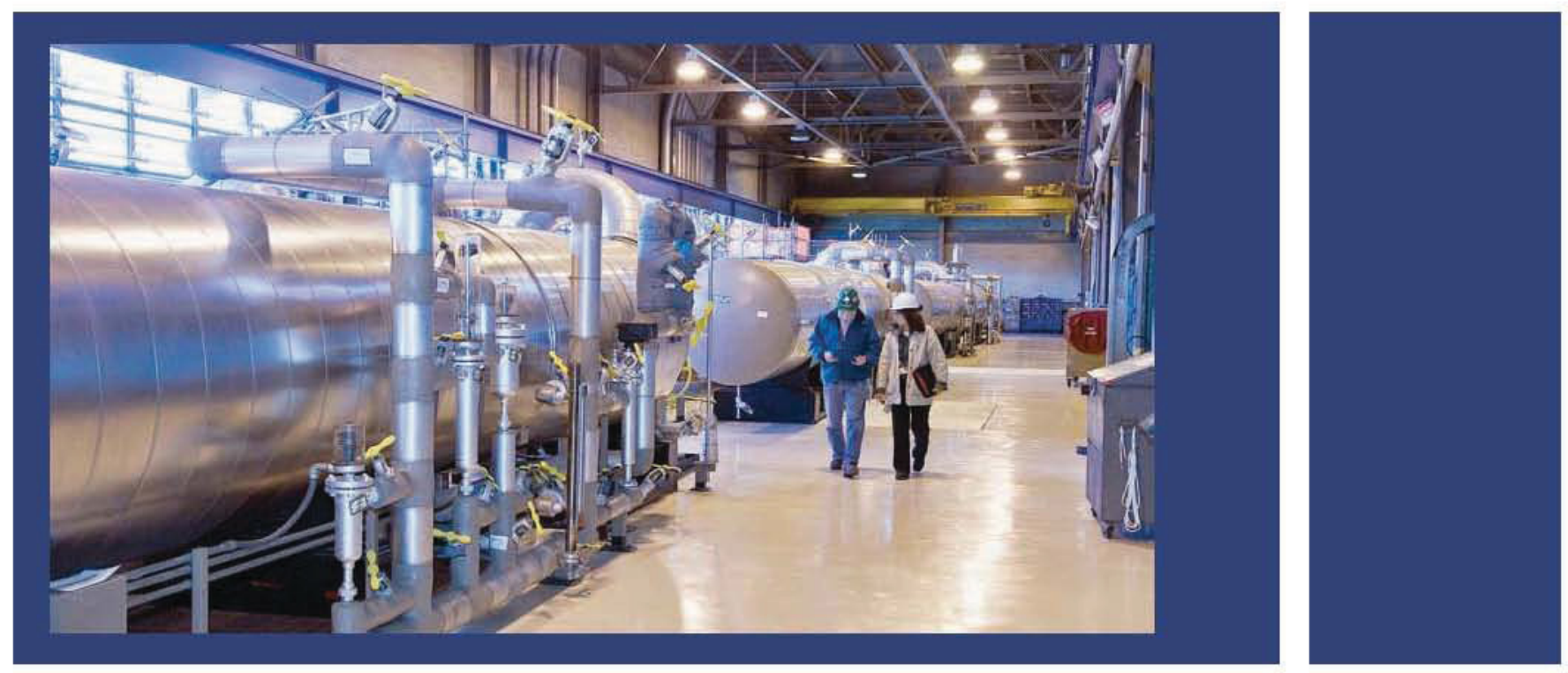


\section{Hydrogen Production}

Two variations in applying the HTGR technology to hydrogen production have been evaluated. The first is to substitute high temperature energy from the HTGR for the burning of natural gas in conventional natural gas steam methane reforming processes. As shown, the HTGR is competitive with steam methane reforming for a natural gas price of $-\$ 6.5 /$ MMBtu. This approach only eliminates about $15 \%$ of the $\mathrm{CO}_{2}$ emissions from the conventional steam methane reforming process; accordingly, the price of hydrogen produced by either of these methods would be affected by any cost imposed on these emissions.

A non- $\mathrm{CO}_{2}$ emission alternative to steam methane reforming is to use high temperature steam electrolysis (HTSE) to generate hydrogen and oxygen using the HTGR to supply high temperature heat and electricity. As shown, this approach would be competitive with conventional steam methane reforming for a natural gas price of $\sim \$ 12 / \mathrm{MMBtu}^{\circ}$ or a $\mathrm{CO}_{2} \operatorname{cost}$ of $-\$ 70 /$ ton. The HTSE process is in an early stage of commercialization; the hydrogen prices for this process shown are judged to be conservative.
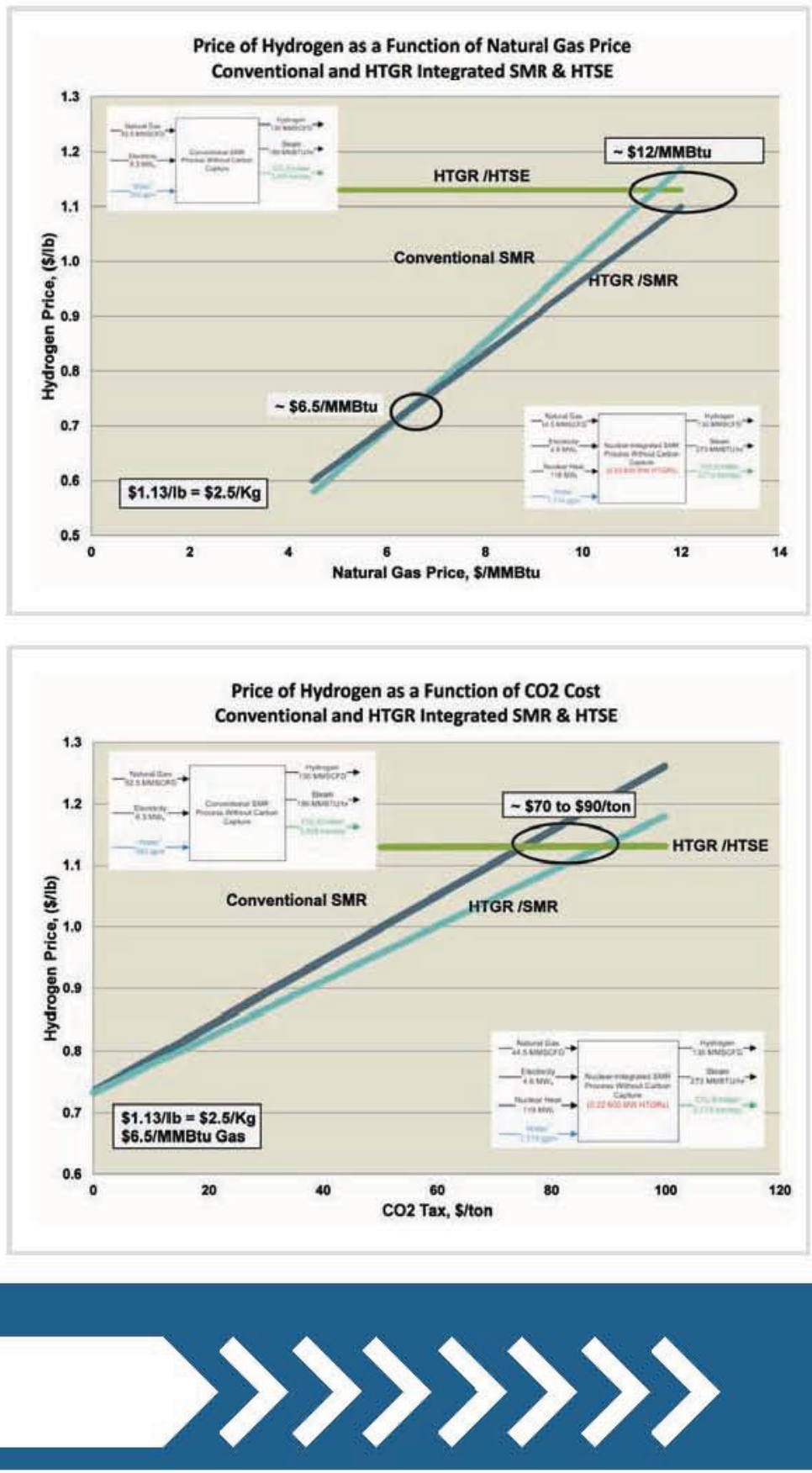


\section{Carbon Conversion to Synthetic Transportation Fuels and Chemical Feedstock}

The following figures show that coal-to-liquids and natural-gas-to-liquids synthetic production of diesel fuel integrating HTGR and HTSE technology with conventional processes could be competitive with traditional petroleum refining at current crude oil prices $(-\$ 80 / \mathrm{bbl}$ at the time of this writing) and in the range predicted by EIA in the 2023 to 2035 timeframe; (e.g., $-\$ 60-\$ 200 /$ bbl $).{ }^{17}$

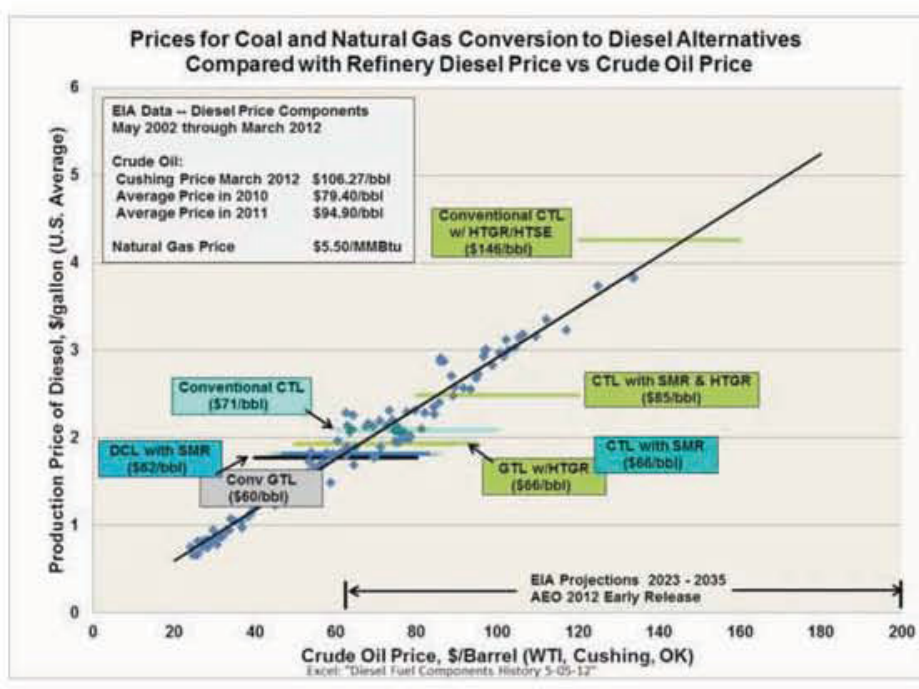

Oil prices in the Reference case rise steadily: the full $A E O 2012$ will include a wide range of oil prices

annual average price of light low sulfur (LLS) crude ol real 2010 dollars per barrel

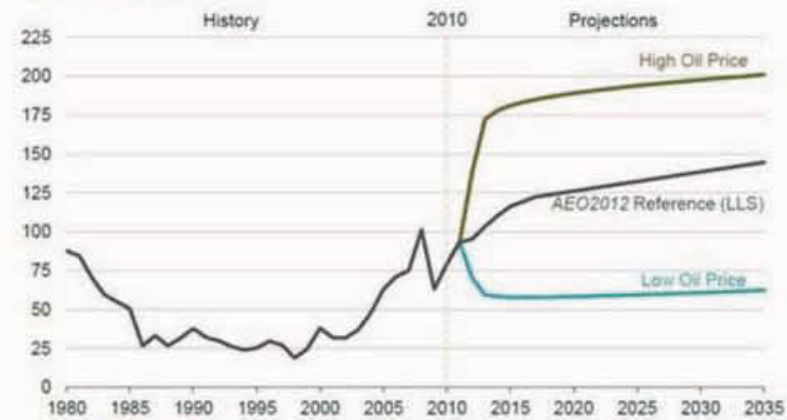

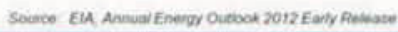

\section{BIBLIOGRAPHY}

17. CTL - Coal to Liquids producing diesel, naphtha and LPG

SMR - Steam Methane Reforming hydrogen production that can be integrated with HTGR technology

GTL - Natural gas to liquids producing diesel, naphtha and LPG

DCL - Direct coal liquefaction using SMR that can be integrated with HTGR technology

\section{REFERENCES}

a. INL, Integration of High Temperature Gas-Cooled Reactors into Industrial Process Applications, INL/EXT-09-16942, Rev. 2, May 2010

b. INL, Integration of High Temperature Gas-Cooled Reactors into Selected Industrial Process Applications, INL/EXT-23008, Rev. O, August 2011

c. INL, NGNP Project Evaluation of Siting a HTGR Cogeneration Plant on an Operating Commercial Nuclear Power Plant, INL/EXT-11-23282, Rev. 1, October 2011

d. INL and Petroleum Technology Alliance Canada, NGNP Integration of High Temperature Gas-cooled Reactor Technology with Oil Sands Processes, INL/EXT-11-23239, Octaber 2011

e. Idaho National Laboratory, High Temperature Gas-Cooled Reactor Projected Markets and Preliminary Economics, INL/EXT-10-19037, Rev. 1, August 201l.

f. TEV-988. INL, 2011, "Sensitivity of HTGR Heat and Power Production to Reactor Qutlet Temperature, Economic Analysis" Idaho National Laboratory, TEV-988, Rev. 1, June 30,2011

g. TEV-672, "HTGR-Integrated Coal and Gas to Liquids Production Analysis", Idaho National Laboratory, September 2011

h. DOE/EIA Annual Energy Outlook 2011 (April 2Oll)

i. NYMEX:NG 1-18-12

j. NERA Economic Consulting, Proposed CATR + MACT, prepared for the American Coalition for Clean Coal Electricity, May 2011 (DRAFT)

$k$ energyB IZ, $1-17-12$ 


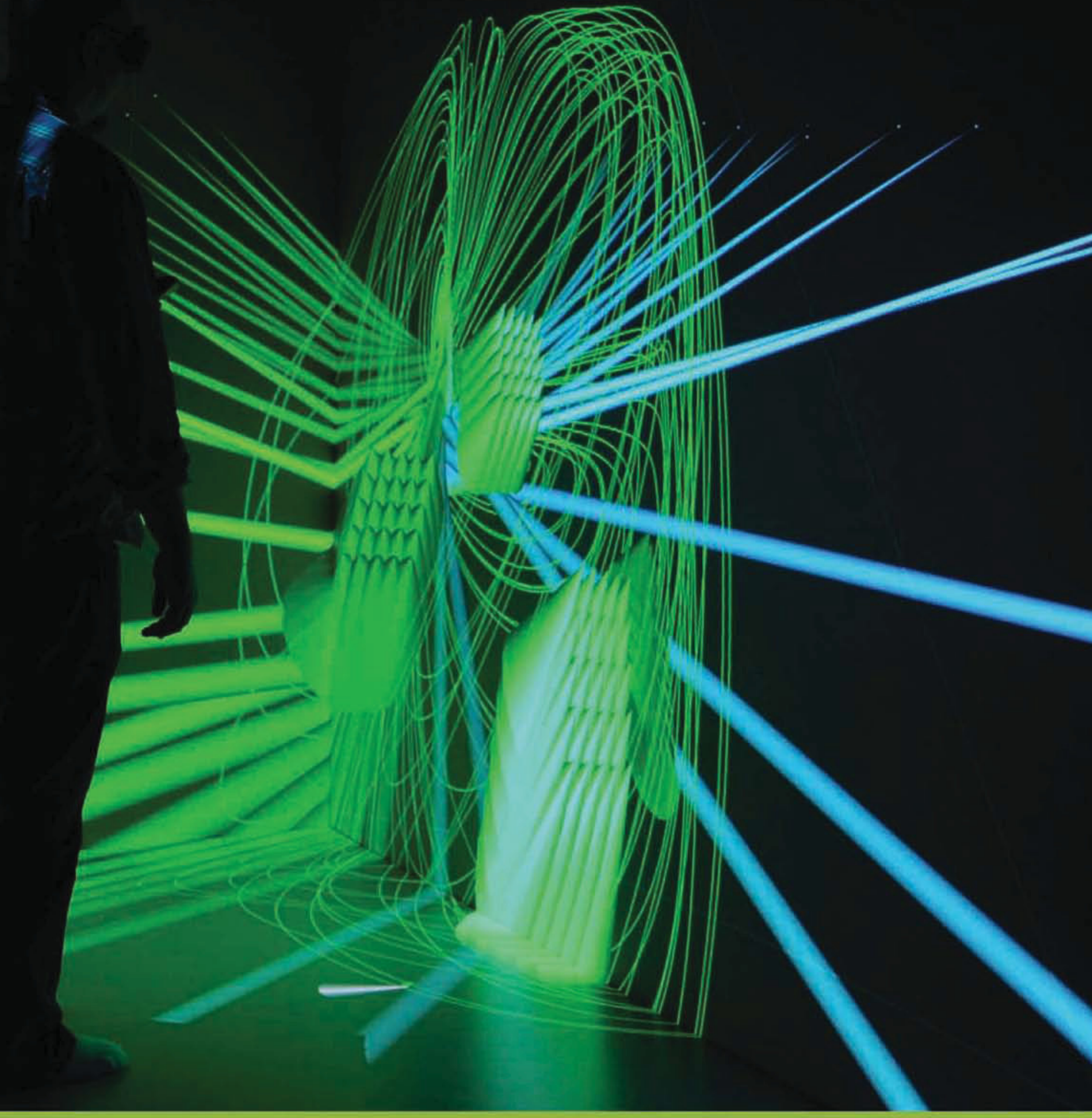

\section{\APPENDIX B}

NENP MALSTAY

DEVELOPMENT VENTURE 


\section{APPENDIX B}

Development Venture

This Appendix provides a summary of a possible approach to executing the Development Venture. Specifics regarding breakdown of scope, the investment framework, the interaction and interdependency with the Deployment Project, investment risk and the character of intellectual property are the subjects for detailed discussions with interested equity investors.

\section{PURPOSES}

The purposes of the Development Venture include providing the technical foundation and regulatory framework for commercialization of modular high temperature gas-cooled reactor (HTGR) technology and supporting licensing and construction of the initial fleet of modular HTGRs for commercial applications. These initial applications are anticipated to be co-generated electricity and process heat as steam, or solely the generation of electricity.

The Development Venture is led by the Nuclear System Supplier (NSS) in collaboration with the prospective Owner entity (the Owner - possibly an Owner Consortium). The NSS will lead completion of technology development, perform design development through final design, support preparation of the license application by the Owner and/or Operator, and ensure that the necessary infrastructure development (e.g., vendors to supply nuclear fuel; structural materials for the reactor core; major equipment) occurs as necessary to support construction of multiple modular HTGRs. This Appendix summarizes the constraints, the business model, the investment opportunities and the anticipated means of achieving a continuing return on investment as the initial fleet of HTGR modules is deployed in a merchant marketplace. The costs estimated to be incurred are one-time costs that support licensing and construction of the initial fleet of plants using HTGR technology.

\section{STATUS OF HTGR TECHNOLOGY COMMERCIALIZATION}

Over the past several years, technology development, pre-conceptual design, design trade-off studies and pre-application licensing activities have been funded in major part by the U.S. Department of Energy (DOE) and managed by the Idaho National Laboratory through the NGNP Project. The NGNP Project builds upon the considerable work performed by industry on HTGR technology in the past. Recently, because of budget restrictions and revised priorities, DOE has reduced support for the NGNP Project.

Essential to commercialization of HTGR technology is completion of government funded R\&D (particularly ongoing irradiation tests) supporting qualification of production fuel and core materials necessary to achieve design completion and licensing of HTGR technology. Additionally, particular attention must be applied to continuing the pre-application activities with the US Nuclear Regulatory Commission (NRC) that have to date primarily focused on the most important policy and high-level technical issues necessary to develop a regulatory framework to support licensing of HTGR technology. Pre-application activities have been led to date by the Idaho National Laboratory NGNP Project. Transition to Entergy Nuclear as the industry license applicant is anticipated for the fourth quarter of 2012. Completing technology development and pursuing a regulatory framework both require continuing progress on a reference design.

The Development Venture is directed toward completing the development activities, continuing licensing pre-application activities with NRC, completing design of the overall plant through preliminary design and safety systems through final design, and supporting preparation of a construction permit application or combined construction and operating license application. The Development Venture activities will transition to a Deployment Project that will complete detailed design and construct and operate the initial plant using the HTGR technology, including the commercial demonstration module that will be used to complete first-of-a-kind testing in support of licensing.

\section{ANTICIPATED EQUITY INVESTORS}

The Development Venture requires a large equity investment for which a return on investment will not be realized for on the order of 25 years. Further, it is expected that a combined equity position of 50 to $60 \%$ of the estimated cost of the Deployment Venture will be required to attract necessary debt financing. 


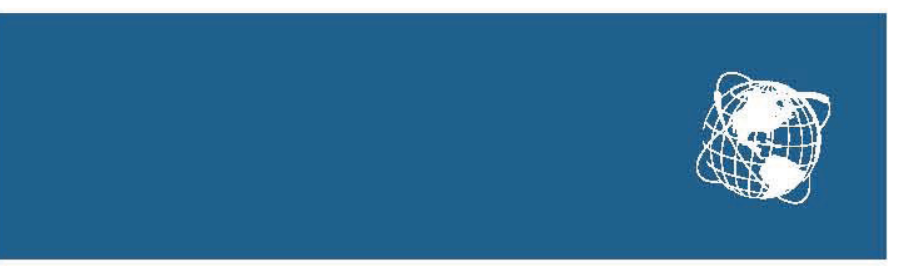

As a consequence, the anticipated major equity investors will have a long-term view of the importance of commercialization and deployment of HTGR technology in the global marketplace with the goals of achieving reduced volatility of energy and feedstock prices, increased energy security, and important reductions in emissions for large industrial applications, as well as for electric power generation. Anticipated equity investors include:

- Nuclear system suppliers

- Vendors of major equipment and materials

- End-users

- Governments

- Private visionary/Angel

\section{SCOPE, ESTIMATED COST AND SCHEDULE FOR THE HTGR DEVELOPMENT VENTURE}

The scope of the Development Venture includes the following:

- Complete technology development - The R\&D activities including: a) qualification of the nuclear fuel; b) qualification and codification of reactor structural materials; c) qualification and codification of high temperature metals and composite materials; and d) development and validation of contemporary analytical methods. ${ }^{18}$

- Complete design - Design for a prismatic reactor concept and a Rankine cycle steam plant for co-generation is required to prepare an application for a construction permit or a combined construction and operating license, and to support long lead development and procurement of materials, equipment and components for constructing a modular HTGR plant.

- Establish the licensing and regulatory requirements - A licensing plan and an iterative process of collaboratively working with the NRC is required to establish a regulatory framework including the safety performance and design requirements for modular HTGRs.

- Develop the supply infrastructure - Establish a supply chain for nuclear fuel, graphite and other core structural materials, and other major equipment to support construction and operation of the initial modular HTGR plant.

- Develop and perform first-of-a-kind inspections and testing - It is anticipated that one-time testing, inspection and modification requirements may be imposed on the demonstration module. This may require FOAK instrumentation and design features.

The overall cost of the Development Venture is summarized as follows. These are one-time costs. This overall estimate is considered to be conservatively high and is based on detailed estimates for these activities developed over the period 2006-2011 by design teams led by AREVA, Westinghouse/PBMR, and General Atomics, and by the Idaho National Laboratory.

\begin{tabular}{|l|r|}
\hline R\&D & $\$ 316 M^{19}$ \\
Conceptual and Preliminary Design & $\$ 280 \mathrm{MM}$ \\
Final Design & $\$ 200 \mathrm{MM}$ \\
Licensing thru COLA Preparation & $\$ 165 \mathrm{MM}$ \\
Equipment and Infrastructure Development & $\$ 648 \mathrm{MM}$ \\
Inspections, Testing and Modifications (FOAK initial operations) & $\$ 75 \mathrm{MM}$ \\
\hline Total & $\$ 1684 \mathrm{MM}$ \\
\hline
\end{tabular}

A notional schedule follows, including the Development Venture and the Deployment Project (see Appendix C), that culminates in completing the first-of-a-kind HTGR technology plant. 


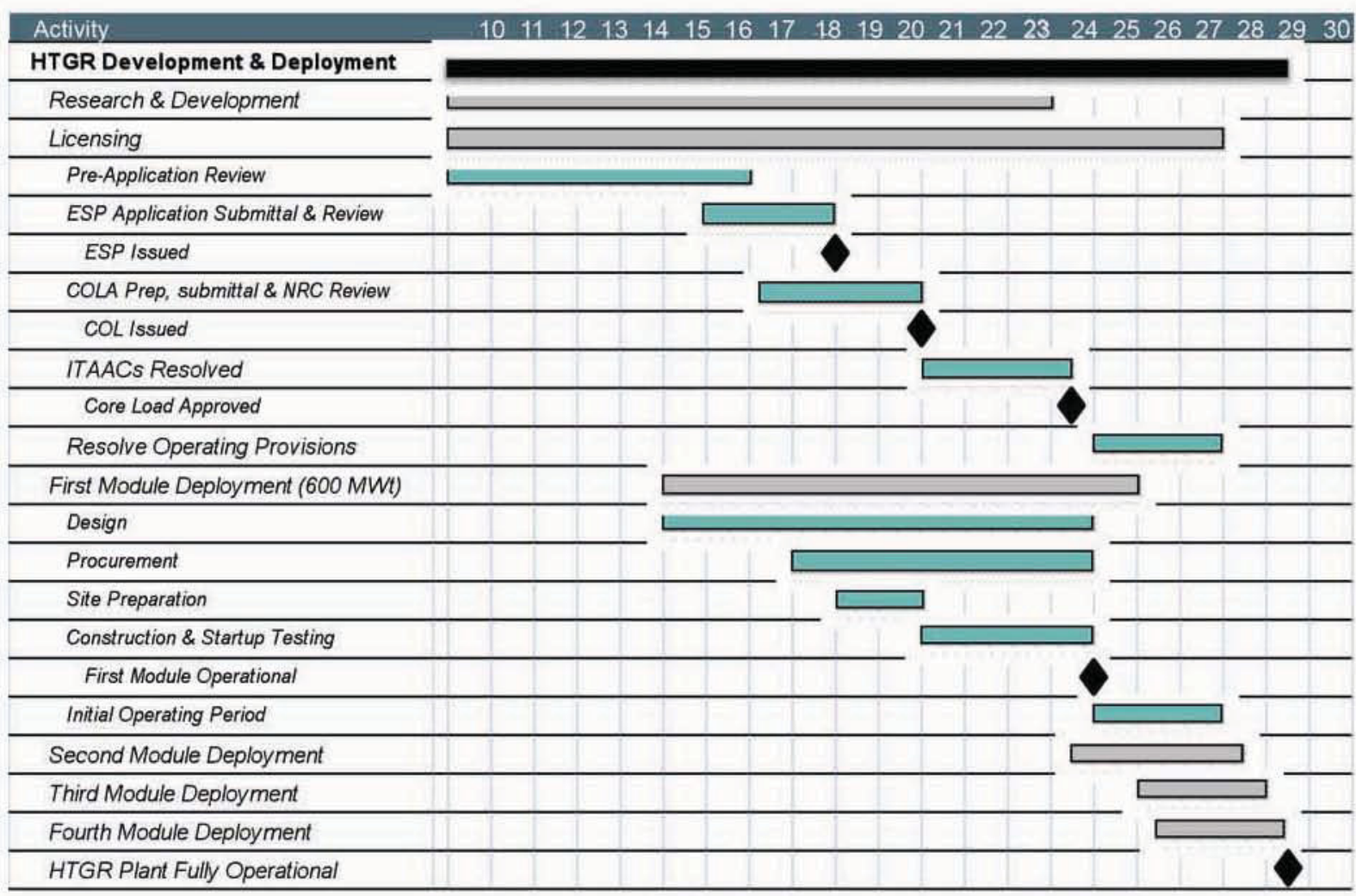

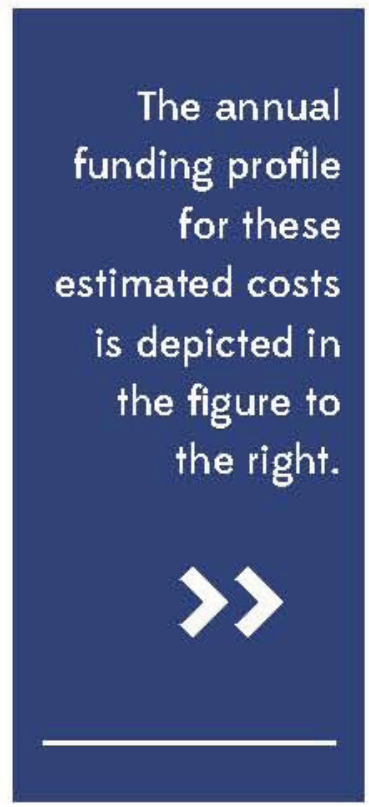

HTGR Commercialization -- Owners Required Funding for First Module Annual and Accumulative Funding Required

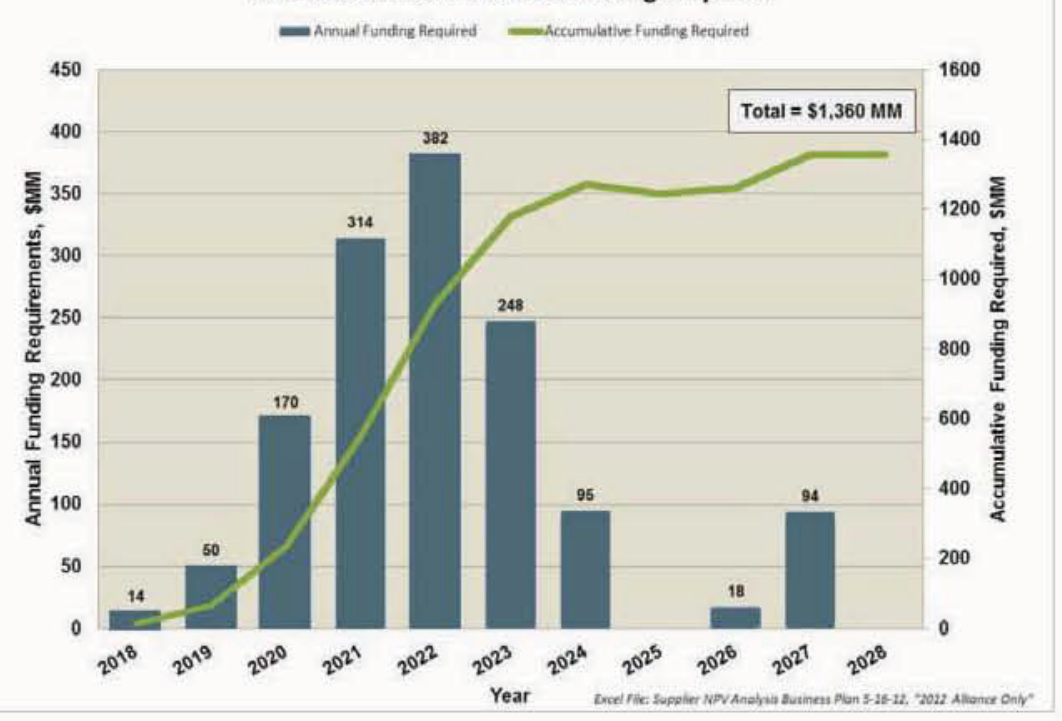

\section{INVESTING IN THE HTGR DEVELOPMENT VENTURE}

The Development Venture is a necessary part of commercializing HTGR technology. The scope of activities for this venture must be completed to provide the energy industry the option to choose HTGR technology for production of high temperature process heat and electricity for industrial applications. The potential market for HTGR technology and evaluation of preliminary economics are summarized in the body of the business plan and described in more detail in Appendix A.

As described in the following, economic evaluations of the overall commercialization and deployment enterprise indicate that penetration of less than $5 \%$ of the conservatively targeted market will create considerable investor value. 


\section{DEVELOPMENT VENTURE BUSINESS MODEL}

The Development Venture is led by the NSS with the collaboration of the Owner. It is anticipated that several equity investors will make the long-term investments as necessary over the timeframe for the venture, with return on investment gained from ownership of the intellectual property for modular HTGR technology and its commercialization. Return on investment is anticipated from modular HTGR plant sales, ongoing nuclear fuel sales and provision of services for the operation, refueling and maintenance of the plants. For purposes of the analyses summarized in the following, the NSS and its venture partners are not assumed to be equity holders with the Owner or in an Owner Consortium in the Deployment Project.

Fundamental to the Development Venture concept is that return on investment will be delayed for an extended period to support plant sales at overnight prices that allow the Owner to realize energy prices to the energy end-user that are competitive with alternative energy sources and comparable to the nth-of-a-kind energy prices that will apply to plants sold beyond the initial offerings. Collocated end-user industrial process facility owners are anticipated to execute multiple-year purchase energy agreements that provide a firm foundation for equity investment in the Development Venture as well as the deployment projects within which the plants are constructed and operated (see Appendix C for description of the initial Deployment Project).

\section{INVESTMENT OPPORTUNITIES}

The Development Venture includes one-time costs of $\$ 1684 \mathrm{MM}$. For the reference case wherein DOE funds completion of $R \& D(\$ 316 M M)$, return on investment is expected to approach an internal rate of return of $-12 \%$ from sales which will be realized after the initial six modular HTGR plants (24 modules) are completed and operating (by about 2037). Additionally, starting with the first plant in about 2028 , the profit on fuel sales and plant services is estimated to run about $\$ 4 M M$ annually for each plant. The investment covers two stages as follows:

First Stage (\$18MM over - fwo years) - a continuation of selected activities that have been ongoing or activities that need to be initiated in the short term including obtaining stakeholder support and financing to initiate the design activity.

1. Assumes continued funding by DOE in FY2O13 and FY 2014 for the R\&D activities on a schedule consistent with that for the Development Venture.

2. Continue pre-application activities with the NRC to develop a regulatory framework for the licensing of HTGR technology.

3. Complete conceptual and initiate preliminary design activities. Detailed design schedules will be developed supporting the R\&D and licensing progress.

4. Select a site for the first HTGR plant, including the demonstration module. Initiate site assessment and evaluation.

Second Stage ( $\$ 1666 \mathrm{MM}$ over $\sim 13$ years) - development, design, licensing and equipment specification activities supporting the initial modular HTGR plant design, licensing and construction. Major activities will include the following:

1. Completing scheduled R\&D activities and acceptance of results into the regulatory framework via Topical Reports, codification in consensus standards or other accepted methods.

2. Completing the reference plant design to support completion of an application for a construction permit or a combined construction and operation license

3. Preparing an application for a construction permit or combined construction and operating license for selected site for the reference design

4. Developing equipment specifications and the supply chain for major procurements including nuclear fuel, graphite and other core structural materials, major equipment and materials. 


\section{EVALUATION OF ALTERNATIVE INVESTMENT SCENARIOS}

Several investment scenarios have been evaluated that consider variations on the extent of government funding contributing to the completion of the Development Venture. These analyses examine the relative viability of investment scenarios recognizing the extended time until a return on the investment may be realized by the Development Venture equity investors.

Assumptions:

- An upper bound energy price of $\$ 10$ per MMBtu to provide competitive pricing with alternative sources of energy. This energy price establishes the overnight price that can be charged for a modular HTGR plant, and acceptable ranges of O\&M and other costs. This assumes no price for carbon. Price for carbon will allow the $\$ 10$ per MMBtu upper bound to increase.

- Within the $\$ 10$ per MMBtu energy price, about $\$ 2$ per MMBtu for nuclear fuel and $\$ 0.30$ per MMBtu for operations, refueling and maintenance services are established as representative based on anticipated TRISO nuclear fuel costs and historical service costs

- An overnight price of $\$ 2,200$ per $\mathrm{KW}$ th $(\$ 5,200 \mathrm{KW}$ e) for the plant rating for a reference four module HTGR plant, each module rated at $600 \mathrm{MW} / \mathrm{th}$

- Construction of the first module commences in 2020 with initial operations at the beginning of 2025 . The second module is operational within three years with six months to each of the third and fourth modules

- Construction of two plants with four modules in each plant begins every year following completion of the initial operation of the demonstration plant

Four cases were considered as follows:

- U.S. Government (DOE) funds and completes required R\&D

- All external/private funding (No US Government cost share)

- $80 \%$ U.S. Government cost share of all Development Venture costs

- $50 \%$ U.S. Government cost share of all Development Venture costs

The result is shown graphically in the following figures. The first case, above, is chosen as the reference for discussion elsewhere within this Appendix based on a judgmental balance between return on investment and expected U.S.
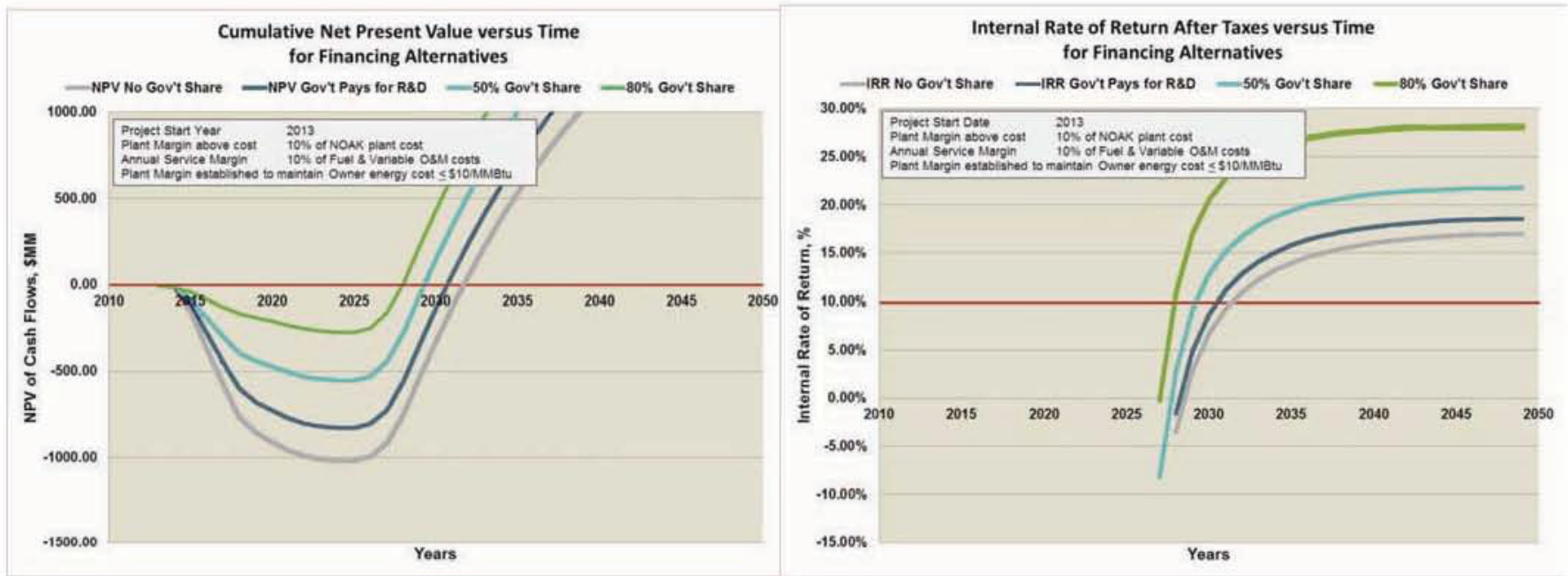


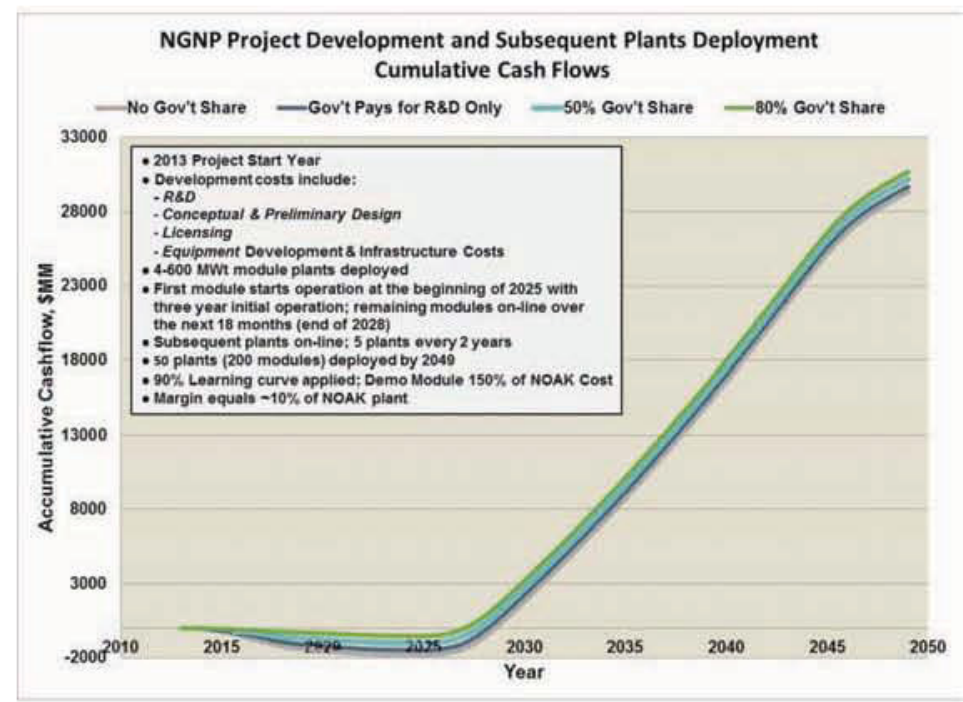

The preceding is based on deployment of fifty 4-600 MW/th module plants with the procurement and construction of the demonstration module starting in 2018. All 50 plants are on line by 2049 .

Government funding and support.

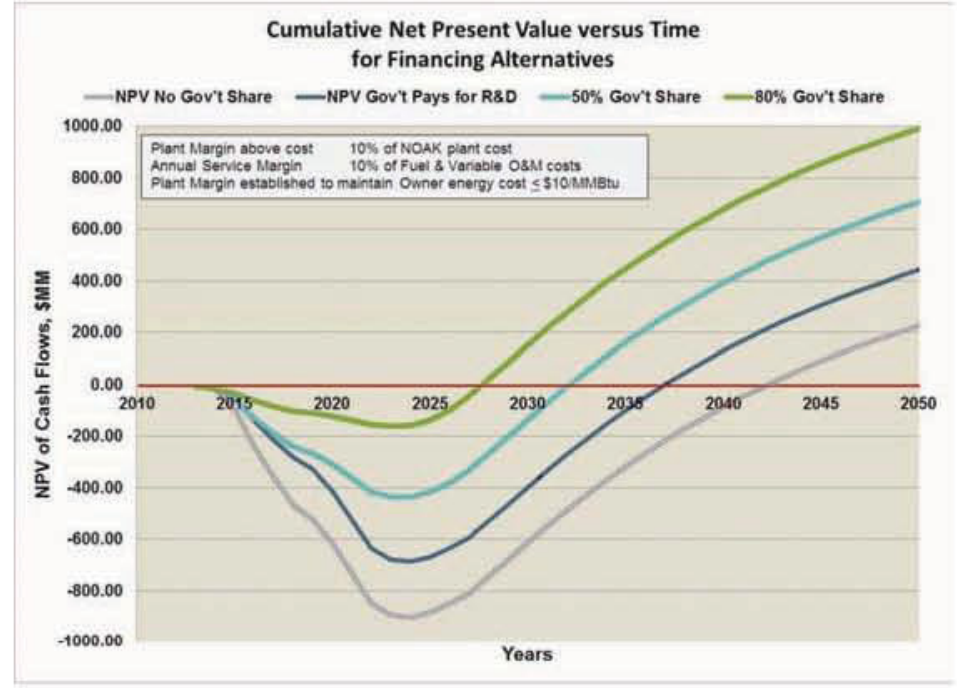

The cumulative net present value figure at left changes the assumed build rate, resulting in 12 fourmodule plants in 2050 instead of 50 as in the prior module. The impact is to delay a positive net present value of the investments from 2031 to 2046, in the case of no government investment. In the event of $50 \%$ government cost share, achieving positive net present value is delayed from 2029 to 2032 .

\section{INVESTMENT RISK AND RISK MITIGATION}

The primary Development Venture investment risks and possible risk mitigation activities are summarized in the following. The specific characterization of risk and its mitigation will depend on the specific equity investment arrangement.

The Alliance is convinced that HTGR technology is unique in its ability to fill a very large energy niche in the U.S. and worldwide, and that the benefits that will accrue from its deployment warrant investment even in light of the substantial residual risks. The Alliance believes that the level of risk will diminish to normal acceptable project levels with time and appropriate investment.

\section{Inadequate Equity Investment and Debt Financing}

\section{Risk mitigation:}

- Aggressive activities to attract necessary equity investment to ensure the success of the Development Venture. The two-stage investment approach supports investors gaining confidence in venture by direct participation in planning activities during First Stage.

- Project management will proceed with development activities only when applicable equity investment and debt financing have been confirmed, including all criteria for exiting the agreements for performance inadequacies or unfulfilled conditions. This is anticipated to require the venture to be phased with value creating activities providing the criteria for proceeding. 
Residual risk (high):

- Development Venture requires large equity investment for which a return will not be realized for over two decades. It is anticipated that the position will need to be about $50-60 \%$ to attract the necessary debt financing.

- In consideration of the costs involved, there are multiple opportunities for differences in expectations being encountered in equity investment and debt financing. Of particular concern are unilateral actions by equity investors and debt holders that may be resolved over time, but are disruptive to the orderly progression of the project.

- Unanticipated Development Venture cost increases.

2. Untimely Technology Development Activities

Risk mitigation:

- Create technology development plan with starting point of INL/EXT-11-23907, NGNP Project - 2011 Status and Path Forward, dated December 2011. The technology development plan should be based on the design and construction needs and schedule for the Deployment Project.

- Develop a formal partnership with the Department of Energy (DOE) for continuation and completion of R\&D activities in the areas of fuel qualification, materials codification and analytical methods verification.

- Continue ongoing interaction with Congress, DOE, and the Office of Management and Budget to ensure adequate funding for completion of technology development activities.

- Develop a contingency plan in the event federal funding is not adequate to support the technology development plan. (Cost estimates for the Development Venture include the estimated cost of completing the R\&D activities irrespective of federal funding.)

Residual risk (Currently high due to uncertainty in federal funding; technical risk due to unforeseen technology hurdles is low):

\section{Untimely Design and Design Support Activities}

Risk mitigation:

Aggressive project management, planning, schedule adherence and open item management.

Residual risk (low):

Future business opportunities incentivize timely support for resolution of design issues.

\section{Untimely Licensing Activities}

This includes ongoing pre-licensing application interactions with the NRC directed toward developing the regulatory technical requirements and review processes applicable to HTGR technology. The development of this licensing framework for the HTGR may require important changes to existing regulatory requirements that have evolved primarily for light water reactor technology. The framework is needed for eventual certification of the HTGR reactor design as well as site licensing requirements for collocation of the reactor with industrial processes. Progress on and the credibility of this developing framework are essential to beginning detailed design work with an acceptable business risk.

The figure below illustrates the effect of a two-year licensing delay on the time to achieve a positive net present value assuming the baseline is to start one new four-module plant every two years. The net effect is the positive NPV is reached at 2029 with a build rate of two plants starting per year, 2032 for one plant every two years, and 2035 with a two-year licensing delay of the demonstrator and a build rate of one plant every two years. Therefore, licensing is one of the key risks to assure mitigation and government support. Each of these results assuming an overall government cost share of $50 \%$.

\section{Risk mitigation:}

- Next Generation Nuclear Plant Licensing Strategy - a report to Congress, August 2008. This report, prepared jointly by NRC and DOE, summarizes the preferred licensing development approach and necessary NRC resources. 

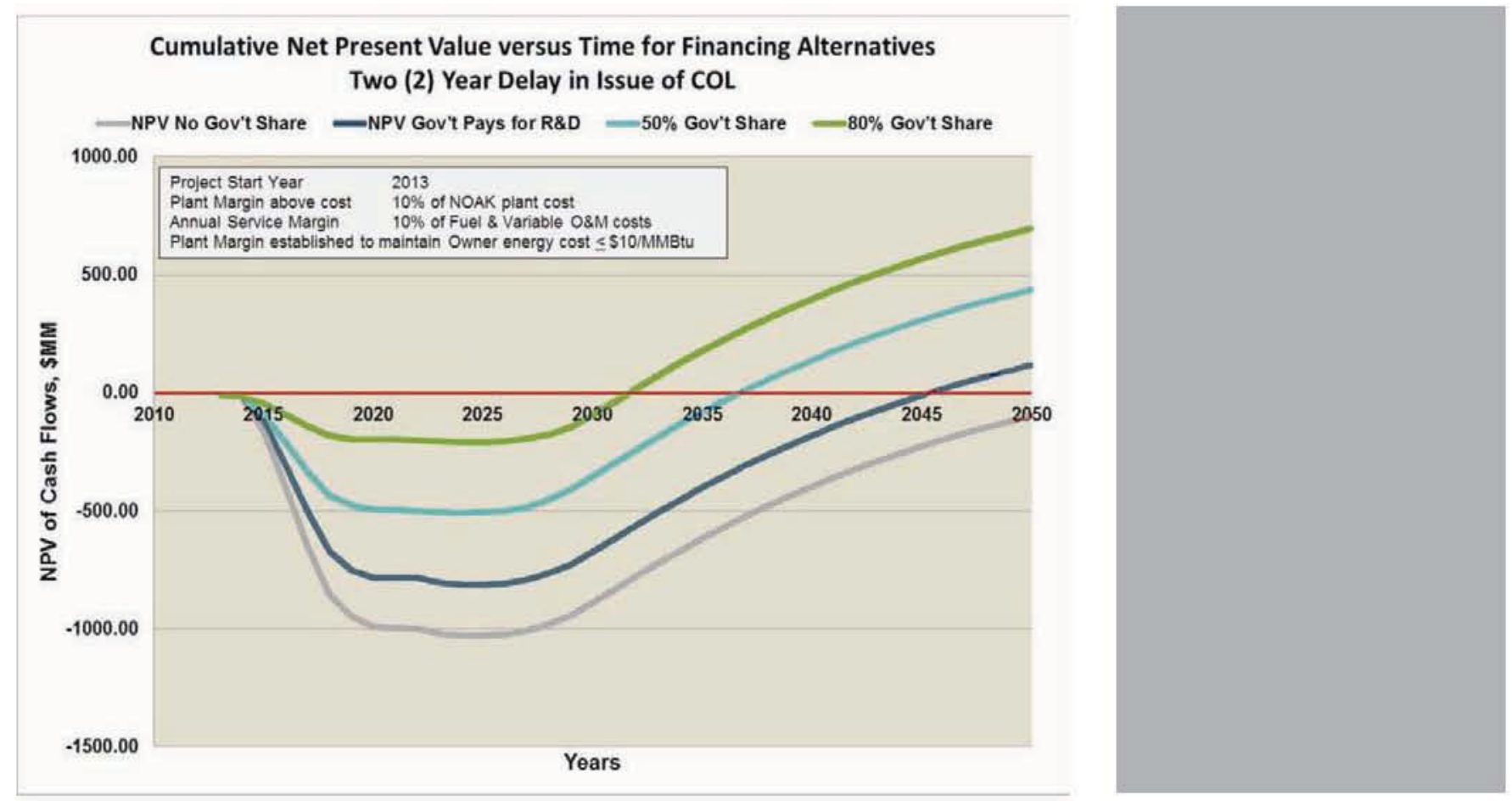

- PLN-3202, NGNP Licensing Plan, June 26, 2009. A detailed implementation plan prepared by INL for DOE that is in effect until January 1, 2013.

- Entergy Licensing Plan for HTGRs - in preparation (a fall 2012 draft is anticipated). This plan, effective January 1, 2013, will describe the licensing implementation approach through completion of pre-application activities, preparation of the construction permit and operating license applications and executing the license for the initial HTGR plant. This licensing plan will be completed under the Development Venture. This plan will enable preparation of design and licensing documents and determine the licensing application requirements. This should include planned topical $5^{20}$ and other design documents intended to be submitted to NRC prior to submittal of the construction permit application or $\mathrm{COL}$ application. This plan will provide input to the technology development plan for necessary R\&D activities.

- Aggressive pre-application activities with NRC to adapt/augment current regulatory requirements for applicability to HTGR technology since 2009 are continuing.

- NSS in collaboration with the license applicant will prepare a detailed plan for development of the detailed design report that is used in lieu of a Design Certification for input to preparation of the construction permit application of the $\mathrm{COL}$ application.

- The reference design is at the conceptual design stage that limits the ability to identify specific design and licensing needs of a more mature design. Selected design studies will be performed as part of the pre-application licensing activities.

Residual risk (high):

- NRC finalization of the requirements framework will not be fully complete until an operating license is issued.

- There is exposure to public hearings during the licensing and permitting process. 
5. Untimely Development of Supply Infrastructure

Risk mitigation:

- Early interaction with potential suppliers of nuclear fuel, major equipment and other materials not readily available in commercial market, particularly if required to be purchased or dedicated for use in safety-related applications.

- Obtain commitment from suppliers regarding investments to develop supply chain. This may include development of supply chain strategies, partnerships and plans.

Residual risk (low):

The NSS and its suppliers are incentivized by future business opportunities to timely development.

6. Unanticipated Technical Issues with Startup and Initial Operations

\section{Risk mitigation:}

- Ensuring that necessary technical resources for resolution are timely available.

- Minimize unanticipated issues via detailed project reviews, FMEA analysis, detailed training, etc.

Residual risk (high for demonstration module; low for subsequent modules):

\section{VALUE CREATION ACTIVITIES FOR THE DEVELOPMENT VENTURE}

During development of the detailed plan and schedule for execution of the Development Venture in the First Stage, value creating activities will be identified that provide an objective means of measuring progress and assessing reduction in investment risk (the largest risks are described in the body of the business plan). The detailed plan and schedule will provide overall milestones, major deliverables, the investment schedule and logic ties between the elements of the Development Venture as well as with the Deployment Project. It is presumed that pre-established progress milestones will be required to be completed before additional investment is made. A complementary plan will be developed during the First Stage that describes the form and substance of intellectual property that is created during the Development Venture and how that intellectual property is apportioned among the initial and subsequent equity investors.
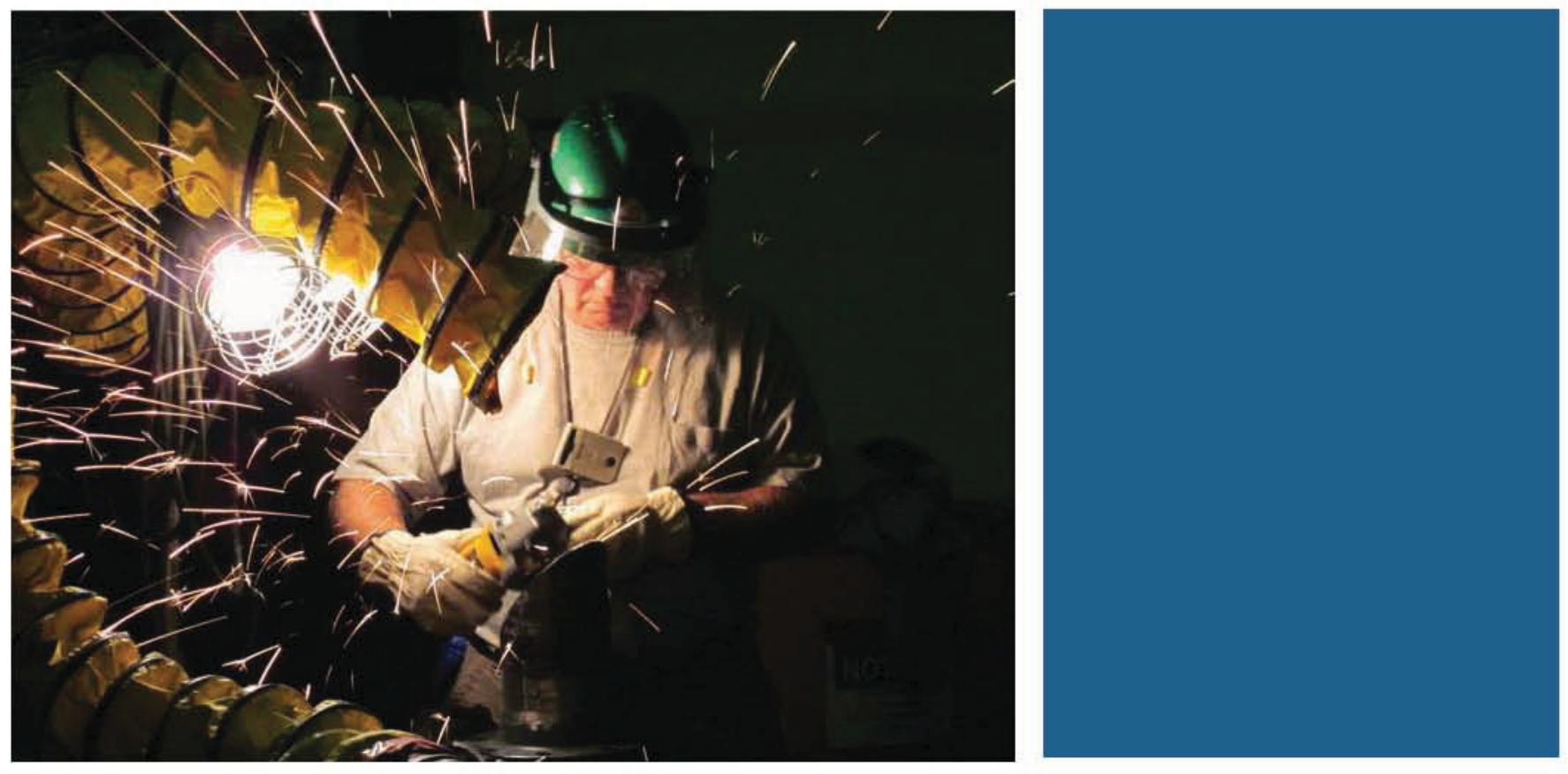
BIBLIOGRAPHY

18. Current status and path forward are summarized in INL/EXT-11-23907, NGNP Projecf-2011 Status and Path Forward, dated December 2011; see also Investment Risk and Risk Mitigation section

19. Assumes that government funds the R\&D activities in fiscal years 2013 and 2014 at about $\$ 87 M M$ total; the R\&D estimated cost is the balance for 2015 through the planned completion in 2026. Federal funding for R\&D through 2013 and 2014 is about $\$ 404 \mathrm{MM}$

20. Topical denotes a subject specific submittal for approval to the NRC that provides a basis for review (e.g., fuel licensing basis) 


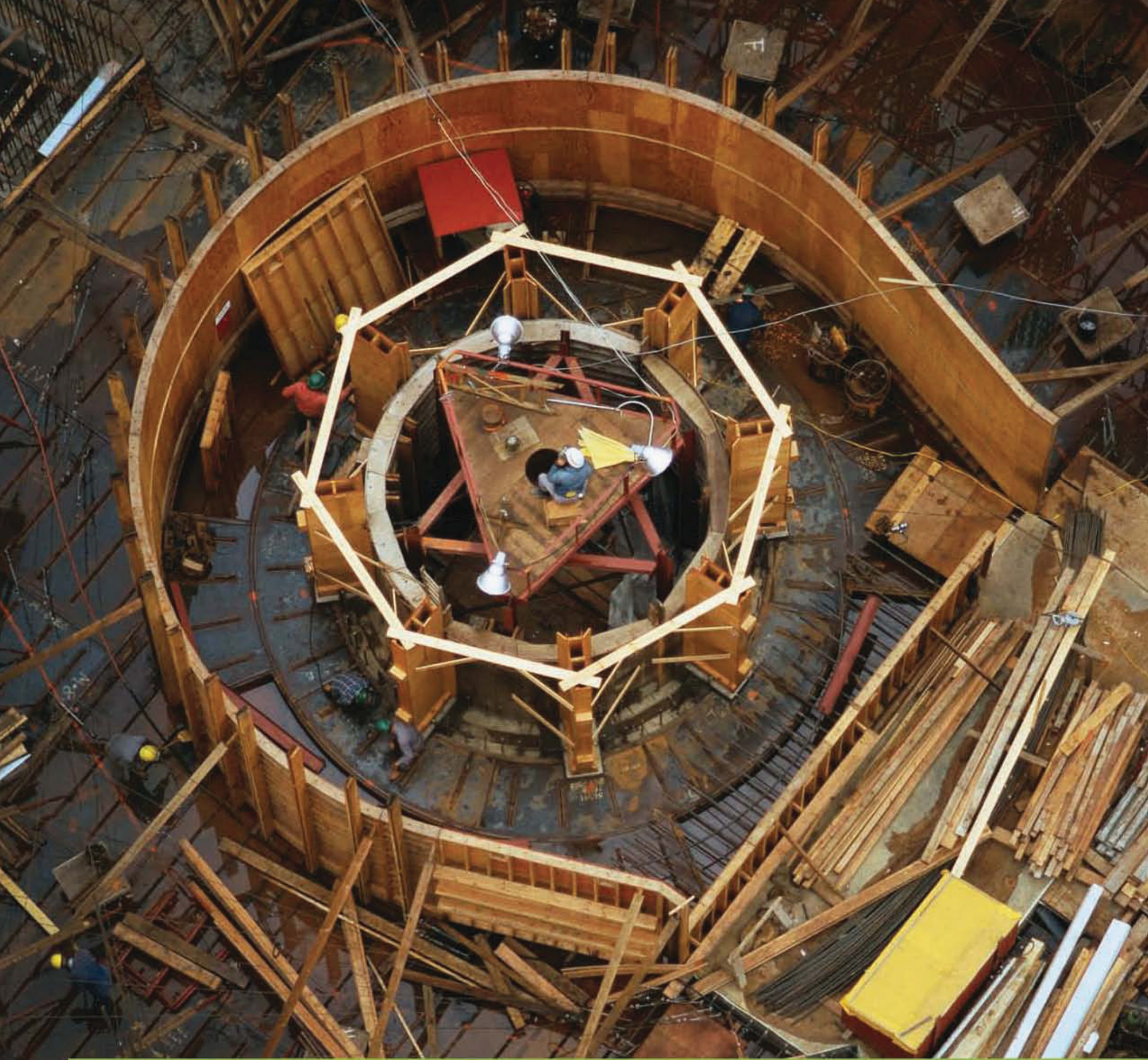

\APPENDIX C 


\section{APPENDIX C}

Deployment Project

This Appendix provides a summary of a possible approach to executing the Deployment Project. General information of interest to equity and debt investors is provided for a proxy scope. Specifics regarding breakdown of scope, the investment framework, the interaction and interdependency with the Development Venture, investment risk and the character of the intellectual property are the subjects for detailed discussion with interested equity investors.

\section{PURPOSE}

The purpose of the Deployment Project is to construct and operate the first-of-a-kind (FOAK) commercial plant based on high temperature gas-cooled reactor (HTGR) technology. This FOAK plant will build on the experience gained in previous HTGR technology demonstrations and establish the economic viability of this technology to co-generate high temperature process heat and electricity for use in industrial applications.

The Deployment Project is led by the Owner entity in collaboration with the Nuclear System Supplier (NSS) and the Architect-Engineer/Constructor $(\mathrm{AE} / \mathrm{C})$. The Owner will complete site-specific design, obtain a construction permit and operating license (or alternatively a combined construction and operating license), construct, start up and initially operate the first-of-a-kind (FOAK) plant comprised of a demonstration HTGR module, additional modules and the associated energy conversion and transport systems necessary for a viable business case. This Appendix summarizes the constraints, the possible business model, the investment opportunities and the anticipated means of achieving a continuing return on investment.

\section{ANTICIPATED EQUITY INVESTORS}

The Deployment Project requires a large equity investment for which a return will be realized upon completion and operation of the HTGR multi-module plant. The return is anticipated to be in the form of a share of operating revenues and ownership of intellectual property on construction and licensing of the FOAK plant that will continue to provide returns for further build-out of the HTGR plant fleet. It is expected that a combined equity position of at least $20 \%(80 / 20$ Debt to Equity) of the estimated cost of the Deployment Project plus a commitment for execution of a purchase energy agreement by the end-user(s) will be required to attract necessary debt financing. Anticipated equity investors include:

- Energy producers (utilities; power-generating companies; independent power/energy producers)

- Municipalities

- Architect/Engineers

- End-users

- Venture capital

\section{DEPLOYMENT PROJECT SCOPE AND ESTIMATED COST}

The scope of the Deployment Project includes the following:

- Complete site-specific design - The design for the standard HTGR prismatic reactor and a reference Rankine cycle steam plant will be completed under the Development Venture (see Appendix B). The Deployment Project will complete the site-specific design to support procurement and construction activities for a reference-four HTGR module plant. Site-specific design will include any application-specific adaptation of the Rankine cycle steam plant 


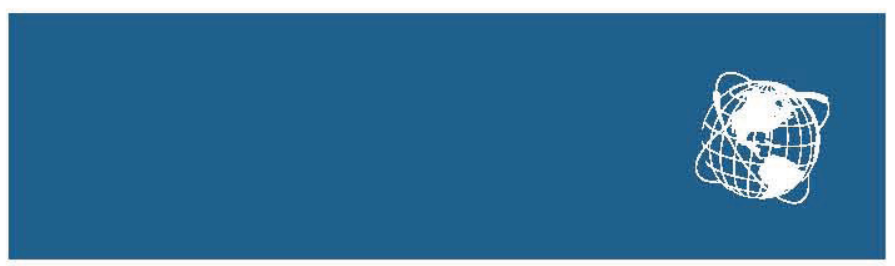

and site-specific support systems and configuration (e.g., condenser cooling system; waste management systems; energy transport systems from the HTGR plant to the industrial end-user; interconnections with the commercial electric grid; utility connections).

- Obtain site NRC license and regulatory permits - An NRC construction permit or combined construction and operating license $(\mathrm{COL})$ will be required to begin substantial on-site construction activities as specified in NRC regulation. This will include major site-specific evaluations of hazards and development of the emergency plan for collocated facilities. A subsequent operating license or $\mathrm{COL}$ will be required to load fuel, start up and operate the reactor facility.

- Construct First-of-a-Kind (FOAK) Plant - This includes constructing the demonstration module and associated energy conversion/transport plant followed by completing the remainder of the four-module plant.

- Perform initial operations - The reference concept for initial operations of the demonstration HTGR module includes supplying energy to the industrial application, providing electricity to industrial user and/or the grid, an initial refueling and first-of-a-kind testing and inspection. It is anticipated that these demonstration activities will require about three years. Construction and initial operations of the other HTGR modules will be as mutually established by the Owner and NRC. This reference concept ends at the completion of the warranty period for the multiple module plant.

The overall cost of the Deployment Project is summarized as follows. These are site-specific costs. All one-time costs are included in the Development Venture. This overall estimate is considered to be conservatively high and is based on detailed estimates developed over the period 2006-2011 by design teams led by AREVA, Westinghouse/PBMR, and General Atomics, and by the Idaho National Laboratory.

The overall cost estimate and initial revenues for the demonstration module portion of the Deployment Project are summarized as follows:

\begin{tabular}{|l|r|}
\hline Complete site-specific design & $\$ 100 \mathrm{MM}$ \\
Construction permit/license application/review & $\$ 65 \mathrm{MM}$ \\
Equipment procurement & $\$ 432 \mathrm{MM}$ \\
Construction & $\$ 625 \mathrm{MM}$ \\
Startup \& testing & $\$ 55 \mathrm{MM}$ \\
Initial operations (3 years) & $\$ 348 \mathrm{MM}$ \\
Revenue (initial 3 years) & $-\$ 265 \mathrm{MM}$ \\
\hline Total & $\$ 1,360 \mathrm{MM}$ \\
\hline
\end{tabular}

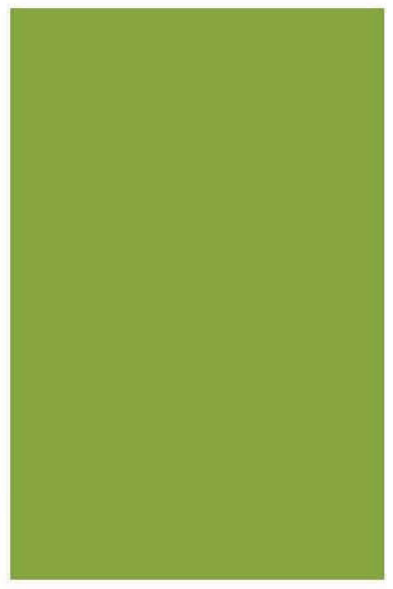


The total estimated cost for the reference four-module plant including the demonstration module is $\$ 4,250 \mathrm{MM}$ and is the all-in overnight capital cost in 2012 dollars. The $\$ 2,890 \mathrm{MM}$ estimated cost beyond the initial module and associated energy conversion/transport systems includes procurement, construction and startup costs. For cost-estimating purposes, it is assumed that the second module achieves initial operations within three years, with six months additional to each of the third and fourth modules.

The annual funding profile for these estimated costs is depicted in the following figures for the demonstration module and associated energy conversion/transport systems, alone, and separately for the entire FOAK multi-module plant (i.e., the cost for the demonstration module is included in the total cost for the FOAK plant).
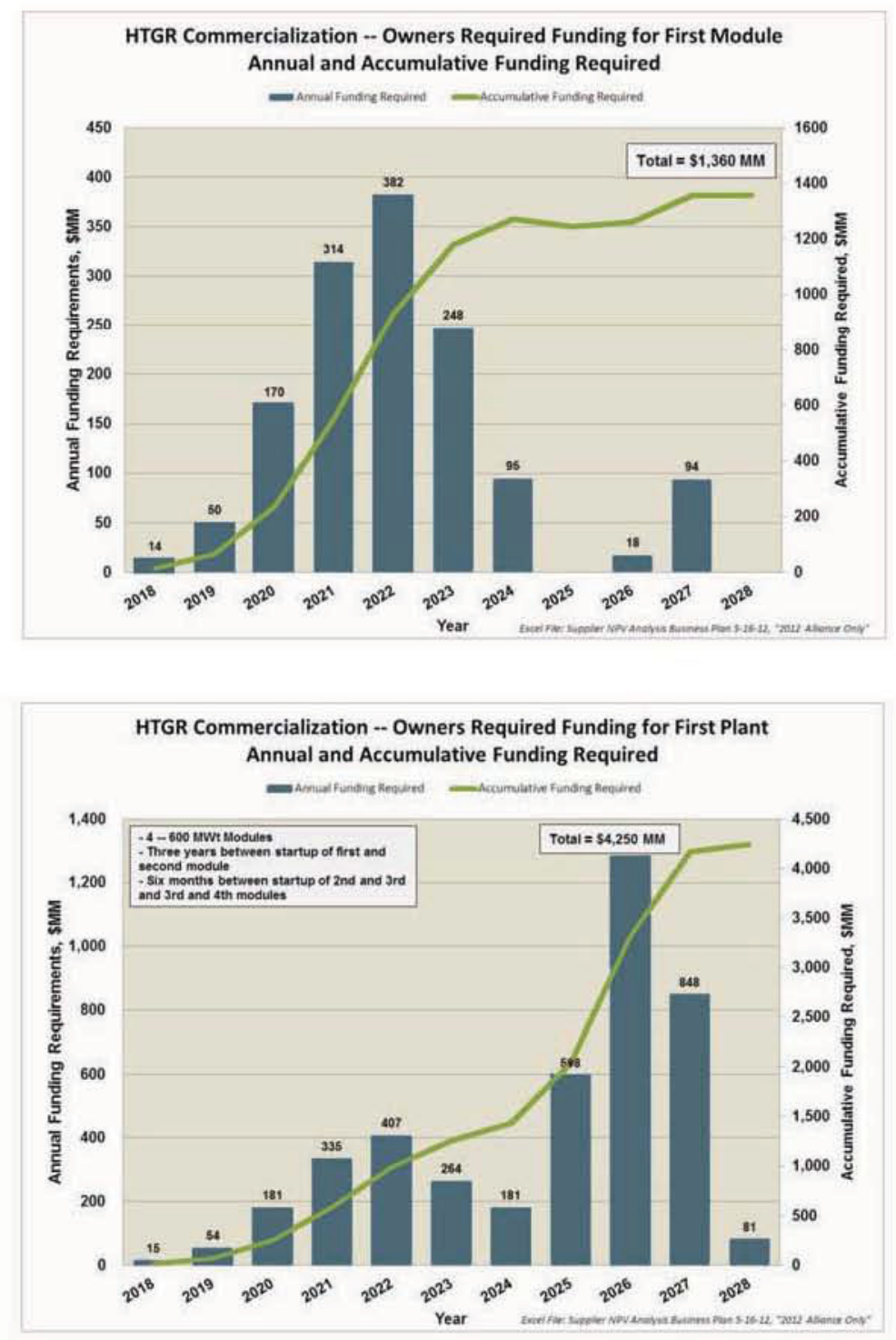


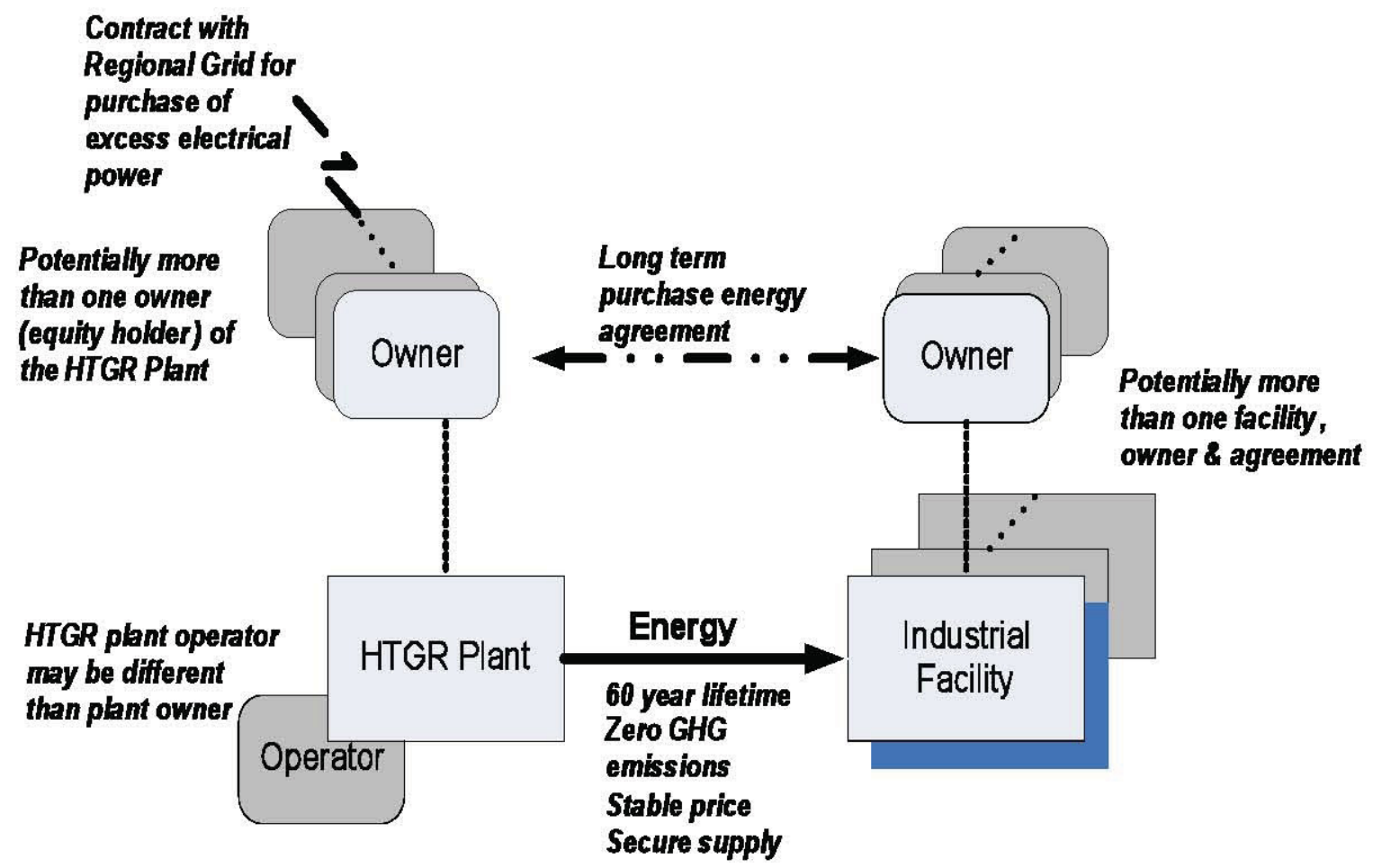

\section{DEVELOPMENT PROJECT BUSINESS MODEL}

Initial deployment via the FOAK plant will be undertaken through a venture that involves one or more entities taking an equity position as the Owner (or consortium of owners) for completing the site-specific design, licensing and constructing the FOAK plant that includes the demonstration module, additional modules, and the energy conversion and transport plant necessary to achieve a credible business case. The anticipated business model is as shown in the figure. The FOAK plant will provide the reference for subsequent deployment of multiple plants for the purpose of providing high temperature process heat and electricity for industrial use. Since the application of HTGR technology is targeted across multiple business sectors, the partnering and contractual arrangements to finance and deploy the follow-on plants could be expected to vary from the model shown. The follow-on plants are intended to use a standardized reactor module design with energy conversion/transport plant design variations as needed for the particular industrial applications.

The return on investment for the FOAK multi-module plant will be in the form of:

- Revenues from plant operations (direct energy sale and capacity support for peak availability)

- Royalties from intellectual property regarding technology deployment and construction techniques for next plant 


\section{INVESTMENT RISK AND RISK MITIGATION}

The primary Deployment Project investment risks and possible risk mitigation activities are summarized in the following. The specific characterization of risk and its mitigation will depend on the specific equity investment arrangement.

\section{Inadequate Equity Investment and Debt Financing}

Risk mitigation:

Project management will proceed with project activities only when applicable equity investment and debt financing have been confirmed, including all criteria for exiting the agreements for performance inadequacies or unfulfilled conditions. This is anticipated to require the project to be phased with value-creating activities providing the criteria for proceeding.

\section{Residual risk (high):}

In consideration of the costs involved, there are multiple opportunities for differences in expectations being encountered in equity investment and debt financing. Of particular concern are unilateral actions by equity investors and debt holders that may be resolved over time, but are disruptive to the orderly progression of the project.

\section{Untimely Design and Design Support Activities}

Risk mitigation:

Aggressive project management, planning, schedule adherence and open item management.

Residual risk (low):

The NSS is incentivized by future business opportunities to timely support resolution of design issues.

\section{Untimely Licensing Activities}

Risk mitigation:

Aggressive project management, planning, schedule adherence and open item management.

Residual risk (high):

Licensing activities typically require action by the NRC. Those activities requiring action in the public stakeholder environment have the potential to be delayed to ensure adequate stakeholder involvement.

\section{Untimely Procurement Activities}

Risk mitigation:

Aggressive project management, planning, schedule adherence and open item management. Selected presence of project management personnel at vendor sites for schedule-critical equipment will be utilized.

Residual risk (low):

The NSS and AE/C are incentivized by future business opportunities to timely support resolution of equipment specification, technical and schedule issues.

\section{Construction Performance and Quality Issues}

Risk mitigation:

Aggressive project management, planning, schedule adherence and open item management. Will utilize modular construction techniques, where practical, with intent to resolve technical and fabrication issues in the vendor's shop rather than at the construction site.

Residual risk (high):

Unproven use of modular construction techniques for the HTGR modular reactor.

\section{Unanticipated Technical Issues with Startup and Initial Operations}

Risk mitigation:

Ensuring that necessary technical resources for resolution are timely available. Minimize unanticipated issues via detailed project reviews, FMEA analysis, detailed training, etc.

Residual risk (high for demonstration module; low for subsequent modules): 


\section{STAKEHOLDER PARTNERING TO MANAGE RISKS}

The Deployment Project will require the stakeholder partners (e.g., Owner, Operator, equity investors, NSS and AE/C) to support the major project phases: 1) project initiation; 2) planning and procurement; 3) construction and performance testing; 4) start-up; 5) transfer to operations; 6) initial operations, testing and inspections necessary to fulfill commercial acceptance testing and licensing conditions; and 7) project close-out. The project will undergo detailed analysis for engineering constructability, licensing requirements and environmental impact as part of the initiation and planning phases. Supplemental expertise for project success may be required and include other skills that are not specifically identified above. These include, but are not limited to, such disciplines as project managers, expert engineering services, environmental and technical consultants, technical integrators and technologist.

The license applicant (Owner or Operator) will lead site and plant licensing and permitting with regulators and will coordinate with the other stakeholders for technical responses and information required to support licensing/permitting activities during the deployment project and into plant operations.

The NSS, Owner and Operator will work collaboratively on operational and technical support training programs and other safety and socialization requirements prior to final acceptance of the plant and in accordance with regulatory requirements for operations.

\section{VALUE CREATION ACTIVITIES FOR THE DEPLOYMENT PROJECT}

During development of the detailed plan and schedule for execution of the Deployment Project, value-creating activities will be identified that provide an objective means of measuring progress and assessing reduction in investment risk. The detailed plan and schedule will provide overall milestones, major deliverables, the investment schedule and logic ties between the elements of the Deployment Project as well as with the Development Venture. It is presumed that pre-established progress milestones will be required to be completed before additional investments are made. A complementary plan will be developed that describes the form and substance of intellectual property that is created and how that intellectual property is apportioned among the initial and subsequent equity investors.
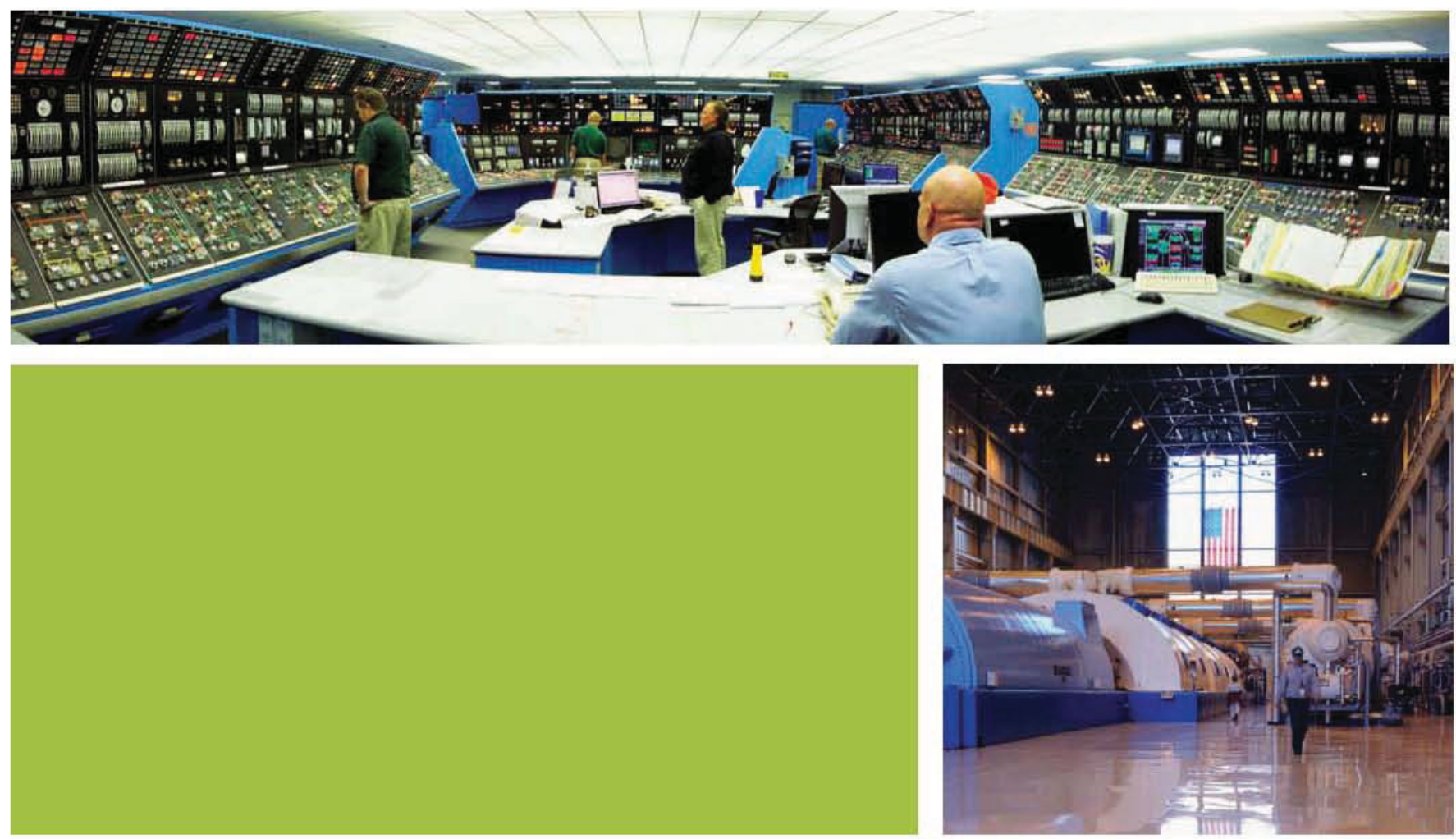
Member companies have joined in this alliance with the primary purpose to promote the development and commercialization of High-Temperature Gas-Cooled Reactor (HTGR) technologies. Our alliance represents the interests and views of our members that intend to mutually support and direct project plans to design, build, operate and use the HTGR technology. We provide a forum and focus to communicate industry needs and requirements and work in concert with the Idaho National Laboratory and others to seek out and promote industrial uses for HTGR technologies within the United States, North America and other continents around the world.

HTGR technology offers a major opportunity to stabilize historically volatile prices for premium fossil fuels and provide a new energy option to provide high temperature process heat for industrial applications. Stabilizing energy costs will encourage a return of process industry facilities to the U.S. from offshore locations where lower and more stably priced fuels and feedstocks have been available. As conventional fossil fuel supplies become more limited in the future due to supply or regulatory restrictions, HTGRs promise to provide new sources of hydrogen and ways to shift chemical and fuels production to new feedstocks with reduced green-house gas (GHG) emissions.

Commercialization of HTGR technology is essential to the National interests in achieving the evolving environmental and energy policy goals. HTGR technology offers benefits including: 1) Reduced GHG through large scale displacement of premium fossil fuels in a wide range of industrial and commercial applications; 2) Reduced reliance on imported oil and gas supplies as industry fuels; 3) Extending life of domestic oil and natural gas supplies as strategic assets for transportation fuels until alternatives become viable technically and economically; 4) Sustainable expansion of American industrial manufacturing capabilities for energy intensive industries; and 5) Job creation within the U.S. supplying materials and equipment to construct and operate HTGR-based industrial infrastructure.

\section{NGNP Industry Alliance Officers}

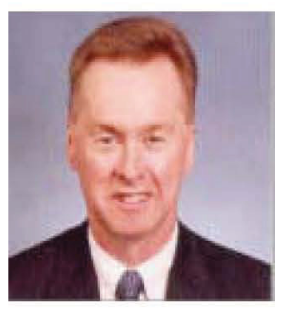

\section{Donald Halter, Executive Director I executivedirector@ngnpalliance.org}

Don is currently Manager of Business Development for ConocoPhillips. He has over 32 years of global energy industry experience with commercial and operating background in crude oil, natural gas, refined products, heavy oil, biofuels, coal, LPG, heavy oil and management consulting. Mr. Halter holds a B.A. in Economics from the State University of New York, Geneseo and a Master of Business Administration, Finance from the Wharton School, University of Pennsylvania. He has held a Commodity Futures Trading Commission Series 3 license for futures and options trading (inactive status).

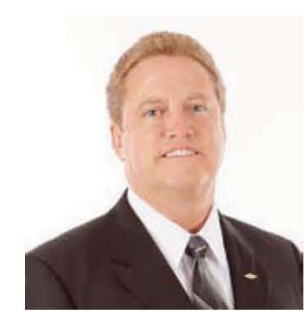

Jeff Jarrell, Vice-Chair (Executive Director-Elect) vicechair@ngnpalliance.org Jeff is currently the Technology Center Director for Energy \& Climate Change at The Dow Chemical Company. In his role, he is responsible for our Energy Systems Technology Center and Dow's Global Improvement Organizations - managing energy process safety requirements, technical support of plant/site energy operations, technology development and capital projects implementation in energy-related technologies. Mr. Jarrell has worked for Dow for 30 years, 25 of those years in manufacturing and engineering. He has been a part of Dow's leadership teams for 14 years and has been supervising project and operational teams for the past 23 years. Jeff holds a Bachelor's of Science degree in Chemical Engineering from Texas Tech University.

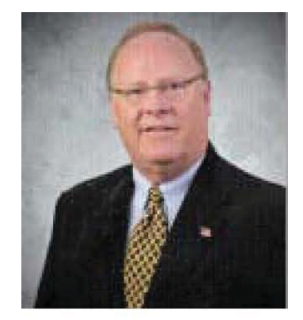

\section{John Mahoney, Secrełary-Treasurer I secretary@ngnpalliance.org}

John Mahoney has more than 30 years of experience in the commercial energy business in managerial and technical positions. In his current position at the Entergy Nuclear fleet headquarters is in business development and project management working with companies and entities globally in the development of nuclear energy opportunities. Mahoney holds a Bachelor of Science degree in business administration from Northwood University and a Master of Science degree in business from Troy University. He is certified by the Project Management Institute as a project management professional and is President Emeritus of the Central Mississippi PMI Chapter. Mahoney is an officer of the Mississippi Section of the American Nuclear Society and was elected in 2011 to the ANS Executive Committee of the Human Factors, Instrumentation and Controls Division for a 3-year term.

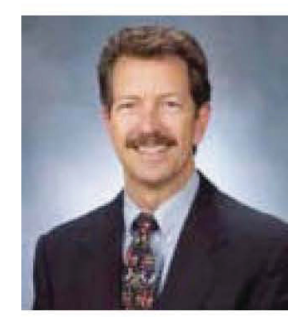

Fred Moore, Executive Director-Emeritus I executivedirector@ngnpalliance.org Fred Moore is the Global Director of Manufacturing \& Technology for the Energy business in Dow. At Dow, he is responsible for the safe and reliable production of power, steam, and other utilities for Dow globally, which represents more than 10\% of Dow's asset base. In his Technology role, he is responsible for development, support and application of Energy technology globally and with Dow's major joint ventures. Fred holds a Bachelor of Science in Environmental Engineering from Purdue University. He was the Alliance executive director from June 2010 to June 2012 and remains a voting member of the Executive Committee in his capacity.

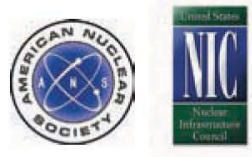




\section{NGNP}

NGNP Industry Alliance Limited P.O. Box 837, Ridgeland, MS 39158-0837 | ngnpalliance.org | find us on facebook 